\title{
A Conservation Strategy for the Northern Spotted Owl
}

\author{
Report of the
}

Interagency Scientific Committee To Address the

Conservation of the Northern Spotted OwI

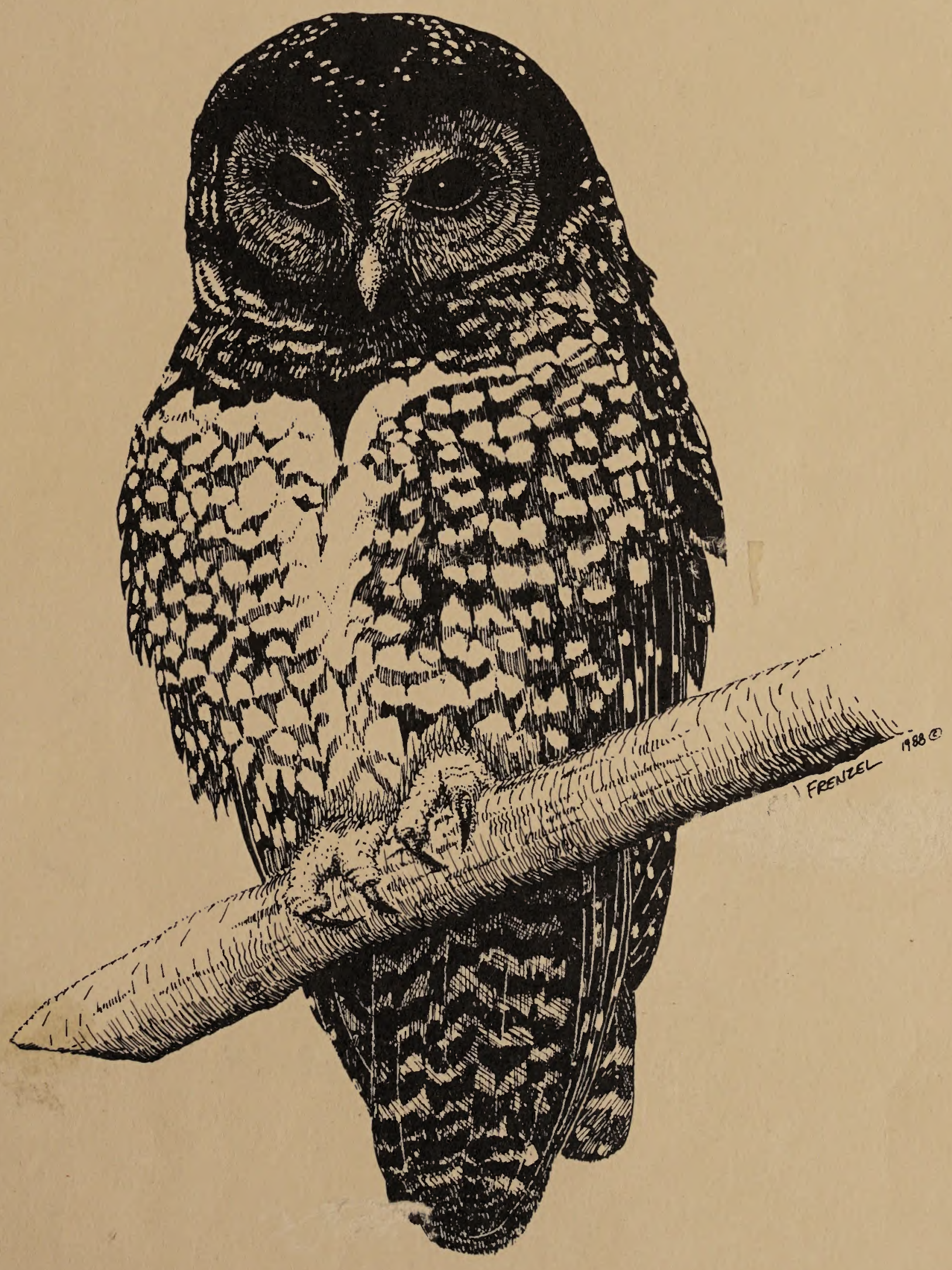


United States Department of Agriculture Forest Service

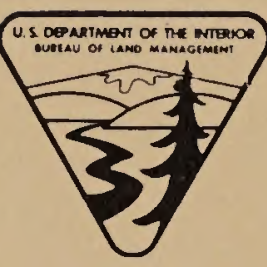

United States Department of the Interior Bureau of Land Management

United States Department of the Interior Fish and Wildlife Service

United States Department of the Interior National Park Service 


\title{
A Conservation Strategy for the Northern Spotted Owl
}

Interagency Scientific Committee to Address the Conservation of the Northern Spotted Owl

\author{
Jack Ward Thomas, Chairman \\ Eric D. Forsman \\ Joseph B. Lint \\ E. Charles Meslow \\ Barry R. Noon \\ Jared Verner
}

Portland, Oregon

May 1990

BLM LIBRARY

SC. 653 , BLDG. 50

DENVER FEDERAL CENTER

P. O. BOX 25047

DENVER, CO 80225-0047 


$\begin{array}{lll}\text { Abbreviations Used } & \text { ASQ } & \text { Allowable Sale Quantity } \\ \text { in This Report } & \text { BIA } & \text { Bureau of Indian Affairs (USDI) } \\ \text { BLM } & \text { Bureau of Land Management (USDI) } \\ \text { CBF } & \text { California Board of Forestry } \\ \text { CDF } & \text { California Department of Forestry (and Fire Protection) } \\ \text { CDFG } & \text { California Department of Fish and Game } \\ \text { CHCP } & \text { California Habitat Conservation Plan } \\ \text { CPR } & \text { California Parks and Recreation } \\ \text { CRA } & \text { California Resources Agency } \\ \text { D.b.h. } & \text { Diameter at breast height } \\ \text { EA } & \text { Environmental Assessment } \\ \text { EIS } & \text { Environmental Impact Statement } \\ \text { FS } & \text { Forest Service (USDA) } \\ \text { FSEIS } & \text { Final Supplement to the Environmental Impact Statement } \\ \text { FWS } & \text { Fish and Wildlife Service (USDI) } \\ \text { FY } & \text { Fiscal year } \\ \text { GIS } & \text { Geographic information system } \\ \text { HCA } & \text { Habitat Conservation Area } \\ \text { HSU } & \text { Humboldt State University } \\ \text { MCP } & \text { Minimum convex polygon technique } \\ \text { NAS } & \text { National Audubon Society } \\ \text { NCASI } & \text { National Council on Air and Stream Improvement } \\ \text { NF } & \text { National Forest } \\ \text { NPS } & \text { National Park Service (USDI) } \\ \text { NWF } & \text { National Wildlife Federation } \\ \text { NWR } & \text { National Wildlife Refuge } \\ \text { O\&C } & \text { Oregon and California Railroad Grant Lands (BLM) } \\ \text { OCWRU } & \text { Oregon Cooperative Wildlife Research Unit } \\ \text { ODF } & \text { Oregon Department of Forestry } \\ \text { OGC } & \text { Office of the General Counsel (USDA) } \\ \text { ODFW } & \text { Oregon Department of Fish and Wildlife } \\ \text { OSU } & \text { Oregon State University } \\ \text { OWIWC } & \text { Oregon-Washington Interagency Wildlife Committee } \\ \text { PNW } & \text { Pacific Northwest Research Station (FS) } \\ \text { PSW } & \text { Pacific Southwest Research Station (FS) } \\ \text { R5 } & \text { Region 5, Pacific Southwest Region (FS) } \\ \text { R6 } & \text { Region 6, Pacific Northwest Region (FS) } \\ \text { ROD } & \text { Record of Decision } \\ & \end{array}$




$\begin{array}{ll}\text { RSA } & \text { Random Sample Area } \\ \text { SEIS } & \text { Supplemental Environmental Impact Statement } \\ \text { SOHA } & \text { Spotted Owl Habitat Area (FS) } \\ \text { SOMA } & \text { Spotted Owl Management Area (BLM) } \\ \text { TAC } & \text { Timber Association of California } \\ \text { TNC } & \text { The Nature Conservancy } \\ \text { UI } & \text { University of Idaho } \\ \text { USDA } & \text { U.S. Department of Agriculture } \\ \text { USDI } & \text { U.S. Department of the Interior } \\ \text { UW } & \text { University of Washington } \\ \text { UWy } & \text { University of Wyoming } \\ \text { WDNR } & \text { Washington Department of Natural Resources } \\ \text { WDW } & \text { Washington Department of Wildlife } \\ \text { WSPR } & \text { Washington State Parks and Recreation }\end{array}$

Metric Equivalents $\quad 1$ inch $=2.54$ centimeters

1 foot $=0.305$ meter

1 square foot $=0.09$ square meter

1 acre $=0.405$ hectare

1 mile $=1.609$ kilometers

1 square mile $=2.59$ square kilometers 


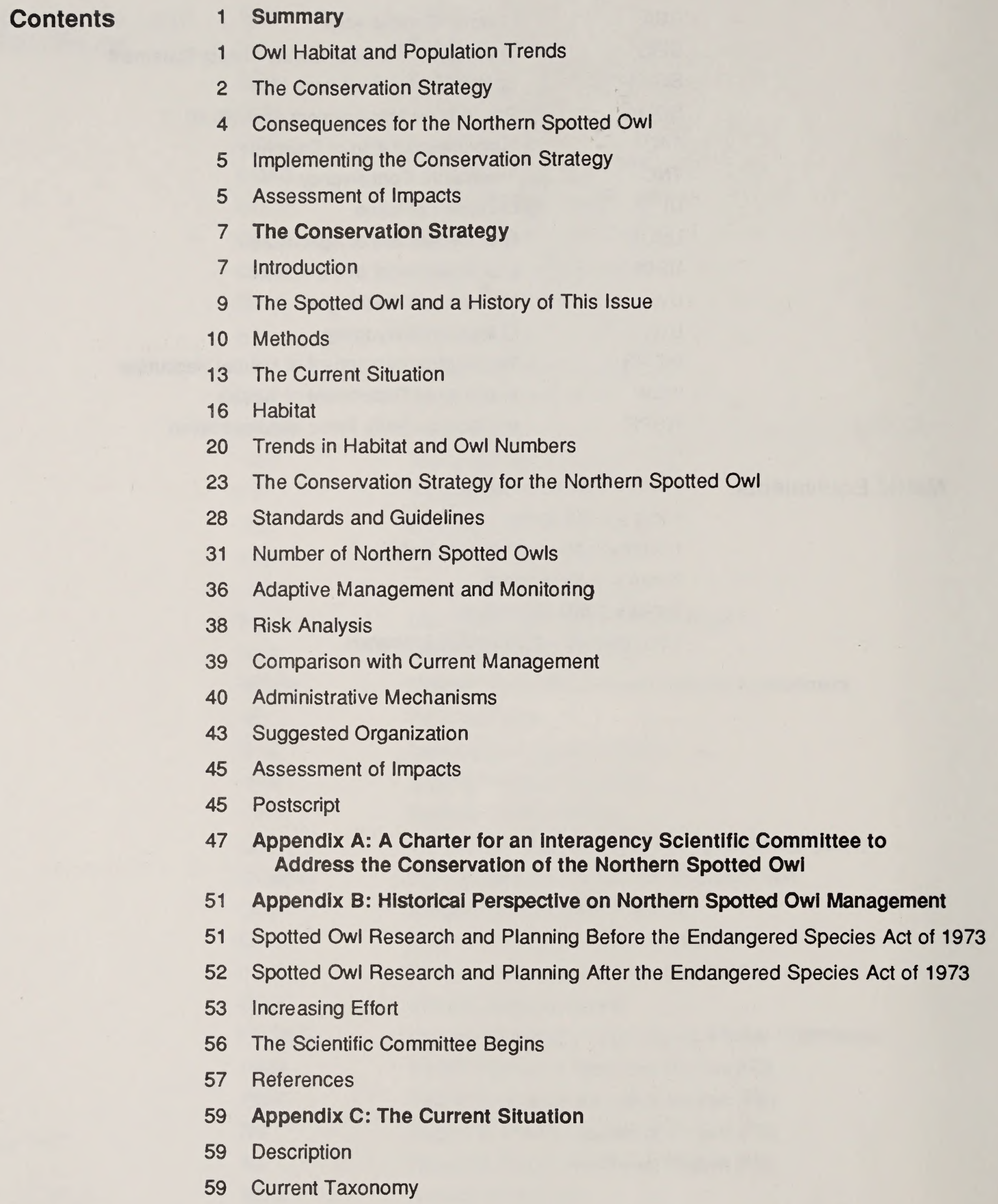


60 Status

60 Range

61 Physiographic Provinces

62. Habitat

63 Population Status and Trend

66 Areas of Special Concern

69 The Current Management Situation

97 Conclusions

97 References

103 Appendix D: Survey: Management of Northern Spotted Owls on National Forests and BLM Districts

103 Introduction

103 Summaries

107 Compiled Analysis of Survey: Management of Northern Spotted Owls on National Forest and BLM Districts

108 Summary of Responses to Questionnaire

108 The SOHA Network

113 Suitable Habitat

117 Evidence of Alternative Habitats

118 Sales Activity

121 Sustained Yield (ASQ)

122 Monitoring and Inventory

124 Sales Surveys

127 Appendix E: Chronology of Committee Activities

143 Appendix F: Characterization of Spotted Owi Habltats in Washington, Oregon, and Northern Callfornia

143 Introduction

145 Methods

149 Results of Habitat Studies in Washington and Oregon

157 Results of Habitat Studies in Northern California

164 Discussion

166 Recommendations for Future Studies and Management

167 References 
171 Appendix G: Reiative Abundance of Spotted Owis in Young, Mature, and Oid Forests

171 Introduction

171 Summary of Relevant Studies

182 Discussion

185 References

187 Appendix H: Abundance of Spotted Owis in Relation to the Amount of Sultable Habitat

187 Introduction

191 Conclusions

191 References

193 Appendix I: Home-Range Sizes and Characteristics

193 Introduction

198 Discussion

199 References

201 Appendix J: Spotted OwI Food Habits and Prey

201 Owl Diets

204 Prey Abundance and Owl Reproduction

205 Habitat Affinities of Prey Species

210 Producing Owl Prey Through Silviculture

211 References

217 Appendix K: Analysis of Forest Service Monitoring Data

217 Introduction

218 Methods

219 Results

226 Discussion

227 References

229 Appendix L: Estimates of Demographic Parameters and Rates of Population Change

229 Introduction

232 Methods - Hypothesis Tests on Lambda

233 Results-Tests on Lambda

234 Discussion

237 References 
239 Appendix M: Population Simulation Models

239 Introduction

240 The Individual-Territory Model

241 Results-Individual-Territory Model

251 Discussion-Individual-Territory Model

253 Territory-Cluster Model

256 Results-Ternitory-Cluster Model

265 Discussion-Ternitory-Cluster Model

267 References

271 Appendix N: Extinction of Species and Populations

271 Causes of Extinction

274 Other Factors

277 Additional Factors

279 Conclusions

279 References

283 Appendix O: A Rationale for the Size and Spacing of Habitat Conservation Areas for Spotted Owis

283 Introduction

286 Population Size, Density, and Local Extinction

292 Dispersal

293 Fragmentation and Edge Effects

294 Predation and Interspecific Competition

294 Catastrophes

295 Providing for Floaters

295 Number of Owls in Relation to the Amount of Suitable Habitat

296 Social Facilitation

296 Monitoring

296 Implementation

296 Possible Advantages of SOHAs Over HCAs

296 References

303 Appendix P: Connectivity: Assuring Successful Dispersal

303 Introduction

303 Dispersal

309 Connectivity 
313 References

315 Appendix Q: Standards and Guidelines

315 Goals

315 Objectives

315 Description of the Conservation Strategy

318 Guidelines Used in Delineating HCAs

320 Testing Application of the Guidelines

322 Guidelines to Use in Delineating Nonmapped HCAS

325 Management Prescriptions

327 Description of the State Strategy

342 Summary of Acreage Totals in HCAs for All Lands

345 Appendix R: Adaptive Management

345 Introduction

347 Suggested Research and Monitoring Program

360 Conceptual Basis for Reviewing the Conservation Plan

362 Summary

363 References

365 Appendix S: Silvicuiturai Experiments for Habltat Management

365 Introduction

366 Importance and Role of Silviculture

366 Silvicultural Treatments and Stand Development Patterns

368 Single-Canopy Structure

370 Multiple-Canopy Structure

370 Implementation

371 References

373 Appendix T: Viability Risk Assessment

373 Maintaining Population Viability

374 Viability Effects

375 Designing a Conservation Plan for Population Viability

378 Areas with Problems of Habitat Distribution

382 Relative Security from Factors that Could Threaten Population Viability

387 References 
389 Appendlx U: The Committee

389 Operations of the Committee

389 Qualifications of the Committee Members

415 Appendlx V: Glossary 

Owl Habitat and Population Trends
The Interagency Scientific Committee to Address the Conservation of the Northern Spotted Owl (hereafter the Committee) was established under the authority of an interagency agreement between the, USDA Forest Service, USDI Bureau of Land Management, USDI Fish and Wildlife Service, and USDI National Park Service. The Committee's charter was signed by the agency heads and subsequently incorporated into Section 318 of Public Law 101-121 in October 1989. The Committee was asked to develop a scientifically credible conservation strategy for the northern spotted owl in the United States.

Since that time, the Committee has reviewed the literature on the northern spotted owl, heard presentations from most of the scientists doing research on spotted owls, considered the concerns of numerous interest groups, and conducted field trips in Washington, Oregon, and northern California to examine the owl's habitat. We have also interviewed dozens of biologists and land managers.

Much of the attention directed toward this bird stems from a growing debate over managing old-growth forests on Federal lands, and from a concern about protecting biodiversity. We understand the significance of these larger issues, but we have kept to our mandate to develop a conservation strategy specifically for the northern spotted owl.

We have concluded that the owl is imperiled over significant portions of its range because of continuing losses of habitat from logging and natural disturbances. Current management strategies are inadequate to ensure its viability. Moreover, in some portions of the owl's range, few options for managing habitat remain open, and available alternatives are steadily declining throughout the bird's range. For these reasons, delay in implementing a conservation strategy cannot be justified on the basis of inadequate knowledge.

The Committee reviewed all available studies dealing with spotted owl habitat, the relative abundance of owls related to stand age, and the relative abundance of owls in relation to various proportions of successional growth stages in the general landscape.

Habitats selected by northern spotted owls typically exhibit moderate to high canopy closure; a multilayered, multispecies canopy dominated by large overstory trees; a high incidence of large trees with large cavities, broken tops, and other indications of decadence; numerous large snags; heavy accumulations of logs and other woody debris on the forest floor; and considerable open space within and beneath the canopy. These attributes are usually found in old growth, but they are sometimes found in younger forests, especially those that contain remnant large trees or patches of 
large trees from earlier stands. In younger forests that support breeding owls, the nest and major roost sites are usually found where large trees from the earlier, older stands remain.

We evaluated the coastal redwood forests of northwestern California, where numerous owls live in stands that are mostly 50 to 80 years old. We believe their presence is attributable to the region's unique set of conditions, including a rapidly growing tree species that sprouts from stumps; intrusion of other conifer and hardwood species into the understory; relatively high rainfall; a long growing season; and abundant prey. Under these conditions, the structural attributes that are usually associated with the presence of owls develop at an accelerated rate. We caution strongly against extrapolating these results to other parts of the owl's range.

Silvicultural prescriptions might be developed that would yield significant volumes of wood products while maintaining suitable habitat for spotted owls, but we find no clear evidence that such prescriptions currently exist. Until they do, the prudent approach to ensuring the viability of the owl is to protect an adequate distribution and amount of existing habitat. Nonetheless, examining younger forests where spotted owls reproduce successfully should yield valuable insights into silvicultural techniques that could produce both wood products and owls.

For at least the past century, loss of spotted owl habitat has exceeded recruitment. By some estimates (perhaps conservative), spotted owl habitat has been reduced by about $60 \%$ since 1800 . The current total population of the owl is likely to be far less than once existed. The loss of habitat has not been distributed evenly across the range of the subspecies.

Owl habitat is also being fragmented, a process that isolates some populations of owls. Fragmentation in the home ranges of individual birds may expose owls to greater risks of predation and competition. It may also result in habitat loss when trees blow down in high winds, and as stands suffer other impacts associated with forest edges.

Determining the number of northern spotted owls in existence has drawn considerable attention. Current data do not permit a statistically reliable population estimate. The approximately 2000 pairs located during the past 5 years or reconfirmed from pre-1985 surveys represent an unknown fraction of the total population. More significantly, demographic studies from the Klamath Mountains in California and the Coast Range in Oregon indicate that populations in these study areas are declining.

The Conservation Strategy
We propose a two-part conservation strategy. The first stage, prescribes and implements the steps needed to protect habitat in amounts and distribution that will adequately ensure the owl's long-term survival. The second stage calls for research and monitoring to test the adequacy of the strategy and to seek ways to produce and sustain suitable owl habitat in managed forests. Insights gained in this second stage can be used to alter or replace habitat conservation areas prescribed in the first stage, but only if the modified strategy can be clearly demonstrated to provide adequately for the long-term viability of the owl. 
Our strategy largely abandons the current and, we believe, flawed system of one- to three-pair spotted owl habitat areas (SOHAs), in favor of protecting larger blocks of habitat-which we term Habitat Conservation Areas, or HCAs.

Large blocks of habitat capable of supporting multiple pairs of owls, and spaced closely enough to facilitate dispersal between blocks, are far more likely to ensure a viable population than the current SOHA system. Owls in an HCA containing multiple pairs will benefit from internal dispersal of juvenile owls as well as recruitment of dispersing birds from other HCAs. Owls in HCAs containing multiple pairs are less vulnerable to random fluctuations in birth and death rates. Large HCAs reduce the impacts of habitat fragmentation and edges, and they are more resistant than SOHAS to small-scale natural disturbances.

The Committee has delineated and mapped a network of HCAs necessary to ensure a viable, well-distributed population of owls. Wherever possible, each HCA contains a minimum of 20 pairs of owls. The maximum distance between these HCAs is 12 miles. Our 20-pair criterion is based on models of population persistence and empirical studies of bird populations. We have chosen 12 miles as the maximum distance between HCAs because this value is within the known dispersal distance of about two-thirds of all radio-marked juveniles studied.

The HCA concept applies primarily to BLM, FS, and NPS lands, as delineated in the enclosed maps. The Committee strongly recommends that HCAs be established on State lands in certain key areas (as shown on the maps) to assure population connectivity. We also recommend that resource managers of other State lands, tribal lands, other Federal lands, and private lands use forestry and silvicultural techniques and practices that maintain or enhance habitat characteristics associated with spotted owls.

In several regions, current habitat conditions and owl densities do not allow us to follow this approach. The Committee has modified the guidelines for these regions. For example, in portions of the Oregon Coast Range, habitat is currently insufficient to fully stock 20-pair HCAs with owls. We have delineated 20-pair HCAs for this area, but they will be not be capable of supporting 20 pairs of owls for many years. In the meantime, individual-pair HCAs are prescribed around all known or future pairs to reach the 20-pair target.

A variety of strategies was used in other areas of special concern to help meet the intent of this strategy. Portions of the Cascade Range of northern Washington contain insufficient habitat capable of supporting 20-pair HCAs over the long term because of inherent landscape patterns. In these areas, we delineated a network of smaller HCAs but shortened the maximum distance between them to 7 miles, to facilitate dispersal.

In portions of the eastern Cascade Range in Washington and Oregon, and northeast of Mount Shasta in California, relatively little owl habitat exists and spotted owls occur at low densities. We prescribe individual-pair HCAs around all known pairs and pairs located in the future. 
Spotted owls on the Olympic Peninsula are probably demographically isolated from other populations by more than 60 miles of intensively managed State and private forest lands. We have established a large HCA on National Forest lands, but we also prescribe individual-pair HCAs around all known pairs outside the HCA and recommend smaller HCAs for State lands. Our hope is that connectivity can be restored by using a combination of HCAs and applying innovative silvicultural techniques on State and private lands.

Land ownership patterns in the Coast Range of California limit our ability to establish 20-pair HCAs. We have tried to do so wherever possible, but we encourage California to work with private land owners to apply innovative silvicultural techniques to maintain or develop additional owl habitat for dispersal and breeding. We encourage Oregon and Washington to do the same.

Logging (including salvage operations) and other silvicultural activities (with the exception of stand regeneration) should cease within HCAs. The Committee recognizes that allowances will have to be made for timber sales already planned and under contract in HCAs, such as sales necessary to meet Section 318 of Public Law 101-121.

We considered dedicating corridors of forests between HCAs to facilitate dispersal by juvenile owls, but decided corridors were unnecessary, provided at least $50 \%$ of the forest landbase outside of HCAs is maintained in stands of timber with an average d.b.h. of 11 inches or greater and at least $40 \%$ canopy closure. We also rely on lands currently allocated to such uses as riparian corridors, streamside management zones, and special management areas for pileated woodpeckers and pine martens to provide additional habitat for dispersing spotted owls.

We recommend retaining at least 80 acres of suitable owl habitat around the activity centers of all known pairs of owls in the managed forest, up to a total of seven per township. These centers will serve as older forest nuclei that could become core areas for future breeding pairs of spotted owls as the surrounding forest matures. If healthy populations of northern spotted owls can be sustained in the managed forest, HCAs will no longer be necessary. Timber havests that affect owl pairs outside the conservation areas are therefore viewed as experiments in managing for spotted owl habitat.

Consequences for the Northern Spotted OwI
The Committee believes this conservation strategy, if faithfully implemented, has a high probability of retaining a viable, well-distributed population of northern spotted owls over the next 100 years. The HCAs on Federal lands contain 925 known pairs of owls, and we estimate the actual number to be about 1465 pairs. Regeneration of younger stands within HCAs on Federal lands should enable the spotted owl population to increase to about 1759 pairs. These numbers are important, but only up to a point; the amount and spacing of habitat are as critical to the viability of the subspecies as the actual numbers. 


\section{Implementing the Conservation Strategy}

\section{Assessment of Impacts}

Under a worst-case scenario, even with this conservation strategy fully implemented, a short-term loss of a significant portion of the existing population of northern spotted owls is likely. We do not take this loss lightly, but we believe the subspecies can withstand a reduction provided our strategy is followed. Even under the most stringent scenarios of habitat protection, a similar reduction in the number of existing pairs over time seems likely because many pairs of owls live in highly fragmented and marginal habitats isolated from other pairs.

Implementing a comprehensive strategy for the spotted owl requires a well-coordinated program of research, monitoring, and habitat management by State and Federal agencies and private landowners. Much room for improvement exists. So far as we can determine, for example, no plans have been made within or among agencies to determine what changes in population size or habitat conditions would trigger a review of, and possible changes in management actions needed to ensure the welfare of the owl.

We urge that a coordinator and interagency staff (State and Federal) be assigned to oversee the conduct of the conservation strategy. The coordinating group would have the additional duty of recommending alterations to our conservation strategy. The plan put together by our Committee, however, is a strategy for the entire U.S. range of the northern spotted owl. No part of the strategy was designed to stand alone, and proposed changes must be considered in that light.

Our assignment was to develop a scientifically credible conservation strategy for the northern spotted owl. We recognize that the impacts of the strategy we propose will be analyzed by others. The immediate response, we expect, will be to focus almost solely on the short-term economic and social impacts of implementing the strategy as it affects the availability of timber. This assessment is critically important. Adoption of the conservation strategy, however, has significant ramifications for other natural resources, including water quality, fisheries, soils, stream flows, wildlife, biodiversity, and outdoor recreation. All of these aspects must be considered when evaluating the conservation strategy. The issue is more complex than spotted owls and timber supply - it always has been. 


\section{The Conservation Strategy}

\section{Introduction}

The Committee

Charter and the Team
The Concern
An Interagency Agreement between the Bureau of Land Management (BLM), the Fish and Wildlife Service (FWS), the Forest Service (FS), and the National Park Service (NPS) provided the authority under which a committee of scientists (hereafter, the Committee) was established to re-evaluate the current management status of the northern spotted owl. ${ }^{1}$ The charter commissioning the Committee was signed by the four agency heads on 5 October 1989 (appendix A). This charter, recognized in law in October $1989,{ }^{2}$ specifically directed the Committee to develop a scientifically credible conservation strategy for the owl in the United States. It did not charge us with analyzing the effects of the developed strategy on timber supply, other natural resources, or the costs and benefits to other user groups. This task falls to others.

The team that carried out the Charter assignment consisted of a six-member Committee, three advisors from involved States (Washington, Oregon, and California), interest-group advisors (representing the timber industry, environmental groups, and academia), and staff and advisors from the four agencies-BLM, FS, FWS, and NPS (see appendix $U$ for participants and their curriculum vitae). Thirteen of the 16 team members have extensive experience with research or management of the owl, or both. The team, collectively, was thoroughly familiar with the geographic areas under consideration, the owl habitat and distribution within those areas, the literature concerning the owl, and with ongoing research. Five team members are currently conducting research on the species.

Why all the fuss about the status and welfare of this particular bird? The numbers, distribution, and welfare of spotted owis are widely believed to be inextricably tied to mature and old-growth forests. Such forests have been significantly reduced since 1850 (mostly since 1950) by clearing for agriculture, urban development, natural events such as fire and windstorms, and most significantly, by logging in recent decades. Nearly all old growth has been removed on private lands. Most of the remainder is under the management of the BLM, FS, and NPS on Federal lands. As its habitat has declined, the owl has virtually disappeared from some areas and its numbers are decreasing in others.

\footnotetext{
1 For convenience, "spotted owl" or "owl" means the northern spotted owl (Strix occidentalis caurina). Full common names are used for all other owls, including other subspecies of the spotted owl. Scientific names of all organisms named in this report are given in appendix V, table V1.

2 Section 318 of Public Law 101-121.
} 
Scientiflc Credibility

The Human Factor
The apparent decline of the spotted owl has attracted the attention of various governing agencies. The State of Washington considers the bird "endangered." Oregon calls it "threatened." The California Department of Fish and Game (CDFG) identifies it as a "species of special concern." The BLM considers it a "special status species" and provides special management. The FWS, after being successfully challenged in court over a recent decision not to list the northern spotted owl, is again considering it for listing as a "threatened species" under the Endangered Species Act of 1973. The FS, following regulations issued pursuant to the National Forest Management Act of 1976, is responsible for maintaining viable populations of all native and desirable non-native, vertebrate species, well-distributed within each planning area. This mandate includes the owl, which the FS also considers a "sensitive species" and an "indicator species" for old-growth ecosystems.

Why all these laws and regulations? The evolution of laws dealing with the management of Federal, State, and private forest lands in the United States reflects increasing societal concern for environmental values. What seems to be emerging from this fermenting brew of law and regulations, public interest, and scientific debate is a growing concern with retaining and enhancing what scientists call "biodiversity." Clarity on the concept of biodiversity is only now emerging, but it is an evolving idea in the science and philosophy of biology that seeks precision in, and a means for applying, the common-sense admonition of Aldo Leopold that "...to keep every cog and wheel is the first precaution of intelligent tinkering." ${ }^{3}$

In gathering information to accomplish our Charter assignment to develop a "scientifically credible" conservation strategy for the owl, we realized that not everyone agrees on what assures scientific credibility. With that noted, we chose a path along which all of our steps, the processes by which we reached conclusions, and the data on which those conclusions rested, were fully open and available to anyone who chose to examine them. The open-door policy lasted until we began to prepare the final report during the last month of a 6 -month process. A nearly final draft was submitted for peer review by knowledgeable scientists selected by the presidents of five professional societies - the American Ornithologists' Union, the Ecological Society of America, the Society for Conservation Biology, the Society of American Foresters, and The Wildlife Society. This report includes many modifications made in response to the constructive comments of those reviewers.

Our conservation strategy was not, nor could it be, formulated solely from biological data. Various Federal and State laws and regulations, land ownership patterns, past and present land uses, landscape features, existing habitat conditions, current and anticipated allocation of forested land to various uses, regional and national cultures, and the reality of trade-offs in all land-use decisions also influenced our choices. To pretend that a workable conservation strategy for the owl can be derived and instituted without considering such factors is unrealistic. We did not, however, feel unduly constrained by these realities. Had we concluded that only total cessation of logging in remaining suitable habitat would save the owl, we would have so recommended. Conversely, we were equally prepared to state that the owl needed no protection, if that were indicated.

\footnotetext{
3 Leopold, A. 1953. Round River-from the journals of Aldo Loopold. Edited by Luna B. Leopold, Oxford University Press, N.Y., p. 147.
} 
How the Findings Are Presented

\section{The Spotted Owl and a History of This Issue}

\section{The Northern Spotted Owl}

HIstorical Perspective of Northern Spotted Owl Management
Conservation problems cannot be solved through biological information alone, nor from applying "scientific truth." Rather, solution comes from a combination of considerations that satisfy society's interests. A strategy that has any chance of adoption in the short term and any chance of success in the long term must include consideration of human needs and desires. To ignore the human condition in conservation strategies is to fail. We have searched for a way to assure the continuing viability of the owl that still allows continuation of some substantial cutting of mature and old-growth forests. Evaluation of the environmental and economic effects of the strategy we propose, however, was not within our purview. Such evaluation will be done by others more expert in these areas than are we.

The strategy is described in some detail in this part of our report, which includes discussion of most of the rationale behind our decisions. In addition, 22 appendices provide what we believe to be sufficient detail for readers to track what we have done and why. Our primary objectives were to develop a strategy to assure the viability of an owl population well-distributed throughout its range in the United States for at least 100 years, and to explain why we believe that strategy will accomplish these goals.

The northern spotted owl is widely distributed in forested regions of western Oregon and Washington, and in northwestern California, primarily in mature and old-growth conifer forests. The American Ornithologists' Union (AOU) recognizes three subspecies-northern, California, and Mexican. The AOU, the accepted authority in such matters, recently ruled that this classification will stand in spite of recent genetic findings that raised some questions about validity of the three subspecies (appendix $\mathrm{C}$ ). The spotted owl is a medium-sized owl with dark eyes, dark brown coloring with whitish spots on the head and neck, and white mottling on the abdomen and breast. Mostly nocturnal, it forages in forests, consuming small mammals such as flying squirrels, mice, and woodrats. During the day, it roosts in trees, frequently close to the nest site.

Pairs tend to occupy the same territories year after year as long as suitable habitat is present. One to three eggs, usually two, are laid in March or April. The female incubates the eggs and broods the young, while the male provides most of the food for the female and young. After leaving the nest in May or June, the young are fed by both parents until August or September. By October, the young become independent and disperse from the parental nest areas. Dispersing young become "4loaters" (see appendix O) and do not typically acquire territories until they are 2 to 3 years of age. Although a pair may occupy and defend a territory, they may not nest every year.

Before the early 1970s, little was known about the spotted owl in Washington, Oregon, or California, except that it resided in a variety of forest types. Early research in Oregon and California indicated an association with mature and old-growth forests.

Interest in uncommon species increased as Federal legislation dealing with endangered species in the late 1960 s culminated in passage of the Endangered Species Act of 1973. Interagency management efforts for spotted owls began in 1977, with the development of management guidelines for public lands in Oregon (appendix B). This effort expanded to Washington and California with the development of Forest planning guidelines for spotted owls under the National Forest Management Act. 
In response to public concern about habitat loss, the FWS undertook their first status review of the species in 1982. They found that Federal listing of the species as threatened was not warranted then. Responding to appeals challenging Forest planning standards and guidelines, however, the FS undertook a supplemental EIS on spotted owl management guidelines in Oregon and Washington. In California, the FS chose to handle management decisions through their Forest Plans. The BLM, in cooperation with the Oregon Department of Fish and Wildlife (ODFW), established habitat areas for spotted owls at 110 sites in Oregon, pending the completion of new District timber management plans.

Federal, State, and private industry research work expanded greatly in all three States during the mid-1980s in an effort to clarify the relation of the owl to its habitat. As a result of these efforts, concern for the species increased. The State wildlife agencies listed the species in Washington as endangered and in Oregon as threatened. The FWS was petitioned in 1987 to list the owl as threatened, but listing was again considered unwarranted. A court appeal led to rescinding that decision and resulted in another status review. A final decision on listing is due in June 1990.

Continuous litigation by interest groups over the logging of old growth resulted in Section 318 in the FY90 Appropriations Act, passed in October 1989, which provided some additional protection for old growth and existing areas now managed for spotted owls. Our Committee was established at the same time to develop a conservation strategy for the owl.

\section{Methods}

The Steps

Operating Sideboards
We established an agenda, schedule, objectives, operating procedures, and guidelines for deliberations. We then acquired information, examined owl habitat in the field, analyzed and synthesized data, and examined the current management situation. With that information as a foundation, we formulated a map-based conservation strategy, suggested administrative procedures to facilitate its implementation, and described a research and monitoring approach to evaluate the strategy and provide a feedback system for modifying it when and if information indicates such a need.

At our initial meeting, we agreed to the following operating procedures and sideboards:

- We will strive diligently for consensus.

- If consensus is impossible to achieve, a minority report will be appropriate. [Note: Consensus was achieved, so a minority report will not be issued.]

- The criteria for a successful conservation strategy will be rooted in the philosophy stated in the regulations pursuant to The National Forest Management Act to maintain viable populations that are well distributed.

- All land ownerships will be considered in the conservation strategy.

- "Hands on" management of habitats and animals will be considered, such as transplanting of owls, enrichment of gene pools, silviculture, and so on. 
- The effects of timber sale programs being carried forward under the HatfieldAdams Amendment will be considered in deriving the conservation strategy.

- Although the spotted owl issue is, to some degree, a surrogate for the old-growth issue-that is, on how much old-growth shall be preserved, where, and in what form-we will focus strictly on questions of spotted owl population viability across its occupied range.

- The best management for the northern spotted owl obviously is to preserve all stands of mature and old-growth timber within the range of the bird and to grow more such stands as soon as possible. Recognizing the real-world situation, however, we will consider a less than optimal approach to spotted owl habitat management that will, to the extent possible, simultaneously provide a high probability of population viability for the northern spotted owl, well-distributed within its range, and still allow the cutting of old-growth and mature timber. The Committee, however, considers as its primary mission (from the Charter) the mandate to "develop a scientifically credible conservation strategy for the northern spotted owl."

Sources of Information

Field Tours

\section{Data Synthesls}

We arranged expert presentations covering topics pertaining to conservation of the owl, (appendix E), and acquired and reviewed the relevant literature. We used information from all sources we considered appropriate, including refereed literature; reports from agencies, organizations, legal firms, and corporations; theses; unpublished data; draft manuscripts; and other sources. Data from this array of sources were extracted, tabulated, and summarized by topic. Most persons who are currently doing research and monitoring on owls presented their information to us. All information collected will be archived at FS Region 6, Portland, Oregon.

We agreed that all members of the team must have first-hand knowledge of owl habitat, management opportunities, and constraints in all portions of the subspecies' range. Accordingly, we spent 11 days touring and hiking through spotted owl habitat, visiting nest and roost sites, and discussing local situations with field biologists at each site visited in the various physiographic provinces in Washington, Oregon, and California (appendix E). This travel included visits to owl sites in a variety of forest age-classes ranging from young to old growth.

The Committee and staff summarized and synthesized data and other information derived from the sources noted above. These analyses, presented in appendices to this report, were the basis for developing and testing alternative, map-based conservation strategies, and ultimately selecting the strategy proposed here. Full understanding of how we reached key decisions cannot be attained without careful, detailed study of certain key appendices (especially C, F, I, and K through T). 
Workshops

Management Review of Ongoing FS and BLM Management

Information Support for a Conservation Strategy

Maps

Physiographic Provinces
We sponsored three workshops to acquire insights and advice from experts (appendix E). Twenty-six wildlife biologists experienced in owl management from the BLM, FS, and FWS met with us for 3 days. These biologists appraised geographically specific constraints and opportunities, reviewed several proposed alternatives for a strategy, and provided us with insights and judgments based on their collective knowledge and experience. We held two additional 3-day working sessions with many of these same biologists, during which they reviewed maps displaying layouts of blocks of habitat for the owl. They suggested some adjustments based on their intimate knowledge of the areas and owl distributions. Most of these biologists continued to provide consultation as our effort proceeded.

A 2-day workshop explored possible silvicultural alternatives to enhance owl habitat, and examined the potential of those alternatives for owl management. Participants included widely recognized silviculturists, landscape ecologists, forest ecologists, and foresters. A group of five silviculturists also was convened to assist us in preparing a report outlining potential silvicultural options (appendix $S$ ).

Our final workshop assembled experts in conservation biology and landscape ecology who, for 2 days, critiqued the evolving conservation strategy for spotted owls in light of their experience with other species and their knowledge of applicable theory (appendix E).

Consistent, high-quality management for spotted owls is critical to the successful implementation of any conservation strategy. We evaluated the quality and consistency of current management by interviewing FS and BLM managers and technical specialists in timber management and wildlife biology (appendix D).

We then considered whether available information sufficiently warrants instituting a conservation strategy, given its obvious economic and social impacts. Variability exists in all biological data, and answers to some important questions will probably always be uncertain, but the knowledge about spotted owls is extensive and impressive. We believe the basic message emerging from the sum of that knowledge, particularly about trends in the amount of suitable habitat and the numbers of owls, justifies a conservation strategy. In some areas of the owl's range, few habitat options remain and those are disappearing rapidly. If our true objective is to assure a viable population of spotted owls, widely distributed throughout their current range, then delay in instituting an adequate conservation strategy for the owl cannot be justified because of inadequate knowledge or understanding.

The process of formulating a strategy next turned to maps. Maps provided us with visual information about the geographic distribution of the owl and suitable owl habitat, current locations of owls, and areas reserved from timber harvestWilderness Areas, National Parks, currently designated owl-management areas, Research Natural Areas, riparian and visual corridors, and so on.

Because the owl's range is so extensive, we subdivided it into smaller areas for practical and analytical purposes. Demographic studies of owls have revealed variations in numbers, distribution, and habitat-use patterns by forest zones (for example, western hemlock versus mixed-conifer). "Physiographic provinces" provide a recognized set of landscapes by which we have subdivided the range (fig. C2, appendix C). 


\section{Developing Standards and Guidelines}

\section{Mapping the Strategy}

\section{The Current Situation}

\section{Distribution}

From literature reviews and consultation with specialists in ecology and conservation biology, we reached a general agreement on basic concepts that should guide conservation planning for numerous species, including the spotted owl. Based on these concepts, we then developed standards and guidelines (appendix Q) for generating a map-based strategy. Working in teams for each geographic province or State, the Committee and agency biologists delineated proposed habitat blocks on acetate map overlays. Decisions on the number, size, shape, and location of the blocks were based on the current and potential distribution of suitable owl habitat, the current distribution and densities of owls, existing land ownerships, owl home-range and habitat use, owl dispersal capabilities, current and potential "bottleneck" areas that might isolate subpopulations of owls, and general ecological principles of conservation biology.

A map was created to represent a unique "solution" with a specific distribution of habitat blocks of various sizes. This map was then evaluated, to the extent possible, by applying both personal judgment (using site-specific knowledge) and quantitative evaluation of specific components of the standards and guidelines (see appendix $Q$ ). Any conclusions drawn from these tests that failed to confirm specific properties of the map (for example, the size or location of management areas) were used to redraw and refine the map. The new map was then similarly tested until a solution was reached that met all criteria specified in the standards and guidelines. We drafted and tested maps for at least 10 iterations using this method. Each iteration was drafted, tested, and adjusted until all map properties were confirmed or explained and the process was considered final.

Descriptions of the management situation in each geographic province occupied by the owl supplemented the map (appendices $C$ and $Q$ ). These descriptions focused on problems and opportunities unique to owls in each area, based on current and anticipated future availability of suitable habitat, considering land ownership, site characteristics, distribution of owls, and management options. The values and rationale used to establish the size of each block were habitat descriptions (appendices $F, G$, and $H$ ), home-range sizes and characteristics (appendix I), and population persistence related to population size (appendices $M$ and $O$ ). Spacing between blocks and the nature of the "connecting" habitat needed to facilitate dispersal of birds from one block to another, were established as described in appendix $P$.

The present range of the spotted owl includes most of its historic range (fig. C1, appendix C), encompassing an area from southwestern British Columbia, southward through the Coast and Cascade Ranges (both west and east sides) of Washington and Oregon, and into southwestern Oregon and northwestern California, north of San Francisco. Although the owl still occupies much of its historic range, its distribution within that range has decreased. For example, spotted owls probably once resided in forested areas of the Puget Trough in Washington and adjacent to the Willamette Valley in Oregon, but those areas have largely been harvested or converted to agricultural and urban uses. Similar but less complete habitat changes appear to have negatively affected owl distribution and abundance in southwestern Washington and northwestern Oregon, where pervasive timber harvest and wildfires have eliminated most older forests. 
Areas of Special Concern

The Situation by Land Ownership
Lands throughout the owl's range differ in quantity and quality of forested habitat. Ownership patterns result in an array of land treatments with various effects on owl habitat. Wildfires, windstorms, and volcanic eruptions have played a major role in shaping conditions in owl habitats today. We identified "areas of special concem" in physiographic provinces where past fires, windstorms, timber cutting, and conversion of forest land to other uses have had greater impacts on owl habitat than elsewhere. Special management for owls is required in these more impacted areas.

FS lands-About $74 \%$ of the 7.1 million acres of owl habitat estimated to exist in 1989 occurred within 17 National Forests that are managed for multiple uses. Forest Service managers must assure the continued existence of spotted owls, welldistributed throughout their range, while at the same time meeting other resource requirements, including timber sale targets. Logging is currently the main cause of decline in suitable habitat for the owl. Harvest rates on National Forests indicate that logging will proceed at the rate of about 71,000 acres of suitable owl habitat per year, if present trends continue. If the FS preferred-alternative plans for Forests with spotted owls are implemented, the acreages of suitable habitat harvested per year will decline by 25 to $30 \%$, even without adoption of our proposed conservation strategy.

The Endangered Species Act of 1973 was probably the catalyst that triggered FS interest in the welfare of the northern spotted owl. That interest intensified with selection of the owl as an "indicator species" for dwindling old-growth ecosystems. As a result, the FS implemented a plan to provide a network of habitat areas to be managed for spotted owls.

Each habitat area established under the FS plan was designed to support one to three pairs of owls through time and intended to assure continued existence of the bird over the long term. To date, 654 of these management areas have been delineated. Standards and guidelines, used to establish the management areas, prescribed significantly less suitable habitat than both the mean and median amount found to occur in home ranges of owl pairs (appendix I), and $161(25 \%)$ of the management areas contain less than the amount of habitat prescribed in the guidelines.

BLM lands-The BLM controls about $12 \%$ of the remaining habitat suitable for northern spotted owls. Most of these lands are in Oregon. The current policy for managing these lands, most of which occur in a "checkerboard" pattern of alternating sections (1 square mile, or 640 acres) of private and public ownership, specifies that timberlands shall be managed under sustained-yield principles to provide a permanent source of timber supply, watershed protection, streamflow regulation, and recreational opportunities. 
A policy statement of 16 March 1983, from the Director of the BLM, interpreted the Oregon and California Railroad Grant Lands Act of 1937 as allowing consideration of Oregon's goals and objectives for State-listed "threatened or endangered" species. The policy specified that timber harvest could be restricted through land-use planning to achieve habitat objectives for such species. In response, the BLM provided some habitat through land-use plans and also established 110 interim management areas in agreement with the ODFW, until land-use plans are completed in 1992. In California, BLM lands are managed under the Federal Land Policy and Management Act of 1976, which calls for multiple use, including consideration for wildlife.

NPS lands-About $8 \%$ of existing suitable owl habitat is found within eight National Park areas in Washington, Oregon, and California. These parks have not been thoroughly or systematically surveyed. About $110 \mathrm{owl}$ pairs are anticipated, based on the total amount of suitable habitat in these areas. Olympic National Park probably contains habitat for 60 to 80 pairs. Populations in other NPS areas range from 1 to 20 pairs. Management objectives for National Parks are generally considered to be compatible with providing habitat for spotted owls.

Indian lands-Tribal lands of the Quinault, Makah, Yakima, Confederated Warm Springs, Confederated Grande Ronde, Siletz, Hoopa, and Round Valley Indian Nations contain significant acreages of forest, most managed for timber production, with most already logged. The amounts of suitable owl habitat are not known precisely and inventories for owls have not been done on most tribal lands. Some Indian Nations presently have some lands reserved from timber harvest; these lands may contain several pairs of owls. The long-term occupancy of those sites probably depends on their proximity to FS and BLM lands with suitable owl habitat.

FWS lands-The FWS administers several National Wildlife Refuges within the range of the owl. Two refuges in Oregon and two in Washington contain small parcels of suitable owl habitat.

State lands-A small percentage of the existing suitable habitat occurs on lands owned by the States, although extensive forested areas exist that could, in time, produce suitable owl habitat. These lands are administered by several agencies within State governments and can be grouped into three categories-parks, forests, and wildlife lands.

State parks with owls range from a few hundred to about 50,000 acres. Because parcel size tends to be small, owl occupancy is strongly influenced by the condition of surrounding forested lands. Management objectives are generally compatible with maintaining owl habitat. No timber harvest is scheduled, but salvage operations often remove trees that have blown down or are a hazard to recreationists. 
Areas of forested lands administered by State wildlife agencies are extremely limited. The Washington Department of Wildlife (WDW) has three areas of 25,000 to 50,000 acres that do not now contain suitable owl habitat. Forests on those lands could develop into suitable habitat, however, and WDW policy calls for more than $50 \%$ of the landbase in these areas to be managed to attain old-growth characteristics. The ODFW has two parcels primarily covered with younger forests. Owl occurrence is unknown on those areas, but surveys are planned for summer 1990. Eel Lake, a small parcel, has a timber-management plan for logging $80 \%$ of the area over 30 years. No logging is planned on the other parcel until a forest-management plan is completed in 1990.

State forests are managed primarily for timber production. The States own extensive forests, but because of past logging and fires, only small amounts of older stands now remain. Rotation schedules currently average 70 to 80 years. Whether suitable owl habitat will develop in the latter part of such rotations depends on site productivity, climate, residual older trees, and dead woody material on the ground. Plans dictate cutting most of the remaining older stands of forest during the next 10 to 30 years, although some areas have been reserved from timber cutting, generally in scattered parcels or corridors.

Forest Policy Acts of each State differ in requirements for streamside corridors or other areas reserved from timber harvest that might provide habitat for owls. The Washington Department of Natural Resources (WDNR) has deferred harvest until the year 2005 on a 15,000-acre block of older forest near the Olympic National Park and the Olympic National Forest. The California Department of Forestry (CDF) currently has no owl-management plan but is leading an effort to prepare one for the State that will address conservation of owl habitat on private and State lands. One State Forest (Jackson) has significant potential to contribute to the welfare of spotted owls in California, but changes in present practices would be required.

Forest management operations on State and private lands in Oregon are governed by rules promulgated under the Oregon Forest Practices Act. The Act, amended in 1987, requires the Board of Forestry to adopt rules protecting State-listed wildlife species and nesting sites of "sensitive" bird species. Interim rules require a written plan to be approved by the State Forester when any forest operation will occur within 300 feet of the nesting or roosting site of a species listed as either sensitive, threatened, or endangered. Until final rules are adopted in 1991, protection is handled case by case.

\section{Habitat}

Evaluation of Habitat Suitability
Private lands-The two major categories of private land include "timber industry" lands (usually large companies), and lands owned by individuals. Most timber industry lands are intensively managed to produce wood. In northwestern California in 1989, owls were reported from 282 sites (99 pairs were verified) on private lands. Because most private lands in California will undergo timber harvest at economically opportune times, the quantity and distribution of owl habitat there will vary. The specifics of such variation, including possible effects on owls, are unknown. 
Amounts of suitable habitat and numbers of owls on timber-industry lands in Oregon and Washington are largely unknown. Most forests are managed on rotation ages of 70 years or less, with some on 40 -year rotations. Clearcutting is the primary silvicultural prescription for harvest and regeneration. Fewer than 30 occurrences of owls have been documented on private lands in these two States. Additional surveys are needed on private lands in these areas to determine whether owls are as uncommon there as current data indicate.

In summary, the large number of State and Federal agencies and entities managing lands with owl habitat, and their varied land-use objectives, produce circumstances not conducive to a comprehensive, biologically based, consistent management strategy. Even between subunits of the same agency, regulations and management directives are often applied differently.

The Current Management Strategy for Spotted Owls
Current management of FS lands in Washington, Oregon, and California and of BLM lands in Oregon includes establishing a network of spotted owl habitat areas that are reserved from logging and are intended to provide enough suitable owl habitat to support one to three pairs of owls. These areas are called SOHAs by the FS and BLM-ODFW Agreement Areas by the BLM; hereafter, we refer to them all as SOHAs.

A circle approximating the annual home range of a pair of spotted owls was used to bound areas within which SOHAs on FS lands were delineated. These circles ranged from 1.5 to 2.1 miles in radius, and amounts of prescribed suitable habitat ranged from 1000 to 3000 acres, depending on physiographic province. These value ranges were based on observed differences in home-range sizes and amounts of suitable habitat used by radio-marked birds in different physiographic provinces. Acreages of suitable habitat are prescribed well below the mean and median amounts used by radio-marked spotted owls (see appendix I). In some areas, SOHAs are clumped into groups of three. Distances between edges of such clumps or clusters can be up to 14 miles. A maximum spacing up to 7 miles, edge-to-edge, is prescribed between single-pair SOHAs.

The actual SOHAs consist of a set of forest stands, within the circle and identified as suitable owl habitat areas and are reserved from logging. The original circle within which these stands were identified is not, itself, the SOHA boundary. Because of past logging and fire history, SOHA habitat is seldom contiguous. The SOHAs, therefore, are most often irregular in shape, with younger patches of unsuitable habitat interspersed among the stands of suitable habitat comprising the SOHA. The result is fragmentation of suitable owl habitat at the landscape scale (the SOHA network) and at the SOHA scale.

Forest fragmentation appears to have a deleterious effect on the quality of owl habitat, but full understanding is lacking (appendices $\mathrm{N}$ and $\mathrm{O}$ ). The creation of abrupt edges by clearcutting makes the remaining stands more vulnerable to blowing down in windstorms. Fragmentation continues to get worse because forest stands within the circle, but not designated as part of the SOHA, are subject to logging. Whatever suitable owl habitat exists between reserved stands that comprise the SOHA will likely be logged, further fragmenting the SOHA from within. 
Review of Current Management
Methods used to delineate SOHAs differ between FS Region 6 (Washington and Oregon) and Region 5 (California). The SOHAs were not allowed to overlap in Oregon or Washington, but a $25 \%$ overlap between SOHAs was allowed in California. No "reserve" habitat to replace stands in SOHAs lost to natural disturbance was provided in Oregon or Washington, but some younger stands were so identified in California.

The BLM SOHA goal was to reserve at least 2200 acres of conifer forest $>80$ years old within 3 miles of owl activity centers. Because suitable owl habitat is usually found in mature and old growth, stands between 80 and 100 years old are better regarded as marginal habitat. No restrictions on logging apply to private lands that occur within SOHAs designated by BLM, and nearly all private lands in this area of checkerboard ownership have already been logged, usually by clearcutting. Some are being logged for a second time. Thus, on a landscape scale, forest conditions described as suitable habitat for spotted owls are already severely fragmented into older and much younger forests. As a result of the checkerboard ownership and the fact that timber on private lands is managed almost exclusively for economic reasons, little or no opportunity presently exists to change the fragmentation that results. The BLM considers their SOHAs to be "interim" until their next generation of Resource Management Plans are completed in 1992. With minor exceptions, logging within these areas on BLM lands has been deferred until then.

Team members interviewed line officers, timber staff, and wildlife biologists from National Forests and BLM Districts and from FS Districts and BLM Resource Management Areas on nine randomly selected Forests in Oregon, Washington, and California, and from three BLM Districts in Oregon. Our objective was to evaluate the implementation of current management guidelines and policies for spotted owls.

Major findings from this effort revealed several problems (see appendix D). Respondents recognized a significant and perhaps irreconcilable conflict between providing required amounts of habitat for spotted owls, and meeting current and anticipated amounts of timber harvest. Several line officers in both the FS and BLM perceive increasing the time and money spent on spotted owl management as usurping resources needed for other programs, especially those aimed at other species of wildlife. Habitat throughout the range of the spotted owl is managed by many agencies and land owners with differing land-use objectives.

The BLM and FS have implemented management plans requiring delineation of SOHAs to be protected for owls, but little consistency exists between agencies. Differences exist even between administrative units of the same agency (see appendix D). The result has been a lack of consistent, comprehensive management planning based on the biological requirements of spotted owls. Inventory efforts differ widely in intensity and technique. Data from inventories between agencies are sometimes not compatible. Consequently, much confusion exists and opportunities that would increase biological understanding of spotted owls have been lost. Credibility of the agencies has also suffered.

We believe that the current situation - that is, the lack of a well-coordinated, biologically based management plan applied consistently throughout the range of the spotted owl-is unacceptable and has contributed to a high risk that spotted owls will be extirpated from significant portions of their range. 
We summarized studies about owl habitat (appendix F), and the relative abundance of owls in relation to stand age (appendix G) and to the proportion of the general landscape in suitable habitat (appendix $H$ ). Appendix $F$ provides details on the structural attributes of stands judged to be suitable or superior habitat for spotted owls. We stress here that less emphasis should be placed on the ages of forests in determining their suitability as owl habitat; instead, emphasis should be on vegetational and structural attrlbutes that comprise good owl habitat. For our evaluation of habitat suitability, we examined the types of forest that were consistently selected for foraging and roosting by radio-marked owls. We consider these stands to be suitable to supenor habitat (appendix F).

Most studies of habitat use (appendix F) indicate that superior habitats for owls in Washington, Oregon, and northwestern California have moderate to high canopy closure ( 60 to $80 \%$ ); a multilayered, multispecies canopy dominated by large ( $>30$ inches in d.b.h.) overstory trees; a high incidence of large trees with various deformities (for example, large cavities, broken tops, dwarfmistletoe infections, and other indications of decadence); numerous large snags (standing dead trees); large accumulations of fallen trees and other woody debris on the ground (appendix F); and considerable open space through which owls can fly within and beneath the canopy.

The attributes of superior owl habitat, found most commonly in old-growth forests or mixed stands of old-growth and mature trees, usually do not become prominent until stands are 150 to 200 years old. Such features are sometimes found in younger forests, and especially in those that include significant remnants of earlier stands that were influenced by fire, windstorms, inefficient logging, or high-grading (removing the most valuable trees and leaving the remainder uncut). We have seen sites throughout the owl's range where these events resulted in old-growth inclusions in relatively young forests $(60+$ years) that now support breeding owls. But, with few exceptions, the nest and major roost sites are found where elements of the earlier, older stands remain.

An interesting exception to the usual time needed for a forest to develop from bare ground into suitable owl habitat occurs in the coastal redwood forests of northwestern California, where owls occur in relatively high numbers in stands 50 to 80 years old. This exception is likely attributable to a unique set of conditions: a rapidly growing tree species (redwood) with stump-sprouting capability; early intrusion of other conifers and several hardwoods into the understory; relatively high rainfall; a long growing season; and an abundance of dusky-footed woodrats and brush rabbits as prey (appendices F, G, and J). Under these conditions, structural attributes needed to support occurrence and breeding of owls apparently develop at an accelerated rate, with suitable conditions for owls occurring in 40 to 60 years on some sites and superior conditions in 80 to 100 years. Because these unique conditions occur only in about $7 \%$ of the owl's range, we strongly caution against assuming that they will occur elsewhere. Additional studies are needed for a better assessment. 


\section{Trends in Habitat and Owl Numbers}

Habitat

Population Densities and Numbers of Owis

\section{Demography}

Habitat for the owl has been declining since the mid-1800s, when European settlers arrived, although the extent of suitable owl habitat before the 1800 s is difficult to quantify. Estimates of 17.5 million acres in 1800 and about 7.1 million acres remaining today indicate a reduction of about $60 \%$ (appendix $\mathrm{C}$ ). This figure may, however, underestimate the full extent of the decline, based on recent inventory data collected by environmental groups. Most of this reduction occurred in the last 50 years. The exact degree of reduction would be interesting to know but not very useful. Undoubtedly, a significant reduction has occurred in owl habitat, and that reduction continues at a rangewide rate of 1 to $2 \%$ per year (appendix C).

Piecemeal inventory and monitoring of owls has occurred throughout the range since the early 1970s. Not until the mid-1980s, however, have these efforts been extensive enough to begin providing reasonably good information about the distribution and abundance of owls throughout their range. These results indicate about 2000 pairs located during the last 5 years, representing some unknown fraction of the true number of pairs. Because a census of the total population is not available, we have no statistically reliable population estimate. Recent claims of actual counts of some 6000 birds in 1989 are not out of line with other information from monitoring and inventory efforts.

Population densities of owls are lowest in the northern portion of the species' range, with fewer than 20 pairs known from recent, extensive surveys in British Columbia. The extent of the historic range in British Columbia leads us to believe that original populations were likely many times greater than the current population. Most of British Columbia within the owl's historic range has been logged, and, as a result, little mature and old-growth forest remains.

A small, demographically isolated population of about 100 to 150 pairs (only 88 pairs are actually known at this time) of owls is located on the Olympic Peninsula, in and around Olympic National Park. Fewer than 40 individual owls have been located in recent surveys in the Coast Ranges of southwestern Washington and northwestern Oregon, north of Corvallis. The population also decreases from the Mendocino National Forest south to Point Reyes, California, and from the Klamath Province east to the contact zone with the California subspecies in the Sierra Nevada.

Results from two study areas where owl demographics were examined-the Klamath Province in California and Roseburg BLM lands in Oregon-suggested that owl populations in both areas were declining during the study period (see appendix $L$ ). The most ready explanation for this decline is the loss of suitable habitat. Loss of habitat area, however, only partially accounts for the magnitude of the decline. The spatial arrangement of the remaining habitat must also be considered. Widely dispersed habitat blocks may be unoccupied because of the low probability of successful dispersal to such patches. We caution that the results of these studies cannot be safely extrapolated into future population changes or to the population of spotted owls as a whole. 
In both areas, the population growth rate was most sensitive to changes in the adult survival rate, distantly followed by the survival rate of 1 st-year birds and fecundity. Two sources of information are relevant to the rate of change of a population. The first is the mathematical sensitivity of the rate of change in a population from one year to the next resulting from variation in the birth and death (vital) rates. The other concerns vital rates that are naturally the most variable (such as 1st-year survival). A population's growth rate may be more affected by a vital rate that changes dramatically from year to year than by one to which it is more sensitive in a mathematical sense. Preliminary estimates of the magnitude of natural variation of vital rates from the Klamath Province of California show little variation in adult survival, but substantial annual variation in the survival of 1st-year birds.

Results of these analyses give us reason to argue strongly that estimates of population parameters (for example, birth and death rates, population turnover) should be used to infer the rate and direction of population change, instead of the counts of individuals and pairs now being used from the FS monitoring program. For example, a long-lived species experiencing a rapid decline in habitat may exhibit increased density from packing (crowding) into remaining habitat by individuals displaced from elsewhere. The disquieting aspect of this phenomenon is the fact that population densities in a given study area may be increasing at a time when the population is not reproducing at a rate sufficient to maintain itself (see appendices $L, N$, and $O$ ). This phenomenon tends to render useless any measures of density as indicators of the general "health" of a population.

Displaced birds may remain nonterritorial and nonbreeding after packing into remaining suitable habitat (that is, they join the floater population-see appendix O), and they may also lower the breeding success and survival rates of territorial birds. These effects result because excess birds, even nonbreeders, may reduce prey availability for territorial birds. A similar effect is believed to have a significant negative impact on survival rates of subadult birds, which are less experienced than adults and tend to be lower in social status. Consequently, any increased competition for prey should have a greater impact on these inexperienced birds.

Conclusions From Modeling
We drew inferences from two simulation models with different structure. The first was developed to crudely approximate the current management design-SOHAs for one to three pairs of owls, dispersed across the landscape with distances between them of 6 to 12 miles. In this model, we varied several parameters, including the distance between SOHAs, dispersal capabilities of adult and young owls, percentage of the landscape that was suitable owl habitat, and different rates of habitat loss from logging. Our purpose was to explore general system properties in an attempt to identify aspects of the owl's life history and behavior that most influence its long-term population dynamics. 
In a second model that considered only females, we allowed territories occupied by females (assuming that they were members of pairs) to be adjacent to each other in clusters of 5 to 25 pairs. The primary goal of this effort was to investigate the advantages of relatively large clusters of ternitories compared to the single- and small-cluster pattern of the current SOHA network. In this model, we assumed that successful dispersal within the natal cluster was more likely than dispersal between clusters. It also seems a logical assumption that the general forest landscape is less hospitable for dispersing birds than the comparatively unfragmented landscape where habitat is aggregated into blocks large enough to support multiple pairs.

We believe that three major conclusions can be drawn from these modeling efforts. First, two rather sharp thresholds exist, either of which can lead to the ultimate extinction of the population. One results from the loss of habitat. As habitat is reduced to small, isolated patches, a dispersing bird's ability to find a suitable territory becomes increasingly difficult and, finally, impossible. The other threshold results from total numbers dropping so low that the probability of finding a mate drops below that required to maintain a stable population. Both results indicate that a species can be severely habitat-limited, even in the presence of suitable but unoccupied habitat.

Second, modeling a dynamically changing system critically affects the analysis and results. The packing of owls into remaining suitable habitat, as a consequence of habitat loss, is likely to produce higher than normal occupancy rates in the short term, and much higher rates than expected under long-term equilibrium conditions. As a result, we recommend care when drawing inferences about long-term abundance from measures of short-term occupancy.

Third, our cluster-model suggests that providing for clusters of pair territories increases the likelihood of owl persistence, primarily by enhancing the successful dispersal of juvenile birds and allowing for rapid replacement of territorial birds that die. Stable population numbers and high rates of territorial occupancy, however, were not observed until clusters contained at least 15 to 20 adjacent territories.

Habitat Fragmentation

Most timber harvest in western Washington, western Oregon, and northwestern California is in patch clearcuts of about 40 acres. This harvest pattern results in both habitat loss and fragmentation. How much of the decline in habitat suitability for owls results from direct loss of habitat and how much, if any, from fragmentation is difficult to discern. Nevertheless, habitat fragmentation may present additional risks for owls, including hypothesized deleterious effects of increased edge between clearcut areas and remaining habitat, and increased risk of predation on adults and young. Fragmentation may also increase the potential for spotted owl displacement by barred owls and great horned owls, the potential loss of microhabitats that lessen effects of weather and provide habitat for prey species, and the potential loss of habitat providing refugia during catastrophic events. 
The Conservation Strategy for the Northern Spotted Owl

\section{Basic Concepts}

Habitat Conservation Areas
These hypothesized effects of habitat fragmentation on the persistence of the owl may be partially lessened by conservation planning. A strategy that attempts to provide the owl with habitat distributed across the landscape, in a fashion most similar to the historical configuration in which the owl evolved, should provide the best hedge against future extinction. Although that historical configuration cannot be precisely described, it can be surmised with some confidence. An examination of remaining pristine tracts of forest and of aerial photographs taken in the 1950s and 1960s before extensive logging took place, reveals that forests of the past were much more extensive and contiguous than the managed forests of today.

We conclude that the persistence of the owl is imperiled in significant portions of its range by continued loss and concomitant fragmentation of its habitat. This loss has included much habitat that was likely to have been superior for the owl, especially at lower elevations. Loss of superior habitat has led to the fractioning of a formerly more continuous population into smaller, more isolated demographic units. Many of these units are at risk of local extinction because of demographic factors and environmental phenomena.

The conservation strategy described here was built on a foundation of five concepts of reserve design that are widely accepted among specialists in the fields of ecology and conservation biology (see appendices $\mathrm{N}, \mathrm{O}$, and $\mathrm{P}$ ):

- Species that are well distributed across their range are less prone to extinction than species confined to small portions of their range.

- Large blocks of habitat, containing multiple pairs of the species in question, are superior to small blocks of habitat with only one to a few pairs.

- Blocks of habitat that are close together are better than blocks far apart.

- Habitat that occurs in less fragmented (that is, contiguous) blocks is better than habitat that is more fragmented.

- Habitats between blocks function better to allow owls to move (disperse) through them the more nearly they resemble suitable habitat for the species in question (that is, blocks that are well connected in terms of habitat are better than blocks that are not).

Our acceptance of these concepts as the foundation for the conservation strategy led us to propose the establishment of an array of habitat blocks containing multiple pairs of owls. These blocks should be well distributed throughout the range of the owl and spaced closely enough to facilitate dispersal of owls among them. In our conservation strategy, we refer to all blocks of habitat designated for owl conservation as Habitat Conservation Areas (HCAs). These areas can vary from being large enough to contain only one pair when better alternatives do not exist (appendix Q) to a size that now contains, or will become capable of containing, over 50 pairs. In fact, some HCAs in our proposed strategy are not known to contain owls now. Some are small blocks of habitat in strategic locations that could become core areas for pairs if the surrounding habitat in the forest matrix is managed appropriately. Targets for HCA 
Setting the Size of HCAS sizes and spacing between them are described below. The conservation strategy is depicted on enclosed maps and spelled out in detail in the standards and guidelines (appendix Q). Although we briefly indicate certain features of the strategy here, they are necessarily abbreviated. All questions concerning implementation of the strategy should rely solely on appendix $Q$.

Inferences from the literature-Empirical data guided us to an HCA size large enough to support some multiple number of owl pairs, but not to a certain "best" number. Existing quantitative studies concern species other than the spotted owl, and most only approximate the geographic and landscape situations we face in designing a strategy. Studies that bear on this question, however, suggest that an HCA with 15 to 20 pairs has a moderate to high likelihood of persistence for at least 50 years and a moderate likelihood of persistence for 100 years, even with relatively little or no movement of individuals between HCAs (appendix O). For example, the Channel Islands of California are 32 to 157 miles from the mainland. Extinction rates of bird populations there suggest that initial populations of about 20 pairs have about an $85 \%$ chance of persisting for about 100 years. "Rescue effects" by immigrants making the trek over water from the mainland, however, must be relatively small in the Channel Islands example. On the other hand, examples from some British islands that are considerably closer to the mainland indicate considerably higher persistence likelihoods for populations of 15 to 20 pairs (appendix 0 ). We believe this difference is because the rescue effects of mainland immigrants entering the island populations occur rather frequently across the moderate water gaps separating the British islands from the mainland. The dynamics of dispersal by spotted owls in forested landscapes more closely approximate the British island situation.

Inferences from modeling-Attributes of clusters of territories, in terms of expected persistence with various numbers of owl pairs, were examined through modeling (appendix M). Similar to other such efforts, our results suggest that clusters of pairs (as compared to single pairs) will increase the likelihood of owl persistence, primarily by facilitating dispersal of juveniles. Estimating a critical cluster size is most difficult. With the structure of our model, clusters equal to or greater than 15 pairs appeared stable if all sites were initially suitable, and if intervening habitat allowed at least moderate dispersal between clusters (see appendix P). Under more realistic conditions in which HCAs would not initially be a continuous habitat, stability seemed to require at least 20-pair clusters and low to moderate connectivity between HCAs. Individual owls that are members of a large-cluster population are less susceptible to the vicissitudes of between-cluster dispersal and the character of the intervening landscape (appendix M).

Number of pairs-Because empirical and modeling results both suggest that clusters of 15 to 20 pairs should be stable over the long term, even given low to moderate rates of dispersal among them by juvenile owls, and because many of the HCAs delineated do not contain homogeneous, unfragmented owl habitat, we concluded that HCAs should, wherever possible, contain or have the potential to contain 20 or more pairs of owls. 
We believe that the system of HCAs suggested provides a very low probability that any given HCA with 15 or more pairs will lose all of its owls at the same time, especially in a network that includes many such habitat blocks separated by distances and habitat connectivity consistent with known owl dispersal capacity (appendix P). Indeed, such an arrangement of HCAs probably functions more like a single, interacting population than as a set of isolated subpopulations. On the other hand, even relatively large HCAs for owls have uncertain fates if they are currently well below their anticipated carrying capacity. Areas with HCAs in this condition, as in portions of the Coast Range in Oregon, will need to be closely monitored while owl habitat there recovers.

Models of population dynamics of long-lived vertebrates are difficult to validate. Perhaps the best confirmation of inferences from our model is that they are generally supported by results from empirical studies (appendix 0 ). The output and inferences drawn from a model are always a reflection of the model's structure; our models are not exceptions. Clearly the patterns observed in simulations reflect the model's structure and the assumptions made about owl behavior. For example, our model and its results are the consequence of assumptions made about the dispersal behavior of juvenile owls within and between clusters. Unfortunately, little is known of owl dispersal behavior and movement patterns through heterogeneous landscapes (but see appendix P).

The theory that increasing HCA size will have a positive effect (with size defined by the potential number of owl territories within) is strongly supported by both empirical and theoretical studies. Populations quickly escape from the dangers of demographic stochasticity (random fluctuations in birth and death rates) with even slight increases in population size. Populations also gain security from environmental uncertainty with increasing numbers, but at a much slower rate than from demographic effects. Therefore, this result from modeling was not surprising. Of interest, however, was that marginal gains in mean occupancy with incremental increases in HCA size were not constant. Rather large gains occurred in moving from HCAs of 5 to HCAs of 10 territories; smaller gains were made in moving from 10 to 20 territories per HCA (appen$\operatorname{dix}$ M). Models that considered the probability of occupancy of all territories within an $\mathrm{HCA}$, as influenced by the size of the HCA and the amount of suitable habitat within it, yielded additional insights. The smaller the HCA and the less the amount of suitable habitat, the lower the percentage of the territories that are likely to be occupied at any one time. Therefore, the number of pairs of owls actually present at any point in the future will likely be less than the potential, as judged from the total number of suitable territories in the HCAs. These models provided information that was used to adjust the number of owl pairs that could be expected from all the HCAs in the network (see appendix Q, table Q3).

Setting the Distance Between HCAs
Dispersal in animals is the relatively permanent movement of individuals from one location to another. Usually dispersal is the movement of juveniles from their natal area to a site where they eventually breed. When large blocks of suitable habitat exist, the rate of successful dispersal from one block to another declines with increasing distance between them. 
Connectivity Between HCAs
Based on available data from 56 juvenile northern spotted owls equipped with radio transmitters, we set the maximum distance between HCAs with at least 20 territory sites (at their nearest points of separation) at 12 miles (appendix P). This distance is within the known dispersal distance of about $66 \%$ of the owls studied (because we know of no objective criteria for setting such a distance, this decision was based on a Delphi approach; see appendix $P$ for discussion of the rationale). Owls that tend to disperse shorter distances will have opportunities to find vacancies in the breeding population within their natal HCA. Where existing conditions precluded delineation of HCAs large enough to contain at least 20 pairs, now or in the future, we opted for a shorter maximum distance between areas. This distance is 7 miles, which is less than the median dispersal distance estimated from 20 color-banded juveniles and within the dispersal range of more than $75 \%$ of all radio-marked juveniles studied (appendix P). Our intent was to increase the likelihood of successful dispersal from one HCA to another as compensation for the increased vulnerability of these smaller HCAs.

"Connectivity" is a measure of the extent to which intervening habitat truly connects blocks of suitable habitat to allow individuals, usually juveniles, of the species in question to disperse between them. Provision of habitat features that enhance dispersal between blocks is essential in a conservation strategy. Otherwise, individuals lost from the breeding population cannot be replaced by recruits (dispersing juveniles or displaced adults), and the population will decline. Providing a moderate amount of connectivity in the form of some forested habitat in that landscape allows dispersing birds to move more successfully from one HCA to another. We believe this increases the likelihoods of persistence, as estimated above, to very high for 50 years and high for 100 years over most of the range of the owl. These estimates, however, are too optimistic for many parts of the owls' range where we have identified problem areas (see appendices $\mathrm{C}$ and $\mathrm{Q}$ ).

A recurrent theme in the literature of conservation biology addresses the need for successful dispersal to ensure population persistence and suggests that corridors of suitable habitat be provided between population centers. What constitutes a suitable corridor varies by species, and experts have expressed concern that narrow corridors may sometimes be more detrimental than beneficial (appendix P).

To address the question of the configuration and composition of habitat in the connecting zones between HCAs (see appendix P), we reviewed available data from dispersing juveniles equipped with radio transmitters. Juveniles tend to disperse in various directions from their natal areas, exhibiting little tendency to follow natural corridors created by topographic features. Dispersing juveniles generally passed through a wide variety of habitats not generally regarded as suitable for reproduction, but most juveniles exhibited selection for old-growth and mature forests during dispersal. No relation was found between the extent of forest fragmentation and either the final distance moved or the number of days survived by juvenile owls. This finding indicates that special "dispersal corridors" designed for this purpose are unlikely to lead owls from one HCA to another. Instead of specially designed corridors, therefore, we envision a general forest landscape between HCAs amenable to dispersal by juvenile owls. 
For the most part, excepting checkerboard ownerships, current management practices should satisfy this objective. The validity of the proposed strategy depends as much on the condition of the habitat between HCAs as it does on the status of the HCAs themselves. If forest management plans are altered significantly to shorten rotations or to reallocate areas currently reserved from timber harvest for other purposes, the need for dedicated corridors between HCAs must be reexamined. In areas of checkerboard ownership, biologists have expressed concern about the dispersal of juvenile owls, but no available data indicate that a problem currently exists.

Many management practices, including those associated with certain timber harvest methods, provide habitat attributes conducive to spotted owl dispersal. Examples include visual corridors, riparian corridors, and streamside-management zones, all of which contain possible stopover spots. These habitat areas tend to be linear in configuration. Additional forested patches that can support dispersal remain unharvested for other reasons. Forests on lands incapable of commercial timber production, on soils prone to slumping, in special management areas for pileated woodpeckers and pine martens, and designated older forest blocks and extended rotation areas on both FS and BLM lands are examples that should provide suitable dispersal habitat for spotted owls. Furthermore, $50 \%$ of the landbase in a regulated forest would be older than 40 years, given a rotation schedule of only 80 years. We expect much of that managed landbase to be suitable for passage by dispersing spotted owls (appendix $R$ recommends studies to evaluate this expectation). The standards and guidelines discussed later ensure adequate dispersal habitat by requiring that $50 \%$ of the forest matrix outside of HCAs be in stands with an average d.b.h. of 11 inches and a $40 \%$ canopy closure.

The general approach to the conservation strategy is summarized in table 1.

Table 1-Description of basic concepts used In developing a conservation strategy for the northern spotted owl ${ }^{2}$

\begin{tabular}{ll}
\hline Recommended strategy & Explanation \\
\hline $\begin{array}{l}\text { Habitat Conservation Areas (HCAs) } \\
\text { Definition }\end{array}$ & $\begin{array}{l}\text { Contiguous block of habitat to be managed and } \\
\text { conserved for spotted owls }\end{array}$ \\
Categories & $\begin{array}{l}\text { Habitat that supports } \geq 20 \text { pairs } \\
\text { Habitat that supports <20 pairs } \\
\text { Habitat for dispersal and future nesting }\end{array}$ \\
& $\begin{array}{l}\text { Assure population viability } \\
\text { Maintain distribution } \\
\text { Intent }\end{array}$ \\
$\begin{array}{l}\text { Enhance habitat conditions } \\
\text { Reverse adverse situations } \\
\text { Hedge against catastrophic loss }\end{array}$ \\
$\begin{array}{l}\text { Forest Matrix } \\
\text { Definition }\end{array}$ \\
$\begin{array}{l}\text { Forest lands outside of HCAs } \\
\text { Categories }\end{array}$ & $\begin{array}{l}\text { Lands suited for timber production } \\
\text { Lands unsuited for timber production } \\
\text { Reserved lands }\end{array}$ \\
Intent & $\begin{array}{l}\text { Provide connectivity } \\
\text { Maintain options for returning owls to forest matrix } \\
\text { Provide opportunities to apply alternative silvicultural } \\
\text { treatments }\end{array}$ \\
\hline
\end{tabular}

See appendix Q-discussion of standards and guidelines. 


\section{Standards and Guidelines}

The Rule Set

We developed standards and guidelines (appendix Q) to apply the five basic concepts considered essential for a successful conservation strategy for the owl (see table 2). The primary data that underpin these standards and guidelines included:

- All portions of the range of the northern spotted owl in the United States were included in the conservation strategy.

- Ideally, HCAs should contain 20 or more pairs of owls. HCA size was determined by selecting areas known to contain, or that were estimated to contain, 20 or more pairs of owls. If that was not possible, the next largest possible HCA within the appropriate distances of other HCAs was designated. If land conditions were conducive to forest production, the sizes of these latter HCAs were adjusted upward to the point at which they should provide for 20 owl territories in the future, after currently unsuitable forests within them have grown back to a condition suitable for spotted owls. Where we were uncertain about the number of pairs occurring now, or that could occur in the future within an HCA, we determined the minimum size of the HCA from the median annual home-range size of an owl pair for that physiographic province. We assumed a $25 \%$ overlap between adjacent or potentially adjacent pairs, based on information on overlap between home ranges of "nearest neighbor" pairs obtained from radio-marked owl pairs (appendix I). Wherever (given site conditions) the target of 20 pairs could be attained, HCA size was estimated from the formula

HCA size $=[($ median annual home range of pairs $) \times 0.75] \times 20$ pairs.

Tabie 2-Description of standards and guidelines for the spotted owl conservation strategy

\begin{tabular}{ll}
\hline Criteria & Rule \\
\hline $\begin{array}{l}\text { Habitat Conservation Areas (HCAs) } \\
\text { Distribution } \\
\text { Location }\end{array}$ & $\begin{array}{l}\text { Widespread distribution across range } \\
\text { Known pairs or potential to support pairs } \\
\text { Sufficient habitat to support } \geq 20 \text { pairs unjess land- } \\
\text { scape limits ability to support } \geq 20 \text { pairs }\end{array}$ \\
$\begin{array}{l}\text { No more than } 12 \text { miles apart (HCAs with } \geq 20 \text { pairs) } \\
\text { No more than } 7 \text { miles apart (HCAs with }<20 \text { pairs) }\end{array}$ \\
$\begin{array}{l}\text { Fuality } \\
\text { Forest Matrix } \\
\text { Connectivity }\end{array}$ & $\begin{array}{l}\text { Contiguous blocks of suitable habitat } \\
\text { Distribution of existing reserved lands and lands } \\
\text { unsuited for timber management } \\
\text { Retention of } 80 \text {-acre stands of suitable habjat } \\
\text { around core areas (up to } 7 \text { per township) } \\
\text { Maintain } 50 \% \text { of forest landscape with mean tree } \\
\text { d.b.h. of } 11 \text { inches and } 40 \% \text { canopy cover }\end{array}$
\end{tabular}

\footnotetext{
See appendix Q-discussion of standards and guidelines.

b See table 3-examples of application of the guidelines in those areas where 20-pair HCAs could not be established.

cAll forest land outside of designated HCAs.

$d$ These areas are a category of HCA.
} 
This estimate was then compared with an HCA size based on known densities of owls in study areas within the applicable province. Other factors, such as the percentage of suitable owl habitat, elevation, and the intensity of surveys to locate owls, were also considered when boundaries of HCAs were delineated. If sitespecific information on the amount of suitable habitat that a site could eventually produce indicated that delineating an HCA with 20 or more pairs would be impossible, the above formula for HCA size used the lower number of potential pairs instead of 20. Usually, we found close agreement between these methods for determining HCA size.

- Distances between HCAs were set at no more than 12 miles at the nearest separation for HCAs containing 20 or more pairs and no more than 7 miles for HCAs with 2 to 19 pairs (appendices $P$ and $Q$ ).

- Adequate portions of the forested areas between HCAs must be in appropriate structural condition to provide at least marginal foraging habitat for dispersing owls. This need is addressed by requiring that $50 \%$ of the forest matrix outside the HCAs be covered with stands of trees averaging 11 inches or more in d.b.h., and with at least $40 \%$ canopy closure.

- At least 80 acres of suitable owl habitat should be designated as HCAs around activity centers of up to seven known pairs of owls per township in the forest matrix. These HCAs may provide core areas for nesting and foraging and allow reoccupation of these sites by owls in 50 to 80 years after harvest of the surrounding stands. Without provision of such areas, we believe the general managed forest of the future is less likely to sustain owls. Then, any chance to alter the HCA strategy proposed here for spotted owls will be markedly reduced.

In applying these standards and guidelines to maps (that is, on-the-ground conditions) we found them to be generally applicable. Some situations, however, did not allow us to apply the idealized conservation strategy. An example of each situation is described in table 3 , along with the altered management strategy derived to deal with each situation (see appendix $Q$ for further details).

Finally, we used the standards and guidelines to map locations of HCAs for the suggested strategy throughout the range of the northern spotted owl (see appendix $Q$ and maps).

The HCA concept applies primarily to BLM, FS, and NPS lands, as delineated in the enclosed maps. The Committee strongly recommends that HCAs be established on State lands in certain key areas (as shown on the maps) to assure population connectivity. We also recommend that resource managers of other State lands, tribal lands, other Federal lands, and private lands use forestry and silvicultural techniques and practices that maintain or enhance habitat characteristics associated with spotted owls. 
Table 3-Examples of application of guidelines In Areas of Speclal Concern for spotted owls

\begin{tabular}{|c|c|}
\hline Identified concern & Recommended strategy \\
\hline $\begin{array}{l}\text { Short term } \\
\text { Habitat currently unable } \\
\text { to support } 20 \text {-pair areas } \\
\text { Example: Oregon Coast Range }\end{array}$ & $\begin{array}{l}\text { Delineate HCAs (20-pair minimum) } \\
\text { Protect additional pairs until target densities attained }\end{array}$ \\
\hline $\begin{array}{l}\text { Long term } \\
\text { Natural landscape limitations } \\
\text { preclude 20-pair areas } \\
\text { Example: Northern Washington Casc }\end{array}$ & $\begin{array}{l}\text { Establish HCAs with } 2 \text { or more pairs } \\
\text { les }\end{array}$ \\
\hline $\begin{array}{l}\text { Natural landscape limitations } \\
\text { and low population density } \\
\text { Example: Eastern Oregon Cascades }\end{array}$ & Protect known pairs \\
\hline $\begin{array}{l}\text { Insufficient public lands } \\
\text { to create } 20 \text {-pair areas } \\
\text { Example: Northern California } \\
\text { Coast Range }\end{array}$ & $\begin{array}{l}\text { Establish HCAs where possible and recommend } \\
\text { silviculture treatments to produce and sustain } \\
\text { owl habitat }\end{array}$ \\
\hline
\end{tabular}
See appendix C-discussion of Areas of Special Concern; see appendix Q-discussion of standards
and guidelines.

Management Actlvities Within HCAs

The Committee recognizes that management on private and State lands differs considerably from management on Federal lands. Therefore, we believe that management of suitable habitat on private and State lands should be carried out under the leadership of the States with the cooperation of private land owners. The States, with their cooperators, should prepare habitat conservation plans, as the State of California is doing, that specify how an owl population can be managed, and how the necessary monitoring and research to guide adaptive management will be carried out.

Activities within HCAs should be consistent with their primary management prescription to assure that owls in HCAs have a high probability of persistence (details in appendices $O$ and $Q$ ). In particular, forests in HCAs should be maintained in superior habitat condition for owls, and younger forests and logged sites should be allowed to mature into superior habitat. Therefore, logging (including salvage operations) and other silvicultural activities (with exception of stand regeneration) should cease within HCAs. Silvicultural treatments that can be shown to benefit owls may be an exception to this rule in the future. The development and testing of such methods should be a major focus of research and management over the next several decades (appendices R and S). Such treatments will be largely experimental in the short term, so they should be tested outside of the HCAs.

Road construction in HCAs is discouraged because it detracts from the quality and amount of owl habitat. Roads should be located in HCAs only when no feasible alternative is possible. When roads are constructed in HCAs, they should be located and engineered to minimize the loss and alteration of habitat. Roads should not come any closer than $1 / 4$ mile to the activity center of any owl pair. 


\section{Management Plans for HCAs}

\section{Number of Northern Spotted Owls}

\author{
A Target Number
}

Some timber sales are currently being prepared within proposed HCA boundaries, such as under provisions of the Hatfield-Adams amendment (Section 318 of Public Law 101-121), to be offered for sale and award in 1990. All of these sales under planning should be shifted to areas outside of HCA boundaries. If options for shifting are not available, then recommendations for awarded sales are followed, as explained next. No sale should be planned within HCAs past fiscal year 1990.

Undoubtedly, other timber sales have been awarded within HCA boundaries, but not yet cut. Cancellation of these sales would result in significant costs to taxpayers and considerable economic and social disruption. These awarded sales may proceed on the condition that they have been intensively surveyed (at least six visits will be needed to conclude no owls are present) for the occurrence of pairs. If a pair exists, all sale units within $1 / 2$ mile of the center of owl activity should be excluded from the timber sale through standard modification procedures. The result may entail buyback of the units.

Management plans will be needed for each HCA to evaluate their vulnerability to fire, windstorms, and damage from insects and diseases. The loss of all suitable habitat in an HCA could create a gap between HCAs of much more than 24 miles, which would be a serious problem for the strategy. Each of these plans will need to seek resolutions between conflicting resource needs, but the overriding consideration should be regenerating and maintaining superior spotted owl habitat. For example, prescribed fire may sometimes be considered for use in HCAs. Plans for such fires must strike a balance between reducing fuel loading, which could carry a conflagration through HCAs, and retaining sufficient downed trees and woody debris. The decomposition of downed wood is needed for growth of subterranean fungi, which are a primary food source for the flying squirrels and other small mammals that are prey for the owl. Woody debris also provides cover for small mammals.

Where HCAs include Wilderness Areas, the FS and BLM should reconsider their current fire policies in light of the value of individual HCAs to the comprehensive conservation strategy for owls. A similar re-evaluation should take place for National Parks.

Before we began delineating HCAs on maps, we agreed that we should consider recommendations from experts who had previously examined the question of how many owl pairs should be afforded habitat protection. The "blue-ribbon panel" convened by the Audubon Society recommended that "The management program for spotted owls in Oregon, Washington, northwest California, and the Sierra Nevada should be directed to maintenance of a minimum total of 1500 pairs of these birds." 4 This estimate included both the northern spotted owl and the California spotted owl. If the California subspecies in the Sierra Nevada is excluded, the estimate for the northern spotted owl would have been 1100 to 1200 pairs. We attach no particular value to this number of pairs except to note that it was suggested by experts who carefully considered the situation and voiced their collective opinion. We also point out that the Audubon Panel stated that they were "...marginally comfortable with this number."

\footnotetext{
4 Dawson, W. R., J. D. Ligon, J. R. Murphy, J. P. Meyers, D. Simberloff, and J. Verner. 1986. Report of the advisory panel on the spotted owl. Audubon Conservation Report 7. National Audubon Society, N.Y. Pp. 32-33.
} 
Total Numbers of Pairs in HCAs
The Panel expressed less concern over the potential for heterozygosity loss and possible inbreeding depression (that is, genetic problems) than with demographic and environmental stochasticity. Their recommendations on population size were rooted in the latter concern. We concur. We are concerned about possible genetic problems only for the isolated population on the Olympic Peninsula. We can do little to solve this problem in the short term except to protect that population, and possibly introduce young owls from other parts of the distribution in Washington and even Oregon. In the long term, we seek to improve habitat conditions in areas that could provide demographic (population) continuity with the remainder of the owl's range.

The total number of pairs in HCAs will probably exceed the suggested minimum number from the Audubon Report (table 4). The HCAs proposed for FS, BLM, and NPS presently include 925 known pairs of owls. Most of the proposed HCAs still have not been completely surveyed, and we believe the number of known pairs underestimates the true number likely to occur within HCA boundaries. To estimate the probable number of pairs within HCAs, we drew on several sources of information-a study of available suitable habitat in each HCA and current knowledge about mean and median home-range sizes in various geographic provinces (see appendix I); the considerable personal knowledge and experience of team members; knowledge of owl densities occurring in comparable habitats from each of the geographic provinces; and in-depth consultation with experienced agency field biologists familiar with conditions in particular HCAs.

Based on the above information, we currently estimate a total of 1465 pairs in the HCAs on Federal lands. The comparable estimate for SOHAs is 880 pairs. Furthermore, we believe the proposed strategy, given time for young forests within HCAs to attain suitable habitat condition over a period of 30 to 150 years, could provide habitat capable of sustaining about 2000 pairs on Federal lands, assuming $100 \%$ occupancy of all territories. Occupancy, however, will be less than $100 \%$, because of demographic and environmental uncertainty (appendix M). Incorporating these measures of uncertainty provides an adjusted estimate of about 1750 pairs in HCAs on Federal lands by the year 2100. In addition, we believe a strong possibility exists that the States, acting in cooperation and concert with private land owners, will provide habitat for additional pairs that will further increase security for the owls. We estimate this capability at about 400 pairs by 2100 . By contrast, we would expect the number of pairs sustained by the SOHA network to decline during this period, not to increase.

Finally, a significant number of floaters should be present in the HCAs, available to fill vacated territories or to replace the loss of one member of a territorial pair. We cannot estimate the potential number of these floaters because they live unobtrusively in the population and are not readily detected or captured.

We are somewhat reassured that the resulting number of pairs known to occur on HCAs in Federal lands, alone, presently exceeds the minimum number accepted by the Audubon Panel. We are even more optimistic about the future because implementing this strategy promises to significantly increase the number of owls as younger forests in HCAs are allowed to mature and become superior habitat for spotted owls. 
Table 4-Pairs of spotted owls In mapped Habltat Conservation Areas

\begin{tabular}{|c|c|c|c|c|}
\hline $\begin{array}{l}\text { State } \\
\text { Ownership }\end{array}$ & $\begin{array}{l}\text { Pairs } \\
\text { presently } \\
\text { known }\end{array}$ & $\begin{array}{l}\text { Total pairs } \\
\text { presently } \\
\text { estimated }\end{array}$ & $\begin{array}{l}\text { Pairs } \\
\text { expected in } \\
\text { the future } c\end{array}$ & $\begin{array}{l}\text { Adjusted } \\
\text { pairs expected } \\
\text { in the future }\end{array}$ \\
\hline \multicolumn{5}{|l|}{ Washington } \\
\hline Forest Service & 200 & 257 & 428 & 369 \\
\hline National Park Service & 20 & 87 & 90 & 85 \\
\hline State & 6 & 10 & 101 & 89 \\
\hline Other Federal & 0 & 0 & 14 & 12 \\
\hline Subtotal & 226 & 354 & 633 & 555 \\
\hline \multicolumn{5}{|l|}{ Oregon } \\
\hline Forest Service & 245 & 467 & 647 & 589 \\
\hline Bureau of Land Management & 185 & 265 & 320 & 285 \\
\hline State & 0 & 4 & 80 & 72 \\
\hline Subtotal & 430 & 736 & 1047 & 946 \\
\hline \multicolumn{5}{|l|}{ California } \\
\hline Forest Senvice & 258 & 341 & 452 & 372 \\
\hline Bureau of Land Management & 14 & 28 & 43 & 21 \\
\hline National Park Service & 3 & 24 & 39 & 38 \\
\hline State & 18 & 42 & 50 & 22 \\
\hline Private & $N^{e}$ & 218 & 238 & $21 \overline{5}$ \\
\hline Subtotals & 293 & 653 & 822 & 668 \\
\hline Totals & 949 & 1,743 & 2,502 & 2,196 \\
\hline \multicolumn{5}{|l|}{ Totals by ownership } \\
\hline Forest Service & 703 & 1065 & 1527 & 1330 \\
\hline Bureau of Land Management & 199 & 293 & 363 & 306 \\
\hline National Park Service & 23 & 111 & 129 & 123 \\
\hline Other Federal & 0 & 0 & 14 & 20 \\
\hline States & 24 & 56 & 231 & 175 \\
\hline Private & $N A^{e}$ & 218 & 238 & 215 \\
\hline Totals: & 949 & 1,743 & 2,502 & 2,196 \\
\hline
\end{tabular}

Numbers of spotted owl pairs found in HCA areas during 1985 to 1989.

${ }^{b}$ Number of pairs estimated to occur in the HCAs, based on an assessment of several factors including known locations, home-range size, amounts of suitable habitat, elevation, and past survey effort.

' Number of pairs expected in the future after habitat recovers, based on home-range size and density adjusted for expected habitat conditions. This assumes $100 \%$ occupancy of home ranges (see appen$\operatorname{dix} M)$.

${ }^{d}$ Number of pairs expected in the future, calculated in $\mathrm{c}$ above but adjusted for demographic and environmental uncertainity (see appendix M).

- Present inventories on private lands are insufficient to determine the number of present pairs; future pairs based on recommended density estimates per township.

Spotted Owls In the Managed Forest Outside of HCAs
Further, we believe that some number of owls will continue to live outside the HCAs. These birds will likely live as single pairs and floaters, relatively isolated from other owls (compared to those in HCAs). They will be subject to the increased vicissitudes of life which are the anticipated results if isolation brought about by fragmentation and reduction of their habitat continues (appendices $\mathrm{N}$ and $\mathrm{O}$ ). Many of the singles and pairs are likely to disappear, and the territories are apt to be vacant for prolonged periods or occupied by only one owl (appendices $M$ and $O$ ). They will, 
Leaving Options to Adapt Management

Expected impact of Habitat Reduction on Numbers of Owis however, provide a source of immigrants for HCAs and provide a hedge against unforeseen events, for as long as they exist. If given appropriate forest management, some of these birds may also be able to persist in viable numbers. If so, that would be reason to rethink the HCA strategy. But that remains to be demonstrated.

On the surface, this conservation strategy may appear too conservative to some people. We think it is not. The Audubon Panel recommendation was a minimum estimate with which they were only "marginally comfortable," and it was only that-an estimate based on their general evaluation of evidence available at the time. We must consider that the success we anticipate for this conservation strategy may be too optimistic; it has yet to be tested. The future habitat conditions we visualize have never existed before. We face a rapidly decreasing ability to designate additional habitat for owls if the assumptions used to construct the proposed strategy prove deficient.

The quality, arrangement, and distribution of HCAs are especially critical. Numbers of owls are also important. In particular, some minimum number of owls and the nature of their demographic interaction are essential to assure genetic viability (no loss of heterozygosity, no inbreeding problems). Authorities who have addressed this question consider genetic problems secondary to those of demography. We agree. Our approach has been to develop a strategy with an array of HCAs providing a high probability for the long-term persistence of spotted owls, and arranged so as to facilitate owl movement between HCAs to assure demographic interaction among them. This interaction also vitally contributes to genetic viability.

We believe, for example, that 3000 pairs of owls distributed across the landscape in solitary SOHAs, many isolated from others by 6 to 12 miles, would be less viable over the long term than 1500 pairs in clusters, distributed in a smaller number of HCAs. Existing numbers and distribution today are much less significant than what can be anticipated to exist in the future. Today is merely the departure point. Conditions have been changing yearly with the annual removal of 71,000 acres of owl habitat by logging on National Forests alone.

Furthermore, we believe random environmental events will occasionally destroy portions of HCAs to an extent that cannot be accurately predicted. In short, we dare not prescribe less and still hope to remain confident that a high probability of success exists to maintain the long-term term viability of the northern spotted owl.

Our strategy does not call for saving all remaining owl habitat or all remaining old growth. Rather, it is based on establishing a distribution of owls and their habitat to provide for long-term viability. In a worst-case scenario, we estimate that the strategy could result in a 50 to $60 \%$ reduction in current owl numbers. This figure assumes that all pair sites outside of HCAs will eventually be lost through habitat removal or become permanently vacant because of demographic factors resulting from increasing isolation. 
But that is a worst-case scenario. What we consider more likely is that some number of owl pairs will occur outside of HCAs, particularly in areas reserved from harvest for other reasons and in stands managed on more than 120-year rotations (many of which exist throughout the owl's range). Other places where owls may occur, intermittently at least, are in Wilderness Areas, parks, and lands containing owl habitat that are not deemed suitable for timber production. The HCAs will probably be the long-term source of owls needed to periodically restock such temitories.

Further, many of the relatively isolated pairs that now exist are likely to disappear, to have reproductive rates below those needed to maintain viability, or to have a low chance of recolonizing vacated habitats. Demographic studies (appendices $L$ and $M$ ) indicate the likelihood of these losses. Thus, some significant portion of the loss in numbers anticipated under the proposed strategy would occur even under a strategy where all remaining suitable habitat was maintained.

We believe any attempt to protect individual pairs, as the sole strategy, is destined to fail (appendices $M, N$, and 0 ). In any strategy that we may propose, a reduction in numbers of owls from the present number is a foregone conclusion. The reduction will continue until an equilibrium between available habitat and the number of owl pairs is attained. This equilibrium will not occur in the proposed conservation strategy until all potential habitat within HCAs has developed conditions suitable for spotted owls, and until the surrounding landscape matrix is in a state of equilibrium between timber harvest and losses to natural causes on the one hand, and regeneration of wood fiber on the other (that is, sustained yield).

Opportunities to adjust the strategy to protect additional suitable habitat will continue in some portions of the range for 5 to 10 years but will diminish at an increasing rate. Unless research can show more quickly than we expect that viable populations can be supported in managed forests, the spotted owl depends on our estimates of what is required. On the other hand, if the present strategy is found to be excessive or no longer needed, many options will remain for modifying the initially imposed management actions.

Adjustment to an Equilibrium Population
An implied assumption of this conservation strategy is that the owl population will reach a new, stable equilibrium at some future time. We are confident in this assumption, even though the amount of suitable habitat and the number of owls will continue to decline over the short term. We hypothesize that once the rate of loss of suitable habitat outside HCAs comes into balance with the rate new habitat is recruited within the HCAs, a stable equilibrium will be attained. This equilibrium will, of course, be at a lower population number than existed historically. Further, because the spotted owl has a low reproductive potential, considerable time may be required for the population to stabilize at a new equilibrium number. 
We cannot demonstrate with complete certainty that a new equilibrium number will be attained. Our conservation strategy, however, addresses the key aspects of the owl's life history that influence its prospects for long-term viability (see appendices $L$ and M). A system of large HCAs increases the likelihood of successful dispersal of both adult and juvenile birds. It increases the expected occupancy of suitable pair territories and thus enhances reproductive output. Finally, results from our simulation models, which were structured on the basis of and use parameter values according to our understanding of owl biology and behavior, have shown that owl populations do reach equilibrium, given an extensive system of HCAs averaging about 20 suitable pair-sites and encompassing about $25 \%$ of the forested landscape.

Adaptive Management and Monitoring

\author{
Monitoring
}

We have developed proposals for adaptive management (appendix R) that rely on monitoring to determine whether the conservation strategy maintains a well-distributed, persistent population of owls, and which depend on research that seeks ways to resolve conflicts between conservation of owls and continued timber harvest.

Monitoring is the primary method for determining whether or not the conservation strategy is accomplishing its intended objectives. We have reviewed the current monitoring program used by the FS to monitor its SOHA network system. We conclude that, if certain thresholds are passed as owl habitat continues to decline around the SOHAs, the existing monitoring program is unlikely to tell us in time to take action to avert possible extinction of the owls. This inability is caused by lag effects resulting from the long life span of spotted owls and from packing phenomena-where remaining suitable owl habitat becomes crowded with owls displaced from habitats lost elsewhere. Inferences drawn only from the number of occupied SOHAs will continue to indicate a "viable" population. If the SOHA network is not viable, however, and we believe for several reasons that it is not (see appendices $\mathrm{M}, \mathrm{N}, \mathrm{O}$, and P), a sharp decline in numbers is likely to ensue within a few years after the SOHAs become clearly separated from one another in a landscape of habitat generally unsuited for owl breeding.

For the HCA strategy proposed here, we recommend monitoring habitat and demographic information (appendix R), including banding as many owls as possible, in selected units that include two or more HCAs and the intervening landscape. This approach would provide information on occupancy rates within HCAs, reproductive activity of owls in and between HCAs, and dispersal of birds between HCAs. Information on the sources and ages of birds that replace members lost from the populations within HCAs (so-called "turnover events") may provide the best measure of whether the conservation strategy is succeeding. Studies of this sort have been underway for several years, and have proved feasible. We also have preliminary assessments of the cost of such a program, which suggest that it will be no more costly than current monitoring efforts. 
Primary objectives of the research proposed under adaptive management are to find ways to extend the period during which forest stands subject to timber harvest are suitable for breeding owls, to learn how to manage existing younger stands to develop conditions suitable for owls sooner than would naturally occur, to learn how to grow suitable owl habitat from bare ground sooner than would naturally occur, and generally, to determine whether silvicultural alternatives can be found that will allow spotted owls to maintain viable populations in managed forests. We emphasize that answers to these research questions will be slow in coming.

The research program implements management experiments that simultaneously evaluate alternative landscape arrangements and stand treatments. Subsequent changes in management may increase protection for the owls or relax constraints on forest production, based on experience gained from the management experiments. This program provides an opportunity for managers and researchers to work together in testing explicit assumptions in the standards and guidelines that drive the conservation strategy. Some management experiments can and should be done in partnerships that include agencies, institutions, and industry. Standard protocols for research design, data collection, and analyses must be developed and agreed upon by all cooperating parties. Only then can we make reasonable comparisons from area to area and from study to study.

Produclng Habltat Through Innovative SIlviculture
Past forestry practices have inadvertently produced some habitats where owls are breeding successfully 60 to 80 years after the event. Similar suitable habitat could reasonably be expected to be produced by silvicultural design. Therefore, we recommend obtaining maximum information from owl pairs that will be influenced by timber harvesting in sites between or around HCAs, and in northwestern California where owls occur in good numbers in redwood forests 40 to 80 years old. Information so gained could lead to new silvicultural treatments that maintain or create owl habitat (appendix S).

Silvicultural modifications may include producing multilayered canopies in stands, and leaving structures such as large trees, snags, and fallen trees in place. If such treatments prove successful for producing owl habitat, timber sales of certain types might eventually be scheduled in HCAs. But such sales can legitimately occur only after conclusive data are obtained showing that associated owl populations are stable or increasing, and after verifying positive owl responses to stands that have been so treated.

Our impression, from detailed working sessions with foresters and silviculturists, is that departing from traditional, even-aged forest management to provide owl habitat will likely entail loss of growing space for trees and, hence, of economic return. But they expressed confidence that various procedures could be implemented to accelerate the development of conditions suitable for owls, and to prolong the period of suitability in stands that will eventually be logged too heavily to provide useful owl habitat. We need to test some of these silvicultural systems and evaluate their cost-benefit ratios. 
Geographic Information Systems

Evaluating the Strategy and Belng Prepared to Adjust

Other Research Needs

Risk Analysis
Furthermore, research into the question of producing suitable owl habitat should also consider the value of such habitat for other species and other values associated with such forest conditions. The focus of this research should not long be confined to owls. We need to be cautious because, as we become adept at producing forests tailored specifically to the habitat requirements of the northern spotted owl, we might produce forests unsuitable for other species associated with old forests.

We recommend developing and using geographic information systems (GISs) linked with software for predicting forest growth and yield, including the ability to identify habitat that supports pairs of owls. A GIS will allow users to simulate and analyze changes in forest stands and landscapes in terms of owl habitat, thus expanding our ability to plan management experiments or schedule stand treatments to produce or sustain owl habitat. A GIS enables decision makers to understand and comment on the involved analytical processes, resulting in ecologically based policy decisions and better linkages between researchers and managers. These systems should be interactive among all users and encompass all land ownerships.

Altogether, the adaptive management program must determine the aggregate value of forest management to maintaining owl persistence in HCAs, and single and multiple pairs in the surrounding managed forests. The primary challenge for the immediate future ( 5 to 10 years) is to determine whether our assumptions about HCA sizes, configurations, distribution, and connectivity are correct. Therefore, cooperators must develop an objective process to assimilate results of management experiments and monitoring to permit review and evaluation of the HCA-based conservation strategy, and to modify it if so indicated.

The Committee was directed in the Charter to consider future research on spotted owls. Questions that need to be asked largely depend on what strategy is adopted for owl conservation. When that becomes clear, the Committee will reconvene to make recommendations on appropriate research. We will also consider in more detail the question of a reliable and workable monitoring system.

In general, smaller and more isolated populations of any species are much more susceptible to extirpation than larger, freely interacting populations. Viability is thus more certain when populations-and habitats for breeding, feeding, dispersal, and other life needs-occur in widely distributed, yet demographically contiguous patterns. Specific objectives for maintaining owl population viability include providing high-quality habitats in HCAs large enough for multiple pairs, spacing HCAs close together in a landscape containing habitat suitable for dispersal to ensure high likelihoods of HCAs being locally recolonized from other HCAs, and providing for a wide distribution of HCAs to facilitate interaction among geographic locations and protection against localized catastrophes. 
Comparison With Current Management
The conservation strategy proposed here provides all of these viability requirements. We conclude that the proposed conservation strategy has a very high probability of sustaining northern spotted owls in viable numbers for at least 50 years (appendix $T$, table T5). The situation, however, varies across the range of the owl (appendix $T$, table T2). Further, during that 50-year period, the strategy is expected to improve conditions for owls in areas where the subspecies persists in marginal conditions. Given continued improvement, we conclude that this conservation strategy has a high probability of assuring a viable population of spotted owls for 100 years (see appendix $T$, table $T 5$ ).

A comparison of the SOHA and HCA strategies leads us to recommend that most of the SOHA system be abandoned in favor of HCAs. The SOHA system manages for owl pairs or small clusters of two and three pairs; by contrast, the HCA system manages for larger assemblages of pairs, ideally at least 20 pairs per cluster. We believe the SOHA network system to be a prescription for the extinction of spotted owls, at least in a large proportion of the owl's range (see appendices $M, N, O$, and $P$ ).

- Every study of the persistence of bird populations shows that the likelihood of extinction increases dramatically with decreasing numbers of pairs in a block of habitat. Consequently, we expect pairs in SOHAs to disappear at a relatively high rate, making the vacated SOHAs at least temporarily nonfunctional. This loss considerably worsens dispersal problems.

- In contrast, the loss of one or even a few pairs of owls from a large HCA subpopulation would not make that HCA a nonfunctional component of the full network of HCAs. The recruitment of replacement individuals for lost members of pairs should occur more rapidly in HCAs than in SOHAs, because recruits can come from within the HCAs themselves (but not from within SOHAs, which depend solely on outside sources for recruitment).

- Where several pairs of birds occur in a cluster, social interaction among owl pairs would almost certainly increase calling frequency (if this were not true, observers should not be able to elicit calling from silent owls by imitating their calls). The higher calling rate expected in HCAs, by comparison with SOHAs, should provide a sort of "vocal guidance" that would help dispersing birds find an HCA. This effect would be minimal at SOHAs.

- Large HCAs reduce the effects of habitat fragmentation and edges, which are major concerns for a species threatened with the systematic removal of suitable habitat (see appendix $\mathrm{N}$ ). SOHAs, on the other hand, have a high ratio of edge to area, so edge effects are more extreme than in HCAs. Logging between patches of habitat left for spotted owls also internally fragments SOHAs, and makes them particularly vulnerable to windstorms. 


\section{Administrative Mechanisms}

Coordination Required

Administrative Nightmares
- Small-scale catastrophes would have less impact on HCAs than on SOHAs. SOHA destruction removes that unit from the network for perhaps 80 to 150 years and increases the mean dispersal distance between remaining units, further reducing the SOHA network's ability to maintain a viable population. Destruction of an equivalent area in an HCA, however, removes only one pair from the unit. The HCA unit remains viable, and dispersal distances are not particularly influenced.

- Floaters exhibit behavioral dynamics toward breeding bird populations that would not seem likely toward individual, isolated pairs of breeders. We believe SOHAs would not provide sufficient conditions needed for the successful recruitment of floaters into the breeding population. In contrast, the strategy proposed here provides larger HCAs that should allow dynamic interaction between breeding pairs and floaters that more closely approximates that found in unfragmented habitats.

- Finally, we believe a more effective monitoring program is possible with HCAS than with SOHAs, because the HCA system lends itself to a study design that would produce information on key population attributes (for example, birth and death rates, turnover events, immigration and emigration rates, and dispersal effectiveness) that are more likely to tell us when the population is in trouble than are simple population counts (see appendix R).

A significant consideration when the adequacy of existing regulatory mechanisms and management activities for the owl are evaluated is the vigor, quality, and consistency of implementing and coordinating management plans. Adequately managing owl habitat implies common understanding, coordination, effectiveness, and the consistent application of agreed-upon plans, both within and among State and Federal land-management and other natural-resource management agencies. Ongoing, standardized, coordinated, and consistent monitoring of results for compliance with management plans, and for the response of owls to the conditions that result from those plans, is vital to success. The monitoring program is the primary feedback mechanism in adaptive management. Results from the monitoring effort must be the guide whenever adjustments in management regimes are considered.

The occupied range of the owl extends across portions of Oregon, Washington, and California in the United States, and also across portions of British Columbia in Canada. Within the United States, existing regulatory mechanisms and their interactions present significant barriers to appropriate, coordinated management that must be overcome. California, Oregon, and Washington each have various authorities and regulations that affect the management of the owl and its habitat. 
In each State, two agencies (the wildlife agency and the forestry agency) have some responsibility for owls or their habitat. Authorities and relationships among these agencies differ markedly among States. Further, the authority of the State forestry agencies applies primarily to State and private lands. These agencies issue regulations and administer State laws that govern forest practices on lands they manage and on private lands. These regulations take into account the fact that private and State lands do not have multiple-use mandates, and that most are managed primarily or solely to produce maximum revenues. Conversely, the authority of the wildlife agencies extends across all land ownerships in each particular State. Management constraints imposed for environmental, wildlife, or fish purposes, however justified, create direct or opportunity costs for the landholder. Current management schemes for such properties, with some minor exceptions, are not conducive to large-scale production or maintenance of habitat for owls.

Most habitat currently occupied by significant numbers of owls is owned in common by the people of the United States (the Federal Lands). Seventeen National Forests and five BLM Districts contain most of the remaining suitable habitat for the northern spotted owl. The seventeen Forests with owls occur in two administrative Regions. Although these Regions are governed by the same laws and regulations, management approaches differ between Regions and among National Forests within each Region (appendix D). Communication between Regions is not cultivated, perhaps because of the long-standing traditional policy of decentralized agency control. Management prerogatives are guarded.

Lands managed by the BLM largely occur in a checkerboard pattern, and primarily in alternating square-mile blocks of private and public ownership. Management of these lands is guided by a different set of laws, regulations, and mandates from those of the National Forests. Other significant Federal landholdings in the owl's range occur in eight NPS areas that operate under yet other laws and mandates.

The FWS is responsible for determining if the owl is to be listed as a threatened species and, if so, to assume leadership with six State and three primary Federal agencies to assure "recovery" of the owl. Obviously, overlapping and sometimes conflicting laws, regulations, and agency mandates seriously challenge the successful execution of any owl conservation strategy. Our investigations (appendices $C$ and D) revealed differing management activities and levels of concern among State agencies, between Federal agencies, and within the administrative units of the various agencies. We believe that current administrative mechanisms constrain the managers responsible for designing, establishing, coordinating, and carrying out an effective management strategy for spotted owls. A comprehensive monitoring scheme that covers all land ownerships should be developed. A unified database and a coordinated, interagency-interstate strategy are likewise needed. Considering the continuously burgeoning biological, economic, political, and social consequences ensuing from a consideration of the status and management of the owl, we believe that developing and instituting a fully coordinated program of management, monitoring, research, and development, which operates across all of the landscape that makes up owl habitat, is both essential and overdue. Spotted owls, after all, are oblivious to our political and institutional boundaries. 
No plans have been made within, and certainly not among, concerned management agencies to determine what population or habitat conditions signal that changes in ongoing management are required, or possible, to ensure the welfare of the owl. Rapid changes in land management obviously have occurred in response to changing political situations and climate, as evidenced by the Hatfield-Adams Amendment, the formation of our Committee, and the temporary increases in the number and size of SOHAs on NF and BLM lands. We believe that "trigger points" in ongoing monitoring efforts should be set that would dictate a re-evaluation of existing management operations. These trigger points should be explicitly stated and followed.

The following list provides some general ideas on which trigger points might be developed. We do not offer these suggestions as the final word because this important aspect of the strategy will depend in part on what we learn from monitoring. These issues could be addressed in more detail, for example, by the spotted owl coordinating group recommended by the Committee. Trigger points might be reached whenever:

- The number of owl pairs found in HCAs rises above or falls below the expected number by some specified percentage (for example, $25 \%$ ).

- The number of pairs in HCAs exhibit marked declines or increases in number within a reasonable period (say 10 years) after monitoring has been fully implemented.

- The amount of suitable habitat exhibits some continuing downward trend as a result of frequent natural disturbances, such as fire.

- The current forest land allocation changes significantly in the forest matrix surrounding HCAs.

- The current rotation schedules for harvesting timber in the forest matrix surrounding HCAs significantly change.

Concerned Federal (BLM, FS, FWS, and NPS) and State agencies (CRA, ODFW, and WDW) have formed the Interagency Spotted Owl Committee (ISOC) with the intent of coordinating activities for managing the owl. We believe that a committee must establish a mechanism for assuring coordinated research, development, and monitoring of owl habitat, numbers, locations, and distribution. That mechanism must also assure compliance with an agreed-upon management strategy across all involved Federal lands and those private and State lands that are included in the management strategy. We recognize that the Federal agencies have low credibility for managing the owl among the conservation and scientific communities. That perception must be quickly changed through the adoption, and prompt and vigorous institution, of a fully coordinated and sound conservation strategy by all concerned agencies. 
Suggested Organization
Monitoring, research, and development activities must then continue in a likewise coordinated fashion for the conservation strategy to succeed both biologically and politically. The function and credibility of that comprehensive conservation strategy can be seriously compromised by a failure in its weakest link. We believe that the weakest link is apt to be inadequate coordination between concerned agencies resulting from various efforts to protect management prerogatives and entrenched ways of doing business.

We do not consider ourselves expert in administrative matters. We recommend, however, the appointment of a coordinator to oversee the conduct of whatever conservation strategy is adopted. That coordinator, who may be an employee of any one of the concerned agencies (BLM, FS, FWS, and NPS), should have assistants assigned (full- or part-time as required) from each of the other Federal agencies. In addition, the coordinator should be able to call on a representative from each of the States, appointed by appropriate agency heads, to participate in any activities concerning owls within their State. Including a mechanism for one advisor-observer each from industry, private-land owner, and environmental groups may also be appropriate. Research and development-and the planning and execution of monitoringshould be under the auspices of this group; it should have the additional duty of considering and advising managers on any necessary alterations to the conservation strategy.

Obviously, the map-based conservation strategy presented by our Committee is sitespecific and may need adjustment to address unforeseen circumstances. Local situations will arise from time to time that must be addressed. The conservation strategy, however, is one for the entire geographic area. Proposed changes should be considered in that light by the broad representation of the coordinating committee.

A possible organizational structure for meeting the challenge presented by a coordinated conservation strategy is presented in figure 1. We attempted to diagram the current situation several times and concluded that it is so confused as to preclude clear description. We recognize that what we suggest will require a new way of doing business. But the issue is too significant and the consequences of failure too great to allow long-standing institutional barriers to stand in the way. We believe that the organization suggested here could accommodate the activities that relate to any species of such high concern as the spotted owl, including any species listed as "threatened" or "endangered" that occurs on Federal lands in the Pacific Northwest. 


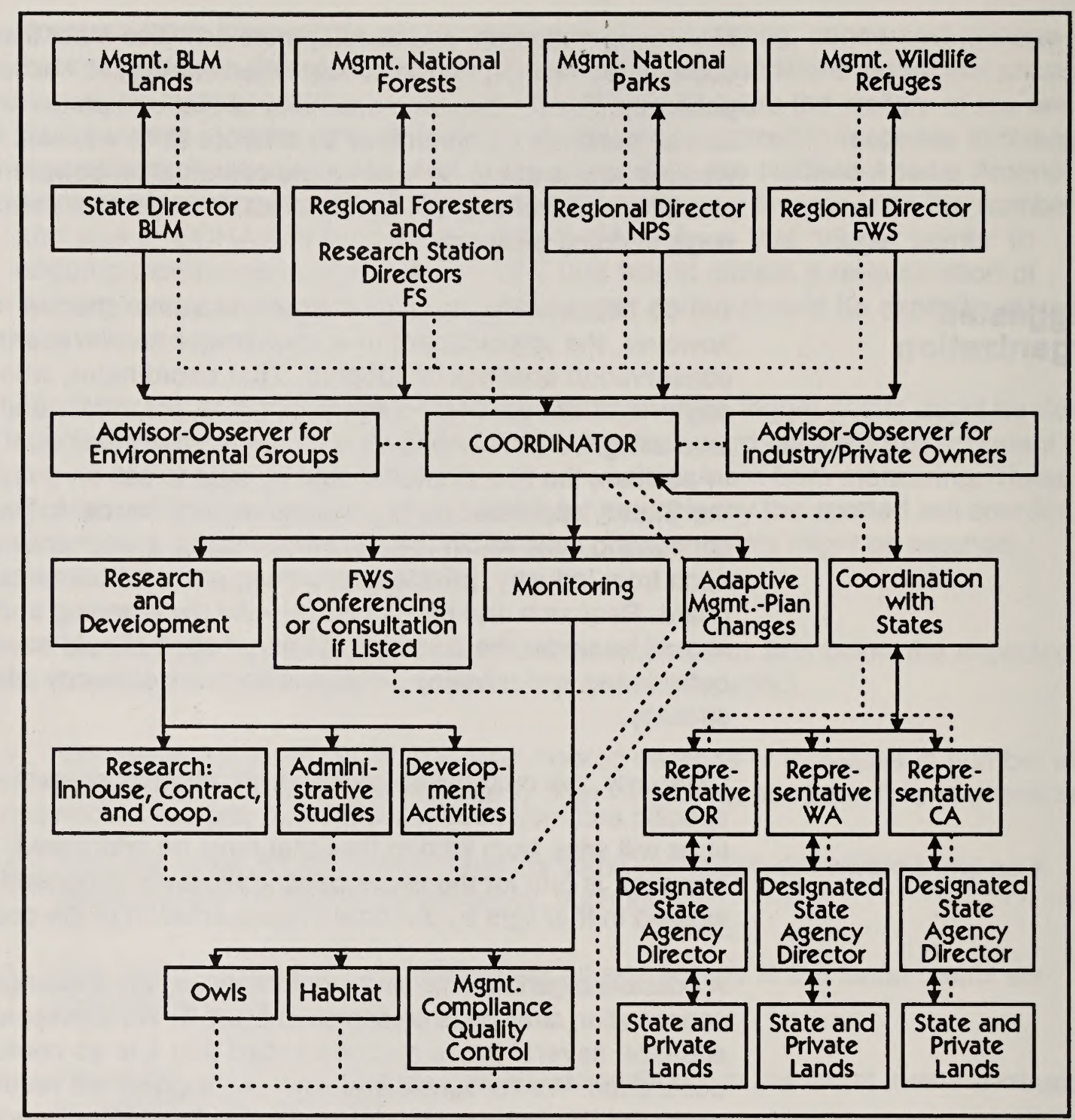

Figure 1-A suggested organization to achieve a coordinated conservation strategy for the northern spotted owl. Solid lines represent lines of authority and communication; dashed lines represent information feedback to facilitate adaptive management. 
Assessment of Impacts

\section{Postscript}

Our assignment was to develop a credible conservation strategy for the owl. We are aware that others will quickly analyze the effects of implementing the strategy we propose here. The immediate response, quite likely, will be to focus almost solely on the economic and social impacts of implementing the strategy in terms of its effect on the availability of timber. Such analysis is important. Adoption of the conservation strategy, however, has significant ramifications for other aspects of land management. A balanced assessment of this strategy's various impacts must consider water quality, fisheries, recreation, soils, stream flows, scenic values, biodiversity, and other species of wildlife. All aspects of such a decision should be weighed in the balance. The issues are not limited to questions of owls and timber supply, as important as those are. The matter is not that simple-it never has been. The entire "spotted owl issue" is just one of many related concerns, all of which should be considered.

The strategy of providing large, relatively intact blocks of suitable owl habitat may not need to be sustained in the long term, depending on the success achieved in maintaining owls on managed forest lands in Oregon, Washington, and northern California. This conservation strategy is designed to sustain the spotted owl-a long-lived bird that can fly between patches of suitable habitat. The landscape design may be less suitable for nonflying invertebrates and vertebrates, particularly reptiles and amphibians, that may be associated with structurally diverse forests. Populations of most of those species, however, should be nearly or totally self-sustaining within HCAs, with a high probability of long-term viability because individuals are likely to number in the several hundreds or thousands.

We were asked to do a scientifically credible job of producing a conservation strategy for the northern spotted owl. We have done our best and are satisfied with our efforts. We have proposed. It is for others-agency administrators and elected officials and the people whom they serve-to dispose. That is the system prescribed in law. It seems to us a good one. We can live with that. 



\section{A Charter for an Interagency Scientific Committee to Address the Conservation of the Northern Spotted Owl}

\section{Purpose:}

Form an Interagency Scientific Committee under the authority of the Interagency Agreement of August 1988 between the USDI Bureau of Land Management, USDI Fish and Wildlife Service, USDI National Park Service, and USDA Forest Service regarding development of a conservation strategy for northern spotted owl management and cooperation.

Task Directive for the Scientific Committee:

\section{General:}

Develop a scientifically credible conservation strategy for the northern spotted owl.

\section{Specific:}

Short Term: 1989-90-Review the biological basis of U.S. Fish and Wildlife Draft Criteria for the Review of Timber Sales (7/21/89 revised 8/09/89) and the basis for conference opinions.

Assess whether current land management strategies of the agencies are reserving options that will allow for long-term strategies to conserve the northern spotted owl.

Provide recommendations to preserve the necessary conservation options from now until the conservation strategy is completed. These may have to consider variables such as legislation or judicial review.

Long Term: 1991 and Beyond-Define habitat relationships for the long-term conservation of northern spotted owls.

Suggest possible options to achieve the amount and configuration of habitat for long-term northern spotted owl conservation throughout its range.

Evaluate current research efforts and identify research, monitoring, and inventory programs to answer existing critical questions and to track the adequacy of management strategies and recommendations. 


\section{Appendix A: Charter}

\section{Structure:}

The Scientific Committee will consist of a Team Leader and Scientists from the Federal agencies involved. The members of the Committee are to be educationally and professionally qualified scientists.

\section{Scientific Committee Members:}

Jack W. Thomas, Team Leader

Chuck Meslow, FWS

Eric Forsman, FS

Jared Verner, FS

Butch Olendorff, BLM

Barry Noon, FS

\section{Primary Contacts:}

A representative from each of the four Federal agencies will be the primary contact for the Team Leader. These agency representatives will be responsible for providing the resources for the team to carry out its responsibilities. Technical experts will be made available to the committee upon request by the agencies.

Agency Representatives:

Robert Smith, FWS

Hugh Black, FS

Stan Butzer, BLM

Jim Larson, NPS
Alternates:

Marv Plenert, FWS

Phil Lee, FS

Paul Vetterick, BLM

Bill Briggle, NPS

\section{Observers of the Scientific Committee:}

Knowledgeable observers will be invited to all proceedings of the Scientific Committee. These observers will represent the following interests or entities:

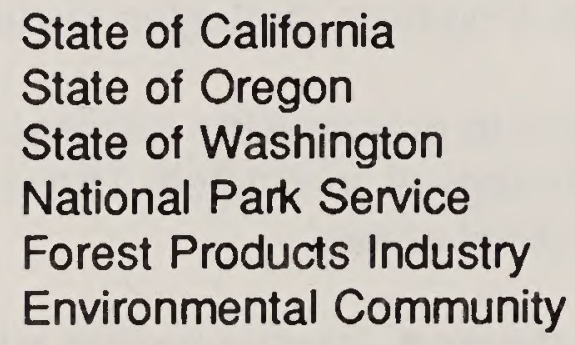

The Team Leader may invite technical experts or others to provide support to the committee.

The Team Leader in consultation with the Agency representatives and appropriate State officials will select the observers.

Timeline:

The Scientific Committee will provide a progress report to the Agency representatives by November 1, 1989. 


\section{Appendix A: Charter}

The Scientific Committee will provide an interim product to be submitted to the public record for the U.S. Fish and Wildlife Service by December 20, 1989.

The final report of the Scientific Committee will be completed by March 1, 1990.

Funding:

Individual travel and salaries will be covered by the respective agencies. Rent and other support costs will be shared as decided upon by the Agency representatives.

/s/ George M. Leonard

for F. DALE ROBERTSON

Chief

Forest Service

/s/ Cy Jamison

CY JAMISON

Director

Bureau of Land Management
/S/ John F. Turner

JOHN TURNER

Director

Fish and Wildlife Service

Is/ Herbert S. Cables

for JAMES M. RIDENOUR

Director

National Park Service 


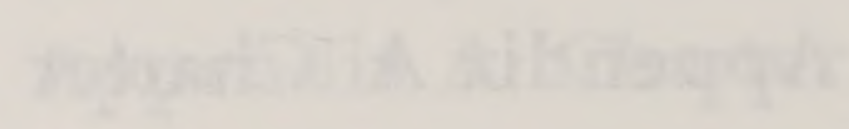




\section{Historical Perspective on Northern Spotted Owl Management}

\section{Spotted Owl \\ Research and \\ Planning Before \\ the Endangered \\ Species Act of 1973}

Before the early 1970 s, relatively little was known about the northern spotted owl except that it resided in a variety of forest types in western Washington, western Oregon, and northwestern California. It was considered a rare or uncommon resident in most of its range (Marshall 1969).

Eric Forsman and Richard Reynolds began searching for spotted owls in Oregon during the late 1960s. Their preliminary work revealed that spotted owls were present in several locations, including some areas where Marshall (1942) and Gabrielson and Jewett (1940) had reported owls many years earlier. Forsman and Reynolds brought their findings to the attention of Howard Wight at Oregon State University, who became intrigued by the owl and its association with older forests.

Forsman, then a graduate student, and Howard Wight (unit leader) began research on the northern spotted owl in 1972 at the Cooperative Wildlife Research Unit at Oregon State University. After only a year of research, they became concemed because many of the owl pairs they were finding were in areas slated for timber harvest. They relayed their concerns to the ODFW, FWS, FS, and BLM.

In 1973, Ed Schneegas at the Regional 5 Office of the FS became interested in the issue and initiated the first survey of the spotted owl in California. That study was conducted in 1973-74 by Gordon Gould, later of the California Department of Fish and Game. This study, which demonstrated that the owl was more abundant in California than was previously believed, generated considerable interest in California (Gould 1974).

Publication of a summany reference for compiling the official list of nationally endangered species drew regional and national attention to the spotted owl in 1973, when it was included as a possible candidate for the list. Shortly after that publication was released, John McKean, then Director of the Oregon Game Commission, proposed that a professional interagency task force be formed to address endangered species management in Oregon. This group, the Oregon Endangered Species Task Force, was formed in 1973. 


\section{Appendix B: History}

Spotted Owl

Research and

Planning After

the Endangered

Species Act of 1973

First Oregon Spotted

Owl Management Plan
At the recommendation of Howard Wight, the Task Force agreed to address the needs of species that used old-growth forests (unpubl. meeting minutes, 1973). The Task Force also agreed that the highest priority should be given to preserving habitat for the spotted owl. The Task Force recommended to State and Federal agencies that 300 acres of old-growth habitat be retained around each spotted owl location as interim protection until Statewide guidelines could be adopted within a year. This recommendation was rejected by R6 of the FS and the Oregon State office of the BLM, who wanted a Statewide population management goal to be established before proceeding further. At the time, owls had been located at only about 100 sites in the State.

The Federal Endangered Species Act, which became law late in 1973, had no immediate effect on spotted owl management, but has served ever since as the yardstick for species protection on public lands. As a result of the Oregon Task Force's work, a State list of threatened and endangered species was submitted to and adopted by the Oregon Wildlife Commission (ODFW 1975). The northern spotted owl was listed as a "threatened" species on the administrative list, which had no statutory authority at the time.

Research efforts in Oregon and California continued over the next few years (Forsman 1976, Gould 1974). Passage of the National Forest Management Act in 1976 and regulations issued pursuant to that Act laid the groundwork for maintaining well-distributed, viable populations of all native species on National Forests. Later that year, the Task Force recommended a long-range goal of maintaining "...400 pairs of spotted owls on public lands in Oregon consistent with the specific habitat requirements of the species." The Task Force also stated that it would "Identify the number of spotted owl habitats and their distribution needed to maintain a viable population throughout their distribution in Oregon." As interim policy, to be followed while the guidelines were being developed, the Task Force recommended that involved agencies "Protect spotted owl sightings and nest sites consistent with the specific habitat requirements as described by Forsman, 1976, and other observers."

Both the Oregon State Director of the BLM and the FS Regional Forester (R6) agreed in early 1977 to protect spotted owl habitat in accordance with Task Force interim recommendations, except where sales under contract or current fiscal year timber sales existed. In late 1977, the Oregon Spotted Owl Management Plan was submitted to the various agency administrators for review and comment. The plan recommended habitat management areas that included clusters of three to six pairs, with a minimum of 1200 acres of contiguous habitat per pair. Each pair was to have a core area of at least 300 acres of old growth or the oldest available contiguous habitat, if 300 acres of old growth did not exist. At least $50 \%$ of the remaining 900 acres were to be covered by forests older than 30 years. Core areas for clustered pairs of owls were to be no more than 1 mile apart, as measured from center to center. Management areas were to be a maximum of 8 to 12 miles apart for multiplepair habitat areas, less for single pairs. Management areas were allocated based on the amount of land administered: FS, 290 pairs; BLM, 90 pairs. State and private ownerships were expected to manage for 20 pairs, although no formal agreement was made by which this plan could be implemented on State or private lands. A major oversight was made in allocating pair numbers to BLM; BLM-administered 


\section{Appendix B: History}

Oregon-Washington Spotted Owl Subcommittee

\section{Increasing Effort}

\section{Oregon Spotted Owl Plan Revised}

lands were actually spread over twice as much area as comparable FS lands (because of the checkerboard pattern of land ownership). The result was that managed owl sites on BLM lands were much more widely spaced than on FS lands.

Both the R6 Regional Forester and the Oregon State Director of BLM agreed to implement the management-plan recommendations through their ongoing land management planning processes. Final decisions on distribution, number, and location of sites managed for owls were to be made with public involvement through the planning process. The year was 1977, 4 years after the Task Force began work on the plan.

A regional interagency organization, called the Oregon-Washington Interagency Wildlife Committee (OWIWC), was established in 1978 because of the various wildlife issues common to Oregon and Washington. One of the first acts of the OWIWC was to disband the Endangered Species Task Force and replace it with a group of biologists and administrators from Oregon and Washington-the Spotted Owl Subcommittee. In December 1978, the Subcommittee further refined the Oregon Spotted Owl Management plan by addressing the need for managing unprotected pairs, private land owner participation, relocating management areas, and a recommended process for regular plan review.

After 1978, the effort expended on owl surveys increased considerably on many $\mathrm{Na}$ tional Forests in Oregon and Washington, and in 1979, a Washington Spotted OWl Working Group was initiated. In 1980, the R6 Regional Forester directed National Forests in Washington to protect spotted owl habitat for all confirmed pairs, in accordance with Oregon Spotted Owl Management Plan criteria. In 1981, Washington Forests were further directed to provide protection to 112 pairs, pending issuance of the draft R6 Regional Guide later that year.

In response to radio-telemetry studies by Forsman $(1980,1981)$, the Spotted Owl Subcommittee revised the 1977 Oregon Spotted Owl Management Plan in 1981 and recommended that 1000 acres of old-growth forest be maintained for each pair within a 1.5-mile radius of the nest area. The 1000-acre figure represented the minimum amount of old growth found within the home ranges of six pairs studied by Forsman and Meslow (1985), and the 1.5-mile radius represented the area within which nesting pairs confined most of their foraging. These recommendations were forwarded to the BLM and FS in Oregon. Region 6 of the Forest Service agreed to the new recommendations only to the extent that they would "maintain the option" to manage for 1000 acres if further research proved it was necessary. The BLM in Oregon continued to protect only 300 acres for managed pairs.

Regional standards and guidelines for the spotted owl (regardless of subspecies) on National Forest lands in California were formulated in 1981. They were modeled after the Oregon Spotted Owl Management Plan, except that the concept of replacement habitat was added. Habitat areas were to contain 1000 acres of the oldest available habitat plus 650 to 1650 acres of replacement habitat. The amount of replacement habitat varied, depending on whether the habitat area was to be fully protected or managed. When possible, owls selected for management were selected in groups of three closely spaced pairs. Implementation started in 1982 under the standards and guidelines identified in the land management planning process. 


\section{Appendix B: History}

\author{
FIrst FWS Status \\ Revlew
}

The Old Growth WIIdlife Research and Development Program

BLM-ODFW Agreement

Research in Washington

FS Reglonal Gulde
The Portland Regional Office of the FWS undertook a status review of the spotted owl in 1981 because of concerns about the decline of old-growth forest (USDI 1982). Although the species was described as "vulnerable" in this review, the FWS concluded that the species did not then meet the listing requirements of the Endangered Species Act of 1973.

The FS, in cooperation with the BLM, initiated the Old Growth Wildlife Research and Development Program in 1982, which addressed species of concern in western Washington and Oregon. (This program was rechartered in 1986 as the Spotted Owl Research, Development, and Application Program and included both the Pacific Northwest and Pacific Southwest Research Stations.) Under the auspices of this program, numerous studies on spotted owls and associated habitats were initiated in Oregon, Washington, and California. These studies are still in progress and have generated numerous progress reports and publications.

The BLM also issued a proposed decision on their Coos Bay District timber management plan in 1982. The Oregon Fish and Wildlife Commission found that the proposed plan failed to meet State wildlife policies and existing Federal laws, and would not provide sufficient protection for the spotted owl. The Oregon Land Conservation and Development Commission sustained this objection. As a result, BLM and ODFW were requested to negotiate a settlement. The negotiation culminated in a 5-year agreement signed in 1983, in which the two agencies agreed that BLM would "...manage habitat to maintain a population of 90 pairs of spotted owls, with appropriate distribution of pairs, as a contribution to maintaining a minimum viable population in western Oregon."

In 1983, WDW began a 3-year cooperative study with the FS to monitor the effectiveness of the proposed FS spotted owl management strategy. This work led to additional studies on home-range size and habitat use.

The FS issued the final Regional Guide (USDA 1984) for the Pacific Northwest Region in 1984. The Regional Guide directed the National Forests to analyze the effects of protecting at least 375 pairs in Oregon and Washington as they developed Forest plans. Management was to follow the 1981 proposed revision of the Oregon Interagency Spotted Owl Management Plan. Shortly thereafter, the R6 Regional Office provided further direction for spacing requirements needed to maintain a welldistributed population. This increased to 551 the number of spotted owl habitat areas proposed for management under Forest plans in Oregon and Washington.

Later in 1984, a consortium of conservation groups appealed the R6 Regional Guide on the grounds that the standards and guidelines it contained were inadequate, and that the proposed plan was a major Federal action requiring an environmental impact statement (EIS). The Chief of the Forest Service denied the appeal, but the Deputy Assistant Secretary for Agriculture reversed that decision and directed the FS to prepare a supplemental EIS (SEIS) on spotted owl standards and guidelines. Preparation of the SEIS began in 1985. 


\section{Appendix B: History}

\section{FS Standards and Guldellnes In Callfornla}

National Audubon Advisory Panel

Prlvate Industry

Becomes Involved In Research

\section{BLM Environmental Assessment}

FWS PetItioned to LIst

Callfornla's Planning Process
Several forests had not yet begun by 1984 to implement the Region 5 standards and guidelines that had been issued 2 years earlier because of delays in preparing individual forest land management plans. The CDFG and R5 (FS) agreed that regional standards and guidelines should be implemented promptly before existing owl management options were lost. As a result, a network of spotted owl habitat areas were established on all western Sierra Nevada and northwestern California National Forests.

The National Audubon Society formed a "blue-ribbon" advisory panel in 1985 to review the status of the spotted owl in Washington, Oregon, and northern California. The panel recommended in 1986 that a minimum of 1500 pairs of spotted owls be maintained in the three States, including in the Sierra Nevada of California, and that much larger amounts of habitat be protected for pairs of owls in the range of the northern subspecies (Dawson et al. 1986). A variation of this recommendation was included as "alternative M" in the spotted owl SEIS being developed at the time by the FS.

After an evaluation of spotted owl management areas, ODFW recommended in 1985 that BLM establish a minimum of 40 additional spotted owl habitat areas. This recommendation was made because many of the 90 sites that BLM was protecting at the time were characterized by poor habitat, scattered distribution, and low occupancy by owls. The BLM did not act on this recommendation until 2 years later, when they agreed to manage for an additional 20 pairs of owls ( 110 total) that would be jointly selected by BLM and ODFW.

Private industry became involved in research efforts on spotted owls in 1986 through the National Council for Air and Stream Improvement in Corvallis, Oregon. Since then, industry research efforts have expanded to all three States on both public and private lands.

In 1986, the BLM initiated a Statewide environmental assessment (EA) on the spotted owl in Oregon to determine if new information required a supplemental EIS on their existing timber management plans. After public review, the BLM decided in 1987 that a supplemental EIS was not warranted.

The FWS acknowledged in early 1987 that they had received a petition from Greenworld to list the spotted owl as an endangered species under the Endangered Species Act of 1973. A new status review was undertaken and, in December 1987, the FWS announced that listing was not warranted. The decision not to list was appealed to the Seattle Federal Court by conservation groups in 1988. The Court determined that the decision not to list was not biologically based and ordered the FWS to readdress the listing decision.

In early 1987, CDFG began filing nonconcurrences with CDF when reviewing timber harvest plans where the cutting of old-growth stands in north coastal California was proposed. By later in the year, environmental groups had brought suit to stop several sales where nonconcurrences had been filed but CDF had approved the sale. This litigation caused a review of the CDF's harvest planning process and of the Board of Forestry rules relating to how sensitive wildlife species are handled. 


\section{Appendix B: History}

\section{Spotted Owi Listed by States}

FWS Proposes Listing Spotted Owl as Threatened

\section{The Scientific Committee Begins}

In 1989, the State Legislature passed AB 1580, which directed CDF to develop a system to better track how harvest planning decisions are made, and to develop a scientific data base on timberland habitats and wildife species so that cumulative impacts of timber harvesting can be better analyzed. At the same time, the Board of Forestry asked CDF to develop a habitat conservation plan so that harvest planning and logging could continue if the northern spotted owl was listed as a threatened species by the FWS at some future date.

The Washington Wildlife Commission listed the spotted owl as "endangered" throughout the State in 1988. As a result of the listing, WDW began to develop a State recovery plan with participation by agency and private organizations. That process is ongoing. Late in the year, the Oregon Wildlife Commission, under a new State endangered species act, reaffirmed listing the spotted owl as "threatened" in Oregon. Such a listing requires protection on all State lands but not on private lands. Protection on private forest lands is now being addressed by ODF under recent (1987) amendments to the State Forest Practices Act.

In April 1988, the Interagency Spotted Owl Subcommittee proposed new management guidelines for the northern spotted owl that, for the first time, addressed the entire range of the subspecies in Washington, Oregon, and northern California. The main features of the Spotted Owl Subcommittee recommendations were to maintain larger population centers, protect all remaining habitat in areas of special concern (such as the Oregon Coast Range), regenerate more habitat in problem areas, maintain an interconnecting network of individual SOHAs of one to three pairs per township, retain an amount of habitat per pair that reflected the mean amount of old growth in home ranges of radio-marked pairs, and provide for replacement habitat. Monitoring and coordination were also addressed. These recommendations were not acted on by any of the agencies responsible for managing the owl. Since that time, the subcommittee has become inactive.

The FWS initiated another status review in January 1989 to supplement the 1987 review. The status review was completed in April, with the result that the northern spotted owl was deemed to warrant protection as a threatened species under the Endangered Species Act of 1973. As a result of this decision, an FWS listing-review team was established in October 1989 to review this proposal and make a final recommendation on whether to list the owl in June 1990. The proposal to list the northern spotted owl triggered requirements that the FS and BLM confer with the FWS under Section 7 of the Endangered Species Act. Interim guidelines were prepared by the FWS to assist the agencies in evaluating timber sales that would impact spotted owls. These guidelines increased the size of SOHAs in northern California to 2000 acres and designated some interim "areas of concern" where timber sales were to be deferred for 1990. This conferencing process is ongoing.

A new interagency agreement was signed in August 1988 by the heads of the BLM, FS, FWS, and NPS. In that agreement, the agencies agreed to work toward a common goal of ensuring population viability for the spotted owl throughout its range. The Interagency Agreement served as the umbrella under which the Interagency Spotted Owl Scientific Committee was formed in 1989. 


\section{Appendix B: History}

The FInal SEIS

The Hatfield-Adams Amendment

Committee Established

\section{References}

In late 1988, the Chief of the FS issued a Record of Decision on the supplemental spotted owl EIS for Oregon and Washington. The selected alternative (F) directed the 13 National Forests with spotted owls to establish a SOHA network. Standards and guidelines differed for physiographic provinces. Amounts of habitat to be provided in SOHAs varied from 1000 acres in southern Oregon to 3000 acres on the Olympic Peninsula. Habitat was to be identified within 1.5 miles of the center area in Oregon and 2.1 miles in Washington; SOHAs containing three or more pairs were to be no more than 12 miles apart, and single-pair SOHAs were to be no more than 6 miles apart. The Record of Decision was shortly appealed by WDW and by timber and environmental groups, but the Assistant Secretary of Agriculture denied the appeals.

Interest groups obtained injunctions prohibiting the sale of old growth on BLM lands near spotted owl sites, and continuous litigation finally resulted in the "Northwest Compromise" (Hatfield-Adams Amendment) of 1989. This legislation applied to Washington and Oregon, and was attached as a rider (Section 318) to the 1990 fiscal-year appropriations bill. It declared the FS's Spotted Owl SEIS and the BLM's spotted owl management plans adequate for preparing FY90 sales. The compromise expanded FS SOHA sizes by 12 to $25 \%$ and established 12 new agreement areas on BLM lands, for a period of 1 year. It also instructed the FS and the BLM to minimize the fragmentation of "ecologically significant" stands of old growth in Oregon and Washington and provided for establishing citizen advisory boards to assist the FS and BLM in preparing and modifying sales. Implementation of Section 318 is ongoing.

As a result of the uncertainty surrounding the status of the northern spotted owl, the FS recommended the formation of an interagency scientific committee to address the issue. This recommendation was agreed upon by the heads of the BLM, FS, FWS, and NPS, and in October 1989, the Interagency Spotted Owl Scientific Committee was established. The charge to the Committee was to "develop a scientifically credible conservation strategy for the northern spotted owl." The task was essentially completed with the publication of this document.

Dawson, W. R., J. D. LIgon, J. R. Murphy, J. P. Myers, D. Simberloff, and J. Verner. 1986. Report of the advisory panel on the spotted owl. Audubon Conserv. Report 7. 46pp.

Forsman, E. D. 1976. A preliminary investigation of the spotted owl in Oregon. M.S. Thesis. Oregon State University, Corvallis. 127pp.

Forsman, E. D. 1980. Habitat utilization by spotted owls in the west-central Cascades of Oregon. Ph.D. Thesis. Oregon State University, Corvallis. 95pp.

Forsman, E. D. 1981 unpubl. Habitat utilization by spotted owls on the Eugene District of the Bureau of Land Management. USDI, Bureau of Land Management, Portland, Oreg. 63pp.

Forsman, E. D., and E. C. Meslow. 1985. Old growth forest retention for spotted owls, how much do they need? Pages 58-59 in R. J. Gutiérrez and A. B. Carey, eds.' Ecology and management of the spotted owl in the Pacific Northwest. U.S. For. Serv. Gen. Tech. Rep. PNW-185. 119pp. 


\section{Appendix B: History}

Gabrieison, I. N., and S. G. Jewett. 1940. Birds of Oregon. Oreg. State College, Corvallis. 650pp.

Gould, G.I. 1974. The status of the spotted owl in California. Calif. Dep. Fish and Game, Sacramento. Rep. 74-6. 56pp.

Marshall, D. B. 1969. Endangered plants and animals of Oregon. III. Birds. Special Report 278, Agricultural Experiment Station, Oreg. State Univ., Corvallis. 23pp.

Marshall, J. T., Jr. 1942. Food and habitat of the spotted owl. Condor 44:66-67.

Oregon Department of Fish and Wildilfe. 1975 unpubi. Threatened and endangered wildlife in Oregon. 1p.

U.S. Department of Agriculture, Forest Service. 1984. Regional guide for the Pacific Northwest Region. USDA-Forest Service, Pacific Northwest Region, Portland, Oreg.

U.S. Department of the interior. 1973. Bureau of Sports Fisheries and Wildlife. Threatened Wildlife of the United States. Research Publication 114. Bureau of Sports Fisheries and Wildlife, Washington, D.C. 289pp.

U.S. Department of the interior. Fish and Wildilfe Service. 1982. The northern spotted owl: a status review. USDI-Fish and Wildlife Service, Endangered Species Program, Portland, Oreg. 29pp. 


\section{The Current Situation}

\section{Description}

\section{Current Taxonomy}

The spotted owl (Strix occidentalis) is a medium-sized bird with a round head, darkbrown plumage, and dark eyes. It has white spots on the head and nape, and white mottling on the breast and abdomen; thus the name "spotted owl". Sexes look alike except that females average slightly larger and have higher pitched calls than males. A distinctive feature of spotted owls is their unwary behavior around humans, often allowing human observers to approach within a few feet before flying (USDA 1988a). Prey consists mainly of small mammals, particularly arboreal or semiarboreal species, although birds, insects, and other types of small mammals are taken as well (see appendix J). Flying squirrels, woodrats, and lagomorphs (rabbits and hares) are especially important.

The only species with which spotted owls might be confused is the closely related barred owl (Strix varia). Barred owls are slightly larger than spotted owls and have a distinct pattern of horizontal bars on the breast and vertical streaks on the abdomen. Unlike spotted owls, barred owls are wary and usually fly away when approached. The barred owl has invaded the Pacific Northwest and northern California in recent years and appears to be displacing spotted owls in some areas (Grant 1966 in USDA 1988a, Taylor and Forsman 1976).

Recent studies of genetic differences among spotted owls over much of their range in the Western United States showed essentially no genetic difference between the northern (Strix occidentalis caurina) and California subspecies (S. o. occidentalis), but a gene substitution was found between the California and Mexican subspecies (S. o. lucida) (Gutiérrez 1989). Barrowclough (pers. comm.) identified several morphological features that exhibit clinal variation from north to south across the range of the northern and California subspecies. In considering the significance of these results at their annual meeting in August 1989, the Committee on Classification and Nomenclature of the American Ornithologists' Union ruled that the northern and California subspecies would be retained as originally described (Johnson 1989). The rationale behind the decision follows a standard used in similar cases reviewed by the taxonomy committee in recent years. If a species exhibits clinal variation across its range, the ends of the cline are judged to be sufficiently distinct to be recognized as separate subspecies.

A decision about where to place the boundary between the two subspecies is based, at least in part, on geographic and biogeographic considerations. For the spotted owl, the Pit River in northern California was originally designated as the boundary. Because this coincides with other known subspecific boundaries of vertebrates, it was retained for these subspecies of spotted owl. Thus, no change of any kind was made in the taxonomy of spotted owls. 


\section{Appendix C: Current Situation}

Status

Range
The need to devote special management attention to a species is conveyed by Federal and State regulations classifying the species according to the perceived attention needed. This classification is accomplished by enabling legislation dealing with threatened and endangered species. In addition to receiving protection under the Migratory Bird Treaty Act of 1918, the northern spotted owl is currently on classification lists maintained by the Federal government and by each of the three States within its geographic range. Under the Endangered Species Act of 1973, as amended, the northern spotted owl is currently proposed for Federal listing as a threatened species. A decision on whether to add it to the Federal threatened-species list will be forthcoming from the FWS in summer 1990. In Washington, the northern spotted owl is classified as endangered, in Oregon as threatened, and in California as a species of special concern. Its classification in California is an administrative action of the Fish and Game Department and not a product of regulations as with the other two States.

Until its recent Federal classification as a proposed threatened species, the spotted owl was provided additional recognition by FS policy, which classified it as a sensitive species. This classification brought into play a set of agency regulations and actions designed to direct specific attention to the spotted owl. The BLM's classification of the spotted owl as a special status species provides similar agency attention. Finally, the spotted owl has been designated an indicator species for old-growth forest ecosystems on all National Forests within its range.

The present range of the spotted owl approximates the limits of its historic range (fig. C1). The range encompasses an area from southwestern British Columbia south through the coastal mountains and Cascade Range (both west and east sides) of Washington and Oregon, south into southwestern Oregon and northwestern California north of San Francisco. Note that although the subspecies' range has not decreased, its distribution within the range has. Of particular note are the Puget Trough in Washington and lands adjacent to the Willamette Valley in Oregon. Both of these areas have undergone significant changes in habitat for spotted owls because of human development and thus no longer support populations of owls. Similar, but less complete habitat changes have negatively affected owl distribution in southwestern Washington and northwestern Oregon. Here, timber cutting and wildfires have played a major role. Spotted owl populations in these areas are low at present. In British Columbia, fewer than 20 pairs are known to exist; much of the owl's range in Canada has been logged, and little mature and old-growth forest remains. 


\section{Appendix C: Current Situation}

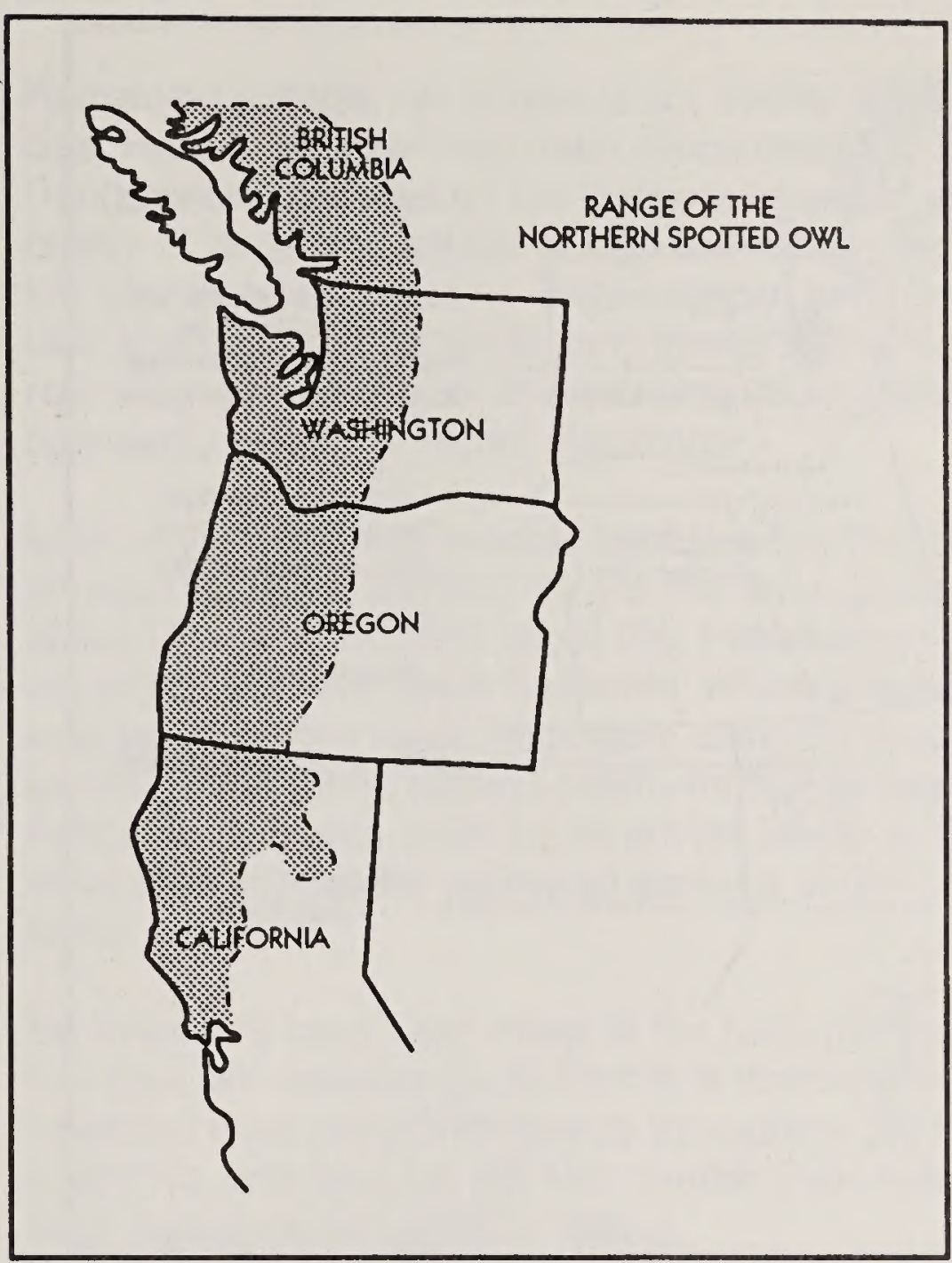

Figure C1-Range of the northern spotted owl.

Physiographic Provinces
Because of the extent of the owl's range, we subdivided it into smaller areas for practical and analytical purposes. Studies have shown differences in numbers, distribution, and habitat-use patterns of the spotted owl relative to various forest zones that occur within its range (for example, western hemlock versus mixedconifer) (appendices F, I, and J). These forest zones and their inherent plant communities are products of the effects of climate and geology on the landscape. Physiographic provinces (Franklin and Dyrness 1988) provided a recognized set of landscape subdivisions incorporating the physical and environmental factors that shape the landscape of the Pacific Northwest. These physiographic provinces were modified and used as the first subdivision of the range of the spotted owl (fig. C2). 


\section{Appendix C: Current Situation}

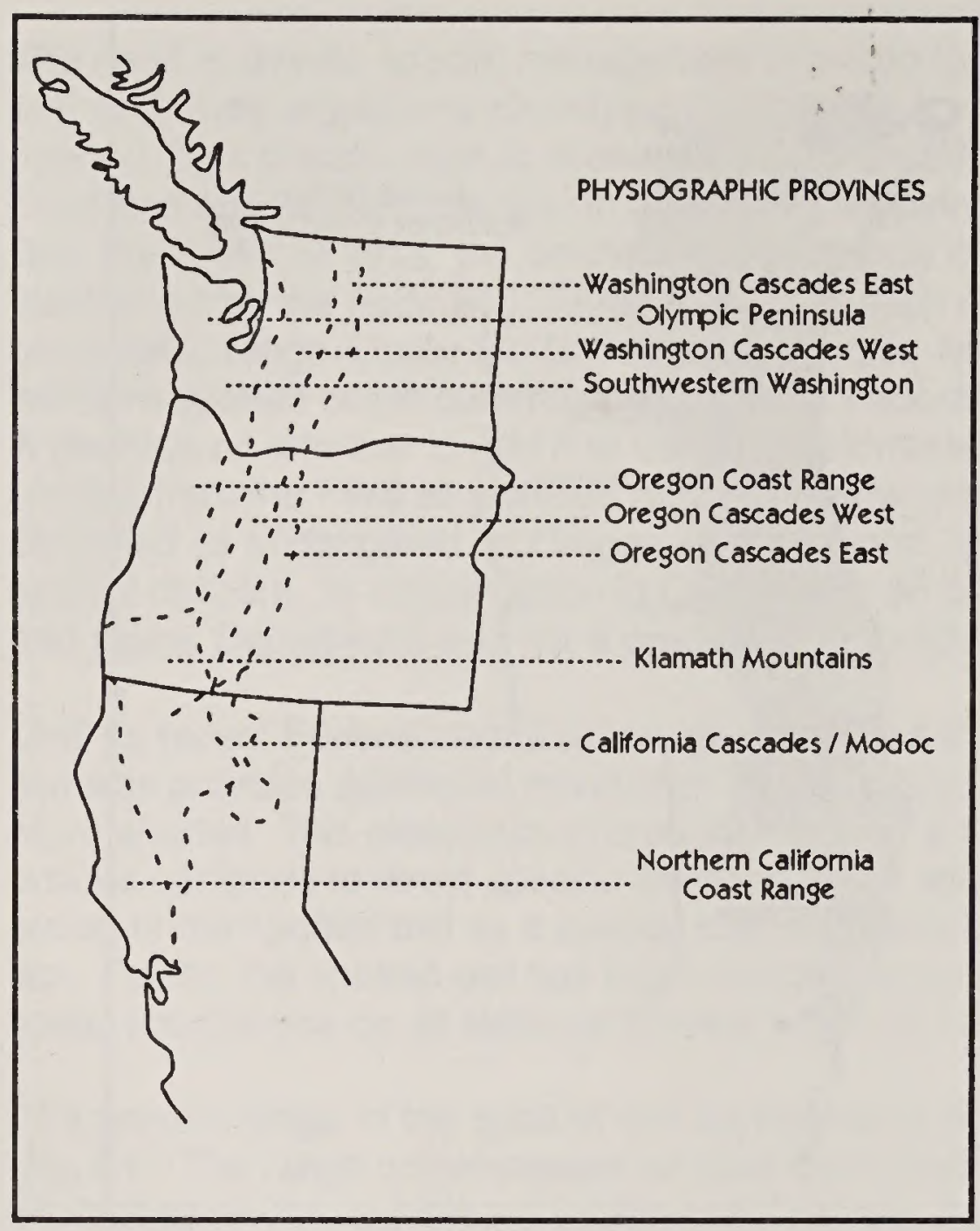

Figure C2-Physiographic provinces within the range of the northern spotted owl.

Habitat

A general characterization of the forested habitat in specific forest types used by spotted owls includes the following attributes (see details in appendices $F, G$, and $H$ ): Large, tall, live trees with cavities, broken tops, dwarfmistletoe, or platforms of branches capable of holding accumulated organic matter suitable for use as a nest; dead standing trees and fallen, decaying trees and limbs to support abundant populations of prey species, especially northern flying squirrels and woodrats; dominant trees in the stand with relatively large diameters; and multilayered tree canopies with a moderate to high canopy closure in overstory, midstory, and understory.

A consensus among spotted owl authorities holds that structure is a more important factor in determining suitability for owls than tree age. Older forests, however, more often exhibit the structural attributes favored by owls than do younger ones.

The total amount of spotted owl habitat has been declining since European settlers arrived in the 1800s (USDA 1989). We do not know the full extent of owl habitat before 1800 , but estimates of about 17.5 million acres in 1800 and 7.1 million acres today indicate a reduction of about $60 \%$ in the past 190 years (USDA 1989). Most of this reduction has occurred in the last 90 years. Current trends indicate annual reductions of about 1 to $2 \%$ of remaining suitable habitat on National Forests. 


\section{Appendix C: Current Situation}

Remaining suitable owl habitat is not evenly distributed over the range of the species. Habitat reduction has been concentrated at low elevations and in the Coast Range, a fact mirrored by the low populations of spotted owls in those areas. The quality of remaining habitat at high elevations may not be as good as it was in those low elevation lands that no longer support owls (see appendices $F, G$, and $H$ ). This lack of quality may be particularly true of the $40 \%$ of the estimated remaining habitat now in reserved areas or in areas unsuited for timber production, which are commonly located at higher elevations.

Most of the remaining suitable habitat is found on Federal lands (about $94 \%$ of the acreage figures available); the FS manages about $74 \%$ of these lands; the BLM about $12 \%$, and the NPS about $8 \%$. Percentages may change as habitat inventories are expanded in northern California, where a significant portion of spotted owl habitat may be on private lands, especially along the Coast Range (west of National Forest lands). Gould (pers. comm.) estimates that as much as $40 \%$ of northern spotted owl habitat in California could be on private lands. In Oregon and Washington, however, more than $95 \%$ of the estimated acreage of owl habitat is found on federally managed lands.

\section{Population Status and Trend}

No estimates have been made of the historical population size of the spotted owl, and few data are available on its historical distribution. Spotted owls are believed to have inhabited most old-growth forests throughout the Pacific Northwest and northwestern California, and they are still found within their historical range in most areas where such habitat remains (USDI 1989a).

Northern Washington and southern British Columbia represent the northern extent of the range of the northern subspecies. Population densities and numbers are lowest in these areas, with less than 20 pairs located in recent extensive surveys along the U.S. border in British Columbia (Dunbar, pers. comm.). A small, potentially isolated population of perhaps 110 pairs of spotted owls lives on the Olympic Peninsula in an area in and around the Olympic National Park (Fredrickson et al. 1989, WDW 1990). Fewer than 40 owls have been found in recent, extensive surveys in the Coast Ranges of southwestern Washington and northwestern Oregon north of Corvallis (Forsman 1986; Forsman et al. 1987; Irwin et al. 1989a, ODFW 1990; USDI 1989a) (see appendix G). The population also decreases in size and density from the Mendocino National Forest south to Point Reyes, California, as well as from the Klamath Province east to the intersection with the California subspecies in the Sierra Nevada (Gould, pers. comm.; USDA 1989).

Most of the present owl population is found from the southern portion of the Cascades in Washington southward, throughout the Cascades and Klamath Provinces in Oregon, and into the Klamath and Coast Range Provinces in northwestern California (see fig. C2) (Advanced Sci. 1989, Beak Cons. 1989, Brown 1989, Diller 1989, Inwin et al. 1989b, Kerns 1989, ODFW 1990, Pious 1989, USDA 1989, WDW 1990). Distribution of remaining habitat is similar to the present distribution of spotted owls (see table $\mathrm{C} 1$ and discussion on habitat status). 


\section{Appendix C: Current Situation}

Over $90 \%$ of the known pairs of owls have been observed on federally managed lands $-68 \%$ on FS lands and $22 \%$ on BLM lands. The distribution of these pairs varies widely by land ownership, State, and physiographic province (see table C1). Distribution is particularly important in California, where up to $40 \%$ of the habitat could occur on private lands. Although inventories are less complete in California, about $30 \%$ of the habitat and population of spotted owls may occur in the Coast Range (Gould, pers. comm.; Self, pers. comm.).

Observations of spotted owl pairs have accumulated for almost 20 years. These counts have been cumulatively tallied over this period as additional and more intensive surveys have been done, particularly in the past 3 years. Censusing is not complete because not all suitable habitat has been fully surveyed. In addition, counts have not accounted for differing inventory intensities, sites lost through habitat reduction or conversion, loss and recolonization of sites by new or displaced pairs, new sites found through recent inventories, or double counting the same pairs in different sites. This type of information is not a good indicator of true population size or trend.

Cumulative numbers of owl pairs observed over their range during the past 5 years (table $\mathrm{C}_{1}$ ) include estimates of both breeding and nonbreeding pairs. The past 5-year period (1985 to 1989) was chosen because we consider it to be a more reliable estimate of actual numbers than a longer cumulative period or any single-year count, given the current habitat situation. It is the period with the most intense inventories, and it is within the average life span of the species (about 8 years), so it should provide a reasonable balance between how recent habitat loss has affected owl survival and occupancy of sites, and an attempt to report a correct count of pairs, given some of the problems noted above.

A total population estimate was not made. Data from the inventories done during the 5-year period indicate a total of about 2000 known pairs of spotted owls in Washington, Oregon, and northern California. This number is a minimum estimate of the true population size. We suspect the true number lies somewhere between 3000 and 4000 pairs.

Population size is primarily a function of the total amount, distribution, and suitability of habitat available to sustain successfully reproducing owl pairs through time. Present analyses indicate that the population of spotted owls is declining because of habitat loss and modification, and the rate is similar to the decline of suitable habitat (see appendix L). 


\section{Appendix C: Current Situation}

Table C1-Estimated spotted owl habitat and number of pairs of spotted owis located in the last 5 years on all lands in Washington, Oregon, and Callfornia (NA = rellable estimates not avallable)

\begin{tabular}{|c|c|c|c|c|c|c|c|}
\hline \multirow[b]{2}{*}{$\begin{array}{l}\text { Land owner } \\
\text { or agency }\end{array}$} & \multicolumn{4}{|c|}{$\begin{array}{l}\text { Estimated acres of spotted owl habitat } \\
\text { timber capability }\end{array}$} & \multicolumn{2}{|c|}{ Owl pairs } & \multirow[b]{2}{*}{ Tota } \\
\hline & Reserved $^{b}$ & Unsuitable $^{c}$ & Suitable & Total acres & $\begin{array}{l}\text { Repro- } \\
\text { ducing }\end{array}$ & $\begin{array}{l}\text { Not re- } \\
\text { producing }\end{array}$ & \\
\hline FS, WA & 433,000 & 384,000 & 818,000 & $1,635,000$ & 166 & 151 & 317 \\
\hline$F S, O R$ & 438,000 & 241,000 & $1,909,000$ & $2,588,000$ & 274 & 393 & 667 \\
\hline $\mathrm{FS}, \mathrm{CA}$ & 151,000 & 209,000 & 474,000 & 834,000 & 169 & 234 & 403 \\
\hline BLM, WA & NA & NA & NA & - & - & - & - \\
\hline BLM, OR & $158,000^{d}$ & - & 701,000 & 859,000 & 224 & 207 & 431 \\
\hline BLM, CA & 13,000 & - & 6,000 & 19,000 & 7 & 7 & 14 \\
\hline NPS, WA & 480,000 & 0 & 0 & 480,000 & 10 & 10 & 20 \\
\hline NPS, OR & 50,000 & 0 & 0 & 50,000 & 2 & 3 & 5 \\
\hline NPS, CA & 40,000 & 0 & 0 & 40,000 & 1 & 2 & 3 \\
\hline Tribal lands, WA & 42,000 & NA & 24,000 & 66,000 & 2 & 3 & 5 \\
\hline Tribal lands, OR & NA & NA & NA & $54,000^{e}$ & 1 & 0 & 1 \\
\hline Tribal lands, CA & NA & NA & NA & NA & NA & NA & NA \\
\hline FWS, WA & 1,700 & NA & 5,000 & 6,700 & 0 & 1 & 1 \\
\hline FWS, OR & 4,100 & NA & NA & 4,100 & 0 & 0 & 0 \\
\hline WDNR, WA & NA & NA & NA & NA & 4 & 9 & 13 \\
\hline WDW, WA & 0 & NA & 5,000 & 5,000 & 0 & 0 & 0 \\
\hline State Parks, WA & 2,000 & 0 & 0 & 2,000 & 0 & 0 & 0 \\
\hline Cities of Seattle, Tacoma & 0 & 0 & $1,500^{t}$ & 1,500 & 0 & 0 & 0 \\
\hline ODF & 2,000 & NA & 78,000 & 80,000 & 1 & 2 & 3 \\
\hline State Parks, OR & 8,000 & 0 & 0 & 8,000 & 1 & 0 & 1 \\
\hline Counties and cities, OR & NA & NA & NA & NA & 1 & 0 & 1 \\
\hline CDF & NA & NA & NA & NA & 0 & 3 & 3 \\
\hline State Parks, CA & 56,000 & 0 & 0 & 56,000 & 5 & 3 & 8 \\
\hline State Lands Comm., CA & NA & NA & NA & NA & NA & NA & NA \\
\hline $\mathrm{BLM} / \mathrm{TNC}, \mathrm{CA}$ & 6,500 & 0 & 0 & 6,500 & 0 & 2 & 2 \\
\hline NAS, CA & 600 & 0 & 0 & 600 & 0 & 1 & 1 \\
\hline Private, CA & NA & NA & NA & NA & 36 & 63 & 99 \\
\hline Private, OR & NA & NA & NA & NA & NA & NA & 20 \\
\hline Private, WA & NA & NA & NA & NA & 2 & 2 & 4 \\
\hline Totals & $1,885,900$ & 834,000 & $4,021,500$ & $6,795,400$ & 906 & 1,096 & 2,022 \\
\hline
\end{tabular}

See text for sources of above information.

${ }^{b}$ Withdrawn from timber harvest (that is, Wilderness and Research Natural Areas).

c Lands unsuited for timber production because of allocation to other uses by land management plans, or technically unsuited for timber production because of soils problems or difficulty of regeneration. 


\section{Appendix C: Current Situation}

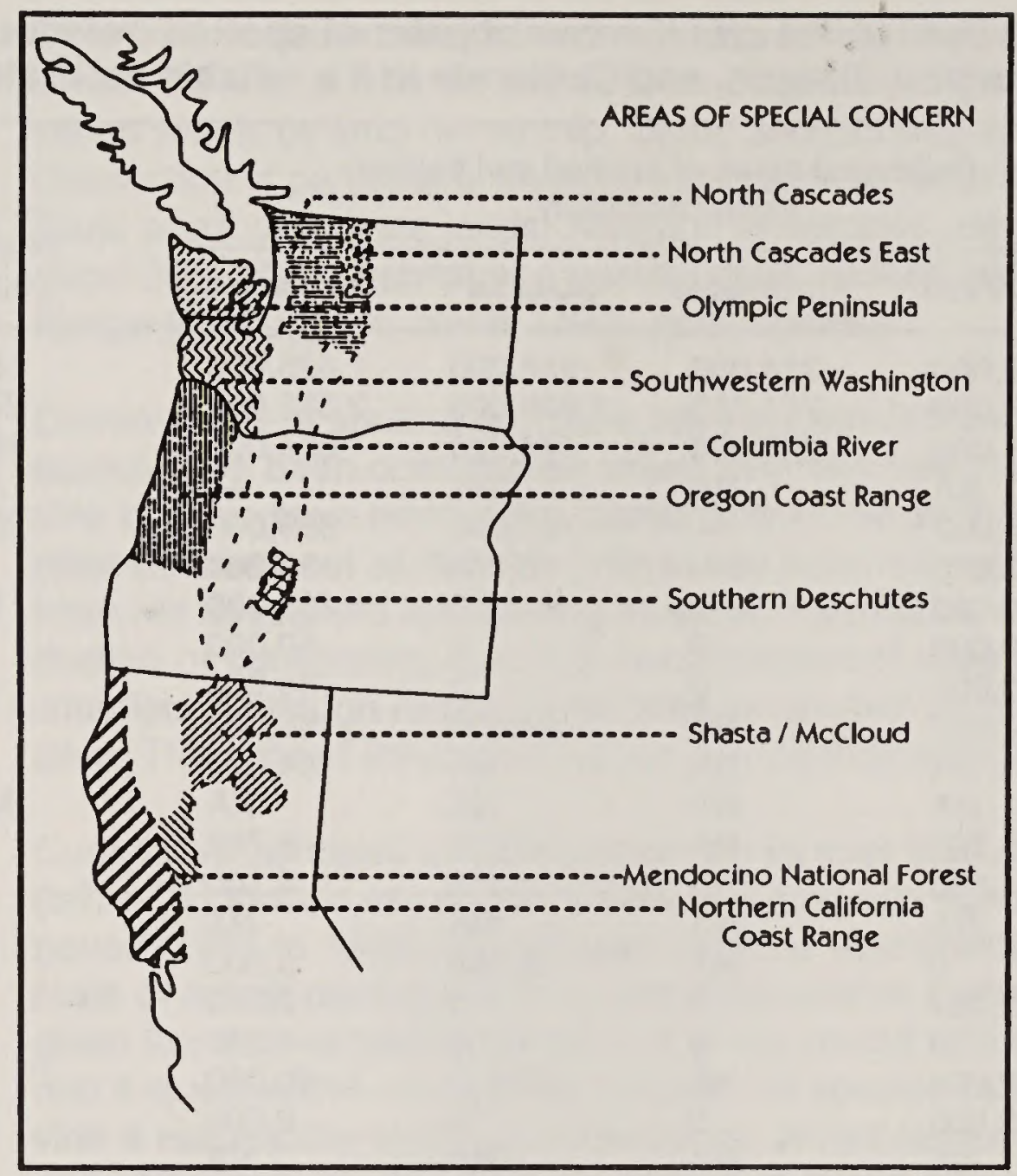

Figure C3-Areas of Special Concern for management of the northern spotted owl.

\section{Areas of Special} Concern

North Cascades
As a result of both natural and human-related activities, all lands in a physiographic province are not the same in quantity and quality of spotted owl habitat. A primary difference is the ownership pattern, which results in an array of land treatments that either retained or eliminated owl habitat to different degrees. Natural events such as large wildfires and volcanic eruptions sometimes have played a major role in shaping habitat conditions. To address these differences, the physiographic provinces were further subdivided by identifying "areas of special concern." These areas-lands where past natural occurrences and human actions have adversely affected habitat more than in the remainder of the province-are discussed individually below (see fig. C3 for locations).

Spotted owls in the Washington Cascades are a special concern because of the likelihood of demographic isolation from populations in Oregon and the Olympic Peninsula, and because of the low numbers of known pairs in that region. Federal ownership is primarily at intermediate and high elevations (2000 to 14,000 feet), where mountainous areas serve as potential barriers to owl distribution and dispersal.

Of particular concern is the northern Washington Cascades, encompassing areas north and northeast of Mount Rainier and the Goat Rocks Wilderness to the Canadian border. Much of the existing and potential owl habitat on Federal lands within this area resembles forested fingers, bordered by steep-walled canyons and high, subalpine ridges. Logging of State, private, and Federal lands has moved inexorably 


\section{Appendix C: Current Situation}

\section{North Cascades East}

\section{Olymplc Peninsula}

\section{Southwestern}

Washington

\section{Columbla River}

Oregon Coast Range from sea level to gently sloped areas, and now encroaches on the steep mountainous terrain of the interior Cascade Range. The gently sloped areas from sea level to about 2000 feet, now primarily under private and State ownership, probably once provided relatively contiguous tracts of habitat supporting high owl densities.

In Okanogan County and the northern portion of Chelan County, owl pairs are known in only six locations, marking the northern-most distribution of the subspecies in the eastern Cascades of Washington.

We believe the spotted owl population on the Olympic Peninsula is now demographically isolated from the Cascade Range by a span of intensively managed State and private forest lands more than 60 miles wide. Spotted owls on the Peninsula live in Olympic National Park, Olympic National Forest, State lands managed by the Department of Natural Resources, and private lands. Isolation of a population of fewer than 150 pairs increases the risk of extirpation, thus the concern about owls in this region.

Only one pair of owls is known in southwestern Washington, a large area of private and State forest that separates the Olympic Peninsula from the Cascade Range. Most lands in this block are intensively managed for timber production using 50- to 70-year rotations. No regulatory mechanisms or management plans are currently in place that will either protect existing owls or provide for future spotted owl habitat within the area.

Bisection of the Cascade Range by the Columbia River Gorge has caused concern that this geologic feature, plus the associated effects of human activities along the river, have created a barrier to the movement of spotted owls between the Washington Cascade Province and the Oregon Cascade Province. Spotted owl habitat in this area now occurs mainly on the Gifford Pinchot National Forest in Washington and the Mount Hood National Forest in Oregon. Hydroelectric dams along the Columbia River have created impoundments that have widened the river. Highways and landuse patterns along the river in both States have further reduced the amount of suitable habitat immediately adjacent to the river. These patterns create a barrier that could either block or restrict owl movement between the Gifford Pinchot and Mount Hood National Forests. The effects of such a barrier are discussed in appendices $\mathrm{N}$ and $\mathrm{P}$.

Recent establishment of the Columbia River National Scenic Area, and FS land acquisitions in the same region, will likely prevent further development of the area and could improve dispersal habitat for spotted owls.

The area of special concern identified in the Coast Range Province of Oregon includes all forested lands north of State Highway 38 and west of Interstate 5 to the Columbia River, a forested land area of about 4.1 million acres. Within this area, the known owl population is extremely low compared to other areas in the State. Existing data indicate 102 known pairs of spotted owls in the entire area, a density of only 0.015 pairs per square mile. This density is only $1 / 8$ that recorded in a study area in the Coast Range outside the area of concern. This low density parallels an equally dire scarcity of suitable owl habitat. Most of the forest is $<80$ years old. The remaining areas of older forest are scattered across the landscape, and are becoming increasingly isolated. 


\section{Appendix C: Current Situation}

\author{
Southern Deschutes
}

\section{Shasta-McCloud Area}

North Coastal California

Mendocino National Forest
The area of concern in the Deschutes National Forest, south of Bend, Oregon, is at the eastern edge of the species' range. Because of the disjunct nature of the mixedconifer forests there, and the patches of habitat that are becoming more isolated, risk to the owl population is high. We believe, however, that maintaining as wide a distribution as possible of occupied plant community associations throughout the range of the spotted owl is important to minimize the impact of potential catastrophic effects (see appendices $\mathrm{N}$ and $\mathrm{O}$ ) and to maintain genetic variability.

The Shasta-McCloud area includes the Shasta portion of the Shasta-Trinity National Forest, as well as eastern parts of the Salmon River and Scott River Ranger Districts and all of the Goosenest Ranger District of the Klamath National Forest. The north Coast Range creates a rain shadow on its east side and beyond. Although this area includes forest, site quality is poor because of the drier, warmer climate and poor soils (for example, extensive areas of old lava flows). Pine forests commonly lack the multiple canopies and other structural attributes that would render them suitable for spotted owls. Areas of suitable habitat are limited in distribution and fragmented where they occur. Much of this area, especially near McCloud, has also been subject to a long history of logging, further reducing the current amount of suitable habitat.

North coastal California extends southward from the Oregon border through Marin County and to the west of National Forest lands, encompassing major portions of the redwood forest zone that are mostly under private ownership. Except for two National Parks and a BLM Wilderness Area, most public land is in small, scattered parcels. The major problem in this area is administering a Federal habitat conservation plan where success and the viability of the subspecies depend on private and State lands. The California Resources Agency (CRA) has assured us that it is actively proceeding with development of a California Habitat Conservation Plan that will address management of the owl on private and State lands. For this particular area, the success of the conservation strategy proposed in our report depends on prompt drafting and implementing of an appropriate plan for California. Because of the combination of competent professional attention to spotted owls by the timber industry in northern California, the mandates of State law, the leadership potential of the CRA, and the high-site timber lands that contain owls in second growth, we believe that an effective plan can be developed and implemented.

The Mendocino National Forest south of the Yolla Bolly Wilderness Area, and to some extent, the Covelo Ranger District, are considerably different from National Forests farther north. Forested habitat is more naturally fragmented and becomes even more so towards the southern end of the Mendocino National Forest. An area of true fir grows at elevations around 6000 feet along the north-south ridge in the middle of the Forest. East of this ridge, and in the southwest quarter of the Forest, conditions are drier and warmer. Extensive brush fields occur on south-facing slopes, and suitable habitat often exists only on north-facing slopes. 


\section{Appendix C: Current Situation}

Radius in which to find suitable habitat for SOHA

( 1.5 or 2.1 miles)

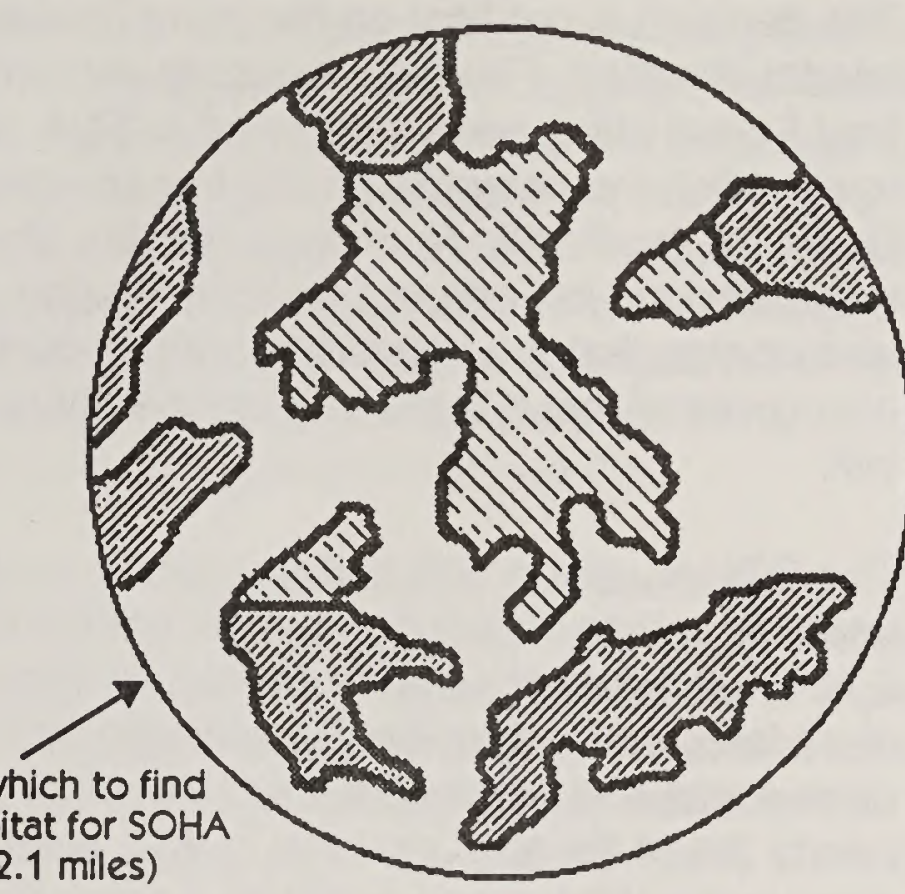

$$
\begin{aligned}
& \text { IV SOHA base habitat } \\
& \text { Other suitable spotted owl habitat subject to harvest } \\
& \text { Currently not suitable as spotted owl habitat } \\
& \text { (subject to timber harvest) }
\end{aligned}
$$

\section{The Current Management Situation}

The FS, Pacific Northwest Region (Washington and Oregon)
Figure $\mathrm{C}_{4}-$ Schematic of a spotted owl habitat area (SOHA) on National Forests in Oregon and Washington.

Spotted owls occur on 13 National Forests ("owl" Forests) in Oregon and Washington (USDA 1988a). Each Forest has developed descriptions characterizing owl habitats that might be termed "typical." These descriptions are narrower than the general description in the "habitat" section of this appendix, and debate continues about the full range of suitable owl habitat in the Pacific Northwest Region (see appendices $F, G$, and $H$ ). Further confusion arises because Forests are usually limited to mapping habitat based on data generated for timber management. Substantial variation in the arrangement of habitat occurs depending on past harvest activities, land ownership patterns, and catastrophic events. Patches of habitat ranging from $<10$ acres to a matrix of relatively contiguous parcels of several thousand acres (usually found in wilderness or roadless recreation areas) occur on National Forests (table C1).

Management direction-Management direction for spotted owls on National Forests in the Pacific Northwest Region (Chief's Record of Decision 1988) has resulted in the designation of 376 Spotted Owl Habitat Acres (SOHAs) ranging from 1000 acres of suitable habitat in southern Oregon to 3000 acres on the Olympic National Forest in Washington (fig. C4). Language in Section 318 of Public Law 101-121 increased the sizes of SOHAs by as much as $25 \%$ for 1 year. To be considered a "designated SOHA," the area must have been at least partially on lands suited for timber production (that is, SOHAs were not delineated on maps in Wilderness Areas, other reserved lands, or lands classified as unsuitable for timber harvest). Forests were allowed the option of dedicating SOHA acreages or developing a silvicultural management strategy that would continually provide the prescribed acreages of suitable owl 


\section{Appendix C: Current Situation}

habitat. Forests with completed land-management plans have opted for dedication. The decision is not final on the other Forests, although all have chosen dedication as interim direction. Flexibility to locate and refine boundaries was also allowed until the final Forest plans were completed (USDA 1989). The standards and guidelines used to establish the networks of SOHAs are contained in Amendment 1 to the Regional Guide for the Pacific Northwest Region, May 1984. This management plan is now being litigated in Federal Courts in Oregon and Washington by forest industry groups, who charge that the network is unnecessary, and by environmental organizations, who contend that it is inadequate to ensure the continued existence of the spotted owl.

The SOHAs, along with existing habitat in Wilderness Areas and areas allocated to uses other than timber production, constitute a network of spotted owl habitat. About $2,024,400$ acres of suitable habitat are included. This acreage represents about $16 \%$ of all forested land on owl Forests and about $48 \%$ of the remaining habitat. Wilderness Areas and lands allocated to uses other than timber production account for nearly $3 / 4$ of the total acreage in the network. Spotted owl surveys have not been done in the Wilderness Areas as frequently or thoroughly as on other National Forest lands. As a result, owl occupancy in these areas is not well known. Amount and arrangements of suitable owl habitat indicate that from 2 to 15 pairs probably occur in each of the various Wilderness Areas, with an average area probably capable of supporting about 5 pairs.

Before 1989, owls were primarily surveyed in areas proposed for inclusion in the SOHA network. Some Forests conducted limited surveys in timber-sale areas. Beginning in 1989, however, a standardized survey effort was initiated by the Regional Forester to locate spotted owls in proposed timber sales. This standard included visiting the sale area at least three times at night and conducting follow-up, daytime visits to determine pair and reproductive status if owls were seen or heard at night.

Management strategies for owl pairs found outside the network differs from Forest to Forest. When they are located in areas to be logged, strategies range from seasonal protection of a nesting area to protection of 5 to 30 acres around the nest area or center of activity (see appendices $C$ and D).

The major impact on owl habitat on National Forest lands comes from logging. About 64,000 acres per year have been cut in Washington and Oregon in the last 9 years (Nunan, pers. comm.). This amount represents a 1.5\% reduction per year in the total amount of spotted owl habitat on National Forests. As the base amount of habitat declines, this annual percentage would increase. The Forest Land Management Plans for the Okanogan and Siskiyou National Forests, and draft plans for the other 11 owl Forests in the Pacific Northwest Region, provide for annual logging averaging about 39,400 acres per year. 


\section{Appendix C: Current Situation}

Present rates of habitat loss will theoretically decline as Forest land-management plans are completed and implemented, assuming that havest rates are established in line with land management plans. Logging units, usually clearcuts (up to 80 acres), are laid out in a patchwork pattern across the landscape to meet the dispersion requirements of the National Forest Management Act of 1976. This pattern results in older forest stands becoming less contiguous - that is, more fragmented. As the patches of suitable habitat become smaller and more widely separated, their use by the birds diminishes (see appendix $\mathrm{H}$ ). Spatial arrangement of habitat is thus a factor that must be considered along with total amounts of habitat, when habitat attributes and trends are assessed (appendices $\mathrm{N}$ and $\mathrm{O}$ ).

The total population of spotted owls is expected to continue to decline as habitat declines (USDA 1988a). Additionally, as older forest stands around SOHAs are logged, the SOHA's ability to maintain reproductive pairs is expected to decline. The Final Supplement to the Environmental Impact Statement for an Amendment to the Pacific Northwest Regional Guide (USDA 1988a) indicates that SOHAs, if they reach full target size, are expected to be occupied by pairs 50 to $60 \%$ of the time in the future. Olympic National Forest SOHAs were an exception. There, because of larger SOHA sizes, a future occupancy rate of about $85 \%$ is predicted. More specific information about expected habitat and population trends can be found in the Final Supplement.

To ascertain whether the network system for spotted owls is functioning adequately, the FS in the Pacific Northwest and Pacific Southwest Regions initiated a research, development, and application program. One of its goals is a monitoring program with two major objectives. The first objective is to track the trend in total owl population. A set of random sample areas (RSAs) of 1000 acres each was selected that is visited each year to determine whether any owl is present, or if pairs are present and if they are breeding. The Final Supplement (USDA 1988a) projected that the population would decline at a rate of about $0.7 \%$ per year for the selected alternative. In the Pacific Northwest Region, information collected from the random survey areas is designed to check the validity of that assumption.

The other major objective is to evaluate the ability of SOHAs to maintain breeding pairs of spotted owls. A subset of SOHAs was randomly selected to be visited annually to determine the presence of owls, and their pair and reproductive status. The purpose is to check assumptions in the Final Supplement on the number of the SOHAs that should be occupied by pairs at any point in time. Methods used to determine owl occurrences in SOHAs and random sample areas are strictly prescribed in a Monitoring and Inventory Handbook (USDA 1988b).

Beginning in 1989, an effort to inventory the larger patches of spotted owl habitat in Wilderness Areas was also initiated through the research, development, and application program. Other relationships between owls and their habitat are also being investigated as a result of data collected in the monitoring and inventory program.

Detailed results of the monitoring and inventory programs for the Pacific Northwest Region are available from the Regional Office in Portland and are also compiled in the FS Report to the FWS (USDA 1989). A brief summary follows. 


\section{Appendix C: Current Situation}

Monitoring-The RSAs have been monitored for only 2 years (1988 and 1989). Although we cannot put much weight on such a limited data set, results showed a slight increase in occupancy by pairs from 1988 to 1989, but they also indicated a slight decrease in the number of reproductive pairs (USDA 1989). They also showed a slight decrease in the presence of any owls in RSAs on lands available for timber harvest, and a slight increase in owl presence on lands not available for timber harvest.

The relation between the amounts of suitable spotted owl habitat and owl occupancy was also analyzed. Data indicated a significant positive relation between the amount of suitable habitat and owl occupancy in RSAs (USDA 1989). That is, areas with more suitable habitat were more likely to be occupied by owls. A similar analysis showed the relation of amounts of habitat and owl occupancy for SOHAs was not significant (see appendix K).

Data collected in 1989 indicate that $92 \%$ of the SOHAs had at least one spotted owl (USDA 1989), $62 \%$ had pairs, and $35 \%$ had pairs with documented reproduction. If 2 years of data are combined for 1988 and 1989 , about $97 \%$ of the SOHAs had at least one owl, $77 \%$ had pairs, and $54 \%$ had pairs that were reproductive in at least 1 of the 2 years.

Inventory-Inventory has continued as part of the research, development, and application program since its inception. The Okanogan and Wenatchee National Forests conducted inventories designed to locate as many owls as possible to aid in establishing SOHAs. This work was completed in 1987 on the Wenatchee and in 1988 on the Okanogan. In 1989, inventory of SOHA-sized patches of habitat in Wilderness Areas and roadless areas resulted in detection of at least one spotted owl in 35 of 45 areas surveyed; 18 sites had pairs; and reproductive pairs were found in 10 sites.

Surveys for owls in areas of proposed timber sales, although not a formal part of the monitoring and inventory program, located additional sites occupied by owls. Numbers of spotted owl pairs and singles in the FS report to the FWS (USDA 1989) are cumulative totals found as a result of monitoring, inventories, and surveys for the last 10 years. Many sites have not been visited for 3 to 5 years, however, so we do not know if a given site remains capable of supporting owls. Neither can we determine the extent of double-counting of birds in different locations. Numbers of pairs reported in table $\mathrm{C}_{1}$ are the cumulative totals based on the last 5 years.

Assessment of current management-Acreages prescribed for SOHAs in the Pacific Northwest Region, even with the Section $\mathbf{3 1 8}$ additions, are significantly smaller than average or median amounts of suitable habitat in annual home ranges of pairs described in the literature (see appendix I). About $20 \%$ of the SOHAs in the Region lack sufficient suitable habitat to comply with existing direction even before Section 318 called for additions (USDA 1989). 


\section{Appendix C: Current Situation}

The current strategy's rationale for selecting smaller SOHAs was based on the assumption that acreages of owl habitat would continue to exist close to SOHAs. The Chief's Record of Decision (1988) said that "Sufficient options will remain at that time [in 5 years] to adjust the course of managing spotted owls and their habitats." Our interviews with FS personnel indicate that this assumption is likely invalid in many places (see appendix D). For the $20 \%$ of the SOHAs that lack even the prescribed acreage, obviously no options exist. Further, an assessment of habitat maps supplied by the agency indicates that many SOHAs are located where current options to adjust management are extremely limited. Other areas retain some flexibility, but continued logging will quickly restrict the ability to increase sizes and numbers of SOHAs. Although total acreages of habitat may remain high in the next 5 to 10 years, as indicated in analyses contained in the Final Supplement (USDA 1988a), much of that habitat will not be uniformly distributed. In short, owl habitat in the areas of greatest concern will continue to decline precipitously in quantity and quality.

Standards and guidelines for establishing the spotted owl network in the Pacific Northwest Region were designed to maintain owl viability with the least possible impact on the economies of Oregon and Washington (Chief's Record of Decision 1988). The attempt to balance the biological and economic aspects of the standards and guidelines resulted in a high degree of dependence on lands already protected from timber harvest. Occupancy by owls in these areas was often unknown. Restrictions controlling the proximity (usually no closer than 6 miles) of SOHAs to Wilderness Areas, National Park boundaries, or Forest boundaries caused some sites occupied by pairs to be passed over and a site of lesser quality to be selected. This strategy also had the effect of holding down the total number of SOHAs. It also significantly reduced the biological effectiveness of the original concept.

Because suitable habitat often exists as fragmented patches, selection of forest stands resulted in SOHAs with patchy configurations (fig. C4). Spaces between the patches of suitable habitat are often younger, previously harvested forest stands or natural stands where key structural components of owl habitat are absent. These intervening forest stands remain available for timber production. This strategy results in the perpetuation of fragmented, patchy SOHAs. In time, a prescription allowing the intervening areas to become suitable habitat would have resulted in more homogeneous SOHAs that would reduce the risk of blowdown and catastrophic loss, and would perhaps afford greater security for owl pairs in SOHAs.

We believe a primary strategy of managing for spotted owls by providing habitat areas for single pairs, or even two to three pairs of owls, results in an unacceptable risk to the population (see appendices $\mathrm{N}, \mathrm{O}$, and $\mathrm{P}$ ). "Trigger points" have not yet been identified whereby results from monitoring or research would indicate a need to change management direction. Furthermore, we strongly doubt whether the current approach to monitoring in SOHAs will permit the identification of such trigger points in time to avert the extinction of the northern spotted owl, because of the lag effects in measures of true population decline (see appendix $M$ ) and the packing phenomena which typically accompany the gradual elimination of a species' habitat (see appendices $M$ and $N$ ). 


\section{Appendix C: Current Situation}

The FS, Pacific Southwest Region (California)
Pairs of spotted owls have been located on four National Forests in northern California-Six Rivers, Shasta-Trinity, Klamath, and Mendocino. A few individuals have been sighted on the western border of the Modoc National Forest, but no pairs have been verified there. No management direction for owls has been prescribed on the Modoc, and it is not considered to be an owl Forest.

The general description of spotted owl habitat in the Pacific Southwest Region is similar to that in the Pacific Northwest Region (appendix F). In practice, however, mapping of habitat has apparently been based on a more restrictive definition in the Pacific Southwest than in the Pacific Northwest Region. Much uncertainty exists about what forest types are being used by owls (see appendix F). As this understanding improves, current estimates of suitable-habitat acreage in California (table $\mathrm{C} 1$ ) will likely be increased in some locations.

Arrangement of habitat varies by geographic location and, as in Oregon and Washington, reflects past logging activities, land ownership, catastrophes, and local site conditions. In some locations, habitat occurs in patches ranging from less than 10 to several hundred acres. Other areas have a matrix of owl habitat interspersed with numerous clearcut patches and other areas that are not suitable habitat. Some relatively large blocks of contiguous habitat occur in Wilderness Areas and sites not yet entered for logging.

Management direction-A strategy to establish a network of SOHAs, similar to that of the Pacific Northwest Region, was adopted. The direction to do so was included in Regional Standards and Guidelines, Land Management Planning Direction, Pacific Southwest Region, FS, 15 January 1984. This document provided direction to the Forests to select and delineate SOHAs, but it allowed flexibility for change in their locations and boundaries until final land management plans for each Forest could be completed.

A total of 278 SOHAs was designated on the four owl Forests. Unlike in the Pacific Northwest Region, this number included SOHAs that were totally in Wilderness Areas. Each SOHA was to provide 1000 acres of suitable spotted owl habitat. If 1000 acres did not exist, additional acreages that would grow into suitable habitat were added to bring the total up to 1000 . A $25 \%$ overlap with another SOHA was allowed. For example, 1750 acres of suitable habitat would be sufficient for two pairs.

In California, SOHAs were also required to have replacement habitat. Forests were allowed the option to dedicate the SOHA (which means no logging activities would be allowed) or to select either uneven-aged or even-aged management. The amount of replacement habitat varies with the selected option. For dedicated SOHAs, 650 acres were prescribed; for uneven-aged management, 1000 acres; and for even-aged management, 1650 acres. Logging activities were allowed only on acres in excess of the 1000 to be maintained as suitable at all times. The replacement habitat does not necessarily need to be currently suitable, but it must have the potential to become suitable. Figure $\mathrm{C} 5$ is a schematic of a SOHA in California. 


\section{Appendix C: Current Situation}

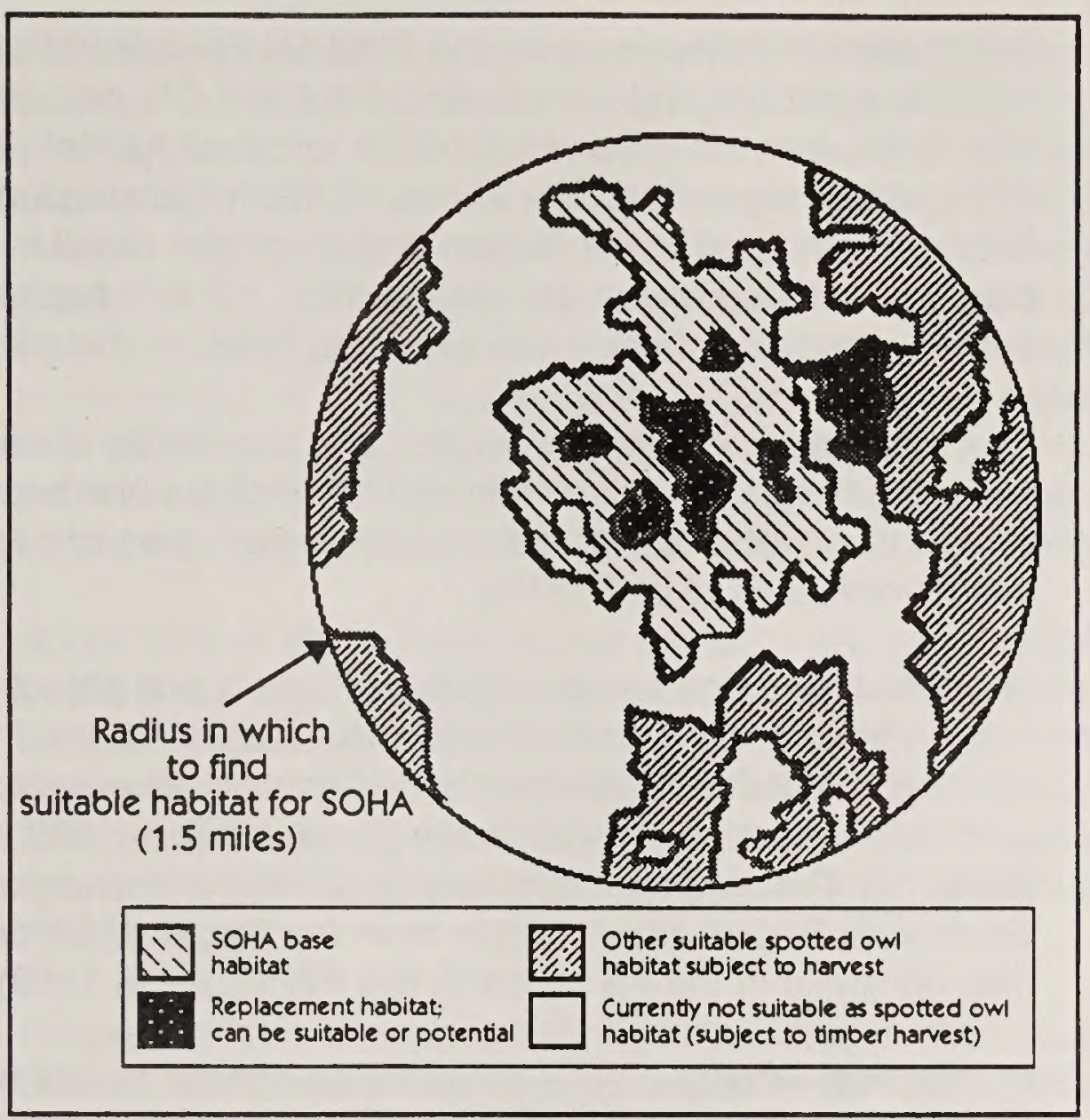

Figure C5-Schematic of a spotted owl habitat area (SOHA) on National Forests in California.

The spotted owl network system in northwestern California-which includes SOHAs, other suitable habitat in Wilderness Areas, and lands unsuited for timber production outside SOHAs-totals 553,700 acres (USDA 1989). This area is about $12 \%$ of the total forested acreage and about $66 \%$ of the remaining owl habitat. About $65 \%$ of this habitat occurs in Wilderness Areas and on lands not suited for timber production. Distribution of habitat in Wilderness Areas, although not totally contiguous, appears to comprise fairly large areas capable of supporting multiple pairs.

Standardized surveys for owls in areas of proposed timber sales were initiated in 1989. The standards are nearly identical to those used in the Pacific Northwest Region described earlier. A detailed description is included in the FS Report to the FWS (USDA 1989).

No comprehensive, consistent management direction for pairs outside the network exists in the Region. Spotted owls found in or adjacent to areas to be logged are evaluated case by case. Generally, logging in areas where a nesting pair occurs is deferred until after the nesting season. A small area (5 to 30 acres) around the nest site or center of activity is often given long-term protection. 


\section{Appendix C: Current Situation}

Information supplied to us by the National Forests indicates that owl habitat on those lands is expected to decrease about 0.8 to $1.0 \%$ per year for the next decade. Dispersion of the harvest units will continue to cause habitat patches to become smaller and more widely separated. The effects of this fragmentation are described in the section for the Pacific Northwest Region and in greater detail in appendices $\mathrm{N}$ and $\mathrm{O}$. Because forest stands that are not currently suitable habitat are included in the SOHAs, some increases in habitat are expected in future decades.

As in the Pacific Northwest Region, the population of owls in National Forests is expected to decline as suitable habitat declines and becomes more fragmented. The Pacific Southwest Region has not estimated rates of population decline or expected occupancy rates of its SOHAs.

The monitoring and inventory program goals and objectives for the Pacific Southwest Region have been described under the section for the Pacific Northwest Region. In addition to activities described in that section, inventories to determine owl occupancy of SOHAs not monitored in the 5 years before 1989 were done on Forests in California. Detailed results of the monitoring and inventory programs for the Pacific Southwest Region are available from the Regional Office in San Francisco and are also compiled in the FS report to the FWS (USDA 1989).

Monitoring - Comparisons of the RSAs survey results from 1988 and 1989 indicate slight decreases in owl occurrence for all categories: pairs, reproductive pairs, and single birds (USDA 1989). Confidence intervals for the 2 years of data are large, so results are inconclusive. As in the Pacific Northwest Region, a positive relation was found between amounts of suitable habitat in the RSAs and occupancy by owls (USDA 1989).

Data from SOHA monitoring for 1989 (USDA 1989) indicated that $95 \%$ of the SOHAS had at least one spotted owl, $58 \%$ had pairs, and $23 \%$ had reproductive pairs. Combined data for 1988 and 1989 showed $97 \%$ of the SOHAs with at least one owl, $78 \%$ with pairs, and $55 \%$ with reproductive pairs.

Inventory-To determine current occupancy, SOHAs that had not been visited since 1984 were inventoried (USDA 1989); 23 were in Wilderness Areas, where no reproductive pairs were found. Results are included in 10-year cumulative totals that include owls detected from surveys of timber-sale areas, inventories, and monitoring. As in the Pacific Northwest Region, all of these efforts-especially surveys of timber sales-resulted in finding new sites where owls were located, or upgrading a site from a single bird to a pair or reproductive pair. How these cumulative totals are related to actual populations is difficult to determine. Pairs reported in table $\mathrm{C} 1$ are based on data supplied by Forests from the last 5 years. These figures probably represent the number of sites that can still support spotted owls more closely than do the 10-year totals. 


\section{Appendix C: Current Situation}

Assessment of current management-The management strategy for spotted owls and their habitat in the Pacific Southwest Region is similar to that of the Pacific Northwest Region. The SOHAs are designed to provide for the needs of an individual pair of owls. More of an effort has been made to clump SOHAs into groups of two and three in California than was done in Washington and Oregon. This practice is an improvement over single-pair areas; however, acreages of suitable habitat designated for the SOHAs are well below average and median amounts observed in annual home ranges of pairs described in the literature (see appendix I). A cluster of SOHAs with less than the observed average or median acreage is unlikely to sustain multiple pairs through time. Wilderness Areas support multiple pairs of owls, but some parts function as several single-pair areas rather than interacting-pair areas.

About $38 \%$ of the SOHAs do not contain 1000 acres of suitable habitat, as defined by the Forests (USDA 1989) (but see appendix $F$ for a discussion of this situation in California). About $70 \%$ of the SOHAs on the Mendocino National Forest fall below 1000 acres of suitable habitat. A broader definition of habitat, however, that includes the full range of forested types and conditions now known to be used by spotted owls in California would likely give higher percentages of SOHAs meeting the requirements.

Present options to expand SOHAs are limited in most areas. Only 2 to $6 \%$ of the SOHAs could reach 2500 acres of suitable habitat on three of the Forests (USDA 1989). About $20 \%$ could be expanded to reach that size on the Six Rivers National Forest. Logging will continue to diminish the amounts of suitable habitat and fragment the remaining patches, further reducing options.

Interviews with personnel on National Forests in California (appendix D) indicate much confusion about timber management in SOHAs. Although some types of management strategies are likely to produce suitable owl habitat, we were not given any management plan that was spatially explicit.

We believe that the current management strategy in the Pacific Southwest Region-managing for a few multiple-pair areas and a series of one-to three-pair areas - combined with factors discussed above, and the implementation problems described in appendix $D$, result in an unacceptable risk to the owl population (see appendices $\mathrm{N}, \mathrm{O}$, and $\mathrm{P}$ ).

BLM

The BLM administers lands in the geographic range of the spotted owl in all three States, but only BLM lands in Oregon and California are occupied by owls. Because of topographic features, inherent plant community types, and ownership patterns, BLM lands in Washington have no potential to contribute to this conservation strategy.

Management direction-Between 1978 and 1983, the BLM completed seven timber management plans for the 2.4 million acres of land administered by the five western Oregon Districts. Through the Records of Decision for these plans, habitat was provided for 79 pairs of owls under the Oregon Interagency Spotted Owl Management Plan (Oregon Endangered Species Task Force 1977). These guidelines called for habitat areas with at least 300 contiguous acres of old-growth or next-oldest forest to be surrounded by an additional 900 acres managed so as to maintain at least $50 \%$ of that area in stands older than 30 years (appendix B). 


\section{Appendix C: Current Situation}

Under the seven management-plan decisions, only the two plans in the Medford District, completed in 1979 and 1980, specifically protected owls by excluding tree cutting on commercial forest lands. Under the remaining five plans, which were completed in 1983, owl habitat was accommodated through land allocations for other resource management purposes. These allocations included maintaining old-growth forest ecosystems by withdrawing them from the commercial forest land base and using longer cutting rotations that constrained timber harvest on specific areas.

In 1983, the BLM and the Oregon Department of Fish and Wildlife (ODFW) entered into an agreement for managing owl habitat on BLM lands in western Oregon (USDI 1983). This agreement, to be in effect for 5 years, expanded on the recently completed land-use plans by adding an additional 11 management areas, bringing the total to 90. In 1987, the agreement was revised (USDI 1988) and now forms the cornerstone for managing habitat until the 1990 decade Resource Management Plans for BLM lands are completed. A longer term management strategy for the birds will be spelled out in these plans, which are projected for implementation in 1992. The 1987 agreement established constrained timber-cutting areas (Agreement Areas) around 110 owl locations, distributed across five western Oregon BLM Districts encompassing 230,400 acres, to maintain a distributed population of 90 pairs of owls on BLM lands. The actual number of areas under the BLM-ODFW Agreement is now 109 because lands containing only one area were transferred to the BIA and have not been replaced. This reduced the total area under the Agreement to 228,000 acres. Figure C6 provides an example of an Agreement Area.

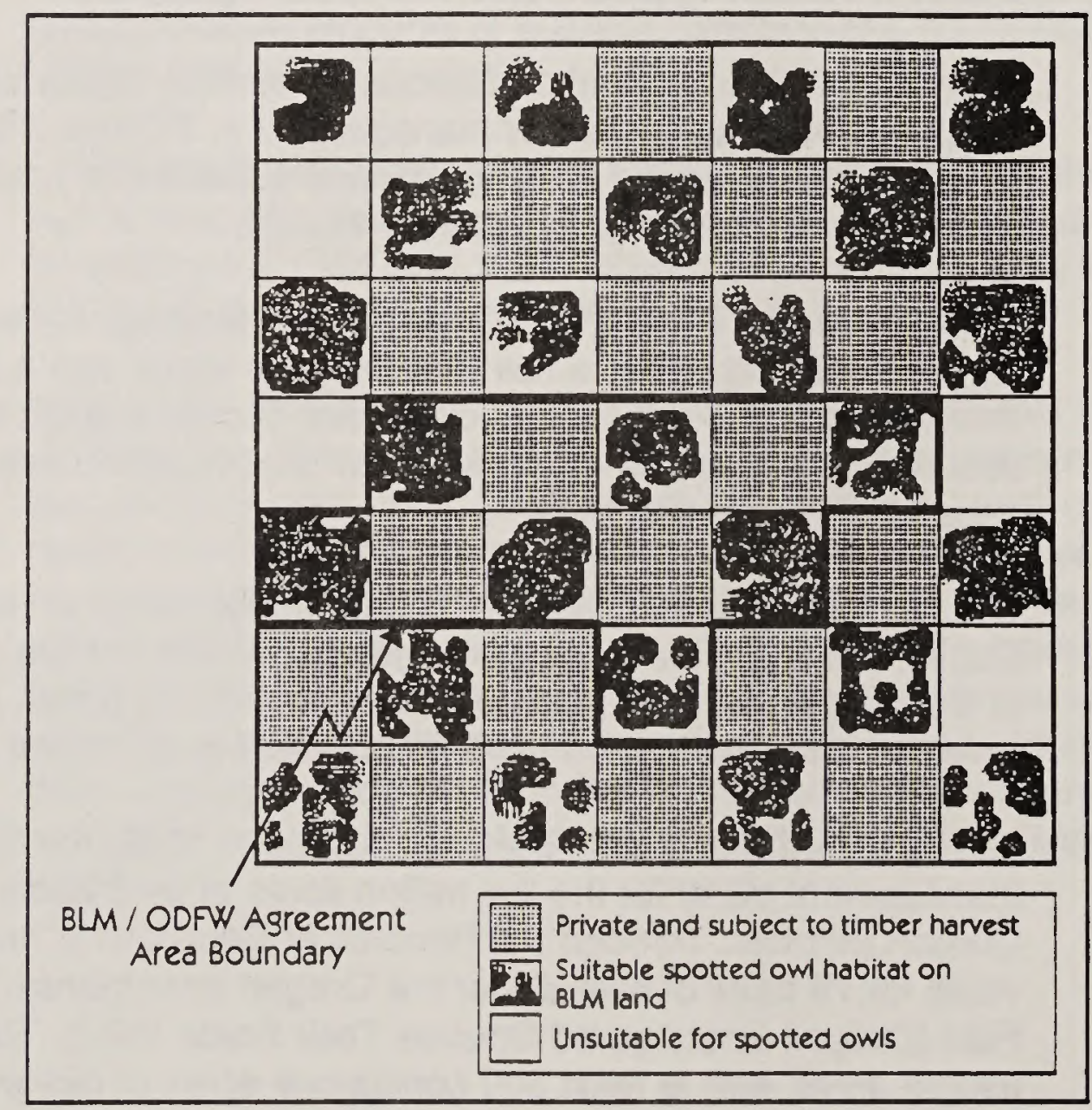

Figure C6-Schematic of a BLM-ODFW Agreement Area. Logging within the boundary is deferred on BLM forested stands over 80 years old. 


\section{Appendix C: Current Situation}

The individual Agreement Areas were delineated around known locations as determined from inventory and monitoring efforts. Guidelines for developing the areas set a goal of delineating at least 2200 acres (based on Forsman and Meslow 1985) of conifer forest over 80 years old, no farther than 3 miles from the known activity center of a single owl or pair. Exceptions occurred where the acreage of $>80$-year-old forests did not exist within the 3-mile limit or where the parties agreed to use on-site information on home-range size collected by using radio-telemetry. This strategy sometimes resulted in delineation of more than 2200 acres and sometimes less. Agreement Areas range from 734 to 4188 acres. Average forest acreage $>80$ years old in Agreement Areas is nearly 2100 acres.

In 1989, an additional 12 habitat areas were established and given 1-year interim protection as a result of instructions to the BLM in Section 318 of the Fiscal Year 1990 Interior Department Appropriations Act. These 12 areas were created under the same guidelines used for the BLM-ODFW Agreement Areas. The added areas bring the total to 121 , for which BLM is deferring harvest of selected forest stands. This management course is based on stipulations in the BLM-ODFW Spotted Owl Agreement and language in the Fiscal Year 1990 Interior Appropriations Act.

These 121 habitat areas provide specific protection for about $28 \%$ of the known pairs occurring on BLM lands, based on data from 1985 through 1989. Additional pairs and individual, unpaired owls may live within the boundary of a given habitat Agreement Area, but habitat was allocated with the intention of maintaining only one pair in each area under the Agreement, over the long term.

Most owl locations with known pairs occur outside the designated Agreement Areas. Much of the habitat used by these birds is subject to harvest in the timber management plans. Currently, no formal policy deals with this habitat. Consideration is given to planning timber harvest units in a manner that reduces or eliminates the impact on the habitat of these pairs. Every effort is made to defer harvesting of stands containing known nest trees. All of these measures, however, are discretionary to the Resource Area Manager. As a result, efforts to reduce or eliminate impacts on pairs outside of the interim protection areas have met with only partial success because the Area Manager must attain the programmed timber-volume quota.

In California, northern spotted owl habitat is located in the Ukiah District of the BLM. Direction for owl management there is described in an excerpt from USDI (1989b):

In 1980 the Ukiah District drafted an environmental impact statement (EIS) on timber management which includes spotted owl and managed old-growth forest mitigation. The 'state-of-the-art' for spotted owl mitigation at the time was to provide 300 acres for each pair of owls. Ukiah's EIS called for 300 acres, or where avallable more, for each pair. The reason or where available more was added to the 300 acre mitigation is that most of the timber stands in the Arcata and Redding Resource Areas are less than 300 acres in size. Moreover, these tracts are only rarely adjacent to other agency lands. 


\section{Appendix C: Current Situation}

As a result of Ukiah's Timber EIS and other planning efforts, over 13,000 acres of known and potential spotted owl habitat have been withdrawn from Ukiah's timber base. This 13,000 acres of owl habitat is within 20 different tracts of land. Six of these tracts have been designated Old-growth Forest Research Natural Areas/Areas of Critical Environmental Concern.

Habitat estimates and trends-The amount and distribution of owl habitat on BLM lands in Oregon and California are influenced by natural events and human activities. Among the major factors contributing to the current status of habitat conditions are the scattered or checkerboard ownership pattern; past land-management activities, primarily timber cutting; and natural occurrences, such as forest succession, wildfire, and windstorms.

These factors combine to create a habitat mosaic for spotted owls that is most commonly a patchwork of stands $>80$ years old, distributed across the landscape in patches ranging most commonly from 50 to 500 acres, occasionally with areas of 2000 to 5000 acres, where ownership is contiguous and the described factors have had less influence. The remainder of the areas are in recent clearcuts or in stands of trees ranging from 5 to 80 years old. In both Oregon and California, most timber cutting has occurred since the end of World War II in 1945.

No intensive, field-based inventory has been done on BLM lands to determine acres of suitable owl habitat. Estimates for the two-State area (table $C_{1}$ ) are from interpretations of aerial photos, forestry-based stand descriptions residing in BLM files, and the knowledge of wildlife biologists and foresters with experience on these areas. For the purposes of these estimates, habitat was considered to be forests 80 to 100 years old and older within the area defined by the current distribution of owls, including marginal to superior components of habitat, as described in appendix $F$.

In Oregon, nearly $82 \%$ of the remaining suitable habitat is available for timber cutting under current land-use plans. Assuming that the current average annual cutting rate of 23,400 acres would be applied to the 700,000 acres of habitat available for harvest, only about 160,000 acres of currently reserved habitat would remain in 30 years-a decline of over $80 \%$ from present conditions. And this decline is just the continuation of a downward trend that began in the 1940s.

The magnitude of the full decline is evident by examining the pattern in the last 20 years. Based on data on forest age-class distribution on Oregon BLM lands, nearly 475,000 acres of suitable habitat have been lost within the past 20 years. If the current trend continues, over 1 million acres of suitable habitat will have been removed from BLM lands in western Oregon over the 50 years from 1968 to 2018. The past and projected trends clearly show that suitable habitat on BLM lands is declining. Opportunities for maintaining suitable habitat on BLM lands have been reduced and will be extremely limited within 30 years. Habitat recruitment on lands where the forest was cut in 1968 is not anticipated to begin until 2048, when the stands cut would reach 80 years of age. Under current cutting schedules, most of 


\section{Appendix C: Current Situation}

these areas would then be harvested a second time and the recruitment negated. The ownership pattern, with sections of private and public lands alternating in checkerboard fashion, compounds these problems. The private lands are managed on short-rotation schedules, so the checkerboard pattern places an extra burden on the ability of BLM lands to maintain spotted owls.

Spotted owl surveys_-Information on spotted owls on BLM lands in western Oregon is a product of inventory and monitoring done at various intensities since the early 1970s. Although surveys have been extensive, not all lands that may support owls have been adequately surveyed, and we have no estimate of the percentage of lands surveyed. Data gathered during the field seasons from 1985 through 1989 provided insight into the number, distribution, and reproductive status of owl pairs on BLM lands (table $\mathrm{C} 1$ ). In addition to the 431 locations where pairs were found in Oregon, about 100 additional locations had individual owls, but the presence of a mate was not determined. Based on past experience, a portion of those individuals are actually pairs.

Survey efforts on BLM lands in California have been less intensive than those in Oregon. Spotted owl locations to date (table $C_{1}$ ) have been found because BLM lands were included as part of a larger general survey by Humboldt State University personnel and field surveys by BLM personnel relative to site-specific, proposed resource management actions such as timber sales. Forest lands in wilderness and wilderness study areas have not been inventoried.

Monitoring - Guidance and standard procedures for monitoring owls on lands administered by BLM in western Oregon are contained in USDI (1986). The objectives of the monitoring are to determine, annually, the occupancy rates and reproductive success of spotted owls within the BLM Spotted Owl Management Areas (SOMAs). Three intensities of monitoring are provided. (1) Minimum level is attained when the occupancy and reproductive success of pairs in individual SOMAs in each District have been determined. (2) Mid-level monitoring is satisfied by increasing the number of pairs monitored to include additional nonmanagement pairs. The same methods are used to determine occupancy and reproductive success as specified for the minimum level. In addition, as many as possible of the adult and young owls in each area are banded. (3) High-level monitoring increases the number of sites monitored for occupancy and reproductive success to include all known sites, regardless of management status. As in mid-level monitoring, as many adults and young are banded as possible, and radio-telemetry techniques are used to monitor SOMA pairs to determine actual use of habitat in their home range. Finally, high-level monitoring also calls for implementing research to study responses of the birds to timber management practices. The research should focus on the impacts of vegetation manipulation (primarily harvest of old-growth forest), the occupancy of a site, the home-range size, rates of reproduction, and on the reoccupation of an abandoned site by a subsequent pair. 


\section{Appendix C: Current Situation}

Presently, all six Districts are monitoring at least at mid-level. Four Districts have initiated investigations under high-level monitoring criteria using radio-telemetry and population studies to explore aspects of home range and response of owls to timbermanagement practices. Biologists in each District are banding all birds that can be captured, to facilitate accurate counts of individuals, gather demographic information, and determine origins and dispersal distances of juvenile owls.

The monitoring plan for western Oregon BLM lands is silent on how data might be used to assess whether a change in management strategy may be needed. Data are presently being used to track the presence of owls and the number of young fledged in specified SOMAs. Data from 1987 through 1989, on occupancy of areas defined in the BLM-ODFW Spotted Owl Agreement, provide an opportunity to compare results with stated objectives-to ensure continued survival of a population of 90 pairs of owls distributed so as to prevent population isolation.

These data indicate that 97 of the 109 areas defined in the BLM-ODFW Spotted Owl Agreement had one pair of owls in at least 1 of the 3 years of survey. Only 83 areas had a pair in at least 2 of the 3 survey years. Based on these values, areas delineated by the agreement are in compliance with meeting the intended purpose of the BLM-ODFW Agreement, although pairs are not present at all sites every year. This variation would be expected, however, because of mortality and movement.

No specific monitoring plan is now in place on BLM lands in California, but additional surveys are planned as personnel and funding permit.

Assessment of current management-We believe that habitat provided by the BLM-ODFW Spotted Owl Agreement falls short of that needed for a persistent and well-distributed spotted owl population on BLM lands in western Oregon. Because the number of pairs is low, the amount of habitat provided is less than indicated from home-range studies in the area (appendix I), and because the habitat provided is widely scattered, individual pairs will become isolated. This isolation will likely lead to low occupancy (50 to $60 \%$ ) and probably to eventual collapse of the population. We perceive a high probability that the known population of owls on BLM lands will decrease $>80 \%$ in the next 30 years under current management direction. Remaining pairs will have little, if any, chance of existence as a functional population.

Current management direction for spotted owls on BLM lands in California is outdated. Revision should be based on an updated assessment of habitat capability and more complete inventory of owl occurrence. Forested lands in the Ukiah District, particularly in the Arcata Resource Area, provide existing and potential linkages between inland and coastal forests. These lands also have short-term and long-term value for supporting individual pairs, especially when taken together with State and private lands that surround them. 


\section{Appendix C: Current Situation}

Table C2-Areas (1000s of acres), dlstrlbutlon, and results of spotted owl surveys on NPS lands

\begin{tabular}{|c|c|c|c|c|c|c|}
\hline \multirow{2}{*}{$\begin{array}{l}\text { State } \\
\text { Locality }\end{array}$} & \multirow{2}{*}{$\begin{array}{l}\text { Total } \\
\text { area }\end{array}$} & \multirow{2}{*}{$\begin{array}{l}\text { Estimated } \\
\text { area of owl } \\
\text { habitat }^{a}\end{array}$} & \multirow{2}{*}{$\begin{array}{c}\text { Habitat } \\
\text { distribution }\end{array}$} & \multicolumn{2}{|c|}{ Owl pairs ${ }^{c}$} & \multirow{2}{*}{$\begin{array}{c}\text { Owl } \\
\text { inventories }\end{array}$} \\
\hline & & & & Known & Estimated & \\
\hline \multicolumn{7}{|l|}{ Washington } \\
\hline North Cascades & $684^{e}$ & 126 & 1 & 0 & 20 & $P$ \\
\hline Mount Rainier & 235 & 31 & 1 & 8 & ? & $P$ \\
\hline Olympic & 924 & 323 & 1 & $12^{f}$ & 40 & $P$ \\
\hline \multicolumn{7}{|l|}{ Oregon } \\
\hline Crater Lake & 183 & 50 & 1 & 4 & 14 & $P$ \\
\hline Oregon Caves & 0.5 & 0.5 & 3 & 1 & 1 & C \\
\hline \multicolumn{7}{|l|}{ California } \\
\hline Redwood & 75 & 20 & 2 & 0 & 5 & $\mathrm{U}$ \\
\hline Point Reyes & 54 & 16 & 2 & 2 & 4 & $P$ \\
\hline Muir Woods & 0.5 & 0.5 & 3 & 1 & 1 & C \\
\hline Whiskeytown & 42 & $4 ?$ & $?$ & 0 & $?$ & $U$ \\
\hline
\end{tabular}

a Generally gross estimates subject to revision except for small areas.

b 1 = Habitat around low-elevation perimeter and separated into blocks by mountains or lakes in the core of the park; 2 = blocks of contiguous low-elevation habitat; 3 = essentially all suitable habitat.

'Known pairs are those located from 1985 to 1989 . Estimates are habitat capability extrapolations, usually from FS or FWS Status Review Supplements.

${ }^{d} P=$ partial surveys with large backcountry areas still unsurveyed; $C=$ complete surveys; and $\mathrm{U}=$ unsurveyed lands.

- Includes Lake Chelan and Ross Lake National Recreation Areas.

' NPS estimates 12 known pairs of spotted owls in Olympic National Park during the last 5 years; WDW tallies 20 pairs. This difference needs to be reconciled.

The spotted owl is known to occur in eight NPS areas from the North Cascades to Muir Woods (table C2). The bird may also occupy the Whiskeytown National Recreation Area because it is known to occur in that region of California. National Park areas may contain as much as 570,000 acres of suitable habitat, but these estimates should be regarded as crude first approximations, particularly for the larger parks. Estimates are being refined currently as inventories of old-growth forests are completed.

The configuration and quality of habitat differ markedly among the areas. Habitat in the large, mountain parks of Washington and Oregon (North Cascades, Mount Rainier, Olympic, Crater Lake) occurs in blocks at low elevations around the perimeters of the parks, separated by unsuitable high-elevation areas in the interior. These parks contain spotted owls at the upper elevational limits of their distribution (still poorly defined). Habitat quality may be poor over large areas at higher elevations. Although habitat at Redwood National Park is discontinuous, the federally managed lands are contiguous with habitat in three State parks. Combined, these parks provide about 47,000 acres of contiguous, low-elevation redwood forest habitat. Similarly, the lowelevation habitat at Muir Woods and Point Reyes in California (about 16,500 acres) is contiguous with habitat in a local water-district area and Tomales Bay State Park. 


\section{Appendix C: Current Situation}

Crude estimates based on "habitat capability" (that is, extrapolations from estimates of home-range size applied to areas of presumed spotted owl habitat) suggest that these NPS units might support a combined total of about 100 pairs of owls, although only about 28 pairs have been documented over the past 5 years (table $\mathrm{C} 2$ ). For the larger parks, owl number estimates are little more than educated guesses.

The extent and quality of owl inventories vary among the NPS units (table C2). Generally, extensive areas remain unsurveyed in the backcountry of all the large parks. (Surveying owls in remote wilderness is difficult and dangerous. Such areas are unlikely ever to be surveyed with the intensity and accuracy of lands that contain networks of roads and trails.) Follow-up monitoring of the persistence and reproductive performance of pairs in National Parks is often sporadic to nonexistent, and sometimes depends on the interest of other agencies or groups. The inadequacies of the information on the status of the owl and its habitat in the National Parks, particularly the Olympic National Park, have presented problems to us in developing the conservation strategy.

Future habitat-About 40,500 acres of additional owl habitat are expected to develop in three National Park areas as forests recover from earlier logging and land clearing. By far the largest amount, 37,000 acres, will occur in Redwood National Park as redwoods are regrown on lands logged about 20 years ago (late 1960 s to early 1970 s). Based on recent observations of spotted owl occurrence on private forest lands, these cutover redwood forests may support an unknown density of owls in 30 to 50 years (Houston, pers. comm.).

In North Cascades National Park, 900 acres of suitable habitat may develop as western hemlock/Douglas-fir forests grow back after being logged during the 1930s to 1960 s. Similarly, 2600 acres of suitable habitat will be regrown at Olympic National Park from a mix of previously logged forests and pastures acquired from 1979 to 1989. About 6000 acres of mixed-conifer forests are being regrown at Whiskeytown on lands that were heavily cutover during the 1950 s to early 1970 s. Finally, habitat quality at Point Reyes is likely to improve as forests continue to recover from earlier selective logging.

National Park management-Generally, the management objectives for National Parks are considered compatible with maintaining owls (for example, Briggle 1985). Park Service policy states that "Natural resources will be managed with a concern for fundamental ecological processes as well as for individual species and features. Managers and resource specialists will not attempt solely to preserve individual species (except threatened or endangered species) or individual natural processes; rather, they will try to maintain all the components and processes of naturally evolving park ecosystems, including the natural abundance, diversity, and ecological integrity of the plants and animals" (NPS 1988). The emphasis on maintaining ecological processes as opposed to particular biological states may be relevant to managing spotted owls, especially in the large parks. Natural fires are recognized as a force that often drives processes of plant succession, and thus they are to be perpetuated in the parks (NPS 1988). Historically, fires in the parks containing owls ranged from frequent, low-intensity, surface fires to infrequent, stand-replacing crown fires (for example, Agee, pers. comm., in press; Henderson et al. 1989). The effects of surface 


\section{Appendix C: Current Situation}

fires on spotted owl habitat are poorly understood; crown fires, however, clearly reduce habitat. The amount of suitable habitat in National Parks can thus be expected to vary over time, to the extent that natural disturbance forces are allowed to operate. Over long periods, maintaining mosaics of different-aged forest communities in parks (which differ in fuel loading and susceptibility to burning) may be an important means of reducing the probability of catastrophic large fires (for example, Romme and Despain 1989).

Policies of the Pacific Northwest Region of the NPS state: "Since single species management is inconsistent with National Park Service management policies, The National Park Service will not designate formal Spotted Owl Management Areas (SOMAs). This should not be construed to mean that the spotted owls within parks are not to be considered in a larger regional planning effort. On the contrary, The National Park Service fully expects that any regional planning effort will incorporate spotted owl data for the park and address the National Park Service's shared concern for longterm preservation of the species" (Briggle 1985).

Management Issues and concerns-Population theory suggests that the numbers of owls in National Parks are too small for the species to persist over time, if isolated from birds in surrounding areas because of habitat fragmentation (see appendices $M$ and N). Considerations of physiography and size of the parks in the Pacific Northwest suggest that survival of the birds in these areas is closely tied to the welfare of birds on surrounding lands. Each park contains owls at the upper elevational limit of their distribution, and the Washington parks-especially North Cascades and Olympic-approach the species' northern geographic-range limits. Spotted owls that exist under such biogeographic constraints may be particularly susceptible to wide fluctuations in abundance over time, with correspondingly increasing probabilities of extinction. Spotted owl. populations on the Olympic Peninsula, including Olympic National Park, already appear to be isolated from other populations and are thought to be especially vulnerable. Biologists are also concerned that a small subset of owls along the coastal strip of Olympic National Park may be additionally isolated from birds occupying the core of the Peninsula.

Although the numbers of owls in parks appear to be too small for them to persist over time if isolated, they sometimes appear to provide key links in the geographic distribution of the species, and may be particularly valuable in contributing to viable populations in some physiographic provinces.

To help remedy this situation, landscape connectors of suitable habitat should be provided outside of the parks to prevent isolation (demographic and genetic) of the owls inside them. Such dispersal habitat appears to be particularly important now on the Olympic Peninsula. In addition, land management allocations and management activities on lands adjacent to the parks should be done with care to help assure the effectiveness of the National Park areas as reserves for the owls. For example, the edges of all clearcuts that abut parks might be "feathered" to reduce unnatural rates of forest blowdown. 


\section{Appendix C: Current Situation}

State of Washington
The amount, distribution, and quality of habitat need to be carefully inventoried in the large parks. This information should be incoiporated into a park-based geographic information system (GIS) that is compatible with systems on adjacent lands, to be effective in tracking changes over time.

Inventory and monitoring of owls should be increased in the larger parks, recognizing the difficulties encountered in the large wilderness settings. Some rate of monitoring over time seems necessary to help evaluate the effectiveness of the interagency conservation strategy for the owl. An adequate and dedicated inventory and monitoring budget for each large park is needed to accomplish these objectives.

National Parks appear to have been underused as research sites for spotted owls. By virtue of their land-use objectives, these parks may represent important "control areas" for conducting long-term studies of the birds in unfragmented or "naturally" fragmented habitats. For example, large blocks of cutover forest added to Redwood National Park in 1978 offer a unique research opportunity. Although owls are known to occupy second-growth redwood forests 50 to 60 years after logging, the age at which stands are first successfully reoccupied by the birds is poorly known. Permanent survey transects could be established in the park to determine when owls first colonize and reproduce in these changing forests. Such studies would require banding and perhaps radio-marking of park birds.

Washington Department of Natural Resources (WDNR)-The WDNR manages about $1,833,000$ acres of State forest lands, primarily to produce funds for public school construction. Spotted owls are known to occur in 24 separate locations on WDNR lands (WDW 1990). In addition, about 180 owl sites are known to occur within 2.5 miles of WDNR-managed land (WDW 1990).

Most spotted owls known to be on these lands are on the Olympic Peninsula. A large block of WDNR-managed land, bordered to the north by the Hoh River and to the south by the Clearwater River, has been intensively surveyed for owls (Anthony and Cummins 1989). Eight pairs have been located in the Hoh-Clearwater Block. In the absence of legislative requirements for protective measures for the owl, guidelines for timber-sale impacts on the birds are developed by the WDNR staff case by case. These guidelines have allowed logging within a half mile of spotted owl nest sites and activity centers, which is likely only to delay logging of the sites and eventually eliminate spotted owls on WDNR lands in the area.

In 1988, Public Lands Commissioner Brian Boyle established a Commission on Old Growth Alternatives for Washington's Forest Trust Lands. The Commission was concerned exclusively with old-growth forest on the northwest corner of the Olympic Peninsula. The Commission's recommendations were to defer from harvest 15,000 acres of old-growth forest for 15 years. These areas were selected to provide habitat for four pairs of owls in the Hoh-Clearwater for 15 years. The Commission also recommended alternative silvicultural practices designed to retain some ecological characteristics of old-growth forests in timber harvest areas on WDNR-managed lands in the northwest portion of the Peninsula. This plan, though it preserves options and provides for research, allows for logging at the end of the 15-year period. 


\section{Appendix C: Current Situation}

Washington Department of Wildlife (WDW)-The WDW manages several large wildlife areas adjacent to the Wenatchee National Forest that could provide suitable habitat (Becksted, pers. comm.). About 5000 to 10,000 acres in the Colockum Wildlife Area may be suitable for owls within the next 30 years. Over 20,000 acres in the L.T. Murray Wildlife Area could be suitable within 100 years. Long-term management goals on WDW lands will be to manage more than $50 \%$ of forest lands to produce old-growth characteristics. No spotted owls are currently known to exist on or near WDW lands.

Washington State Parks-Washington State Parks manages several widely scattered, forested parcels within the known distribution of the owl. No standing timber over 10 inches in d.b.h. is harvested unless conflicts occur with roads, trails, or campground facilities (Ramsey, pers. comm.). Of particular importance to spotted owls are Beacon Rock State Park (4500 acres), located along the Columbia River near Stevenson; Lake Easton (200 acres) and Olale (350 acres) State Parks, located along Interstate 90 in the central Cascade Range; Federation Forest State Park (600 acres of old growth), located along the White River near Enumclaw; and Rockport State Park (500 acres of old growth), located along the Skagit River in the North Cascades. These State parks may provide important linkages and travel corridors for owls.

Indlan trlbal lands-Significant areas of suitable habitat occur on the Quinault and Yakima Indian Reservations in Washington State. The Quinault Indian Nation has about 4000 acres of older forest west of Lake Quinault, recently acquired from the Olympic National Forest. Two spotted owls were located on this parcel in 1989 (James, pers. comm.). The Yakima Indian Nation manages 123,000 acres of forest land in reserve management status, about half of which may be suitable for owls (Hansen, pers. comm.). Five pairs and four single owls are known within the reservation. These owls are primarily within designated primitive areas near Mount Adams.

U.S. FIsh and WIIdlife Servlce (FWS)-The FWS has two refuges in Washington that presently contain owl habitat. Willapa National Wildlife Refuge, on Long Island along the southern coast, contains about 5000 acres of coniferous forest, including a 274-acre old-growth reserve natural area that previously contained a pair. Those birds disappeared about 3 years ago and have been replaced by a pair of barred owls. Annual surveys have not since indicated any spotted owls in the area. Most of the 5000 acres outside of the reserve are now available for timber production because of an agreement tied to its acquisition. Timber harvesting can be curtailed, however, if owls are observed in the area.

The FWS also has about 1500 acres of coniferous forest on the Conboy Lake National Wildlife Refuge on the eastern side of the Gifford Pinchot National Forest. No owls have been observed on the Refuge, although they have been heard in the vicinity, and no timber production is permitted. 


\section{Appendix C: Current Situation}

City of Seattie-The Seattle Water Department currently manages about 68,000 acres of forest land in the Cedar River Watershed near North Bend (Erckman, pers. comm.). About 3000 acres remain in old-growth, with 1500 acres below 4200 feet in elevation. Current management provides for the preservation of all existing old-growth forest; in addition, 50 to $65 \%$ (about 40,000 acres) of second-growth forest will be managed as a permanent reserve. Three single owls and one pair have been located in intermingled FS and City of Seattle lands within the watershed.

Private lands-Few spotted owls are known to inhabit private timber lands in Washington. Two or three pairs have been located in a large area bordering the Columbia River, which extends northward to the Olympic National Forest, and eastward to the Gifford Pinchot National Forest (Hays et al. 1989, Irwin et al. 1989a) (see appendix G). Two pairs were located on private lands on the Olympic Peninsula, and about seven pairs are known to occur along the eastern Cascades (WDW 1990). As many as 20 pairs are estimated to occur on private lands in Washington (Inwin, pers. comm.).

Fort Lewis Military Reservation-South of Tacoma, the Fort Lewis Military Reservation includes about 68,000 acres of contiguous forest, generally between 50 and 70 years old. Current plans are for intensive, uneven-aged management on 40,000 to 45,000 acres. Some lands will be left in natural condition, but no estimate of acreage is currently available. The nearest known spotted owl pair is located about 15 miles southeast of the reservation on the Gifford Pinchot National Forest. Spotted owl surveys to date have been done in older stands along the Nisqually River, but most of the military reservation has not been surveyed.

State of Oregon

Oregon Department of Fish and Wildife (ODFW)-The ODFW manages two partially forested properties in the range of the owl, one on the south coast adjacent to Eel Lake (619 acres), and a larger area on the eastern slope of Mount Hood known as the White River Management Area. The area is about 30,000 acres, of which about 8600 acres are in mixed conifer-pine-oak woodlands. In addition, about 6000 acres of primarily oak woodland are scattered throughout the area. An existing timber management plan for Eel Lake allows timber harvest to generate funds for wildlife management programs throughout the State. Timber is second-growth, even-aged, and generally about 50 years old. The White River Management Area has received some small harvest units in the past, but no additional logging will occur until a forestmanagment plan is completed in 1990. The forest has a mean age of 60 to 70 years, with scattered older trees throughout (130 to 160 years). The area is currently managed primarily as deer and elk winter range. Neither area has been surveyed for owls, but surveys are planned for 1990. Few owls are expected, given the ages and sizes of these areas. 


\section{Appendix C: Current Situation}

Oregon State Board of Forestry and State Land Board-The Oregon Department of Forestry (ODF) manages 786,000 acres of forest lands in Oregon-654,000 acres under its own jurisdiction and 132,000 acres managed by the Division of State Lands (Jones 1988). The Division also manages the South Slough Sanctuary near Coos Bay, which includes a 3800-acre block of upland forest. Most ODF lands are in western Oregon, but one major block-known as Sun Pass Forest-is on the east slopes of the Cascades. The Department manages about 625,000 acres of their own forest lands within the range of the owl and also about another 120,000 acres of State Land Board lands (Gedney et al. 1989: ODF 1984, 1987, 1989). In western Oregon, 25,000 acres of the State Forest land base is reserved for purposes other than timber management, such as watershed protection, fish and wildlife habitat, and administrative purposes. These reserved areas are scattered throughout State Forest lands, generally in small patches or corridors.

The ODF has logged an average of 4600 acres per year for the last 10 years (ODF 1989). Currently, $12 \%$ of the forests on these State lands in western Oregon are more than 80 years old; $74 \%$ of the forests are less than 50 years old (Jones 1988). With a planned average rotation age of 70 years, all forests over 80 years old could be harvested in about 17 years. The South Slough Sanctuary block is less than 50 years old and has been logged from one to three times. The Sanctuary area will be managed as a reserve in the future. The Elliott State Forest has the best potential for occupied owl habitat. It contains about 50,000 acres with trees ranging from 80 to 120 years old, with scattered old growth. Sun Pass Forest is managed primarily as an uneven-aged forest and may provide some suitable habitat.

Spotted owl surveys on State Forest lands have been limited to random surveys in the Clatsop and Tillamook Forests by Forsman (1988) and Forsman et al. (1977), and to partial surveys in recent years in Elliot and Santiam State Forests (ODFW, unpubl. data). Responses from owl pairs have been obtained from three locations in these areas. Spotted owls located to date have been associated primarily with mature and old-growth forests. Based on the Forsman surveys, few additional birds are expected in the Clatsop and Tillamook Forests because stands in those areas are young and homogeneous in structure (see appendix $\mathrm{G}$ ).

In the central Coast Range, State Forest lands are often intermingled with BLM lands occupied by owls. Spotted owls are assumed to be at least foraging on State lands in some areas. In eastern Oregon, no surveys have been done on Sunpass Forest or on scattered State lands south of Klamath Falls, but spotted owls have been located on National Forest and National Park lands adjacent to Sun Pass Forest.

In summary, probably fewer than 20 pairs will be located on State Forest lands. Most suitable owl habitat more than 80 years old, however, will be harvested in the next 10 to 20 years under current management plans.

State Parks Department-The Oregon State Parks Department manages about 165 parks and waysides in western Oregon, ranging from 1 to 8700 acres and averaging 280. Many areas have some forest land, but only 13 are known to have more than 90 acres (the range is 90 to 2500 acres) of forest more than 80 years old. Forested lands usually are fairly contiguous, but $50 \%$ of the mature forest is found in only two parks: Silver Creek Falls and Oswald West. 


\section{Appendix C: Current Situation}

About $50 \%$ of the parks have management plans, and some of them are out of date. Current direction for forest lands is generally protection, except that individual trees considered safety hazards can be removed. A portion of one coastal park was clearcut because of extensive winter-storm blowdown. The master plan for Silver Creek Falls calls for thinning 1500 to 2000 acres of young stands to enhance tree growth and stand health (Oregon State Parks and Recreation Division 1982).

Preliminary surveys for owls in State parks began in 1989 by ODFW (1989). One adult was located in Silver Creek Falls Park and two juveniles were later reported. Spotted owls have been reported on Christmas bird counts near Cape Meares Park. Intensive surveys are planned on selected State park lands by ODFW in 1990.

Although habitats for owls are expected to increase on State park lands in future years, few parks are expected to have enough suitable habitat to maintain breeding pairs in the long term. Because of the wide distribution of park lands, however, some parks could support dispersing birds.

Counties and clties-At least 142,000 acres of forest lands are owned by county and municipal governments in western Oregon (Gedney 1986, 1987; Gedney et al. 1986, 1989; Lettman 1988). These lands are primarily located in 16 of the 19 counties. Land parcels are generally scattered, but some counties have larger blocks of a section or more. Coos County apparently has two of the largest individual blocks of commercial forest, one of 2200 and the other of 11,000 acres. From preliminary information, most county forest lands are generally young to mid-aged but less than 100 years old. Timber management plans usually call for shorter rotations, although municipal watershed plans may call for a combination of reserved and managed forests. Some older timber exists on some lands (for example, the Corvallis watershed).

Based on Statewide figures, at least 35,000 acres of city and municipal forest lands are reserved for various purposes, such as parks and watersheds (Jones 1988). Forest Park in the city of Portland, for example, contains 4300 acres of younger mixed-conifer-hardwood forest. In Federal fiscal years 1987 and 1988, local governments logged the timber on an average of 1800 acres per year (amounting to a 60 -year rotation). In addition, 1000 to 3000 acres were partially cut.

County and municipal lands generally have not been surveyed for owls. One pair is known to nest in the Corvallis watershed, where habitat is a mix of mature and oldgrowth forest.

Indian tribal lands-Three Indian reservations occur within the range of the spotted owl in Oregon. The Grand Ronde, in the western Oregon Coast Range, has 9800 acres of commercial forests in a contiguous block $\leq 120$ years old. This is a fir forest type on a harvest rotation of $\leq 80$ years. The Siletz, also in the Coast Range, has 3600 acres in scattered small parcels $\leq 120$ years old. It, too, is harvested-on a rotation schedule $\leq 80$ years. And Warm Springs Reservation, in the eastern Cascades, has 311,000 acres of commercial forest in a large, contiguous block ranging in age 


\section{Appendix C: Current Situation}

from young to $>120$ years. About half of this land is in ponderosa pine, generally unsuitable as owl habitat, and about 60,000 acres are reserved for purposes other than timber production. Harvest rotations are 80 to 120 years in the fir zone on the Warm Springs Reservation.

At least one owl pair occurs on the Grande Ronde Reservation, and birds have been detected on the Warm Springs Reservation. Systematic surveys, however, have not been done on any of the three reservations. Future surveys are being considered on the Siletz and Grande Ronde reservations.

FWS-Two National Wildlife Refuges (NWR) in Oregon now contain owl habitat. Cape Meares NWR has only 138 acres of old growth administered as a Research Natural Area. Although owls have been observed in the area, their regular occurrence on the refuge has not been confirmed. The FWS is presently acquiring habitat that will be included in the Bear Valley NWR near Worden, along the border with California. This area will contain about 4000 acres of older ponderosa pine, with a mix of other coniferous types. Timber production does not occur in this area, which has never been surveyed for owls.

Private lands_-Private lands in western Oregon encompass about 6.2 million acres of forest lands (Gedney 1988), of which about $10 \%$ are considered incapable of producing commercial forests. Additional private lands occur along the east side of the Cascades, but published inventories are insufficient to identify those that may be within the range of the spotted owl. We estimate about 100,000 acres of commercial forest lands on the eastside.

Private lands are divided into "forest industry" (usually large-company owners) and "other private," owned by individuals. Forest industries own about $4,046,000$ acres of commercial forest lands and other private landowners about 1,858,000 acres.

Based on $1985-86$ inventories, $80 \%$ of forests on industry lands are $\leq 50$ and $90 \%$ are $\leq 80$ years old (Gedney 1988). In fiscal years 1987 and 1988, the forest industry clearcut an average of 60,000 acres per year and partial-cut 43,000 acres (ODF 1989). Fifty-six percent of other private forest are $\leq 50$ and $89 \%$ are $\leq 80$ years old. In the same years, an average of 27,000 acres were clearcut and 65,000 acres were partially cut. Based on the above harvest rates and a known decreasing rotation age, most suitable habitat on lands managed under even-aged methods will be removed in $<10$ years.

Systematic surveys for owls have not been done on private lands in Oregon, although extensive surveys have occurred in association with Federal and State land surveys and research. Where BLM checkerboard lands occur, $\geq 50 \%$ of adjacent private lands have been surveyed (Lint, pers. comm.). In demographic study areas, such as on the Roseburg District, nearly all private land has been surveyed. About 25 pairs have been located on private lands Statewide in the last 5 years. 


\section{Appendix C: Current Situation}

State of California

\begin{abstract}
Management status-The spotted owl is listed as threatened in Oregon by the Fish and Wild life Commission. Under Oregon statutes, such a listing requires that protection be given the species on State lands only (not private lands). All State agencies must coordinate with the ODFW when a project or action may affect a listed species. Forest management operations on State and private lands are governed by rules under the Oregon Forest Practices Act. The Act was amended in 1987 and requires that the Board of Forestry adopt rules to protect State-listed species or nest sites of sensitive birds. Interim rules have been adopted that require a written plan to be approved by the State Forester when any forest operation is proposed within 300 feet of a nesting or roosting site of a listed species. We do not know, however, how much or what kind of habitat protection will be given to a pair on State lands. Until specific guidelines are adopted in 1991, however, protection will be handled case by case.
\end{abstract}

California Department of Forestry and Fire Protection (CDF)-The CDF manages three State forests, totaling 53,648 acres, in the range of the northern spotted owl. The portion of these lands containing suitable habitat is unknown. The Jackson State Forest is in coastal Mendocino County and contains slightly more than 50,000 acres of redwood forest with some Douglas-fir. The redwood forest is second growth, with about 1000 acres of old growth remaining in scattered parcels of $<80$ acres. Ponderosa pine covers about $90 \%$ of Boggs Mountain State Forest, farther inland in southwestern Lake County. The 160-acre Ellen Pickett State Forest is near Weaverville, in eastern Trinity County.

Spotted owls are known from six sites in the Jackson Forest but have not been reported from the Boggs Mountain or Ellen Pickett Forests. Surveys in 1989 disclosed three pairs and two single birds at five sites in the Jackson Forest. A single individual was located at a sixth site in 1974, but that area has not been checked for owls since then. No spotted owl surveys have been done on the other two Forests. The dry, inland pine-forest type on the Boggs Mountain is not known to regularly support owls.

Both the Jackson and Boggs Mountain Forests have active sale programs and are managed with the intent of providing a sustained yield of saw timber. At the Jackson Forest, both clearcutting and selective-cutting are used. Rotation age is about 80 years, although good growth rates in redwood continue beyond 100 years of age. With an annual cut of about 30 million board feet, and a possible extension of the rotation age to more than 100 years, the current quantities of forest in various age groups should remain relatively stable or show an increase in older second-growth forest.

Small educational and recreational facilities exist on both forests, but they do not significantly influence the timber management program. A minor land-exchange program is aimed at consolidating holdings, but no significant changes are planned.

Currently, the CDF has no spotted owl management plan, and no active management is occurring on its forests. The Department is leading a State effort to write a California Habitat Conservation Plan (CHCP) for spotted owls, which would concentrate on management of the owl on private and State lands. We assume such a plan will address owl management on State forests. 


\section{Appendix C: Current Situation}

If current conditions continue, and the Califomia plan for owls is not implemented, owl numbers will likely fluctuate over time as various, previously cut redwood habitats become suitable. At no time is all land likely to be unsuitable, but suitable habitat may be so fragmented that the population may decline. A longer rotation age for those forests, however, might allow them to support as many as 10 to 14 pairs. At present, no plans are in place to monitor owls on the Jackson Forest or to survey Boggs Mountain.

Department of Fish and Game (CDFG)-The CDFG does not manage any State lands with habitat suitable for the northern spotted owl.

Department of Parks and Recreation (CPR)-The CPR manages 28 park units in the north coast of California that are within the range of the northern spotted owl and contain potential habitat. These units occur in Del Norte, Humboldt, Mendocino, Sonoma, Napa, and Marin Counties and total 132,625 acres. About 56,000 acres are suitable habitat (table $\mathrm{C} 1$ ), $88 \%$ in old-growth redwood forest types and another $5 \%$ in second-growth redwood forest (Schaub, pers. comm.).

The State park units are small, with all but two smaller than 10,000 acres and nine smaller than 1000 acres. Eighty blocks of suitable habitat were identified from the 28 units; stands in these units ranged from 12 to 3361 acres and averaged only 563 acres. Only three units currently contain enough suitable habitat to individually sustain a pair of owls, based on recent radio-telemetry studies of home-range sizes in this region.

Records of spotted owls are verified at 27 sites in 19 units. Two units have unverified records, and owls have been reported near two other units since 1973. In the last 5 years, however, owls were recorded from only 12 different sites (eight pairs and four singles) in nine units (table $\mathrm{C} 1$ ). This estimate is undoubtedly low because extensive recent surveys have been done on only four units. All other units need complete inventories.

State parks are managed for their natural qualities and for recreation. No tree cutting occurs except where necessary for safety, to maintain healthy forests, and to develop recreational facilities. In general, habitat management policy is to maintain the natural qualities of the redwood parks, which serves to maintain old-growth forests and provides long-term benefits for owls.

Management plans for the north coast park units are being developed. Because of limited information about owls within each unit, plans often do not specifically address this species. Management trends will continue to benefit owls as secondgrowth forests mature and become suitable habitat. We have no current estimate of the amount of habitat expected to become suitable in the future. 


\section{Appendix C: Current Situation}

We expect the California conservation plan to use State park lands with established spotted owl territories as a basis for the plan on State and private lands in north coastal California. If the California plan is not implemented, then the viability of many State park units south of Humboldt County will depend on forest management practices on private lands. State park units, even in the presence of scattered parcels of suitable habitat on BLM lands, are too small and too widely spaced to individually sustain a viable population of owls.

In preparing management plans for the park units, CPR is conducting biological surveys of each unit. Part of the survey is to determine each unit's suitability for owls, assessing the current number occupying the unit, and delineating the suitable habitat believed to be used by spotted owls. No monitoring of the owl population in park units is planned.

Cailfornia Lands Commission-Currently, the CDF manages 3836 acres of California Lands Commission property, in 18 parcels throughout the State. Twelve of these small parcels, ranging from 11 to 640 acres, are in the Shasta/Trinity area. The 10-year management agreement between these two agencies expires in mid-1990.

The situation on other Lands Commission parcels is not currently known. We know of no other major blocks of State land not already managed by another State agency in the range of the spotted owl in California. Any remaining small parcels are likely to be scattered "school lands" (the mile-square Sections 16 and 36 , granted to the States). Such areas are relatively unimportant to owls in aggregate. These sections may, however, be important to the maintenance or integrity of individual spotted owl management areas, and an inventory of these sites should be done during the preparation of the California plan and reviewed for local importance.

The Nature Conservancy-The Nature Conservancy manages two parcels of land with suitable habitat in the range of the northern spotted owl in California. The Northern California Coast Range Preserve in northern Mendocino County contains about 6500 acres of old-growth Douglas-fir in an 8000-acre tract managed in about equal parts by the Conservancy and the BLM. The second area, the McCloud River Preserve in north-central Shasta County, contains 2300 acres of forests, with about 1600 acres in old-growth Douglas-fir and mixed-conifer stands considered suitable habitat. Habitat in both areas is fairly contiguous along major watercourses.

Three pairs are known from the Northern California Coast Range Preserve, two basically using the Conservancy land and one using BLM land. Pairs have been found at all three known sites in the last 5 years, and two pairs have reproduced during that period. No owls have been found at the McCloud River Preserve.

Management of both areas is to preserve their natural qualities, including the continued maintenance of old-growth Douglas-fir forests. At the Northern California Coast Range Preserve, management of the whole area also depends on the BLM. In the preferred alternative for this area, in the resource-management plan for the Arcata Planning Area, the BLM will continue to manage their land as an Area of Critical Environmental Concern. 


\section{Appendix C: Current Situation}

- The future management of both areas indicates a continued presence of suitable habitat. The Northern California Coast Range Preserve is relatively small and isolated from other big blocks of suitable habitat, however, and it will depend on the California conservation plan to provide other areas of suitable habitat nearby and a population of birds large enough to maintain itself through time. The McCloud River Preserve is adjacent to the Girard HCA, the major population center for spotted owls in the connecting zone between the ranges of the northern and California subspecies. It should continue to be maintained in a state suitable for use by owls.

National Audubon Society-The National Audubon Society manages a 1000-acre tract of second-growth redwood forest in coastal Marin County. The area provides about 600 acres of suitable habitat and maintains one pair (Schwartz, pers. comm.). Management direction is, and should continue to be, to manage the area for its natural values, including the redwood forest. This small area depends on adjacent National Park, State park, and municipal water-district lands to continue to support owls. Management direction on these neighboring lands is generally consistent with maintaining suitable habitat. The area also is within the block of habitat that supports about 24 pairs of owls at the southern terminus of the owl's range.

Private lands-Private timber lands in California usually fall into one of three major categories: industrial lands, large private landholdings, and small private landholdings (TAC and VESTRA 1989). These ownerships manage a total of $8,613,699$ acres, or $53 \%$ of all forested lands in northwestern California (industrial lands-2,514,583 acres, large private landholdings-210,170 acres, and small private landholdings$5,888,916$ acres). Lands designated primarily for timber production total $6,793,382$ acres, of which $2,188,460$ acres are industrial lands (TAC and VESTRA 1989). From 10 to $15 \%$ of the industrial land base is inoperable for timber harvest because of physiographic considerations, and production is constrained by regulations on an additional $10 \%$ of these areas.

Inwin et al. (1989b), using data from Lloyd (1986a, 1986b) and Colclasure et al. (1986), estimated the following as current acreages of small and large saw timber on private lands in the range of the northern spotted owl in California (total $=2,170,000$ acres): for stands ranging from 9 to 20.9 inches in d.b.h. $-658,000$ acres in the northwestern area and 1,163,000 acres in the northern interior area and for stands $\geq 21$ inches in d.b.h. $-217,000$ acres in the northwestern area and 132,000 acres in the northern interior area.

Of the 1,750,767 acres of industrial timber lands to be "managed" (see TAC and VESTRA figures above: $80 \%$ of $2,188,460$ acres), the TAC (1989) predicts that 700,307 acres will be in stands old enough to provide suitable habitat at any given time. They assumed that all such habitat is capable of supporting spotted owls, and used rotation ages for coastal areas of 50 to 60 years and inland areas of 80 to 90 years, with suitable habitat being produced in 25 to 35 years and 40 to 45 years in each area, respectively. Although some habitats in these age-classes contain owls, we believe they underestimate the age at which habitats in these areas typically become suitable for most life requisites of spotted owls (for example, Pious 1989; see appendices $F$ and $G$ for a discussion). More investigations of habitat use in the managed forests are warranted. 


\section{Appendix C: Current Situation}

Using the same basic process, TAC (1989) predicted that $1,037,671$ of $2,599,177$ acres of timber-emphasis lands owned by small land owners will be suitable at any given time. We believe this is an optimistic estimate.

An additional 1,844,240 acres not emphasized for timber production is owned by small, private landowners and by industry (TAC 1989). These are lands dominated by hardwoods and not likely to be subject to intensive harvest in the future; TAC estimates that about 1,475,392 acres of these lands should be suitable for owls.

Private industrial forest habitat occurs regularly in larger blocks, aggregated for management purposes. Blocks, however, may be dispersed. Small, private forest lands also form large areas, but their ownership patterns are complex and parcel sizes are small.

A segment of the timber industry in California performed three major surveys and inventory efforts in the last 2 years. Spotted owls were located at 290 sites (Kerns 1989, Pious 1989, TAC 1989). Ninety-nine pairs were confirmed, and reproduction was documented at 36 sites. About $10 \%$ of all sites found duplicated sites previously known.

In 1989, CDFG surveys found 13 pairs on 20 sites on private lands (Wooster, pers. comm.). An additional 68 records of spotted owls have been reported previously, although only 11 of those were sightings of pairs in the last 5 years (Gould, pers. comm.).

The TAC (1989) believes that substantial suitable habitat is now available and being used by the owls under past and current timber management practices on private lands, without any past attention having been given to habitat requirements of spotted owls. They predict no changes in land management that will decrease the amount of suitable habitat. Part of the reasoning for this philosophy is the relatively small percentage of timber that is clearcut in inland areas, the presence of regulations and physiographic constraints on harvesting timber on more than $80 \%$ of the industrial land base, and the additional proportion of the land that will support suitable habitat while attaining full rotation age.

Because a large proportion of the private land base will be subjected to harvest, the quantity and distribution of suitable habitat will vary locally over time. The extent to which future conditions will differ from current conditions depends on the timber market and on land owners' individual philosophies about land management. Decreases in the world timber supply, increased use of wood and wood fiber from new uses or increased human population, changes in company ownership, and the vulnerability of standing timber crops as objects of corporate takeovers can markedly affect future timber harvest rates. 


\section{Appendix C: Current Situation}

If current conditions continue, forests in California managed for timber are likely to be more intensively harvested, leading to younger average stand ages, even in forests selectively cut. Higher harvest rates and the need to achieve regrowth will result in reduced canopy closure in selectively cut stands and further fragmentation. The direction appears to be changing, however, and this outlook could be considerably altered by several public and industry measures intended to improve forest conditions. These measures include drafting and implementing the California Habitat Conservation Plan that will focus on spotted owls, initiatives addressing long-term forest planning and cumulative impacts, and an evolutionary development of the California Forest Practices rules by the Board of Forestry. Effects of these measures on industrial and other private forest lands are currently unknown.

Several large timber companies have instituted spotted owl surveys and inventories in the last 2 years. Six companies will continue extensive inventories, extending over the next 2 years. The main objective of most of these inventories is to document that the owls use second-growth and managed forests. Currently, no monitoring is planned, because no long-term management plans have been implemented.

Indlan trlbal lands-Reservation lands of the Hoopa and Round Valley Tribes contain significant acreages of forest, managed mostly for timber production. Amounts of suitable habitat are unknown, and no information about owl occurrence is available.

\section{Conclusions}

References
Habitat of the northern spotted owl throughout its range is managed by numerous agencies and land owners with diverse land-use objectives. Regulations requiring consideration of the habitat needs of the owl are often nonexistent. The BLM and FS have implemented management plans requiring delineation of areas to be protected for use by owls, but little consistency exists between agencies. Differences exist even between administrative units of the same agency (see appendix $\mathrm{D}$ ). The result has been the lack of consistent, comprehensive management planning based on the biological requirements of spotted owls. Inventory efforts vary widely-some ownerships have never been surveyed, or if they have, results are unknown. Sometimes data from inventories between agencies are not comparable. Consequently, much confusion exists and opportunities that would increase biological understanding of spotted owls have been lost. Credibility of the involved agencies has also suffered.

We believe that the current situation-that is, the lack of a well-coordinated, biologically based management plan, applied consistently throughout the range of the spotted owls-is unacceptable and contributes to a high risk that spotted owls will be extirpated from significant portions of their range.

Advanced Sciences, Inc. 1989 unpubl. Population monitoring of the northern spotted owl on Coast Pacific Industries timberlands. Sierra Pacific Industries, Redding, Calif.

Agee, J. K. In press. Fire history of Douglas-fir forests in the Pacific Northwest. In Wildlife and vegetation in managed Douglas-fir forests. U.S. For. Serv. Gen. Tech. Rep.

Agee, J. K. Pers. comm. Univ. Wash., Seattle. 


\section{Appendix C: Current Situation}

Anthony, J. L., and E. B. CummIns. 1989. 1988-1989 Hoh-Clearwater spotted owl inventory project. Coop. Proj.: Wash. Dep. Nat. Res. and Wash. Dep. Wildl., Olympia.

Barrowciough, G. F. Pers. comm. Am. Museum Nat. Hist., New York.

Beak Consultants. 1989 unpubl. Survey of spotted owls on managed forestlands in interior northern California. Sierra Pacific Industries.

Becksted, M. Pers. comm. WDW, Olympia, Wash.

BourhIII, R., and G. Lettman. 1989 unpubl. Harvested acres in Oregon for Federal fiscal year 1988. Oreg. Dep. For., news release, 20 September 1989. 5pp.

Briggle, W. J. 1985 unpubl. Spotted owl management policy. Memo. Pacific Northwest Reg., Natl. Park Serv. Seattle, Wash. 2pp.

Brown, J. 1989 unpubl. Arcata redwood spotted owl survey. Arcata Redwood Co., Arcata, Calif.

Bruce, C. R. Pers. comm. ODFW, Corvallis, Oreg.

Chief of the Forest Service-Record of Decision, 1988. Amendment to the Pacific Northwest Regional Guide. Final Suppl. to the Final Environmental Impact Statement. U.S. For. Serv., Washington, D.C.

Coiclasure, P., J. Moen, and C. L. Bolsinger. 1986. Timber resource statistics for the northern resource area California. USDA For. Serv. Resour. Bull. PNW-135.

Dawson, W., J. D. Ligon, J. R. Murphy, J. P. Myers, D. Simberioff, and J. Verner. 1986. Report of the advisory panel on the spotted owl. Audubon Conserv. Rep. 7. Natl. Audubon Soc., New York.

Dilier, L. 1989 unpubl. Status of the northern spotted owl in managed forests on Simpson Redwood lands in northern California. Interim rep. Simpson Redwood Co., Arcata, Calif.

Dunbar, D. Pers. comm. Ministry Environ., Vancouver, Brit. Col.

Erckman, J. Pers. comm. Seattle Water Dep., Seattle, Wash.

Forsman, E. D. 1988. A survey of spotted owls in young forests in the northern Coast Range of Oregon. Murrelet 69:65-68.

Forsman, E. D., C. R. Bruce, M. A. Walter, and E. C. Mesiow. 1987. A current assessment of the spotted owl population in Oregon. Murrelet 68:51-54.

Forsman, E. D. 1986 unpubl. Spotted owls in young forests-additional surveys in the northern Coast Range of Oregon. U.S. For. Serv., Olympia, Wash. 


\section{Appendix C: Current Situation}

Forsman, E. D., and E. C. Meslow. 1985. Old growth forest retention for spotted owls, how much do they need? Pages 58-59 In R. T. Gutiérrez and A. B. Carey, eds. Ecology and management of the spotted owl in the Pacific N.W., U.S. For. Serv. Gen. Tech. Rep. PNW-185.

Forsman, E. D., E. C. Meslow, and M. J. Strub. 1977. Spotted owl abundance in young versus old-growth forests, Oregon. Wildl. Soc. Bull. 5:53-47.

Franklin, J. F., and C. T. Dyrness. 1988. Natural vegetation of Oregon and Washington. Oreg. State Univ. Press, Corvallis. 452pp.

Fredrickson, R. J., L. S. Mills, and B. B. Moorhead. 1989 unpubl. Spotted owl surveys in the Olympic National Park. Final rep. Olympic National Park, Port Angeles, Wash. 29pp.

Gedney, D. R. 1986. Timber resource statistics for non-Federal forest land in northwest Oregon. U.S. For. Serv. Resour. Bull. PNW-140. 26pp.

Gedney, D. R. 1987. Timber resource statistics for non-Federal forest land in westcentral Oregon. U.S. For. Sen. Resour. Bull. PNW-143. 26pp.

Gedney, D. R. 1988. The private timber resources. Pages 53-57 In G. L. Lettman, ed. Assessment of Oregon's Forests. Oreg. Dep. For. Salem.

Gedney, D. R., P. M. Bassett, and M. A. Mel. 1986. Timber resource statistics for non-Federal forest land in southwest Oregon. U.S. For. Serv. Resour. Bull. PNW-138. 26pp.

Gedney, D. R., P. M. Bassett, and M. A. Mel. 1989. Timber resource statistics for all forest land, except National Forests, in eastern Oregon. U.S. For. Serv. Resour. Bull. PNW-164. 25pp.

Gould, G. Pers. comm. CDFG, Sacramento, Calif.

Grant, J. 1966. The barred owl in British Columbia. Murrelet 47:39-45.

Gutlérrez, R. J. 1989 unpubl. Genetic variation and differentiation in spotted owl (Strix occidentalis). Final rep., U.S. For. Serv. Contr. PSW 88-0014. Humboldt State Univ., Arcata, Calif. 32pp.

Hansen, E. Pers. comm. Yakima Indian Nation, Yakima, Wash.

Hays, D. Pers. comm. WDW, Olympia, Wash.

Hays, D. W., H. C. Allen, and L. H. Egtvedt. 1989 unpubl. Spotted owl surveys of randomly selected transects in Washington. Prelim. Washington Dep. Wildl., Olympia. 31pp. 


\section{Appendix C: Current Situation}

Henderson, J. A., D. H. Peter, R. D. Lesher, and D. C. Shaw. 1989. Forested plant associations of the Olympic National Forest. U.S. For. Serv. R6-ECOL-TP001-88. $502 \mathrm{pp}$.

Houston, D. Pers. comm. NPS, Port Angeles, Wash.

IrwIn, L. Pers. comm. NCASI, Corvallis, Oreg.

Irwin, L. L., T. L. Fleming, S. M. Spelch, and J. B. Buchanan. 1989a unpubl. Spotted owl presence in managed forests of southwestern Washington. NCASI. 30pp.

Irwin, L., S. Self, and L. Smlth. 1989b unpubl. Status of the northern spotted owl on managed forestlands in northern California. Timber Assoc. Calif., Sacramento.

James, K. Pers. comm. FS, R6, Olympic NF, Olympia, Wash.

Johnson, N. K. 1989 unpubl. Museum of Vertebrate Zoology, Univ. California, Berkeley. Letter to U.S. Dep. Inter. Fish and Wildl. Serv. 12 December 1989.

Jones, L. 1988. State forest lands. Pages 49-52 in G. L. Lettman, ed. Assessment of Oregon's forests. Oregon Dep. For., Salem.

Kerns, S. 1989 unpubl. Occurrence of spotted owls in managed timber stands on lands of the Pacific Lumber Company. Prog. rep. Wildland Resource Managers.

Lettman, G. J., ed. 1988. Assessment of Oregon's forests. Oreg. Dep. For., Salem. 263pp.

LInt, J. B. Pers. comm. BLM, Roseburg, Oreg.

Lloyd, J. D., Jr., J. Moen, and C. L. BolsInger. 1986a. Timber resource statistics for the North Coast Resource Area of California. USDA For. Serv. Resour. Bull. PNW-131.

Lloyd, J. D., Jr., J. Moen, and C. L. Bolsinger. 1986b. Timber resource statistics for the Sacramento Resource Area of California. USDA For. Serv. Resour. Bull. PNW-134.

National Park Servlce. 1988. Management policies: U.S. Dep. Interior, Natl. Park Serv. U.S. Gov. Printing Off., Washington, DC.

Nunan, John. Pers. comm. FS, R6, Portland, Oreg.

Oregon Department of FIsh and WIIdllfe. 1989 unpubl. Eel Lake timber harvest plan summary. 6pp.

Oregon Department of Flsh and WIIdllfe. 1990 unpubl. Spotted owl database. 


\section{Appendix C: Current Situation}

Oregon Department of Forestry. Oregon Endangered Specles Task Force. 1977 unpubl. Oregon interagency spotted owl management plan. Oreg. Dep. Fish and Wildl., Portland. 3pp.

Oregon Department of Forestry. 1984 unpubl. Long-range timber management plan northwest Oregon area State forests. Rep. 3-0-1-300D. 13pp.

Oregon Department of Forestry. 1987 unpubl. Long-range timber management plan southern Oregon region State forests. Rep. 3-0-2-220. 18pp.

Oregon Department of Forestry. 1989 unpubl. Long-range timber management plan Willamette region State forests. Rep. 3-0-2-210. 23pp.

Oregon State Parks and Recreation Department. 1982 unpubl. Silver Falls State Park master plan.

Plous, M. 1989 unpubl. The northern spotted owl in second growth forests of Mendocino County, Calif. Prelim. results. Louisiana Pacific Corp., Calpella, Calif.

Ramsey, M. Pers. comm. WSPR, Olympia, Wash.

Romme, W. H., and D. G. Despain. 1989. Historical perspective on the Yellowstone fires of 1988. BioScience 39:695-698.

Schaub, D.B. Pers. comm. CPR, Sacramento, Calif.

Schwartz, S. Pers. comm. National Audubon Society, Stinson Beach, Calif.

Self, S. Pers. comm. TAC, Sacramento, Calif.

Steele, P. Pers. comm. The Nature Conservancy, Branscomb, Calif.

Stroud, G. Pers. comm. The Nature Consenvancy, McCloud, Calif.

Taylor, A. L., and E. D. Forsman. 1976. Recent range extensions of the barred owl in western North American, including the first records for Oregon. Condor 78:560-561.

TImber Assoclation of Callfornla. 1989 unpubl. Executive summary-Timber Association of California comments on the proposed listing of the northern spotted owl. Timber Association of California, Sacramento. 12pp.

TImber Assoclation of Callfornia and VESTRA Resources, Inc. 1989 unpubl. California timberland wildlife habitat st Idy. Timber Association of California, Sacramento.

U.S. Department of Agriculture. 1988a. Final supplement to the Environmental Impact Statement for an amendment to the Pacific Northwest regional guide. Spotted owl guidelines. 2 Vols. U.S. For. Serv., Pac. Northwest Reg., Portland, Oreg. 


\section{Appendix C: Current Situation}

U.S. Department of Agriculture. 1988b. Spotted owl inventory and monitoring Handbook. U.S. For. Serv., Pac. Northwest Reg., Portland, Oreg., and Pac. Southwest Reg., San Francisco, Calif. February 1988. Addendum of May 1988. $18 \mathrm{pp}$.

U.S. Department of Agriculture. 1989 unpubl. Report for Fish and Wildife Service Response. For. Serv., Pac. Northwest Reg., Portland, Oreg. Transmittal letter dated December 20, 1988. Signed by John Butruille, Regional Forester.

U.S. Department of Interlor. 1983 unpubl. Bureau of Land Management. BLMODFW agreement for spotted owl management on BLM lands western Oregon. Oreg. State Office, Portland.

U.S. Department of Interlor. 1986. Monitoring western Oregon records of decision. Oreg. State Office BLM Manual Suppl. 11-1734-1, Portland. 150pp.

U.S. Department of Interlor. 1988 unpubl. Bureau of Land Management. BLMODFW agreement for spotted owl management on BLM lands in western Oregon. Oreg. State Office Instr. Memo. OR-88-230, Portland. 8pp.

U.S. Department of Interior. 1989a unpubl. Fish and Wildlife Service. The Northern Spotted Owl-A Status Rev. Suppl. Final rep.

U.S. Department of Interlor. 1989b unpubl. Bureau of Land Management, BLM screening process for conferencing with the U.S. FWS on the northern spotted owl. Calif. State Office Instr. Memo. CA-90-73. Sacramento. 6pp.

WashIngton Department of Wildilfe. 1989 unpubl. Nongame data systems, interagency spotted owl database, Olympia, Wash,

Washington Department of Wildllfe. 1990 unpubl. Nongame data system, interagency spotted owl database, Olympia, Wash.

Wooster, T. A. Pers. comm. CDFG, Yountville, Calif. 


\section{Survey: Management of Northern Spotted Owls on National Forests and BLM Districts}

\section{Introduction}

\section{Summaries}

One of the Committee's charges was to "assess whether current management strategies of the agencies are reserving options that will allow for long-term strategies to conserve the northern spotted owl." In an effort to accomplish this task, and to familiarize all members of the Committee with current management strategies, we interviewed various line and staff personnel in the FS and BLM. Interviews were only one means of gaining an overview of the management situation from the perspective of some field offices of the various agencies. The survey was not intended to give the Committee a statistical sample of the agencies' current management strategies; nevertheless, the Committee individually and collectively gained important insights on the status of owl management in late 1989.

Nine National Forests and three BLM Districts were randomly selected. One Ranger District (FS) and one Resource Area (BLM) for each of the selected Forests or Districts was also randomly chosen. The NPS has jurisdiction over significant acreage of owl habitat, but was not included in these interviews because the NPS normally does not undertake activities that alter owl habitat.

\section{Personnel interviewed were:}

National Forests-Forest Supervisor, Timber Staff, and Wildlife Biologist; Ranger Districts-District Ranger, Timber Staff, and Wildlife Biologist; BLM Districts-District Manager, Timber Staff, and Wildlife Biologist; and Resource Areas-Area Manager, Timber Staff, and Wildlife Biologist.

Compiled analyses of the survey and specifics of methodology comprise the last section of this appendix. These results were evaluated and categorized in the following six sections to provide a summary of the findings of the Committee.

Management Direction and Policy-Several questions assess directly or indirectly the availability and usefulness of existing policy and direction.

Findings: Differences in understanding direction and inconsistencies in implementing direction were evident throughout the interviews. Many respondents noted problems such as lack of long-term direction and "ever-changing" sets of rules. Concern was also expressed over the lack of, or inconsistencies with, short-term direction, particularly relating to timber sale activities and nonnetwork owls (those found outside areas of protected habitat). The general sense appeared to be that the situation is so dynamic that policy is not keeping up with events. 


\section{Appendix D: Management Survey}

The expressed lack of policy was more apparent in the Pacific Southwest Region (Region 5, FS), which has less-specific and required guidance, and in the BLM, which is in the process of planning for future direction for spotted owl management and timber sales. Major differences were also noted among the FS Regions and BLM regarding standards, protocols for monitoring, and general direction.

Responses to several questions indicated significant inconsistencies between Forest and District staffs within National Forests and between District and Resource Area staff on BLM Districts. Inconsistencies were also evident among respondents on particular administrative units. Responses often indicated a lack of communication between units. High turnover rates of personnel further contribute to inconsistencies, caused by a lack of understanding of the policies and regulations and, often, by differences in interpretation of management direction.

SOHAs and Habitat Management-The objective was to assess how well agencies have followed management direction to establish SOHAs and manage for spotted owls.

Findings: In general, although a timber bias was clearly evident in the guidelines for setting up networks, management direction has been followed; much effort has been devoted to providing owl habitat. Some improvement in the efforts in the last few years was indicated, which should be commended. A few notable exceptions were observed (see Summary of Responses). Unfortunately, such exceptions create mistrust and are often the root of credibility problems that extend well beyond the specific problem or administrative unit. The exceptions point to the need for thorough and continued oversight and more standardized management direction throughout the owl's range.

Uncertainty exists, especially in the BLM and Region 5, FS, regarding the longevity of current management strategies. The interviews showed that planned silvicultural management of SOHAs has caused confusion. Whether any approved plans have been developed was unclear, and no consensus exists about whether any silvicultural systems would produce the desired results. The ability to harvest timber in currently suitable owl habitat-and have that habitat remain suitable - has not been clearly demonstrated.

The adequacy and accuracy of the data base for owl habitat is a major concern, apparently more so in the FS than in BLM. Responses indicated that data bases were not generated to identify timber stand attributes of importance for wildlife habitat, and data bases were often outdated and lacked ground-truthing.

Options to Adjust Management Strategies for the Owi-Several questions were intended to provide information about opportunities to change the amount or direction of management.

Findings: Current management direction in the FS is predicated on the assumption that sufficient options will exist through the next 5 to 15 years to allow adjustments in management strategy, should such adjustments be needed (adaptive management). 


\section{Appendix D: Management Survey}

In general, options to adjust the SOHA networks would consist of adding acreages to SOHAs, increasing the number of SOHAs, or both. Responses indicated that options to increase the size of SOHAs exist but, in general, fewer than half could be expanded by 50 percent. This figure is particularly disconcerting because existing SOHAs, for most physiographic provinces, would need increases in the range of 20 to $60 \%$ to reach median amounts of suitable habitat in spotted owl home ranges, as described in the literature. Options to expand appear to be unevenly distributed across Forests and Ranger Districts. In areas of highest fragmentation, which are of greatest concern, SOHAs that are already the maximum size attainable are still smaller than the prescribed acreage, with no options to increase them. Responses indicate that options to increase the number of SOHAs are also limited. Here again, opportunities are not homogeneously distributed across the National Forest landscapes.

Much concern was expressed that present options for management are rapidly diminishing. Timber sales of fiscal year (FY) 1989 and scheduled for FY90 are near a high proportion of the SOHAs. Those adjacent timber stands would be the logical additions to SOHAs, if a need were identified to enlarge them. Additionally, high proportions of owl pairs outside the network are in areas with scheduled timber sales-areas that might logically become new SOHAs or that may be important in the long-term management of the owl.

Responses by the BLM mirrored concerns of the FS about their ability to increase the size, numbers, or both of BLM-ODFW agreement areas.

Responses by both agencies indicated that they have no formal policy regarding owl pairs (or individual owls) found outside the network sites, and in or adjacent to timber sales. This lack of policy requires that each case be reviewed independently. Responses further indicated that even where the sale was in the planning stage, only minor modifications were routinely made. The lack of a policy to maintain significant options around non-network pairs further erodes confidence that long-term options will exist and that opportunities to adjust management in the future will be possible. Many forest stands that may now exist as option areas are apparently being subjected to greater fragmentation. Adaptive management can work only if options are available to modify current management.

Determination of Suitable Habitat-The objective of this question was to determine the methods and information used by agencies to classify, map, and quantify owl habitat.

Findings: Concerns about the data bases and ground-truthing as they relate to determining suitable habitat were expressed by many respondents (discussed earlier). 


\section{Appendix D: Management Survey}

Responses indicated serious concems with definitions of owl habitat and suggested that further refinement of these definitions is needed. Most habitat data are still based on information collected for timber havest. New definitions should be developed by physiographic province, describing the continuum of habitats used by the owl, and providing comments on the relative value of habitats to the owl.

Monitoring, Inventory, and Sale Surveys-The objective was to determine how agencies carry out these programs.

Findings: Responses indicated that both agencies are generally conducting monitoring programs in an acceptable manner. Concerns over funding (amounts and timing) and staffing were expressed, and indications were that some decrease in efficiency and quality resulted. Spotted owl activities often were usurping virtually all wildlife funds and personnel to the detriment of other aspects of the wildlife program.

Significant differences exist between the FS and BLM monitoring programs. Protocols for determining occupancy and reproduction are not standardized between the agencies.

Extensive efforts were made to survey all timber sales for FY89 and FY90 by both agencies. Personnel in both agencies noted that this effort was initiated across all Forests and BLM Districts for the first time last field season, mostly in response to conferences with the FWS, as indicated by Section 7 of the Endangered Species Act. For the most part, standardized direction was followed.

Questions received mixed responses on whether new data on the owl were being used to improve SOHA networks and owl management. The general feeling was that new data are being used to improve networks. Responses further indicated a desire by both agencies to "fix" management areas geographically to facilitate completion of land and resource management plans and simplify timber sale planning.

Compatibility of Owl and Timber Management Direction-This section was to provide insights into the perceptions of personnel responsible for meeting management direction for spotted owls and timber harvest targets.

Findings: Most respondents indicated a significant conflict between owl management and current timber harvest rates. A general belief that present rates of timber harvest could not be sustained was expressed by several respondents in all disciplines.

Concerns were also expressed that, with the exception of one Forest, no adjustments to timber harvest have been made to account for smaller timber bases. The result was difficulty in balancing competing demands. The emphasis on owl management was believed to have negatively influenced timber programs and other wildlife programs. 


\section{Compiled Analysis of Survey: Management of Northern Spotted Owls on National Forests and BLM Districts}

This report analyzes responses to a set of questions posed by Committee members and advisers to selected individuals on National Forests in Regions 5 and 6 and their counterparts in BLM Districts in Oregon. The objective of this survey was to assess the implementation of management direction for spotted owls in these units.

We randomly selected nine National Forests, subject to the constraint that each physiographic province would be represented in the sample in proportion to the number of Forests in each. After all Forests were drawn, we randomly selected one Ranger District on each Forest. To obtain an overview of owl management in both Forests and Districts, we interviewed the Forest Supervisor (or Deputy), a Timber Staff Officer, and the Forest Biologist on each Forest; we interviewed the District Ranger, Timber Staff Officer, and District Biologist on each District. A team of two interviewers from the Committee, together, interviewed each Forest and District person separately. We managed to complete interviews with all but two persons scheduled with the National Forest system $(n=52)$. When all interviews on a given Forest were completed, the Committee team then visited a few SOHAs with the District Biologist and other staff.

For interviews with the BLM, we randomly selected three Districts and then randomly selected one Resource Management Area from each District. District Managers, Timber Staff Officers, and Biologists were interviewed on each District; Resource Area Managers, Timber Staff Officers, and Biologists were interviewed on each Resource Management Area. We managed to complete interviews with all but one person scheduled with BLM $(n=17)$. As with the National Forests, interviewers visited a few SOMAs with the Area Biologists after inttiviews were completed.

We assured all persons interviewed that their responses would be anonymous. This analysis therefore does not identify any person or management unit, but represents our assessment of all responses to each question. Most questions did not permit a quantitative analysis. When reading this report, bear in mind that though "Districts" are subunits of National Forests, "Districts" in the BLM are administratively equivalent to National Forests. The BLM subunit equivalent to a National Forest District is termed a Resource Management Area. 


\section{Appendix D: Management Survey}

\section{Summary of Responses to Questionnaire}

The SOHA Network
Following each question is a letter identifying to whom the question was addressed:

$A=$ Forest Supervisors/District Managers, District Rangers/Resource Area Managers, Forest/District Timber Staff Officers, District/Resource Area Timber Staff Officers, Forest/District Wildlife Biologists, District/Resource Area Wildlife Biologists;

$B=$ All of the above except Forest Supervisors/District Managers; and

$C=$ Only Forest/District and District/Resource Area Wildlife Biologists.

1. What do you conslder to be the document that guldes your spotted owl management activites? (A)

\section{Forest Service:}

At all organizational levels, National Forests in Region 6 generally agreed that the ROD/FSEIS provided basic guidance for owl management. Many Forests recognized the impact of the Hatfield/Adams amendment, and many anticipated using the pending Forest Plans. Forests in Region 5 responded in a less certain fashion, citing the "Rainbow Book" (Regional Standards and Guidelines), FWS conferencing, and Regional Directives as guiding documents. Forests in Region 5 expressed lack of specific long-term direction; those in Region 6 seemed more comfortable with the guidance.

Bureau of Land Management:

The BLM cited the ODFW agreement, Hatfield/Adams amendment, and lawsuits as providing guidance. The BLM, like Forests in Region 5, expressed lack of specific long-term direction.

2. How many SOHAs are called for In plans for your administrative unlt? (A)

With only two exceptions, personnel on each Forest or BLM District agreed within one or two SOHAS/SOMAs to the number assigned to their unit for management. Timber-management officers were the least knowledgeable of the individuals interviewed, sometimes deferring to the biologist for numbers of SOHAs/SOMAs assigned. On one Forest, the number of SOHAs assigned seemed in the process of change (increasing).

3. For how many SOHAs has a general location been identlfled and dellneated on a map? (B)

All SOHAs on FS land and ODFW agreement areas on BLM land have been delineated on maps. On Districts/Forests where radio-telemetry data are available, personnel noted that use by owls may not coincide well with mapped areas "designated" for those owls. 


\section{Appendix D: Management Survey}

4. Has your SOHA network been approved by the Reglonal Office? (A)

Both the BLM and FS expressed confidence that their "networks" met with approval of the Regional or State office. In fact, official approval of FS networks awaits final approval of Forest Plans. BLM Districts negotiated the agreement areas with ODFW.

5. For how many of these SOHAs/SOMAs have stands been mapped and acreages totaled by forest type and seral stage combinations? (B)

Forest Service:

In Region 6, essentially all SOHAs have been classified by stand as suitable, unsuitable, or marginally suitable as owl habitat. Traditional mapping by forest type and seral stage was apparently not undertaken for SOHAs, however. In Region 5, whether mapping has identified seral stage is unclear, but it has apparently identified forest type. On one Forest, the final layout of SOHAs was being reconfigured, thus precluding final mapping. Region 5 forests did not map habitat as suitable, unsuitable, or marginally suitable for spotted owls.

Bureau of Land Management:

The BLM mapped by forest type and five seral stages all ODFW-agreement areas on two Districts; the third District has completed mapping as suitable or unsuitable on about half of the agreement areas.

6. For those mapped, was mapping based on aerial photo interpretation, or ground-truthing, or a combination? (B)

Forest Service:

A combination of methods was generally used by the FS. One Forest relied primarily on aerial photo interpretation; another relied on aerial photo interpretation alone for mapping about half the SOHAs. Five forests strongly indicated the need or desire to do more ground-tiuthing of mapped SOHAs.

Bureau of Land Management:

The BLM also used a combination of aerial photo interpretation, operations inventory, and ground-truthing to produce the maps of the ODFW agreement areas. The BLM was more confident than the FS that maps reflected actual conditions on the ground.

7. If not, how were they mapped? (B)

(Answers to this question are incorporated in answer to question (6) 


\section{Appendix D: Management Survey}

8. How many of your SOHAs have approved management plans? (B)

Forest Service:

No Forests in Region 6 have SOHA management plans because all SOHAs are reserved from entry for timber harvest. One Region 5 Forest had no SOHAs with completed plans, but another indicated about half the SOHAs had approved management plans. Many of these SOHAs are also dedicated, however-that is, no timber can be harvested.

Bureau of Land Management:

No ODFW agreement areas managed by BLM have site-specific management plans; agreement areas are excluded from entry for timber harvest unless agreed to with ODFW.

9. If you have no approved plans, please explain. (B)

Forest Service:

Answers to this question were consistent within the various Forests. For Region 6 Forests, no plans are required, and all respondents knew this. For Region 5, similar consistency was evident; however, plans are a part of their direction, and responses consistently expressed an inability to make them a reality. Among reasons given for not having plans completed were lack of funds, lack of staff, too many other priorities, and an underlying suspicion that because the rules are ever-changing, no clear picture exists of what the plan should look like.

Bureau of Land Management:

For the most part, only biologists responded to this question. One District stated that no plans would be done until the 1990 decadal land-use plans were completed. A second District offered that a plan on owls was attempted under the premises set forth in a 1983 land-use plan, but it was never completed.

10. How many of the SOHAs in your management unit meet acreage criterla for suitable habitat? (B)

Forest Service:

Answers to this question were inconsistent both within and among Forests. Barely half of the responses were consistent within the Forest. We assumed the Forest Biologist provided the definitive answer. 


\section{Appendix D: Management Survey}

Inconsistency within a Forest was exhibited in several ways. In one instance, the District was internally consistent and so was the Forest, but the District and Forest Biologists' answers were not consistent. Sorting this out in retrospect was impossible. In another instance, answers differed at all levels. Assuming that the biologist was correct, answers from others bracketed those of the biologist.

Among Forests, inconsistency was most evident in actual number of SOHAs meeting the requirement. Answers ranged from "none" (one Forest) to "all." Only four of the nine Forests responded that all SOHAs met acreage criteria.

Bureau of Land Management:

Much variation was evident in answers within the three Districts, with nearly everyone interviewed having a different understanding or knowledge of the situation. Less variation existed in the biologists' responses among Districts than within them. Two of the three Districts recognized a goal of 2200 acres per owl pair protected, and the third specified a 2500 -acre goal.

For the two Districts that reported numbers of sites meeting or exceeding the 2200-acre goal, percentages were 59 and 50 . The third District offered that their agreement areas averaged 2000 acres.

11. How many of your SOHAs meet the specifled habltat arrangement criteria (300-acre core area, 60-acre block sizes within a prescribed radius, in as contiguous a block as possible, and so on? (B)

\section{Forest Service:}

With one exception, answers within a given Forest were consistent. That exception was opposite opinions expressed by the District Biologist and the Forest Biologist, and explaining this difference from available information was impossible.

All criteria were met on four of the seven Forests in Region 6, with three reporting that over $95 \%$ met the criteria. For one Forest in Region $5,75 \%$ of the SOHAs met the criteria; none did on the other Forests.

\section{Bureau of Land Management:}

Answers were consistent, in that no criteria existed or that the responders simply did not know. 


\section{Appendix D: Management Survey}

12. How many of your SOHAs meet spacing requirements? (B)

Forest Service:

Answers were generally consistent both within and among Forests. Only one discrepancy occurred-between the Forest and District staffs, with the Forest Biologist presumably providing the correct answer because it verified the other responses. On one Forest, however, both the District and Forest Biologists provided information that indicated they did not understand the spacing requirements.

In all but one case, SOHAs were believed to have met spacing requirements. In one case where all SOHAs met criteria, extensions ("buds") had been added to satisfy spacing criteria.

\section{Bureau of Land Management:}

Answers indicated that no spacing requirements existed or responders did not know. Relying on the biologist's response, we concluded that specific requirements on spacing were not part of the agreement, but distribution of sites was assured during the process of building the areas.

13. Do you have other acreages adjacent to SOHA network sites that could be used to increase the amount of protected habitat within a 2.1-mile radius of SOHA centers? How many could you increase by $10 \%$ ? by $25 \%$ ? by $50 \%$ ? (B)

\section{Forest Service:}

Biologists seemed to know most about possibilities for expanding SOHAs. In most cases, other respondents usually deferred to biologists or made estimates far different from the biologist's. Occasionally, estimates by different people were similar. Six of the nine Forests could expand acreages for all SOHAs by at least $10 \%$. The remaining three Forests could expand most of their SOHAs by $10 \%$.

Only two of nine Forests could expand all SOHAs by $25 \%$. The remainder ranged from an estimated 15 to $75 \%$ of the SOHAs that could be expanded that much.

Only one Forest indicated that it could expand all SOHAs by $50 \%$. That Forest also has the highest number of additional sites available for addition to the network. The remaining Forests indicated opportunities ranging from 0 to $75 \%$, with most indicating about $30 \%$ of their SOHAs could be expanded by $50 \%$.

Ranger District estimates tracked those of the Forest except where conditions precluded any increase above $10 \%$. Thus, options may exist at the Forest scale, but in areas where the need may be greatest, few, if any, options may be available to improve SOHAs by expanding acreage. 


\section{Appendix D: Management Survey}

Bureau of Land Management:

Answers varied among and within Districts. Estimates indicated that nearly all sites could be expanded by $10 \% ; 40$ to $50 \%$ could be expanded by $25 \%$; increases of $50 \%$ were limited to less than $20 \%$ of the sites.

14. How many additional sltes on your administrative area meet network criteria and could be used to add to the existing network of SOHAs? (B)

Forest Service:

Much variation existed among Forests in the number of sites available. Six of nine Forests indicated that fewer than 20 new sites could be added. One important fact emphasized by several respondents was that existing options are rapidly decreasing as timber targets are pursued. Responses indicated that few Forests had a wide option to expand on the existing network. The same situation exists with respect to increase in numbers as with size of SOHAs—opportunities differ from District to District within Forests.

Bureau of Land Management:

Estimates identified six to eight potential sites on each of two Districts. On the remaining District, although the total was unclear, a Resource Area Biologist offered that his unit might have eight to ten potential sites.

15. How many network SOHAs on your administrative unit had palr occupancy during 1, 2, or 3 of the past 3 years (base estimates on monitoring results)? (C)

This question was not interpreted uniformly and responses were therefore not comparable.

16. What definition of "sultable" habitat has been used on your administrative area? (B)

\section{Forest Service:}

All Forests in Region 6 referred to the definition in the SEIS or, in one case, to the definition in the Regional Guide. In practice, most Forests apparently included a wide range of forest types and conditions, from young forests with inclusions of old growth to very old, multilayered stands. At least two Forests increased the elevational limits stipulated in the SEIS because they believed the limits were set too low. Forests in Region 5 indicated that they were using the "Rainbow Book." 


\section{Appendix D: Management Survey}

\section{Bureau of Land Management:}

All three Districts answered that all stands at least 80 years old were considered suitable owl habitat. Beyond this, criteria did not appear to be standardized, although criteria such as " $65 \%$ canopy closure" and "lots of dead and down material" were mentioned.

17. Do you feel that this definition adequately defines spotted owl habltat? (B)

\section{Forest Service:}

Almost all respondents in Region 5 said "no." In general, they indicated that the definition was not broad enough to cover owls located in mixed-conifer/ hardwoods in California. In Region 6, most respondents said "yes" or "adequate" or "the best we've got." Many reservations were expressed, however. Some believed the definition was adequate only for defining fully suitable, but not for marginal habitat. One Forest considered an additional category, "candidate" habitat, that included forest stands smaller in stature and at higher elevations than limits set in the "suitable" definition.

\section{Bureau of Land Management:}

All respondents on one District were comfortable with the definition, but most biologists and some foresters on the other Districts had reservations. One Resource Area Manager believed that the definition did not match what owls were using.

18. Is the definition written down somewhere? If so, please provide a copy. (B)

Forest Service:

Forests in Region 5 had written definitions, but responses reflected a pervasive belief that definitions were inadequate because they did not cover all conditions where owls were found. In Region 6, all Forests but one had a written definition. The exception reported that they were "working on it." Some definitions were specific, others were not.

\section{Bureau of Land Management:}

Two of the three Districts had no written definition. The third had a written definition in their 1987 Spotted OwI EA, and also said they were using the interim old-growth definition in Franklin et al. (1986. Interim definitions for old-growth Douglas-fir and mixed-conifer forests in the Pacific Northwest and California. USDA Forest Service, Pacific Northwest Research Station, Research Note PNW-447.) 


\section{Appendix D: Management Survey}

19. What stand data/Inventory (TRI system, photos, data, etc.) were avallable for delineating sultable habltat? (B)

Forest Service:

Both Forests in Region 5 reported using their timber inventory data and aerial photos. Responses among personnel were fairly consistent. All Region 6 Forests reported using a variety of resources, including TRI data, aerial photos, local knowledge of the ground, and precruise data. Most Forests relied on the TRI system and photos. Responses at all levels were largely consistent.

Bureau of Land Management:

Respondents on all Districts reported that they had used their operations inventory, aerial photos, ground-truthing, and personal knowledge of the ground.

20. How do you feel about the rellability of data used to map sultable habltat on your administrative unit? (B)

\section{Forest Service:}

In Region 5, some concern was expressed on one Forest that data were more reliable on some Districts than others. Several individuals on one Forest expressed a lack of confidence in data used to map habitat in 1986, but recent improvements in the data base had considerably reduced these concerns. Responses generally indicated that data used to map suitable habitat were reasonably reliable.

In Region 6, two of three Forests in Washington reported only moderately accurate mapping, with estimates of accuracy ranging from 50 to $90 \%$. On the third Forest, responses indicated that mapping data were "pretty good." Much variation was seen in responses from personnel on Forests in Oregon. Concerns expressed were that the definition was too broad, that more ground-truthing was needed, that some data bases provided information only on tree species as opposed to structure, and that habitat outside SOHAs was not mapped. On two Oregon Forests, respondents indicated that they felt the mapping was only 70 to $90 \%$ accurate - within the range estimated by several people on the Washington Forests.

Bureau of Land Management:

Responses on two Districts indicated some discomfort, but respondents in all disciplines believed they had done the best they could under the circumstances. The general feeling on the third District was that mapping was only about 60 to $80 \%$ accurate. 


\section{Appendix D: Management Survey}

21. On a Forest/BLM District-wide basis, how do you feel about the reliabliity of data used to map suitable habitat? (A)

Forest Service:

Respondents on one Forest in Region 5 were comfortable with the data. On the other, the general impression was that some Districts were in good shape, but others were not. Mapping of nonconiferous forest types was a problem mentioned repeatedly. Responses in Region 6 were highly varied. Several Forests reported accuracy in the 70 to $90 \%$ range. Two Forests did not think their data were "very good." Problems mentioned were no data on stand structure in some areas, and difficulty in mapping "marginal" habitat because nobody knew for sure what it is.

Bureau of Land Management:

Responses on all three Districts indicated a general feeling that the data were pretty good, but much opportunity remains for improvement.

22. Who determines whether a proposed timber sale is in sultable habitat? (A)

Forest Service:

With the exception of one District on one Forest, all Forests reported that District Biologists make this call, but most respondents also emphasized that the Biologist is a member of an interdisciplinary team, and that all assessments are reviewed and approved by the team. In other words, the approach is interdisciplinary. The one exception was a District where the Biologist reported, and the Ranger concurred, that the District Ranger determines suitable habitat. This determination is often counter to that made by the District Biologist.

Bureau of Land Management:

All responses indicated that Biologists are making this call. On one District, the Timber Staff assumed that all timber sales were in owl habitat, so this was not an issue.

23. Are you comfortable with the way it's being done? (A)

Forest Service:

Generally the response was "yes," but several Timber Staff voiced the opinion that the response should be more interdisciplinary. The Ranger and Biologists on one District both responded "no." In this case (referred to in response to the previous question), the Ranger and Biologist apparently did not always agree on what should be called owl habitat. 


\section{Appendix D: Management Survey}

\section{Evidence of Alternative Habitats}

\section{Bureau of Land Management}

Biologists generally said "yes," except that one felt that input should be solicited before timber sales were planned, not after. They did not like always being in a reactive mode. Some Timber Staff and Biologists were also a bit uncomfortable with the status quo because Biologists were having to make many judgment calls.

24. How many "good sltes" are being excluded from the network because they do not meet the SEIS or ODFW agreement criterla? ("good" = consistent occupancy and documented reproduction). (estimate o.k.) (C)

A great deal of uncertainty was reported concerning the number of good sites that have been excluded.

Ranger Districts and Resource Area personnel consistently identified proportionately more sites than Forest or District personnel. This discrepancy could be due, in part, to uncertainty about whether sites identified in the past are still capable of supporting spotted owl pairs. Some commented that good sites do occur outside the networks, but they are being impacted by timber sale activities.

One Forest responded that no "good sites" were being excluded, but not all of their SOHAs are occupied with pairs, and good sites are known to exist adjacent to some of these SOHAs.

Biologists reported being unable to determine whether new sites were consistently occupied by reproductive pairs because thorough surveys had not been done before the 1989 field season and no previous data were available.

Some individuals indicated that, if the definition of a good site did not include consistent reproduction (often not adequately determined), additional sites exist outside the network.

25. How many others have been excluded to avold planned timber sales? (C)

Turnover in personnel made this question difficult to answer; therefore, quantified answers were not obtained. Some responded that they were not in place at the time the networks were being planned so could not be sure if this happened. Others commented that they knew of such cases in the early years of establishing network SOHAs. Most responses indicated that, once the distribution pattern or quota for sites was achieved, the network was set. Additional sites known at the time, or sites found since, have often been impacted by planned timber sales because no real direction has been given to avoid them and few options exist to harvest in other areas. Apparently, some sales planned near sites were determined by the agencies to have minimal impacts on spotted owl habitat. Planned sales were generally eliminated as the networks were developed, but sales under contract were not. SOHAs were laid out around the sales under contract. 


\section{Appendix D: Management Survey}

Sales Activity
For the BLM-ODFW sites, planned sales were agreed upon and completed, or will be completed.

26. Does your unit plan to "rotate" the core area or other sultable habitat through even-aged or uneven-aged timber management? (that is, is management of your SOHAs planned?) (A)

\section{Forest Service:}

Of the nine Forests interviewed, only one indicated that SOHAs were to be managed with timber harvest allowed. Two responses indicated that some salvage was planned. A high degree of consistency was found among personnel on the administrative units and between the units on those Forests indicating that SOHAs would be dedicated.

On the Forest where management of SOHAs was planned, confusion existed as to whether plans were in place and whether SOHAs were to be dedicated or managed.

Bureau of Land Management:

BLM-ODFW Agreement Areas are being held in a reserve status; future management plans could change that status. One District Manager indicated that they were planning to "manage" the stands. All other responses indicated that no management was planned.

27. If so (to the above question), explain how you are confldent that this can be accomplished, and provide coples of representative plans showing how you will proceed. (A)

Of those responding that some type of management was planned, primarily on one Forest, only one response indicated that written plans had been completed. No copies of plans were provided. A great deal of hope was expressed that some sorts of management strategies could be developed that would work.

28. In what proportion of your 1989 and 1990 timber sales (within the known geographic distribution of spotted owis) did you find owis when you surveyed the sale area in this or in prior years? (B)

Responses generally indicated a high proportion of timber sales with spotted owls in the vicinity (the average was $60 \%$, median $70 \%$, range 5 to $100 \%$ ). These proportions were similar for both agencies. We detected some confusion as to when owls are in a sale or how close they must be to be considered affected by the sale. Actual estimates varied widely among personnel on the units and between the administrative levels of Forests and BLM Districts. 


\section{Appendix D: Management Survey}

Biologists reported higher occurrences of spotted owls in timber sales than did line officers or timber managers $60 \%$ of the time, and lower occurrences of owls in sales $22 \%$ of the time. Only about $18 \%$ of the estimates agreed. A fair number of respondents ( 7 of 48 ) indicated that they did not know in what proportion of sales spotted owls were found.

Ranger Districts and Resource Areas tended to report higher percentages of timber sales with spotted owls than did Forests or BLM Districts.

29. Of sales without owis, how many times were the sites visited? (B)

Forest Service:

Most responses indicated that at least three visits were made to assess the presence or absence of spotted owls.

Bureau of Land Management:

The BLM respondents indicated no official policy or direction for the number of visits from the State Office, leaving it to the discretion of the Districts. This lack of policy caused considerable variation.

Personnel from both BLM and FS indicated that the field season of 1989 was the first time any concerted effort was made to locate spotted owls in timber sales.

30. How many SOHAs in your unit have planned sales within a 2.1-mile radius of the nest site, center of actlvity, or geometric center in FY90$91 ?$ (B)

This question and question 32 were answered for FY89-90 versus 90-91. Personnel indicated that often sales were not specifically identified for FY91 or FY91 sales had been brought forward to FY90 to meet the timber volume requirements for the Hatfield/Adams Amendment.

Responses to this question varied widely among personnel within and among units. Biologists' estimates were consistently higher than those of Timber Staff or line officers. For respondents who supplied proportions (18 of 58), values ranged from 0 to $100 \%$ with a mean of $53 \%$ and a median of $59 \%$. Nearly $30 \%$ (17 of 58 ) of the respondents did not know how many SOHAs had sales planned within 2.1 miles. 


\section{Appendix D: Management Survey}

31. How many SOHAs are not as contiguous as they could be because of planned timber sales? (B)

Forest Service:

Responses ranged from "none" to "all," and the question did not yield uniformly interpretable responses. Responses within and among units were highly variable, with Biologists indicating more of a problem than Timber Staff or line officers. Variability may have been due in part to differences in tenure on the unit.

Bureau of Land Management:

Most respondents agreed that this has not been a problem. SOHAs were set up under agreements with ODFW, and at that time some were impacted by sales under contract.

32. How many of your non-network pairs will have FY90-91 sales within a 2.1-mile radius of the nest site or center or activity? (B)

(See notation for question 30 ).

Forest Service:

Responses, especially within Forests, were highly variable ranging from "none" to "all." We used the Biologists' responses as most definitive, as they routinely counted from maps; most other responses seemed to be personal estimates. Responses indicated means of about $80 \%$ of the non-network pairs in Region 5 and about $90 \%$ of the non-network pairs in Region 6 have timber sales scheduled within 2.1 miles.

Bureau of Land Management:

We found general agreement among responses from most persons interviewed that sale programs would affect a large proportion of non-network pairs. Biologists' counts from maps indicated that $78 \%$ of non-network pairs will have timber sales within a 2.1 -mile radius.

33. What is your administrative unit's pollcy regarding pairs of spotted owis found outside SOHAs and in proposed timber sales? (A)

Forest Service:

Responses indicated no formal policy. Cases are dealt with individually through the formal Biological Evaluation process. Most individuals indicated that, in the absence of confirmed nesting, the sale will proceed as planned. 


\section{Appendix D: Management Survey}

Bureau of Land Management:

Responses indicate that no clear, written policy exists. Situations are dealt with case by case.

34. What is your administrative unit's policy regarding pairs of spotted owis found outside SOHAs in sales under contract? (A)

Forest Service:

Answers indicated no policy. Little or no adjustment is apparently made in a sale under contract, unless a nest tree is located. Only two actual "buybacks" were cited. Respondents indicated that adjustments (within terms of the contract) were possible in units or sale boundaries, with mutual consent.

Bureau of Land Management:

Responses indicated that no clear policy exists. Most indicated that seasonal restrictions would be implemented to avoid cutting during the nesting season, if nesting was occurring.

35. Is it any different if the pair is nesting? (A)

Forest Service:

Answers reflected confusion about actual policy. Some persons stated that they knew of no policy; others cited a variety of guidelines. The general situation seems to be that the nest tree is saved and an area (differing in size from Forest to Forest) is protected around it for the nesting season. Usually, the area is cut thereafter. The primary concern is to avoid violation of the Migratory Bird Treaty Act.

Bureau of Land Management:

No policy exists. Answers varied and reflected a difference in approach among BLM Districts-either to treat all discoveries of pairs as if a nest existed or to treat nest discoveries differently. Generally, an area around the nest is protected through the nesting season.

Sustained yield (ASQ)
36. Are management considerations for spotted owis constralning your ability to meet timber harvest targets? Or is it the other way around? Are timber harvest targets constraining your ablilty to meet spotted owi management direction as it currently exists? (A)

Forest Service:

The following tabulation summarizes responses from the 52 FS personnel interviewed:

Owls constrain timber harvest

Timber sales constrain management of owls
19

0 


\section{Appendix D: Management Survey}

Both situations are true

Answers too vague or evasive to classify

Several comments indicated frustration over the current situation lacking stable guidelines: "The guidelines are too fluid, so I can't plan." "We have conflicting management direction now."

Although the question did not specifically ask whether current harvest plans (allowable sale quantity, or ASQ) were sustainable over the long term, 20 of 52 respondents volunteered that they were not. These responses were about equally distributed among line officers, Timber Staff, and Biologists.

\section{Bureau of Land Management:}

The following tabulation summarizes responses from the 17 BLM personnel interviewed:

Owls constrain timber harvest

Timber sales constrain management of owls

Both situations are true

Neither situation is true

Answers too vague or evasive to classify

Four of the 17 persons interviewed volunteered that their current harvest rate exceeds sustainable yield. Several expressed a concern that they were being forced to sustain their timber harvest on a more limited land base.

Many persons commented on the current fluidity of management guidelines: "direction hard to pin down," "direction conflicting," "still uncertain what we're doing for owls," "need to know how many owls to protect," "don't know what direction BLM has for the owls," "no clear objectives for owls," "need interim directives."

Monitoring and Inventory
37. How many of your SOHAs are currently being monltored through the regional monitoring program (FS) or the monitoring handbook program (BLM)? (C)

\section{Forest Service:}

Totaled responses indicated that 184 of 438 SOHAs reported by Forests interviewed were being monitored. In general, all Forests in both Regions are apparently monitoring all or nearly all of the SOHAs called for in the monitoring program design.

Bureau of Land Management:

Sixty-eight of 71 agreement areas reported by Districts interviewed are being monitored. 


\section{Appendix D: Management Survey}

38. Is your administrative unit monitoring additional SOHAs above this number or gathering additlonal data? (C)

Of the 22 FS and BLM Biologists responding, 16 indicated that they were monitoring additional SOHAs or gathering additional data.

Additional effort went into surveys of timber sales and monitoring of non-network sites, areas of low occupancy, and random areas.

39. Are monitoring protocols being followed? (C)

Forest Service:

Of the 18 Forest Service responses, all answered "yes."

Bureau of Land Management:

Of six BLM Biologists, three said "yes," and three "no." The number of visits to a site varies (from three to seven, according to responses). The negative $\mathrm{BLM}$ responses were related to inadequate time to complete the maximum number of visits stipulated by protocol.

40. Were you funded in an adequate and timely fashion to accomplish your monltoring, Inventory, and sale survey actlvitles? (A)

Seventy-two persons responded to this question (yes-33; no-39). This was nearly evenly split within the FS (yes-29; no-27), but only $25 \%$ of the BLM units responded "yes" (yes-4; no-12).

Respondents often answered "yes" for monitoring but "no" for inventory or sale surveys. Funding arrived late for many Forests. Many respondents indicated that the rest of the wildlife program suffered because so much effort went into the owl work. Funding was insufficient to cover all costs. The time was often too short to hire and adequately train field personnel.

41. Are staffing levels adequate to complete all facets of spotted owl work required on your unit? (Includes project surveys, monltoring, habltat surveys, SOHA delineation, and verification, etc.) (A)

Sixty-four persons responded to this question (FS: yes-10; no-37) (BLM: yes-4; no-13).

Those who said "yes" were most often line officers or Timber Staff. Some Forest Service and BLM Districts assigned nonbiologists to accomplish spotted owl assignments. 


\section{Appendix D: Management Survey}

Sale Surveys

42. Have you had difficulty hirlng fleld crews for monitoring and project survey work? (A)

Sixty-two persons responded to this question (FS: yes-20; no-25) (BLM: yes-9; no-8).

Problems mentioned were "not enough experienced people are available"; "had to use staff to do sale surveys"; "need more lead time to hire, plan, and train"; and "need more permanent biologists and technicians for consistency."

43. Have all project areas been surveyed for spotted owls to a minimum standard? (A)

Sixty-nine persons responded (FS: yes-46; no-6) (BLM: yes-12; no-5).

Most areas were completed. Projects not surveyed are planned to be done next season.

44. Is so, please explain the standard. (A)

National Forests:

Most people who responded were aware of the three-visit "mini-protocol" for checking occupancy on sale areas. The few who did not know said that visits were done "to protocol" and probably were referring to the Inventory and Monitoring Protocol. Persons so responding, or who responded with "I don't know," were usually Timber Staff.

Bureau of Land Management:

BLM responses varied; most indicated a three-visit minimum. Others responded that one to two visits were minimums.

45. If not, please explain. (A)

Reasons given at the few places where not all sites received three visits were "too many sale areas to check"; "not enough time"; and "got a late start." Not making three visits was mentioned only at the Forest District level, however. 


\section{Appendix D: Management Survey}

46. Are new data about spotted owl locations belng used and evaluated to Improve spotted owl networks (that Is move SOHAs to sltes with better occupancy)? (A)

Thirty-four of 51 respondents answered that new data were being used to improve networks. This belief was pervasive in Forests, but only half the respondents in Districts felt that changes were being made. Adjustments to SOHAs were definitely being made on three of the nine Forests in our sample. One Forest indicated that some changes had been made, but they were a result of conferencing with the Fish and Wildlife Service, not in response to new data.

Contradictions were noted in responses from two Forests. A line officer on one Forest assumed that changes were being made, but this assumption was not supported by staff. In the other, District staff thought some significant changes were in order but would not suggest them because the network was supposedly handled by the Forest. The Forest staff said, however, that some minor changes had been made but that no proposals for change had been received from the District.

In at least two cases, changes were not made because they would require changes in the Land Management Plan (or the interim Plan). In another instance, a line officer thought that with the SEIS completed, they should try to hold things constant and not make changes.

Bureau of Land Management:

Answers were evenly divided among those responding "yes" and "no." District personnel tended to believe changes were being made, but the reverse was true at the Area level. One District felt that no changes were being made because the ODFW sites were fixed by agreement. Several respondents noted a need to make some modifications and hoped this could be accomplished in the next round of planning.

47. If not, please explain. (A)

(Responses included in question 46 above) 


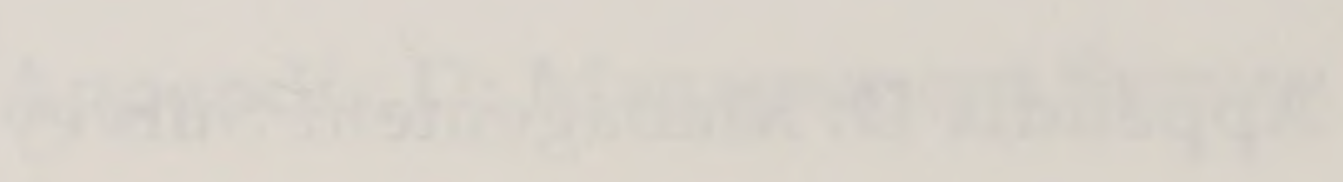




\section{Chronology of Committee Activities}

This appendix documents Committee activities, and identifies the individuals and groups we consulted in the course of this study. The list of abbreviations in the front of the report identifies contributors' affiliations.

\section{1-29 September 1989}

Committee members and their supervisors were contacted and arrangements made for serving on the Committee. Office space was obtained in the Forum Building in Portland. Committee members are named below:

\section{The Interagency Spotted OwI Scientific Committee ${ }^{1}$}

Jack Ward Thomas, Ph.D., Chief Research Wildlife Biologist, USDA Forest Service, La Grande, Oregon

Erlc D. Forsman, Ph.D., Research Wildlife Biologist, USDA Forest Service, Olympia, Washington

Joseph B. LInt, District Wildlife Biologist, USDI Bureau of Land Management, Roseburg, Oregon

E. Charles Meslow, Ph.D., Leader, Oregon Cooperative Wildlife Research Unit, USDI Fish and Wildlife Service, Corvallis, Oregon

Barry R. Noon, Ph.D., Research Wildlife Biologist, USDA Forest Service, Arcata, California

Jared Verner, Ph.D., Chief Research Wildlife Biologist, USDA Forest Service, Fresno, California

\footnotetext{
1 Richard R. Olendorff, Ph.D., Leader, Birds of Prey Research Staff, USDI Bureau of Land Management, Boise, Idaho, was an original member of the Committee. Circumstances precluded his continued service. He was replaced by Joseph B. Lint.
} 


\section{Appendix E: Chronology}

\section{4-6 October}

The Committee met in Portland to plan activities necessary to accomplish its mission. This schedule covered the period 11 October to 20 December, the date set in the charter for comments to the FWS for use in their decision process for whether to list the northern spotted owl as a threatened species pursuant to the Threatened and Endangered Species Act. Observer-advisors and technical support staff were selected. Those persons are named below:

\section{State Observers-Advisors to the Committee}

Charles R. Bruce, Nongame Wildlife Biologist, Oregon Department of Fish and Wildlife, Convallis, Oregon

Gordon I. Gould, Jr., Nongame Wildlife Biologist, California Department of Fish and Game, Sacramento, California

David W. Hays, Nongame Wildlife Biologist, Washington Department of Wildlife Olympia, Washington

Interest Groups-Observer-Advisors to the Committee

Larry L. Irwin, Ph.D., Wildlife Program Leader, National Council for Air and Stream Improvement, Corvallis, Oregon

Dennis D. Murphy, Ph.D., Associate Director, Center for Conservation Biology, Stanford University, Palo Alto, California

David S. Wilcove, Ph.D., Chief Ecologist, The Wilderness Society, Washington, DC.

\section{Technical Staff-Advisors}

Mary Anne Bishop, Ph.D., Research Wildlife Biologist, USDA Forest Service, La Grande, Oregon

A. Grant Gunderson, Wildlife Biologist, Pacific Northwest Regional Office, USDA Forest Service, Portland, Oregon

Douglas B. Houston, Ph.D., Research Biologist, Pacific Northwest Region, National Park Service, Port Angeles, Washington

Bruce G. Marcot, Ph.D., Area Wildlife Ecologist, USDA Forest Service, Portland, Oregon

Barry S. Muider, Coordinator for the Spotted OwI Program, U.S. Fish and Wildlife Service, Portland, Oregon 


\section{Appendix E: Chronology}

\section{Administrative Officer}

Nancy F. DeLong, Contracting Specialist, USDA Forest Service, Pendleton, Oregon

\section{Editor}

Martha H. Brookes, Technical Publications Editor, USDA Forest Service, Corvallis, Oregon

Note: Additional contributors are listed at the end of the chronological section.

\section{6-18 October}

This period was taken up by background briefings for the Committee as follows:

Barry Mulder, FWS, Portland, OR. The Endangered Species Act and FWS activities in consideration of listing of the northern spotted owl.

Terri Simon-Jackson, FS, Region 5, San Francisco, CA. Overview of spotted owl management issues in National Forests in California, USDA Forest Service.

Kathy O'Halloran, FS, Region 6, Portland, OR. Spotted owl monitoring and inventory, Pacific Northwest Region, USDA Forest Service.

Terri Simon-Jackson, FS, Region 5, San Francisco, CA. Spotted owl monitoring and inventory, Pacific Southwest Region, USDA Forest Service.

Joe Lint, BLM, Roseburg, OR. Monitoring and inventory of spotted owls on BLM lands.

Joe Lint, BLM, Roseburg, OR. Overview of northern spotted owl habitat management on BLM lands.

Grant Gunderson, FS, Region 6, Portland, OR. Overview of northern spotted owl habitat management on National Forests in the Pacific Northwest Region.

Charles Bruce, ODFW, Corvallis, OR. Activities and recommendations to date of the spotted owl subcommittee of Oregon/Washington Interagency Wildlife Committee.

Russ Peterson and Randy Tweeten, FWS, Portland, OR. Fish and Wildlife Service criteria for evaluating timber sales as related to the overall welfare of the northern spotted owl.

Russ Peterson and Randy Tweeten, FWS, Portland, OR. A Fish and Wildlife Service field office perspective of the spotted owl situation.

David Hays, WDW, Olympia, WA. Overview of the current status of spotted owls in Washington. 


\section{Appendix E: Chronology}

Charles Bruce, ODFW, Corvallis, OR. Overview of the current status of spotted owls in Oregon.

Gordon Gould, CDFG, Sacramento, CA. Overview of the current status of spotted owls in California.

Rick Brown, National Wildlife Federation, Portland, OR. The environmental community's view on the spotted owl management situation.

Larry Imwin, NCASI, Corvallis, OR. The NCASI view of the spotted owl management situation.

Hal Salwasser, FS, Fish and Wildlife, Washington, DC. Development of the Final Supplemental Environmental Impact Statement and the Forest Service Chief's Record of Decision on spotted owl management.

David Hays, WDW, Olympia, WA. Spotted owl monitoring and inventory in Washington.

Charles Bruce, ODFW, Corvallis, OR. Spotted owl monitoring and inventory in Oregon.

Gordon Gould, CDFG, Sacramento, CA. Spotted owl monitoring and inventory in California.

Douglas Houston, NPS, Port Angeles, WA. Spotted owl inventory and the National Park Service perspective on management of spotted owl habitat.

Roger Nesbitt, Office of Solicitor, Portland, OR; Val Black, OGC, Portland, OR; and Ron Swann, Office of Solicitor, Portland, OR. Current legislation and litigation concerning the spotted owl.

\section{9-20 October}

This period was taken up with inspection of spotted owl habitat and research study areas in the Olympic Peninsula, including the Quinault, Soleduck, and Quilcene Ranger Districts, Shelton Cooperative Sustained Yield Unit, and the Department of Natural Resources' Clearwater Block. The I-90 "corridor" within the Mount BakerSnoqualmie National Forest in the Cascades was visited, as well as the Lake Wenatchee and Leavenworth Ranger Districts of the Wenatchee National Forest on the eastside of the Cascades. Participants included:

Heather Murphy, FS, Wenatchee NF, WA

Jeff Lewis, FS, PNW, Olympia, WA

David Rolph, FS, PNW, Olympia, WA 


\section{Appendix E: Chronology}

\section{3-25 October}

This period was devoted to presentations concerning on-going research on the northern spotted owl. Speakers and topics were as follows:

Eric Forsman, FS, PNW, Olympia, WA. Spotted owl research on the Olympic Peninsula-Home-range size, habitat utilization, prey studies.

Gary Miller, OSU, Corvallis, OR. Home-range and habitat use by the spotted owl in the central Oregon Cascades.

Robert Anthony, FWS, Corvallis, OR. Spotted owl prey studies in the Oregon Cascades.

E. Charles Meslow, FWS, Corvallis, OR. Home-range and habitat use of spotted and great horned owls as related to forest fragmentation in Oregon and Washington.

Andrew Carey, FS, PNW, Olympia, WA. Quality of spotted owl habitat in the southern Cascades.

Andrew Carey, FS, PNW, Olympia, WA. Interaction and movement of spotted owls.

Andrew Carey, FS, PNW, Olympia, WA. Home-range and habitat use in the southern Coast Range.

Jared Verner, FS, PSW, Fresno, CA. Spotted owl research in the Sierra Nevada: Home-range size and composition.

Barry Noon, FS, PSW, Arcata, CA. Review of ongoing research in the Klamath Province.

Steve Seff, TAC, Sacramento, CA; Steve Kerns, Pacific Lumber Co., Scotia, CA; Malcom Pious and Chris Rowney, Louisiana-Pacific Corp., Calpella, CA. Occurrence of spotted owls in managed timber stands on private lands in California.

Mark Boyce, Univ. Wyoming, Laramie. Research of the U.S. Forest Service spotted owl viability modeling and an overview of NCASI-sponsored research on metapopulation modeling.

Larry Irwin and Joe Buchanan, NCASI, Corvallis, OR. Review of nest tree (habitat) studies on the Wenatchee National Forest.

Larry Imwin and Joe Buchanan, NCASI, Corvallis, OR. Review of studies of spotted owls in managed forests of southwest Washington.

Alan Franklin, HSU, Arcata, CA. Review of ongoing spotted owl research in Northern California-The Willow Creek Study Area.

R.J. Gutiérrez and Pat Ward, HSU, Arcata, CA. Review of ongoing spotted owl research in northern California, southem California, central California, and Utah. 


\section{Appendix E: Chronology}

Chris Servheen, FWS, Missoula, MT. Grizzly bear recovery planning.

\section{6-29 October}

This period was taken up with on-the-ground inspection of spotted owl habitat in coastal and interior northern California at the invitation of the Timber Association of California. Coastal redwood forests on private timber-company lands south and east of Arcata were visited, as well as mixed-conifer interior forest lands north of Redding near Dunsmuir and Hilt. For comparison, tours were conducted through an FS study area for the California spotted owl subspecies in the Sierra National Forest east of Fresno. Participants included:

Steve Avery, FS, PSW, Fresno, CA Lowell Diller, Frostburg State University/Simpson Timber Co., Korbel, CA Bill Houston, Simpson Timber Co., Korbel, CA Steve Kerns, Pacific Lumber Co., Scotia, CA Ed Murphy, Sierra Pacific Industries, Redding, CA Don Neal, FS, PSW, Fresno, CA Tom Nelson, Sierra Pacific Industries, Redding, CA Malcom Pious, Louisiana-Pacific Co., Calpella, CA Steve Self, Timber Association of California, Sacramento, CA George Steger, FS, PSW, Fresno, CA Grace Terrazas, FS, Sierra NF, Fresno, CA Scott Warner, Sierra Pacific Industries, Redding, CA Jeff Webster, Fruit Growers Supply Co., Hilt, CA

\section{October-3 November and 6-10 November}

In Oregon, Washington, and California, 17 National Forests and 6 BLM Districts (roughly equivalent to a National Forest) provide habitat for the northern spotted owl. Nine National Forests and one Ranger District within each of these Forests were randomly selected for study on the status of spotted owl management and survey efforts. Three BLM Districts and one Area (roughly equivalent to a Ranger District in a National Forest) in each District were likewise selected. Interviews were conducted with the Forest Supervisors and District Managers, the Timber Management Officers, the Wildlife Biologists, and the District Rangers or Area Managers on various aspects of spotted owl management activities. These interviews were aimed at disclosing the quality and consistency of management efforts. Each Forest or BLM District was visited for 2 to 3 days by a Committee member and advisor. 


\section{Appendix E: Chronology}

\section{November}

The following people continued with the briefing the Committee:

Harriet Allen, WDW, Olympia, WA. Spotted owl research and status in Washington.

Tom Hamer, FS, PNW, Olympia, WA. The cooperative study on barred owls and spotted owls in the Washington Cascades.

Michael Lennartz, FS, Clemson, SC. Development of the red-cockaded woodpecker conservation plan.

\section{November}

Portland workshop on alternative silvicultural systems. Presenters included:

Mike Amaranthus, FS, Siskiyou NF, OR. Salvaging the ecosystem after the 1987 fires.

Dean DeBell, FS, PNW, Olympia, WA. Alternative silviculture on Washington Department of Natural Resource lands.

Jerry Franklin, FS, PNW; UW, Seattle, WA. Perspectives and directions.

Bob Lewis, BLM, Medford District. Modeling old-growth management regimes.

Peter Morrison, Wilderness Society, Seattle, WA. Results of old-growth forest inventory.

Chadwick Oliver, UW, Seattle, WA. Perspectives and directions.

David Perry, OSU, Corvallis, OR. Climate change and forest stability considerations.

Karel Stoscek, UI, Moscow, ID. Alternative silviculture in the interior west.

John Tappeiner II, OSU, Corvallis, OR. Experiments on the OSU School Forest. Jared Verner, FS, PSW, Fresno, CA. Spotted owl habitat perspectives. 


\section{Appendix E: Chronology}

\section{November}

Group discussion workshop on technically feasible silvicultural alternatives that may produce spotted owl habitat. Participants included:

Phil Aune, FS, PNW, Redding, CA

Dean DeBell, FS, PNW, Olympia, WA

Jerry Franklin, UW/FS, PNW, Seattle, WA

Alex Goedhard, Weyerhaeuser Company, Centralia, WA

Miles Hemstrom, FS, Willamette NF, OR

Ross Johnson, CDF, Sacramento, CA

Logan Jones, ODF, Salem, OR

Wendall Jones, FS, Region 6, Portland, OR

Walt Knapp, FS, Region 6, Portland, OR

Bob Lewis, BLM, Medford District, OR

Bob Metzger, BLM, Portland, OR

Tom Nelson, Sierra Pacific Industries, Redding, CA

Tom Spies, FS, PNW, Corvallis, OR

John Tappeiner II, OSU, Corvallis, OR

\section{November}

Presentations continued with the following speakers:

Dan Doak, UW, Seattle, WA. Population modeling.

Peter Morrison, Wilderness Society, Seattle, WA. Old-growth mapping on National Forests.

Charles Sisco, National Audubon Society, Olympia, WA. Old-growth mapping on National Forests.

\section{1-3 December}

This period was taken up with on-the-ground inspection of spotted owl habitat and research areas near the H.J. Andrews Experimental Forest and the BLM Eugene District McKenzie Resource Area plus private lands in the central Oregon Cascades, the Coast Range Province study areas of the Eugene and Roseburg BLM Districts, and the Klamath Province study area on the Medford District BLM. Participants included:

Richard Bonn, BLM, Medford, OR

Ray Bosch, BLM, Eugene, OR

Robin Bown, BLM, Roseburg, OR

Larry Irwin, NCASI, Corvallis, OR

Lee Lauritzen, BLM, Eugene, OR

Gary Miller, OSU, OCWRU, Corvallis, OR

Greg Miller, BLM, Eugene, OR

Frank Oliver, BLM, Roseburg, OR

Janice Reid, FS, PNW, Roseburg, OR 


\section{Appendix E: Chronology}

Gail Schaefer, BLM, Roseburg, OR

Steve Speich, NCASI, Corvallis, OR

James Sweeney, Amer. For. Res. Alliance, Washington, DC

Charles Thomas, BLM, Eugene, OR

Jim Thrailkill, OSU, OCWRU, Corvallis, OR

Frank Wagner, OSU, OCWRU, Corvallis, OR

\section{4-20 December}

Comments were compiled and submitted to the FWS on their proposed rule to list the northern spotted owl as "threatened" under the Endangered Species Act.

\section{December-18 January 1990}

Committee continued data analysis and writing of conservation plan.

19 January

Briefing of the Committee by members of the Northwest Forest Resources Council including:

John Hampton, Willamina, OR

Dennis Hayward, Eugene, OR

Ross Mickey, Eugene, OR

Mark Rutzick, Portland, OR

Ralph Saperstein, Portland, OR

\section{2-23 January}

Agency biologists from the Forest Service and BLM from California, Oregon, and Washington were invited to a Portland workshop on spotted owl conservation. The group provided appraisals of management options and opportunities within their respective States and work areas. Attendees included:

Bea Anderson, FS, Mendocino NF, CA

Norm Barrett, FS, Willamette NF, OR

Jim Bottorff, FWS, Portland, OR

Don DeLorenzo, FS, Region 5, San Francisco, CA

Phil Detrich, FWS, Sacramento, CA

Tony Hacking, FS, Klamath NF, CA

Jim Harper, BLM, Medford, OR

Barbara Hill, FS, Gifford Pinchot NF, WA

Wayne Logan, BLM, Salem, OR

Jeff Mattison, FS, Six Rivers NF, CA

Jim Michaels, FWS, Olympia, WA

Bill Neitro, BLM, Oregon State Office, Portland, OR

Rick Newton, FS, Mount Hood NF, OR

Kathy O'Halloran, FS, Region 6, Portland, OR

Frank Oliver, BLM, Roseburg, OR

A. Sonny Paz, FS, Mount Baker-Snoqualmie NF, WA 
Karen Raftery, FS, Klamath NF, CA Jo Richards, FS, Wenatchee NF, WA Lynn Roberts, FS, Six Rivers NF, CA Terri Simon-Jackson, FS, Region 5, San Francisco, CA Steve Spangle, FWS, Sacramento, CA Dede Steele, FS, Willamette NF, OR Marilyn Stoll, FS, Olympia, WA Charles Thomas, BLM, Eugene, OR Lee Webb, FS, Siskiyou NF, OR

\section{4-25 January}

Many Committee members and advisors attended the Forest Service/Spotted Owl Research and Development meeting in Portland. Results of research and monitoring of all three subspecies were reviewed. Attendees included:

Jim Baldwin, FS, PSW, Berkeley, CA

Tom Beebe, FS, Wenatchee NF, WA

Charles Bruce, ODFW, Corvallis, OR

Andy Carey, FS, PNW, Olympia, WA

Robert Crabtree, UI, Moscow, ID

Don DeLorenzo, FS, Region 5, San Francisco, CA

Ken Dixon, WDW, Olympia, WA

Leon Fisher, FS, Region 3, Albuquerque, NM

Keith Fletcher, FS, Region 3, Albuquerque, NM

Eric Forsman, FS, PNW, Olympia, WA

Chris Foster, FS, PNW, Olympia, WA

Alan Franklin, HSU, Arcata, CA

Gordon Gould, CDFG, Sacramento, CA

Grant Gunderson, FS, Region 6, Portland, OR

Tom Hamer, FS, PNW, Olympia, WA

Eric Hansen, Yakima Indian Nation, WLF, Toppenish, WA

David Hays, WDW, Olympia, WA

Scott Horton, FS, PNW, Olympia, WA

Larry Irwin, NCASI, Corvallis, OR

Fred LeBan, UI, Moscow, ID

Jeff Lewis, FS, PNW, Olympia, WA

Joe Lint, BLM, Roseburg, OR

Sandra Martin, FS, PNW, Wenatchee, WA

Garland Mason, FS, PSW, Berkeley, CA

Tim Max, FS, PNW, Portland, OR

Charles Meslow, FWS, OCWRU, Corvallis, OR

Joe Meyer, UW, McKinleyville, CA

Gary Miller, OSU, OCWRU, Corvallis, OR

Barry Mulder, FWS, Portland, OR

Bill Neitro, BLM, Portland, OR

Barry Noon, FS, PSW, Arcata, CA

Kathy O'Halloran, FS, Region 6, Portland, OR

Kevin Peeler, FS, PNW, Olympia, WA 


\section{Appendix E: Chronology}

Martin Raphael, FS, PNW, Olympia, WA

Keith Severson, FS, RMS, Tempe, AZ

Terri Simon-Jackson, FS, Region 5, San Francisco, CA

Steve Spangle, FWS, Sacramento, CA

Nancy Tilghman, FS, FER, Washington, DC

Jared Verner, FS, PSW, Fresno, CA

Ed F. Wicker, FS, RMS, Fort Collins, CO

Cindy Zabel, FS, PSW, Arcata, CA

\section{January}

Jack Thomas and Kent Mays met with an interagency group in Sacramento to discuss ongoing Committee activities and to solicit advice on spotted owl management in northern California. Attendees included:

Dean Cromwell, CBF

Robert Ewing, CDF

Gordon Gould, CDFG

Harley Greiman, FS, Region 5

Dave Harlow, FWS Region 1

David Jay, FS, Region 5

Jon Kennedy, FS, Region 5

Robert Motroni, CDF

Kent Smith, CDFG

Steve Spangle, FWS Region 1

Christine Sproul, Counsel, CRA

\section{3-4 February}

Meeting with leading conservation biologists to discuss alternative conservation strategies. Attendees included:

Mark Boyce, University of Wyoming, Laramie, WY

R.J. Gutiérrez, Humboldt State University, Arcata, CA

Hal Salwasser, FS, Washington, DC

Daniel Simberloff, Florida State University, Gainesville, FL

Michael Soulé, University of California, Santa Cruz, CA

Tom Spies, FS, PNW Research Station, Corvallis, OR

Dean Urban, University of Virginia, Charlottesville, VA

John Wiens, Colorado State University, Fort Collins, CO 


\section{Appendix E: Chronology}

\section{8, 15-16 February}

Work with silvicultural alternatives group in Portland led to preparation of Appendix S-Silvicultural Experiments for Habitat Management.

Dean DeBell, FS, PNW, Olympia, WA

David Hays, WDW, Olympia, WA

Walt Knapp, FS, Region 6, Portland, OR

Chadwick Oliver, UW, Seattle, WA

John Tappeiner II, OSU, Corvallis, OR

\section{February}

Thomas met with the Interagency Spotted Owl Committee representatives from R5 and R6 FS, State wildlife directors from California, Oregon, and Washington, BLM, and National Park Service. The group was briefed on the progress of the Scientific Committee. Attendees included:

Ed Allen, FS, Portland, OR

D. Dean Bibles, BLM, Portland, OR

Hugh Black, FS, Portland, OR

John Butruille, FS, Region 6, Portland, OR

Mike Crouse, BLM, Portland, OR

John Fay, FWS, Washington, DC

Randy Fisher, ODFW, Portland, OR

Dave Harlow, FWS, Sacramento, CA

Richard Johnson, BLM, Sacramento, CA

Catherine Kennard, CRA, Sacramento, CA

Mietek Kolipinski, NPS, Sacramento, CA

Bill Martin, FWS, Portland, OR

Kent Mays, FS, PNW, Portland, OR

Charles Odegaard, NPS, Seattle, WA

Charlie Philpot, FS, PNW, Portland, OR

Marvin Plenert, FWS, Portland, OR

Ed Shepard, BLM, Washington, DC

Curt Smitch, WDW, Olympia, WA

Kent Smith, CDFG, Sacramento, CA

Robert P. Smith, FWS, Portland, OR

Elaine Zielinski, BLM, Portland, OR

\section{February}

Research meeting with forest-industry group concerning planned research on private land in northern California. Attendees included:

Larry Irwin, NCASI, Corvallis, OR

Ross Mickey, Northwest Timber Association, Eugene, OR

Tom Nelson, Sierra Pacific Industries, Redding, CA

Tharon O'Dell, Simpson Timber Co., Korbel, CA

Malcom Pious, Louisiana Pacific, Calpella, CA 


\section{Appendix E: Chronology}

\section{2-16 March}

Draft of conservation plan was completed and submitted for peer review to scientists selected by scientific or professional societies:

American Ornithologists' Union

Russell Lande, Ph.D.

Department of Ecology \& Evolution

University of Chicago

Chicago, IL

Ecological Society of America

John Weins, Ph.D.

Department of Biology

Colorado State University

Fort Collins, CO

Society for Conservation Biology

Michael Gilpin, Ph.D.

Department of Biology

University of California, San Diego

La Jolla, CA

Society of American Foresters

W. H. Lawrence, Ph.D.

905 Spring Lane

Centralia, WA

The Wildife Society

Larry Harris, Ph.D.

Department of Wildlife \& Range Sciences,

University of Florida

Gainesville, FL

\section{March}

The agency directors were briefed in Portland, OR, on the content of the draft plan.

\section{March}

Wildlife biologists from BLM Districts in Oregon were invited to provide information on options under consideration for the final conservation plan.

Ray Bosch, BLM, Eugene, OR

Robin Bown, BLM Roseburg, OR

Ralph Culbertson, BLM, Coos Bay, OR

Jim Harper, BLM, Medford, OR

Bill Hudson, BLM, Coos Bay, OR

Carole Jorgensen, BLM, Eugene, OR

Wayne Logan, BLM, Salem, OR 


\section{Appendix E: Chronology}

Larry Mangan, BLM, Coos Bay, OR

Greg Miller, BLM, Eugene, OR

Jerry Mires, BLM, Roseburg, OR

Frank Oliver, BLM, Roseburg, OR

Gayle Sitter, BLM, Klamath Falls, OR

Charles Thomas, BLM, Eugene, OR

Joe Witt, BLM, Roseburg, OR

1st Week in April 1990

Final report completed.

Additional Contributors to This Report

Name

Edie Asrow

Bruce Bingham

Ray Bosch

Robin Bown

Mark Brown

Don DeLorenzo

Phil Dietrich

Chris Foster

Mike Gertsh

Rob Horn

Nancy Hutchins

Rolland Lamberson,

Jeff Lewis

Jeff Mattison

Kevin McKelvey

Kim Mellen

Gary Miller

Linda Mullens

Peter Paton

Ann Potter

Karen Raftery

Janice Reid

Howard Sakai

Steve Spangle

Amy Strine

Randy Tweeten

Curt Voss

Dale Weyermann
Agency/work unit

FS, Klamath NF, Yreka, CA

FS, PSW, Arcata, CA

BLM, Eugene District, OR

BLM, Roseburg District, OR

OSU, OCWRU, Corvallis, OR

FS, R-5, San Francisco, CA

FWS, Sacramento, CA

FS, PNW, Olympia, WA

FS, Shasta-Trinity NF, Redding, CA

FS, PNW, Roseburg, OR

FS, Shasta-Trinity NF, Redding, CA

Dept. Math, HSU, Arcata, CA

FS, PNW, Olympia, WA

FS, Six Rivers NF, Eureka, CA

FS, PSW, Arcata, CA

FS, Siskiyou NF, Powers, OR

OSU, OCWRU, Corvallis, OR

FS, Siskiyou NF, Grants Pass, OR

FS, PSW, Arcata, CA

WDW, Olympia, WA

FS, Klamath NF, Yreka, CA

FS, PNW, Roseburg, OR

FS, PSW, Arcata, CA

FWS, Sacramento, CA

BLM contractor, Caldwell, ID

FWS, Portland, OR

FS, PSW, Arcata, CA

FS, PNW, Portland, OR

\section{Office Staff}

Susan Barr
Lillie Battie
Julie Beaver
FS, R-6, Portland, OR

FS, PNW, Portland, OR

FS, R-6, Portland, OR 


\section{Appendix E: Chronology}

Alexis Chaffee Andrea Edwards Florissa Fuentes

Tonya Henderson Maria Merrian

Ruth Ann Nicklin Deanna Rae

Catherine Smith

Zoe Spriet

Michelle Volk

Erma White

Mary Ann Witherow

\section{Editoriai Staff}

\section{Denise Clement Karen Esterholdt Max Geier Cliff McClellan William R. Meehan Robin Peterson Delbert E. Thompson Kelly Wenzlick Carolyn Wilson}

\section{Media Design Staff}

Kathy Bowman Dianne Harris Gail Saunders Steve Sichau
FS, PNW, Portland, OR

FS, R-6, Portland, OR

FS, PNW, Portland, OR

FS, R-6, Portland, OR

Snelling Temporaries, Portland, OR

FS, PNW, Portland, OR

FS, Wallowa-Whitman NF, Baker City, OR

FS, PNW, Portland, OR

FS, Wallowa-Whitman NF, Baker City, OR

FS, R-6, Portland, OR

FS, R-6, Portland, OR

FS, PNW, Portland, OR

Edit. Asst., FS, PNW, Portland, OR

Group Leader FS, PNW, Portland, OR

Editor, Lebanon, OR

BLM Printer, Portland, OR

Edit. Asst., FS, PNW, Juneau, AK

Edit. Asst., Portland, OR

Art Dir., FS, PNW, Portland, OR

Edit. Asst., FS, PNW, Portland, OR

Edit. Asst., FS, PNW, Portland, OR

FS, R-6, Portland, OR

FS, R-6, Portland, OR

FS, R-6, Portland, OR

FS, R-6, Portland, OR 


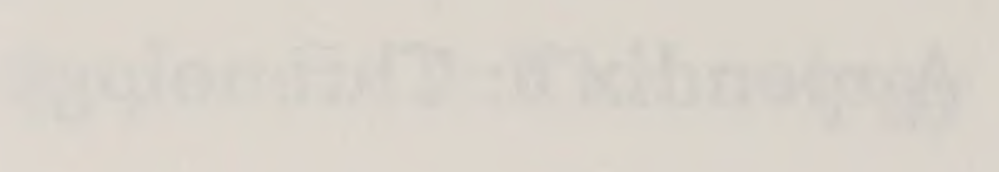




\section{Characterization of Spotted Owl Habitats in Washington, Oregon, and Northern, California}

Introduction

Habltat Quality
In this appendix, we characterize spotted owl habitat as reported in many different studies of habitat that spotted owls use for foraging, roosting, and nesting. Although we cannot "define" their habitat, we can describe the attributes of forest stands that spotted owls use. To set some ground rules, we first explain terminology used to describe various qualitative states of owl habitat and explore the question of habitat "need."

Discussions of an organism's habitat usually include assessments of its relative "value" or "suitability." For any species, habitat suitability for various life functionsbreeding, feeding, and cover-is not identical in all possible habitats. Suitability of different types of habitat can be graded from excellent to poor, which means that habitat suitability values tend to be continuous as opposed to discrete. Partitioning of habitats into categories, however, facilitates discussion. For the purposes of this report, we follow the traditional approach of evaluating habitat quality based on use versus availability of different types of habitat. Habitats selected in excess of availability by the majority of owls were considered to be suitable for classification as superior habitat. Superior habitat may be optimum, meaning that it is the best possible for the organism. We can never know whether better habitat exists elsewhere for a species, however, so we reject "optimum habitat" as potentially misleading.

Habitats that were seldom used in excess of availability, were used in proportion to availability by many individuals, and were used less than expected by many others are considered marginal. Marginal habitat at the upper end of the scale may be adequate for all life-history needs of a species, but marginal habitat at the lower end may be unsuitable for most or all of its life-history needs. This does not mean that marginal habitats are unimportant to a given species. They may be vital for maintaining a reservoir of individuals (floaters, see appendix $O$ ) that can replace others lost from suitable or superior habitats. They may also contain scarce habitat elements critical to the species, but used infrequently enough that measures of "use" provide poor indices of their importance. Furthermore, in areas with an amount of superior and suitable habitat slightly less than an organism typically requires, availability of additional marginal habitats may tip the balance in favor of successful occupancy or even occasional breeding. This property of "marginal" habitats means that caution must be used when interpreting their significance to a species. 


\section{Appendix F: Habitat}

Habitat Need

Habitats that were selected less than expected by the majority of owls were considered to be poor in quality, or unsuitable habitat. Over the long term, unsuitable habitat typically fails to provide the needs of a species, either for breeding, feeding, or cover. Unsuitable habitat is normally unoccupied; breeding occurs infrequently there and is typically unsuccessful. Even survival by single individuals is tenuous. We realize that organisms sometimes turn up in strange places, especially if they are capable of long-distance movements-usually flying species such as insects, birds, and bats. But the significance of these events lies in the mobility of the species, not in the capacity of the habitat to support them.

For analyses of habitat suitability, an important consideration is the relative proportion of available locations or amounts of time spent in the different habitats. Those habitats that consistently account for the greatest proportion of use should be considered at least adequate, even if they are not used in excess of availability.

The issue of habitat "need" commonly arises in developing a strategy for conservation of a species. Discussion here is largely appropriated from the excellent summary of this issue by Ruggiero et al. (1988). Wildlife biologists who provide information to aid management decisions are often challenged to distinguish between what a species uses and prefers, and what it must have. We contend, however, that the full range of a species' needs cannot be determined-that it is generally unknowable and unresearchable. Instead, we have adopted the following operational approach in dealing with the ecological dependency of spotted owls:

When patterns of a species' abundance and distribution show a consistent, close association with a particuiar type or types of habitat, we assume that the habitat is essential for the species' persistence. We contend that habitat selection is a behavior that reflects the longterm needs of a given species, and that it has so evolved over thousands of years of varying environmental conditions as a resuit of natural selection. Consequently, preference for a given habitat or habitat attribute ilkely indicates a need.

We believe this is the only tenable position, for several reasons. First, unequivocal determination of whether habitat use or preference reflects the true "needs" of a species could be settled only by experimentation, which we consider unfeasible. An experiment to test a state of habitat dependency must consider responses of populations rather than individuals. The occasional occurrence of breeding by even one pair or a few individuals in a given habitat must be weighed against the preponderance of occurrence and breeding in another. To manage a species on the assumption that exceptional behavior is the norm would be imprudent.

An experiment on habitat dependency must deal with long-term persistence as well as short-term existence. Habitat that can sustain a population in the short term may be inadequate in the face of, say, a 50-year drought (the eventual occurrence of which is virtually certain). 


\section{Appendix F: Habitat}

Because of lag effects, especially for species such as the spotted owl that have a long life span, certain processes leading to extinction may not be expressed in experimental results for decades. Meanwhile, habitat conditions could deteriorate to the point that some critical threshold is passed and the extinction of the species is assured.

Experimental verification of the ecological dependency of spotted owls would entail the potential sacrifice of a large portion of the population. Replication of the experiment could jeopardize the population. This option is unacceptable for a species whose very persistence is in question. Unplanned, large-scale experiments are in progress in forested landscapes, as logging reduces the amount of remaining habitat. By taking advantage of these uncontrolled experiments, we may learn something about the effects of habitat loss on spotted owls.

Although we do not believe that experimentation can tell us the precise kinds, amounts, and configurations of habitat that would meet minimum population needs, we do believe that research and experimentation can provide us with much better information than is currently available on habitat needs of spotted owls. That information will allow us to determine a range of habitats within which we can continue to meet the species' needs.

\section{Methods}

In Washington and Oregon, northern spotted owls occur in a variety of forest zones including western hemlock, white fir, Pacific silver fir, Sitka spruce, mixed-evergreen, mixed-conifer, and coastal redwoods. In northern California, the birds find suitable habitats in a variety of forest zones: Douglas-fir, often with a hardwood component; redwood/Douglas-fir; redwood, often with a hardwood component; Douglas-fir/white fir; mixed-evergreen (tanoak, Pacific madrone, Douglas-fir); and mixed-conifer.

Within these zones, habitat used by the owls can be described at three scales: stand structure, stand condition, and landscape. Stand structure is based on quantitative measurements of vegetative plots centered at or around a roost, foraging, or nest location. Information on stand structure usually includes canopy closure, size and abundance (basal area and density) by tree species, and ground cover. Stand condition is a broad seral-stage classification based on such factors as tree age and d.b.h., and canopy closure. At the landscape scale, habitat use is described in several ways, including the proportions of habitat types within a home range compared to the general landscape, and through indices of habitat fragmentation.

Although numerous spotted owl surveys demonstrate associations with stand or landscape conditions (for example, Forsman et al. 1987, Hays et al. 1989a, Inwin et al. 1989b, Pious 1989), they do not provide information on habitat use and selection by stand structure. Nighttime response locations are often estimated from owls calling a considerable distance from the observer (Hays et al. 1989a). Spotted owls will also travel as far as $3 / 4$ of a mile to respond to taped calls. In addition, although recorded and oral calls may elicit a response from territorial owls defending a nest site, nonbreeders or birds outside their defended territories may not respond (Mills et al. 1989). 


\section{Appendix F: Habitat}

For the above reasons, the following information on habitat use is primarily based on studies that examined stand structure and stand conditions in areas known to be used by owls. Use and selection of foraging and roosting habitat were determined from locations of radio-marked owls. Use of nesting habitat was determined from nest sites of radio-marked, banded, and unbanded owls.

In all of the radio-telemetry studies that we examined, the spotted owl's habitat use was described in terms of stand conditions, which were usually determined by a combination of photo interpretation; inventory records of BLM, FS, or both; Landsat imagery; and ground reconnaissance. Stands were typically classified as old growth, mature or large sawtimber, young or pole/medium, and pole/sapling or shrub/forb/ sapling.

With the exception of old growth, definitions for stand conditions varied widely among studies (table F1). Old growth was usually defined as a dominant overstory $>200$ years old, with a multilayered, multispecies canopy, relatively high canopy closure, and large numbers of snags and logs. Definitions of old-growth d.b.h. sizes for dominant trees ranged from $>30$ to $>39$ inches, and for two studies in Washington (Allen et al. 1989, Hays et al. 1989b) required codominant trees $>16$ inches in d.b.h. Definitions of stands designated as mature or large sawtimber typically included an evenaged stand with a minimum age of dominant trees ranging from $>70$ to $>100$ years, and minimum d.b.h. ranging from 16 to 21 inches.

Table F1-Deflnitlons of stand conditions In varlous studles used to complle tables F2, F3, F4, F5, and F9

\begin{tabular}{|c|c|c|}
\hline Study & Condition & Definition \\
\hline $\begin{array}{l}\text { Sisco and } \\
\text { Gutiérrez 1984; } \\
\text { Solis } 1983\end{array}$ & $\begin{array}{l}\text { Old-growth/ } \\
\text { mature } \\
\text { Pole/medium } \\
\text { Brush/seedling/ } \\
\text { sapling } \\
\text { Grass/forb }\end{array}$ & $\begin{array}{l}\text { Mixture of old-growth trees }>200 \text { years } \\
\text { old, }>35 \text { inches in d.b.h.; mature trees } \\
>70 \text { years old, }>21 \text { inches in d.b.h. } \\
\text { Trees } 15 \text { to } 70 \text { years old, } 5 \text { to } 20 \text { inches } \\
\text { in d.b.h. } \\
\text { Trees } 0 \text { to } 15 \text { years old, }<5 \text { inches } \\
\text { in d.b.h. }\end{array}$ \\
\hline $\begin{array}{l}\text { Forsman et al. } \\
1984\end{array}$ & $\begin{array}{l}\text { Old-growth } \\
\text { Mature } \\
\text { "Young" in the } \\
\text { Cascades } \\
\text { "Young" in the } \\
\text { central Coast } \\
\text { Range } \\
\text { "Sapling" in } \\
\text { the Cascades }\end{array}$ & $\begin{array}{l}\text { Trees }>200 \text { years old, }>39 \text { inches in } \\
\text { d.b.h.; multilayered stands; unlogged } \\
\text { Trees } 81 \text { to } 200 \text { years old, } 15.7 \text { to } 51 \\
\text { inches in d.b.h.; unlogged } \\
\text { Trees } 61 \text { to } 80 \text { years old, } 10 \text { to } 29.5 \\
\text { inches in d.b.h.; unlogged } \\
\text { Trees } 31 \text { to } 60 \text { years old, } 8 \text { to } 24 \text { inches } \\
\text { in d.b.h. } \\
\text { Trees } 61 \text { to } 80 \text { years old, } 10 \text { to } 29.5 \\
\text { inches in d.b.h.; unlogged } \\
\text { Trees } 36 \text { to } 60 \text { years old, } 8 \text { to } 24 \text { inches } \\
\text { in d.b.h. } \\
\text { Trees } 21 \text { to } 30 \text { years old, } 4 \text { to } 7.9 \text { inches } \\
\text { in d.b.h. } \\
\text { Trees } 5 \text { to } 20 \text { years old }\end{array}$ \\
\hline
\end{tabular}




\section{Appendix F: Habitat}

Table F1-continued

\begin{tabular}{|c|c|c|}
\hline Study & Condition & Definition \\
\hline & $\begin{array}{l}\text { "Sapling" in } \\
\text { the central } \\
\text { Coast Range } \\
\text { Clearcut }\end{array}$ & $\begin{array}{l}\text { Trees } 25 \text { to } 35 \text { years old, } 4 \text { to } 7.9 \text { inches } \\
\text { in d.b.h. } \\
\text { Trees } 5 \text { to } 24 \text { years old } \\
\text { Overgrown with shrubs, or grass/forb }\end{array}$ \\
\hline \multirow[t]{5}{*}{$\begin{array}{l}\text { Allen et al. } \\
1989\end{array}$} & Old growth & $\begin{array}{l}\text { Trees }>30 \text { inches in d.b.h.; codominants } \\
>16 \text { inches in d.b.h.; multilayered }\end{array}$ \\
\hline & Large sawtimber & $\begin{array}{l}\text { Trees in canopy } 20 \text { to } 31 \text { inches in d.b.h.; } \\
\text { few canopy layers }\end{array}$ \\
\hline & $\begin{array}{l}\text { Small sawtimber } \\
\text { Pole }\end{array}$ & $\begin{array}{l}\text { Trees } 14 \text { to } 20 \text { inches in d.b.h. } \\
\text { Trees } 6 \text { to } 14 \text { inches in d.b.h. }\end{array}$ \\
\hline & & $\begin{array}{l}\text { Canopy cover } 40 \text { to } 60 \% \text {; variety of tree } \\
\text { sizes }\end{array}$ \\
\hline & Other & $\begin{array}{l}\text { Shrub/forb/sapling; shrub/forb/ grass; } \\
\text { rock/barren; water; snow/shadow }\end{array}$ \\
\hline \multirow[t]{5}{*}{$\begin{array}{l}\text { Hays et al. } \\
1989 \mathrm{~b}\end{array}$} & Old growth & $\begin{array}{l}\text { Trees }>32 \text { inches in d.b.h.; codominants } \\
>16 \text { inches in d.b.h.; multilayered }\end{array}$ \\
\hline & Large sawtimber & $\begin{array}{l}\text { Trees } 20 \text { to } 34 \text { inches in d.b.h.; few } \\
\text { canopy layers }\end{array}$ \\
\hline & $\begin{array}{l}\text { Small sawtimber } \\
\text { Pole }\end{array}$ & $\begin{array}{l}\text { Trees } 13 \text { to } 20 \text { inches in d.b.h. } \\
\text { Trees } 6 \text { to } 13 \text { inches in d.b.h. }\end{array}$ \\
\hline & Open canopy & $\begin{array}{l}\text { Canopy cover } 40 \text { to } 60 \% \text {; variety of tree } \\
\text { sizes }\end{array}$ \\
\hline & Other & $\begin{array}{l}\text { Shrub/sapling; grass/forb; rock; water; } \\
\text { snowfield }\end{array}$ \\
\hline \multirow[t]{3}{*}{$\begin{array}{l}\text { Miller and Meslow } \\
1989\end{array}$} & Old growth & $\begin{array}{l}\text { Douglas-firs }>32 \text { inches in d.b.h., }>200 \\
\text { years old; multilayered }\end{array}$ \\
\hline & Mature & $\begin{array}{l}\text { Trees }>21 \text { inches in d.b.h., but not } \\
\text { old growth }\end{array}$ \\
\hline & <Mature & All other stands including clearcuts \\
\hline \multirow{6}{*}{$\begin{array}{l}\text { Thrailkill and } \\
\text { Meslow 1989; } \\
\text { Thrailkill and } \\
\text { Meslow } 1990\end{array}$} & Old growth & $\begin{array}{l}\text { Trees }>34 \text { inches in d.b.h., }>200 \text { years } \\
\text { old, more than two canopy layers }\end{array}$ \\
\hline & Mature & $\begin{array}{l}\text { Trees }>21 \text { inches in d.b.h., } 80 \text { to } 199 \\
\text { years old }\end{array}$ \\
\hline & Young & $\begin{array}{l}\text { Trees } 1 \text { to } 21 \text { inches in d.b.h., } 10 \text { to } 79 \\
\text { years old: canopy cover }<60 \%\end{array}$ \\
\hline & Mixed & $\begin{array}{l}\text { Primarily young growth with poorly stocked } \\
\text { mature/old growth in the overstory; } \\
\text { canopy closure variable }\end{array}$ \\
\hline & Clearcut & $\begin{array}{l}\text { Trees } 0 \text { to } 9 \text { years old; shrub canopy } \\
<40 \% \text { or devoid of vegetation; trees }<1 \\
\text { inches in d.b.h. }\end{array}$ \\
\hline & $\begin{array}{l}\text { Hardwood/ } \\
\text { riparian }\end{array}$ & $\begin{array}{l}\text { Dominated by hardwoods along stream or } \\
\text { river; } 50 \text { to } 100 \% \text { canopy cover }\end{array}$ \\
\hline
\end{tabular}




\section{Appendix F: Habitat}

Table F1-continued

\begin{tabular}{|c|c|c|}
\hline Study & Condition & Definition \\
\hline \multirow[t]{6}{*}{$\begin{array}{l}\text { Carey et al. } \\
1990\end{array}$} & Old growth & $\begin{array}{l}\text { Trees }>200 \text { years old, }>39 \text { inches in d.b.h. } \\
\text { multilayered canopy }\end{array}$ \\
\hline & Mature & $\begin{array}{l}\text { Trees } 100 \text { to } 200 \text { years old, } 20 \text { to } 39 \\
\text { inches in d.b.h., even-aged }\end{array}$ \\
\hline & Young & $\begin{array}{l}\text { Trees } 50 \text { to } 100 \text { years old, } 8 \text { to } 19 \text { inches } \\
\text { in d.b.h. }\end{array}$ \\
\hline & Pole/sapling & $\begin{array}{l}\text { Trees }<50 \text { years old, } 1 \text { to } 8 \text { inches in } \\
\text { d.b.h. }\end{array}$ \\
\hline & Mixed ages & $\begin{array}{l}\text { Generally old growth with inclusions of } \\
\text { young or mature stands of }<10 \text { acres }\end{array}$ \\
\hline & $\begin{array}{l}\text { Nonforest } \\
\text { Hardwood } \\
\text { riparian }\end{array}$ & $\begin{array}{l}\text { Grass, forb, shrub, and clearcut } \\
\text { All ages (no further definition) }\end{array}$ \\
\hline \multirow[t]{6}{*}{$\begin{array}{l}\text { Carey, pers. } \\
\text { comm. }\end{array}$} & Old growth & $\begin{array}{l}\text { Trees }>39 \text { inches in d.b.h.; multilayered } \\
\text { canopy }\end{array}$ \\
\hline & Mature & $\begin{array}{l}\text { Trees } 20 \text { to } 39 \text { inches in d.b.h.; even- } \\
\text { aged stands }\end{array}$ \\
\hline & $\begin{array}{l}\text { Young } \\
\text { Pole } \\
\text { Sapling } \\
\text { Mixed old }\end{array}$ & $\begin{array}{l}\text { Trees } 8 \text { to } 19.9 \text { inches in d.b.h. } \\
\text { Trees } 4 \text { to } 7.9 \text { inches in d.b.h. } \\
\text { Trees } 1 \text { to } 3.9 \text { inches in d.b.h. } \\
\text { Old growth with inclusions of young or } \\
\text { mature stands of }<10 \text { acres }\end{array}$ \\
\hline & Mixed young & $\begin{array}{l}\text { Young stands with inclusions of other } \\
\text { seral stages }\end{array}$ \\
\hline & $\begin{array}{l}\text { Hardwood forest } \\
\text { Clearcut }\end{array}$ & Grace forh. chrub \\
\hline & & \\
\hline \multirow[t]{2}{*}{$\begin{array}{l}\text { Bown, pers. } \\
\text { comm. }\end{array}$} & $\begin{array}{l}\text { Old growth } \\
\text { Mature }\end{array}$ & $\begin{array}{l}\text { Trees } 35 \text { inches in d.b.h.; multilayered } \\
\text { Trees } 20 \text { to } 40 \text { inches in d.b.h; relatively } \\
\text { uniform size }\end{array}$ \\
\hline & Young & $\begin{array}{l}\text { Trees } 11 \text { to } 20 \text { inches in d.b.h., some up } \\
\text { to } 30 \text { inches; closed canopy }\end{array}$ \\
\hline
\end{tabular}

Young stands were lumped into one broad category in some studies (Thrailkill and Meslow 1989, Miller and Meslow 1989) or split into several categories (pole/sapling, pole/medium, small sawtimber, and so on) in others (Carey et al. 1990, Forsman et al. 1984, Kerns 1989). In general, all of the above definitions for young stands included dominant trees <19 inches in d.b.h. An exception was that of Kerns (1989), who worked in young stands of redwoods that commonly were up to 40 inches in d.b.h. 
Results of Habitat

Studies in

Washington and Oregon

Characterization of
Habltat Used for
Foraging and Roosting
Ten studies of habitat use by spotted owls have been completed in Oregon and Washington since 1975 (Allen et al. 1989; Carey, pers. comm.; Carey et al. 1990; Egtvedt and Manuwal 1988; Forsman 1980, 1981; Forsman et al. 1984; Hamer et al. 1989; Hays et al. 1989b; Miller and Meslow 1989; Thrailkill and Meslow 1989, 1990). Some of these studies provided separate analyses of foraging and roosting habitat selection. Others combined foraging and roosting locations and analyzed them as one data set. All studies provided information on habitat use related to stand condition.

Results were similar in all studies (tables F2 to F4 for habitat selection). Old growth was the only stand condition that owls consistently used more than expected for foraging and roosting. Among 115 owls radio-tracked in these studies, 97 (84\%) used old-growth forests significantly more than expected, and $18(16 \%)$ used them in proportion to availability. The majority $(65 \%)$ used mature forests in proportion to availability, $21 \%$ used them significantly less than expected, and $14 \%$ used them significantly more than expected. Young forests were used significantly more than expected by only 4 of 115 owls $(3 \%)$, but they were used less than expected by $>50 \%$ of the owls. Clearcuts and very young forest plantations were used very little by any owl studied.

These results suggest that, in general, old-growth forests are superior habitat for spotted owl foraging and roosting in Oregon and Washington. Mature stands are less suitable habitat than old growth, young stands provide marginal habitat, and clearcuts and young plantations (saplings, poles, or both) are unsuitable habitat.

In the only study that provided detailed data on stand structure, Allen et al. (1989) reported on stands intensively used by radio-marked owls in three different areas of Washington (Olympic Peninsula, Gifford-Pinchot National Forest, and Mount BakerSnoqualmie National Forest). Average densities of live trees in that study were:

$\begin{array}{ll}\text { Olympic National Forest } & (190 / \text { acre, } n=4) \\ \text { Gifford Pinchot National Forest } & (205 / \text { acre, } n=14) \\ \text { Mount Baker-Snoqualmie National Forest } & (210 / \text { acre, } n=10)\end{array}$

Trees $>32$ inches in d.b.h. accounted for $11 \%$ (Gifford Pinchot National Forest) to $19.7 \%$ (Olympic National Forest) of the live trees. Snag densities on the three areas averaged from 25 to 41 per acre. Densities of large snags (>39 inches in d.b.h.) ranged from two per acre (Gifford Pinchot and Mount Baker-Snoqualmie National Forests) to four per acre (Olympic National Forest). 


\section{Appendix F: Habitat}

Table F2-Habltat selectlon for foraging and roosting by spotted owis ${ }^{a}$ (habltat descriptions for each study are summarized in table F1)

\begin{tabular}{|c|c|c|c|c|}
\hline \multirow{2}{*}{$\begin{array}{l}\text { Stand } \\
\text { condition }\end{array}$} & \multirow{2}{*}{$\begin{array}{l}\text { Selection } \\
\text { category }\end{array}$} & \multirow{2}{*}{$\begin{array}{l}\text { Oregon Coast } \\
\text { Range and Klamath } \\
\text { Mountains } \\
\text { A }\end{array}$} & \multicolumn{2}{|c|}{$\begin{array}{c}\text { Washington } \\
\text { Cascades and } \\
\text { Olympic Peninsula }\end{array}$} \\
\hline & & & B & C \\
\hline Old growth & $\stackrel{+}{\mathrm{N}}$ & $\begin{array}{l}39 / 47^{b} \\
8 / 47 \\
0 / 47\end{array}$ & $\begin{array}{l}5 / 10^{b} \\
5 / 10 \\
0 / 10\end{array}$ & $\begin{array}{c}12 / 16^{b} \\
4 / 16 \\
0 / 16\end{array}$ \\
\hline $\begin{array}{l}\text { Old with some } \\
\text { mature and } \\
\text { young }\end{array}$ & $\stackrel{+}{N}$ & $\begin{array}{r}4 / 43 \\
31 / 43 \\
8 / 43\end{array}$ & & \\
\hline Mature & $\stackrel{+}{\mathbf{N}}$ & $\begin{array}{r}0 / 20 \\
12 / 20 \\
8 / 20\end{array}$ & $\begin{array}{l}2 / 10 \\
8 / 10 \\
0 / 10\end{array}$ & $\begin{array}{r}1 / 14 \\
12 / 14 \\
1 / 14\end{array}$ \\
\hline Young & $\stackrel{+}{\mathrm{N}}$ & $\begin{array}{r}1 / 44 \\
24 / 44 \\
19 / 44\end{array}$ & $\begin{array}{l}1 / 10 \\
8 / 10 \\
1 / 10\end{array}$ & $\begin{array}{r}1 / 16 \\
14 / 16 \\
1 / 16\end{array}$ \\
\hline Pole/sapling & $\stackrel{+}{\mathrm{N}}$ & $\begin{array}{l}0 / 45^{c} \\
13 / 45 \\
32 / 45\end{array}$ & $\begin{array}{l}0 / 10 \\
8 / 10 \\
2 / 10\end{array}$ & $\begin{array}{l}0 / 16 \\
9 / 16 \\
7 / 16\end{array}$ \\
\hline Sapling & $\stackrel{+}{N}$ & $\begin{array}{r}0 / 43 \\
16 / 43 \\
27 / 43\end{array}$ & & \\
\hline Open canopy & $\stackrel{+}{N}$ & $\begin{array}{l}0 / 10 \\
6 / 10 \\
4 / 10\end{array}$ & $\begin{array}{l}0 / 16 \\
9 / 16 \\
7 / 16\end{array}$ & \\
\hline Clearcut & $\stackrel{+}{\mathrm{N}}$ & $\begin{array}{r}0 / 38 \\
10 / 38 \\
28 / 38\end{array}$ & & \\
\hline Nonforest & $\stackrel{+}{\mathrm{N}}$ & $\begin{array}{r}0 / 16 \\
5 / 16 \\
11 / 16\end{array}$ & $\begin{array}{l}0 / 10 \\
2 / 10 \\
8 / 10\end{array}$ & $\begin{array}{r}0 / 16 \\
4 / 16 \\
12 / 16\end{array}$ \\
\hline
\end{tabular}

Numerators are numbers of birds in a category ( $+=$ used more than expected; $\mathbf{N}=$ neutral, used in proportion expected; - = used less than expected); denominators are numbers of birds with that stand condition in their home range.

'Data in column A from Carey (pers. comm.), in column B from Hays et al. (1989b), and in C from Allen et al. (1989).

c In this study, use of the pole/sapling category applied to poles only. Selection for saplings was calculated separately and is indicated below. 


\section{Appendix F: Habitat}

Table F3-Habitat selection by foraging spotted owls ${ }^{a}$ (habitat descriptions for each study are summarized In table F1)

\begin{tabular}{|c|c|c|c|c|c|c|}
\hline \multirow{2}{*}{$\begin{array}{l}\text { Stand } \\
\text { condition }\end{array}$} & \multirow{2}{*}{$\begin{array}{l}\text { Selection } \\
\text { category }\end{array}$} & \multicolumn{3}{|c|}{ Oregon Coast $^{b}$} & \multicolumn{2}{|c|}{ Oregon Cascades ${ }^{C}$} \\
\hline & & A & B & C & D & $E$ \\
\hline \multirow[t]{3}{*}{ Old growth } & + & $5 / 5$ & $6 / 6$ & $9 / 9$ & $8 / 8$ & $13 / 14$ \\
\hline & $\mathrm{N}$ & $0 / 5$ & $0 / 6$ & $0 / 9$ & $0 / 8$ & $1 / 14$ \\
\hline & - & $0 / 5$ & $0 / 6$ & $0 / 9$ & $0 / 8$ & $0 / 14$ \\
\hline \multirow[t]{3}{*}{ Mature } & + & $3 / 5$ & $0 / 2$ & $0 / 9$ & $1 / 7$ & $4 / 13$ \\
\hline & $\mathrm{N}$ & $2 / 5$ & $1 / 2$ & $6 / 9$ & $3 / 7$ & $8 / 13$ \\
\hline & - & $0 / 5$ & $1 / 2$ & $3 / 9$ & $3 / 7$ & $1 / 13$ \\
\hline \multirow[t]{3}{*}{ Young } & + & $0 / 5$ & $1 / 6^{d}$ & $0 / 7$ & $0 / 5^{d}$ & $0 / 14^{e}$ \\
\hline & $\mathrm{N}$ & $0 / 5$ & $1 / 6$ & $1 / 7$ & $3 / 5$ & $0 / 14$ \\
\hline & - & $5 / 5$ & $4 / 6$ & $6 / 7$ & $2 / 5$ & $14 / 14$ \\
\hline \multirow[t]{3}{*}{ Pole/sapling } & + & & $0 / 4^{f}$ & $0 / 9$ & $0 / 7^{g}$ & \\
\hline & $\mathrm{N}$ & & $1 / 4$ & $0 / 9$ & $0 / 7$ & \\
\hline & - & & $3 / 4$ & $9 / 9$ & $7 \Pi$ & \\
\hline \multirow[t]{3}{*}{ Mixed age } & + & $1 / 5$ & & $0 / 6$ & & \\
\hline & $\mathrm{N}$ & $2 / 5$ & & $3 / 6$ & & \\
\hline & - & $2 / 5$ & & $3 / 6$ & & \\
\hline \multirow{3}{*}{$\begin{array}{l}\text { Hardwood } \\
\text { riparian }\end{array}$} & + & $1 / 5$ & $1 / 2$ & $0 / 9$ & $0 / 1$ & \\
\hline & $\mathrm{N}$ & $4 / 5$ & $1 / 2$ & $6 / 9$ & $1 / 1$ & \\
\hline & - & $0 / 5$ & $0 / 2$ & $3 / 9$ & $0 / 1$ & \\
\hline \multirow{3}{*}{$\begin{array}{l}\text { Clearcut/grass/ } \\
\text { shrub/other }\end{array}$} & + & $0 / 5$ & $0 / 6$ & $0 / 9$ & $0 / 6$ & \\
\hline & $\mathrm{N}$ & $0 / 5$ & $0 / 6$ & $1 / 9$ & $0 / 6$ & \\
\hline & - & $5 / 5$ & $6 / 6$ & $8 / 9$ & $6 / 6$ & \\
\hline
\end{tabular}

a Numerators are numbers of birds in a category $(+=$ used more than expected; $\mathrm{N}=$ neutral, used in proportion expected; - = used less than expected); denominators are numbers of birds with that stand condition in their home range.

${ }^{b}$ Column A is from Thrailkill and Meslow (1989); B is from Forsman et al. 1984); $C$ is from Carey et al. (1990).

${ }^{6}$ Column D is from Forsman et al. (1984); $E$ is from Miller and Meslow (1989).

${ }^{d}$ In this study, several categories of young forest were evaluated. We presented results for stands that were 60 to 80 years old and 10 to 30 inches in d.b.h.

Includes all other stands younger than mature, including clearcuts.

'Data presented for stands 25 to 35 years old.

9 Data presented for stands 21 to 30 years old.

All studies that reported separate data on roosting habitat found strong selection for roosting in old-growth forests (table F4). In the Oregon Coast Range and Oregon Cascades, Forsman et al. (1984) found that $>90 \%$ of all roosts were in old-growth conifer stands. In the Oregon Cascades and Coast Range, three studies (Carey et al. 1990, Miller and Meslow 1989, Thrailkill and Meslow 1990) found that all of the owls they studied $(n=27)$ roosted in old-growth forests significantly more than expected. Three other stand conditions were also used significantly more often than expected by a few birds - young stands with a mature/old-growth component ( 1 of 27 birds), mature (2 of 27), and hardwood riparian ( 1 of 27 ) (table F4). Twenty (74\%) of the owls in the three studies roosted in mature stands in proportion to their availability. Young and pole/sapling stands with trees $<20$ inches in d.b.h. were used significantly less than expected for roosting by about $96 \%$ of the owls studied. Clearcuts and unforested areas were rarely used for roosting. 
Tabie F4_Habitat selection for roosting by spotted owis (habitat descriptions from each study are summarlzed in tabie F1)

\begin{tabular}{|c|c|c|c|c|}
\hline \multirow{2}{*}{$\begin{array}{l}\text { Stand } \\
\text { condition }\end{array}$} & \multirow{2}{*}{$\begin{array}{l}\text { Selection } \\
\text { category }\end{array}$} & \multicolumn{2}{|c|}{ Oregon Coast ${ }^{b}$} & \multirow{2}{*}{$\frac{\text { Oregon Cascades }^{\circ}}{\text { C }}$} \\
\hline & & $A$ & B & \\
\hline Old growth & $\stackrel{+}{\mathrm{N}}$ & $\begin{array}{l}4 / 4 \\
0 / 4 \\
0 / 4\end{array}$ & $\begin{array}{l}9 / 9 \\
0 / 9 \\
0 / 9\end{array}$ & $\begin{array}{r}14 / 14 \\
0 / 14 \\
0 / 14\end{array}$ \\
\hline Mature & $\stackrel{+}{\mathrm{N}}$ & $\begin{array}{l}0 / 4 \\
4 / 4 \\
0 / 4\end{array}$ & $\begin{array}{l}0 / 9 \\
7 / 9 \\
2 / 9\end{array}$ & $\begin{array}{l}2 / 11 \\
9 / 11 \\
0 / 11\end{array}$ \\
\hline Young & $\stackrel{+}{N}$ & $\begin{array}{l}0 / 4 \\
0 / 4 \\
4 / 4\end{array}$ & $\begin{array}{l}0 / 7 \\
1 / 7 \\
6 / 7\end{array}$ & $\begin{array}{l}0 / 12^{d} \\
0 / 12 \\
12 / 12\end{array}$ \\
\hline Pole/sapling & $\stackrel{+}{N}$ & & $\begin{array}{l}0 / 9 \\
1 / 9 \\
8 / 9\end{array}$ & \\
\hline Mixed age & $\stackrel{+}{\mathrm{N}}$ & $\begin{array}{l}1 / 4 \\
3 / 4 \\
0 / 4\end{array}$ & $\begin{array}{l}0 / 6 \\
4 / 6 \\
2 / 6\end{array}$ & \\
\hline $\begin{array}{l}\text { Hardwood } \\
\text { riparian }\end{array}$ & $\stackrel{+}{N}$ & $\begin{array}{l}1 / 4 \\
3 / 4 \\
0 / 4\end{array}$ & $\begin{array}{l}0 / 9 \\
3 / 9 \\
6 / 9\end{array}$ & \\
\hline $\begin{array}{l}\text { Clearcut/grass/ } \\
\text { shrub/other }\end{array}$ & $\stackrel{+}{\mathrm{N}}$ & $\begin{array}{l}0 / 4 \\
0 / 4 \\
4 / 4\end{array}$ & $\begin{array}{l}0 / 9 \\
1 / 9 \\
8 / 9\end{array}$ & \\
\hline
\end{tabular}

Numerators are numbers of birds in a category $1+=$ used more than expected; $\mathrm{N}=$ neutral, used in proportion expected; - = used less than expected);

denominators are numbers of birds with that stand condition in their home range.

${ }^{b}$ Data in column A are from Thrailkill and Meslow (1990); B are from Carey et al. (1990).

cData in column C are from Miller and Meslow (1989).

$\checkmark$ Includes all other stands younger than mature, including clearcuts.

Attributes of roost trees in the Oregon Cascades and Coast Range were described by Forsman (1980) and Forsman et al. (1984). They found that roost site selection was influenced by weather, with owls using large trees (d.b.h. 20 to 70 inches) in the forest overstory during cool or wet weather, and small trees in the forest understory during warm weather. Forsman et al. (1984) suggested that spotted owls prefer older forests because the layered structure of the canopy provided a range of roosting microenvironments.

In summary, for both roosting and foraging in Washington and Oregon, old-growth was the only stand condition that was used in greater proportion than its availability by a majority of owls, and it was never used less than expected. More than $60 \%$ of the owls studied were neutral in their use of mature stands (interpreted to be marginal habitat). Stands $<80$ years old were used by $96 \%$ of the owls either in proportion to or less than expected. Clearcuts and other nonforested areas were used significantly less than expected by most owls studied and more than expected by none. 


\section{Appendix F: Habitat}

Studles at a Landscape Scale
Some studies suggest that spotted owls select areas from the general landscape that have higher concentrations of old-growth forest. Using the modified minimum convex home range as a basis for studying habitat selection patterns, Carey (pers. comm.) tested for landscape-scale habitat selection by companing mean percentages of old growth (including mixed-aged old growth) within home ranges of owl pairs to the general landscape composition. In all five landscapes examined, old growth within the pairs' home ranges averaged 1.5 times the proportion of old growth in the general landscape. Selection for old growth was significant in four of the five landscapes. No other stand condition was overused by the population at the landscape scale (Carey, pers. comm.).

In the Washington Cascades, Allen et al. (1989) also compared percentages of stand conditions within home ranges with randomly located circles 2.1 miles in radius. On the Gifford Pinchot National Forest, both the mean percentage of old growth (dominant trees $>30$ inches in d.b.h., and codominants $>16$ inches in d.b.h.) and the mean percentage of old-growth and mature stands combined (dominant trees $>20$ inches in d.b.h.) within home ranges were significantly higher than in the surrounding landscape. On the Mount Baker-Snoqualmie National Forest, however, the difference between coverage of old growth in owl home ranges and the randomly selected circles was not significant.

Few studies have investigated the effects of habitat fragmentation on the spotted owl's habitat use. In the Washington Cascades, habitat fragmentation (expressed as the frequency of cover-type polygons per 0.6 mile) was not significantly different between home ranges and the surrounding landscape (Allen et al. 1989). In the Oregon Coast Range, Thrailkill and Meslow (1990) found no significant difference in fragmentation (expressed as habitat changes along transects) between nest locations $(n=3)$ and random locations.

Although the number of studies is small, some evidence indicates that habitat fragmentation may affect home-range size. In a study of 47 owls in the Oregon Coast Range and Klamath Province, Carey (pers. comm.) examined the effects of habitat fragmentation on home-range size in five study areas in two forest zones-western hemlock and mixed-evergreen/mixed-conifer. Using a variety of measures of fragmentation, he found that owls in areas with more clumped distributions of old-growth forest had smaller home ranges on average than owls in areas where old-growth forests were more fragmented.

General stand conditions have been described at nest sites in Oregon and the Olympic Peninsula in Washington by Forsman (1976, pers. comm.), Forsman et al. (1984), and Bown (pers. comm.). As was true for habitat selection by roosting and foraging birds, owls nested primarily in old-growth forests (table F5): $79 \%$ of 130 nests were located in old-growth stands, and $16 \%$ were in stands where old-growth, mature, and young trees were intermixed, or where old growth occurred in patches or as scattered trees. Only 6 of the 130 nests (4\%) were found in mature or young stands (table F5). 


\section{Appendix F: Habitat}

Most spotted owl nests in Oregon and on the Olympic Peninsula are in old-growth trees: 39 of 47 nests $(83 \%)$ found in three physiographic provinces in Oregon were in trees $>200$ years old, $15 \%$ were in trees 100 to 200 years old, and one $(2 \%)$ was in a tree that was only 80 years old (Forsman et al. 1984). Ages of nest trees on the Olympic Peninsula were unavailable, but Forsman (pers. comm.) found that all known nests were in large, very old trees or snags. An exception is the eastside Cascades of Washington, where most nest trees were 100 to 200 years old $(58 \%$ of nests), $27 \%$ were in trees $>200$ years old, and $15 \%$ were in trees $<100$ years old, possibly as a result of the fire and logging history in the area (Irwin, pers. comm.).

In contrast to the predominance of platform nests on the east slope of the Cascades of Washington, all nests on the Olympic Peninsula and most nests in western Oregon were in tree cavities. In the mixed-conifer forests of the Klamath Mountains and on the east slope of the Cascades in Oregon, however, nests were about equally divided between cavities and platforms (Forsman 1976, Forsman et al. 1984).

Stand structure at 52 spotted owl nest sites on the Wenatchee and Okanogan National Forests in the Washington Cascades was measured by using nested plots in and around nest sites (Irwin et al. 1989a) (table F6). Mixed-conifer was the dominant forest zone in both study areas. The average age of dominant overstory trees was 166 years, and the average age of intermediate dominants was 101 years. Douglas-fir was the dominant species, accounting for $48 \%$ of the basal area. Mean live-tree basal area was 162 square feet per acre. The average nest site contained 14.9 trees per acre that were 21 to 36 inches in d.b.h., and 1.7 trees per acre $>36$ inches in d.b.h. Average basal area of snags was 25 square feet per acre.

The low basal area of trees at nest sites studied by Inwin et al. (1989a) reflects the fact that much of the study area had been subjected to a long history of fire and highgrade logging. Many of the large, overstory trees had been removed during selective logging operations. Although the stands still have multilayered canopies with relatively high closure, both the average size and basal area of trees were much lower than in old-growth forests used for nesting in California (for example, see table F13). Past fires and logging in these areas, however, frequently left large numbers of old-growth trees that survived into the next stand of young trees. These remnant old trees are typically infected with dwarfmistletoe, and often contain debris platforms that result when raptors or arboreal mammals build nests in or among the dense clusters of deformed limbs.

These debris platforms supported $77 \%$ ( 41 of 53 ) of the nests, including $47 \%$ abandoned hawk nests and $30 \%$ mistletoe-broom nests. Sixty-six percent of all owl nests were in trees infected with dwarfmistletoe. Cavities and broken-topped trees were used for nest sites by only $19 \%$ (10 of 52 ) of the owls. Most nests (92\%) were in Douglas-fir trees. Ages of nest trees determined from core samples ranged from 67 to 700 years $(\bar{x}=194$ years $)$. 
Table F5-Stand conditions at spotted owi nest sites in Oregon and the Olymplc Peninsula of Washington

\begin{tabular}{lcccc}
\hline & \multicolumn{2}{c}{ Oregon $^{b}$} & & \multicolumn{2}{c}{ Olympic Peninsula } \\
\cline { 2 - 3 } $\begin{array}{l}\text { Forest } \\
\text { condition }\end{array}$ & A & B & & C \\
\hline Old growth & $42 / 47$ & $38 / 50$ & & $23 / 33$ \\
$\begin{array}{l}\text { Old growth/ } \\
\text { old growth scatter/ } \\
\text { old growth patch }\end{array}$ & & $11 / 50$ & & $10 / 33$ \\
Mature & $2 / 47$ & & \\
Young & $3 / 47$ & $1 / 50$ & \\
\hline
\end{tabular}

Numerators show nests in each forest condition; denominators show total sample.

Data in column A from Forsman (1976) and Forsman et al. (1984); column B are from Bown (pers. $\infty \mathrm{mm}$.).

Data in column $\mathrm{C}$ are from Forsman (pers. comm.).

Table F6 - Mean stand attributes at spotted owl nest sites in the eastern Washington Cascades, 1988 and 1989 (estimates based on 52 1/4-acre plots centered at nest sites) ${ }^{2}$

\begin{tabular}{lrc}
\hline $\begin{array}{l}\text { D.b.h. class } \\
\text { in inches }\end{array}$ & $\begin{array}{c}\text { Mean number of } \\
\text { of stems/acre }\end{array}$ & $\begin{array}{c}\text { Basal area in } \\
\mathrm{ft}^{2} / \text { acre }\end{array}$ \\
\hline $\begin{array}{l}\text { Conifers and } \\
\text { hardwoods }\end{array}$ & & \\
4.0 to 10.9 & 105.05 & 25.65 \\
11.0 to 20.9 & 51.82 & 59.61 \\
21.0 to 35.9 & 14.86 & 54.93 \\
$36+$ & 1.65 & 22.32 \\
Subtotal & 173.38 & 162.51 \\
Snags & 27.80 & 24.90 \\
Grand total & 201.18 & 187.41 \\
\hline
\end{tabular}

Data are from Buchanan (pers. comm.) and Irwin et al. 1989a.

${ }^{b}$ Hardwoods represent $<1 \%$ of the total basal area (Irwin et al. 1989a). 


\section{Appendix F: Habitat}

Other Information on Habltat Structure
Although most habitat-use studies of spotted owls in Oregon and Washington did not provide detailed measurements of stand structure, such studies are available for the general stand structure of old-growth, mature, and young forests within the range of the owl (tables F7 and F8) (Forsman et al. 1986; Spies et al. 1988; Spies and Franklin 1988, in press). These studies were not designed to look at specific owluse areas, but most old-growth sample plots were located in areas known to be occupied by spotted owls (Forsman, pers. comm.). Consequently, we believe the standcondition data from these studies should provide guidance for silvicultural prescriptions for producing superior habitat within the western hemlock and mixed-conifer zones in western Oregon and western Washington (for example, table F6). Additional studies on stand structure are needed in other provinces.

Tabie F7-Densities of trees (stems/acre) greater than 20 inches In d.b.h. in natural stands of Douglas-fir and western hemlock in the Oregon Coast Ranges and Olympic Mountains (data were based on 4 circular, 0.7 -acre plots per stand; values are grand means for each stand condition)

\begin{tabular}{lccc}
\hline $\begin{array}{l}\text { D.b.h. class } \\
\text { (inches) }\end{array}$ & $\begin{array}{c}\text { Old-growth }^{a} \\
\text { stands }(n=26)\end{array}$ & $\begin{array}{c}\text { Mature stands }^{a} \\
(n=10)\end{array}$ & $\begin{array}{c}\text { Young-growth }^{a} \\
\text { stands }(n=13)\end{array}$ \\
\hline $20-29.9$ & 10.2 & 23.6 & 29.9 \\
$30-39.9$ & 5.3 & 14.3 & 8.5 \\
$40-49.9$ & 4.0 & 4.0 & 1.7 \\
$50-59.9$ & 3.2 & 0.8 & 0.6 \\
$50-69.9$ & 2.4 & 0.1 & 0.2 \\
$70-79.9$ & 0.9 & $<0.1$ & 0.0 \\
$80-89.9$ & 0.3 & 0.0 & 0.0 \\
$90-100$ & 0.1 & 0.0 & 0.0 \\
\multicolumn{1}{c}{ Total } & 26.4 & 42.8 & 40.9
\end{tabular}

a Data are from Forsman et al. (1986). Stand ages were based on core samples and counts of annual rings on felled trees or stumps at stand edges. Old-growth stands were characterized by a dominant overstory of trees $>200$ years old, mature stands had dominant overstories 100 to 200 years old; and young-growth stands had overstory dominants 60 to 99 years old. All of these were unmanaged stands that had regenerated naturally after wildfires or other catastrophic events. 


\section{Appendix F: Habitat}

Table F8-Densitles of trees (stems/acre) in young ( 40 to 79 years old), mature (80 to 195 years old), and oid-growth (196+ years oid) stands in western Oregon and western Washington (data from 5 1/4-acre circular plots per stand, and stand age was determined from core samples of dominant trees and from ring counts in adjacent clearcuts) ${ }^{a}$

\begin{tabular}{|c|c|c|c|c|c|c|c|c|c|}
\hline \multirow[b]{2}{*}{$\begin{array}{l}\text { Species and } \\
\text { d.b.h class }\end{array}$} & \multicolumn{3}{|c|}{ Oregon Coast Range } & \multicolumn{3}{|c|}{ W. Oregon Cascades } & \multicolumn{3}{|c|}{ W. Washington Cascades } \\
\hline & $\begin{array}{l}\text { Young } \\
(n=6)\end{array}$ & $\begin{array}{c}\text { Mature } \\
(n=10)\end{array}$ & $\begin{array}{c}\text { Old } \\
(n=25)\end{array}$ & $\begin{array}{c}\text { Young } \\
(n=18)\end{array}$ & $\begin{array}{c}\text { Mature } \\
(n=25)\end{array}$ & $\begin{array}{c}\text { Old } \\
(n=51)\end{array}$ & $\begin{array}{c}\text { Young } \\
(n=13)\end{array}$ & $\begin{array}{c}\text { Mature } \\
(n=16)\end{array}$ & $\begin{array}{c}\text { Old } \\
(n=40)\end{array}$ \\
\hline $\begin{array}{l}\text { Douglas-fir } \\
39+\text { inches }\end{array}$ & 0.4 & 3.6 & 12.1 & 0.0 & 2.0 & 10.1 & 0.4 & 0.8 & 6.1 \\
\hline $\begin{array}{l}\text { All species } \\
39+\text { inches }\end{array}$ & 0.4 & 4.5 & 13.4 & 0.0 & 2.4 & 13.4 & 0.4 & 1.2 & 10.1 \\
\hline $\begin{array}{l}\text { Douglas-fir } \\
31.5+\text { inches }\end{array}$ & 2.0 & 9.3 & 16.2 & 0.0 & 6.5 & 13.0 & 0.4 & 4.9 & 9.3 \\
\hline $\begin{array}{l}\text { All species } \\
30.5+\text { inches }\end{array}$ & 2.0 & 10.9 & 19.0 & 0.4 & 7.7 & 19.4 & 0.4 & 6.1 & 19.0 \\
\hline $\begin{array}{l}\text { Shade-tolerant } \\
16+\text { inches }\end{array}$ & 5.7 & 10.5 & 13.0 & 5.3 & 4.9 & 20.2 & 1.2 & 15.0 & 30.0 \\
\hline $\begin{array}{l}\text { Shade-tolerant } \\
10+\text { inches }\end{array}$ & 18.6 & 26.7 & 27.9 & 28.3 & 12.6 & 36.4 & 15.0 & 36.4 & 47.0 \\
\hline
\end{tabular}

Data are from Spies (pers. comm).

${ }^{b}$ Shade-tolerant species include western hemlock, Pacific silver fir, western redcedar, grand fir, and white fir.

Table F9-Habltat selection by foraging and roosting spotted owis on the Six Rivers National Forest, California $^{a}$

\begin{tabular}{lccc}
\hline $\begin{array}{l}\text { Forest } \\
\text { condition }\end{array}$ & $\begin{array}{c}\text { Selection } \\
\text { category }\end{array}$ & $\mathrm{A}^{b}$ & $\mathrm{~B}^{c}$ \\
\hline $\begin{array}{l}\text { Old-growth and } \\
\text { mature mix }\end{array}$ & + & $7 / 7$ & $3 / 5$ \\
& - & $0 / 7$ & $2 / 5$ \\
Pole/medium & + & $0 / 7$ & $0 / 5$ \\
& $\mathrm{~N}$ & $0 / 7$ & $2 / 5$ \\
& - & $0 / 7$ & $2 / 5$ \\
Brush/seedling/ & + & $7 / 7$ & $1 / 5$ \\
sapling & $\mathrm{N}$ & & $0 / 5$ \\
& - & & $1 / 5$ \\
& & & $4 / 5$
\end{tabular}

Results of Habitat Studies in Northern California

Characterization of Habltat Used for Foraging and Roosting

\footnotetext{
Numerators are numbers of birds in a category $1+=$ used more than expected; $\mathrm{N}=$ neutral, used in proportion expected; $-=$ used less than expected); denominators are numbers of birds with that stand condition in their home range.

Data from from Solis (1983)

c Data are from Sisco and Gutiérrez (1984).
}

Solis (1983) analyzed roosting and foraging habitat selection by seven owls in the Six Rivers National Forest in two stand types-mature/old-growth (d.b.h. $>21$ inches, $>70$ years old) and pole/medium (d.b.h. 5 to 20.9 inches, 15 to 70 years old). All owls used the old-growth/mature stands significantly more, and the pole/medium stands significantly less than expected (table F9). Although home ranges included 16 to $40 \%$ brush/sapling condition (d.b.h. $<5$ inches, 0 to 15 years old), only $2.3 \%$ of the observations occurred in this stand condition. 


\section{Appendix F: Habitat}

More recent studies on the Six Rivers National, Forest (Paton and Bingham, pers. comm.) examined habitat selection at the landscape scale by 14 radio-marked pairs over a 3-year period in the Mad River (7 pairs) and Ukonom (7 pairs) areas. Landscape boundaries for each study area were delineated by a minimum convex polygon around the pooled locations of all owls in each area. The pooled locations for all owls in each study area were compared with the proportion of each stand condition within the pooled landscape.

At each study area, northern spotted owls showed significant, nonrandom use of stand conditions, both for foraging and roosting during breeding and nonbreeding seasons. Individual comparisons of use versus availability were not made, but $79 \%$ and $74 \%$ of the foraging locations on the Mad River and Ukonom areas, respectively, were in forests with dominant canopy trees $>21$ inches in d.b.h. The proportion of roosting locations in stands with overstory trees $>21$ inches in d.b.h. was $86 \%$ at Mad River and $81 \%$ at Ukonom. Until ground-based habitat analyses can be completed and integrated into the various analyses of habitat selection by spotted owls in these areas, however, results presented here must be considered incomplete.

Kerns (1989) examined habitat use by a sample of eight radio-marked owls in young forests of coastal redwood and Douglas-fir in northwestern California. Old-growth stands were almost entirely absent from the study area ( $<1 \%$ coverage). Not surprisingly, the owls foraged and roosted primarily in young forests or in selectively logged stands of young and mature trees because few other forest types were present from which to select. Descriptions of young forests provided by Kerns indicate that the young and mature stands on his study area frequently had multilayered, multispecies canopies of conifers and hardwoods with overstory trees 28 to 40 inches or more in d.b.h. These conditions are structurally similar to conditions attained only in relatively old forests in most areas of the range of the northern spotted owl. Although this study could be cited as an exception to the general rule that old-growth forests generally provide superior habitat for spotted owls, it actually reinforces our view that the structural attributes of owl habitat are critical (for example, multilayered, multispecies stands with large overstory trees). In most of the species' range, these conditions normally develop only in very old forests.

In northern California, spotted owls tend to use the same roost trees repeatedly throughout the summer. Although stand conditions were not designated by age-class, Solis (1983) noted that owls selected roosts in stands with a two-layered canopy. Barrows and Barrows (1978) and Barrows (1981) hypothesized that spotted owls selected roosts in cooler microclimates in lower portions of the canopy to reduce heat stress.

Stand Structure: Foraging and Roosting
Two studies on the Six Rivers National Forest (Sisco and Gutiérrez 1984, Solis 1983) quantified habitat used by spotted owls for foraging and roosting in northwestern California (table F10). In both studies, the sample unit was a circular, 0.1-acre plot at or near roosting and foraging locations of radio-marked owls. Within the study area, Douglas-fir/tanoak/Pacific madrone was the most extensive forest type; white fir was dominant at elevations $>4000$ feet. 
Table F10-Mean stand attributes in foraging and roosting sites used by spotted owis on the Six Rivers National Forest in 1980 to $1982^{\circ}$ (data are from 7230.1 -acre plots)

\begin{tabular}{|c|c|c|}
\hline $\begin{array}{l}\text { D.b.h. class } \\
\text { in inches }\end{array}$ & $\begin{array}{l}\text { Mean number } \\
\text { of stems/acre }\end{array}$ & $\begin{array}{l}\text { Basal area } \\
\text { in } \mathrm{tt}^{2} / \text { acre }\end{array}$ \\
\hline $\begin{array}{l}\text { Conifers } \\
4.0-4.9 \\
5.0-10.9 \\
11.0-20.9 \\
21.0-35.9 \\
36.0+ \\
\text { Subtotal }^{b}\end{array}$ & $\begin{array}{r}7.26 \\
30.16 \\
19.54 \\
10.39 \\
11.16 \\
78.51\end{array}$ & $\begin{array}{r}0.81 \\
9.89 \\
24.78 \\
42.76 \\
155.71 \\
233.95\end{array}$ \\
\hline $\begin{array}{l}\text { Hardwoods } \\
4.0-4.9 \\
5.0-10.9 \\
11.0-20.9 \\
21.0-35.9 \\
36.0+ \\
\text { Subtotal }^{c}\end{array}$ & $\begin{array}{r}18.70 \\
62.38 \\
19.24 \\
3.97 \\
0.51 \\
104.80\end{array}$ & $\begin{array}{r}2.10 \\
19.17 \\
22.92 \\
14.24 \\
5.67 \\
64.10\end{array}$ \\
\hline Total live & 183.31 & 298.05 \\
\hline Snags & 21.67 & 32.99 \\
\hline Grand total & 204.98 & 331.04 \\
\hline
\end{tabular}

Data are from Sisco and Gutiérrez (1984) and Solis (1983).

$b$ Tanoak constituted 60.33 trees per acre, 25.19 square feet per acre.

${ }^{c}$ Douglas-fir constituted 69.5 trees per acre, 216.3 square feet per acre.

Mean values for stand structures associated with foraging and roosting indicate that the owls used stands characterized by an overstory of moderately dense, large (d.b.h. $>21$ inches), live conifers, and an understory of moderately dense pole- to medium-sized trees (d.b.h. 5 to 20 inches, 15 to 70 years old) (table F10). Overstory/ understory canopies were multilayered, with conifers averaging 0.5 to 2 times the hardwood height in trees $\geq 11$ inches in d.b.h. (Sisco and Gutiérrez 1984). Douglas-fir was the predominant species in the overstory, with the understory dominated by hardwoods, primarily tanoak. Mean canopy closure in stands was $87 \%$ for summer locations and $80 \%$ at winter locations (Gutiérrez et al. 1984).

Average density of snags was 22 per acre, and the average basal area of snags was 33 square feet per acre. Douglas-fir snags occurred most frequently (Sisco and Gutiérrez 1984, Solis 1983). Twenty-eight percent of the snags had been dead for $<1$ year; $24 \%$ had been dead from 1 to 5 years; and $48 \%$ had been dead $>5$ years. Dead, woody debris accounted for $8.6 \%$ of the ground cover (table F11). 


\section{Appendix F: Habitat}

Table F11-Percentage composition of ground cover in stands used by spotted owis for foraging, roosting, and nesting in northwestern Californla (dead-and-downed woody material included fallen, dead, or dying woody debris on the forest floor)

\begin{tabular}{|c|c|c|c|c|c|c|}
\hline \multirow[b]{2}{*}{ Situation } & \multirow{2}{*}{$\begin{array}{c}\text { Trees/shrubs } \\
<4 \text { inches in } \\
\text { d.b.h. }\end{array}$} & \multirow[b]{2}{*}{ Shrubs } & \multirow[b]{2}{*}{ Herbs } & \multirow[b]{2}{*}{ Litter } & \multicolumn{2}{|c|}{$\begin{array}{l}\text { Dead-and-downed } \\
\text { wood }^{a}\end{array}$} \\
\hline & & & & & 1 to 12 & $>12$ \\
\hline $\begin{array}{l}\text { Foraging and } \\
\text { roosting }\end{array}$ & 35 & 8 & 9 & 92 & 6 & 2 \\
\hline Nesting $_{d}^{c}$ & 22 & 9 & 13 & 75 & 10 & 5 \\
\hline Nesting $^{d}$ & 27 & 1 & 7 & 78 & 5 & 3 \\
\hline Nesting $^{\theta}$ & 11 & 9 & 16 & 78 & 16 & 2 \\
\hline
\end{tabular}

Diameters (in inches) are from the large end of a piece.

brom Sisco and Gutiérrez (1984) and Solis (1983); $n=7230.1$-acre vegetation plots.

${ }^{c}$ In Douglas-fir/tanoak stands; data from one plot on each of the four cardinal compass directions 82 feet from the nest tree; $n=32$ nests (LaHaye 1988).

In mixed-conifer stands; data from one plot on each of the four cardinal compass directions 82 feet from the nest tree; $n=6$ nests (LaHaye 1988).

- In redwood stands; data from one plot on each of the four cardinal compass directions 82 feet from the nest tree; $n=6$ nests (LaHaye 1988).

Stand structure differed between roosting and foraging sites. Canopy closure, stem density, and basal area for both old-growth conifers $>35$ inches in d.b.h. and all hardwoods were greater in roosting habitats (Gutiérrez et al. 1984, Sisco and Gutiérrez 1984 , Solis 1983). Summer roosting habitat had the highest density and basal area of large conifers (d.b.h. $>35$ inches; 16.4 stems per acre, 215 square feet per acre) and the nighest canopy closure (92.8\%) (Solis 1983). In a study on the Klamath National Forest (Asrow 1983), stand attributes were estimated in roost areas and areas of "intensive use," but these designations were not accompanied by comparisons of proportional use in different stand types (table F12). The data provide additional insight into the structure of stands frequented by spotted owls in mixedconifer forests in northern California.

LaHaye (1988) determined the stand structure of 44 nest sites in three forest types in northwestern California (table F13): redwood/California bay $(n=6)$, Douglas-fir/tanoak $(n=32)$, and mixed-conifer $(n=6)$. Stand structure was measured at variable plots located at the nest and at 82, 492, and between 656 and 4920 feet from the nest for each of the four cardinal compass directions. Here, we report results only from plots 82 feet from the nest (on the four cardinal compass directions) as most representative of conditions in the immediate nest stand. Results were similar to those for foraging and roosting locations on the Six Rivers National Forest. Spotted owls nested in habitats dominated by old-growth conifers (d.b.h. $>35$ inches) with an understory dominated by hardwoods. Canopy closure in nest stands ranged from 81 to $82 \%$ in the three forest types.

Spotted owls nested primarily in old-growth Douglas-fir (57 of 69 nests $=83 \%$ ) (LaHaye 1988). Ages of 50 nest trees determined from core samples ranged from 57 to 688 years; $35(70 \%)$ were $>200$ years old. Forty-one of the nests $(60 \%)$ were in cavities in the tops of broken-topped trees, $14(20 \%)$ were in cavities elsewhere in the trunk, and 14 were on platforms, including abandoned goshawk or Cooper's hawk nests or natural accumulations of debris. 
Table F12-Mean stand attributes in "Intensive use" and roost areas from 4 SOHAs on the Klamath National Forest (5 variableradlus samples were taken at six plots each in the stands, means were computed for each stand) ${ }^{a, b}$

\begin{tabular}{|c|c|c|c|c|}
\hline \multirow{2}{*}{$\begin{array}{l}\text { D.b.h. in } \\
\text { inches }\end{array}$} & \multirow{2}{*}{$\begin{array}{c}\text { Stems } \\
\text { per acre }\end{array}$} & \multirow{2}{*}{$\begin{array}{c}\text { Basal } \\
\text { area }\end{array}$} & \multicolumn{2}{|c|}{ Tree ages $^{c}$} \\
\hline & & & Mean & Range \\
\hline \multicolumn{5}{|l|}{ Conifers } \\
\hline $1-10$ & 154.0 & 31 & 73 & $64-79$ \\
\hline $11-17$ & 33.3 & 38 & 97 & $87-110$ \\
\hline $18-29$ & 19.9 & 60 & 146 & $130-178$ \\
\hline $30+$ & 9.5 & 79 & 250 & $210-367$ \\
\hline Subtotal & 216.7 & 208 & & \\
\hline \multicolumn{5}{|l|}{ Hardwoods } \\
\hline $1-10$ & 14.3 & 4.5 & & \\
\hline $11-17$ & 3.0 & 3.0 & & \\
\hline $18-29$ & 0.4 & 1.0 & & \\
\hline $30+$ & 0.0 & 0.0 & & \\
\hline Subtotal & 17.7 & 8.5 & & \\
\hline Total live & 234.4 & 216.5 & & \\
\hline \multicolumn{5}{|l|}{ Snags } \\
\hline $1-10$ & 5.6 & 5.0 & & \\
\hline $11-17$ & 2.7 & 3.5 & & \\
\hline $18-29$ & 8.1 & 8.3 & & \\
\hline $30+$ & 7.3 & 8.0 & & \\
\hline Total dead & 23.7 & 24.8 & & \\
\hline Grand total & 258.1 & 241.3 & & \\
\hline
\end{tabular}

a Tabled values are grand means of the four SOHAs' basal areas in square feet per acre.

b Data are from Asrow (1983).

c Numbers of core samples taken on trees were large and differed between d.b.h. classes. Mean age was determined from basal-area weighted average. Because sample sizes cannot be ascertained at this time, values should be considered reasonable estimates only on an ordinal scale. 


\section{Appendix F: Habitat}

Table F13-Mean basal area ( $\mathrm{ft}^{2} / \mathrm{acre}$ ) and other site attributes In different forest stand types used for nesting by northern spotted owis in northwestern Callfornia (data are based on 4 variable-radius plots on the 4 cardinal compass direction 82 feet from the nest trees) ${ }^{a, b}$

\begin{tabular}{lccc}
\hline $\begin{array}{l}\text { D.b.h. class } \\
\text { in inches }\end{array}$ & $\begin{array}{c}\text { Douglas-firl } \\
\text { tanoak stands } \\
(n=32)\end{array}$ & $\begin{array}{c}\text { Mixed-conifer } \\
\text { stands } \\
(n=6)\end{array}$ & $\begin{array}{c}\text { Redwood/ } \\
\text { Calif. laurel } \\
(n=6)\end{array}$ \\
\hline Conifers & & & \\
$0.4-12$ & 27 & 91 & 23 \\
$12-24$ & 18 & 41 & 58 \\
$24-35.4$ & 33 & 42 & 73 \\
35.4+ & 133 & 94 & 59 \\
Subtotal & 211 & 268 & 213 \\
Hardwoods & & & \\
$0.4-8$ & 33 & 12 & 33 \\
$8-16$ & 48 & 19 & 43 \\
16-24 & 27 & 3 & 18 \\
$24+$ & 18 & 6 & 59 \\
Subtotal & 126 & 40 & 312 \\
$\quad$ Grand total & 337 & 306 & \\
\cline { 2 - 4 } & & & 82 \\
Mean canopy & 81 & 81 & 42 \\
cover (\%) & & 4261 & \\
Mean elevation (ft) & 2572 & 40 & \\
Mean slope (\%) & 49 & & \\
\hline
\end{tabular}

- Tabled values include both live trees and snags.

bata are from LaHaye (1988).

In 1989, nesting was documented at 41 sites on privately owned lands in northern California (Inwin et al. 1989b; Kerns 1988, 1989; Pious 1989). Only four of the nesting pairs were in stands $>80$ years old. In Pious' (1989) work and some of Diller's (1989) surveys in young redwood forests, data indicated a trend of greater occupancy by pairs in stands dominated with redwoods $>60$ years old, when compared to data from stands primarily younger than 60 years. These trends were not statistically significant.

Parts of the areas surveyed (for example, coastal redwood) contained highly productive growing sites, which may explain the relatively high number of nest sites in relatively young forests. The comparatively high site productivity of coastal areas was probably reflected in data of Irwin et al. (1989b) showing that spotted owl responses per mile of transect surveyed were over $50 \%$ more frequent in young coastal redwood and redwood/Douglas-fir forests than in interior mixed-conifer and Douglas-fir forests. Furthermore, $75 \%$ of the 28 pairs producing young in 1989 in the study by Inwin et al. were found in the coastal forests. 
Table F14-Average densltles of trees (stems/acre), snags, and logs (pleces/acre) In young (40 to 100 years old), mature (101 to 200 years old), and oldgrowth ( $>200$ years old) Douglas-flr/hardwood stands in northwestern California and southwestern Oregon (data from five 1/4-acre circular plots per stand; stand age was determined from core samples of dominant trees and from ring counts In adjacent clearcuts) ${ }^{B}$

\begin{tabular}{|c|c|c|c|}
\hline D.b.h. class & $\begin{array}{l}\text { Young } \\
(n=14)\end{array}$ & $\begin{array}{l}\text { Mature } b \\
(n=14)\end{array}$ & $\begin{array}{c}\text { Old } \\
(n=28)\end{array}$ \\
\hline $\begin{array}{l}\text { Conifers } \\
36+\text { inches }\end{array}$ & 0.4 & 5.5 & 11.7 \\
\hline $\begin{array}{l}\text { Hardwoods } \\
36+\text { inches }\end{array}$ & 0.1 & 0.2 & 0.4 \\
\hline $\begin{array}{l}\text { Conifers } \\
18-35 \text { inches }\end{array}$ & 12.6 & 23.0 & 8.8 \\
\hline $\begin{array}{l}\text { Hardwoods } \\
18-35 \text { inches }\end{array}$ & 8.9 & 4.7 & 8.3 \\
\hline $\begin{array}{l}\text { Conifers }^{c} \\
2-17 \text { inches }^{-}\end{array}$ & 203.0 & 94.7 & 30.3 \\
\hline $\begin{array}{l}\text { Hardwoods } \\
2-17 \text { inches }\end{array}$ & 345.2 & 206.4 & 228.0 \\
\hline $\begin{array}{l}\text { Snags }^{\theta} \\
4+\text { inches }\end{array}$ & 36.1 & 34.7 & 12.9 \\
\hline $\begin{array}{l}\operatorname{Logs}^{f} \\
4+\text { inches }\end{array}$ & 168.9 & 121.8 & 124.6 \\
\hline
\end{tabular}

Data are from B. Bingham (pers. comm).

b All young and half of the mature stands originated after logging.

${ }^{c}$ Douglas-fir dominated all stands. Minor conifers included redwood, Port-Orford-cedar, western redcedar, ponderosa pine, sugar pine, and incense-cedar.

'Hardwoods included tanoak, madrone, canyon live oak, giant chinkapin, California-laurel, California black oak, and Oregon white oak.

- Snag diameter measured at breast height or top diameter for snags less than 4.5 feet tall.

' Log diameter measured at large end.

Other Information on Habitat Structure
Bingham and Sawyer (in press) described the structure of young, mature, and oldgrowth Douglas-fir/hardwood forests in the Klamath and northern California Coast Range provinces (table F14). Although their study was not intended to evaluate owl use, as in Oregon and Washington (Spies and Franklin, in press), sample plots were located in stands occupied by owls. Numerous samples were from the Northern California Coast Range Preserve in stands known to be used by owls for more than 10 years, and on the Six Rivers National Forest in stands that have been or are currently included in owl studies. We believe that the stand condition data from their study should provide guidance for silvicultural prescriptions for producing superior owl habitat within the mixed-evergreen zone of northern California. 


\section{Appendix F: Habitat}

Habitat In the Sierra

Nevada

\section{Discussion}

Recently, several pairs of California spotted owls have been found nesting in or near riparian habitats in canyons at elevations ranging from about 1000 to 3000 feet in foothill woodlands of the western Sierra Nevada, east of Fresno (Neal et al. 1990). Tree-canopy closure commonly exceeds $70 \%$ in these sites, with stands composed of mixtures of interior live oak, California sycamore, California buckeye, and blue oak. Some very old trees occur, and sycamores often exceed 21 inches in d.b.h. Shrubs and smaller trees provide multilayered canopies, and considerable space beneath the canopy provides open flight space for the owls. Decadence is common in the form of dead-and-downed woody material, dead trees and limbs, and natural cavities in the trees. Dusky-footed woodrats comprise over $80 \%$ of the diet of owls in this area. These foothill woodland habitats are similar to woodland riparian areas in the southern part of the State, where California spotted owls have long been known to breed. Although breeding in these habitats is thus far known only in the range of the California subspecies, some areas in the Klamath Province (within the range of the northern spotted owl), particularly in the foothills bordering the Sacramento Valley, may provide similar habitat. These areas need to be surveyed to learn whether spotted owls are breeding there as well.

With the exception of recent studies in the coastal redwoods of California, all studies of habitat use suggest that old-growth forests are superior habitat for spotted owls. Throughout their range and across all seasons, spotted owls consistently concentrated their foraging and roosting in old-growth or mixed-aged stands of mature and old-growth trees. For nest sites, owls used primarily old-growth trees, whether in oldgrowth stands or in remnant old-growth patches. Exceptions were found, but even they tended to support the usual observations that spotted owls nested in stands with structures characteristic of older forests. For example, although many of the nests described by Irwin et al. (1989a) on the east slope of the Washington Cascades were in mature stands that had been logged or burned in previous years, most nests were in remnant trees $>100$ years old. Furthermore, many of the remnant trees in these stands were characterized by heavy infestations of dwarimistletoe, which provided nest and roost sites.

Structural components that distinguish superior spotted owl habitat from less suitable habitat in Washington, Oregon, and northwestern California include: a multilayered, multispecies canopy dominated by large ( $>30$ inches in d.b.h.) conifer overstory trees, and an understory of shade-tolerant conifers or hardwoods; a moderate to high (60 to $80 \%$ ) canopy closure; substantial decadence in the form of large, live coniferous trees with deformities-such as cavities, broken tops, and dwarfmistletoe infections; numerous large snags; ground-cover characterized by large accumulations of logs and other woody debris; and a canopy that is open enough to allow owls to fly within and beneath it. 


\section{Appendix F: Habitat}

In the conifer-dominated forest zones where the northern spotted owl occurs, succession from an even-aged young stand to a multilayered canopy with decadence may take 150 to 200 years. A significant exception is the coastal redwood zone of northwestern California, where stands can attain old-growth structural attributes within $\mathbf{5 0}$ to 60 years after harvest. This ability is attributable to a unique set of conditions in that region: a rapidly growing tree species with stump-sprouting capability, early intrusion of other conifer species and several hardwood species into the understory, relatively high rainfall and frequent fog, a long growing season, and an abundance of dusky-footed woodrats, a common prey species of northern spotted owls where available (appendix J).

Given the conditions found in the coastal redwood zone, apparently most or all structural attributes of forest stands typically associated with the occurrence and breeding of spotted owls develop at an accelerated rate-perhaps attaining suitable conditions for spotted owls in as few as 50 to 60 years on some sites and superior conditions in 80 to 100 years. Because these conditions do not occur in most areas within the range of the northern spotted owl, we caution strongly against applying results from the California coastal redwood zone to all other parts of the range of the northern spotted owl.

Several possibilities might explain why spotted owls select forests with old-growth structure. For foraging, such forests may have higher densities of preferred prey; studies on prey abundance, however, have not consistently supported this hypothesis (see appendix J). Another possibility is that the owls are able to forage more efficiently in old stands because of the openness of the individual canopy layers and the range of foraging perches from near-ground height to the upper canopy.

Selection of old stands for nesting is most likely related to the high availability of suitable nest trees in such stands. Unless they contain remnant old-growth trees, young stands generally provide few suitable nest sites. Selection for roosting in oldgrowth stands may be related to thermoregulation. Barrows (1981) and Forsman et al. (1984) reported that spotted owls tend to roost in small trees in the forest understory during warm weather and high up in large trees during cold or wet weather. The layered canopy structure in old forests provides both types of roosts, whereas even-aged stands tend to include one roost type but not the other.

Although selection of old forests by spotted owls was relatively consistent among studies, considerable use of mid-aged and young stands also occurred. This use suggests that, as forests develop along the continuum from young to old, they gradually become more suitable for spotted owls. At the same time, the structural components typical of old growth are sometimes found in young forests, especially those that have regenerated from early disturbances (fire, wind, inefficient logging, and so on) that left behind large trees, snags, and logs from the earlier stands. 


\section{Appendix F: Habitat}

\section{Recommendations for Future Studies and Management}

\author{
Questions to be \\ Addressed
}

Detailed information on stand structure is still needed for many of the forest types inhabitated by spotted owls. Given the considerable confusion regarding the characterization of stand conditions based on stand age, we recommend that future studies of habitat use by spotted owls provide detailed information on stand structure. Such information should include tree densities and basal area by d.b.h.-class and species, canopy closure, and occurrence of trees and snags with large cavities, broken tops, dwarfmistletoe infections, and other indications of decadence.

The full range of suitable habitats for spotted owls in California has not yet been determined, although much is known. Current FS guidelines for spotted owl habitat in northern California (Simon-Jackson, pers. comm.) specify multilayered stands of mature timber, with $\geq 70 \%$ canopy closure, at least $40 \%$ of that in trees $\geq 21$ inches in d.b.h., and with obvious decadence (for example, many snags, including some large ones; broken-topped trees; logs and other woody debris on the ground). Because many owls in California occupy areas where relatively little suitable habitat occurs as defined by current FS guidelines, the adequacy of these guidelines is open to question.

For example, in the Klamath Province only $35.4 \%$ of all established SOHAs $(n=257)$ have at least 1000 acres of suitable habitat as characterized in Regional and Forest guidelines, and many SOHAs have fewer than 500 acres of suitable habitat. In spite of the fact that many SOHAs in these Forests have fewer than 1000 acres of "suitable" habitat, $95 \%$ of the monitored SOHAs ( $n=60$ in 1988, $n=66$ in 1989; randomly drawn) were confirmed to have owls in 1989, and $97 \%$ had owls in 1988 or 1989. For sites with pairs, the respective values were 58 and $80 \%$. For pairs with young, they were 46 and $80 \%$, and for total SOHAs with young, the values were 23 and $58 \%$. In three of the six SOHAs with less than 100 acres of suitable habitat, breeding occurred at least once in 1987, 1988, or 1989. Two of the six had known pairs in at least 1 of the 3 years, and one had no birds detected in any of the 3 years. These findings indicate that the definition of suitable habitat either is not adequate or that the amounts of suitable habitat required may differ locally. Additional long-term studies are needed to further evaluate both the types and amounts of habitats required to support pairs of owls in northern California.

Outside of the HCAs, we recommend that future silvicultural treatments, experiments, and other habitat management practices in managed forests emphasize producing and maintaining the vegetational and structural components of superior spotted owl habitat (see appendix S). For example, in mixed-conifer and conifer/hardwood forests of northern California, and on the east slope of the Washington Cascades, breeding spotted owls have been located on lands where historical timber harvesting activity emphasized overstory removal or other partial-cutting techniques that retained relatively high canopy cover. We believe this practice, where feasible, has potential for extending the life of a timber stand for use by spotted owls. Similarly, we recommend that forest managers enhance the suitability of selectively logged areas by leaving either single old-growth trees or patches scattered within logged stands. 


\section{Appendix F: Habitat}

Management of Habitat Within HCAs

\section{References}

Results of the nesting study on the east slope of the Cascades in Washington (Inwin et al. 1989a) suggest to us that control of forest pathogens such as dwarfmistletoe may be detrimental to spotted owls and other raptors, especially in areas where large trees with cavities are not available as alternative nest sites. One way to test this relationship would be to remove trees infected with dwarfmistletoe from a sample of nest sites and see if those sites continue to be used for nesting. Nest boxes could be placed in experimental stands to test their suitability as substitutes for dwarfmistletoe platforms. In addition, studies should be designed to determine if the removal of trees infected with dwarfmistletoe affects the abundance of flying squirrels-the main prey of spotted owls on the east slope of the Cascades in Washington (see appendix J). Until such studies have been done, however, we recommend against the wholesale removal of trees infected with dwarfmistletoe from forests stands on the east slope.

And, finally, we recommend that future surveys for spotted owls be designed to determine the relative abundance of owls in all forest zones and stand conditions within the range of the owl.

Given the current distribution of old forests, we see no alternative in the short term but to protect significant amounts of the remaining superior habitat for northern spotted owls through the creation of HCAs. Under the conservation strategy proposed here, most logging activities within HCAs would cease. The ultimate management goal within HCAs, therefore, is to recreate a relatively unfragmented, natural landscape. This strategy will ultimately maximize the amount of superior habitat and minimize the amount of marginal and unsuitable habitat.

Until we can demonstrate that silvicultural treatments can benefit spotted owls, natural succession will be the primary means to achieve an unfragmented landscape within HCAs. In the long-term, we hope that silviculturists, foresters, and wildlife biologists will be able to work interactively to develop techniques that produce suitable habitat within the managed forest and make the HCAs unnecessary.

Allen, H. L., K. R. Dixon, and K. L. Knutson. 1989 unpubl. Cooperative administrative study to monitor spotted owl management areas in National Forests in Washington: Final report. Wash. Dep. Wildl., Olympia. 165pp.

Asrow, E. S. 1983 unpubl. Scott River Ranger Distric: spotted owl habitat analysis project. Klamath National Forest, Yreka, Calif. 62pp.

Barrows, C. W. 1981. Roost selection by spotted owls: An adaptation to heat stress. Condor 83:302-309.

Barrows, C., and K. Barrows. 1978. Roost characteristics and behavioral thermoregulation in the spotted owl. West. Birds 9:1-8.

Bingham, B. B. Pers. comm. U. S. For. Serv. PSW, Arcata, California.

Bingham, B. B., and J. O. Sawyer, Jr. In press. Distinctive features and definitions of young, mature, and old-growth Douglas-fir/hardwood forests. In L. F. Ruggiero, K. B. Aubry, A. B. Carey, M. H. Huff, tech. coords. Wildlife and vegetation of unmanaged Douglas-fir forests. U. S. For. Serv., Gen. Tech. Rep. 


\section{Appendix F: Habitat}

Bown, R. Pers. comm. BLM, Roseburg Dist., Roseburg, Oreg.

Buchanan, J. B. Pers. comm., National Council of the Paper Industry for Air and Stream Improvement, Inc., Olympia, Wash.

Carey, A. B., J. A. Reld, and S. P. Horton. 1990. Spotted owl home range and habitat use in southern Oregon Coast Ranges. J. Wildl. Manage. 54:11-17.

Carey, A. B. Pers. comm. U.S. For. Serv., PNW, Olympia, Wash.

Diller, L. 1989 unpubl. Status of the northern spotted owl in managed forests on Simpson redwood land in northern California. Interim rep., Simpson Redwood Co., Arcata, Calif. 25pp.

Egtvedt, L. H., and D. A. Manuwal. 1988 unpubl. Documentation of spotted owls and interspecific relationships among forest owls in the Cedar River Watershed, Washington: Final report to Water Department, City of Seattle. College of For. Res., Univ. Wash., Seattle. 45pp.

Forsman, E. D. 1976. A preliminary investigation of the spotted owl in Oregon. M. S. Thesis. Oreg. State Univ., Corvallis. 127pp.

Forsman, E. D. 1980. Habitat utilization by spotted owls in the west-central Cascades of Oregon. Ph.D. Thesis, Oreg. State Univ., Corvallis. 95pp.

Forsman, E. D. 1981 unpubl. Habitat utilization by spotted owls on the Eugene District of the Bureau of Land Management. Bur. of Land Manage., Eugene, Oreg. 63pp.

Forsman, E. D. Pers. comm. U.S. For. Serv., PNW, Olympia, Wash.

Forsman, E. D., C. R. Bruce, M. A. Walter, and E. C. Meslow. 1987. A current assessment of the spotted owl population in Oregon. Murrelet 68:51-54.

Forsman, E. D., E. C. Meslow, and H. M. Wight. 1984. Distribution and biology of the spotted owl in Oregon. Wildl. Monogr. 87:1-64.

Forsman, E. D., J. F. Franklln, and E. C. Meslow. 1986 unpubl. Structure and composition of old-growth, mature, and second-growth forests of Douglas-fir and western hemlock in the Oregon Coast Ranges and Olympic Mountains, Washington. Oreg. Coop. Wildl. Res. Unit, Oreg. State Univ., Convallis. 71pp.

Gutierrez, R. J., D. M. Solls, and C. SIsco. 1984. Habitat ecology of the spotted owl in northwestern California: Implications for management. Pages 368-373 in Proc., Soc. Am. For.

Hamer, T. E., S. G. Selm, and K. R. Dlxon. 1989 unpubi. Northern spotted owl and northern barred owl habitat use and home range size in northwest Washington: Preliminary report. Wash. Dep. Wildl., Olympia. 64pp. 


\section{Appendix F: Habitat}

Hays, D. W., H. L. Allen, and L. H. Egtvedt. 1989a unpubl. Spotted owl surveys of randomly selected transects in Washington: Preliminary report. Wash. Dep. Wildl. Manage.-Nongame, Olympia. 31pp.

Hays, D. W., H. L. Allen, L. H. Egtvedt, and K. R. Dixon. 1989b unpubl. Home range size and habitat use of spotted owls in Washington: Preliminary report. Wash. Dep. Wildl. Manage.-Nongame, Olympia. 30pp.

Irwin, L. L. Pers. comm. NCASI, Corvallis, Oreg.

IrwIn, L. L., J. B. Buchanan, E. McCutchen, and C. PhIllips. 1989a unpubi. Characteristics of spotted owl nest sites in eastside National Forests, Washington: Progr. rep. for 1988-89. 61pp.

Irwin, L. L., S. Self, and L. Smlth. 1989b unpubl. Status of northern spotted owls on managed forestlands in northern California. Final Rep., Timber Assoc. Calif., Sacramento. 31pp.

Kerns, S. J. 1988 unpubl. Observations of wildlife diversity on lands of the Pacific Lumber Company. Typescript prelim. rep., Wildlife Resource Managers, Scotia, Calif.

Kerns, S. J. 1989 unpubl. Occurrence of spotted owls in managed timber stands on lands of the Pacific Lumber Company. Progr. rep., Pacific Lumber Co., Scotia, Calif. 29pp.

LaHaye, W. S. 1988. Nest site selection and nesting habitat of the northern spotted owl (Strix occidentalis caurina) in northwestern California. M.S. Thesis, Humboldt State Univ., Arcata, Calif. 111pp.

Milier, G. S., and E. C. Meslow. 1989 unpubl. The ecology of spotted owls on the Willamette National Forest: Supplement to 1989 annual report (spotted owl demography and habitat use segments, 1 September 1988-31 August 1989). Oreg. Coop. Wildl. Res. Unit., Oreg. State Univ., Corvallis. 16pp.

Mills, L. S., R. J. Frederickson, and B. B. Moorhead. 1989 unpubl. Characteristics of old-growth forests associated with northern spotted owls in Olympic National Park. 29pp.

Neal, D. L., J. Verner, G. N. Steger, and G. P. Eberleln. 1990 unpubl. A study of spotted owl home-range size and composition in the Sierra National Forest: Annual progress report for 1989. U.S. For. Serv., PSW For. Range Exp. Stn., Fresno, Calif. 44pp.

Paton, P., and B. BIngham. Pers. comm. U.S. For. Serv., PSW, Arcata, Calif.

Plous, M. 1989 unpubl. The northern spotted owl in second-growth forests of Mendocino County, California. Prelim. results. Lousiana Pacific and Georgia Pacific Corps., Samoa and Ft. Bragg, Calif. 22pp. 
Rugglero, L. F., K. B. Aubry, R. S. Holthausen, J. W. Thomas, B. G. Marcot, and E. C. Meslow. 1988. Ecological dependency: The concept and its implications for research and management. Trans. 53rd N.A. Wildl. Nat. Res. Conf. 53:115-126.

Simon-Jackson, T. Pers. comm. U.S. For. Serv., R5, San Francisco, Calif.

Sisco, C., and R. J. Gutlérrez. 1984 unpubl. Winter ecology of radio-tagged spotted owls on Six Rivers National Forest, Humboldt Co., CA. Six Rivers National Forest, Eureka, Calif. 140pp.

Solls, D. M. 1983. Summer habitat ecology of spotted owls in northwestern California. M.S. Thesis, Humboldt State Univ., Arcata, Calif. 169pp.

Sples, T. A., and J. F. Frankiln. 1988. Old growth and forest dynamics in the Douglas-fir region of western Oregon and Washington. Nat. Areas J. 8:190-201.

Sples, T. A., and J. F. Franklln. In press. The structure of natural young, mature, and old-growth forests in Washington and Oregon. In L. F. Ruggiero, K. B. Aubry, A. B. Carey, M. H. Huff, tech. coords. Wildlife and vegetation of unmanaged Douglas-fir forests. U.S. For. Serv., Gen. Tech. Rep.

Sples, T. A., J. F. Franklln, and T. B. Thomas. 1988. Coarse woody debris in Douglas-fir forests of western Oregon and Washington. Ecology 69:1689-1702.

Sples, T. A. Pers. comm. U.S. For. Serv., PNW, Corvallis, Oreg.

ThrallkIII, J. A., and E. C. Meslow. 1989 unpubl. Home range size and habitat utilization of northern spotted owls in the Wolf Creek Study area, Eugene BLM District, Oregon. Progress Rep. for 1 June 1987-1 September 1989. Oregon Coop. Wildl. Res. Unit, Oreg. State Univ., Convallis. 26pp.

ThrallkIII, J. A., and E. C. Meslow. 1990 unpubl. Home range size and habitat utilization of northern spotted owls in the Wolf Creek Study area, Eugene BLM District, Oregon: Draft final rep. Oreg. Coop. Wildl. Res. Unit, Oreg. State Univ., Corvallis. 68pp. 


\section{Relative Abundance of Spotted Owls in Young, Mature, and Old Forests}

\section{Introduction}

\section{Summary of Relevant Studies}

Forsman et al. (1977)
Studies that have investigated spotted owl occurrence in forests of different ages cannot be easily compared because researchers used different methods and worked towards different objectives. Particularly important for this comparison is the fact that the ages of sampled stands were not based on a fixed standard. Some researchers grouped stands by age-class, but not everyone used the same grouping intervals. Some researchers also did not specify stand ages, relying instead on an estimate of successional stage as an index to age. Finally, few studies were confined to extensive tracts of relatively even-aged forest, so most sampled tracts contained at least some mixing of patches of different ages. Because of these factors, we cannot give unambiguous definitions of young and mature forests. Generally, however, "old growth" was consistently used to mean stands where the dominant canopy was at least 200 years old.

Because of these problems, we caution readers against comparing results between different studies. Our objective in this summary was to determine whether the studies are consistent in suggesting a correlation between spotted owl abundance and forest age. The most useful studies are those in which the same observers, using the same sampling procedures, compared spotted owl abundance between samples from southwestern Washington and parts of the Olympic Peninsula and Washington Cascades, and between samples from northwestern Oregon and extensive stands of older forests to the south, in the Oregon Coast Range.

These comparisons seek to determine when forests regenerating from clearcuts first begin to develop attributes that support breeding pairs of spotted owls. Forests in predominantly second-growth condition, where the owls are breeding in the eastern Cascades of Washington and in parts of northern California, are not germane to this question. They are examples of how selective logging that left some old-growth attributes in stands has apparently maintained conditions suitable for breeding spotted owls

Sample areas (fig. G1) were surveyed using the "leapfrog" method, in which observers called and listened for responses as they walked slowly along roads or trails (Forsman 1983). Surveys began on 12 July and ended on 11 August 1976. They were concentrated in stands $<80$ years old and stands $>200$ years old, because no extensive stands could be located in the intervening age group. This survey was designed to determine relative abundance of spotted owls, not total numbers or densities. 


\section{Appendix G: Owl Abundance}

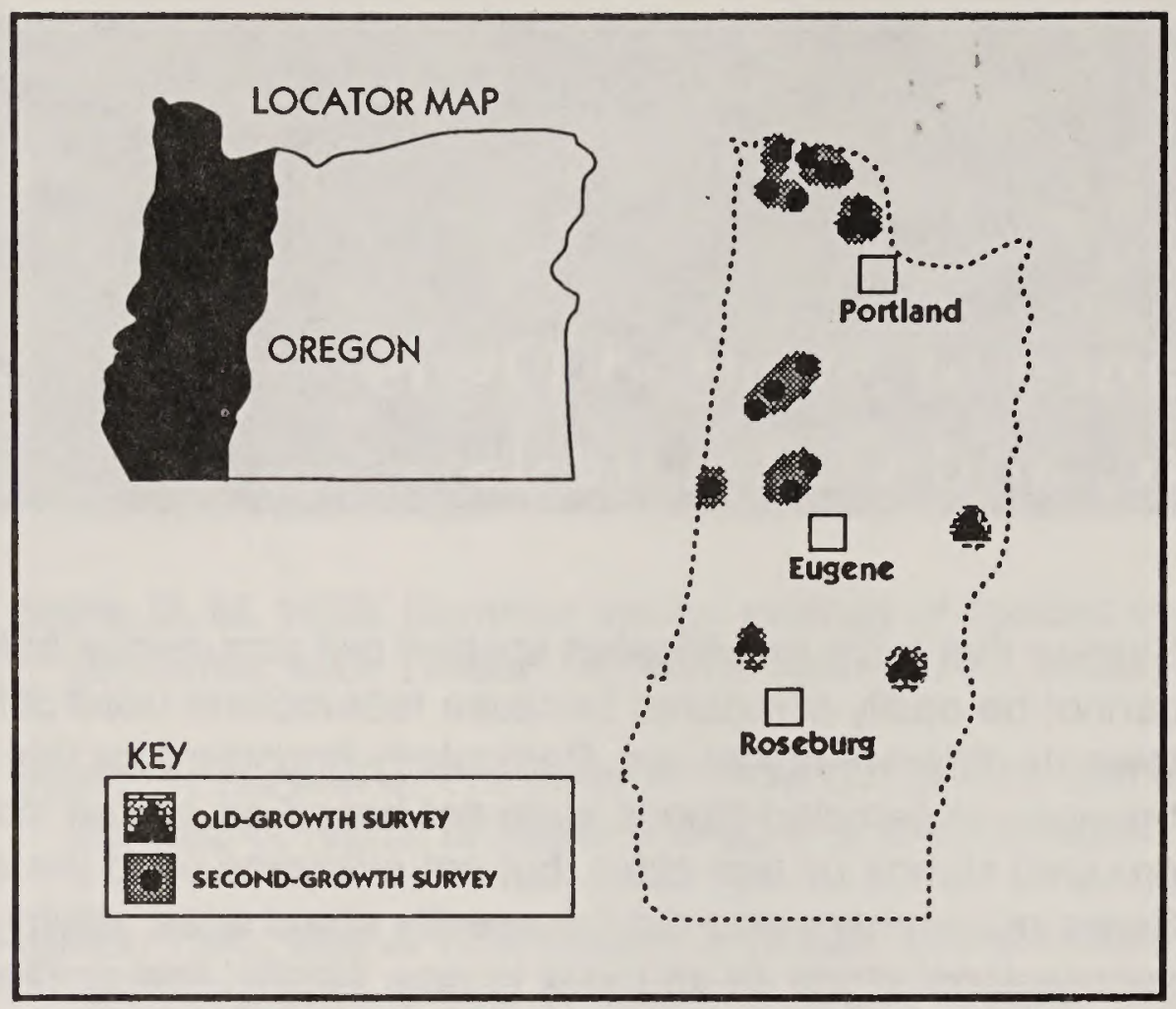

Figure G1-General survey areas sampled by Forsman et al. (1977).

Table G1-Detection rates of spotted owls on survey routes In western Oregon in 1978 (Forsman et al. 1977)

\begin{tabular}{|c|c|c|c|c|}
\hline $\begin{array}{l}\text { Age of } \\
\text { stands }\end{array}$ & $\begin{array}{l}\text { Miles } \\
\text { surveyed }\end{array}$ & $\begin{array}{l}\text { Pairs } \\
\text { located }\end{array}$ & $\begin{array}{l}\text { Singles } \\
\text { located }\end{array}$ & $\begin{array}{c}\text { Owls } \\
\text { per mile }\end{array}$ \\
\hline \multicolumn{5}{|c|}{ Younger forests (north Coast Range) } \\
\hline $20-35$ & 20 & 0 & 0 & 0 \\
\hline $36-45$ & 64 & 1 & 3 & 0.08 \\
\hline $46-60$ & 11 & 0 & 1 & 0.09 \\
\hline $61-80$ & 9 & 0 & 0 & \\
\hline \multicolumn{5}{|c|}{ Older forests (central Coast Range, central Cascades) } \\
\hline $200+$ & 29 & 10 & 7 & 0.93 \\
\hline
\end{tabular}

Results - In their analysis, Forsman et al. (1977) assumed that any response represented a pair of spotted owls. They now feel, however, that this was an incorrect approach, because it assumes equal proportions of paired versus single owls in all forest types (Forsman, pers. comm.). For this reason, we reanalyzed their data using actual numbers of individuals responding per mile of transect surveyed (table G1). The difference between detection rates in young and old stands was significant ( $P<0.001$; Mann-Whitney $U$ test) (table G1).

Only one pair was located in young forests; the four other responses in young forests were all from single owls. Two of the five sites where owls were located in young forest were near small, remnant patches of old growth. Another site with apparently good growing conditions (trees 42 to 45 years old were 30 to 36 inches in d.b.h.) also had pockets of forest 90 to 100 years old. 


\section{Appendix G: Owl Abundance}

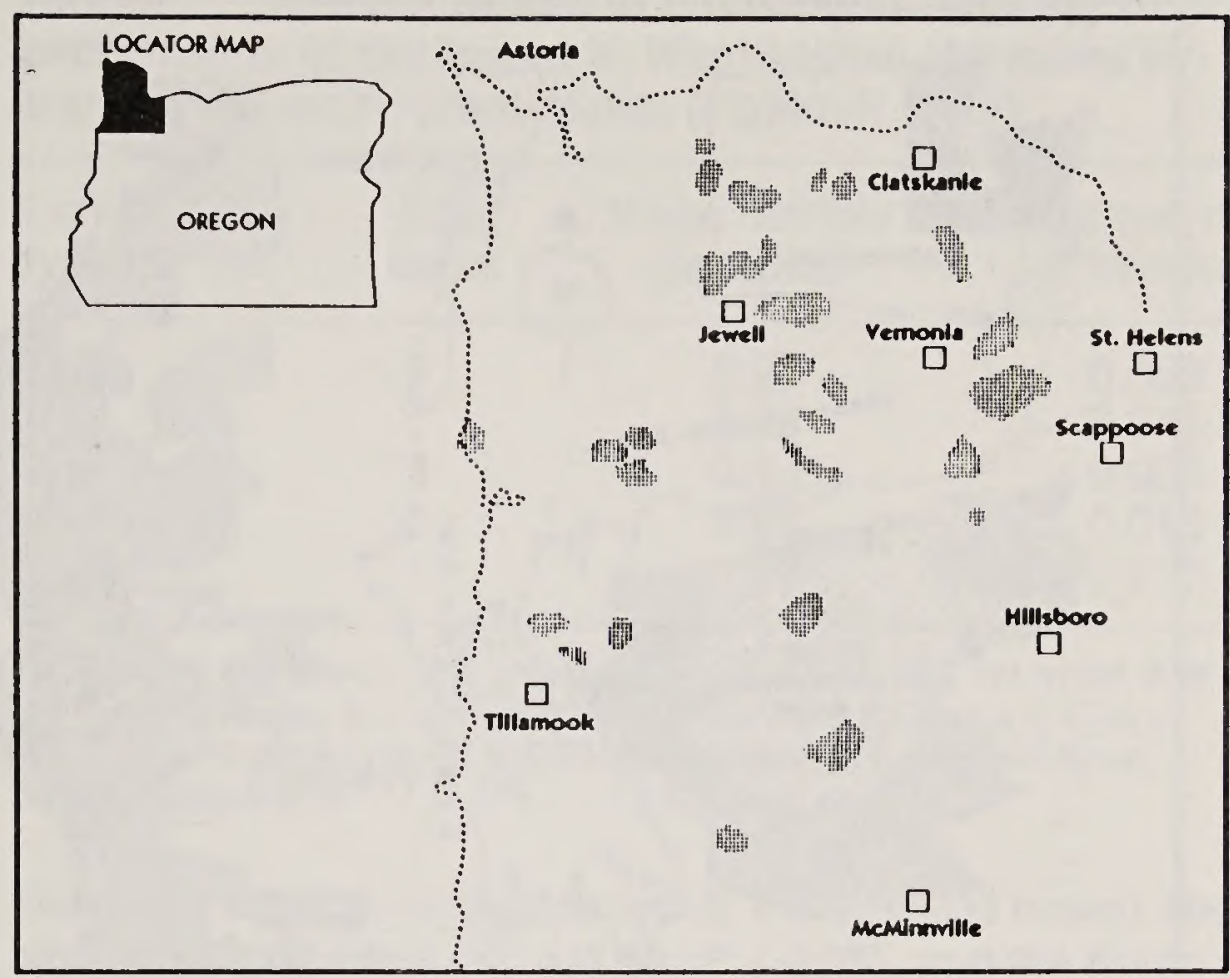

Figure G2-General survey areas sampled by Forsman (1988).

Searching for broods was not intensive, but two were found in old growth. No broods were found in young forests.

Forsman (1988)

Observers at sample locations (fig. G2) surveyed along roads, and stopped at $0.2-$ mile intervals to play recordings of spotted owl calls for at least 5 minutes at each station. Surveys began on 31 March and ended on 21 July 1986-10 years after surveys were done in the same areas in 1976 (Forsman et al. 1977). Some areas inaccessible by road or trail were surveyed by calling for 10 to 30 minutes from one or more vantage points overlooking canyons. When possible, daytime searches were made to locate owls found by nighttime surveys. Survey routes were systematically chosen to place them in forested habitat as uniformly as possible throughout the study area. Routes were intentionally chosen to traverse the oldest and most extensive forests present in a given area. "Mature" (110 to 140 years of age) and "old-growth" (200+ years old) stands were pooled for analyses because of small sample sizes. As in the study by Forsman et al. (1977), the objective was to obtain an index of abundance, not to determine the total number or density of owls.

Results - Spotted owls were found in two mature/old-growth stands (response rate $=0.06$ individuals per mile; 29 miles surveyed). Both stands where owls responded were dominated by overstory trees 110 to 140 years old and contained residual old-growth trees. Two recently fledged young were found at one of these sites. In younger stands (46 to 64 years old), spotted owls were located at five sites (response rate $=0.03 /$ mile; 151 miles surveyed). Most trees in these stands were 10 to 30 inches in d.b.h., but overstory trees 30 to 40 inches in d.b.h. were not uncommon on good growing sites. No evidence of nesting was found in any young stand, and all responses in young stands were from single birds. 


\section{Appendix G: Owl Abundance}

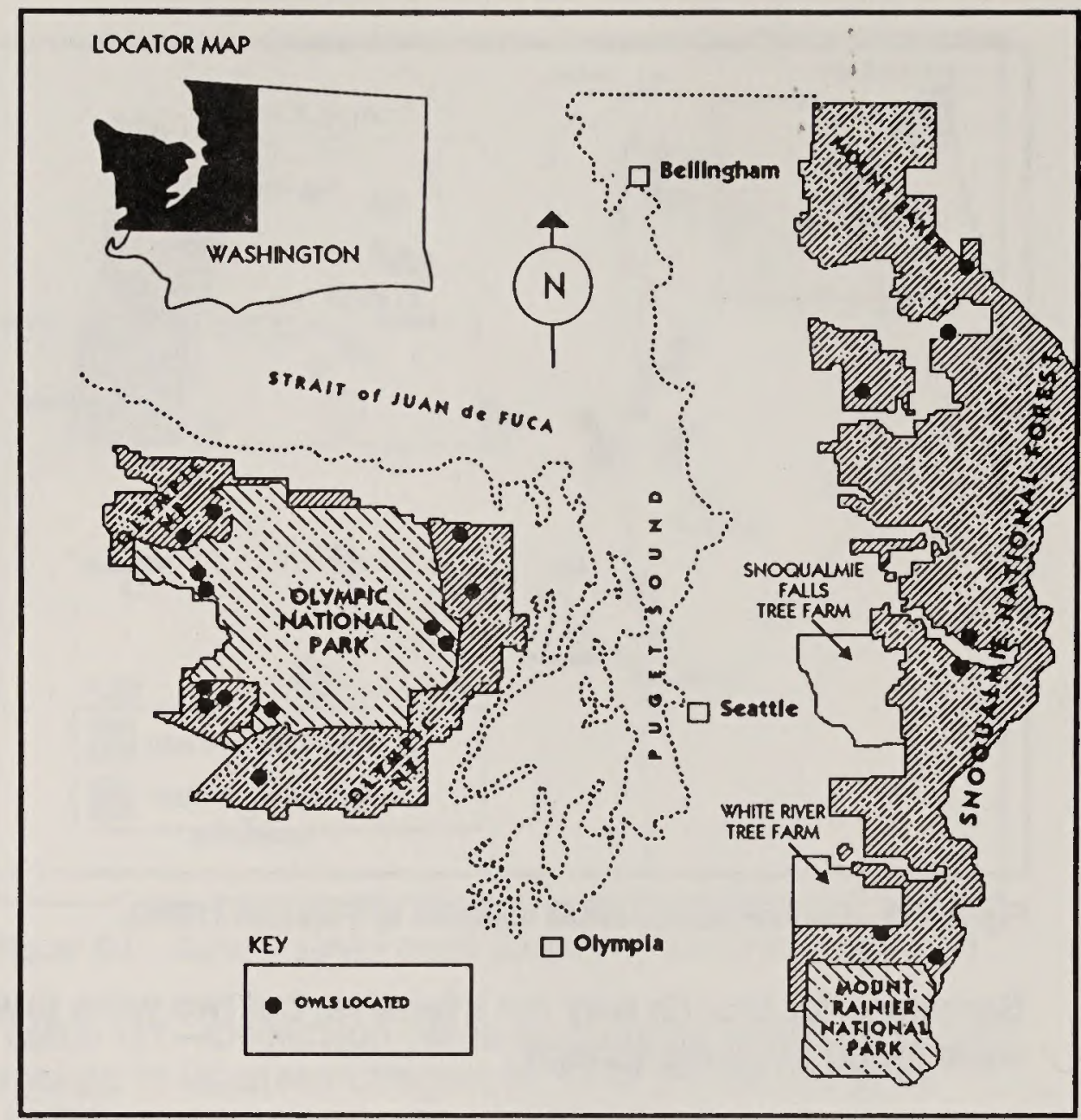

Figure G3 - Owl sightings by Postovit (1979).

Results of this survey agree with those in Forsman et al. (1977), except that the response rate in younger forests was even lower than during the earlier survey. Again, this response rate suggested low abundance of spotted owls in young forests of the northern Coast Range of Oregon. Some sites with owls in 1976 (Forsman et al. 1977) also contained spotted owls in 1986 (Forsman, pers. comm.). The authors suggested that the low response rate in the older forests of the northern Coast Ranges may be attributable to their isolation from spotted owl population centers in more extensive stands of old forest.

Postovit (1979)

Sampling areas (fig. G3) were on routes that passed through stands of unharvested old forest, mosaics of old and young forest, and unbroken young forest. Oldgrowth stands were at least 120 years old, and most had overstory trees older than 200 years. Younger forests were less than 120 years old, and most were less than 70 years old. Routes were chosen randomly from township, range, and section data. Thirty 2-mile routes were surveyed in each of five landscape types (see footnote to table G2 for descriptions). Recorded calls and vocal imitations were broadcast a prescribed number of times at prescribed intervals along the routes walked.

Results-Spotted owls were found on 18 of the 150 routes-single birds on 14 routes and two birds on each of 4 routes (two cases confirmed as pairs), for a total of 22 birds. Pairs were located only in landscape types 1 and 2, which consisted of at least $66 \%$ older forest (table G2). 


\section{Appendix G: Owl Abundance}

Table G2-Detectlon rates of spotted owls along randomly selected routes in landscapes with different proportions of old forest in Washington (60 miles of transect in each forest class) (Postovit 1979)

\begin{tabular}{lccc}
\hline $\begin{array}{l}\text { Landscape } \\
\text { type }\end{array}$ & $\begin{array}{c}\text { Total } \\
\text { count }\end{array}$ & $\begin{array}{c}\text { Mean number } \\
\text { per route }\end{array}$ & $\begin{array}{c}\text { Owls per mile } \\
\text { of transect }\end{array}$ \\
\hline 1 & 8 & 0.27 & 0.052 \\
2 & 7 & 0.23 & 0.045 \\
3 & 4 & 0.13 & 0.026 \\
4 & 2 & 0.07 & 0.013 \\
5 & 1 & 0.03 & 0.006 \\
\hline
\end{tabular}

a $1=>95 \%$ old forest, $<5 \%$ young forest; $2=66$ to $95 \%$ old forest, 5 to $34 \%$ young forest; $3=33$ to $65 \%$ old forest, 35 to $67 \%$ young forest; $4=5$ to $32 \%$ old forest, 68 to $95 \%$ young forest; $5=<5 \%$ old forest, $>95 \%$ young forest.

Irwin et al. (1989)

Detection rates in landscape types 1 ( $>95 \%$ old forest) and 5 ( $<5 \%$ old forest) were significantly different $\left(X^{2}=4.04 ; P<0.05\right)$, and the mean number of owls responding per route was positively correlated with the proportion of the landscape in older forest (Spearman's rho $=1 ; 0.02 P>0.01$ ).

Observers at sample areas (fig. G4) called at 0.3-mile intervals on road transects, using recorded and vocal calls, for 7 to 20 minutes at each calling station. Although an objective of the study was to sample stands mostly 40 to 120 years old, observers were unable to find extensive tracts in that age group. Reanalysis of the survey tracts indicated that an average of $86 \%$ of the area was $<60$ years old (Irwin, pers. comm.). Only the Matlock area contained much forest $>60$ years old. Altogether, this area had 20,000 acres of forest (34\% of the total) 61 to 80 years old (not contiguous). Areas sampled were in relatively unfragmented forest stands of at least 10,000 acres; a few stands contained snags and scattered large trees.

Results-The study produced no conclusive evidence of breeding anywhere in seven township-sized survey tracts in southwestern Washington in either year. In one instance in the Matlock area, however, observers heard what they believed to be a juvenile spotted owl in 1987. Barred owls were not detected in the area, and adult spotted owls were found on several occasions (table G3).

The study included more effort per stop than in other Washington studies, but generally had lower detection rates (see table G3).

The Nemah-Naselle area had at least five spotted owls in early 1986 (Atkinson, pers. comm.). This area had a block of about 250 acres of old-growth forest, which contained a pair of spotted owls, but it was 30 miles from the nearest known population of spotted owls.

Observers found no evidence to support the hypothesis that site occupancy would increase with decreased distance from a major source population in an area of extensive old-growth forest. The sample sizes (number of birds per site), however, were inadequate for any such test. 


\section{Appendix G: Owl Abundance}

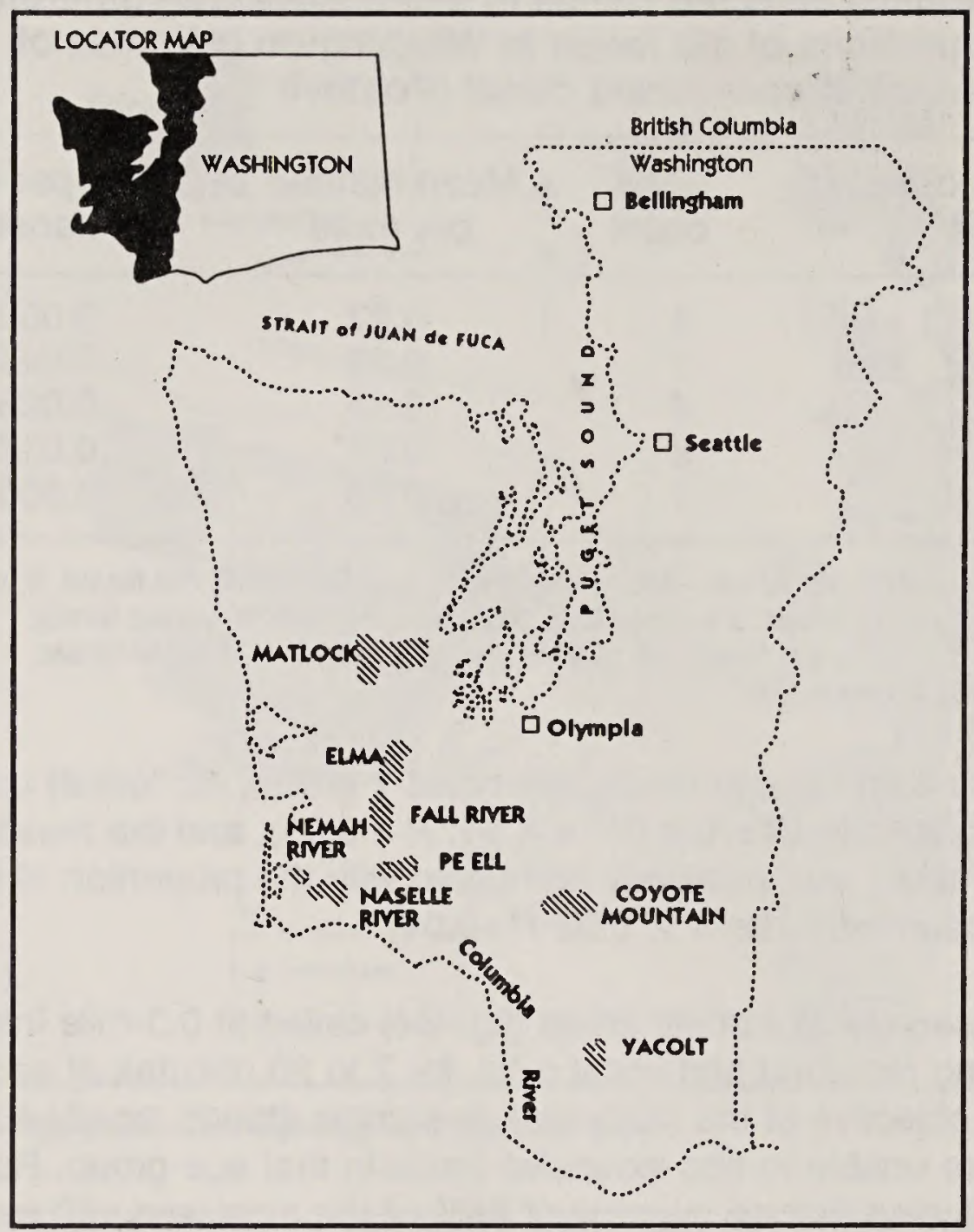

Figure G4-Study areas sampled by Irwin et al. (1989).

Table G3-Detectlons of spotted owls In forests malnly 20 to 60 years old In southwestern Washington (IrwIn et al. 1989)

\begin{tabular}{|c|c|c|c|c|c|c|c|c|}
\hline \multirow[b]{2}{*}{ Location } & \multicolumn{4}{|c|}{1987} & \multicolumn{4}{|c|}{1988} \\
\hline & Miles & Stops & Pairs & Singles & Miles & Stops & Pairs & Singles \\
\hline $\begin{array}{l}\text { Matlock } \\
\text { Elma } \\
\text { Nemah-Naselle } \\
\text { Fall River } \\
\text { Pe Ell } \\
\text { Coyote Mtn. } \\
\text { Yacolt }\end{array}$ & $\begin{array}{l}62.1 \\
71.8 \\
26.4\end{array}$ & $\begin{array}{l}622 \\
690 \\
132\end{array}$ & $\begin{array}{l}1 \\
0 \\
1\end{array}$ & $\begin{array}{l}3 \\
1 \\
1\end{array}$ & $\begin{array}{r}188.5 \\
60.6 \\
23.5 \\
63.2 \\
46.2 \\
99.2 \\
17.0\end{array}$ & $\begin{array}{r}1237 \\
409 \\
156 \\
435 \\
340 \\
651 \\
253\end{array}$ & $\begin{array}{l}0 \\
1 \\
0 \\
0 \\
0 \\
0 \\
0\end{array}$ & $\begin{array}{l}0 \\
0 \\
0 \\
1 \\
0 \\
0 \\
0\end{array}$ \\
\hline $\begin{array}{l}\text { Total } \\
\text { Birds/stop } \\
\text { Birds/mile }\end{array}$ & 160.3 & $\begin{array}{r}1444 \\
0.006 \\
0.06\end{array}$ & 2 & 5 & 498.2 & $\begin{array}{r}3481 \\
0.0009 \\
0.006\end{array}$ & 1 & 1 \\
\hline
\end{tabular}

Hays et al. (1989)

The design of this study involved random selection of 47 transects in western Washington, from the coast into the eastern Cascades. Each transect included 40 counting stations at $1 / 2$-mile intervals (fig. G5). "Virtually all forested vegetative zones...in western Washington and the eastern Cascade Range were surveyed. Elevations of calling stations ranged from sea level to over $6,000 \mathrm{ft}$." 


\section{Appendix G: Owl Abundance}

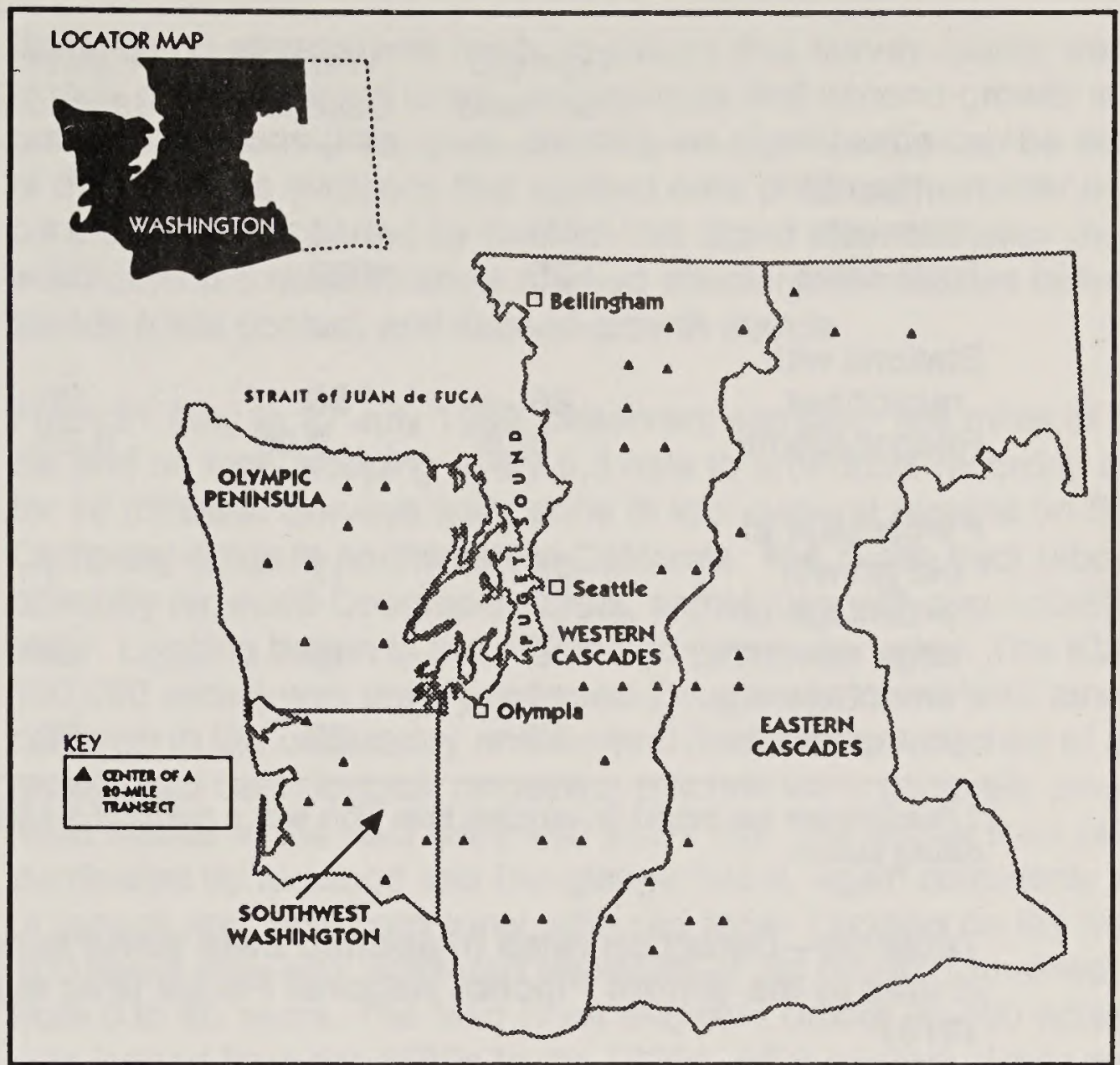

Figure G5-Centers of 20-mile transects sampled by Hays et al. (1989).

Estimates of habitat types were made over a 1/4-mile radius from each survey station. In addition, a subsample of 52 calling stations was randomly drawn from 22 transects. Vegetation based on Landsat imagery was characterized in a 2-mile square centered on each calling station in the subsample.

At each station, alternating tape-recorded and vocal calls were given for 7 to $10 \mathrm{~min}$ utes. When an owl was detected at a station, the surveyer skipped the next 1/2-mile stop to reduce the likelihood of double counting. Surveys were done twice in 1982 and twice in 1983, but not all transects were sampled every time because of a shortage of volunteers.

Results-Spotted owls were detected at 106 different calling stations; these counts were judged to represent 60 different single birds and nine pairs (table G4).

Routes in southwest Washington had the least old growth, as well as the lowest percentage of large sawtimber, based on the 1/4-mile-radius plots centered on counting stations. This area also had more than twice the amount of closed sapling-and-pole habitat than any other area.

Fourteen transects were in forests with less than $10 \%$ old growth (all six of the transects in southwest Washington and eight in other parts of the State). In a cumulative total of 1674 visits to 561 calling stations along these transects, over 2 years, only two birds were detected (0.0012/visit; $0.0023 /$ mile of transect). 


\section{Appendix G: Owl Abundance}

Table G4-Detection rates of spotted owls on randomly selected routes In forests of varlous ages throughout western Washington (Hays et al. 1989)

\begin{tabular}{lccccc}
\hline & $\begin{array}{c}\text { Olympic } \\
\text { Peninsula }\end{array}$ & $\begin{array}{c}\text { Western } \\
\text { Cascades }\end{array}$ & $\begin{array}{c}\text { Eastern } \\
\text { Cascades }\end{array}$ & $\begin{array}{c}\text { Southwest } \\
\text { Washington }\end{array}$ & Total \\
\hline $\begin{array}{l}\text { Number of } \\
\text { transects }\end{array}$ & 9 & 18 & 14 & 6 & 47 \\
Total miles & 585 & 1089 & 886 & 367 & 2927 \\
$\begin{array}{l}\text { Stations with } \\
\text { responses } \\
\text { Responses/mi }\end{array}$ & 28 & 56 & 20 & 2 & 106 \\
$\begin{array}{l}\text { Percentage of } \\
\text { old growth }\end{array}$ & 0.05 & 0.05 & 0.02 & 0.005 & 0.037 \\
$\begin{array}{c}\text { Percentage of } \\
\text { large sawtimber }\end{array}$ & 25 & 17 & 7 & 0 & 12 \\
$\begin{array}{c}\text { Percentage of } \\
\text { young forest }\end{array}$ & 35 & 15 & 23 & 7 & 14 \\
\hline
\end{tabular}

a Percentages are based on samples from plots with a radius of $1 / 4$ mile centered on each calling station.

Table G5-Detectlon rates of spotted owls along survey routes In the Gifford PInchot Natlonal Forest (Paz et al. 1979)

\begin{tabular}{ccrcc}
\hline Year & $\begin{array}{c}\text { Stand age } \\
\text { (years) }\end{array}$ & $\begin{array}{c}\text { Miles of } \\
\text { survey }\end{array}$ & $\begin{array}{c}\text { Owl sites } \\
\text { located }\end{array}$ & $\begin{array}{c}\text { Owl sites } \\
\text { per mile }\end{array}$ \\
\hline 1978 & $0-80$ & 6.50 & 2 & $\overline{-a}^{a}$ \\
& $80-200$ & 34.25 & 8 & 0.23 \\
Total & $200+$ & 85.25 & 10 & 0.12 \\
1979 & & 126.00 & 20 & 0.16 \\
& $0-80$ & 45.30 & 3 & 0.07 \\
Total & $80-200$ & 166.10 & 14 & 0.08 \\
& $200+$ & 131.20 & 22 & 0.17 \\
& & 342.60 & 39 & 0.11 \\
\hline
\end{tabular}

${ }^{2}$ Inadequate sample to estimate detection rate.

Based on results from the 52 randomly selected calling stations ( 32 stations where spotted owls were detected, 20 where they were not), stations with owl detections had significantly more old-growth conifers $(t=2.4 ; P=0.02)$, more large sawtimber $(t=2.4 ; P=0.02)$, less in pole stands $(t=3.0 ; P=0.004)$, less sapling/shrub/forb habitat $(t=1.0 ; P=0.03)$, and less grass/shrub/forb habitat $(t=2.6 ; P=0.01)$.

Paz et al. (1979)

Surveys were done in 1978 and 1979, using the leapfrog method to cover a total of 468.6 miles of routes.

Results-Nineteen pairs were located, 11 in old growth; five pairs had young, of which three were in old growth. Seven pairs were found in mature stands, and two had young. One pair was found in a second-growth stand that resulted from fire (table G5). 


\section{Appendix G: Owl Abundance}

DIIler (1989)

Pious (1989)
Because no attempt was made to assure that survey routes were in large, extensive stands of similar-aged forest, or to assure that second-growth stands lacked oldgrowth inclusions (Paz, pers. comm.), no significance can be attached to the results of this study as evidence that spotted owls prefer either older or younger forests. This conclusion is supported by the fact that stand characteristics measured where owls were detected failed to show marked structural differences between old-growth/mature stands (data pooled) and second-growth stands.

From 31 May to 27 July 1989, observers sampled 129 miles of survey routes by vehicle and on foot, stopping every 0.3 mile to broadcast recorded calls of spotted owls for 10 minutes. Surveys were done in four general regions on Simpson Redwood Company lands in northwestern California. The Smith tract (about 29,000 acres) was primarily redwood-Douglas-fir forest, sometimes with an understory of tanoak or red alder. Logging began in the 1920 s and continues today. The Klamath tract (about 100,000 acres) was mainly redwood-Douglas-fir forest, with tanoak and red alder common in the understory and several interspersed patches of grassland. Most old growth had been logged; remaining patches were generally smaller than 60 acres. Most stands in the tract were $<50$ years old. The Korbel tract $(42,000$ acres) was dominated by redwood and Douglas-fir forest, again commonly with an understory of tanoak and, less commonly, with red alder. Logging on the tract began more than 100 years ago; only scattered remnants of old growth remained. Stand ages ranged from 0 to 80 years. The Mad River segment (about 20,000 acres) of the Korbel tract was logged from the 1880 s to the 1930s. After harvest, areas were burned in an attempt to produce pasture land. Logging of second growth began in 1979, and less than half remains. Ages of remaining stands ranged from 55 to 80 years. The Fortuna tract (about 10,000 acres) was primarily second-growth redwood and Douglas-fir. Stand ages ranged from 0 to 60 years. Habitat measures were taken from 1988 aerial photos, existing timber inventories, and various maps.

Follow-up visits were made during the daytime to as many nighttime locations as possible, in an effort to locate roost and nest sites and to determine possible pairing and breeding status.

Results - In addition to spotted owls located during surveys and follow-ups, others were located by spot calling in areas not surveyed. The study produced a total of 46 males, 29 mated pairs, and 20 young of the year (table G6). Fifteen reproductive pairs were confirmed; $57 \%$ of the nesting and roosting areas were in stands dominated by redwood and Douglas-fir. Hardwoods of various species were abundant in $48 \%$ of the nesting and roosting sites. Stand ages in nesting and roosting areas ranged from 30 to 100 years ( $\bar{x}=57$ years). Stand height ranged from 40 to 160 feet, with a median of 101 feet. Canopy closure ranged from 50 to $90 \%$, with a mean of $81 \%$. Distances to old-growth stands ranged from 2 to 14 miles $(\bar{x}=8.6$ miles).

From 1 April to 1 September 1989, observers surveyed 857 miles of roads in secondgrowth coastal redwood and Douglas-fir forests in north-coastal California (fig. G6). A subset of 31 sites where owls were detected was chosen for further investigation seeking evidence of nesting, following the standard monitoring protocols used by the FS. Redwoods or Douglas-fir dominated all stands, with trees ranging in size to at least 4 feet in d.b.h. 


\section{Appendix G: Owl Abundance}

Table G6-Summary of results from calling surveys for spotted owls In second-growth forests (malnly redwood and Douglas-fir) In northwestern Cailfornla In 1989 (Diller 1989)

\begin{tabular}{lcccc}
\hline Tract & $\begin{array}{c}\text { Miles } \\
\text { surveyed }\end{array}$ & $\begin{array}{c}\text { Owl } \\
\text { responses }\end{array}$ & $\begin{array}{c}\text { Responses } \\
\text { per mile }\end{array}$ & $\begin{array}{c}\text { Mean age } \\
\text { of stands }\end{array}$ \\
\hline $\begin{array}{l}\text { Smith River } \\
\text { Klamath }\end{array}$ & 22.6 & 4 & 0.18 & 46.0 \\
$\begin{array}{l}\text { Korbel and } \\
\text { Fortuna }\end{array}$ & 64.8 & 7 & 0.11 & 41.0 \\
\hline
\end{tabular}

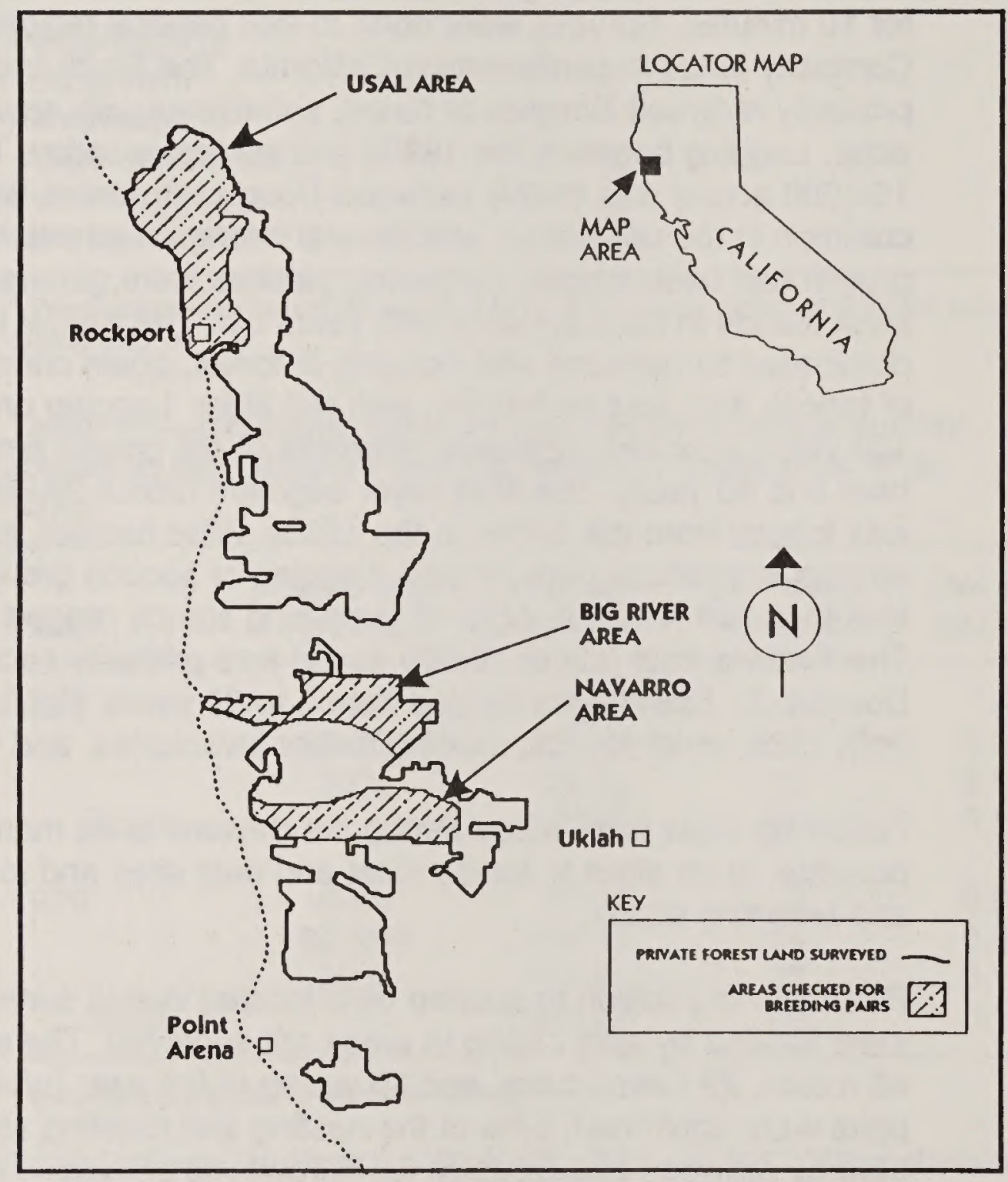

Figure G6-General study areas sampled by Pious (1989).

Results - Spotted owls were found in 90 sites in the study area and pairs were found at 51 sites; owls were detected at a rate of 0.06 per mile of road traveled. Stand ages were estimated from core samples of trees in the dominant overstory canopy. From data presented in appendix 5 of the report by Pious (1989), we summarized stand ages in relation to spotted owls breeding by geographic area. Results in 1989 showed a trend toward a higher mean age of stands in sites with nesting pairs $(\bar{x}=80.9$ years, $S D=33.0, n=8)$ than in sites without them $(\bar{x}=69.7$ years, $\mathrm{SD}=27.0, n=21)$. The difference was not significant $(t=0.94 ; \mathrm{df}=27 ; 0.4>$ $P>0.3)$. Results also showed an increasing percentage of nesting pairs in areas 


\section{Appendix G: Owl Abundance}

Table G7-Mean stand ages in 3 geographic areas in coastal redwood and Douglas-fir forests of California in relation to the proportion of breeding pairs of spotted owis located (based on data from Plous 1989)

\begin{tabular}{lcccccc}
\hline \multirow{2}{*}{$\begin{array}{l}\text { Geographic } \\
\text { area }\end{array}$} & \multicolumn{3}{c}{ Stand age } & & \multicolumn{2}{c}{ Nesting pairs } \\
\cline { 2 - 3 } & Mean & SD & $n$ & & $n$ & Percent \\
\hline Usal & 59.7 & 19.3 & 7 & & 1 & 13 \\
Big River & 64.8 & 30.7 & 12 & & 2 & 17 \\
Navarro & 91.6 & 23.2 & 10 & & 5 & 50 \\
\hline
\end{tabular}

Bart and Forsman (unpubl.) with older stands (table G7). The mean age of stands in the Navarro area, which had a much higher percentage of nesting pairs than either of the other areas, was significantly different from that in the Big River area $(t=2.3 ; \mathrm{df}=20 ; 0.05>P>0.02)$ and the Usal area $(t=2.9 ; \mathrm{df}=15 ; 0.05>P>0.02)$.

In this study, Bart and Forsman (unpubl.) compared the densities of spotted owls in areas dominated by clearcuts and young forest ( 50 to 80 years) with nearby areas where old-growth forest was more abundant (fig. G7). Twelve of these pairwise comparisons were made. The objective was to assess the effects of widespread clearcutting on spotted owl numbers, so areas were excluded where extensive selection cutting or partial burns had occurred. Data were summarized from several sources, including unpublished reports and direct communication with FS and BLM personnel. Second-growth study areas ranged in size from 5 to 277 square miles $\left(\bar{x}=60.3 \mathrm{mi}^{2}\right.$; $S D=83.1)$. Old-growth study areas ranged in size from 11 to 113 square miles $\left(\bar{x}=57.0 \mathrm{mi}^{2} ; \mathrm{SD}=36.7\right)$. Nearly all study areas covered at least 8 square miles (the few exceptions are noted below), and all were surveyed at least three times in at least one year. Results were expressed as mean annual numbers of owl pairs and singles per 100 square miles.

Resuits - In study areas dominated by young forests, stands 50 to 80 years old covered from 33 to $92 \%$ of the landbase $(\bar{x}=59.3 \%$; SD $=18.1)$, stands 81 to 120 years old covered from 0 to $67 \%(\bar{x}=7.1 \% ; S D=19.4)$, and stands older than 160 years covered from 0 to $15 \%(\bar{x}=4.1 \%$; $S D=5.2$ ) (table G8). In old-growth study areas, stands 50 to 80 years old covered 0 to $39 \%$ of the total area $(\bar{x}=6.1 \%$; SD $=$ 12.4). Stands 81 to 120 years old were missing from all but one site, which had $10 \%$ coverage by that age-class, and stands $160+$ years old covered an average of $49.1 \%$ of the land $(S D=18.8$; range $=19$ to $73 \%$ ) (table $G 8$ ).

Results indicated that forests $<80$ years old, regenerating from clearcut logging and lacking appreciable amounts of older forest in remnant patches, were poor habitat for spotted owls (table G8) (see appendix F for details on suitable owl habitat). The study did not provide enough data to address the question of habitat suitability in stands 81 to 120 years old. Pairs of spotted owls were documented in only 2 of the 12 second-growth study areas. One area included $15 \%$ mature age-class stands ( 81 to 120 years old), and $5 \%>160$-year-old stands. The other area had $4 \%$ of its area in the $>160$-year class. The mean density of spotted owl pairs on the secondgrowth areas was $0.83 / 100$ square miles $(S D=1.99)$. Old-growth study areas had a mean of 12.75 pairs per 100 square miles $(S D=11.3)$, and all old-growth areas had owl pairs (range $=2 / 100$ square miles to $36 / 100$ square miles). 


\section{Appendix G: Owl Abundance}

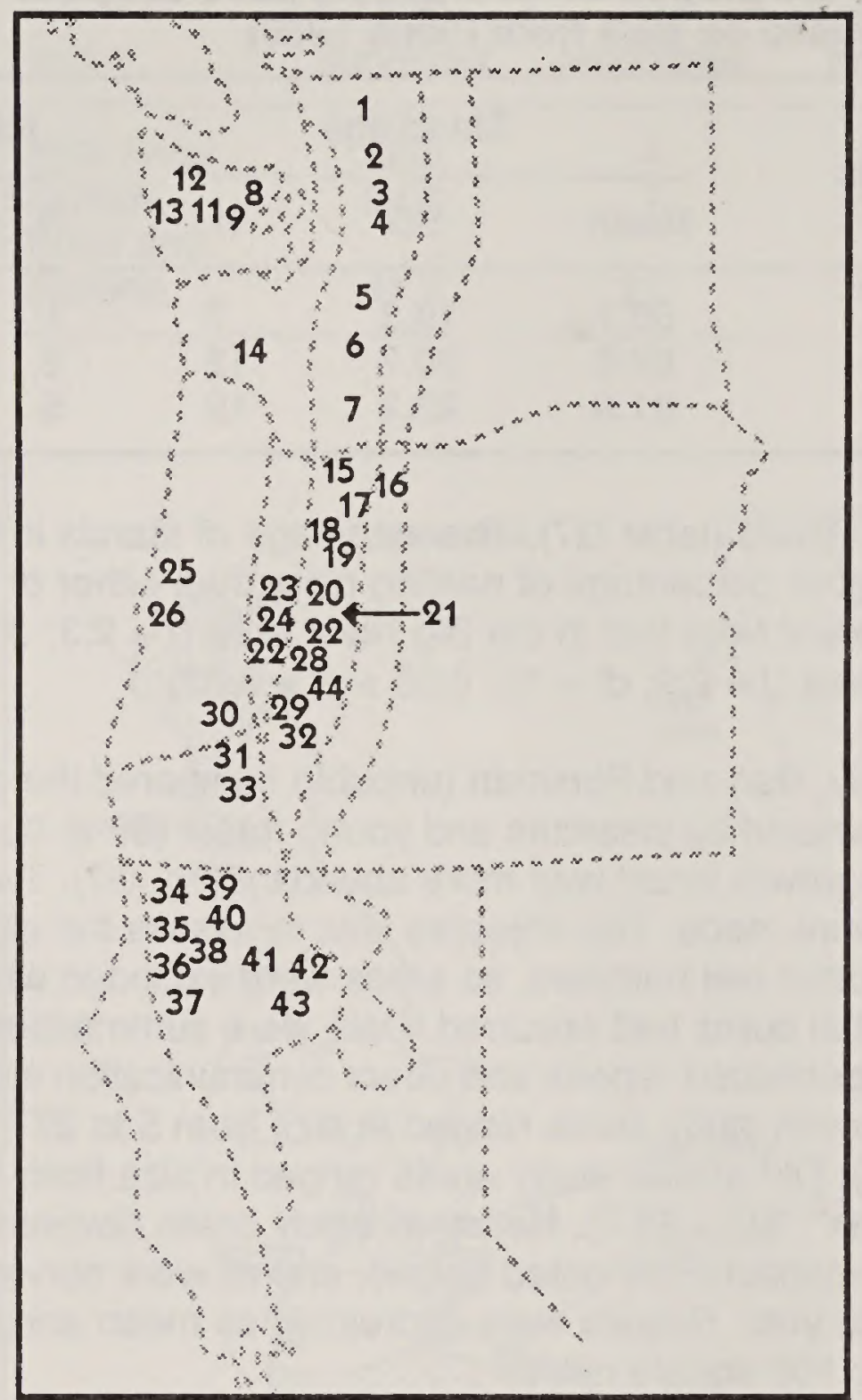

Figure G7-Approximate study areas of Bart and Forsman.

Discussion

Washington and Oregon
Data from Washington and Oregon are inadequate to determine the general ages when conifer forests begin to develop stand conditions suitable for spotted owls to breed. Not all studies directly compared both young and old forests, and even the set of all studies had relatively few survey routes in extensive stands of forests in the age group from about 80 to about 120 years. But the data suggest that this is the most likely period when forests "come of age" for spotted owls. Relatively young stands (20 to 60 years old), however, were generally unsuitable as owl habitat in Douglas-fir-hemlock forests in western Oregon and Washington. 


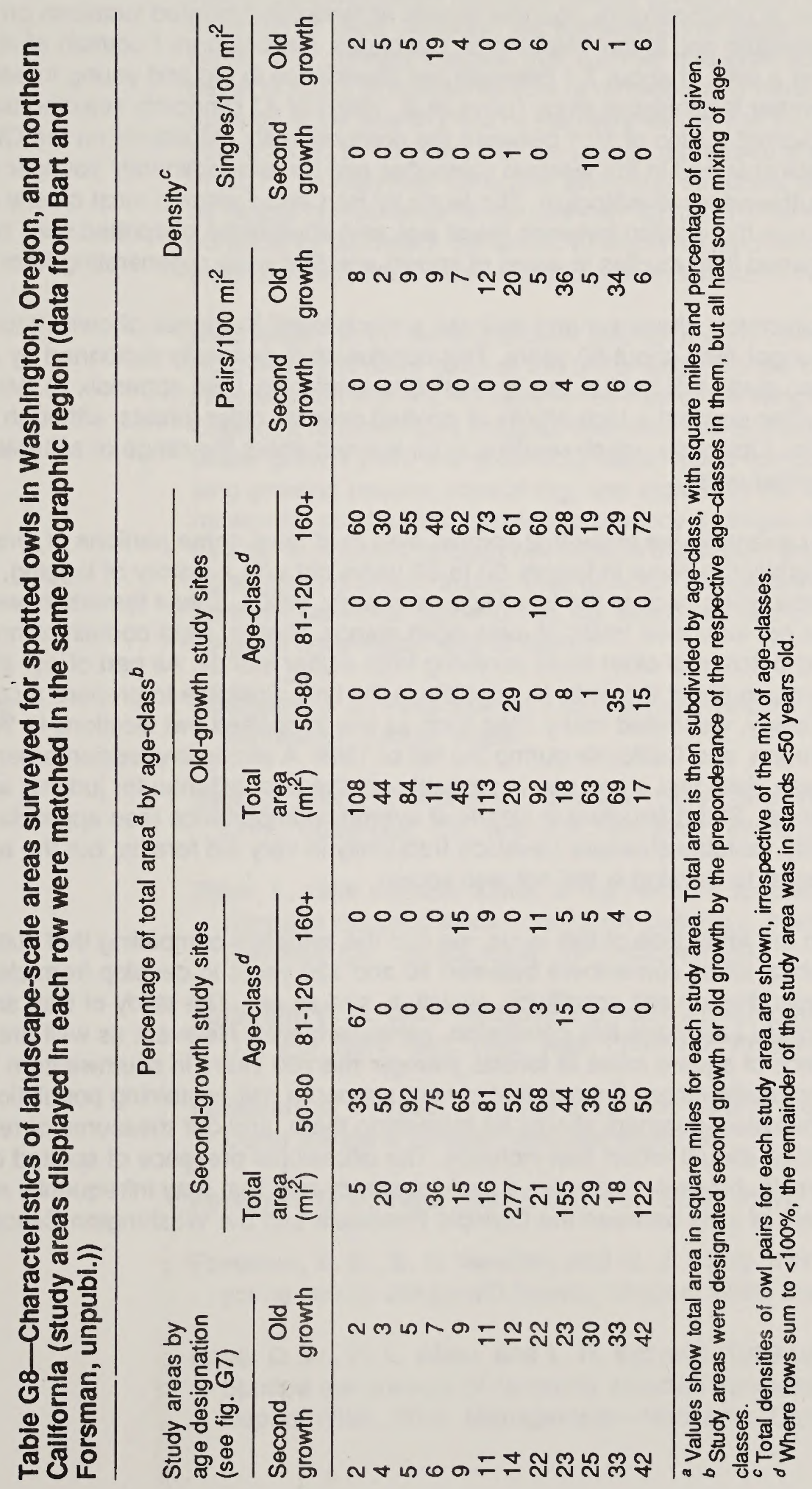




\section{Appendix G: Owl Abundance}

In studies that used standardized methods to sample the relative abundance of spotted owls in a variety of habitats, comparing indices of abundance by forest age or stand condition is reasonable. For example, Postovit's (1979) results indicate that the owls are about eight times more abundant in predominantly old-growth forests than in predominantly younger stands at randomly selected locations on the Olympic Peninsula and in the Washington Cascades. Results from Forsman et al. (1977) suggest a ratio of about 7:1 between owl abundance in old and young forests in Oregon. Another Washington study (Hays et al. 1989) of 47 randomly selected transects indicated a ratio of 10:1 between the predominantly old stands on the Olympic Peninsula and in the western Cascades and the predominantly younger stands of southwestern Washington. The study by Bart and Forsman most clearly demonstrates the relation between forest age and abundance of spotted owls because they focused their studies in areas of known age that were regenerating from clearcuts.

Collectively, these surveys indicate a much lower incidence of owls in forests younger than about 80 years. This conclusion is generally supported by results from studies of habitat use in relation to availability (see appendix F). Most of those studies suggest a high affinity of spotted owls for older forests, although exceptions exist. Obviously, much remains to be learned about the range of suitable habitats for spotted owls.

For example, we know that spotted owls in at least some portions of Oregon and Washington occur in forests 50 to 80 years old with a history of logging, fire, or windthrow going back to the late 1800 s and early 1900 s. These forests, however, typically are not extensive tracts of even-aged stands. Rather, most contain remnant trees and patches of older trees surviving from earlier stands. As part of our effort to learn as much about the owls as possible in the time available to prepare a conservation strategy, we visited many sites such as this in spotted owl locations in Washington, Oregon, and Califomia during the fall of 1989. A strong impression emerged from those visits that stand age is probably not the best criterion for judging suitable owl habitat. Stand structure is clearly of overriding importance (see appendix F). Apparently, suitable structure develops frequently in very old forests, but the age when it begins to develop is still not well known.

On the other side of this issue, we find the evidence compelling that suitable owl habitat takes somewhere between 80 and 120 years to develop from clearcut stands, depending on site conditions, elevation, and so on. The study of Bart and Forsman (unpubl.) supports this conclusion particularly well. Relevant as well are the hundreds of square miles of forests younger than 60 years in southwestern Washington and northwestern Oregon that cannot support a self-sustaining population of owls. Otherwise, numbers should be increasing there, and our measures of relative abundance should reflect that increase. The occasional presence of spotted owls in these forests, however, indicates a low occupancy rate that may infrequently result in movement of owls between the Olympic Peninsula and the Washington Cascades. 


\section{Appendix G: Owl Abundance}

California

References
Recent studies supported by the timber industry in northern coastal California suggest that conditions suitable for occupancy and breeding by spotted owls develop rapidly in the redwood forests of north coastal California. Extensive tracts of relatively young, second-growth redwood forests contain owls, several of which were found breeding in 1989. Although the implications of these studies are not yet fully understood, they strongly suggest that suitable and even superior spotted owl habitat can develop faster in coastal forests of redwood and mixed redwood and Douglas-fir than appears to be true in most of the owl's range. For example, even in some forests as young as 60 to 70 years old, we toured impressive stands with many trees 3 to 4 feet in d.b.h., multilayered canopies, and other structural attributes generally recognized as typical components of suitable owl habitat. These studies in California need to continue to document the extent to which spotted owls may be able to sustain a breeding population within second-growth forests in the coastal redwood belt.

Meanwhile, no evidence indicates that such early development of suitable habitat is typical in most other parts of the owl's range. To the contrary, available evidence indicates that it is not. Relative to the rest of the range of the spotted owl, coastal California redwood and Douglas-fir forests are probably anomalous. Conditions for timber growth there are apparently ideal-good soil conditions, high rainfall, relatively long growing season, coastal fog, and especially the stump-sprouting capability of redwoods, all of which combine to produce a unique situation among western conifer forests. In addition, spotted owl diets in this region are dominated by dusky-footed woodrats and brush rabbits, both of which are common in young, coastal forests in northern California (appendix J), but which are rare or absent in much of the owl's range in Washington and Oregon.

Atkinson, J. B. Pers. comm. U.S. Fish and Wildlife Service, Willapa National Wildlife Refuge, Ilwaco, Wash.

Bart, J., and E. D. Forsman. Unpubl. Ohio Coop. Wildl. Res. Unit, Ohio State Univ., Columbus, Oh., and U.S. For. Serv., PNW, Olympia, Wash.

Diller, L. 1989 unpubl. Status of the northern spotted owl in managed forests on Simpson redwood lands in northern California. Interim report submitted to Simpson Redwood Co., Arcata, Calif., 20 October 1989.

Forsman, E. D. 1983. Methods and materials for locating and studying spotted owls. U.S. For. Serv. Gen. Tech. Rep. PNW-162. Portland, Oreg. 8pp.

Forsman, E. D. 1988. A survey of spotted owls in young forests in the northern Coast Range of Oregon. Murrelet 69:65-68.

Forsman, E. D. Pers. comm. U.S. For. Serv., PNW, Olympia, Wash.

Forsman, E. D., E. C. Mesiow, and M. J. Strub. 1977. Spotted owl abundance in young versus old-growth forests, Oregon. Wildl. Soc. Bull. 5:43-47.

Hays, D. W., H. L. Allen, and L. H. Egtvedt. 1989 unpubl. Preliminary report: Spotted owl surveys of randomly selected transects in Washington. Washington Dep. of Wildl., Wildl. Management-Nongame, Olympia. 31pp. 


\section{Appendix G: Owl Abundance}

Irwin, L. L. Pers. comm. NCASI, Corvallis, Oreg.

IrwIn, L. L., T. L. FlemIng, S. M. Spelch, and J. B. Buchanan. 1989 unpubl. Spotted owl presence in managed forests of southwestern Washington. Typescript report. National Council of the Paper Industry for Air and Stream Improvement. West Coast Regional Center, Corvallis, Oreg. 30pp.

Paz, A. H. Pers. comm. U.S. For. Serv., Gifford Pinchot National Forest, Vancouver, Wash.

Paz, A. H., D. Mengel, W. Ruediger, and E. Garcla. 1979 unpubl. Gifford Pinchot National Forest spotted owl survey and habitat analysis. Typescript.

Plous, M. 1989 unpubl. The northern spotted owl in managed, second-growth coastal redwood forests, Mendocino County, California: Preliminary results. Louisiana Pacific Corporation, Calpella, Calif. 105pp.

Postovit, H. R. 1979 unpubl. A survey of the spotted owl in northwestern Washington. Forest Industry Resource and Environment Program. Natl. For. Prod. Assoc., Washington, D.C. 15pp. 


\section{Abundance of Spotted Owls in Relation to the Amount of Suitable Habitat}

\section{Introduction}

Forsman et al. (1987)
Much observational information suggests that spotted owl densities decline as portions of the remaining unlogged forest are harvested, but few well-designed studies have specifically addressed this matter in a way that excludes alternative explanations. For example, Forsman et al. (1987) reviewed all available information on the status of spotted owls in Oregon through 1984, concluding that the owls are found primarily in older (200 years) forests that have not been logged, and that owl numbers are declining in areas subjected to considerable harvest of such older forests. Their conclusions can be challenged, however, because sampling effort was not proportional to the total areas of different forest types and ages. Nonetheless, their summary compiles a massive data base representing 15 years of field effort by many biologists. Here, we briefly summarize available studies with information on the relative abundance of owls in relation to the amount of unlogged forest remaining in the landscape.

Forsman et al. compare the status of owl pairs between 1976 and 1987 from sites where extensive logging during that period reduced the amount of remaining oldgrowth forest. Spotted owl numbers were well known in the region in the 1970 s.

Results-The best-documented case is irom private and public lands, in a checkerboard ownership pattern, within the Roseburg District of the BLM in Oregon. At 56 sites where owl pairs were located between 1976 and 1977, 11 no longer had owls in 1987, and 8 others were believed to be unoccupied, based on 1 or 2 years of negative survey results after timber harvest. This amounted to an estimated loss of 20 to $34 \%$ of the spotted owl sites as a result of logging activity from 1976 to 1987. This rate is probably higher than occurred on National Forest lands during the same period, because the checkerboard ownership pattern of BLM and private holdings tends to fragment the habitat more in western Oregon than elsewhere.

Forsman (pers. comm.) also summarized the proportion of all known sites where owls were located from 1969 to 1984 in logged and unlogged areas in Oregon. Although his summary was based on surveys unweighted by forest type and age-class, extensive effort by numerous observers has gone into searching for owls in a large variety of forest conditions in the State during the past decade or more. We are therefore impressed that only $2.1 \%$ of all known spotted owl sites in Oregon have been found in logged areas and only $14.7 \%$ of known sites were found in forests $<200$ years old. 


\section{Appendix H: Owl Abundance and Habitat}

O'Hailoran (1989) and

Simon-Jackson (1989)
Using standard protocols, field biologists surveyed for owls in random sample areas (RSAs) and Spotted Owl Habitat Areas (SOHAS) in 1988 and 1989. Because RSAs were established as 1000 -acre circles centered on points randomly selected throughout the National Forests of both Regions, results from the RSA surveys are well suited to test the null hypothesis that the occurrence of owls is not related to the amount of suitable habitat.

Resuits - In all 12 comparisons between RSAs with $<500$ acres of suitable habitat and RSAs with $>500$ acres of suitable habitat, the percentage of occupancy was higher in RSAs with more suitable habitat (table H1). Only two of the data sets were fully independent, however, so a test (for example, sign test) of the statistical significance of this result is inappropriate. The mean acreage of suitable habitat in occupied RSAs was, however, significantly greater than that in unoccupied RSAs in three of four comparisons (Region 5, 1988; Region 6, 1988 and 1989-table H2). In the fourth comparison (Region 5, 1989), the mean was greater in occupied RSAs but not significantly so.

Tabie H1-Occupancy rates in reiation to the amount of suitabie spotted owi habitat in random sample areas (RSAs) ${ }^{a}$ in the FS monitoring program of Region 5 (Pacific Southwest Region) (Simon-Jackson 1989) and Region 6 (Pacific Northwest Region) (O'Hailoran 1989)
RSAs with $<500$ acres of suitable habitat

Region 5 Region 6
RSAs with $>500$ acres of suitable habitat

Region 5 Region 6
Reserved and nonreserved areas combined
1988 Number RSAs sampled RSAs with pairs or singles RSAs with pairs only

1989 Number of RSAs sampled RSAs with pairs or singles RSAs with pairs only

Nonreserved areas only

1988 Number RSAs sampled RSAs with pairs or singles RSAs with pairs only

1989 Number of RSAs sampled RSAs with pairs or singles RSAs with pairs only

Reserved areas only

1988 Number RSAs sampled RSAs with pairs or singles RSAS with pairs only

1989 Number of RSAs sampled RSAs with pairs or singles RSAs with pairs only
83

$40 \%$

$16 \%$

93

$52 \%$

$16 \%$

66

$45 \%$

$17 \%$

54

$65 \%$

$20 \%$

17

$18 \%$

$12 \%$

39

$33 \%$

$10 \%$
130

$38 \%$

$13 \%$

91

$43 \%$

$23 \%$
21

$81 \%$

$52 \%$

42

$57 \%$

$29 \%$

15

$80 \%$

$47 \%$

17

$71 \%$

$41 \%$

6

$83 \%$

$67 \%$

$30 \%$

$11 \%$

33

$45 \%$

$24 \%$
54

$76 \%$

$22 \%$

48

$73 \%$

$29 \%$

\footnotetext{
${ }^{a}$ RSAs are 1000-acre circles with center points selected randomly from within National Forest boundaries. Points drawn from lake surfaces were excluded.
} 


\section{Appendix H: Owl Abundance and Habitat}

Table H2-Comparisons of mean acreages of sultable habitat in the 1000-acre circles comprising random sample areas (RSAS) occupled and not occupled by spotted owis In Reglons 5 and 6 In 1988 and 1989 (our analyses, based on O'Halloran 1989, and Simon-Jackson 1989)

\begin{tabular}{|c|c|c|c|c|c|c|c|c|c|}
\hline \multirow[b]{2}{*}{ Location } & \multirow[b]{2}{*}{ Year } & \multicolumn{3}{|c|}{ Occupied RSAs } & \multicolumn{3}{|c|}{ Unoccupied RSAs } & \multirow[b]{2}{*}{$t$-value } & \multirow[b]{2}{*}{$P$} \\
\hline & & $\begin{array}{l}\text { No. } \\
\text { sites }\end{array}$ & $\begin{array}{l}\text { Mean } \\
\text { acres }\end{array}$ & SD & $\begin{array}{l}\text { No. } \\
\text { sites }\end{array}$ & $\begin{array}{l}\text { Mean } \\
\text { acres }\end{array}$ & SD & & \\
\hline Region 5 & $\begin{array}{l}1988 \\
1989\end{array}$ & $\begin{array}{l}50 \\
72\end{array}$ & $\begin{array}{l}397 \\
394\end{array}$ & $\begin{array}{l}272 \\
262\end{array}$ & $\begin{array}{l}54 \\
63\end{array}$ & $\begin{array}{l}161 \\
356\end{array}$ & $\begin{array}{l}211 \\
274\end{array}$ & $\begin{array}{r}4.93 \\
-0.84\end{array}$ & $\begin{array}{r}<0.00 \\
0.40\end{array}$ \\
\hline Region 6 & $\begin{array}{l}1988 \\
1989\end{array}$ & $\begin{array}{l}91 \\
74\end{array}$ & $\begin{array}{l}475 \\
485\end{array}$ & $\begin{array}{l}259 \\
251\end{array}$ & $\begin{array}{r}93 \\
110\end{array}$ & $\begin{array}{l}246 \\
274\end{array}$ & $\begin{array}{l}237 \\
254\end{array}$ & $\begin{array}{l}-6.25 \\
-5.58\end{array}$ & $\begin{array}{l}<0.00 \\
<0.00\end{array}$ \\
\hline
\end{tabular}

Table H3-Percentage cutover in 7 plot sizes centered on 30 spotted owl nest sites and 30 randomiy selected points in the Cascade Range of western Oregon (Ripple et al. unpubl.)

\begin{tabular}{|c|c|c|c|c|c|c|c|c|c|c|}
\hline \multicolumn{2}{|c|}{ Plot size } & \multicolumn{4}{|c|}{$\begin{array}{l}\text { Percentage cutover } \\
\text { around nest sites }\end{array}$} & \multicolumn{4}{|c|}{$\begin{array}{l}\text { Percentage cutover } \\
\text { around random sites }\end{array}$} & \multirow[b]{2}{*}{$P$-value } \\
\hline Acres & radius & Mean & Min & Max & SD & Mean & Min & Max & SD & \\
\hline 642 & 0.56 & 21.8 & 0 & 49 & 11.8 & 36.8 & 0 & 85 & 20.2 & 0.0008 \\
\hline 1087 & 0.75 & 23.7 & 0 & 52 & 11.9 & 36.5 & 3 & 75 & 17.7 & 0.0016 \\
\hline 1531 & 0.87 & 23.6 & 3 & 53 & 11.3 & 36.7 & 5 & 72 & 15.7 & 0.0004 \\
\hline 1976 & 1.00 & 24.4 & 3 & 55 & 11.1 & 37.5 & 10 & 74 & 15.3 & 0.0003 \\
\hline 2421 & 1.10 & 24.9 & 3 & 58 & 11.1 & 38.4 & 13 & 73 & 14.5 & 0.0002 \\
\hline 4510 & 1.50 & 26.4 & 6 & 55 & 9.9 & 39.2 & 14 & 74 & 13.5 & 0.0001 \\
\hline 8862 & 2.10 & 35.0 & 21 & 60 & 8.7 & 42.7 & 22 & 78 & 13.2 & 0.0101 \\
\hline
\end{tabular}

Similarly, our analysis of the data for RSAs, using logistic regression models, indicated that percentage of occupancy by spotted owls increased significantly with an increasing amount of suitable habitat in Region 5 in 1988 (but not in 1989) and in Region 6 in both years (appendix K).

Logistic regression models using the SOHA data indicated that the percentage of owl occupancy increased significantly with an increasing amount of suitable habitat within 2.1 miles of SOHA centers in Region 6 in 1989. Such a relation was not found between owl occupancy and the amount of suitable habitat within 1.5 miles of SOHA centers in Region 5 in 1989.

Ripple et ai.

Using dot grids on orthophoto quadrangles, Ripple et al. (unpubl.) estimated percentages of the landscape that were "cutover" at 30 nest sites, and at 30 matched sites randomly selected in the same general areas in the Cascade Range of western Oregon. Cutover was defined as "all areas not consisting of mature or old-growth forests (that is, harvested units, stands less than 80 years old, and water bodies)." Estimates were made for seven circular plot sizes (table H3) centered at nest trees and at randomly selected points. 


\section{Appendix H: Owl Abundance and Habitat}

Table H4-Pairs of spotted owis per 100 square miles in relation to the proportion of sultable habltat (forests $160+$ years old) In varlous large blocks (mean of 59 square miles) of habitat distributed widely throughout Washington, Oregon, and northern Callfornia (see fig. G7 in appendix G)

\begin{tabular}{|c|c|c|c|c|c|}
\hline \multirow[b]{2}{*}{ Region } & \multicolumn{5}{|c|}{ Percentage of areas in suitable habitat } \\
\hline & $0-20$ & $21-40$ & $41-60$ & $61-80$ & $81-100$ \\
\hline \multicolumn{6}{|c|}{ Washington Cascades } \\
\hline Pairs $/ 100 \mathrm{mi}^{2}$ & 0 & 5 & 7 & 11 & \\
\hline Number of sites & 5 & 8 & 13 & 3 & 0 \\
\hline \multicolumn{6}{|l|}{ Olympic Peninsula } \\
\hline Pairs/100 mi ${ }^{2}$ & 1 & 4 & 5 & 8 & 15 \\
\hline Number of sites & 8 & 5 & 8 & 5 & 5 \\
\hline \multicolumn{6}{|c|}{ N. Oregon Cascades } \\
\hline Pairs/100 mi ${ }^{2}$ & 3 & 10 & 10 & 17 & 35 \\
\hline Number of sites & 1 & 4 & 8 & 10 & 1 \\
\hline \multicolumn{6}{|l|}{ Willamette } \\
\hline Pairs/100 mi² & 8 & 36 & & & \\
\hline Number of sites & 5 & 3 & 0 & 0 & 0 \\
\hline \multicolumn{6}{|c|}{ S. Oregon Caşcades } \\
\hline Pairs/100 mi ${ }^{2}$ & 10 & 12 & 12 & 31 & 21 \\
\hline Number of sites & 1 & 5 & 2 & 3 & 3 \\
\hline \multicolumn{6}{|l|}{ Oregon Klamath } \\
\hline Pairs/100 mi ${ }^{2}$ & 6 & 16 & & & \\
\hline Number of sites & 1 & 4 & 0 & 0 & 0 \\
\hline \multicolumn{6}{|l|}{ Willow Creek, CA } \\
\hline Pairs/100 mi ${ }^{2}$ & 9 & 30 & 45 & & \\
\hline Number of sites & 1 & 6 & 5 & 0 & 0 \\
\hline
\end{tabular}

${ }^{a}$ Data are from study by Bart and Forsman (unpubl.).

Results-For each plot size, the mean percentage of cutover area at random sites was significantly greater than that at the nest sites ( $t$-tests: $P<0.01$ in all cases and $P<0.003$ in six of the seven cases) (table H3).

Bart and Forsman

Bart and Forsman (unpubl.) summarized existing data in publications and reports on spotted owls and in FS and BLM files to determine owl densities in more than 40 large blocks of landscape $\left(\bar{x}=59 \mathrm{mi}^{2}\right)$, widely distributed throughout Washington, Oregon, and northern California (see fig. G7, appendix G). Estimates of density were based on repeated visits (minimum of three but most blocks were surveyed more often) to each block by agency and private personnel. Data for most blocks came only from visits in 1989, and blocks were included in the analysis only if the biologists responsible for surveys there expressed a high degree of confidence in the thoroughness of their surveys.

Results-An increasing trend in owl densities is clearly shown with increasing proportion of the landscape providing suitable owl habitat, as well as regional differences in densities in relation to available suitable habitat (table H4). For example, estimated densities in the Willamette and Willow Creek areas considerably exceed those for 


\section{Appendix H: Owl Abundance and Habitat}

Conclusions

References other areas with 21 to $40 \%$ of the area in suitable habitat. Whether or not packing (see appendix $\mathrm{N}$ ) is manifested in these areas is uncertain. A demographic study in the Willow Creek area of northwestem California indicates that a large and increasing number of replacements of birds lost from that area are adults from outside the study area (Franklin and Noon, pers. comm.). Normally, in a stable population, we expect most replacements to be by subadult birds.

Although each of these studies alone would not provide a strong basis for evaluating the relation between the amount of old-growth forest in a given landscape and the relative abundance of spotted owls there, coincidence is unlikely to account for the general pattern. In considering the collective results of these studies, therefore, we conclude that removal of old-growth forests generally results in a decrease in the abundance of spotted owls. We know of no study that has reached an opposite conclusion.

Bart, J., and E. D. Forsman. Unpubl. ms. Ohio Coop. Wildl. Res. Unit, Ohio State Univ., Columbus, Oh., and U.S For. Serv., PNW, Olympia, Wash.

Forsman, E. D., C. R. Bruce, M. A. Walter, and E. C. Meslow. 1987. A current assessment of the spotted owl population in Oregon. Murrelet 68:51-54.

Forsman, E. D. Pers. comm. U.S. For. Serv., PNW, Olympia, Wash.

Franklin, A. B., and B. R. Noon. Pers. comm. Humboldt State Univ., Arcata, Calif., and FS, PSW, Arcata, Calif.

O'Halloran, K. 1989 unpubl. Spotted owl inventory and monitoring: Annual report for 1989. U.S. For. Serv., Region 6, Portland, Oreg.

SImon-Jackson, T. 1989 unpubl. Spotted owl inventory and monitoring program: Annual report for 1989. U.S. For. Serv., Region 5, San Francisco, Calif.

Ripple, W. J., D. H. Johnson, K. T. Hershey, and E. C. Meslow. Unpubl. ms. Dep. For. Res., and Dep. Fish. and Wildl., Oreg. State Univ., Corvallis. 


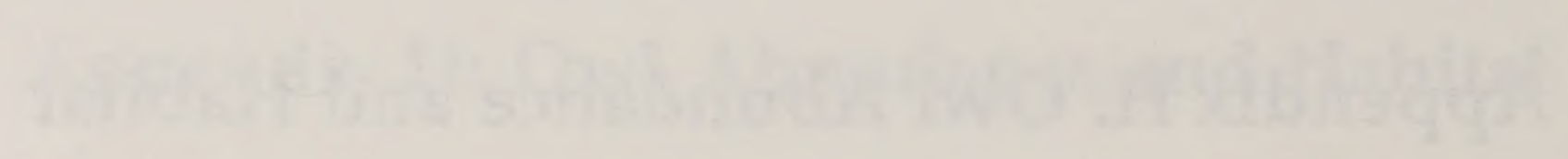




\section{Home-Range Sizes and Characteristics}

\section{Introduction}

In this summary of home-range information, we followed several conventions in an effort to make comparisons among studies as similar as possible. First, we used only $100 \%$ minimum-convex-polygon (MCP) estimates of home-range size for individual owls because that was the only measure consistently used in all studies. This method delineates a convex polygon that connects the outermost points where an animal was observed, and the area within the polygon is calculated. Second, to calculate pair home-range sizes, we used only home-range data from pairs that were tracked for most of one annual cycle so that we could be sure the tracking period included movements during the breeding season (1 March to 30 August), and during the nonbreeding season (1 September to 28 February). Third, if pairs were tracked for 2 years or more, we treated the data from each year separately. Each year's data for owls in this category is referred to as an annual pair home range. Fourth, we used the median (as opposed to the mean) home-range size for pairs in each geographic region, because we were concerned that a few very large or very small home ranges might result in a mean value that was not typical of most owls in a given area. The median is the middle value in a distribution, with half the sample larger and half smaller than the median. Fifth, we used the combined home ranges used by pairs of owls as the best measure of the area and habitat required to sustain pairs. Owl pair home ranges were determined by overlaying the male and female ranges and summing the area shared by the pair with the exclusive areas of the home ranges of each.

Readers who may compare estimates of home-range sizes and composition in this report with those from preliminary reports of the same studies should be aware that many data sets were enhanced through personal communications with researchers in March 1990. Values reported in tables I1 and I2 are, therefore, the most up-to-date estimates available. We have also excluded large bodies of water, such as reservoirs, from home-range areas.

All available information on home-range characteristics was based on radio-telemetry studies. Researchers usually used back-pack transmitters weighing 19 to 23 grams. Comparisons were made of survival and reproduction of radio-marked, adult spotted owls in California (Paton et al. 1990) and in Washington and Oregon (Foster et al. 1990 ) with survival and reproduction of color-banded adults in the same regions and periods. Results indicated that backpack radio transmitters may negatively affect the reproduction, and in some areas, the survival of radio-marked owls. Because we have no evidence to the contrary, however, we assume that radio transmitters have no significant effect on habitat selection or home-range use by the owls. 


\section{Appendix I: Home Range}

Table I1-Median annual home-range areas (In acres) of spotted owl pairs In different study areas and physlographic provinces

\begin{tabular}{|c|c|c|c|c|c|c|}
\hline \multirow{2}{*}{$\begin{array}{l}\text { State } \\
\text { Location } \\
\text { Site }\end{array}$} & \multirow[b]{2}{*}{$n$} & \multirow{2}{*}{$\begin{array}{l}\text { Foresst } \\
\text { type }\end{array}$} & \multirow[b]{2}{*}{ Median } & \multicolumn{2}{|c|}{ Range } & \multirow[b]{2}{*}{ Sources $^{c}$} \\
\hline & & & & Min & Max & \\
\hline \multicolumn{7}{|l|}{$\begin{array}{l}\text { California } \\
\text { Klamath Mountains }\end{array}$} \\
\hline Ukonom & 9 & $M C$ & 3,314 & 2,056 & 7,8231 & 1 \\
\hline Mad River & 12 & $M C$ & 2,975 & 1,803 & 4,685 & 1 \\
\hline Willow Creek & 2 & $M C$ & 1,692 & 1,258 & 2,126 & 2 \\
\hline \multicolumn{7}{|l|}{ Oregon } \\
\hline South Coast & & & & & & \\
\hline Chetco & 4 & MH & 5,614 & 5,327 & 6,197 & 1 \\
\hline \multicolumn{7}{|l|}{ Klamath Mountains } \\
\hline South Umpqua & 3 & MC & 1,411 & 1,035 & 1,504 & 3 \\
\hline Cow Creek & 6 & $M C$ & 4,106 & 2,499 & 7,494 & 3 \\
\hline \multicolumn{7}{|l|}{ Coast Ranges } \\
\hline Tyee & 5 & DF/HEM & 3,387 & 1,880 & 8,272 & 3 \\
\hline Peterson & 4 & DF/HEM & 6,318 & 3,483 & 10,189 & 3 \\
\hline Eugene BLM & 4 & DF/HEM & 6,390 & 3,715 & 8,180 & 4 \\
\hline Otherd & 4 & DF/HEM & 4,183 & 2,849 & 9,748 & 5 \\
\hline Kellogge ${ }^{\theta}$ & 5 & $M C$ & 4,072 & 1,618 & 6,281 & 3 \\
\hline Western Cascades & 11 & DF/HEM & 2,955 & 1,443 & 9,758 & 6,7 \\
\hline \multicolumn{7}{|l|}{ Washington } \\
\hline Western Cascades & 13 & DF/HEM & 6,308 & 1,927 & 30,961 & $8,9,10$ \\
\hline Olympic Peninsula & 10 & HEM/DF & 9,930 & 4,497 & 27,309 & 9,11 \\
\hline
\end{tabular}

a Pair ranges were calculated by delineating 100\% MCPs: total = exclusive area of male + exclusive area of female + the area of overlap shared by the two sexes.

${ }^{b} \mathrm{MC}=$ mixed-conifer, $\mathrm{MH}=$ mixed-conifer/evergreen, $\mathrm{DF} / \mathrm{HEM}=$ Douglas-fir, western hemlock, HEM/DF = mostly western hemlock with Douglas-fir intermixed.

$c 1$ = Paton et al. (1990), 2 = Solis (1983), 3 = Carey (pers. comm.), 4 = Thrailkill and Meslow (pers. comm.), 5 = Carey et al. (1990), 6 = Forsman and Meslow (1985), $7=$ Miller (pers. comm.), $8=$ Allen et al. (1989), 9 = Hays et al. (1989), 10 = Hamer (pers. comm.), 11 = Forsman (pers. comm.). $\checkmark$ Includes four sites in the southern Coast Ranges near Roseburg.

- This was a relatively dry area bordering the Umpqua River Valley, characterized by mixed-conifer forest more typical of the Klamath Mountains Province than the Coast Ranges. 


\section{Appendix I: Home Range}

Table I2-Medlan amounts of old-growth and mature forest (In acres) In annual palr home ranges of spotted owls, by State and physlographic province

\begin{tabular}{|c|c|c|c|c|c|c|}
\hline \multirow{2}{*}{$\begin{array}{l}\text { State } \\
\text { Location } \\
\text { Site }\end{array}$} & \multirow[b]{2}{*}{$n$} & \multirow{2}{*}{$\begin{array}{c}\text { Forest } \\
\text { type }^{a}\end{array}$} & \multirow[b]{2}{*}{ Median } & \multicolumn{2}{|c|}{ Range } & \multirow[b]{2}{*}{ Sources $^{b}$} \\
\hline & & & & Min & Max & \\
\hline \multicolumn{7}{|l|}{ California } \\
\hline \multicolumn{7}{|l|}{ Klamath Mountains } \\
\hline Ukonom & 9 & MC & 2,484 & 1,030 & 5,654 & 1,2 \\
\hline Mad River & 12 & MC & 1,365 & 835 & 1,953 & 1,2 \\
\hline Six Rivers NF & 2 & MC & 800 & 367 & 1,233 & 3 \\
\hline \multicolumn{7}{|l|}{ Oregon } \\
\hline \multicolumn{7}{|l|}{ Klamath Mountains } \\
\hline South Umpqua & 3 & MC & 615 & 563 & 768 & 4 \\
\hline Cow Creok & 6 & MC & 1,549 & 1,450 & 1,983 & 4 \\
\hline \multicolumn{7}{|l|}{ Coast Ranges } \\
\hline Tyөe & 5 & DF/HEM & 2,031 & 1,645 & 3,984 & 4 \\
\hline Peterson & 4 & DFAEM & 2,609 & 1,284 & 3,196 & 4 \\
\hline Eugene BLM & 4 & DF/HEM & 1,783 & 799 & 3,580 & 5 \\
\hline Other ${ }^{c}$ & 4 & DF/HEM & 2,375 & 1,795 & 2,625 & 6 \\
\hline Kellogg ${ }^{d}$ & 5 & MC & 1,018 & 697 & 1,983 & 4 \\
\hline West Slope Cascades & 9 & DF/HEM & 1,796 & 1,050 & 3,786 & 7,8 \\
\hline \multicolumn{7}{|l|}{ Washington } \\
\hline West Slope Cascades & 13 & DF/HEM & 3,281 & 1,927 & 20,561 & $9,10,11$ \\
\hline Olympic Peninsula & 7 & HEM/DF & 4,579 & 2,787 & 8,448 & 12 \\
\hline
\end{tabular}

Home-Range Studles by State

a $M C=$ mixed-conifer, DF/HEM = Douglas-fir, western hemock, HEMDF = mostly western hemlock with Douglas-fir intermixed.

${ }_{1} 1$ = Paton et al. (1990), 2 = Paton (pers. comm.), 3 = Solis (1983), 4 = Carey (pers. comm.),

5 = Thrailkill and Meslow (pers. comm.), 6 = Carey et al. (1990), 7 = Forsman and Meslow (1985),

8 = Miller (pers. comm.), 9 = Allen et al. (1989), 10 = Hays et al. (1989), 11 = Hamer (pers. comm.),

12 = Forsman (pers. comm.).

cIncludes four sites in the southern Coast Range near Roseburg.

${ }^{d}$ This was a relatively dry area bordering the Umpqua River Valley, characterized by mixed-conifer forest more typical of the Klamath Mountains Province than the Coast Ranges.

Washington-Five studies of home-range characteristics of spotted owls in Washington have been reported (Allen et al. 1989.; Egtvedt and Manuwal 1988; Forsman, pers. comm.; Hamer, pers. comm.; Hamer et al. 1989; Hays et al. 1989). The studies of Allen et al. (1989) and Hays et al. (1989) were done concurrently from 1982 to 1986 by the Washington Department of Wildlife (WDW), and followed a total of 32 owls located in various areas of the Washington Cascades and the Olympic Peninsula. We had adequate samples to estimate annual pair home ranges of five owl pairs in the Cascades and two pairs on the Olympic Peninsula (table I1). 


\section{Appendix I: Home Range}

Forsman (pers. comm.) followed 22 owls (10 pairs, 2 singles) on the west side of the Olympic Peninsula from April 1987 to September 1989. Eight of the 10 pairs were tracked for at least 9 months and were considered adequate for estimating annual pair home ranges (table I1). Hamer (pers. comm.) reported eight annual pair ranges on the west slope of the North Cascades near Baker Lake. Egtevedt and Manuwal (1988) reported a home range of 8868 acres for one owl on the Cedar River Watershed, but sample size was inadequate for determining the annual home range. The amount of overlap (47\%) between home ranges of adjacent pairs was reported for only two neighboring pairs in Washington (Hays et al. 1989).

Some of the individuals in the above studies had winter and summer home ranges that were largely nonoverlapping. To estimate the total home-range size for those individuals, the MCP areas of the winter and summer home ranges were summed. Median owl-pair home-range sizes in Washington were 6308 acres on the west slope of the Cascades, and 9930 acres on the Olympic Peninsula (table I1).

Oregon-Nine studies of spotted owl home-range characteristics have been reported in Oregon (Carey, pers. comm.; Carey et al. 1990; Forsman 1980, 1981; Forsman et al. 1984; Inwin, pers. comm.; Miller, pers. comm.; Miller and Meslow 1989; Paton et al. 1990; Thrailkill and Meslow 1990; Wagner and Meslow 1989). The two studies by Irwin and by Wagner and Meslow are still in progress.

Median, annual pair home-range size varied considerably, both within and among geographic provinces (table I1). Carey (pers. comm.) suggested that pairs in his study had smaller home ranges in areas where old growth occurred in a more clumped (contiguous) distribution. Forsman (1981) and Thrailkill and Meslow (1990) suggested a similar relation between home-range size and distribution of older forest.

Most spotted owls in Oregon had overlapping winter and summer home ranges. A single exception was reported by Miller (pers. comm.), who observed a female with separate winter and summer home ranges. Information on overlap between home ranges of adjacent pairs in Oregon was reported in only two studies. Carey (pers. comm.) found that the mean overlap of home ranges of neighboring pairs in five different areas near Roseburg ranged from 1 to $26 \%$. Miller (pers. comm.) reported a mean overlap of $18 \%$ for three neighboring pairs.

Northwestern Callfornia-Within the range of the northern spotted owl in California, four studies of home ranges of spotted owls have been reported (Kerns 1989, Paton et al. 1990, Sisco and Guttiérez 1984, Solis 1983). Sisco and Gutiérrez (1984) and Solis (1983) studied owls in the same area of Six Rivers National Forest. Because of small sample sizes, we report pair home ranges for only two of the pairs they followed (table I1). Paton et al. (1990) reported 21 annual pair ranges from two study areas in the Klamath Mountains. On those study areas, median annual pair ranges were about 3000 acres, with a range of 1803 to 7823 acres (table I1). Kerns (1989) reported on movements of eight owls but did not analyze home-range size. 


\section{Appendix I: Home Range}

Summary of HomeRange Studies

Amount of Old Forest Within Annual Pair Home Ranges
We could not detect any consistent patterns between home-range size relative to forest type or geographic region, except that home ranges in Washington were very large compared to most areas farther south (table I1). Median pair home ranges of 3000 to 5000 acres seemed typical of most areas, with the smallest median (1411 acres) reported for an area with a clumped distribution of older forest at the northern edge of the Klamath Mountains (Carey, pers. comm.).

In Oregon, areas with median pair ranges greater than 5000 acres were typically in heavily logged areas where the proportion of the landbase covered by older forests was low (Carey, pers. comm.; Forsman and Meslow 1985; Paton et al. 1990; Thrailkill and Meslow 1990). This relationship suggests that a reduction in the proportional coverage of suitable foraging habitat causes spotted owls to increase the size of their home ranges to encompass additional foraging habitat (Carey 1985, Forsman et al. 1984, Thrailkill and Meslow 1990).

Although the data are not presented in table I1, we also consider a study by Forsman and Meslow (1985) to be significant. They reported on three pairs of owls tracked for a period of 3 to 4 months in a heavily logged portion of the Oregon Coast Range in 1980. Even though the tracking period was inadequate to determine the annual pair range, the median home range for the three pairs ( 8343 acres) was much larger than reported for areas with a relatively high proportion of coverage by old forests, such as the western Oregon Cascades and the Tyee study area in the Oregon Coast Ranges (table I1).

Another factor apparent from the data was that the home-range size of both individuals and pairs varied considerably from year to year (Paton et al. 1990, Thrailkill and Meslow 1990). Dramatic differences in home-range size and shape were sometimes associated with changes in individuals occupying a site (Miller, pers. comm.; Paton et al. 1990). We cannot segregate such changes from yearly variation, however.

The amount of older forest within the annual home ranges of owl pairs may be a good indicator of the amount of that type of habitat needed to sustain the pair (see appendix $\mathrm{F}$ for a discussion of habitat requirements). Median amounts of old-growth and mature forest within annual pair home ranges in mixed-conifer forests ranged from 615 to 2484 acres (table I2). The smallest median value (615 acres) was from a study area where the remaining old forests were clumped rather than fragmented (Carey, pers. comm.).

In forests of Douglas-fir and western hemlock in western Oregon, median acreages of older forest in annual pair ranges were between 2031 and 2609 acres (table I2). Median areas of old forest in pair ranges in Washington were 4579 acres on the Olympic Peninsula and 3281 acres on the west slope of the Cascade Range (table I2).

Kerns (1989) studied eight owls in an area with $<1 \%$ old-growth forest. As discussed in appendix $F$, however, the young redwood stands in his study area had structural attributes somewhat similar to old-growth forests in other forest types within the range of the owl. Kerns did not have enough locations to calculate amounts of habitat within annual home ranges. 


\section{Appendix I: Home Range}

\author{
Discussion
}

The considerable effort expended in recent years to determine home-range size and composition for spotted owls was largely a response to previous owl management plans that emphasized habitat-management units for single pairs (SOHAs), rather than large groups of pairs that would occupy large HCAs, as proposed in this conservation strategy. One of the primary pieces of information needed to develop those plans was information on the amount and kinds of habitat required to sustain single pairs. In our proposed strategy, the need to manage single pairs is largely eliminated in the long term, except in a few problem areas where owl numbers are particularly low, or where natural fragmentation of the habitat makes management of large clusters of pairs impossible.

In our plan, the primary goal is to ensure that areas delineated as HCAs are large enough to contain at least 20 pairs of owls in the long term. This goal requires an estimate of future populations in the HCAs.

Existing knowledge of local owl density was considered our best guide for determining HCA sizes. Information on owl density was available from several study areas in California, Oregon, and Washington. Estimates were calculated only for relatively large study areas (>30 square miles) where owl densities were determined by systematic surveys of the entire area. Density was expressed as pair numbers or territories per square mile.

In the absence of good information on owl density, we used home-range data to guide us in estimating the sizes of HCAs needed in various parts of the owl's geographic range. These estimates were made independently from those based on information on actual or probable owl densities in delineated HCAs. We used the median home-range area from data in sites most like those under consideration. Because we know that neighboring pair home ranges overlap to some extent, we allowed for $25 \%$ overlap of the home ranges in HCAs. This number could be debated, but we consider it to be reasonable, based on the available data.

For a 20-pair HCA, then, the total size needed was estimated using the formula

$$
\text { HCA size }=20 \text { pairs } \times \text { the median annual pair home-range size } \times 0.75 \text {. }
$$

This estimate was then compared with the one independently derived from known owl densities in the region under consideration. When these values differed considerably, the areas were re-examined to resolve the discrepancy (see appendices $M$ and $Q$ for more details on this procedure). If further adjustments were made in HCAs to assure at least 20 pairs, they were based on such conditions as inclusions of significant areas of unsuitable habitat, high elevation, extensive fragmentation, and checkerboard ownership. 


\section{Appendix I: Home Range}

References
Ailen, H. L., K. R. Dixon, and K. L. Knutson. 1989 unpubl. Cooperative administrative study to monitor spotted owl management areas in National Forests in Washington: Final report. Unpubl. rep., Wash. Dep. Wildl., Olympia. 165pp.

Carey, A. B. 1985. A summary of the scientific basis for spotted owl management. Pages 100-114 in R. J. Gutiérrez and A. B. Carey, eds. Ecology and management of the spotted owl in the Pacific Northwest. U.S. For. Serv. Gen. Tech. Rep. PNW-185. Portland, Oreg.

Carey, A. B. Pers. comm. U.S. For. Serv., PNW, Olympia, Wash.

Carey, A. B., J. A. Reid, and S. P. Horton. 1990. Spotted owl home range and habitat use in southern Oregon coast ranges. J. Wildl. Manage. 54:11-17.

Egtvedt, L. H., and D. A. Manuwal. 1988 unpubl. Documentation of spotted owls and interspecific relationships among forest owls in the Cedar River Watershed, Washington: Final report to Water Dep., City of Seattle. Unpubl. rep., Coll. For. Res., Univ. Wash., Seattle. 45pp.

Forsman, E. D. 1980. Habitat utilization by spotted owls in the west-central Cascades of Oregon. Ph.D. Thesis, Oreg. State Univ., Corvallis. 95pp.

Forsman, E. D. 1981 unpubl. Habitat utilization by spotted owls on the Eugene District of the Bureau of Land Management. Unpubl. rep., Bur. Land Manage., Eugene, Oreg. 63pp.

Forsman, E. D. Pers. comm. U.S. For. Serv., PNW, Olympia, Wash.

Forsman, E. D., and E. C. Meslow. 1985. Old-growth forest retention for spotted owls-how much do they need? Pages 58-59 in R.J. Gutiérrez and A.B. Carey, eds. Ecology and management of the spotted owl in the Pacific Northwest. U.S. For. Serv. Gen. Tech. Rep. PNW-185. Portland, Oreg.

Forsman, E. D., E. C. Meslow, and H. M. Wight. 1984. Distribution and biology of the spotted owl in Oregon. Wildl. Monogr. 87:1-64.

Foster, C., E. D. Forsman, E. C. Mesiow, G. S. Miller, J. A. Reid, and A. B. Carey. 1990 unpubl. The effects of radio backpacks upon the survival and reproduction of the northern spotted owl in Oregon and Washington. Unpubl. typescript. U.S. For. Serv., PNW, Olympia, WA.

Hamer, T. E. Pers. comm. U.S. For. Serv., PNW, Olympia.

Hamer, T. E., S. G. Selm, and K. R. Dixon. 1989 unpubi. Northern spotted owl and northern barred owl habitat use and home range size in Northwest Washington: Preliminary report. Wash. Dep. Wildl., Olympia. 64pp.

Hays, D. W., H. L. Allen, L. H. Egtvedt, and K. R. Dixon. 1989 unpubl. Home range size and habitat use of spotted owls in Washington: Preliminary report. Wash. Dep. Wildl.-Nongame, Olympia. 30pp. 


\section{Appendix I: Home Range}

Irwin, L. L. Pers. comm. NCASI, Corvallis, Oreg.

Kerns, S. J. 1989 unpubl. Occurrence of spotted owls in managed timber stands on lands of The Pacific Lumber Company. 15 December. Unpubl. rep., The Pacific Lumber Co., Scotia, Calif. 8pp.

Miller, G. S. Pers. comm. Oreg. State Univ., Corvallis.

Miller, G. S., and E. C. Meslow. 1989 unpubl. The ecology of spotted owls on the Willamette National Forest: Supplement to 1989 annual report (spotted owl demography and habitat use segments, 1 September 1988-31 August 1989). Unpubl. rep. Oreg. Coop. Wildl. Res. Unit., Oreg. State Univ., Corvallis. 16pp.

Paton, P. W. C. Pers. comm. U.S. For. Serv., PSW, Arcata, Calif.

Paton, P. W. C., C. Zabel, B. BIngham, H. Sakal, and C. Ogan. 1990 unpubl. Examination of home range size and habitat use of the spotted owl in the Klamath Province: Progress report covering the period from spring 1987-December 1989. Unpubl. rep., PSW Forest and Range Exp. Stn., Arcata, Calif. 15pp.

Paton, P. W. C., C. J. Zabel, N. G. Tllghman, and B. R. Noon. 1990 unpubl. Effects of radio tags on spotted owls. Unpubl. typescript. U.S. For. Serv., PSW Res. Lab, Arcata, California.

SIsco, C., and R. J. Gutlérrez 1984 unpubl. Winter ecology of radio-tagged spotted owls on Six Rivers National Forest, Humboldt Co., CA. Unpubl. rep., Six Rivers National Forest, Eureka, Calif. 140pp.

Solls, D. M. 1983. Summer habitat ecology of spotted owls in northwestern California. M.S. Thesis, Humboldt State Univ., Arcata, Calif. 169pp.

ThrallkIII, J. A., and E. C. Meslow. 1990 unpubl. Home range size and habitat utilization of northern spotted owls in the Wolf Creek Study area, Eugene BLM District, Oregon: Draft final report. Oreg. Coop. Wildl. Res. Unit, Oreg. State Univ., Corvallis. 68pp.

ThrallkIII, J. A., and E. C. Meslow. Pers. comm. Oreg. State Univ., Corvallis.

Wagner, F. F., and E. C. Meslow. 1989 unpubl. Spotted owl monitoring: Medford segment, Miller Mountain study area: Prog. rep. January 1989. Oreg. Coop. Wildl. Res. Unit, Oreg. State Univ., Corvallis. 


\section{Spotted Owl Food Habits and Prey}

This appendix summarizes spotted owl ${ }^{1}$ food habits and the habitat affinities of their major prey species. It also considers the possibilities for deliberately manipulating the owl's prey base through silvicultural prescriptions.

\section{Owl Diets}

Information on the composition of spotted owl diets over the bird's range from British Columbia to southern California (table J1), for both the northern and California subspecies, was gleaned from published and unpublished sources representing over 15,100 individual prey items examined in regurgitated owl pellets. For broad comparison, diets are presented as the percentage of individual prey identified in each sample of pellets. Species were sometimes lumped into generic or broader categories (for example, woodrats, voles, lagomorphs) to facilitate comparisons.

Although spotted owls eat a wide variety of prey, small mammals-particularly nocturnal arboreal or semi-arboreal species-predominate in diets when composition is expressed in either numbers or biomass consumed. Samples from individual studies often show that 70 to $90 \%$ of the prey biomass is contributed by just two or three species, particularly northern flying squirrels, dusky-footed or bushy-tailed woodrats, and various lagomorphs (hares and rabbits). Additionally, pocket gophers, red tree voles, and deer mice are regionally important. Flying squirrrels are especially important in mesic forests of the Western Hemlock/Douglas-Fir Zones; woodrats often predominate in samples from drier mixed-conifer/mixed-evergreen forests. These trends are reflected in broad geographic differences in owl diets: flying squirrels tend to predominate from British Columbia to central Oregon, and woodrats predominate from southern Oregon through southern California. California and Oregon studies suggest that elevational differences in owl diets mirror latitudinal changes, with flying squirrels more abundant at higher elevations (particularly in true fir associations) and woodrats at lower elevations (Barrows 1980, Forsman et al. 1984, Neal et al. 1989, Paton et al. 1990).

Additional studies also support these interpretations. Forsman et al. (1989) report that flying squirrels were important owl prey on the Olympic Peninsula of Washington State. Bushy-tailed woodrats and western red-backed voles were important on the drier east side of the Peninsula, but not in west side rain forests. They also report that owl diets from the Roseburg, Oregon, area were dominated by woodrats in xeric mixed-evergreen forest types and by flying squirrels in more humid Douglas-fir types. Beebe and Schonewald (1977) note that owls in Marin County, California, consumed woodrats and deer mice.

\footnotetext{
${ }^{1}$ Scientific names of mammals and birds are listeo in appendix V, table V1.
} 


\section{Appendix J: Food Habits and Prey}
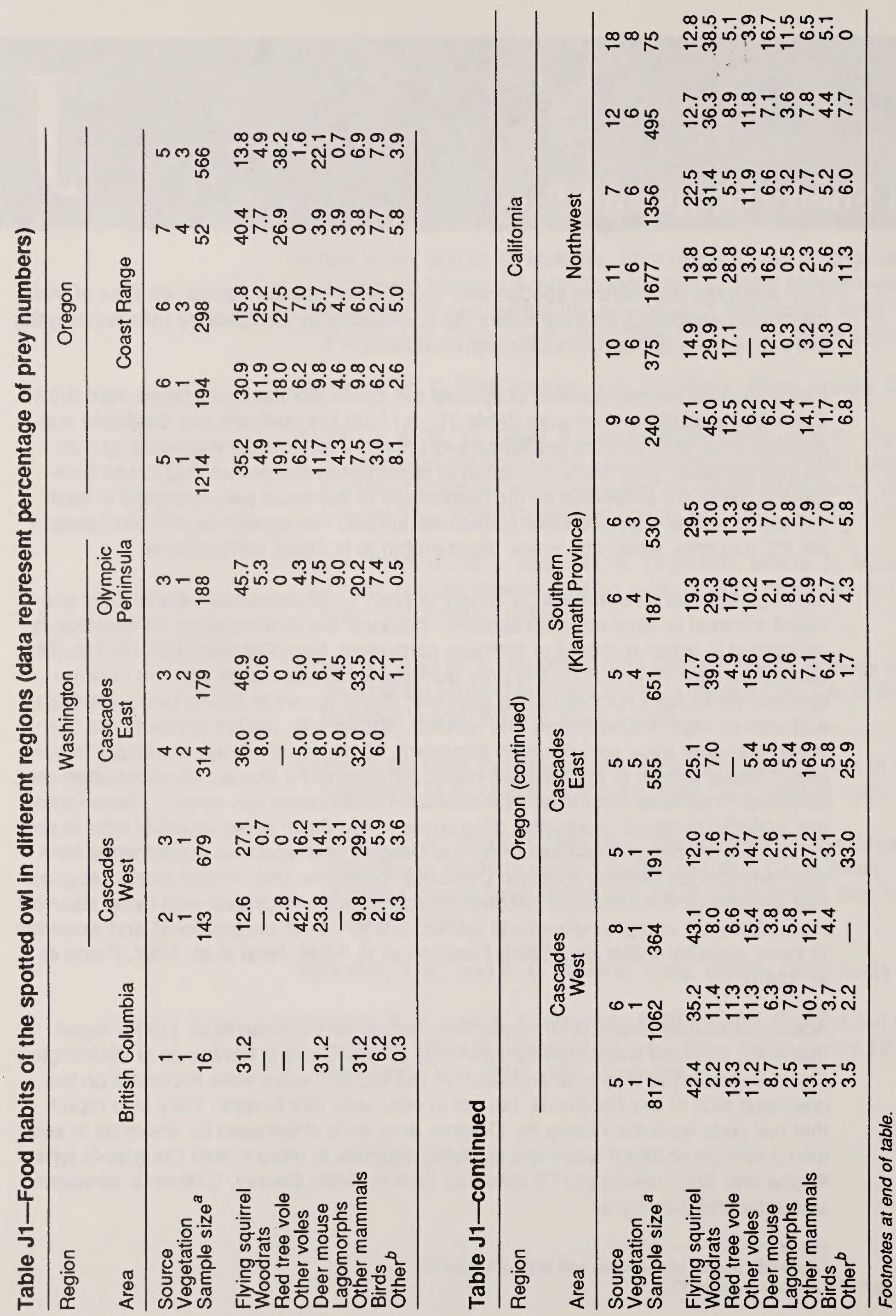


\section{Appendix J: Food Habits and Prey}

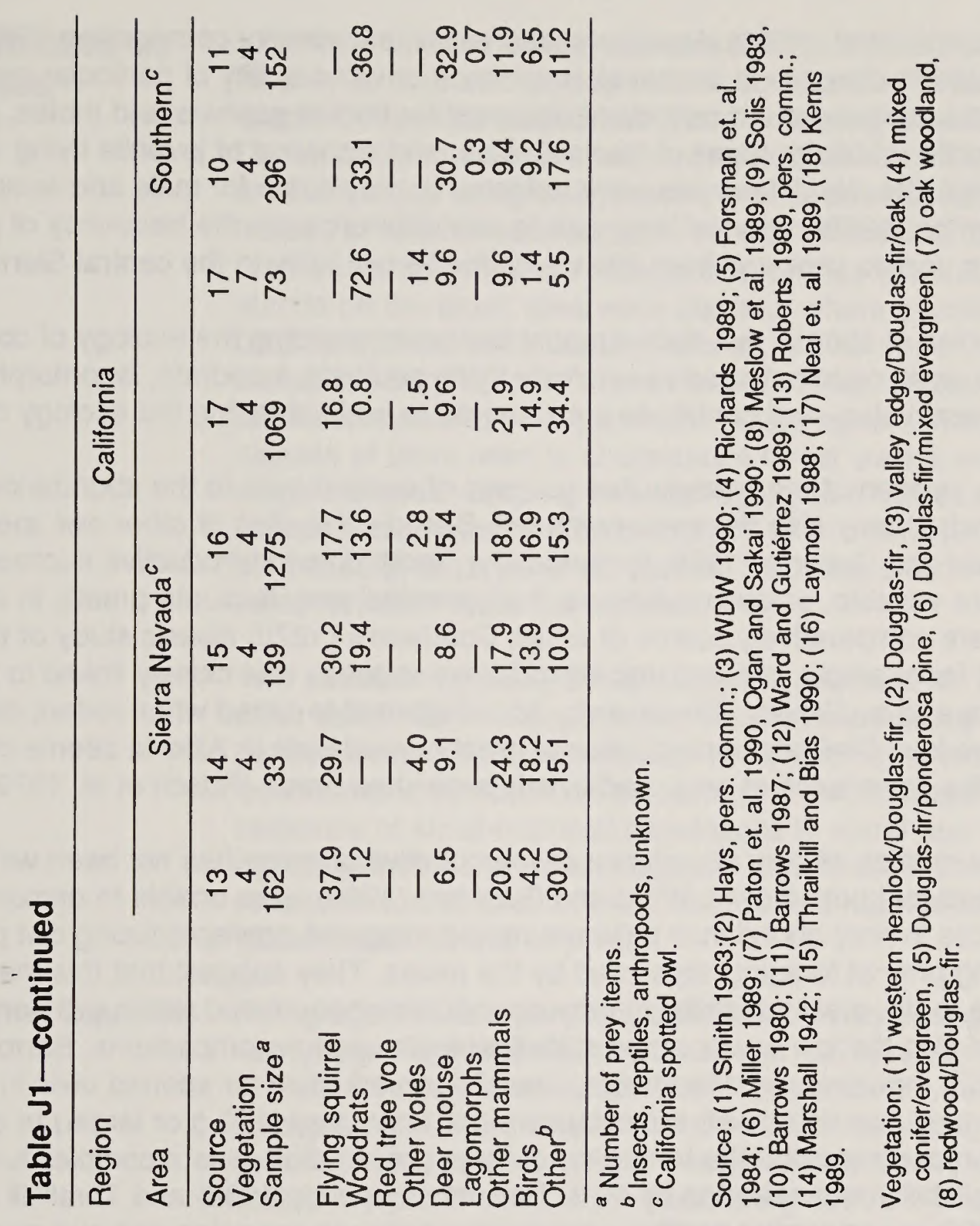




\section{Appendix J: Food Habits and Prey}

\section{Prey Abundance and Owl Reproduction}

Forsman et al. (1989) describe seasonal shifts in dietary composition. Shifts seemed related to changes in seasonal abundance or vulnerability of particular prey: for example, above-ground periods of dispersal for pocket gophers and moles, presence of juvenile rabbits or hares of tractable size, and dispersal of juvenile flying squirrels from nests. No differences were detected in prey items for male and female owls. Laymon (1988) reported large pair-to-pair differences in the frequency of prey type from year to year and from site to site for 14 owl pairs in the central Sierra Nevada.

Studies of spotted owl diets suggest that understanding the ecology of comparatively few small mammal species-namely flying squirrels, woodrats, lagomorphs, and several voles-will contribute substantially to understanding the ecology of the owl.

The relation of the reproductive success of spotted owls to the abundance of their principal prey also deserves comment. Based on studies of other owl species (see Ward and Gutiérrez 1989, for summary), spotted owl reproductive success could be more variable, or lower, wherever their principal prey fluctuate greatly in abundance, or are comparatively scarce or small. Southern's (1970) classic study of the tawny owl for example, showed that reproductive success was closely linked to prey numbers and availability. Tawny owls did not attempt to breed when rodent densities were low. Similarly, reproduction of great horned owls in Alberta seems closely tied to the abundance of prey, particularly snowshoe hares (Rusch et al. 1972).

The relation of prey abundance to reproductive success has not been well established for spotted owls. Ward and Gutiérrez (1989) were unable to demonstrate differences in prey abundance between reproducing and nonreproducing owl pairs by sampling prey at foraging sites used by the males. They suggest that this may have been due to the great variability in prey abundance encountered within owl home ranges, and also the low power of the statistical tests used in comparisons. Barrows (1985, 1987), however, reported that successful reproduction for spotted owls in Califomia seemed correlated with the occurrence of large prey (100 g or larger) in owl diets. He recognized that the frequency of large prey in diets was a complex function of its availability and selection by owls. Recently, Laymon (1988) and Thrailkill and Bias (1990) report similar positive associations between prey size and owl reproductive success, but Ward and Gutiérrez (1989) could not detect such differences. The question of whether or not this association reflects abundance of prey or selection by owls (that is, either differential capture or merely differential transport of large prey to nest sites) has not been answered satisfactorily and needs field experimentation. Hansen (1987), for example, reported that offspring survival is greater for free-ranging pairs of bald eagles that are fed supplemental food than for unfed pairs. Given the tameness of spotted owls toward humans, analogous feeding experiments might be possible. 


\section{Appendix J: Food Habits and Prey}

\section{Habitat Affinities of Prey Species}

Northern Flying Squirrels

\section{Dusky-Footed Woodrats}

Information on the abundance and habitat affinities of five mammal species important as prey to northern spotted owls is summarized in tables J2 to J5. Studies that reported mammal abundance along or among forest seres were of primary interest. Direct, detailed comparisons among studies were often not possible because of differences in study design, objectives, or measures of abundance, which ranged from indices of relative abundance to reports of absolute density. Where necessary, measures of abundance were recalculated or data were summarized. Origins of forest stands on the study sites were classed, where possible, as "naturally regenerated" (that is, derived from fire, blowdowns, and so on) or "managed" (from logging). This distinction may become blurred where stands of natural origin receive some silvicultural treatments at young or intermediate ages. Finally, we assumed that the sizeclasses of trees used to characterize forest stands were roughly similar among studies (that is, seedling and saplings, 0 to 5 inches in d.b.h.; pole timber, 5 to 11 inches in d.b.h.; small saw timber, 11 to 21 inches in d.b.h.; large saw timber, 21 to 35 inches in d.b.h.; and old growth, 35 or more inches in d.b.h.). Tree diameters, however, were often not reported.

Two caveats regarding interpretation of the mammal studies seem necessary. First, most small mammal populations fluctuate notoriously in abundance over time; consequently, short-term studies-that is, most of those reported here-are often insufficient to establish broad ecological relationships (Wiens 1981). Secondly, the response of small-mammal populations to stand age may vary depending on the agents initiating the seres. Naturally regenerated forest stands, for example, may retain more structural diversity than stands regenerated by clearcut silviculture (Gilbert and Allwine, in press).

Flying squirrels are generally absent from very young forests (for example, clearcuts $<20$ years old) (table J2, and Gashwiler 1970). Squirrel abundances tend to increase in older forests (Carey et al. 1989), but trends are inconsistent. Several studies report no significant differences in abundance across young (about 30 to 60 years) to oldgrowth seres for either naturally regenerated (Aubry et al., in press) or managed stands (Raphael et al. 1986, Rosenberg 1990). Flying squirrels show sensitivity to fragmentation in Douglas-fir forests of northwestern California; they tend to decline in relative abundance as old-growth stands are reduced in size (Rosenberg and Raphael 1986).

Typical squirrel densities reported for mature and old-growth forests are 0.4 to 1.2 animals per acre. Data on squirrel densities are too limited to suggest meaningful geographic or elevational trends in abundance.

Woodrats are most abundant in early seral forests (for example, brushy clearcuts, and pole-timber stands), they decline in intermediate-age forests, and may increase to some degree in older forests (table J3). In northwestern California, woodrats seem positively associated with the amount of forest fragmentation, especially where hardwoods occur as components of Douglas-fir stands (Rosenberg and Raphael 1986). Preliminary information for redwood forests in northwestern California indicates that appreciable woodrat populations persist into stands of intermediate age (Kerns 1988). 
Table J2-Abundance of northern flying squirrels by region and forest age-class

\begin{tabular}{|c|c|c|c|c|c|c|}
\hline Region/area & $\begin{array}{l}\text { Vegetation } \\
\text { type }\end{array}$ & $\begin{array}{l}\text { Seral } \\
\text { stage } \\
\end{array}$ & $\begin{array}{c}\text { Squirrels } \\
\text { (numbers) }\end{array}$ & $\begin{array}{l}\text { Census } \\
\text { technique }\end{array}$ & $\begin{array}{c}\text { Index of } \\
\text { abundance }\end{array}$ & Source \\
\hline \multicolumn{7}{|l|}{ Washington } \\
\hline Cascades (W) & 1 & $\begin{array}{l}\text { Young+ } \\
\text { Mature+ } \\
\text { Old }\end{array}$ & $\begin{array}{l}0.015 \\
0.025 \\
0.032\end{array}$ & 1 & 2 & 1 \\
\hline \multirow[t]{2}{*}{ Olympics } & 1 & SMS* & $0.2(0-0.5)$ & 2 & 1 & 2 \\
\hline & 1 & $\begin{array}{l}\text { SMS }^{\star} \\
\text { Old }\end{array}$ & $\begin{array}{l}0.1-0.6 \\
0.1-0.8\end{array}$ & 2 & 1 & 9 \\
\hline \multicolumn{7}{|l|}{ Oregon } \\
\hline \multirow[t]{4}{*}{ Coast Range } & 1 & $\begin{array}{l}\text { SMS+" } \\
\text { Old }\end{array}$ & $\begin{array}{l}0.04(0-0.10) \\
0.35(0.21-0.71\end{array}$ & 1) 2 & 1 & 3 \\
\hline & 1 & Young+ & 0.017 & 1 & 2 & 1 \\
\hline & & $\begin{array}{l}\text { Mature+ } \\
\text { Old }\end{array}$ & $\begin{array}{l}0.014 \\
0.027\end{array}$ & & & \\
\hline & 1 & $\begin{array}{l}\text { Young } \\
\text { Old }\end{array}$ & $\begin{array}{l}0.4(0.1-0.8) \\
0.7(0.1-1.9)\end{array}$ & 2 & 1 & 2 \\
\hline \multirow[t]{4}{*}{ Cascades } & 1 & $\begin{array}{l}\text { SMS+ } \\
\text { LAS+ } \\
\text { Old }\end{array}$ & $\begin{array}{l}0.07 \\
0.01 \\
0.03\end{array}$ & 1 & 2 & 4 \\
\hline & 1 & SMS* & $0.9(0.7-1.4)$ & 2 & 1 & 5 \\
\hline & 1 & $\begin{array}{l}\text { Mature* } \\
\text { Old }\end{array}$ & $\begin{array}{l}0.6 \\
13(08-17)\end{array}$ & 2 & 1 & 6 \\
\hline & 1 & $\begin{array}{l}\text { Young+ } \\
\text { Mature+ } \\
\text { Old }\end{array}$ & $\begin{array}{l}0.028 \\
0.010 \\
0.029\end{array}$ & 1 & 2 & 1 \\
\hline \multicolumn{7}{|l|}{ California } \\
\hline \multirow[t]{5}{*}{ Northwest } & 2 & $\begin{array}{l}\text { Clearcut* } \\
\text { POT-SMS*+ } \\
\text { LAS+ } \\
\text { Old }\end{array}$ & $\begin{array}{l}0 \\
0.122 \\
0.154 \\
0.167\end{array}$ & 3 & 3 & 7 \\
\hline & 2 & $\begin{array}{l}\text { Brush/ } \\
\text { Sapling* }\end{array}$ & 0 & 3 & 3 & 8 \\
\hline & & $\begin{array}{l}\text { POT** }^{*} \\
\text { SMS }^{*}\end{array}$ & $\begin{array}{l}15 \\
9\end{array}$ & & & \\
\hline & & LAS+ & 18 & & & \\
\hline & & Old & 13 & & & \\
\hline
\end{tabular}

Census technique: (1) pitfall traps; (2) live-trap grids; (3) track plates.

Index of abundance: (1) mean (range) of number/acre (2) mean number/100 trap-nights; (3) percentage occurrence. Vegetation type: (1) western hemlock/Douglas-fir; (2) Douglas-fir/mixed evergreen. Seral stage: Small saw timber (SMS); pole timber (POT), large saw timber (LAS); old growth (old), managed stand $(*)$, natural regeneration $(+)$.

Source: (1) Carey 1989; (2) Biswell and Carey 1989; (3) Witt 1989; (4) Gilbert and Allwine, in press; (5) Rosenberg 1990; (6) Volz 1986; (7) Raphael et al. 1986; (8) Raphael 1988; (9) Carey et al. 1989. 


\section{Appendix J: Food Habits and Prey}

Table J3-Abundance of dusky-footed and bushy-talled woodrats by region and forest age-class

\begin{tabular}{|c|c|c|c|c|c|c|}
\hline Region/area & $\begin{array}{l}\text { Vegetation } \\
\text { type }\end{array}$ & $\begin{array}{l}\text { Seral } \\
\text { stage }\end{array}$ & $\begin{array}{l}\text { Woodrats } \\
\text { (numbers) }\end{array}$ & $\begin{array}{l}\text { Census } \\
\text { technique }\end{array}$ & $\begin{array}{l}\text { Index of } \\
\text { abundance }\end{array}$ & Source \\
\hline \multicolumn{7}{|c|}{ Dusky-footed Woodrat } \\
\hline \multicolumn{7}{|l|}{ Oregon } \\
\hline Coast Range & 4 & $\begin{array}{l}\text { SMS* } \\
\text { Old }\end{array}$ & $\begin{array}{l}0.02 \pm .02 S E \\
0\end{array}$ & 2,3 & 1 & 3 \\
\hline \multirow[t]{2}{*}{ Southern } & 2 & $\begin{array}{l}\text { SES* } \\
\text { POT* } \\
\text { SMS }\end{array}$ & $\begin{array}{l}0 \\
0.43 \pm .19 \\
0.16 \pm .16\end{array}$ & 2,3 & 1 & 3 \\
\hline & 2,3 & $\begin{array}{l}\text { SMS* } \\
\text { Old }\end{array}$ & $\begin{array}{l}0.57 \pm 1.57 \\
0.17 \pm .05\end{array}$ & 2,3 & 1 & 3 \\
\hline \multicolumn{7}{|l|}{ California } \\
\hline \multirow[t]{2}{*}{ Northwest } & 1 & $\begin{array}{l}\text { SES }^{*} \\
\text { POT }^{*} \\
\text { SMS } \\
\text { LAS* } \\
\text { Old }\end{array}$ & $\begin{array}{l}0.8 \\
50 \\
0 \\
0 \\
0.01\end{array}$ & 1 & 1 & 1 \\
\hline & 1 & $\begin{array}{l}\text { Clearcut" } \\
\text { POT* }^{*} \\
\text { SMS+ } \\
\text { LAS+ } \\
\text { Old }\end{array}$ & $\begin{array}{l}2.7 \\
0.2 \\
1.2 \\
4.4 \\
3.4\end{array}$ & 2 & 2 & 2 \\
\hline \multicolumn{7}{|c|}{ Bushy-tailed Woodrat } \\
\hline \multicolumn{7}{|l|}{ Oregon } \\
\hline Coast Range & 4 & $\begin{array}{l}\text { SMS* } \\
\text { Old }\end{array}$ & $\begin{array}{l}0.2 \pm .01 \\
0.01 \pm .01\end{array}$ & 2,3 & 1 & 3 \\
\hline \multirow[t]{2}{*}{ Southern } & 2 & $\begin{array}{l}\text { SMS* } \\
\text { Old }\end{array}$ & $\begin{array}{l}0.44 \pm .21 \\
0.01 \pm .03\end{array}$ & 2,3 & 1 & 3 \\
\hline & 2 & $\begin{array}{l}\text { SES* } \\
\text { POT* }^{*} \\
\text { SMS }^{*}\end{array}$ & $\begin{array}{l}0.03 \pm .03 \\
0.19 \pm .08 \\
0\end{array}$ & 2,3 & 1 & 3 \\
\hline
\end{tabular}

Census technique: (1) belt transect and nest count, live-traps at nests; (2) live-trap grid; (3) parallel transects, live-trapped. Index of abundance: (1) mean number/hectare; (2) mean number/100 trapnights. Vegetation type: (1) Douglas-fir/mixed evergreen; (2) mixed conifer; (3) riparian (4) western hemlock/Douglas-fir.

Seral stage: Seedling/sapling (SES); pole timber (POT); small saw timber (SMS); large saw timber (LAS); old growth (old); managed stand ("), natural regeneration (+).

Source: (1) Sakai et al. 1989; (2) Raphael 1988; (3: Carey, pers. comm.

Bushy-talled Woodrats

Densities of dusky-footed woodrats range considerably, from just a few animals to $>40$ per acre in early pole-timber stages, to perhaps 0.4 to 1.2 per acre in large saw timber and old growth (table J3, and Ward and Gutiérrez 1989). Substantial woodrat populations may occupy brushy riparian areas. Wallen (1982) reports densities of 18.2 animals per acre from one such site at Point Reyes, California.

Bushy-tailed woodrats are frequently associated with cliffs, rock outcrops, and talus, but they also occupy hollow trees and logs (Maser et al. 1981). Information on their relative abundance in different forest types or size-classes is limited (table $\sqrt{3}$ ). 


\section{Appendix J: Food Habits and Prey}

Table J4-Abundance of deer mlce by reglon and forest age-class

\begin{tabular}{|c|c|c|c|c|c|c|}
\hline Region/area & $\begin{array}{l}\text { Vegetation } \\
\text { type }\end{array}$ & $\begin{array}{l}\text { Seral } \\
\text { stage }\end{array}$ & $\begin{array}{c}\text { Mice } \\
\text { (number) }\end{array}$ & $\begin{array}{c}\text { Census } \\
\text { technique }\end{array}$ & $\begin{array}{c}\text { Index of } \\
\text { abundance }\end{array}$ & Source \\
\hline \multicolumn{7}{|l|}{ Washington } \\
\hline Cascades (W) & 1 & $\begin{array}{l}\text { POT+ } \\
\text { LAS+ } \\
\text { Old }\end{array}$ & $\begin{array}{l}0.062-0.128 \\
0.143-0.223 \\
0.168-0.332\end{array}$ & 1,3 & 1 & 1 \\
\hline \multirow[t]{2}{*}{ Olympics } & 1 & $\begin{array}{l}\text { SMS* } \\
\text { LAS/Old }\end{array}$ & $\begin{array}{l}2.5 \\
4.8\end{array}$ & 2 & 1 & 2 \\
\hline & 1 & $\begin{array}{l}\text { SMS* } \\
\text { LAS/Old }\end{array}$ & $\begin{array}{l}2.9 \\
8.1\end{array}$ & 2 & 1 & 7 \\
\hline \multicolumn{7}{|l|}{ Oregon } \\
\hline \multirow[t]{3}{*}{ Coast Range } & 1 & $\begin{array}{l}\text { SMS+ } \\
\text { LAS/Old }\end{array}$ & $\begin{array}{l}1.2 \\
1.9\end{array}$ & 2 & 1 & 2 \\
\hline & 3 & $\begin{array}{l}\text { SMS* } \\
\text { LAS+ } \\
\text { Old }\end{array}$ & $\begin{array}{l}0.132 \\
0.053 \\
0.138\end{array}$ & 1 & 1 & 3 \\
\hline & 1 & $\begin{array}{l}\text { YOUNG* } \\
\text { Old }\end{array}$ & $\begin{array}{l}1.3 \\
1.5\end{array}$ & 2 & 1 & 7 \\
\hline \multirow[t]{2}{*}{ Cascades (W) } & 2 & $\begin{array}{l}\text { SMS+ } \\
\text { LAS+ } \\
\text { Old }\end{array}$ & $\begin{array}{l}0.08 \\
0.04 \\
0.10\end{array}$ & 1 & 1 & 4 \\
\hline & 1 & $\begin{array}{l}\text { SMS* } \\
\text { Old }\end{array}$ & $\begin{array}{l}3.8(2.0-5.8) \\
2.7(0.6-6.0)\end{array}$ & 2 & 2 & 5 \\
\hline \multicolumn{7}{|l|}{ California } \\
\hline Northwest & 2 & $\begin{array}{l}\text { Clearcut" } \\
\text { POT* } \\
\text { SMS* } \\
\text { LAS+ } \\
\text { Old }\end{array}$ & $\begin{array}{l}0.41 \\
0.04 \\
0.06 \\
0.10 \\
0.13\end{array}$ & 1 & 1 & 6 \\
\hline
\end{tabular}

Census technique: (1) pitfall; (2) live-trap grids; (3) snap-trap grids.

Index of abundance: (1) mean number/100 trap-nights, (2) mean (range) of number/acre

Vegetation type: (1) western hemlock/Douglas-fir; (2) Douglas-fir/mixed evergreen; (3) Douglas-fir.

Seral stage: Small saw timber (SMS), pole timber (POT), large saw timber (LAS), old growth (old),

managed stand (*), natural regeneration $(+)$.

Source: (1) West 1990; (2) Carey et al. 1988; (3) Corn and Bury, in press; (4) Gilbert and Allwine, in press; (5) Anthony and Rosenberg 1988; (6) Raphael 1988; (7) Carey et al. 1989.

Deer Mice

Habitat affinities for the ubiquitous deer mouse are difficult to interpret (table J4).

Several early studies report deer mice to be more abundant in recent clearcuts than in old growth (Gashwiler 1970; Gilbert and Allwine, in press). Additionally, deer mice were found to be more abundant at sites with adjacent clearcuts and more edge in highly fragmented, old-growth Douglas-fir forests in California (Rosenberg and Raphael 1986).

Studies of deer mouse densities along forest seres of somewhat more advanced ages (small saw timber through old growth) report either no significant associations of deer mice with stand age (Anthony and Rosenberg 1988; Corn and Bury, in press), or greater abundances in old-growth (Aubry et al., in press; Biswell et al. 1989; Gilbert and Allwine, in press; West, in press). 


\section{Appendix J: Food Habits and Prey}

Table J5-Abundance of pitfall-trapped red tree voles by reglon and forest age-class

\begin{tabular}{|c|c|c|c|c|c|}
\hline Region/area & $\begin{array}{l}\text { Vegetation } \\
\text { type }\end{array}$ & $\begin{array}{l}\text { Seral } \\
\text { stage }\end{array}$ & $\begin{array}{c}\text { Voles } \\
\text { (number) }\end{array}$ & $\begin{array}{l}\text { Index of } \\
\text { abundance }\end{array}$ & Source \\
\hline \multirow{2}{*}{$\begin{array}{l}\text { Oregon } \\
\text { Coast Range }\end{array}$} & & & & & \\
\hline & 3 & $\begin{array}{l}\text { Young+ } \\
\text { Mature+ } \\
\text { Old }\end{array}$ & $\begin{array}{l}0.004 \\
0.000 \\
0.021\end{array}$ & 1 & 4 \\
\hline \multirow[t]{3}{*}{ Cascades (W) } & 1 & $\begin{array}{l}\text { SMS+ } \\
\text { LAS+ } \\
\text { Old }\end{array}$ & $\begin{array}{l}0 \\
0.01 \\
0.03\end{array}$ & 1 & 1 \\
\hline & 2 & $\begin{array}{l}\text { Clearcut* } \\
\text { POT } \\
\text { LAS } \\
\text { Old }\end{array}$ & $\begin{array}{r}1 \\
1 \\
2 \\
13\end{array}$ & 2 & 2 \\
\hline & 3 & $\begin{array}{l}\text { Young+ } \\
\text { Mature+ } \\
\text { Old }\end{array}$ & $\begin{array}{l}0.000 \\
0.006 \\
0.018\end{array}$ & 1 & 4 \\
\hline \multicolumn{6}{|l|}{ California } \\
\hline Northwest & 1 & $\begin{array}{l}\text { Clearcut* } \\
\text { POT* }^{*} \\
\text { SMS }^{*} \\
\text { LAS+ } \\
\text { Old }\end{array}$ & $\begin{array}{l}0.04 \\
0.05 \\
0.05 \\
0.08 \\
0.10\end{array}$ & 1 & 3 \\
\hline
\end{tabular}

Index of abundance: (1) mean number/100 trap-nights; (2) total number caught.

Vegetation type: (1) Douglas-fir/mixed evergreen; (2) Douglas-fir; (3) western hemlock/

Douglas-fir.

Seral stage: Small saw timber (SMS), pole timber (POT), large saw timber (LAS),

old growth (old), managed stand (*), natural regeneration (+).

Source: (1) Gilbert and Allwine, in press; (2) Corn and Bury 1986; (3) Raphael 1988;

(4) Carey 1989.

Generalizations are tenuous, but the deer mouse may show habitat affinities broadly parallel to those of the dusky-footed woodrat: high densities initially in clearcuts, reduced abundance in intermediate-aged stands, and increased densities in old growth. Very large fluctuations in abundance over short periods also characterize this species (for example, Gashwiler 1970).

In western Washington, the forest deer mouse shows a significant positive association with old-growth in the Western Hemlock/Douglas-Fir zone (Aubry et al., in press; West, in press).

The red tree vole seems to be positively associated with stand age in Oregon and northwestern California (Carey 1989; Corn and Bury 1986; Gilbert and Allwine, in press; Raphael 1988), and may reach significantly greater densities in old-growth forests (Aubry et al., in press; Corn and Bury, in press; table J5). The animal seems to depend heavily on Douglas-fir for food and nest sites (Maser et al. 1981; Meiselman and Doyle, in press). Beyond the observation that red tree voles are absent from Washington, information is too limited to suggest trends in abundance by geography or elevation. 


\section{Appendix J: Food Habits and Prey}

\author{
Lagomorphs
}

Producing Owl Prey Through Silviculture
Snowshoe hares and brush rabbits often dominate the lagomomh component of owl diets, but data on habitat affinities or densities for these species are limited. Brush rabbits are strongly associated with dense cover, have relatively small home ranges, and may be locally very abundant (Chapman 1971, Shields 1960). The amount of habitat for brush rabbits is thought to have increased markedly along brushy roadsides in forests of the Oregon Coast Range (Maser et al. 1981). Snowshoe hares may increase in clearcuts after brushy cover is established (Gashwiler 1970), but responses are very unpredictable in forests of the Pacific Northwest (Black, pers. comm.). Hare densities in Washington show a lag in response to silvicultural treatments; increases may occur 4 to 5 years after logging where clearcuts are burned, and in less time if logging slash is left unburned, (Campbell, pers. comm.).

Species composition and densities of mammalian prey for spotted owls clearly change after disturbances on the scale of clearcut logging, even though predicting species-specific responses over time is sometimes difficult (that is, beyond the obvious, where arboreal species like flying squirrels and red tree voles are eliminated by tree removal). The possibility of deliberately manipulating prey densities in spotted owl habitat to benefit owls through silvicultural prescription deserves consideration: specifically, can silviculture produce more diverse prey bases, more abundant prey populations, or reduce fluctuations in the abundance of major prey species?

The survey of habitat affinities for prey species suggests that the ability to deliberately increase owl prey populations may differ among physiographic provinces, although no direct experimental evidence supports such speculation. A little fragmentation of the forest may benefit spotted owls in the short term in Douglas-firl mixed-evergreen or mixed-conifer forests by increasing both prey diversity and the abundance of seasonally important prey species (Carey, pers. comm.). Sakai et al. (1989) suggest that owls hunting along edges of suitable habitat in mixed-evergreen forests may prey on woodrats produced in or dispersing from adjacent clearcuts. They also note that silvicultural prescriptions (such as herbicide applications or mechanical clearing) aimed at eliminating brush or hardwoods to favor conifers may reduce woodrat populations. An alternative treatment to retain woodrats would remove competing vegetation only around individual conifers, sparing the intervening brush habitat.

Modification of clearcut logging, as currently practiced, in Western Hemlock/DouglasFir Zone forests would seemingly be necessary to deliberately produce or maintain certain species of owl prey. For example, Mowrey and Zasada (1984) recommend that small clearcuts (no wider than about 100 feet) with large intervening "leave strips" may be necessary to maintain flying squirrel populations in Alaska. They also recommend that "broom trees" be retained to serve as survival sites for squirrels during periods of cold weather. Deliberate removal of dense, brushy vegetation in early seral forests may result in dramatic declines in snowshoe hare abundance (Sullivan and Moses 1986). Leaving or enhancing such vegetation could presumably benefit hares or, possibly, brush rabbits. Retaining forests near rock outcrops and talus may provide the combined foraging and tree nesting sites preferred by bushy-tailed woodrats. 


\section{Appendix J: Food Habits and Prey}

A major synthesis is underway on the relation of silviculture to the ecology of animal species that "damage" forest stands in the Pacific Northwest (Black, pers. comm.). Although the aim is to manipulate silviculture to limit animal damage (Loucks et al., in press), some of the same mammals of concern to foresters are also important to spotted owls, and the information being assembled could also provide a basis for manipulating owl prey.

Although the prey base for spotted owls might be enhanced under some conditions where food is considered to limit owl densities or reproductive success, how this enhancement can be accomplished without violating the other habitat requirements of the bird is not yet clear. Manipulations that enhance prey for spotted owls also risk providing habitat well suited to predators or species presumed to be competitors of the spotted owl. Thus, the net benefits from habitat manipulation must be assessed carefully; managers who seek to deliberately manipulate prey densities must simultaneously monitor owl reproductive success and survival rates.

\section{References}

Anthony, R. G., and D. K. Rosenberg. 1988 unpubl. Patterns of distribution and abundance of small mammals in old-and second-growth Douglas-fir forests in the Oregon Cascades. Unpubl. rep., Oreg. State Univ., Corvallis. 16pp.

Aubry, K. B., M. J. Crites, and S. D. West. In press. Patterns of small mammal abundance and community composition in Douglas-fir forests of Washington and Oregon. In L. F. Ruggiero, K. B. Aubry, A. B. Carey, and M. H. Huff, tech. coords. Wildlife and vegetation of unmanaged Douglas-fir forests. U.S. For. Serv. Gen. Tech. Rep.

Barrows, C. W. 1980. Feeding ecology of the spotted owl in California. J. Raptor Res. 14:73-78.

Barrows, C. W. 1985. Breeding success relative to fluctuations in diet for spotted owls in California. Pages 50-54 in R. J. Gutiérrez and A. B. Carey, eds. Ecology and management of the spotted owl in the Pacific Northwest. U.S. For. Serv. Gen. Tech. Rep. PNW-185.

Barrows, C. W. 1987. Diet shifts in breeding and non-breeding spotted owls. J. Raptor Res. 21:95-97.

Beebe, G., and J. Schonewald. 1977. Spotted owls near Palomarin. Point Reyes Bird Observatory Newsletter 42:6-7.

Biswell, B. L., J. G. Boulanger, and A. B. Carey. 1989 unpubl. Comparison of small mammal abundance in climax and young forests of the Olympic Peninsula, Washington. Abstract in L. F. Ruggiero, K. B. Aubry, A. B. Carey, and M. H. Huff, tech. coords. Wildlife and vegetation of unmanaged Douglas-fir forests. U.S. For. Serv. Gen. Tech. Rep.

Blswell, B. L., and A. B. Carey. 1989 unpubl. Flying squirrel abundance in young and old-growth forests of the Pacific Northwest. Abstract in L. F. Ruggiero, K. B. Aubry, A. B. Carey, and M. H. Huff, tech. coords. Wildlife and vegetation in unmanaged Douglas-fir forests. U.S. For. Serv. Gen. Tech. Rep. 


\section{Appendix J: Food Habits and Prey}

Black, H. C. Pers. comm., FS, PNW, Portland, Oreg.

Campbell, D. Pers. comm., APHIS, Olympia, Wash.

Carey, A. B. Pers. comm., FS, PNW, Olympia, Wash.

Carey, A. B., et al. 1988 unpubl. Wildlife habitat relationships in western Oregon and Washington. U.S. For. Serv., Olympia For. Sci. Lab., unpubl. annu. prog. rep.

Carey, A. B., et al. 1989 unpubl. Patterns of flying squirrel and woodrat abundance: spotted owl prey base study. U.S. For. Serv., Olympia For. Sci. Lab., unpubl. annu. prog. rep., $5 \mathrm{pp}$.

Carey, A. B. 1989. Wildlife associated with old-growth forests in the Pacific Northwest. Nat. Areas J. 9:151-162.

Chapman, J. A. 1971. Orientation and homing of the brush rabbit (Sylvilagus bachmani). J. Mammal. 52:686-699.

Corn, P. S., and R. B. Bury. 1986. Habitat use and terrestrial activity by red tree voles in Oregon. J. Mammal. 67:404-406.

Corn, P. S. and R. B. Bury. In press. Small mammals in the Oregon Coast Range. In L. F. Ruggiero, K. B. Aubry, A. B. Carey, and M. H. Huff, tech. coords. Wildlife and vegetation of unmanaged Douglas-fir forests. U.S. For. Serv. Gen. Tech. Rep.

Forsman, E. D., E. C. Meslow, and H. M. Wight. 1984. Distribution and biology of the spotted owl in Oregon. Wildl. Monogr. 87. 64pp.

Forsman, E. D., I. Otto, and A. B. Carey. 1989 unpubl. Diet of spotted owls on the Olympic Peninsula, Washington, and the Roseburg District of the Bureau of Land Management. Abstract in L. F. Ruggiero, K. B. Aubry, A. B. Carey, and M. H. Huff, tech. coords. Wildlife and vegetation of unmanaged Douglas-fir forests. U.S. For. Serv. Gen. Tech. Rep.

Gashwiler, J. S. 1970. Plant and mammal changes on a clearcut in west-central Oregon. Ecology 51:1018-1026.

Gilbert, F. F., and R. AllwIne. In press. Small mammal communities in the Oregon Cascades. In L. F. Ruggiero, K. B. Aubry, A. B. Carey, and M. H. Huff, tech. coords. Wildlife and vegetation of unmanaged Douglas-fir forests. U.S. For. Serv. Gen. Tech. Rep.

Hansen, A. J. 1987. Regulation of bald eagle reproductive rates in southeast Alaska. Ecology 68(5):1387-1392.

Hays, D. Pers. comm., WDW, Olympia, WA.

Kerns, S. J. 1988 unpubl. Observations of wildlife diversity on lands of the Pacific Lumber Co. Prelim. rep., Pac. Lumber Co., Scotia, Calif. 26pp. 


\section{Appendix J: Food Habits and Prey}

Kerns, S. J. 1989 unpubl. Occurrence of spotted owls in managed timber stands on lands of the Pacific Lumber Co. Prog. rep., Pac. Lumber Co., Scotia, Calif. 43pp.

Laymon, S. D. 1988. The ecology of the spotted owl in the central Sierra Nevada, California. Ph.D. Dissertation. Univ. California, Berkeley. 285pp.

Loucks, D. M., N. C. Block, M. L. Roush, and S. R. Radosevich. In press. Animal damage assessment and management in Pacific Northwest forests: an annotated bibliography. U.S. For. Serv. Gen. Tech. Rep.

Marshall, J. T. 1942. Food and habitat of the spotted owl. Condor 44:66-67.

Maser, C., B. R. Mate, J. F. Franklln, and C. T. Dyrness. 1981. Natural history of Oregon Coast mammals. U.S. For. Serv. Gen. Tech. Rep. PNW-133. 496pp.

Melselman, N., and A. T. Doyle. In press. Habitat and microhabitat selection by red tree voles. Am. Midl. Naturalist.

Meslow, E. C., E. D. Forsman, et al. 1990 unpubl. Ecology of spotted owls on the Willamette National Forest: habitat use and demography. Unpubl. annu. res. rep. FWS, Oregon State Univ., Corvallis.

Miller, G. S. 1989. Dispersal of juvenile northern spotted owls in western Oregon. M.S. Thesis. Oregon State Univ., Corvallis. 139pp.

Mowrey, R. A., and J. C. Zasada. 1984. Den tree use and movements of northern flying squirrels in interior Alaska and implications for forest management. Pages 351-356 in Meehan, W. R., T. R., Merrell, and T. A. Hanley, eds. Fish and wildlife relationships in old-growth forests. Am. Inst. Fish. Res. Biol., Juneau, Alaska.

Neal, D. L., J. Verner, G. N. Steger, and G. P. Eberline. 1989 unpubl. A study of spotted owl home-range size and composition in the Sierra National Forest. U.S. For. Serv. Unpubl. rep. 9pp.

Ogan, C., and H. F. Sakal. 1990 unpubl. Spotted owl food habits. U.S. For. Serv. Redwood Sci. Lab, Arcata, Calif. Unpubl. data.

Paton, P., C. Zabel, B. Blngham, H. Sakal, and C. Ogan. 1990 unpubl. Examination of home-range size and habitat use of the spotted owl in the Klamath Province. U.S. For. Serv. Redwood Sci. Lab., Arcata, Calif. Unpubl. rep. 15pp.

Raphael, M. G. 1988. Long-term trends in abundance of amphibians, reptiles and mammals in Douglas-fir forests of northwestern California. Pages 23-31 in R. C. Szaro, K. E. Severson, and D. R. Patton, eds. Management of amphibians, reptiles and small mammals in North America. U.S. For. Serv. Gen. Tech. Rep. RM-166.

Raphael, M. G., C. A. Taylor, and R. H. Barrett. 1986. Smoked aluminum track stations record flying squirrel occurrence. U.S. For. Serv. Res. Note PSW-384. 3pp. 


\section{Appendix J: Food Habits and Prey}

Richards, J. E. 1989. Spotted owl food habits and prey availability on the east slope of the Washington Cascades. M.S. Thesis. Colorado State Univ., Fort Collins. $45 \mathrm{pp}$.

Roberts, C. K. 1989 unpubl. Pellet analysis of the California spotted owl in Sequoia and Kings Canyon National Parks. Unpubl. rep. 18pp.

Rosenberg, D. K. 1990 unpubl. Habitat selection and abundance of northern flying squirrels in second- and old-growth Douglas-fir forests, Oregon. Unpubl. rep. Oreg. State Univ., Corvallis.

Rosenberg, K. V., and M. G. Raphael. 1986. Effects of forest fragmentation on vertebrates in Douglas-fir forests. Pages 263-272 in J. Verner, M. L. Morrison, and C. J. Ralph, eds. Modeling habitat relationships of terrestrial vertebrates. Univ. Wisconsin Press, Madison.

Rusch, D. H., E. C. Meslow, P. D. Doerr, and L. B. Kelth. 1972. Response of great horned owl populations to changing prey densities. J. Wildl. Manage. 36:282-296.

Sakal, H. F., B. R. Noon, and C. A. Taylor. 1989 unpubl. The feasibility of using an indirect counting method to determine dusky-footed woodrat (Neotoma fuscipes) abundance and distribution in different-aged Douglas-fir/hardwood stands of northwestern California. Unpubl. rep. U.S. For. Serv. Redwood Sci. Lab., Arcata, Calif. 16pp.

Shlelds, P. W. 1960. Movement patterns of brush rabbits in northwestern California. J. Wildl. Manage. 24:381-386.

Smlth, C. C. 1963. First recorded breeding record of the spotted owl in British Columbia. Condor 65:440.

Solls, D. M. 1983. Summer habitat ecology of spotted owls in northwestern California. M.S. Thesis. Humboldt State Univ., Arcata, Calif. 168pp.

Southern, H. N. 1970. The natural control of a population of tawny owls (Strix aluco). J. Zool. 162:197-285.

Sullivan, T. P., and R. A. Moses. 1986. Demographic and feeding responses of a snowshoe hare population to habitat alteration. J. Appl. Ecol. 23:53-63.

ThrallkIII, J., and M. Blas. 1990 unpubl. Diets of breeding and non-breeding California spotted owls (manuscript submitted).

Volz, K. 1986. Habitat requirements of northern flying squirrels in west-central Oregon. M.S. Thesis. Wash. State Univ., Pullman. 21pp.

Wallen, K. 1982. Social organization in the dusky-footed woodrat (Neotoma fuscipes): a field and laboratory study. Animal Behav. 30:1171-1182. 


\section{Appendix J: Food Habits and Prey}

Ward, J. P., and R. J. Gutiérrez. 1989 unpubl. Spotted owl reproduction and prey abundance in northwest California. Humboldt State Univ., Arcata, Calif. Unpubl. rep. $61 \mathrm{pp}$.

WDW. 1990 unpubl. Food habits of spotted owls in Washington. 2pp.

West, S. D. In press. Small mammal communities in the southern Washington Cascades. In L. F. Ruggiero, K. B. Aubry, A. B. Carey, and M. H. Huff, tech. coords. Wildlife and vegetation of unmanaged Douglas-fir forests. U.S. For. Serv. Gen. Tech. Rep.

Wiens, J. A. 1981. Single sample surveys of communities: Are the revealed patterns real? Am. Naturalist 117:90-98.

Witt, J. W. 1989 unpubl. Ecological aspects of the northern flying squirrel in western Oregon. BLM, Roseburg, Oreg. Unpubl. rep. 23pp. 


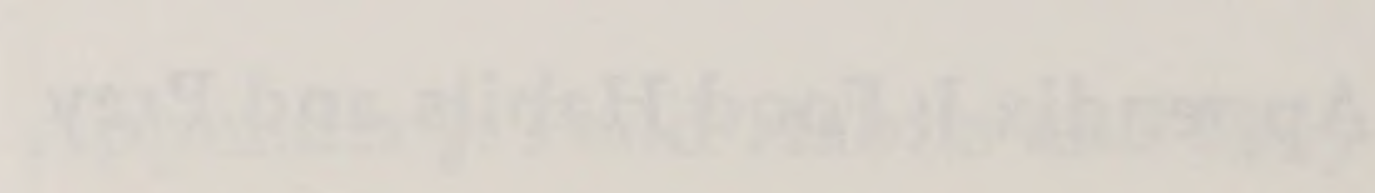




\section{Analysis of Forest Service Monitoring Data}

Introduction
Providing for spotted owl population viability requires an adequate amount and distribution of suitable habitat for owl pairs. Planning for owl conservation requires specifying some degree of certainty that the population will persist over some period of time. Suitable habitat must be distributed to provide for the rates of genetic and demographic interchange needed to assure numbers that will adequately minimize the risk of extinction. Suitable spotted owl habitat in California, Oregon, and Washington is found both on lands reserved from timber harvest (reserved lands), and on lands open to harvest (nonreserved lands). To meet the distributional requirements of the species, the FS considered necessary the protection of areas of suitable habitat in nonreserved lands that would provide for the needs of reproductive pairs and link the suitable owl habitat found in reserved lands (USDA 1988). Each designated "island" of suitable owl habitat was identified as a Spotted Owl Habitat Area (SOHA). Together with SOHA sites on reserved lands, this collection of SOHAs formed the SOHA network. By addressing issues of owl distribution and number, the FS proposed the SOHA network as its solution to the spotted owl viability requirement (USDA 1988). The network was designed with maximum distances among SOHAs that were believed to support a high likelihood of dispersal among them.

An important assumption of the management plan for the spotted owl was that the proportion of network SOHAs occupied by owl pairs would show no significant decline over time. Owl populations outside the network were assumed to decline because of habitat loss, but would continue to provide future alternatives should the occupancy rate within the network show a significant declining trend. The FS began a monitoring program in 1987 to check the validity of these assumptions.

A census of all owls on FS lands was impossible, so a subset of the network SOHAs and several random sample areas (RSAS) were monitored to estimate owl occupancy. The sample sizes were determined separately by physiographic province with the goal of estimating the occupancy rate with $10 \%$ precision at the $95 \%$ confidence level (Azuma et al. 1989). The RSAs were 0.7-mile-radius circles (1000 acres) located at random within National Forest lands, conditioned on the polygon area being within the geographic range of the spotted owl on each National Forest, within the elevational range of the subspecies, and excluding large bodies of water. If $\geq 50 \%$ of the sample unit fell within reserved land, the RSA was categorized as reserved status. 


\section{Appendix K: Monitoring Data}

\section{Methods}

\section{Parameters Estimated}

Basic Sampling Scheme
The size of SOHAs varied geographically to reflect variation in spotted owl homerange sizes. The SOHA sizes ranged from 1000 acres in the Klamath and Sierra Nevada Provinces to 3000 acres on the Olympic Pennisula. The basic assumption underlying monitoring was that the occupancy rates of the two sample unit populations (network SOHAs and RSAs) were a valid index for the trends in population size and reproductive rate. Occupancy rates were proposed to be monitored through time as an index to population trends. The trends in occupancy rates are compared between the SOHAs and RSAs in an effort to evaluate the efficiency of the network.

The detailed estimates of occupancy proportions, by physiographic province and individual National Forest, are provided in O'Halloran (1989) and Simon-Jackson (1989). Our goal was to extend, not duplicate, the existing syntheses of the monitoring data for FS Regions 5 (R5) and 6 (R6). The primary focus of the analyses discussed below was to explore for relationships between SOHA or RSA occupancy status and several attributes associated with these sample units. Currently, the number of attributes is somewhat limited; for example, no fragmentation indices were available to associate with the sample units. Despite these limitations, we believe that some meaningful patterns have emerged.

The basic variable estimated for each sample unit was "occupancy." Occupancy was defined in a variety of ways including occupancy by a single owl (either male, female, or unknown sex); a pair of owls; or a reproductive pair of owls. The parameters used in our analyses were occupancy by pairs, or occupancy by either a pair or a single bird. Although information on reproductive patterns is extremely relevant, the numbers of sample units (SOHAs or RSAs) occupied in any one year by reproductive pairs were too small for meaningful analysis. Yearly estimates of occupancy, by physiographic province or land classification (reserved, nonreserved), and changes in occupancy between years, have been reported for 1988 and 1989 (O'Halloran 1989; Simon-Jackson 1989).

In addition to the occupancy status of each SOHA or RSA, we also estimated a variety of other sample unit attributes, including latitude, longitude, acres of suitable spotted owl habitat, status (reserved or nonreserved), average elevation (R6 only), and elevational range (R6 only). For SOHA samples, acres of suitable habitat were estimated within a 2.1-mile (R6) or 1.5-mile (R5) radius of the SOHA center; for RSAs, suitable habitat was estimated within the 1000-acre circle.

The basic sampling scheme for the SOHA and RSA populations assumed $N$ sites, of which $N_{1}$ had owls and $N_{2}$ were vacant $\left(N_{1}+N_{2}=M\right.$. We sampled $n$ of these $N$ sites at random. A site was visited until an owl was detected or until six visits were completed. The likelihood of detecting an owl, given presence, can be computed from the distribution of detection frequency by visit number (Azuma et al. 1989). Based on analyses of the 1988 RSA and SOHA monitoring data, the likelihood of detecting an owl in six visits, given presence at a site, was high and ranged from 0.87 to 0.97 (Azuma et al. 1989). In each year, a binomial proportion, or the proportion of sites occupied, was estimated. Occupancy was either a single bird, a pair, or a reproductive pair; each was a different classification and was represented by the estimation of a distinct proportion. The details of the sampling design and methods of calculation are given in Max et al. (1987) and Azuma et al. (1989). 


\section{Appendix K: Monitoring Data}

Analysis

\section{Results}

\section{R5 and R6 RSA Analyses}

Analyses were conducted separately by year and Region for both the RSA and SOHA samples. Data were not combined across Regions because of slight differences in sampling methods and explanatory variables. For all analyses, occupancy status (occupied by a single or a pair of spotted owls; occupied by a pair; not occupied) was the dependent variable. We considered the sample unit attributes (for example, amount of suitable habitat) as explanatory variables. We performed three types of analyses: we compared the occupancy proportion for RSAs with $<500$ acres of suitable habitat to those with $>500$ acres; we investigated the relation between occupancy history (occupied in both 1988 and 1989; occupied in one of the 2 years; not occupied in either year) and the amount of suitable habitat with a one-way analysis of variance; and we investigated the relation between occupancy status of a sample unit and the explanatory variables with stepwise logistic regression (Neter et al. 1985:361-367).

Occupancy proportion conditioned on the amount of suitabie habitat-An exploratory analysis was made to determine any consistent patterns of occupancy, by either pairs or any owls, with the amount of suitable habitat within the RSA. For R5, the estimated occupancy rates for RSAs with $>500$ acres of suitable habitat were greater than for those with less suitable habitat in both 1988 and 1989 (table K1A). When the data were partitioned by land status (reserved or nonreserved), the occupancy rates were again consistently higher, given more suitable habitat (table K1B, $\mathrm{K} 1 \mathrm{C})$. Data from R5 included occupancy information from both the Klamath and Sierra Nevada Provinces. Because the northern spotted owl occurred only in the Klamath Province, we investigated occupancy solely in this subset of the data. Again, occupancy rates were higher, given more suitable habitat, in both the 1988 and 1989 samples (table K1D).

For R6, as in R5, the occupancy rates were positively related to the amount of suitable habitat in both years (table K2A). This pattern remained when the data were partitioned by land status (table $\mathrm{K} 2 \mathrm{~B}, \mathrm{~K} 2 \mathrm{C}$ ). In terms of absolute amount, the difference between occupancy proportions, by habitat amount, was less for pairs than for all owls.

Occupancy history and the amount of suitable habitat-Based on the detection of either a single owl or a pair, no significant relation was found between the occupancy history of RSAs sampled in both years in R5 and their acreage of suitable habitat $(F=2.09, P=0.131$; table $K 3)$. The rank order by mean acreage of suitable habitat, however, suggested a positive correlation between occupancy history and the amount of suitable habitat (table K3).

The R6 data, based on the detection of either a single owl or a pair, showed a strong relation between occupancy history and the amount of suitable habitat for RSAs sampled in both years $(F=9.81, P<0.001$; table $K 4)$. RSAs with more suitable acres had higher occupancy rates and were more likely to be consistently occupied. 


\section{Appendix K: Monitoring Data}

Table K1-Occupancy proportion (O) conditioned on the amount of sultable spotted owl habitat acres (SA) within a clrcular, 1000-acre Random Sample Area (RSA); results are based on the 1988 and 1989 monltoring data from National Forest lands in Region $5^{a}$

\begin{tabular}{|c|c|c|c|}
\hline Occupancy (O) & Year & $\operatorname{Pr}(O \mid S A<500)$ & $\operatorname{Pr}(O \mid S A>500)$ \\
\hline \multicolumn{4}{|c|}{ A. Reserve and nonreserve combined } \\
\hline Singles and pairs & 1988 & $33 / 83=.40$ & $17 / 21=.81$ \\
\hline Pairs & 1988 & $13 / 83=.16$ & $11 / 21=.52$ \\
\hline Singles and pairs & 1989 & $48 / 93=.52$ & $24 / 42=.57$ \\
\hline Pairs & 1989 & $15 / 93=.16$ & $12 / 42=.29$ \\
\hline \multicolumn{4}{|l|}{ B. Nonreserve only } \\
\hline Singles and pairs & 1988 & $30 / 66=.45$ & $12 / 15=.80$ \\
\hline Pairs & 1988 & $11 / 66=.17$ & $7 / 15=.47$ \\
\hline Singles and pairs & 1989 & $35 / 54=.65$ & $12 / 17=.71$ \\
\hline Pairs & 1989 & $11 / 54=.20$ & $7 / 17=.41$ \\
\hline \multicolumn{4}{|l|}{ C. Reserve only } \\
\hline Singles and pairs & 1988 & $3 / 17=.18$ & $5 / 6=.83$ \\
\hline Pairs & 1988 & $2 / 17=.12$ & $4 / 6=.67$ \\
\hline Singles and pairs & 1989 & $13 / 39=.33$ & $12 / 25=.48$ \\
\hline Pairs & 1989 & $4 / 39=.10$ & $5 / 25=.20$ \\
\hline \multicolumn{4}{|c|}{ D. Klamath Province only } \\
\hline Singles and pairs & 1988 & $12 / 42=.29$ & $6 / 8=.75$ \\
\hline Pairs & 1988 & $2 / 42=.05$ & $4 / 8=.50$ \\
\hline Singles and pairs & 1989 & $20 / 39=.51$ & $7 / 10=.70$ \\
\hline Pairs & 1989 & $5 / 39=.13$ & $6 / 10=.60$ \\
\hline
\end{tabular}

a Sample sizes were 104 in 1988 and 135 in 1989. 


\section{Appendix K: Monitoring Data}

Table K2-Occupancy proportion (0) conditloned on the amount of sultable spotted owl habltat acres (SA) within a clrcular, 1000-acre Random Sample Area (RSA); results are based on the 1988 and 1989 monltoring data from Natlonal Forest lands In Reglon $6^{a}$

\begin{tabular}{lrrr}
\hline Occupancy $(O)$ & Year & $\operatorname{Pr}(O \mid S A<500)$ & $\operatorname{Pr}(O \mid S A>500)$ \\
\hline $\begin{array}{l}\text { A. Reserve and nonreserve combined } \\
\text { Singles and pairs }\end{array}$ & 1988 & $50 / 130=.38$ & $41 / 54=.76$ \\
$\begin{array}{l}\text { Pairs } \\
\text { Singles and pairs }\end{array}$ & 1988 & $17 / 130=.13$ & $12 / 54=.22$ \\
Pairs & 1989 & $39 / 91=.43$ & $35 / 48=.73$ \\
& 1989 & $21 / 91=.23$ & $14 / 48=.29$ \\
$\begin{array}{l}\text { B. Nonreserve only } \\
\text { Singles and pairs }\end{array}$ & & \\
Pairs & 1988 & $37 / 86=.43$ & $24 / 26=.92$ \\
Singles and pairs & 1988 & $12 / 86=.14$ & $5 / 26=.19$ \\
Pairs & 1989 & $24 / 58=.41$ & $17 / 25=.68$ \\
C. Reserve only & 1989 & $13 / 58=.22$ & $8 / 25=.32$ \\
Singles and pairs & & & \\
Pairs & 1988 & $13 / 44=.30$ & $17 / 28=.61$ \\
Singles and pairs & 1988 & $5 / 44=.11$ & $7 / 28=.25$ \\
Pairs & 1989 & $15 / 33=.45$ & $18 / 23=.78$ \\
\end{tabular}

Sample sizes were 184 in 1988 and 139 in 1989.

Table K3-Results of an analysls of varlance test of the relation between the occupancy historles of clrcular, 1000-acre Random Sample Areas (RSAS) and the amount of sultable spotted owl habltat; results are based on the 1988 and 1989 monltoring data from Natlonal Forest lands In Reglon $5^{a}$

\begin{tabular}{lccrrr}
\hline Source & $\begin{array}{c}\text { Degrees of } \\
\text { freedom }\end{array}$ & $\begin{array}{c}\text { Sum of } \\
\text { squares }\end{array}$ & $\begin{array}{c}\text { Mean } \\
\text { square }\end{array}$ & F-statistic & P-value \\
\hline Occupancy & 2 & 267,323 & 133,662 & 2.09 & 0.131 \\
Error & 75 & $4,801,392$ & 64,019 & & \\
\cline { 2 - 5 } Total & 77 & $5,068,715$ & & & \\
\cline { 2 - 5 } Level & Sample & & Standard & & \\
\hline 0 & size & Mean & deviation & & \\
1 & 20 & 256.9 & 230.5 & & \\
2 & 22 & 338.9 & 234.7 & & \\
\hline
\end{tabular}

The groups were defined as: not occupied in any year (0); occupied in either 1988 or 1989 (1); occupied in both years (2). The dependent variable was acres of suitable habitat within the 1000-acre RSA circle. 


\section{Appendix K: Monitoring Data}

Tabie K4-Resuits of an analysis of variance test of the reiation between the occupancy histories of circuiar, 1000-acre Random Sampie Areas (RSAS) and the amount of sultabie spotted owi habitat; resuits are based on the 1988 and 1989 monitoring data from National Forest lands in Region $6^{a}$

\begin{tabular}{lccccc}
\hline Source & $\begin{array}{c}\text { Degrees of } \\
\text { freedom }\end{array}$ & $\begin{array}{c}\text { Sum of } \\
\text { squares }\end{array}$ & $\begin{array}{c}\text { Mean } \\
\text { square }\end{array}$ & F-statistic & P-value \\
\hline Occupancy & 2 & $1,075,791$ & 537,896 & 9.81 & 0.001 \\
Error & 136 & $7,460,597$ & 54,857 & & \\
\cline { 2 - 4 } Total & 138 & $8,536,388$ & & & \\
\cline { 2 - 4 } & Sample & & & & \\
Level & size & Mean & Standard & & \\
\hline 0 & 44 & 294.2 & 210.1 & & \\
1 & 35 & 411.4 & 236.2 & & \\
2 & 60 & 500.0 & 249.2 & & \\
\hline
\end{tabular}

The groups were defined as: not occupied in any year (0); occupied in either 1988 or 1989 (1); occupied in both years (2). The dependent variable was acres of suitable habitat within the 1000-acre RSA circle.

The reiation between occupancy status and the expianatory variabies-From the R5, 1988 occupancy data, the stepwise logistic regression model selected both land status and acres of suitable habitat as significant predictor variables (table $\mathrm{K} 5 \mathrm{~A}$ ). The model interpretation suggested that the probability of detection, of either a single owl or a pair, increased with both the amount of suitable habitat and in nonreserved lands. For the 1989 sample, only land status was selected as a significant predictor of occupancy; consistent with 1988, the probability of owl detection increased in nonreserved lands (table K5B).

For the 1988 R6 sample, three variables were selected as significant predictors of occupancy likelihood (table K6A). The probability of detecting an owl increased with the amount of suitable habitat, was higher in nonreserved lands, and was higher at lower latitudes. In the 1989 sample, only acres of suitable habitat was a significant, positive predictor of occupancy likelihood (table K6A).

R5 and R6 SOHA Analyses
Occupancy history and the amount of suitabie habitat - We detected no relation between pair-occupancy history and amount of suitable habitat for either the R5 (table K7) or R6 (table K8) SOHA samples.

The reiation between occupancy status and the expianatory variabies-For the R5 SOHA samples, no variables were selected in the logistic regression of pair occupancy on the explanatory variables in either 1988 or 1989. In the R6 samples, pair occupancy was significantly related to latitude in 1988 (table K9A) and to longitude in 1989 (table K9B). Model interpretation from these years suggests that pair occupancy was higher at inland sites in mid to southern Oregon (Southern Cascades and Klamath Province).

Our findings suggest that this assumption may be invalid. We encourage increased inventory efforts in reserve lands to further explore their potential to support spotted owls. 


\section{Appendix K: Monitoring Data}

Table K5-Results of the stepwlse logistlc regression analysis of the occupancy status of circular, 1000-acre Random Sample Areas (RSAS) and a number of predictor varlables; results are based on the 1988 (A) and 1989 (B) monltorlng data from Nationai Forest lands In Region $5^{a}$

A. 1988 results

\begin{tabular}{lrr}
\hline Variable & Coefficient & P-value \\
\hline Status & 0.6086 & 0.065 \\
Acres & -0.0044 & 0.001 \\
Constant & 1.5932 & 0.001
\end{tabular}

Model:

$\operatorname{Pr}($ no owls detected $)=\exp [1.59-0.0044$ (acres) +0.61 (status) $y$

$$
(1+\exp [1.59-0.0044 \text { (acres) }+0.61 \text { (status) }])
$$

Model interpretation:

Pr(owls detected) increased: a) with the amount of suitable habitat,

b) in nonreserve lands

B. 1989 results:

\begin{tabular}{lrr}
\hline Variable & Coefficient & P-value \\
\hline Status & 0.5584 & 0.002 \\
Constant & -0.1137 & 0.530
\end{tabular}

Model:

$\operatorname{Pr}($ no owls detected $)=\exp [-0.11+0.56($ status $)] /(1+\exp [-0.11+0.56($ status $)])$

Model interpretation:

Pr(owls detected) increased in nonreserved lands

a The dependent variable was occupancy status ( $0=$ no owls detected; $1=$ single or pair detected). Possible predictor variables for selection were land status, acres of suitable habitat, latitude, and longitude. Sample sizes were 104 in 1988 and 135 in 1989. 


\section{Appendix K: Monitoring Data}

Table K6-Results of the stepwise logistic regression analysis of the occupancy status of circular, 1000-acre Random Sample Areas (RSAs) and a number of predictor varlables; results are based on the 1988 (A) and 1989 (B) monitoring data from Natlonal Forest lands In Reglon $6^{2}$

A. 1988 results

\begin{tabular}{lrr}
\hline Variable & Coefficient & P-value \\
\hline Status & 0.4935 & 0.008 \\
Acres & -0.0041 & 0.001 \\
Latitude & 0.1877 & 0.020 \\
Constant & -6.8735 & 0.057
\end{tabular}

Model:

$\operatorname{Pr}($ no owls detected $)=\exp [-6.87-0.0041$ (acres) +0.49 (status) +0.19 (latitude) $]$ $(1+\exp [-6.87-0.0041$ (acres) +0.49 (status) + 0.19 (latitude)])

Model interpretation:

Pr(owls detected) increased: (a) with the amount of suitable habitat

(b) in nonreserve lands

(c) at lower latitudes

B. 1989 results:

\begin{tabular}{lcc}
\hline Variable & Coefficient & P-value \\
\hline Acres & -0.0028 & 0.001 \\
Constant & 0.9921 & 0.006
\end{tabular}

Model:

$\operatorname{Pr}($ no owls detected $)=\exp [0.99-0.0028($ acres $)] /(1+\exp [0.99-0.0028($ acres $)])$

Model interpretation:

Pr(owls detected) increased with the amount of suitable habitat

The dependent variable was occupancy status $(0=$ no owls detected; $1=$ single or pair detected). Possible predictor variables for selection were land status, acres of suitable habitat, average elevation, elevational range, latitude, and longitude. Sample sizes were 184 in 1988 and 139 in 1989. 


\section{Appendix K: Monitoring Data}

Table K7-Results of an analysis of varlance test of the relationship between the palr-occupancy hlstorles of Spotted Owl Habitat Areas (SOHAs) and the amount of sultable habltat; results are based on the 1988 and 1989 monltoring data from National Forest lands in Reglon $5^{a}$

\begin{tabular}{|c|c|c|c|c|c|}
\hline Source & $\begin{array}{l}\text { Degrees of } \\
\text { freedom }\end{array}$ & $\begin{array}{l}\text { Sum of } \\
\text { squares }\end{array}$ & $\begin{array}{l}\text { Mean } \\
\text { square }\end{array}$ & F-statistic & P-value \\
\hline $\begin{array}{l}\text { Occupancy } \\
\text { Error }\end{array}$ & $\begin{array}{r}2 \\
108\end{array}$ & $\begin{array}{r}32,440 \\
24,861,152\end{array}$ & $\begin{array}{r}16,220 \\
230,196\end{array}$ & 0.07 & 0.932 \\
\hline Total & 110 & $2,489,3584$ & & & \\
\hline Level & $\begin{array}{l}\text { Sample } \\
\text { size }\end{array}$ & Mean & $\begin{array}{l}\text { Standard } \\
\text { deviation }\end{array}$ & & \\
\hline $\begin{array}{l}0 \\
1 \\
2\end{array}$ & $\begin{array}{l}25 \\
33 \\
53\end{array}$ & $\begin{array}{l}1060.2 \\
1039.5 \\
1079.3\end{array}$ & $\begin{array}{l}545.6 \\
385.3 \\
499.3\end{array}$ & & \\
\hline
\end{tabular}

The groups were defined as: not occupied in any year (0); occupied in either 1988 or 1989 (1); occupied in both years (2). The dependent variable was acres of suitable habitat within a 1.5-mile radius of the SOHA center.

Table K8-Results of an analysis of variance test of the relation between the palr-occupancy hlstories of Spotted Owl Habltat Areas (SOHAs) and the amount of sultable habltat; results are based on the 1988 and 1989 monitoring data from National Forest lands in Reglon $6^{a}$

\begin{tabular}{|c|c|c|c|c|c|}
\hline Source & $\begin{array}{l}\text { Degrees of } \\
\text { freedom }\end{array}$ & $\begin{array}{l}\text { Sum of } \\
\text { squares }\end{array}$ & $\begin{array}{l}\text { Mean } \\
\text { square }\end{array}$ & F-statistic & $P$-value \\
\hline $\begin{array}{l}\text { Occupancy } \\
\text { Error }\end{array}$ & $\begin{array}{r}2 \\
190\end{array}$ & $\begin{array}{r}3,722,675 \\
326,258,176\end{array}$ & $\begin{array}{l}1,861,338 \\
1,717,148\end{array}$ & 1.08 & 0.340 \\
\hline Total & 192 & $329,980,672$ & & & \\
\hline Level & $\begin{array}{l}\text { Sample } \\
\text { size }\end{array}$ & Mean & $\begin{array}{l}\text { Standard } \\
\text { deviation }\end{array}$ & & \\
\hline $\begin{array}{l}0 \\
1 \\
2\end{array}$ & $\begin{array}{l}57 \\
72 \\
64\end{array}$ & $\begin{array}{l}3029 \\
3370 \\
3233\end{array}$ & $\begin{array}{l}1301 \\
1315 \\
1313\end{array}$ & & \\
\hline
\end{tabular}

The groups were defined as: not occupied in any year (0); occupied in either 1988 or 1989 (1); occupied in both years (2). The dependent variable was acres of suitable habitat within a 2.1-mile radius of the SOHA center. 


\section{Appendix K: Monitoring Data}

Table K9-Results of the stepwise logistic regression analysis of the palroccupancy status of Spotted Owl Habltat Areas (SOHAs) and several predictor variables; results are based on the 1988 (A) and 1989 (B) monitoring data from National Forest lands In Reglon $6^{a}$

A. 1988 results

\begin{tabular}{lcc}
\hline Variable & Coefficient & P-value \\
\hline Latitude & 0.1487 & 0.099 \\
Constant & -6.9464 & 0.084
\end{tabular}

Model:

$\operatorname{Pr}($ no owls detected $)=\exp [-6.95+0.1487$ (latitude $)] /(1+\exp [-6.95+0.1487$ (latitude)])

Model interpretation:

$\operatorname{Pr}$ (owls detected) increases at lower latitudes

B. 1989 results

\begin{tabular}{lrc}
\hline Variable & Coefficient & P-value \\
\hline Longitude & 0.3383 & 0.020 \\
Constant & -8.0595 & 0.013
\end{tabular}

Model:

$\operatorname{Pr}($ no owls detected $)=\exp [-8.06+0.34$ (longitude $)] /(1+\exp [-8.06+0.34$ (longitude $)])$

Model interpretation:

$\operatorname{Pr}($ owls detected) increases with decreasing longitude (that is, away from the coast)

Discussion

\footnotetext{
The dependent variable was occupancy status $(0=$ no owl pair detected; 1 = owl pair detected). Possible predictor variables for selection were land status, acres of suitable habitat, average elevation, elevational range, latitude, and longitude. Sample sizes were 136 in 1988 and 192 in 1989.
}

The RSA sample data provided the most useful insights into the correlation between site occupancy and a number of possible explanatory variables. The association of SOHA occupancy status with these same variables may have been weaker because of the purposeful placement of SOHA sites. To a large extent, SOHAs were placed around known pairs of spotted owls and in sites with relatively large amounts of suitable habitat. As a consequence, the observed variation in occupancy, and in the explanatory variables, was less than in the RSA sample. The RSA samples more accurately reflected the magnitude of variation in landscape and habitat attributes and their relation to occupancy status.

Analyses of RSA data showed consistent and strong, positive associations between the amount of suitable habitat and occupancy by either pairs or single birds. Further, the results indicated the likelihood of consistent occupancy across years was related to the amount of suitable habitat within the RSA. Land status was also selected as a significant predictor in three of four logistic regression analyses. These results indicated that occupancy was higher in nonreserved lands; that is, lands available for timber harvest. We believe this finding is significant. The current SOHA managment plan for the spotted owl (USDA 1988) puts great emphasis on the capacity of reserve lands (primarily Wilderness Areas) to support large numbers of spotted owls. 


\section{Appendix K: Monitoring Data}

\section{References}

Geographical position (latitude and longitude) was also related to occupancy in both the RSA and SOHA samples in R6. Collectively, these results suggested a significantly lower likelihood of occupancy, in both SOHAs and random sites, in the Coast Range of Oregon and the Olympic Pennisula in Washington. Further, an independent analysis (Noon, pers. comm.) demonstrated that fecundity rates were significantly lower in the Oregon Coast Range province. The finding of both lower occupancy rates and fecundity values indicate that these locations should be given special consideration when designating the number and size of HCAs needed for an effective conservation strategy.

Azuma, D., J. Baldwin, and B. R. Noon. 1989 unpubl. A sampling scheme for estimating occupancy of spotted owl habitat areas (SOHAs). Manuscript. U.S. For. Serv., Pacific Southwest Region, Berkeley, Calif.

Max, T. A., R. A. Souter, and K. A. O'Halloran. 1987 unpubl. Statistical estimators for monitoring spotted owls in Oregon and Washington. U.S. For. Serv., Pacific Northwest Region, Portland, Oreg.

Neter, J., W. Wasserman, and M. H. Kutner. 1985. Applied linear statistical models. R. D. Inwin, Inc., Homewood, III. 1127pp.

Noon, B. Pers. comm. FS, PSW, Arcata, Calif.

O'Halloran, K. 1989 unpubl. Spotted owl inventory and monitoring: Annual report for 1989. U.S. For. Serv., Pacific Northwest Region, Portland, Oreg. 13pp.

SImon-Jackson, T. 1989 unpubl. Spotted owl inventory and monitoring program: Annual report for 1989. U.S. For. Serv., Pacific Southwest Region, San Francisco, Calif. 10pp.

U.S. Department of Agriculture, Forest Service. 1988. Final supplement to the environmental impact statement for an amendment to the Pacific Northwest regional guide. Two volumes. U.S. For. Serv. Portland, Oreg. 



\section{Estimates of Demographic Parameters and Rates of Population Change}

Introduction
Standard Lotka-Leslie (Lotka 1956, Leslie 1945, 1948) methodology was applied to the estimates of the vital rates to make inferences to rates of population change from three geographic locations. We assumed that reproduction was characteristic of a birth-pulse population (Caughley 1977:6). Further, the analyses presented below assumed no density-dependence, were based on a 1:1 sex ratio at birth, and were formulated exclusively in terms of females.

Following standard representation, the basic demographic life history of the spotted owl is presented in table L1. The parameter $b_{x}$ denotes the expected number of female fledglings produced by a female of age $x$. Because the ages of females breeding, or attempting to breed, are seldom known, we assumed $b_{x}=b$ ( $x \geq 2$ yrs). The parameter $l_{x}$ represents the probability of survival to age $x$ (by definition $b=1.0$ ). The number of age-classes for which annual survival probabilities were assumed to be distinct was three; $1 s t$ ( $s_{0}$ [juvenile]) and 2 nd ( $s_{1}$ [subadult]) years, and adults ( $s$ ). Probability of survival to age $x$ is thus given by $I_{x}=s_{0} s_{1} s^{x-2}$ (table L1). For these analyses, we did not partition 1st-year survival into predispersal and postdispersal probabilities as was done by Lande (1988). Parameter estimates used in our analyses of the three locations are given in tables L2 to L4.

Table L1-Spotted owl life history (age at first reproduction $=2$ years)

\begin{tabular}{|c|c|c|c|}
\hline$x^{a}$ & $1 x^{b}$ & $b_{x}^{c}$ & $b_{x} b_{x}^{d}$ \\
\hline 0 & 1.0 & 0 & 0 \\
\hline 1 & so & 0 & 0 \\
\hline 2 & $s_{0} s_{1}$ & $b$ & $s o s 1 b$ \\
\hline 3 & $s_{0} s_{1} s$ & $b$ & $s_{0} s_{1} s b$ \\
\hline 4 & $s_{0} s_{1} s^{2}$ & $b$ & $s o s 1 s^{2} b$ \\
\hline • & • & • & - \\
\hline - & - & - & • \\
\hline - & • & • & • \\
\hline$x$ & $s_{0} s_{1} s^{x-2}$ & $b$ & $s_{0} s_{1} s^{x-2} b$ \\
\hline
\end{tabular}

a $x$ denotes age expressed in years.

b $1_{x}$ denotes the probability that an individual aged 0 (a newly hatched bird) will survive to enter age-class $x$.

${ }^{c} b_{x}$ denotes the expected number of female fledglings pro-

duced by a surviving female aged $x$.

${ }_{1} b_{x}$ denotes the net maternity function. 


\section{Appendix L: Population Change}

Tabie L2-Ninety-five percent confidence intervais on $\lambda$ and tests of the hypothesis that $\lambda \geq 1.0$ based on parameter estimates from Six Rivers National Forest, Cailfornia, 1985-89 (Frankiln et al. 1990a)

\begin{tabular}{lccccc}
\hline & & & & \multicolumn{2}{c}{ Sensitivity } \\
\cline { 5 - 7 } Parameter & Estimate & $\begin{array}{c}\text { Sample } \\
\text { size }\end{array}$ & $\begin{array}{c}\text { Standard } \\
\text { error }\end{array}$ & $\mathrm{a}$ & $\mathrm{b}$ \\
\hline $\mathrm{so}^{\mathrm{a}}$ & 0.138 & 63 & 0.046 & 0.305 & \\
$\mathrm{so}^{\mathrm{b}}$ & 0.290 & 17 & 0.110 & & 0.280 \\
$\mathrm{~s}_{1}$ & 0.903 & 34 & 0.024 & 0.046 & 0.090 \\
$\mathrm{~s}$ & 0.903 & 164 & 0.024 & 0.956 & 0.918 \\
$\mathrm{~b}$ & 0.335 & 280 & 0.046 & 0.126 & 0.243 \\
$\lambda^{\mathrm{a}}$ & 0.947 & & 0.027 & & \\
$\lambda^{\mathrm{b}}$ & 0.991 & & 0.039 & & \\
\hline
\end{tabular}

(a) $\lambda \pm(Z .05) 6 \lambda$

$0.947+(1.96)(0.027)$

$(0.893-1.000)$

$Z=\mid(0.947-1 / 0.027 \mid=1.924, P<0.027$

Conclusion: reject $\mathrm{H}_{0}$.

(b) $\lambda \pm(Z .05) 6 \lambda$

$0.991+(1.96)(0.039)$

$(0.914-1.069)$

$Z=|(0.991-1) / 0.039|=0.2152, P=0.415$

Conclusion: do not reject $\mathrm{H}_{0}$.

Table L3-Ninety-five percent confidence intervais on $\lambda$ and test of the hypothesis that $\lambda \geq 1.0$ based on parameter estimates from Roseburg District, BLM, Oregon, 1986-89 (Forsman, pers. comm.)

\begin{tabular}{lcccc}
\hline Parameter & Estimate & $\begin{array}{c}\text { Sample } \\
\text { size }\end{array}$ & $\begin{array}{c}\text { Standard } \\
\text { error }\end{array}$ & Sensitivity \\
\hline so & 0.219 & 181 & 0.072 & 0.201 \\
s1 & 0.588 & 44 & 0.086 & 0.048 \\
s & 0.812 & 213 & 0.025 & 0.959 \\
b & 0.310 & 215 & 0.115 & 0.115 \\
$\lambda$ & 0.858 & & 0.033 & \\
\hline
\end{tabular}

$\lambda \pm(\mathrm{Z} .05) 6 \lambda$

$0.873 \pm(1.96)(0.038)$

$(0.798-0.948)$

$Z=|(0.8731-1) / 0.0283|=3.3091, P<0.005$

Conclusion: Reject $\mathrm{H}_{0}$. 


\section{Appendix L: Population Change}

Tabie L4-Ninety-five percent confidence intervais on $\lambda$ and test of the hypothesis that $\lambda \geq 1.0$ based on parameter estimates from Oiympic National Forest, Washington, 1987-89 (Forsman, pers. comm.)

\begin{tabular}{|c|c|c|c|c|}
\hline Parameter & Estimate & $\begin{array}{l}\text { Sample } \\
\text { size }\end{array}$ & $\begin{array}{c}\text { Standard } \\
\text { error }\end{array}$ & Sensitivity \\
\hline so & 0.150 & $n / a$ & 0.050 & 0.299 \\
\hline$s_{1}$ & 0.935 & & 0.035 & 0.041 \\
\hline$s$ & 0.935 & 96 & 0.035 & 0.960 \\
\hline$b$ & 0.280 & 47 & 0.216 & 0.138 \\
\hline$\lambda$ & 0.975 & . & 0.047 & \\
\hline
\end{tabular}

$\lambda \pm(Z .05) 6 \lambda$

$0.975 \pm(1.96)(0.047)$

$(0.882-1.068)$

$Z=|(0.975-1) / 0.047|=0.521, P=0.302$

Conclusion: Do not reject $\mathrm{H}_{0}$.

In our analyses, "adult" referred to ages subsequent to the 2 nd year of life; within this age-class, survival rate was assumed constant. Pre-adult survival rate (/2) represented the probability of survival from fledging to age 2 and was given by the product of so and $s_{1}$.

Estimates of the rates of population change from the basic demographic life table (table $L 1$ ) required the estimation of five parameters, $s_{0}, s_{1}, s, b$, and a (age at first reproduction). Preliminary estimates of these parameters were available for all three studies analyzed here. Because these terms were expected to vary geographically, separate analyses were conducted.

Estimates of all the parameters needed for a completely age-specific Leslie matrix were unavailable. With long-lived species, data are often limited, and estimates of all the age-specific parameters are impossible to attain or have large sampling variances because of small sample sizes. Repeated multiplication of imprecise estimates in fully age-specific models is likely to lead to uncontrolled error propagation (Dobson and Lyles 1989). A useful approximation to an age-structured model is a stagestructured model called a Lefkovitch matrix (Lefkovitch 1965). Structurally, the dynamics of the two models are usually very similar, but the Lefkovich model is more tractable (Boyce 1987). Estimating the population dynamics of spotted owls with a stage matrix would yield misleading conclusions only if the species experienced reproductive senescence before about 15 years (Noon and Biles 1990). Given the current high estimates for $S$, early senescence seemed unlikely. For spotted owls, we divided the population into three stages, juveniles, J; subadults, S; and adults, A. Time was expressed on an interbirth interval of 1 year, and we assumed an age at first reproduction of 2 years. Given that spotted owl populations were censused shortly after the birth-pulse, the Lefkovitch matrix had the following structure:

$$
\left[\begin{array}{c}
J_{t+1} \\
S_{t+1} \\
A_{t+1}
\end{array}\right]=\left[\begin{array}{lll}
0, & s_{1} b, & s b \\
s_{0}, & 0, & 0 \\
0, & s_{1}, & s
\end{array}\right]\left[\begin{array}{l}
J_{t} \\
S_{t} \\
A_{t}
\end{array}\right]
$$




\section{Appendix L: Population Change}

The location of $s$ along the diagonal of the matrix reflects our assumption of constant adult survival and no senescence. The possibility of very old owls in the population had no effect on our estimate of population growth rate $(\lambda)$, assuming that adult survival was estimated irrespective of adult age from an unbiased sample of all adults in the population (Boyce 1987). For all three studies, we believe this assumption was valid.

The basic characteristic equation of the matrix is given by

$$
\lambda^{2}-s \lambda-\operatorname{sos} 1 b=0
$$

Equation (1) has two solutions; the dominant, real-valued solution $\left(\lambda_{1}\right)$ is an estimate of the annual rate of change of the population. If $\lambda>1.0$, the vital rates suggest the population was increasing; if $\lambda=1.0$, the population size was stable; and if $\lambda<1.0$, the population was declining. We urge caution in using the computed estimates of $\lambda$ (tables L2 to L4) to forecast future population sizes or to infer the size of historical populations. Lamdba was merely an estimate of how the population was changing over the period of study. Using the estimate of $\lambda$ to project future population size must be based on the unrealistic assumption that current estimates of the vital rates remain constant. Populations governed by Leslie or Lefkovich matrices grow, or decline, exponentially (except for the unlikely case where $\lambda=1.0$ ). This model is clearly unrealistic for the long-term growth or decline of any natural population. For example, all growing populations experience density-dependent limitation when they reach the carrying capacity of their environment.

\section{Methods- Hypothesis Tests on Lambda}

Estimates of the demographic characteristics of spotted owls were available from three locations: Klamath Province, Six Rivers National Forest (Franklin et al. 1990), Oregon Coast Range Province, Roseburg, Oregon District of the BLM (Forsman, pers. comm.), and Olympic Peninsula, Olympic National Forest (Forsman, pers. comm.). In all three study areas, estimates of age-specific survival rates, ages at first reproduction, and adult fecundity were based on the histories of banded birds. For the California (Franklin et al. 1990a) and Oregon (Forsman, pers. comm.) studies, estimates of adult female survival rates $(s)$ were based on the methods of Jolly (1965) and Seber (1965) and assumed an open population. For Forsman's study on the Olympic Pennisula, data were too sparse for Jolly-Seber estimates. Survival rates were estimated empirically with the subadult and adult age-classes combined across the sexes. First-year survival rate (so) was estimated empirically in all studies. The demographic studies varied in duration from 3 (Olympic Peninsula) to 5 (Oregon) to 6 (California) years.

The sensitivities (partial derivatives) of $\lambda$ with respect to the individual life-history characteristics indicate which of the parameters most affects variation in the population growth rate (Lande 1988, Noon and Biles 1990). In addition, sensitivities are needed to estimate the standard error of $\lambda$ and to perform hypothesis tests. Sensitivities were computed by implicit differentiation of the characteristic equation (Goodman 1971, Lande 1988). Sensitivities for spotted owl parameters are: 


\section{Appendix L: Population Change}

The values of the sensitivity coefficients for the three geographic areas are given in tables L2 to L4. For all areas, change in population growth rate was most sensitive to variation in adult survival rate, and next most sensitive to variation in the 1 st-year survival rate (Lande 1988, Noon and Biles 1990).

The sensitivities of $\lambda$ appear in the formula that approximates the sampling variance of the $\lambda$ estimate (Lande 1988:602):

$$
6^{2} \lambda=\sum(\partial \lambda / \partial \pi)^{2} 6 \pi^{2}
$$

where $\pi$ represents each of the parameters and $6 \pi^{2}$ their sampling variance. Following Lande (1988), we assumed the survival probabilities for the Washington study, and for the 1st- and 2nd-year survival rates for California and Oregon, had binomial sampling distributions and computed their variance as $6 \pi^{2}=\pi(1-\pi) / N \pi$. The variances of the adult survival rates from California and Oregon were estimated according to the methods of Jolly (1965) and Seber (1965). The variance of the annual fecundity was based on the variance among females across the years of study divided by the appropriate sample size.

Equation (2) neglects possible covariances among the demographic parameters and fails to account for between-year changes in the vital rates. Between-year changes, estimated by factoring out the temporal component of variation from the total variance estimates of the vital rates and $\lambda$, are currently being estimated for the California data (Noon, pers. comm.).

The components of the sampling variance of $\lambda$ were computed by using equation (2), based on the sensitivities and estimates of the vital rates given in tables L2 to L4. The standard error of $\lambda$, computed as the square root of the variance, was used to construct a confidence interval around $\lambda$. For example, the $95 \%$ confidence interval on $\lambda$ was computed as: $\lambda \pm(1.96)(6 \lambda)$. An estimate of $\lambda$ and its standard error also allowed tests of hypotheses. Of most interest, relative to concern for the species' persistence, was whether $\lambda$ was significantly $<1.0$. Tests were conducted as one-tailed tests of the hypothesis: $H_{0}: \lambda \geq 1$, versus the alternative hypothesis: $H_{A}: \lambda<1$. The appropriate test statistics followed a $Z$-distribution and was given by: $Z=|(\lambda-1) / 6 \lambda|$. Tests were one-tailed with a specified probability of a Type 1 error $=0.05$.

Estimates of survival and reproductive rates used in the subsequent demographic analyses were based exclusively on banded birds. In some studies, backpackmounted radio transmitters appeared to affect reproduction (Foster et al. unpubl.) or both survival and reproduction (Paton et al. unpubl.). For this reason, we did not include information from any birds with radio transmitters.

Results-Tests on Lambda
We report results from two different analyses of the demographic parameters from California (table L2). They differ in the estimate used for 1st-year survival, and its associated standard error and sensitivity coefficient. In scenario b, we used $s 0=$ 0.290 , the maximum survival rate observed for a juvenile cohort (1985 cohort; Franklin et al. 1990a). The estimate of adult survival we used $(s=0.903$ ) differed from that reported in Franklin et al. (1990). Our estimate was based on a reanalysis of Franklin's data (Anderson and Franklin, pers. comm.). 


\section{Appendix L: Population Change}

Based on the vital rates for scenario a $(s 0=0.138 ; s=0.903), \lambda=0.947$ and, by a one-tailed test, was significantly $<1.0(P=0.027)$. This value of $\lambda$ suggests that the study population in northwestern California was undergoing a significant population decline during the period 1984-89. If the vital rates were to remain constant, this value of $\lambda$ suggests an annual rate of population decline equal to $5.3 \%([1-\lambda]$ $100 \%$ ). This estimated rate of decline slightly exceeded the estimated rate of loss of suitable owl habitat from the study area over the interval 1985-88 (Franklin et al. 1990b).

The estimate of so from the 1985 cohort may be more reliable because of the increased opportunity to have reobserved these color-marked individuals. Based on this consideration, when we used the more optimistic estimate for $s 0(0.290), \lambda$ was still $<1.0(\lambda=0.991)$ but was no longer significant $(P=0.415)$. Conditioned on constant parameter values, a $\lambda=0.991$ suggests a $0.9 \%$ annual rate of population decline.

Based on the estimates of the vital rates for the Oregon BLM land, $\lambda(=0.858)$ was significantly $<1.0(P<0.001)$. This estimate suggests that the study population in the Oregon Coast Range had undergone a significant population decline during the period 1986-89. If the vital rates were to remain constant, this value of $\lambda$ suggests an annual rate of population decline equal to $14.1 \%$. The sensitivities (table $L 2$ ) indicate that the low value of $\lambda$ was most attributable to the low adult survival rate (s). A portion of the estimated decline in population may have been attributable to loss of suitable habitat. From 1986-89, the estimated rate of loss, from BLM lands, of mature and old-growth forest on the study area was $5.1 \%$ (Lint, pers. comm.). This was a minimum estimate of the rate of loss. A large portion of the study area included private timber lands that were heavily harvested during the period of study and from which no data were available.

Estimates of the vital rates for the Olympic Peninsula yielded a $\lambda=0.975$, which was not significantly $<1.0(P=0.302)$. Because $\lambda$ could not be demonstrated to be significantly $<1.0$, these data did not support the conclusion that the spotted owl population had experienced a significant population decline during the interval 1986-89. If the vital rates were to remain constant, however, this value of $\lambda$ suggests an annual rate of population decline equal to $2.5 \%$. The results of this analysis must be interpreted cautiously because they are based on only 3 years of study and as a result, rely on small sample sizes and imprecise parameter estimates (table L3). In addition, we were unable to develop a female-based model for this study because insufficient data were available from adult female owls. If female owls on the Olympic Peninsula had lower survival rates than males, as they did in northwestern California over a similar period of study (Franklin et al. 1990a), then our estimate of $\lambda$ was too high.

\section{Discussion}

All three demographic study areas - Klamath Province in California, Coast Range in Oregon, and the Olympic Peninsula in Washington-yielded estimates of $\lambda<1.0$, which suggested that, in all three areas, spotted owl populations had experienced declines. The $\lambda$ estimates from California and Oregon, the studies of longest duration and with largest sample sizes, were statistically significant. 


\section{Appendix L: Population Change}

Estimates of parameter sensitivities from all three study areas suggests that $\lambda$ values were most sensitive to estimates of adult survival rate $(s)$, distantly followed by 1 styear survival rate $\left(s_{0}\right)$ and fecundity $(b)$. The sensitivity coefficient associated with age at first reproduction (a), which was not reported here, was $<0.0001$ (Noon and Biles 1990). Note, however, that two sources of information are relevant to a species' rate of population change $(\lambda)$ : one is the sensitivity of $\lambda$ to variation in the vital rates as reflected in parameter sensitivity coefficients; and the other concerns those lifehistory attributes that show the most natural variation. Variations in growth rate $(\lambda)$ may be more closely associated with attributes that are naturally more variable than to attributes that are less variable but to which growth rate is more sensitive in a mathematical sense. Estimates of the magnitude of natural variation in demographic parameters are just now becoming possible. Preliminary analyses of data from the Klamath Province of California (Franklin et al. 1990a) suggest that true, year-toyear variation in $\lambda$ may have been most attributable to annual variation in 1 st-year survival rate (Noon, pers. comm.).

On the surface, the separate estimate of population trend from the California study area (Franklin et al. 1990b) appears to contradict inferences from the estimate of $\lambda$ $(0.947)$ for the same population. To understand this apparent contradiction, several points are particularly relevant. First, when the demography of spotted owls is studied, the sampled population in a given field season consists almost entirely of territorial birds and their offspring. Nonterritorial (floater) birds were seldom captured unless they eventually entered the territorial population. Thus, the estimates of the vital rates were based almost exclusively on the dynamics of the territorial population.

Second, all of the spotted owl demography studies have taken place in areas that experienced declines in the amount of suitable habitat during the study period (Franklin et al. 1990b; Forsman, pers. comm.). Assuming some degree of site fidelity, territorial spotted owls displaced by habitat loss would then enter a local floater population. Local populations have additional sources of floaters, particularly from areas experiencing habitat loss. These floaters include juvenile and subadult birds unable to find a vacant territory or a mate.

Third, the Jolly-Seber model used to estimate population size (Franklin et al. 1990b) did not discriminate between internal recruitment events resulting from natality, and those that were a consequence of immigration into the territorial population. In contrast, the estimate of $b$ used in the computation of $\lambda$ (equation 1) reflected only the internal recruitment (natality) potential of the territorial birds. Thus, even a territorial population whose death rate far exceeded its birth rate could remain relatively stable over the short-term if it experienced rapid replacement of territorial birds by floaters. Estimates of $\lambda$ from demographic models, however, are functions of a population's survival and fecundity rates. As a result, $\lambda$ estimates discriminate between population stability from the recruitment of floaters and stablity from an internal balance between birth and death rates. The $\lambda$ estimate from Franklin's study indicates that the death rate of the territorial population exceeded its birth rate. 


\section{Appendix L: Population Change}

Immigration into a territorial population can occur from both inside and outside the general study area. In northwestern California, the age distribution of new recruits into the population, which strongly favors adults (Franklin et al. 1990b), suggests that the observed increases in population size resulted from immigration. The source of the adult immigrants could have been from outside the study area, or from birds floating within the study area for two or more years. We think a plausible explanation for Franklin's results is one that attributes much of the population increase to recruitment of birds from outside the study area, possibly the result of an influx of individuals displaced by timber harvest.

The Jolly-Seber model provides estimates of the magnitude of annual recruitment into a population. The difference between this estimate and that portion attributable to internal natality $(b)$ is even more dramatic in the Oregon Coast Range than in northwestern California (Anderson and Forsman, pers. comm.). In contrast, however, the new recruits into the territorial population in Oregon were an even mix of subadult and adult birds (Meslow, pers. comm.). Forsman and Meslow (pers. comm.) believe the age-ratio data suggest immigration into the territorial population from both inside and outside their study area. During the period of study (1986 to 1989), the Oregon Coast Range, including Forsman's study area, experienced extensive harvest of suitable spotted owl habitat.

An additional consideration, particularly relevant for a species like the spotted owl, argues strongly for the use of estimates of demographic parameters to infer the rate and direction of population change. A long-lived species experiencing a rapid decline in suitable habitat may show an increased density from the packing of individuals in the remaining habitat. Even though these nonterritorial individuals (floaters) do not contribute to the breeding population, they may have significant negative impacts on population dynamics because of density-mediated declines in the survival and fecundity rates of the territorial birds. Such declines could occur, for example, as a result of localized prey depression. For example, studies of the tawny owl demonstrated density-dependent declines in reproductive success, and related the declines to changes in prey availability (Southern 1970). The existence of floaters can also introduce a lag in detecting declines in the territorial population. This lag occurs because floaters quickly replace territorial birds that die, making the territorial population appear stable.

Based on the two studies of spotted owl demography that provide reliable survival rate estimates (Klamath Province, California [Franklin et al. 1990a); Oregon Coast Range [Forsman, pers. comm.]), we accept the hypothesis that spotted owl populations were declining $(\lambda<1.0)$ in parts of their range from 1985-89. Further, if the vital rates estimated from these two populations remained the same, these populations would continue to decline in the future.

Acknowledging the possibility of a Type 2 error is important, if the survival rate estimates were negatively biased. Bias can occur if a large number of banded birds permanently left the study area and survived. We believe this was likely for 1 st-year birds because they were the most likely to emigrate, but not for adults. Given the relatively low sensitivity of $\lambda$ to $s 0$ and, in contrast, $\lambda$ 's extreme sensitivity to $s$, that the estimates of $\lambda$ were appreciably affected by any confounding of mortality with permanent emigration is unlikely. 


\section{Appendix L: Population Change}

Studies of radio-marked, adult spotted owls provided a way of estimating the magnitude of permanent emigration. To make this estimate, we computed the number of emigrations per bird-year. A bird-year was defined as one adult bird tracked for one calendar year. From radio-telemetry studies near Roseburg, Oregon, only one occurrence of permanent emigration was recorded in $>100$ bird-years (Forsman, pers. comm.). Radio-telemetry studies in northwestern California recorded one permanent emigration in 60 bird-years (Paton, pers. comm.). These findings suggest that the estimates of adult survival rate were not affected by permanent emigration from the study areas.

The most ready explanation for the apparent population decline in northwestern California (Franklin et al. 1990a) and the Oregon Coast Range (Forsman, pers. comm.) was the decline in the amount of suitable owl habitat during the study period. This explanation, however, only partially accounts for the magnitude of the population decline. In addition to the decline predicted from the absolute amount of habitat loss, the spatial arrangement of the remaining habitat must also be considered. Habitat that is widely dispersed and isolated into small blocks may be unoccupied because of the low probability of successful dispersal to those patches, and because of higher pair turnover rates. The difficulty of finding suitable habitat that has both a vacant territory and an individual of the opposite sex, might quickly become insurmountable in a highly fragmented landscape. The influence of these factors on the owl's population dynamics are explored in appendix $M$.

\section{References}




\section{Appendix L: Population Change}

Franklin, A. B., J. P. Ward, R. J. Gutlerrez, and G. I. Gould, Jr. 1990b. Density of northern spotted owls in northwestern California. J. Wildl. Manage. 54:1-10.

Goodman, L. A. 1971. On the sensitivity of the intrinsic growth rate to changes in the age-specific birth and death rates. Theoret. Popul. Biol. 2:339-354.

Jolly, G. M. 1965. Explicit estimates from capture-recapture data with both death and dilution-stochastic model. Biometrika 52:225-247.

Lande, R. 1988. Demographic models of the northern spotted owl (Strix occidentalis caurina). Oecologia 75:601-607.

Lefkovich, L. P. 1965. The study of population growth in organisms grouped by stages. Biometrics 21:1-18.

Leslle, P. H. 1945. On the use of matrices in certain population mathematics. Biometrika 33:183-212.

Leslie, P. H. 1948. Some further notes on the use of matrices in population mathematics. Biometrika 35:213-245.

Lint, J. Pers. comm. BLM, Roseburg, Oreg.

Lotka, A. J. 1956. Elements of mathematical biology. Dover, New York.

Meslow, E. C. Pers. comm. FWS, Oreg. State Univ., Corvallis.

Noon, B. R. Pers. Comm. FS, PSW, Arcata, Calif.

Noon, B.R., and C.M. Biles. 1990. The mathematical demography of the spotted owl in the Pacific northwest. J. Wildl. Manage. 54:18-27.

Paton, P. W. C. Pers. comm. FS, PSW, Arcata, Calif.

Paton, P. W. C., C. J. Zabel, N. G. Tilghman, and B. R. Noon. Unpubl. Effects of radio tags on spotted owls. Manuscript in preparation.

Seber, G. A. F. 1965. A note on the multiple recapture census. Biometrika 52:249-259.

Southern, H.N. 1970. The natural control of a population of tawny owls (Strix aluco). J. Zool. London 162:197-285. 


\section{Population Simulation Models}

Introduction
Previous analyses of the demography of the spotted owl (Lande 1988, Noon and Biles 1990) have suggested that variation in the age-specific survival rates, and particularly changes in adult survival, strongly affect population growth. Therefore, exploring those factors that strongly affect the survival rates of all age-classes is essential. As territories become more patchy in their distribution because of habitat loss and fragmentation, we predict the likelihood of successful dispersal to suitable habitat areas will decrease. Failure to successfully locate and colonize suitable habitat will be an additional source of mortality for all age-classes. We believe the population dynamics of the owls are complicated by factors associated with habitat loss and fragmentation. These factors include difficulties in finding both mates and suitable territories, changes in prey density and distribution, and increased dispersal mortality from increases in search time. We believe that our model structure captures some of this reality, and that our simulation results demonstrate the significance of these effects to the long-term viability of the northern spotted owl.

We discuss results from two simulation models with different structure. In the first, we explored the dynamics of a two-sex, single-ternitory (home-range) model and the effects that different magnitudes of suitable habitat loss had in the context of varying dispersal capabilities (Lamberson et al. 1989). This model was developed to crudely approximate the current management design for spotted owl viability; that is, single-pair spotted owl habitat areas (SOHAs) and small ternitory clusters dispersed across the landscape at specified distances (USDA 1988). Our purpose in developing this model was to explore very general system properties in an attempt to gain insights into what aspects of the species' life-history and behavior most influence its long-term population dynamics.

In a second, single-sex model (Lamberson et al. 1989), we allowed female (pair) territories to be adjacent to each other in clusters of various sizes. The primary goal of this modeling effort was to specifically investigate the advantages of territory clusters of various sizes relative to the single and small-cluster territory pattern of the current management plan (USDA 1988). In this model, we assumed-like Doak (1989)-that successful dispersal within a cluster was more likely than between clusters. This difference arose because of the "resistance" to successful dispersal that occurred within the landscape matrix.

Clarifying the role that computer simulation models, and the inferences drawn from them, played in developing our conservation plan is important. Their role was secondary. Our primary guidance derived from the results of empirical studies of the spotted owl's ecology and life history. The models provided one means of synthesizing this 


\section{Appendix M: Population Models}

The IndividualTerritory Model

Model Description information and suggested aspects of the animal's life history and behavior that may most affect its long-term population dynamics. We sought confirmation of model results from empirical studies of the spotted owl or other vertebrate species, and from the predictions of theoretical models (see discussion in appendices $N, O$, and $P$ ). $A$ necessary caution is that the quantitative results of our models should only be interpreted as general qualitative guidelines; they should not be interpreted literally. We have used insights provided by our models as a way of ranking, from most to least important, the many factors that influence the species' population dynamics. Our models, like most, are also a great simplification of all the factors that influence the dynamics of "real" spotted owls.

In the individual-territory model, we assumed that all newly fledged juveniles dispersed even though a low probability exists that some juveniles may inherit their natal territory. In addition, adult birds ( $\geq 1$ year old) that experienced loss of their territory (from timber harvest) also dispersed. The model focused on a landscape of fixed spatial extent and contained a fixed number of potential home-range territories (or "sites"). Only a fraction of these sites, however, could be occupied (meaning, in a probabilistic sense, that they allowed survival, mate attraction, and reproductive success) - namely those that were stocked by suitable habitat.

The state variables in the model, which were updated annually, were:

- The number $T$ of currently suitable sites (which may be decreasing over time from timber harvest);

- The number $P$ of suitable sites that are occupied by nesting pairs; and

- The number $S$ of suitable sites that are occupied by single males.

A nesting pair annually produced young (according to either some deterministic likelihood or stochastically fluctuating fecundity). These young would disperse at the end of the season, the males seeking an unoccupied site and the females seeking a site occupied by a solitary male. Our simulated landscape can be envisioned as a grid composed of 1000 cells or sites. Each site is either suitable for a territory or unsuitable. Search capability was expressed as the percentage of the landscape that could be searched before the owl died. The likelihood of successful search was affected by whether we assumed an Allee effect (Allee 1935, 1938). If search efficiency was set at $2 \%$, for example, then up to 20 sites could be searched for a suitable site that was unoccupied (no Allee effect), or occupied by an individual of the opposite sex (Allee effect). Dispersal success was density-dependent and was calculated by assuming random search of accessible sites. Various assumptions can be made about the bird's search efficiency; we expressed this as the number of sites an individual was capable of searching before dying. Search capabilities, together with the occupancy ratio of searched sites, determined the bird's potential for successful dispersal. (This calculation was consistent with Lande [1987].) In our model, we allowed dispersing adult birds and females to search twice the number of sites searched by juvenile males. We believed that adult birds were more effective dispersers than juveniles and assumed that females may bypass a suitable territory unless it is occupied by a single male owl. 


\section{Appendix M: Population Models}

Adult birds ( $\geq 1$ year) were subject to mortality, and adults occupying territories were subject to site disturbance (for example, timber harvest); consequently, some surviving adults were also forced to disperse. Juvenile birds also were subject to mortality; in particular, birds that were unsuccessful in dispersal were assumed to have died. To condense the model, we assumed that the number of male and female solitary owls remained equal, that the single females were retained as a floater population, and that all solitary owls had the same vital rates. This assumption allowed considerable simplification without (at our present state of empirical knowledge) any significant loss of accuracy.

We ran the model under a number of alternative assumptions about the proportion of the landscape that was suitable habitat (specified as Tover time), the owl's biology and environment (specifying survival and fecundity parameters and search efficiency), and initial population sizes (specifying $S$ and $P$ at time 0 ). After we specified the proportion of the landscape considered suitable, this proportion of sites was distributed at random across the landscape. We also varied the amount of environmental stochasticity, primarily through a fluctuating fecundity rate to reflect variability in food supply (for example, small rodents).

Model Parameterization

Model parameters were set based on the demographic studies of Franklin et al. (1990) and values published by Marcot and Holthausen (1987). We assumed an annual adult survival probabilty of 0.92 , juvenile predispersal survival of 0.60 , fecundity (number of young fledged per adult female) of 0.66 , and a 1:1 sex ratio at birth. Single birds (floaters) were assumed to survive at the estimated annual subadult survival rate of 0.77 (table M1).

Results-IndividualTerritory Model

\section{Deterministic Analyses}

First, we ran the model deterministically (that is, with no environmental fluctuations), while varying the initial population size (initial $S$ and $P$ being kept in fixed proportion). Owl biology (demographic parameters; table M1) and the proportion of the landscape that was suitable habitat $(25 \%)$ were held constant.

If the initial population was sufficiently large and the search efficiency was relatively high, the population tended to reach a stable equilibrium (fig. M1), but an initially small population crashed (fig. M1). If search efficiency was low, even very large initial populations crashed (fig. M2).

The stable equilibrium was actually two-dimensional $\left(S^{\star}, P^{*}\right)$, which is shown more clearly in a phase-plane portrait (fig. M3). The curve $M$ shown there is an attracting manifold, so that an initial population ( $S, P$ ) moves quickly, in two or three generations, to its close vicinity. The curve $M$ contains three equilibria; at $\left(S^{\star}, P^{*}\right),(0,0)$, and an intermediate, unstable equilibrium at ( $S \#, P \#)$. A population on $M$ above $(S \#, P \#)$ is drawn quickly to $\left(S^{\star}, P^{\star}\right)$, but one below it moves inevitably to extinction at $(0,0)$.

Figures M1 to M3 illustrate an Allee effect, the result of diminishing female success in finding a mate as the population becomes smaller and more dispersed. Note that, in this two-sex model, the Allee effect arose from an explicit nonlinear mating searchsuccess probability function. Alternative hypotheses on search and the Allee effect are explored by Dennis (1989). 


\section{Appendix M: Population Models}

Table M1-Estimates of parameter values for spotted owl life history used in the model simulations

\begin{tabular}{lll}
\hline Parameter & Estimate & Source \\
\hline$s^{\prime} 0=\begin{array}{l}\text { fledgling survival } \\
\text { probability (predispersal) }\end{array}$ & 0.60 & Marcot \& Holthausen (1987) \\
$s_{d}=\begin{array}{l}\text { juvenile probability of } \\
\text { successful dispersal }\end{array}$ & 0.18 & Marcot \& Holthausen (1987) \\
$s_{1}=\begin{array}{l}\text { subadult annual } \\
\text { survival probability }\end{array}$ & 0.77 & Franklin et al. (1988) \\
$s=\begin{array}{l}\text { adult annual survival } \\
\text { probability }\end{array}$ & $0.92^{a}$ & Franklin et al. (1988) \\
$b=\begin{array}{l}\text { adult female average } \\
\text { annual fecundity }\end{array}$ & 0.33 & Franklin et al. (1988) \\
$a=\begin{array}{l}\text { age at first breeding } \\
h=\begin{array}{l}\text { current percentage of } \\
\text { landscape suitable for } \\
\text { spotted owls }\end{array}\end{array}$ & $2 \mathrm{yrs.}$ & Noon \& Biles (1990) \\
\hline
\end{tabular}

a This estimate is higher than that reported in Franklin et al. (1990). They report adult female survival rate $=0.90$.

'This estimate is based on the proportion of the forested landscape estimated as suitable spotted owl habitat on National Forest lands in Oregon and Washington.

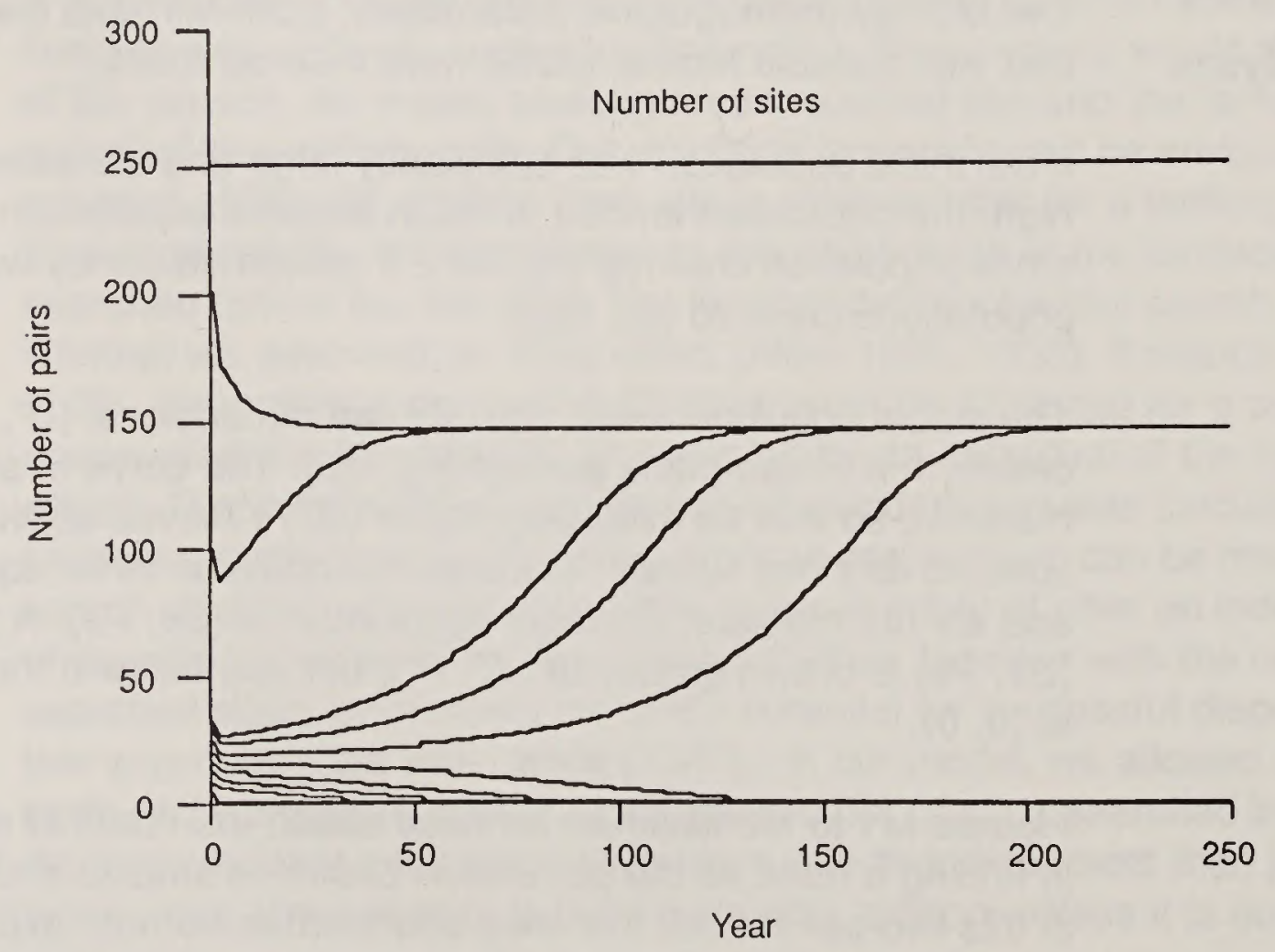

Figure M1-Trend in number of pairs of spotted owls based on a 250-year simulation. Each curve was initialized at a different population size. We assumed that $25 \%$ of the landscape was suitable owl habitat, and that juvenile owls could search $3 \%$ of the landscape. 


\section{Appendix M: Population Models}

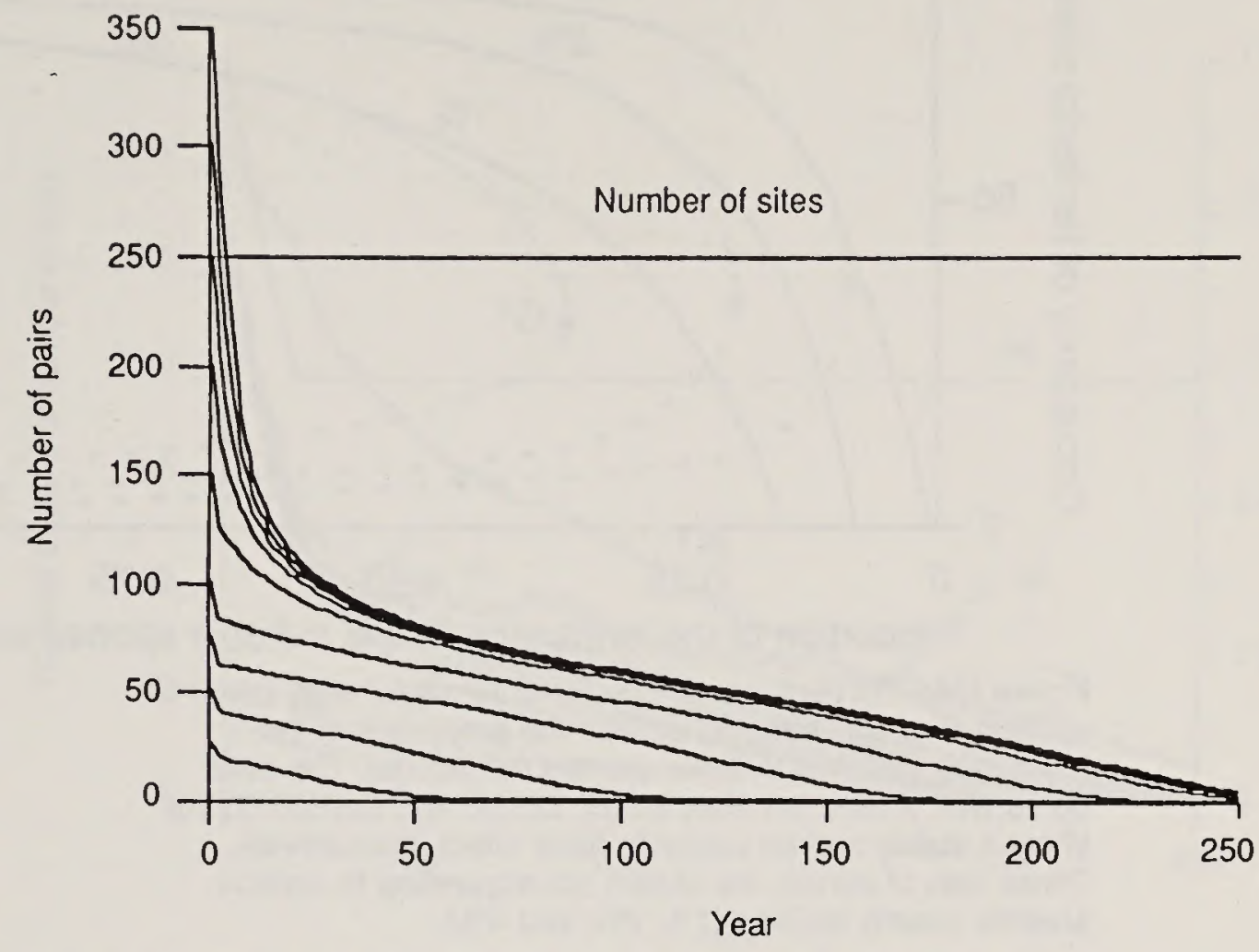

Figure M2-Trend in number of pairs of spotted owls based on a 250-year simulation. Each curve was initialized at a different population size. We assumed that $25 \%$ of the land-scape was suitable owl habitat, and that juvenile owls could search $1 \%$ of the landscape.

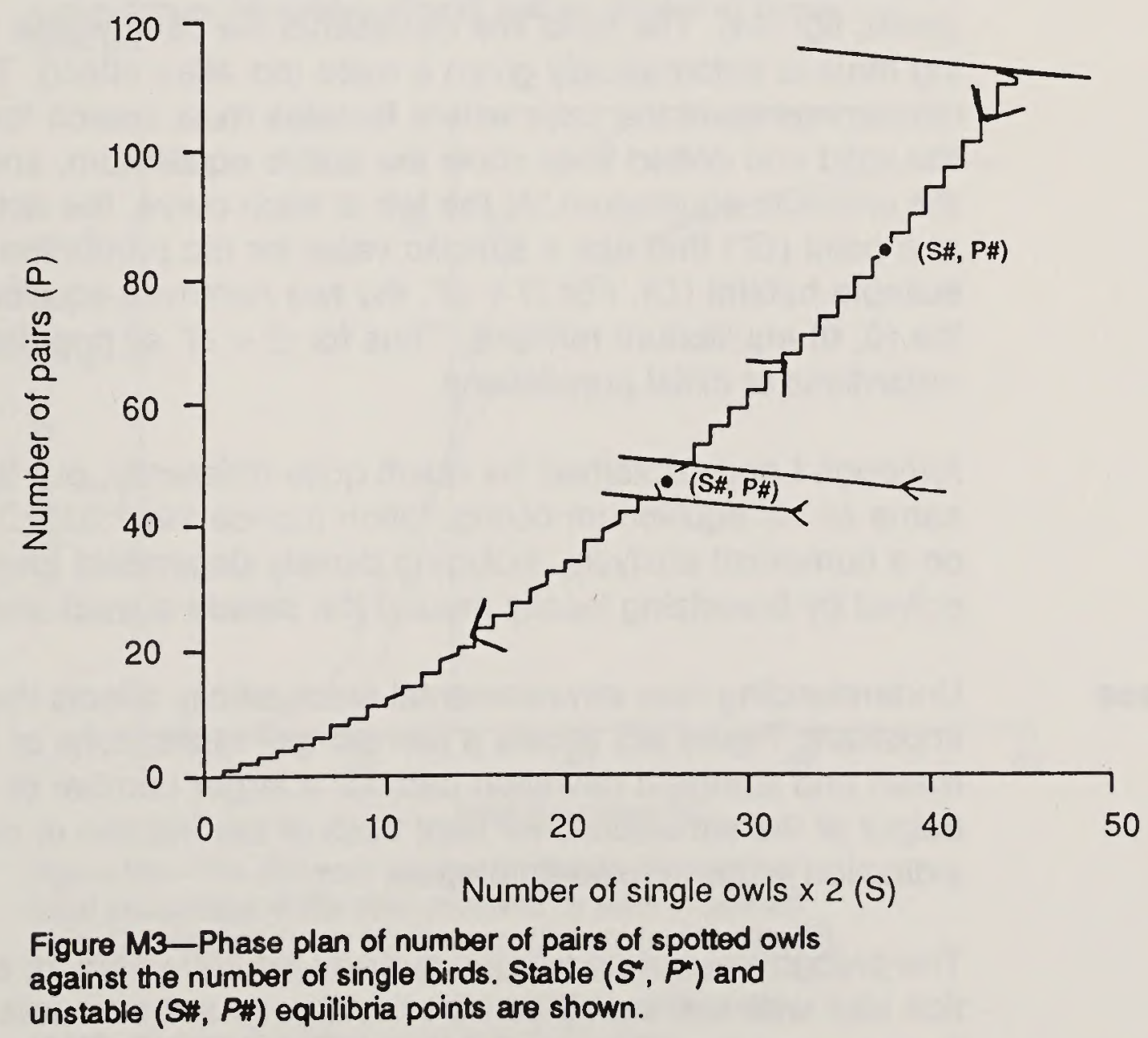




\section{Appendix M: Population Models}

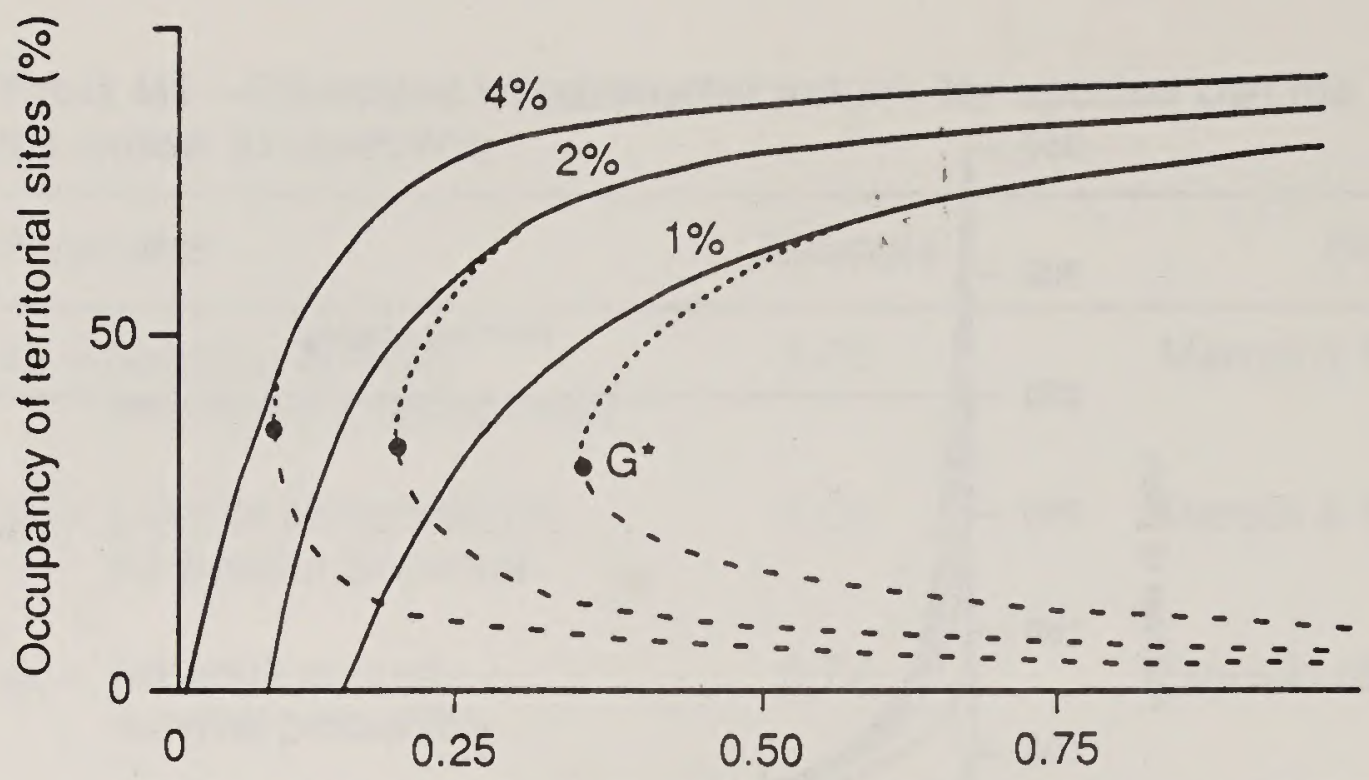

Proportion of the landscape that is suitable spotted owl habitat

Figure M4-Percentage occupancy of territorial sites (pairs of spotted owls and singles) against the proportion of the landscape that was suitable spotted owl habitat. The solid curve was without an Allee effect. Dotted and dashed curves show a stable and an unstable Allee effect, respectively. Three sets of curves are shown corresponding to various juvenile search abilities $(1 \%, 2 \%$, and $4 \%)$.

The locations of the stable and unstable equilibria will depend on the quality of the habitat, as measured by the fraction that is suitable. This dependence is depicted in figure M4 (note that the vertical axis is total occupancy $(S+P) / T$ ). The various curves correspond to alternative assumptions about the owl's search efficiency (that is, of the maximum percentage of the forest that juvenile males can search before death; fig. M4). The solid line represents the case where every successfully dispersing male is automatically given a mate (no Allee effect). The dotted and dashed curves represent the case where females must search for a mate. On each curve, the solid and dotted lines show the stable equilibrium, and the dashed line indicates the unstable equilibrium. At the left of each curve, the dotted and dashed lines meet at a point $\left(G^{*}\right)$ that has a specific value for the proportion of the landscape that is suitable habitat $(G)$. For $G<G^{\star}$, the two nontrivial equilibria have disappeared; only the $(0,0)$ equilibrium remains. Thus for $G<G^{*}$ all populations become extinct, regardless of initial populations.

Although Lande obtained his result quite differently, our figure M4 is qualitatively the same as his equilibrium configuration (Lande 1987:629). Lande's result was based on a numerical analysis, including density-dependent juvenile survival, and then solved by linearizing locally around the steady-state (Lande, pers. comm.).

Stochastic Analyses

Understanding how environmental stochasticity affects the deterministic patterns is important. Figure M5 shows a few sample realizations of the process, as well as the mean and standard deviation bars for a larger number of runs. To summarize the output of the simulation, we kept track of the fraction of sample runs that led to extinction within a fixed time span.

The probability $p$ of population survival for 250 years as a function of initial population size was expressed as a percentage of suitable sites occupied (fig. M6). The three curves correspond to the three alternative assumptions about environmental stochasticity. With no stochasticity, $p$ is a stairstep function, rising abruptly from 0 to 1 at the unstable equilibria of figures M1 to M3. 


\section{Appendix M: Population Models}

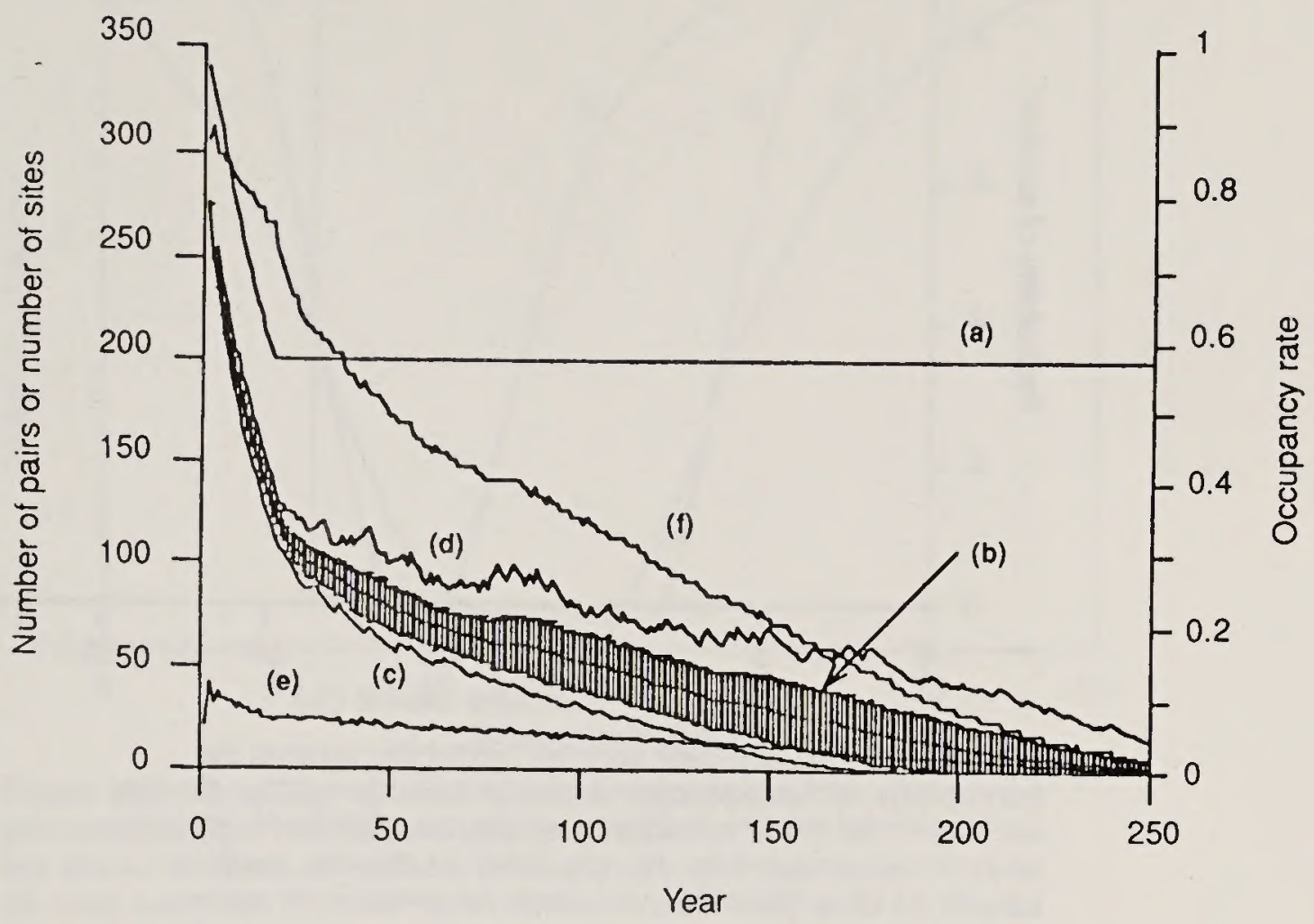

Figure M5-Trends in suitable sites (a), mean number of pairs of spotted owls (b), and mean site occupancy (f) based on 100250 -year simulations. Suitable habitat was lost at the rate of $4 \%$ per year until $20 \%$ of the landscape remained suitable spot-ted owl habitat. Juvenile birds were able to search $2 \%$ of the landscape. Also shown are the minimum (c) and maximum (d) number of pairs and the number of single birds $(\theta)$.

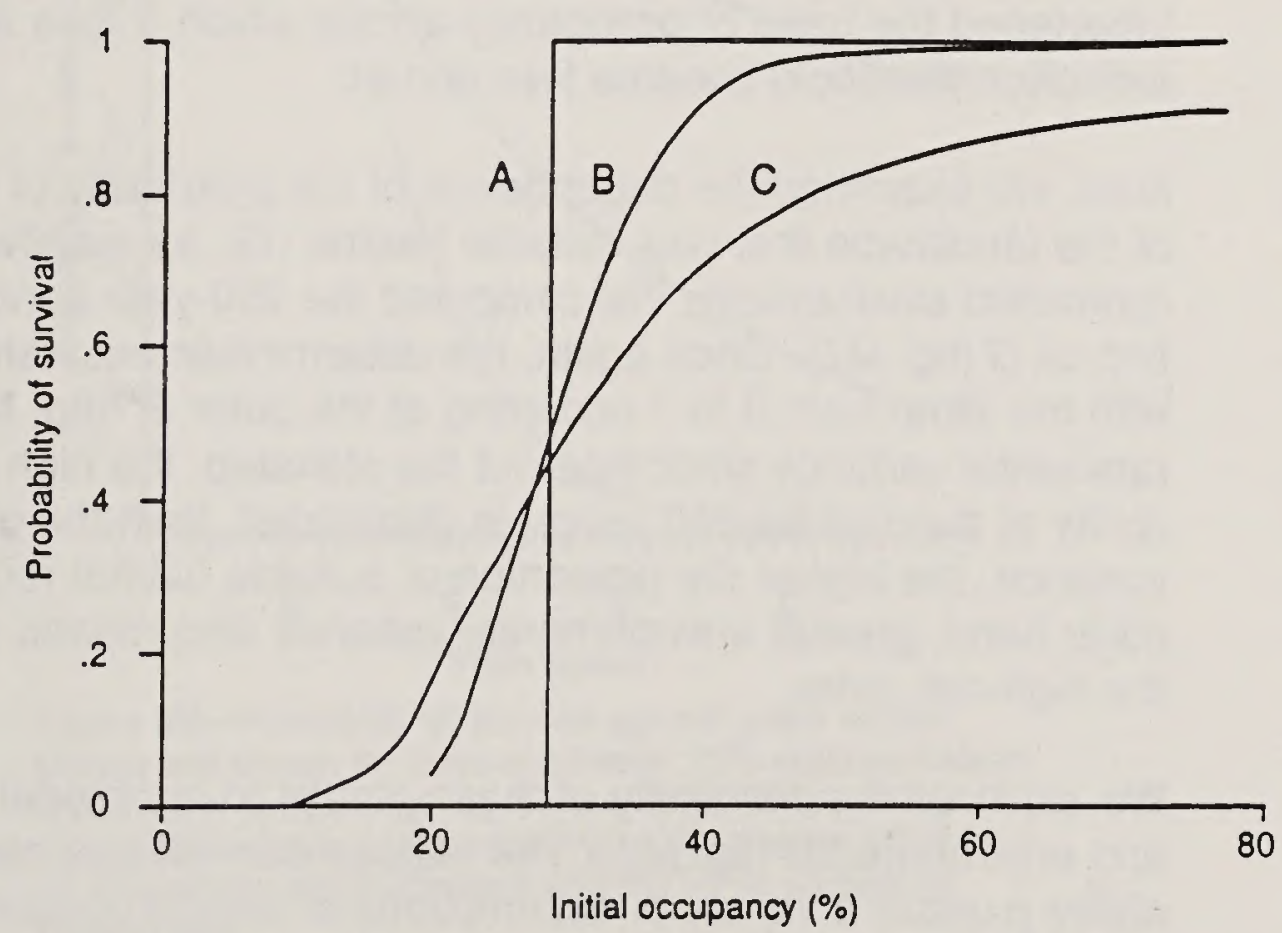

Figure M6-The 250-year survival probability against the initial percentage of the sites occupied by pairs of spotted owls. Curves are shown for three conditions: no (A), low (B), and high (C) environmental variance. We assumed $18 \%$ of the landscape was suitable habitat and that adults could search 40 sites (juveniles could search 20 sites). 


\section{Appendix M: Population Models}

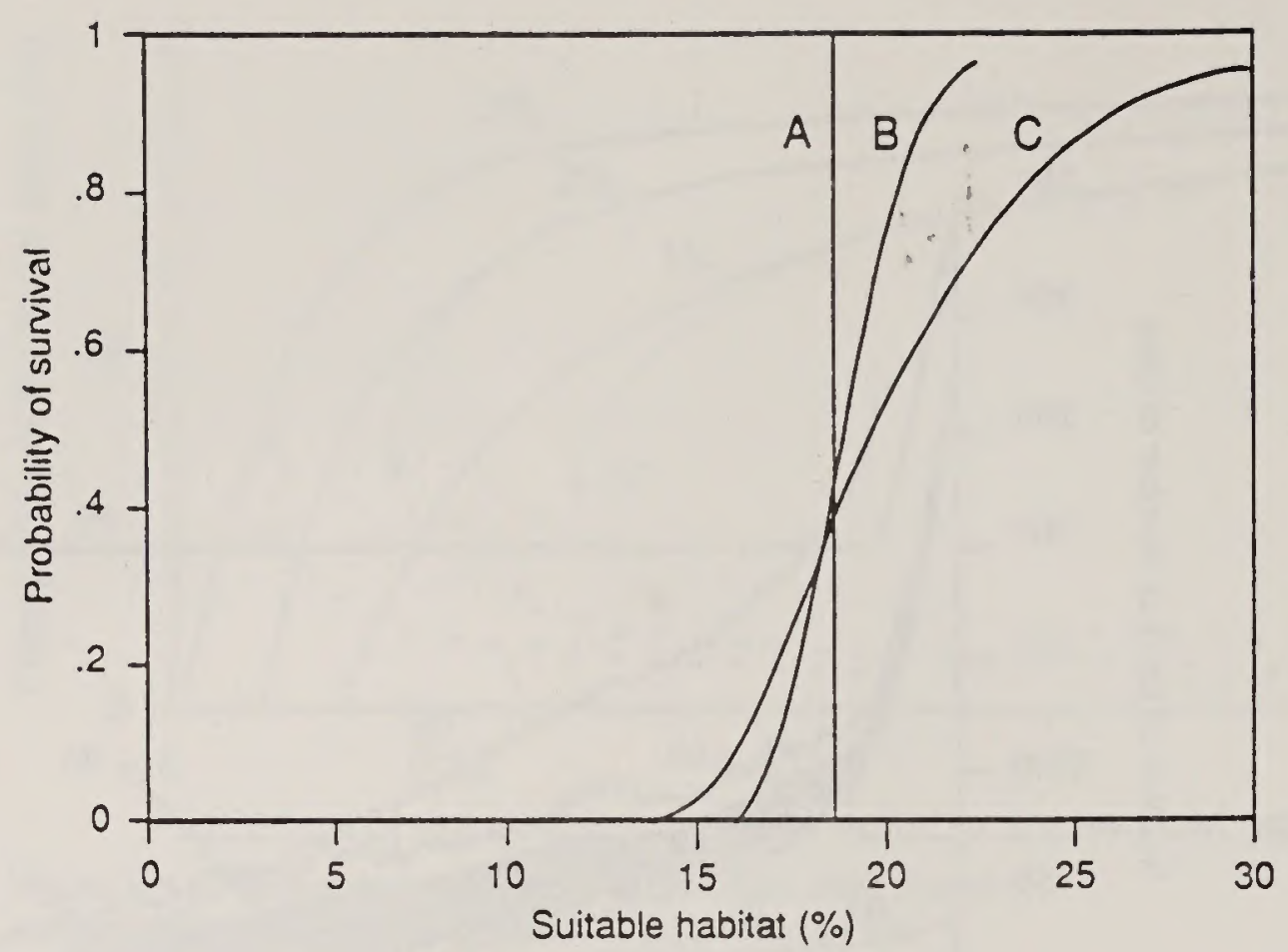

Figure M7-The 250-year survival probability against the percentage of the landscape that was suitable habitat. Curves are shown for three conditions: no (A), low (B), and high (C) environmental variance. We assumed adults owls could search 26 sites (juveniles, 13 sites). All simulations were initialized with the same number of spotted owls.

Adding environmental stochasticity smoothed out the stairstep, as the other two curves, for low and high environmental variance show. Note that for a given high probability $p$, an increase in environmental variance increased the initial occupancy needed to guarantee $p$; for a given low probability $p$, an increase in variance decreased the needed initial occupancy. Thus, increasing environmental variance broadened the band of occupancy across which $p$ rose from 0 to 1: that is, the extinction threshold became less abrupt.

Next, we examined the dependence of the probability of survival on the percentage of the landscape that was suitable habitat (G), as manifested in the presence of environmental stochasticity. We computed the 250 -year survival probability $p$ as a function of $G$ (fig. M7). Once again, the deterministic case showed a stairstep function, with the jump from 0 to 1 occurring at the point $G^{*}$ (fig. M4). As before, adding environmental variance smoothed out the stairstep. If a high $p$ (for example, $90 \%$ probability of survival for 250 years) is demanded, then the greater the environmental variance, the higher the proportion of suitable habitat required to guarantee it. On the other hand, greater environmental variance also means a less abrupt threshold into the high-risk zone.

We explored the sensitivity of these results to our model assumptions, both biological and environmental (fig. M8). The various curves illustrate the 250 -year survival probability $p$ under a variety of assumptions of search capability and environmental variance. Note that the threshold into the high-risk zone was always quite steep, indicating an extreme sensitivity to the amount of habitat in the landscape that remained suitable at a given point in time. Increasing the owl's dispersal capabilities shifted the threshold to the left but did not change its abruptness (fig. M8). 


\section{Appendix M: Population Models}

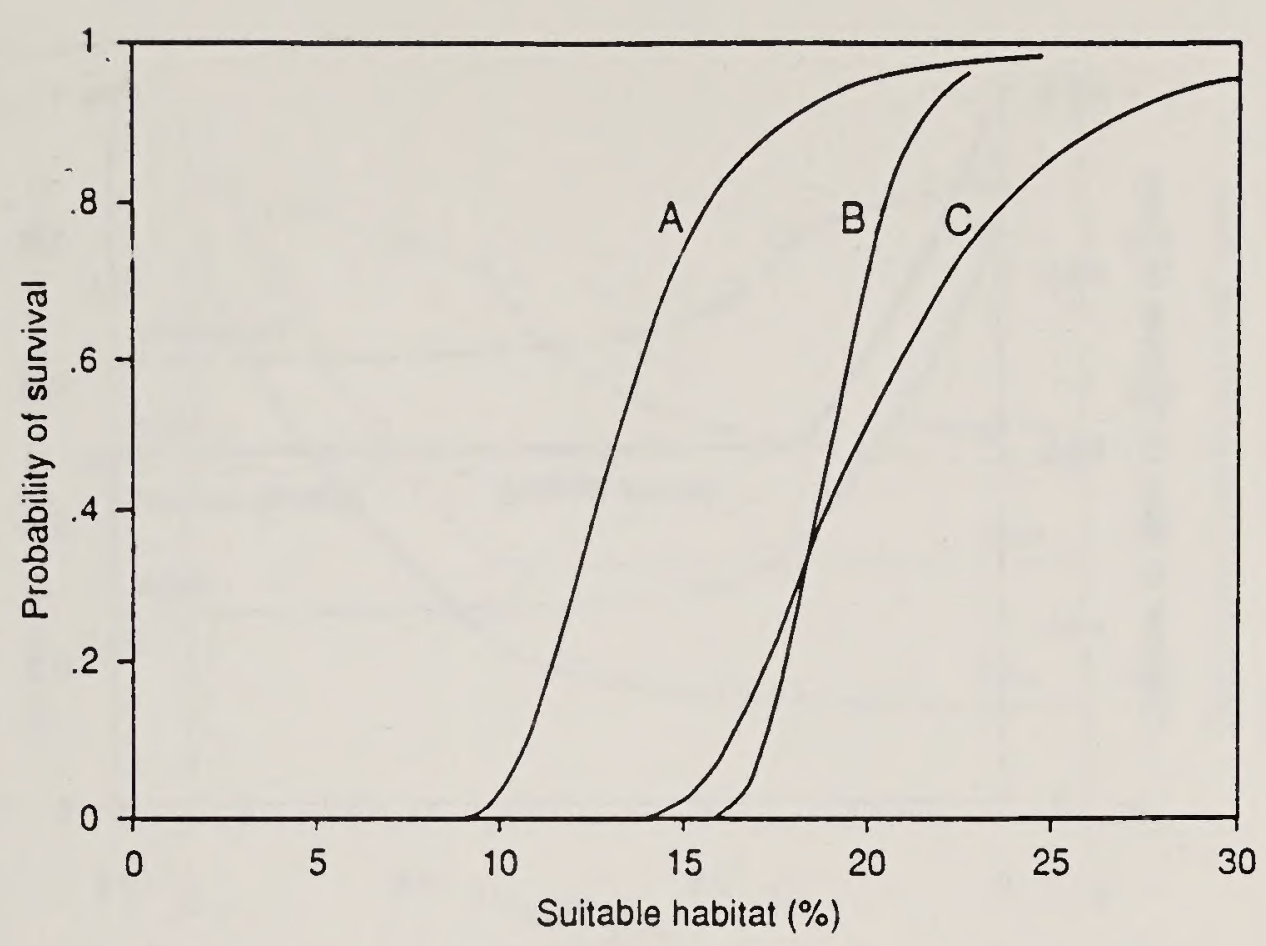

Figure M8-The 250-year survival probability against the percentage of the landscape that was suitable habitat. Curves are shown for three conditions: low environmental variance, 26 sites searched (B); and high environmental variance, 40 (A) and 26 (C) sites searched. Search refers to adult spotted owls (juvenile search is half adult search). All simulations were initialized with the same number of owls.

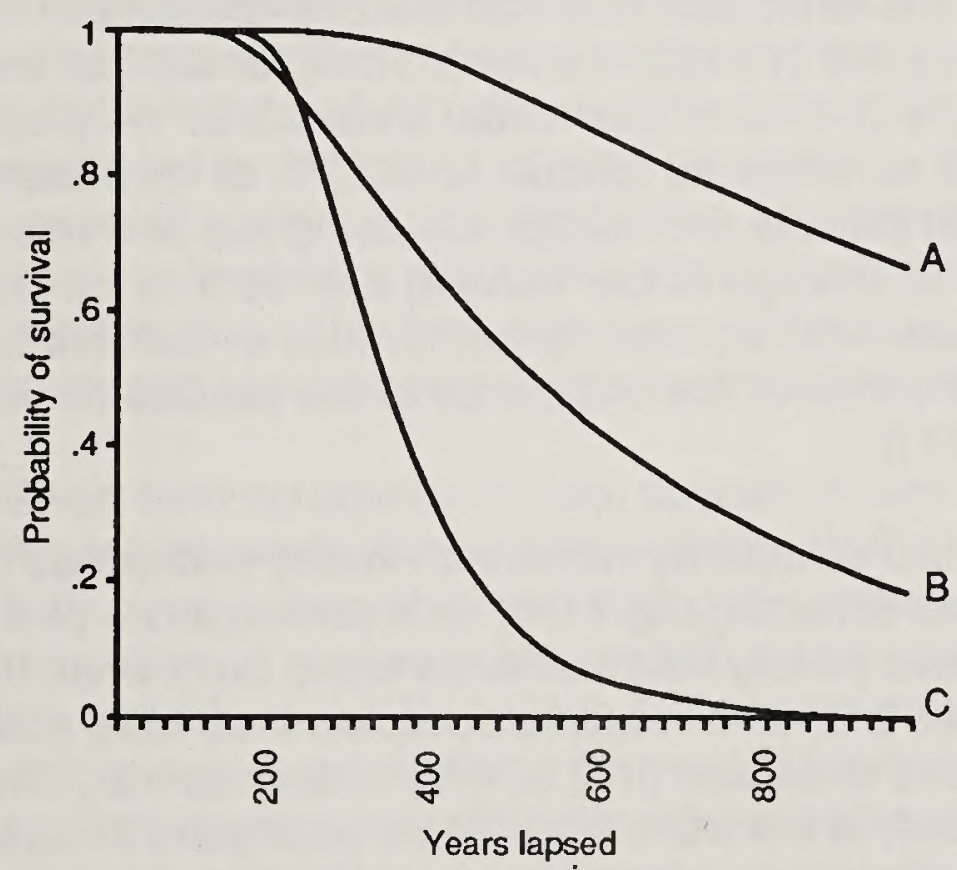

Figure M9-Probability of survival against years lapsed. Curves are shown for three conditions: $27 \%$ suitable habitat and $(A)$ low and $(B)$ high environmental variance, and

(C) $21.5 \%$ suitable habitat and low environmental variance. All simulations were initialized with the same number of spotted owls.

For specified amounts of suitable habitat and environmental variance, we computed the population survival probability $p$ as a function of time (fig. M9). Survival to 250 years was but a single point on each of these curves; implying that this single statistic carries very incomplete information about the viability of a stochastically driven population. 


\section{Appendix M: Population Models}

Introducing Landscape Dynamics

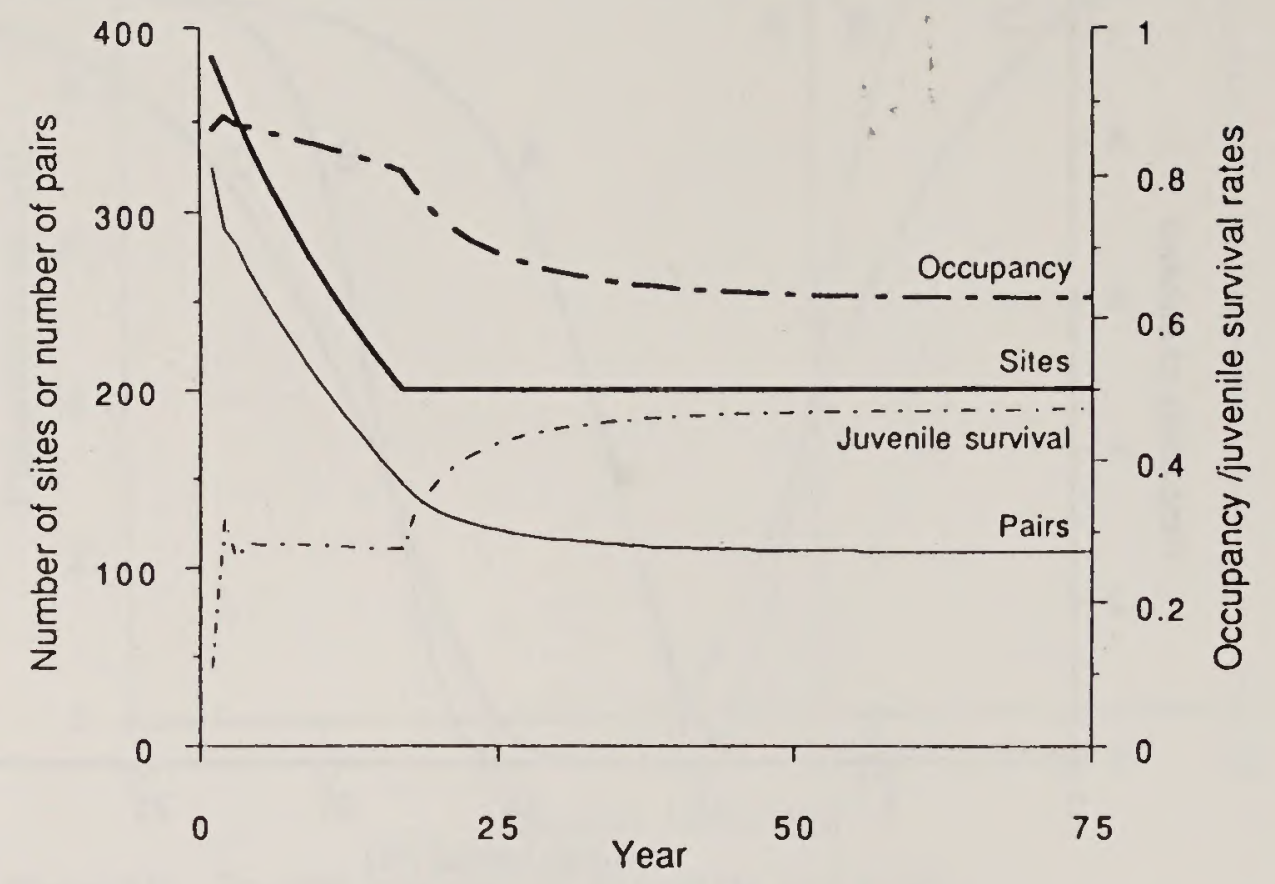

Figure M10-Trend in number of pairs of spotted owls, number of sites, site occupancy by pairs, and juvenile survival rate based on a 75 -year simulation. We assumed that $4 \%$ of the suitable owl habitat was lost per year until $20 \%$ remained, and that juvenile owls could search $2 \%$ of the landscape.

We examined the model both deterministically and stochastically but allowed the proportion of the landscape that was suitable spotted owl habitat to be diminished (for example, by fire or timber harvest). Thus, for the first time, the dynamic nature of the landscape was entered into model simulations. We plotted the proportion of the landscape that remained as suitable habitat, $T$, as a function of time (fig. M10). We assumed that suitable owl habitat was being lost at a rate of $4 \%$ of the remainder per year (that is, through timber harvest) until $20 \%$ of the landscape remained as suitable habitat. At this point, no further loss of suitable habitat took place. Simultaneously, we tracked the occupancy of the suitable habitat (number of sites occupied by pairs; $P / T$.

Note that site occupancy remained virtually unchanged during the period when habitat loss was occurring (fig. M10) as a consequence of a population crowding effect. The owls that initially held territories found them when the amount of suitable habitat was greater and, as a result, unoccupied sites were easier to locate. As suitable habitat continued to decline (that is, from timber harvest), the amount of suitable habitat was reduced; at the same time, some adult pairs of owls were displaced from their territories. Displaced adults were in competition with dispersing juveniles for the remaining, smaller amount of suitable habitat. The juveniles in our model (and probably in reality) were less likely than adults to be successful in their search for a suitable territory. Thus, the remaining suitable habitat was more densely occupied than we would expect at equilibrium. Further, suitable habitat was highly occupied by owls that were, on the average, older than expected from an equilibrium population. Simultaneously, we observed unusually low juvenile survival rates because of the difficulty juveniles had in finding suitable, unoccupied territories (fig. M10). 


\section{Appendix M: Population Models}

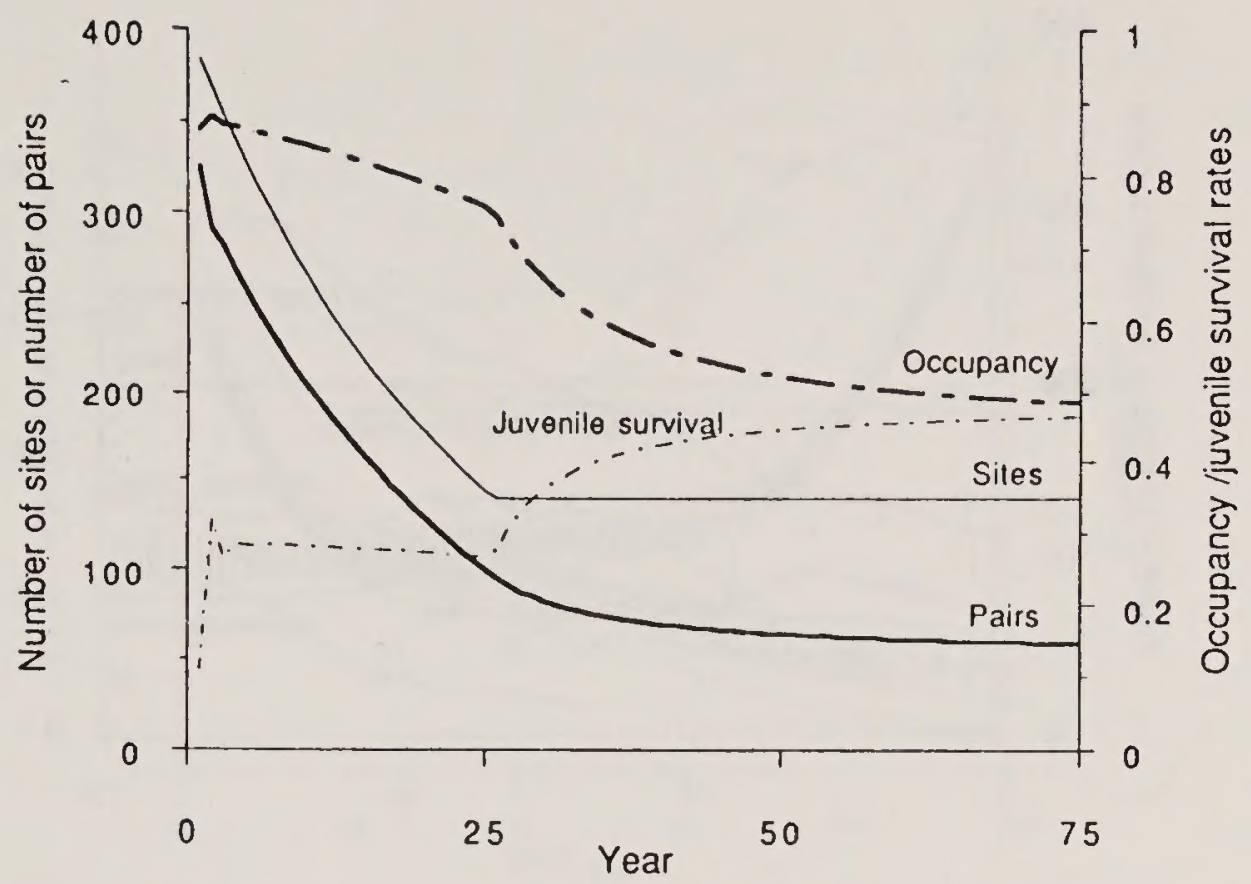

Figure M11-Trend in number of pairs of spotted owls, number of sites, site occupancy by pairs, and juvenile survival rate based on a 75-year simulation. We assumed that $4 \%$ of the suitable owl habitat was lost per year until $14 \%$ remained, and that juvenile owls could search $2 \%$ of the landscape.

As the population passed beyond the period of declining suitable habitat, it eventually came into equilibrium with a landscape that contained less-and more dispersedsuitable habitat. Even after suitable habitat was no longer being lost, the population continued to decline for several generations. Gradually, the population age-structure assumed a more stable distribution, less dominated by older owls. At the same time, the juvenile survival rate increased because of decreased competition for unoccupied, suitable sites. This increase occurred because logging was no longer displacing adult owls, and because new territories were becoming available as adult birds died.

Given both an adequate initial population size and final amount of suitable habitat, the model reached an equilibrium (fig. M10). The equilibrium population was substantially smaller than observed during the period of habitat loss. Note, however, that this population, if assessed only by occupancy, would have appeared relatively stable for the first 20 years. We believe that assessing population trends from data collected during periods of declining carrying capacity (for example, the harvest of suitable owl habitat) may be very difficult because of the difficulty of distinguishing a collapsing population (fig. M11) from one that eventually reaches a long-term stable equilibrium (fig. M10). Recall that our most reliable estimates of the finite rate of population change $(\lambda)$ have been made from populations in areas that were experiencing loss of suitable habitat (see appendix L).

Environmental uncertainty, coupled with habitat loss, was simulated through stochastic fecundity. The trends in population, occupancy, and juvenile survival were similar in the stochastic version of the model to that previously discussed (compare fig. M10 with fig. M12). 


\section{Appendix M: Population Models}

Introducing a Secondary Habitat Type

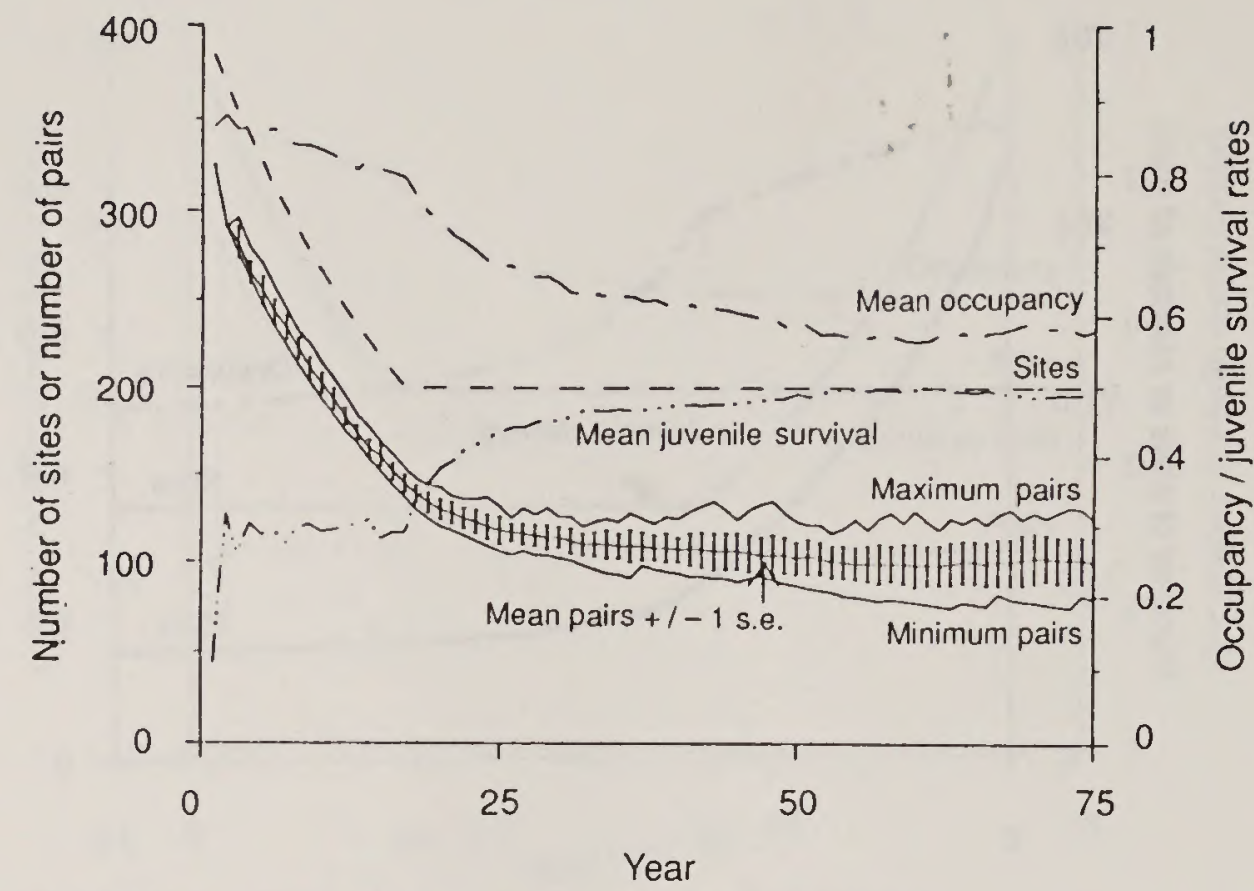

Figure M12-Trend in number of pairs of spotted owls, number of sites, site occupancy by pairs, and juvenile survival rate based on a $75-y e a r$ stochastic simulation. We assumed that $4 \%$ of the suitable owl habitat was lost per year until $20 \%$ remained, and that juvenile owls could search $2 \%$ of the landscape.

To introduce a population of owls that occupied secondary habitat, we assumed that all dispersing juvenile owls that were unsuccessful in their search for a suitable territory in primary habitat entered a secondary habitat. The survival rate for this population was arbitrarily chosen to be 0.6. These owls were assumed to search each year for a site in primary habitat. If they failed to find a suitable territory they returned to the secondary population. The model provided for reproduction in this population at a rate that was $30 \%$ of the rate in primary habitat.

During the period of ongoing habitat loss, the population that occupied secondary habitat was a measurable fraction of the total population. As habitat loss ceased, however, this population gradually shifted to primary habitat and, in the long term, became only a minor part of the total (fig. M13). The contribution of the secondary population was to provide a source of owls to occupy sites that became available during the restructuring of the population subsequent to the end of habitat loss. As a result, the length of the long-term decline in the population was extended, as was the "bump" in the occupancy curve. The presence of secondary habitat may also have slightly lowered the extinction likelihood resulting from habitat loss. We need to investigate this possibility further but, at this time, believe that the effects of secondary habitats are relatively small. 


\section{Appendix M: Population Models}

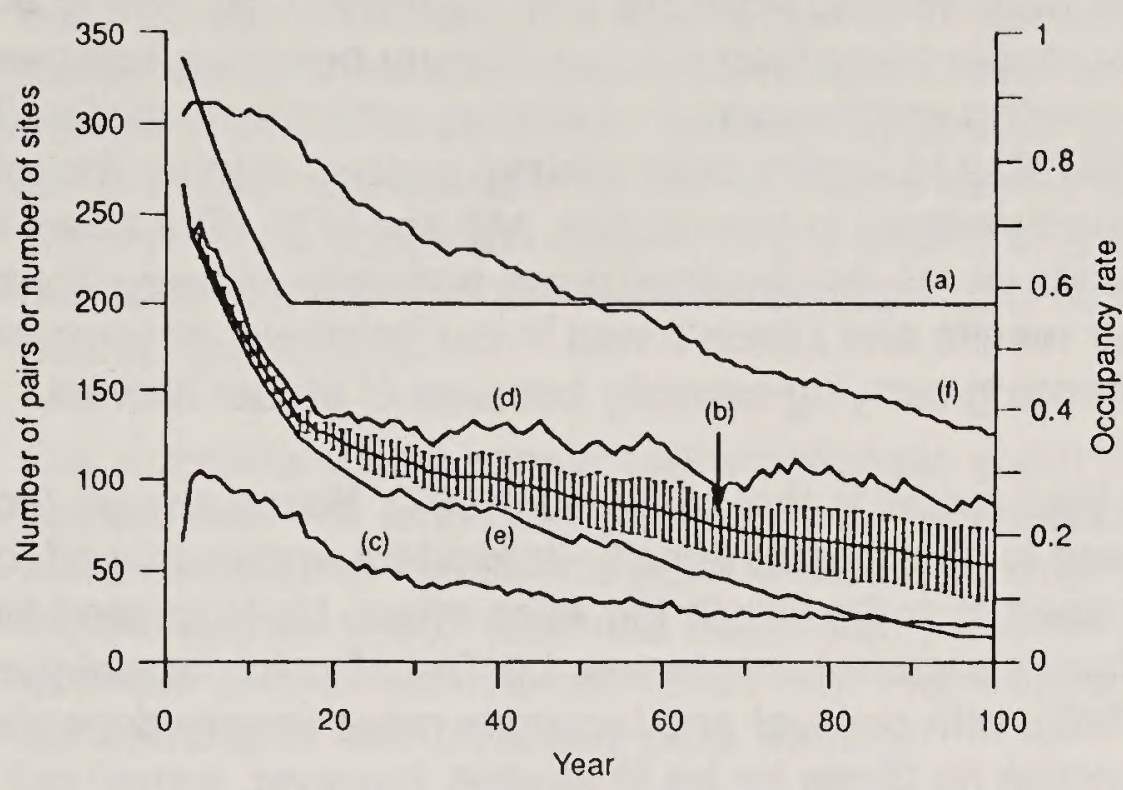

Figure M13-Trend in number of pairs of spotted owls in primary (b) and secondary (c) habitat, number of sites (a), and site occupancy by pairs (f), based on a 100-year stochastic simulation. We assumed that $4 \%$ of the suitable owl habitat was lost per year until $20 \%$ remained, and that juvenile owls could search $2 \%$ of the landscape. Also shown are the minimum (e) and maximum (d) number of pairs.

Edge Effects

DiscussionIndividual-Territory Model
We have done some preliminary analyses of edge effects. Edge effects were introduced into the model by allocating some of the search time of juveniles, originating from sites adjacent to edge, to be in unsuitable habitat beyond the edge. In general, edge effects reduced the viability of the population. The reduction was small for our simulated landscape with 1000 suitable sites and a minimum of edge, but the edge effect may be important for highly fragmented landscapes with irregular-shaped polygons of suitable habitat imbedded in a landscape matrix of high contrast. In this scenario, edges may act as partial or total absorbing boundaries and significantly contribute to the annual mortality rate. We plan to explore the significance of edges in considerably more detail.

Several models have investigated the population dynamics of spotted owls. The most detailed one was developed as part of the original FS spotted owl viability analysis, and is described in detail in the FSEIS (USDA 1988; see also Marcot and Holthausen 1987). That analysis used a linear, single-sex, Leslie matrix model, which has been criticized (Boyce 1987), in part because its linear structure caused it to display unrealistic, stochastic output. Our most direct comparison with the linear model is displayed in our phase-plane portrait (fig. M3). For a linear model, the attracting manifold $M$ would be a straight line, with the coordinates of a representative point being in stable-age proportion. An initial population would move to $M$ (how quickly would depend on the degree of dominance of the leading eigenvalue, $\lambda$, the implicit growth rate). The population then would grow geometrically (if $\lambda>1$ ) or collapse to the origin (if $\lambda<1$ ). Only for $\lambda=1$ would the population remain stable.

In our model, the presence of nonlinear search success effectively made $\lambda$ density dependent (with the corresponding age distribution also density dependent). Also, $\lambda=1$ only at the stable and unstable equilibria, and $\lambda>1$ only above the latter. 


\section{Appendix M: Population Models}

Our search functions are patterned after a second model, that of Lande (1987), and our deterministic equilibrium configuration (fig. M4) is equivalent to his result. Because his model prescribed only equilibrium behavior, however, it was not well adapted to exploring environmental or demographic stochasticity. (But see equation 17 in Lande 1987:632.) Lande's deterministic analysis can be thought of as leading to the stairstep threshold functions (figs. M6 and M7). (The exact locus of the step-break depends on the assumptions about parameter values.) Thus, the real difference between our results and Lande's was in our treatment of environmental stochasticity and a changing carrying-capacity because of timber harvest.

A third model is that of Boyce (1987). Boyce argued (correctly, we believe) for the need to incorporate density-dependent and spatial effects into any model, and he discussed at some length the Allee effect. He illustrated his ideas through a standard stage-structured, single-sex, Leslie-Lefkovich model (Leslie 1945, 1948; Lefkovitch 1965), with survival and fecundity made density dependent. The depensatory fecundity function he chose for his illustration, however, turned out to be too mild for the Allee effect to become operative. When we incorporated into Boyce's model a searcheffectiveness function like Lande's (or like ours), we found that the Allee effect was operative, with results consistent with our own.

We believe two major conclusions can be drawn from our modeling efforts. First, two rather sharp thresholds occur, both of which can lead to the ultimate extinction of the population. One results from the loss of habitat: if the amount of suitable habitat is reduced to an excessively small fraction of the landscape, then the difficulty in finding a suitable territory becomes an insurmountable barrier to the population. The second threshold is due to the Allee effect: if the population numbers fall too low, then the probability of finding a mate drops below that required to maintain the reproductive rates necessary to support a stable population. Both of these results indicate that a species can be severely habitat limited even in the presence of suitable, but unoccupied habitat.

Second, the fact that we are modeling a dynamically changing system critically affects our analysis and results. The crowding of older owls into the remaining suitable habitat as a consequence of habitat loss is likely to produce high occupancy rates-much higher than expected under long-term equilibrium conditions (no decline in carrying capacity). Equilibrium occupancy rates are well below those observed while loss of suitable owl habitat is continuing. As a result, we suggest care when drawing inferences to long-term abundance or population trend from short-term occupancy. To illustrate, figure M11 shows that occupancy during the habitat-loss phase remains virtually unchanged, but the population ultimately crashes, long after habitat loss has ceased. Assuming our model results are reliable, they suggest that the current FS monitoring program, based on SOHA occupancy rates, may be slow to reflect even substantial population declines. 


\section{Appendix M: Population Models}

The juvenile survival rate was substantially depressed during the habitat loss phase, but it increased after suitable habitat was no longer being lost (figs. M10 to M12). This habitat effect, a consequence of competition between juvenile and adult birds for access to available sites, may partially explain the very low estimates of the 1st-year survival rates computed from field studies (Franklin et al. 1990; Forsman, pers. comm.). For a population experiencing a decline in its carnying capacity, a habitatmediated reduction in 1 st-year survival rate would contribute to a long-term growth rate $(\lambda)$ that is $<1.0$.

Our simulations may appear overly optimistic about the long-term survival of the spotted owl. The long-term growth rate of the population is an order of magnitude more sensitive to variation in adult survival rate than to other demographic parameters (Lande 1988, Noon and Biles 1990), and our simulations used a higher estimate of adult survival rate $(s=0.92)$. The most current estimate of adult female survivorship is 0.90 (Franklin, pers. comm.).

Our individual-territory model provided some important, general insights and suggests the wisdom of proceeding cautiously in making management decisions that affect spotted owl habitat. Some sharp population threshold points are likely which, once passed, could lead to the local extinction of owl populations. At the same time, none of our numbers should be taken as exact measures of where these threshold points lie. Our model is of sufficient sophistication to examine the system and discover the existence of threshold points. Our knowledge of the model structure and of spotted owl dispersal and search capabilities is incomplete, however, and we cannot accurately predict the population size, suitable habitat, or amount of habitat fragmentation thresholds that, once crossed, would lead to a population crash.

Territory-Cluster Model

Model Description
The basis of the territory-cluster model was a continuous, rectangular array of potential owl habitat clusters. The usual assumption was that these clusters comprised $35 \%$ of the total landscape. We assumed the clusters to be circular and every owl site (territory) within a cluster was considered to be of identical size (for example, 3000 acres). The matrix between clusters was assumed to be entirely unsuitable for owl territories, and the clusters were either partially or totally suitable. Thus, a cluster was a collection of sites. All sites, or only a subset of the sites, within a cluster were considered capable of supporting pairs. The carrying-capacity of a cluster was equal to its number of suitable sites.

The territory-cluster model was an all-female stage projection model with the stageclasses being juveniles, subadults, and adults. This structure was similar to that of Boyce (1987) and Lande $(1987,1988)$. Fecundity in this model was stochastic and varied to represent good and bad years for reproduction. We assumed a fecundity of 0.25 female young per adult female in bad years (75\% of the time) and 0.50 in good years (25\% of the time). These values and year-type probabilities gave a deterministic fecundity, 0.33 , equal to that estimated from the data (table M1). 


\section{Appendix M: Population Models}

Each cluster was composed of an assigned number of sites (territories) with a given number (or percentage) of them considered suitable habitat. The carrying capacity of a cluster, measured in terms of female owls ( $\geq 1$ year old), or owl pairs, was the total number of suitable sites in that cluster. Within each cluster, owl numbers were stored in a numerical array in terms of adults ( $\geq 2$ years old), subadults ( $1 \leq$ age $<2$ years), and postdispersal juveniles ( $0<$ age $<1$ year). The total for a cluster was never allowed to exceed the carrying capacity of that cluster.

Before dispersal, the number of juvenile owls was reduced by predispersal mortality (table M1). These deaths were assigned at random to juvenile owls throughout the array of clusters.

The model distinguished between dispersal within a cluster and dispersal between clusters (compare Doak 1989). The dispersal within a cluster followed Lande (1987), with each dispersing owl allowed to sample with replacement a given number, $m$, of sites within the cluster. The probability of successful dispersal within the cluster was computed as 1 minus the probability of failing to find a suitable, unoccupied site within the given number of trials,

$$
\text { prob (success) }=1-[1-\# \text { available sites/total \# sites }]^{m} \text {. }
$$

No further mortality was assigned to juveniles that succeeded in finding a site within their natal cluster.

If the juvenile female owl did not succeed in finding a temitory within her natal cluster, she was forced to disperse between clusters. When the owls dispersed from their natal cluster, two sources of mortality existed. First, the juvenile female may have gone in a direction that failed to intercept an adjacent cluster (the direction of dispersal, within a specified search angle, was chosen at random). As an example, when clusters each contained 10 sites and accounted for $35 \%$ of the landscape, juvenile mortality from this source occurred about $22 \%$ of the time. Second, given the selection of an appropriate direction, the likelihood of successful dispersal was modeled by a decaying exponential,

$$
\exp \left(-k^{\star} \text { distance between clusters in } \mathrm{km}\right) \text {. }
$$

Based on an average cluster size of 10 sites, when $k=0.1$, about $58 \%$ of juveniles that chose the correct direction successfully arrived at the nearest, adjacent cluster, about $5.6 \mathrm{~km}$ ( 3.5 miles) away, the distance to the four nearest clusters when $35 \%$ of the landscape was in clusters. With $k=0.3$, about $20 \%$ were successful, and for $k=0.03$, over $85 \%$ were successful. 


\section{Appendix M: Population Models}

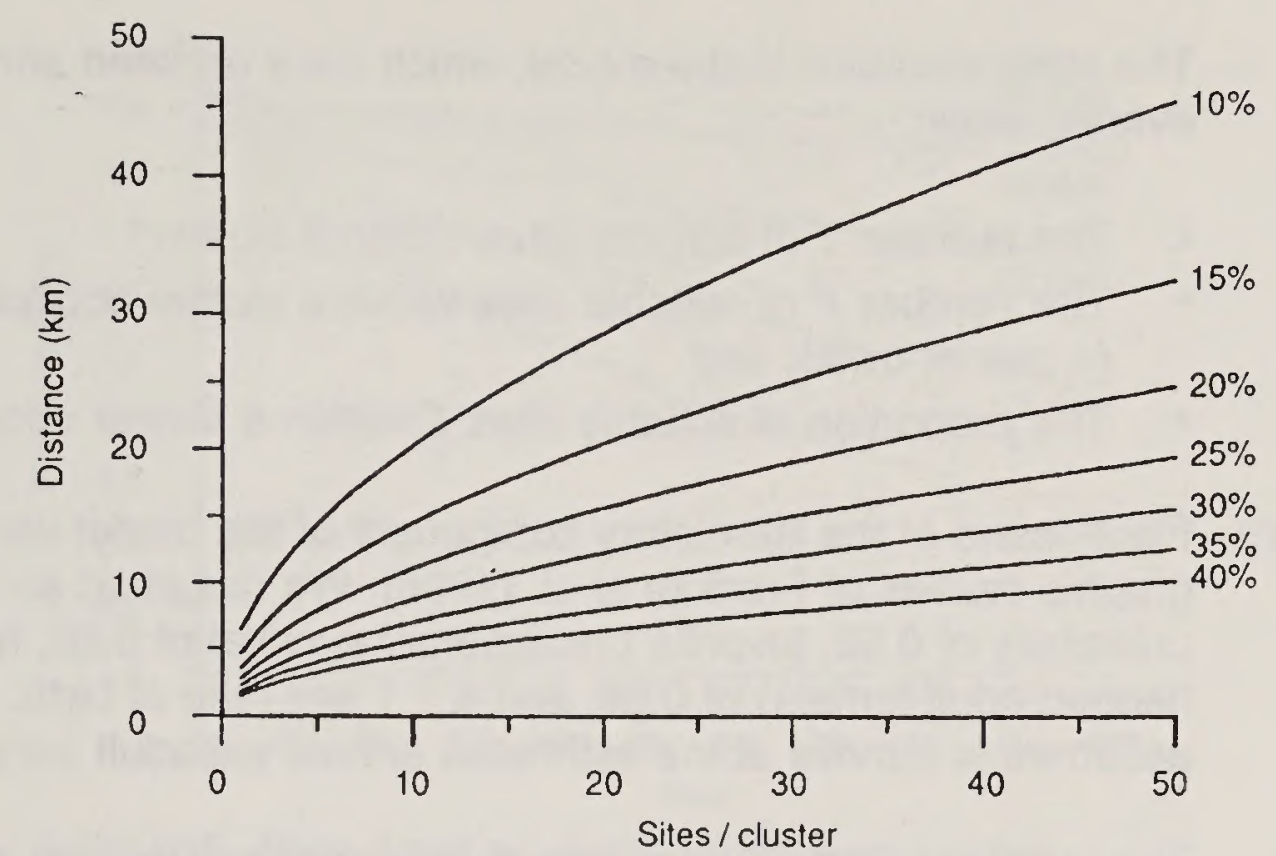

Figure M14-Nearest neighbor distance between clusters against cluster size. Each curve represents a different percentage of the landscape assumed to be suitable spotted owl habitat and loccated within the clusters.

Assuming that a constant percentage of the landscape was potentially suitable owl habitat, and restricting the habitat to the clusters, had two important consequences. First, as average cluster size increased, the distance between adjacent clusters increased in a predictable way (fig. M14). We believe this consequence accurately reflected real-world constraints encountered in developing a species' conservation strategy. We envision that most conservation plans will reflect a compromise between the size of habitat conservation areas and the distance between them. Second, the dispersal angle and the probability associated with selecting this angle were constant regardless of the average cluster size.

Once a juvenile had successfully traveled to an adjacent cluster, she repeated the within-cluster search process as in the natal cluster (equation 1). The number of clusters that could be searched could be systematically varied. If unsuccessful in the first cluster, travel to an additional cluster(s), was allowed. The likelihood of successful movement between clusters declined exponentially with distance (equation 2). Dispersing owls were chosen in order, and the occupancy data (age distribution) within each cluster were updated after each dispersal.

For the results reported here, the landscape simulated by the model had a "wraparound" structure and did not include edge effects. The clusters on the right side of the grid were treated within the model just as though they were immediately to the left of those on the left side of the grid. The top and bottom rows of clusters were treated in a similar fashion.

Unless otherwise noted, the model was initialized at $80 \%$ of the carrying capacity with the age-structure near that expected at equilibrium (stable age-structure about 20 juvenile : 5 subadult : 75 adult). The owls were distributed to the clusters at random, making sure that none of the clusters exceeded its carrying capacity. All simulations were stochastic with 10 replications per simulation. 


\section{Appendix M: Population Models}

The state variables in the model, which were updated annually after the dispersal events, were:

- The number $T$ of suitable sites within a cluster;

- The number $P$ of suitable sites within a cluster occupied by a female owl (= pair of owls); and

- The proportion of suitable sites $O$ within a cluster occupied by pairs $(=P / T)$.

Setting Model Parameters

Parameters of the life-history component of the model were based on the demographic studies of Franklin et al. (1990). We assumed an annual adult survival probabilty of 0.92 , juvenile predispersal survival of 0.60 , fecundity (number of young fledged/adult female) of 0.66 , and a $1: 1$ sex ratio at birth. One-year-old birds were assumed to survive at the estimated annual subadult survival rate of 0.77 (table M1).

Results-TerritoryCluster Model
The number of model parameters, their range of values, and their possible combinations were immense (table M2). We report on only a small subset of the possible combinations of parameters, in an attempt to portray the sensitivity of the owls' population dynamics to variations in parameter values. In general, we varied the model parameters one at a time, holding all others constant. Variations in some model parameters had little affect on model outcome. Therefore, conditioned on the reality of our model structure, we inferred that they were of little relevance to the owls' population dynamics.

Table M2-Values of model parameters used in the simulations

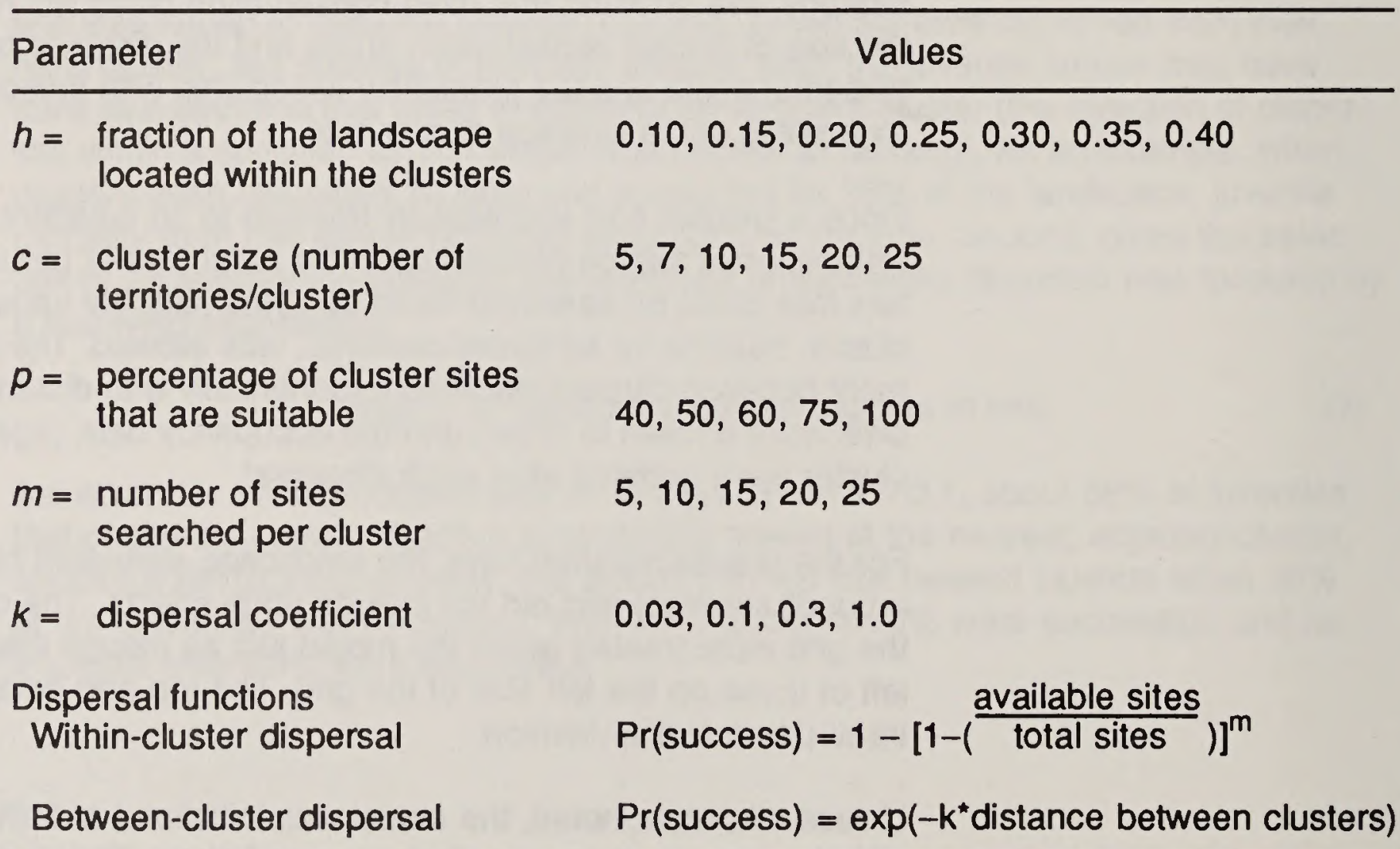




\section{Appendix M: Population Models}

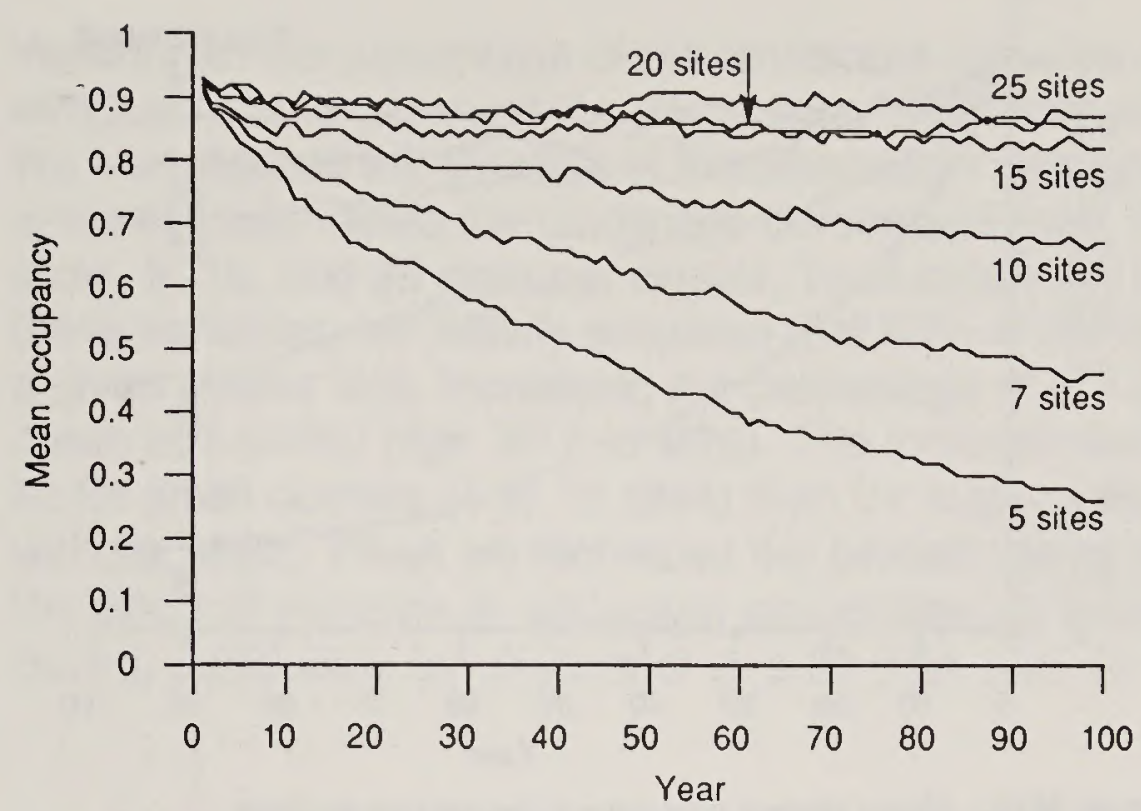

Figure M15-Mean cluster occupancy proportion against time for a 100-year simulation. The number of suitable sites per cluster was varied from 5 to 25 . Model parameters (table M2) were: $h=35 \% ; p=100 \% ; m=12 ; k=0.1$.

Variation in Cluster Size
We varied the number of sites per cluster over a range of values (table M2) and plotted the trend in average pair occupancy per cluster out to 100 years (fig. M15). For this simulation, all sites within a cluster were assumed suitable, 12 sites could be searched per cluster $(m=12)$, and the dispersal coefficient equaled $0.1(k=0.1)$. Recall that when all sites within a cluster were considered suitable, the carrying capacity of the cluster was equal to the number of sites. Given these conditions, we did not observe a stablization of mean occupancy until at least 15 suitable sites were in each cluster. Below 15 sites per cluster, mean occupancy did not reach an equilibrium other than zero. The occupancy rate in clusters with $<7$ sites declined rapidly. Once clusters contained 15 suitable sites, however, increasing cluster size had little effect on the equilibrium level of mean occupancy (fig. M15).

At a given point in time, two possible explanations exist for why all sites within a cluster may not be suitable. First, when the clusters, or habitat conservation areas (HCAs), are initially designated, many will not contain sites all of which are suitable. In general, far less than $100 \%$ of the potentially suitable sites within a cluster will be suitable at the initiation of the conservation plan. Second, many HCAs will contain one or more sites which can never become suitable. Both these factors result in a maximum HCA carrying capacity that is less than the total number of potential sites within the HCA.

We hypothesized that the cluster size at which mean occupancy would reach an equilibrium would depend on how far clusters were below their potential carrying capacities. To test this hypothesis, we performed a simulation as above except that $<100 \%$ of the sites within a cluster were suitable. When $<100 \%$ of the sites were suitable, the carrying capacity of a cluster was changed to the number of sites it contained times the percentage suitable. In this simulation, assuming that $60 \%$ of the sites were suitable, mean occupancy did not reach an equilibrium until clusters contained $\geq 20$ sites (that is, $\geq 12$ suitable sites per cluster; fig. M16). 


\section{Appendix M: Population Models}

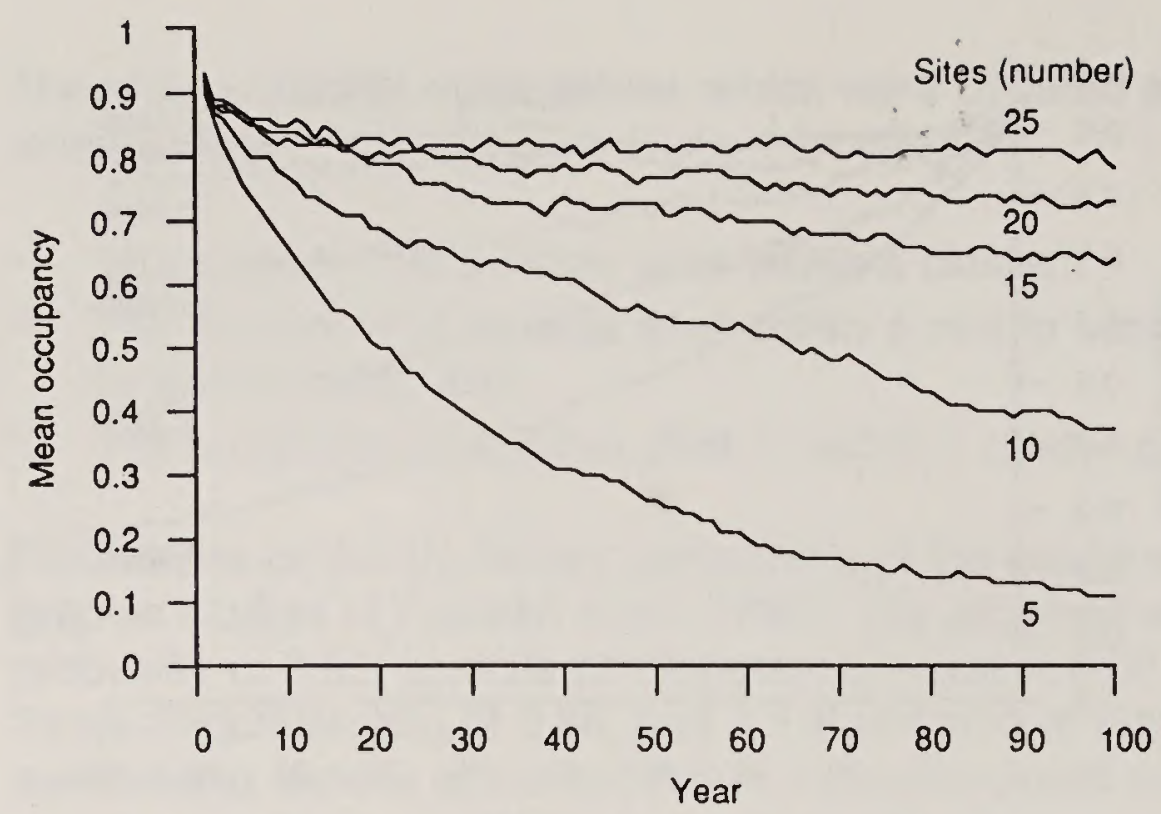

Figure M16-Mean cluster occupancy proportion against time for a 100-year simulation. The number of suitable sites per cluster (cluster size) was varied from 5 to 25 . Model parameters (table M2) were: $h=35 \% ; p=60 \% ; m=12$; $k=0.1$.

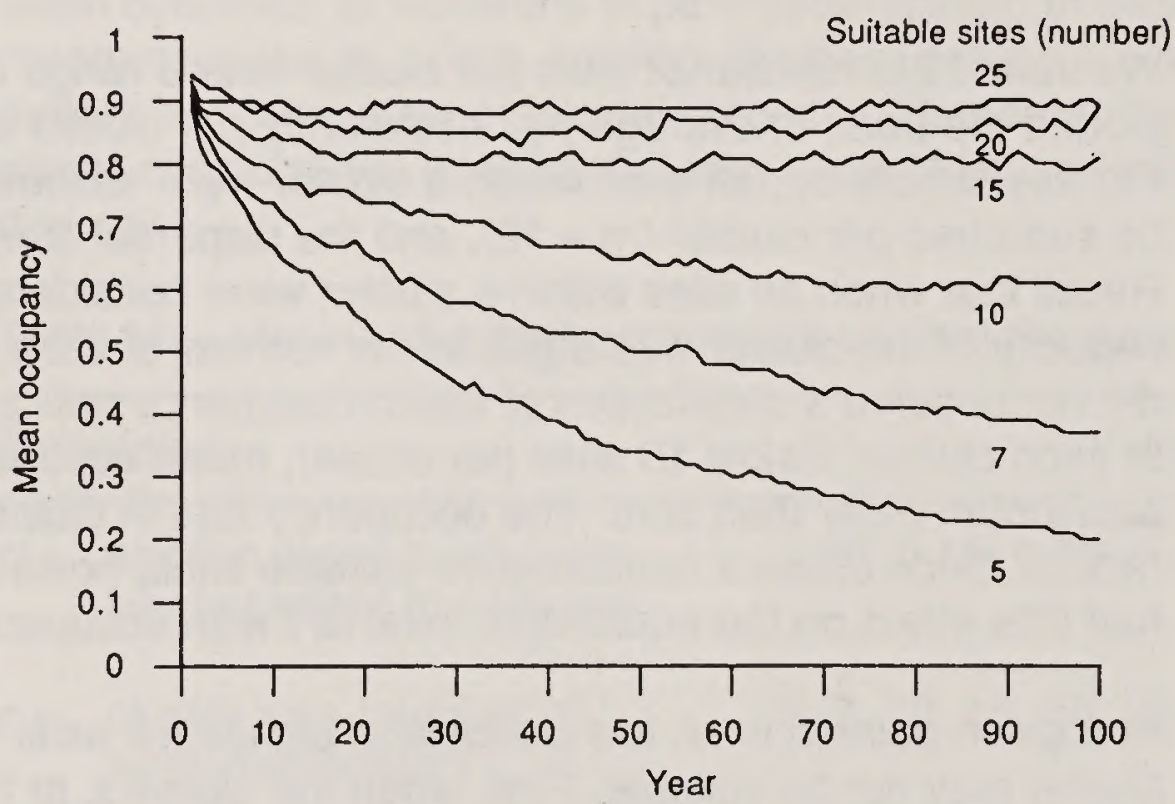

Figure M17-Mean cluster occupancy proportion against time for a 100-year simulation. The number of suitable sites per cluster was varied from 5 to 25 . Cluster size was fixed at 25. Model parameters (table M2) were: $h=35 \% ; c=25$; $p=100 \% ; m=12 ; k=0.1$.

We explored the effect, on mean occupancy, of clusters being below their potential carrying capacities in another way. We assumed a variable number of suitable sites within clusters, all with a potential carrying capacity of 25 pairs (fig. M17). The proportion of suitable sites within clusters ranged from $0.2(5 / 25)$ to $1.0(25 / 25)$. All other model parameters in this simulation were identical to those in figures M15 and M16. The results suggest that mean occupancy did not stabilize, over the long term, until $40(10 / 25 \times 100)$ to $60(15 / 25 \times 100)$ percent of the sites within a block were suitable. For smaller HCAs, the percentage of suitable sites required for equilibrium would increase. 


\section{Appendix M: Population Models}

Variation in the percentage of the landscape included within the clusters interacted with both cluster size and the percentage of suitable sites to affect mean occupancy. We investigated the strength of this interaction through a series of simulations. We systematically varied the landscape percentage from 15 to $35 \%$, for three cluster sizes, 5,10 , and 20 sites per cluster. To illustrate the pattern of interaction among these variables, we initially assumed that $60 \%$ of the cluster sites were suitable. For a given cluster size, increasing the percentage of the landscape in clusters increased mean occupancy (figs. M18 to M20). The increase, however, was much more dramatic for small clusters ( 5 or 10 sites) than for large clusters (20 sites; compare fig. M18 with fig. M20). When we increased the percentage of suitable sites from 60 to $100 \%$, the effect of variation in landscape percentage on mean occupancy was much reduced, particularly for clusters of size 20 (figs. M21 to M23).

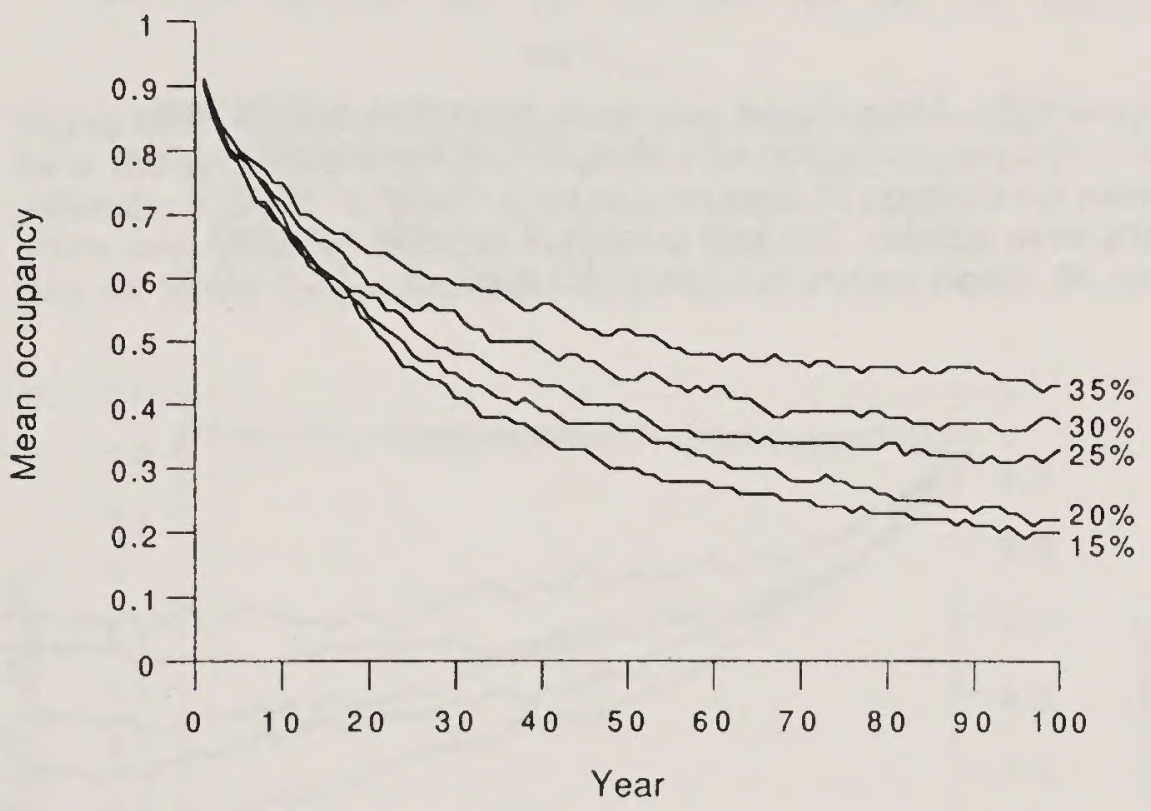

Figure M18-Mean cluster occupancy proportion against time for a 100 -year simulation with 15 to $35 \%$ of the landscape within the clusters; 5 sites per were in each cluster, of which $60 \%$ were suitable. The total number of possible searches was 30 . Model parameters (table M2) were: $m=5 ; k=0.1$.

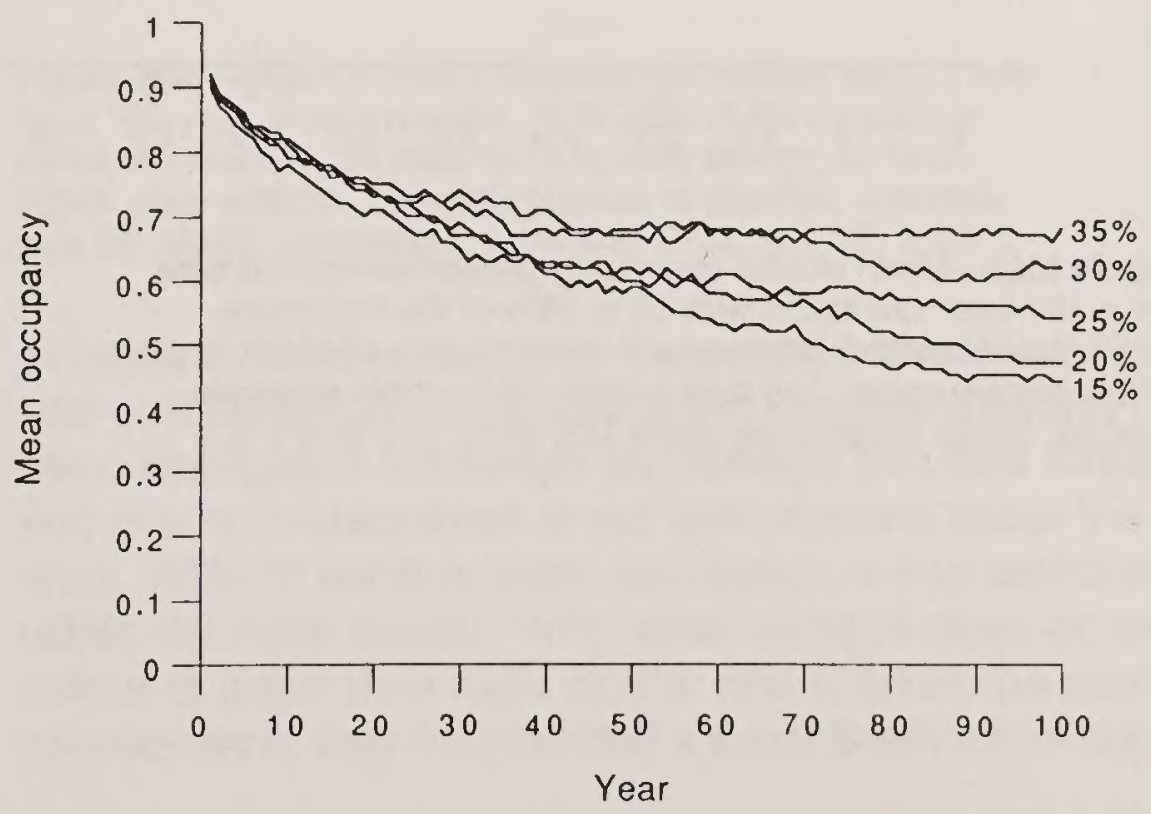

Figure M19-Mean cluster occupancy proportion against time for a 100-year simulation with 15 to $35 \%$ of the landscape within the clusters; 10 sites were in each cluster, of which $60 \%$ were suitable. The total number of possible searches was 30 . Model parameters (table M2) were: $m=10 ; k=0.1$. 


\section{Appendix M: Population Models}

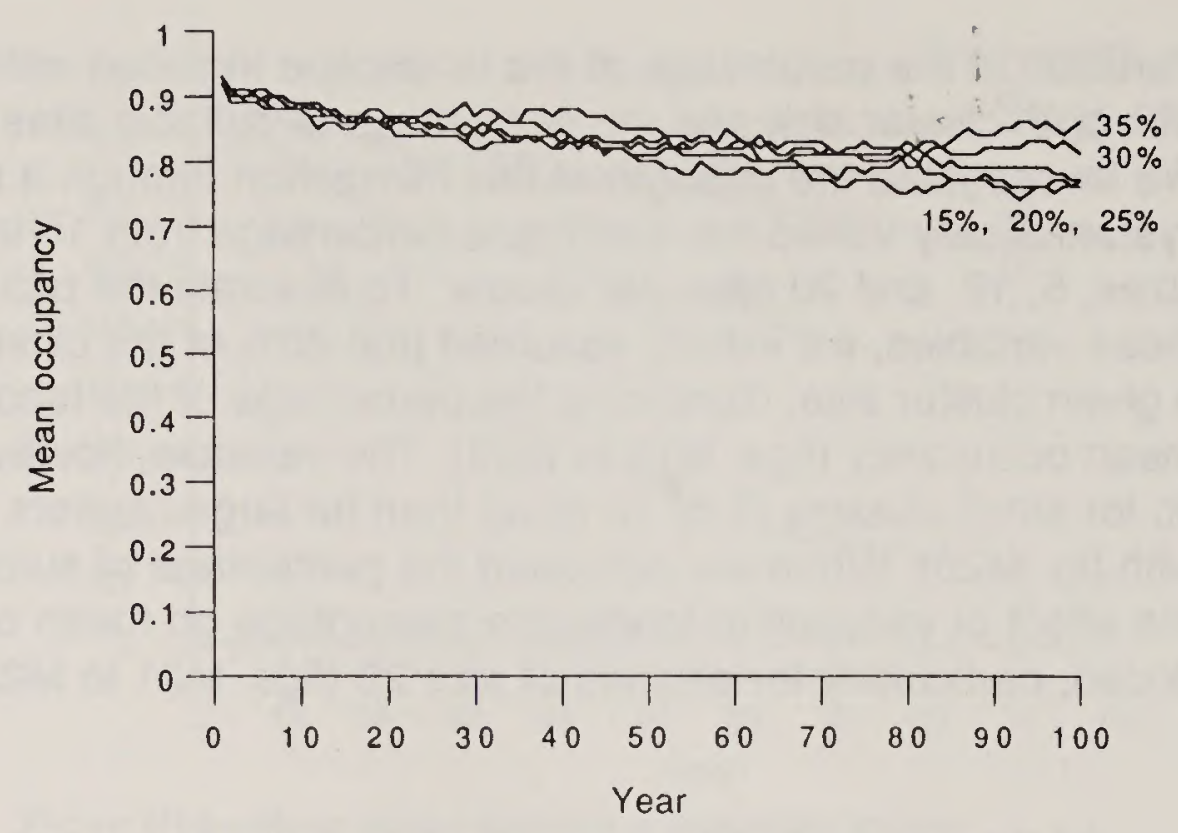

Figure M20-Mean cluster occupancy proportion against time for a 100 -year simulation with 15 to $35 \%$ of the landscape within the clusters; 20 sites were in each cluster, of which $60 \%$ were suitable. The total number of possible searches was 30 . Model parameters (table M2) were: $m=20 ; k=0.1$.

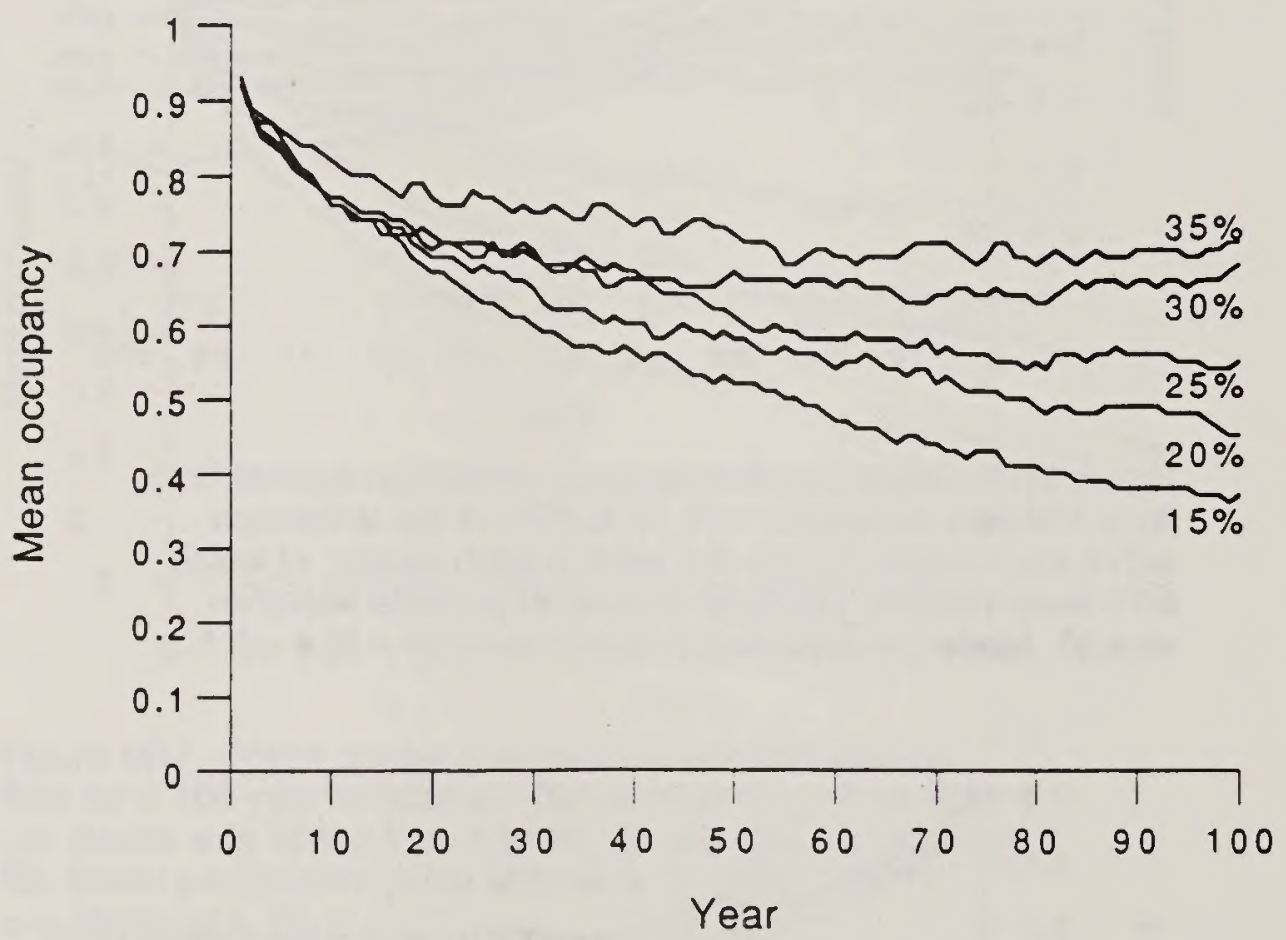

Figure M21-Mean cluster occupancy proportion against time for a 100 -year simulation with 15 to $35 \%$ of the landscape within the clusters; 5 sites were in each cluster, of which $100 \%$ were suitable. The total number of possible searches was 30 . Model parameters (table M2) were: $m=5 ; k=0.1$. 


\section{Appendix M: Population Models}

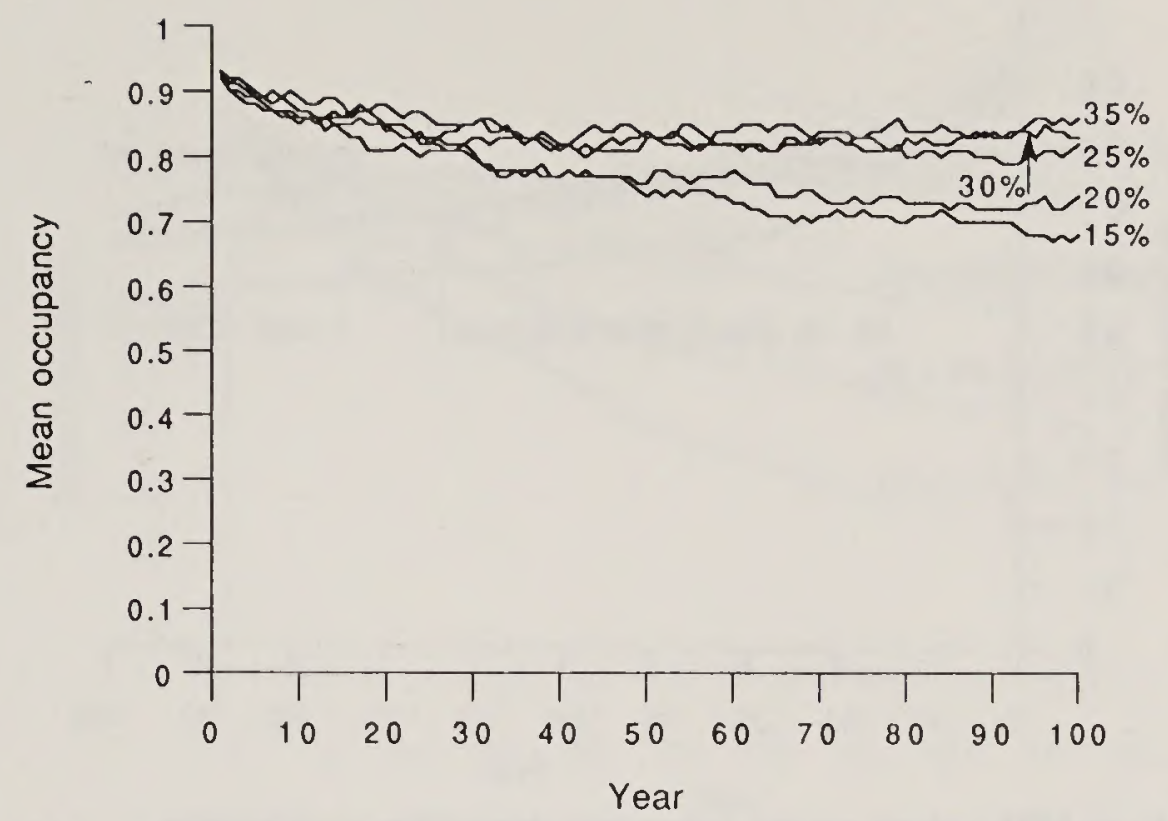

Figure M22-Mean cluster occupancy proportion against time for a 100 -year simulation with 15 to $35 \%$ of the landscape within the clusters; 10 sites were in each cluster, of which $100 \%$ were suitable. The total number of possible searches was 30. Model parameters (table M2) were: $m=10 ; k=0.1$.

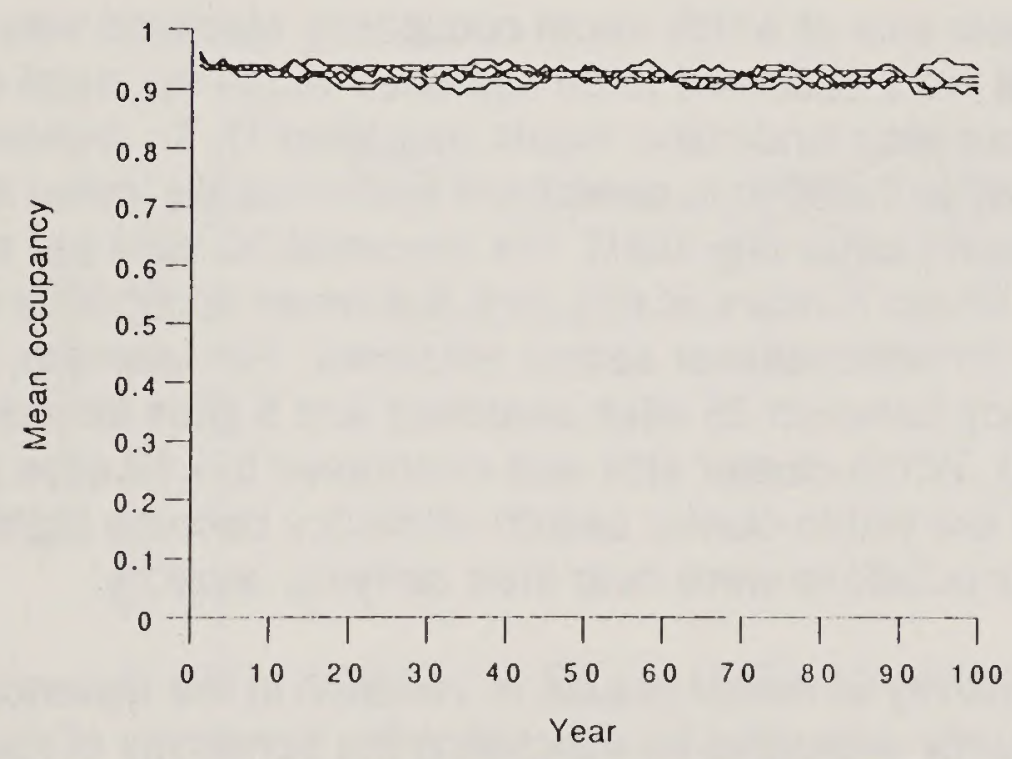

Figure M23-Mean cluster occupancy proportion against time for a 100-year simulation with 15 to $35 \%$ of the landscape within the clusters; 20 sites were in each cluster, of which $100 \%$ were suitable. The total number of possible searches was 30 . Model parameters (table M2) were: $m=20 ; k=0.1$.

In general, mean occupancy increased with cluster size, percentage of suitable sites, and percentage of the landscape in clusters. Beyond clusters of about size 20, however, changes in landscape percentage had little effect on mean occupancy. This result was a consequence of our assumptions about the behavior of dispersing juveniles. With 20 suitable sites per cluster, a successful dispersal event usually occurred within the natal cluster. With fewer suitable sites, or smaller clusters, birds were forced to leave their natal cluster and entered the surrounding forest matrix. As a consequence, they experienced a lower likelihood of successful dispersal (equation 2). 


\section{Appendix M: Population Models}

Varying Within-Cluster Search Efficiency

Varying Between-Cluster Dispersai

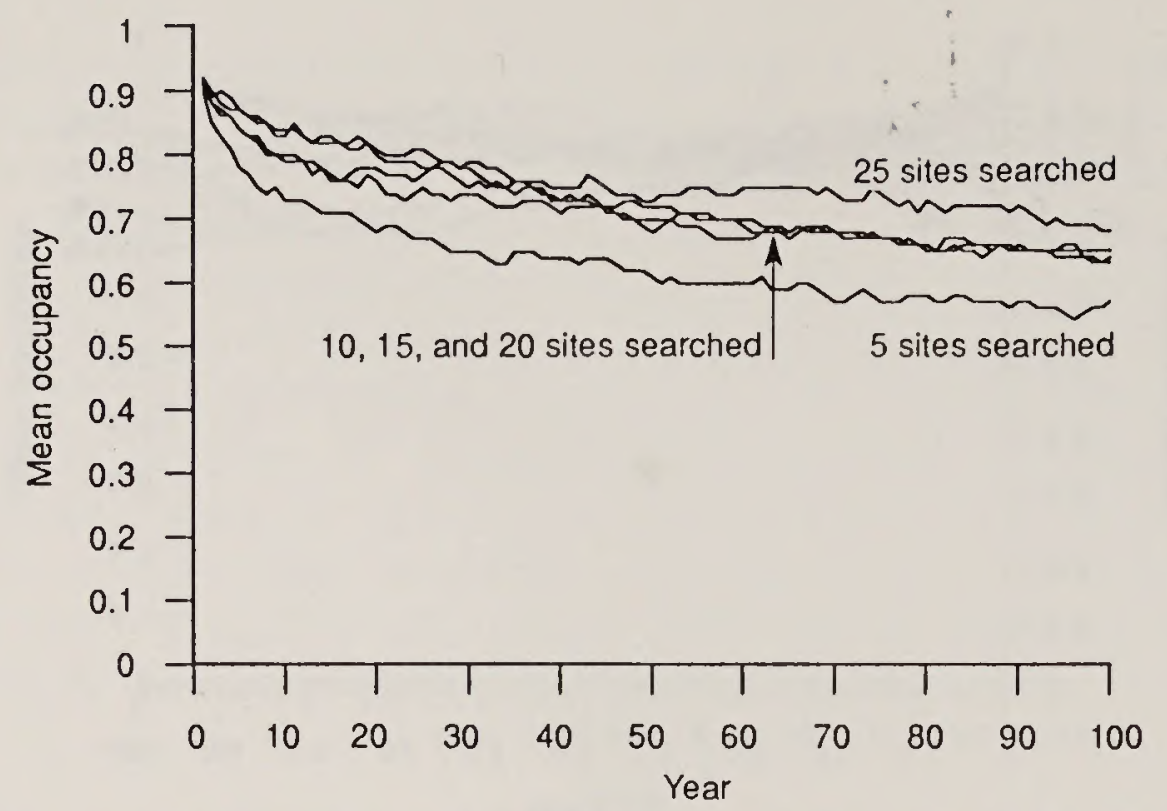

Figure M24-Mean cluster occupancy proportion against time for a 100-year simulation. The number of sites searched per cluster was varied from 5 to 25. Cluster size was fixed at 20; $50 \%$ were suitable. Model parameters (table M2) were: $h=$ $35 \% ; c=20 ; p=50 \% ; m=12 ; k=0.1$.

The cluster size at which mean occupancy stablized was affected by the number of sites that were assumed to be searched within the natal cluster before dispersal into the surrounding landscape matrix (equation 1). To explore the sensitivity of mean occupancy to variation in search, we systematically varied the number of sites searched in the natal cluster (fig. M24). We assumed 20 sites per cluster, 100\% suitable, and $k=0.1$. Given clusters of this size, the mean occupancy was relatively insensitive to variation in within-cluster search efficiency. For example, the difference in equilibrium occupancy between 25 sites searched and 5 sites searched was $0.1(0.68-0.58$; fig. M24). When cluster size was decreased to $<10$ sites per cluster, however, the effect of low within-cluster search efficiency became significant, particularly when cluster populations were near their carrying capacity.

The sensitivity of model results to variation in the distance between clusters was most directly evaluated by estimating the sensitivity of mean occupancy to variation in the dispersal coefficient (equation 2). For this simulation, we assumed clusters of size 5 with all sites suitable. All other model parameters were as before, except that up to five clusters could be searched. With clusters of size 5, even with opportunity to search five clusters, varying the dispersal coefficient strongly affected mean occupancy (fig. M25). Given high resistance to dispersal within the matrix $(k=1.0)$, no equilibrium was reached, and the populations went to extinction. When the matrix offered little resistance to dispersal $(k=0.03)$, mean occupancy equilibrated at a high value. Other values of $k$ showed intermediate results.

The significance of between-cluster dispersal strongly depended on cluster size. For example, a simulation based on 20 sites per cluster, with $50 \%$ of the sites suitable, was relatively insensitive to variation in $k$ (fig. M26): all coefficients supported a longterm equilibrium in mean occupancy. The difference in the 100-year level of mean occupancy between $k=0.03$ and $k=0.30$ was about 0.12 . Thus, to the extent that our between-cluster dispersal equation (2) reflects reality, we conclude that cluster size is more important than cluster spacing. 


\section{Appendix M: Population Models}

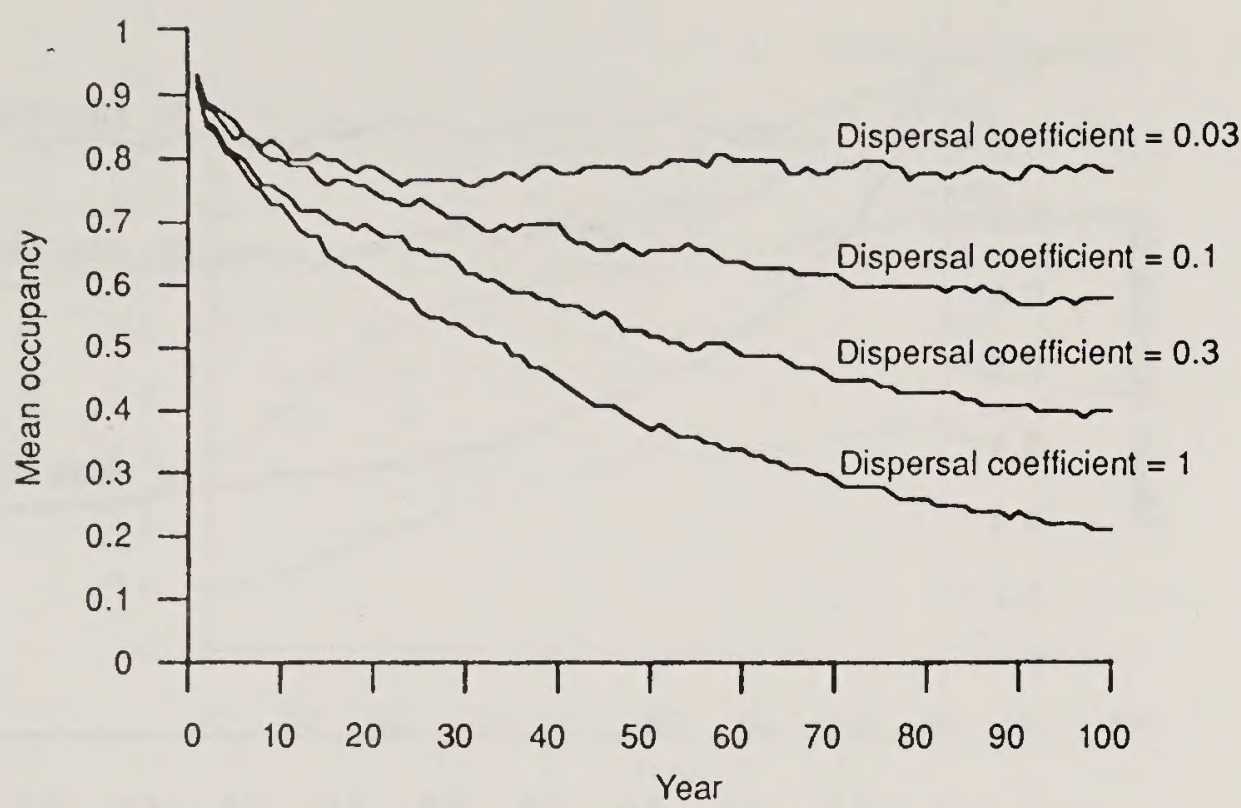

Figure M25-Mean cluster occupancy proportion against time for a 100-year simulation for four values of the dispersal coefficient. A maximum of five clusters could be searched. Model parameters (table M2) were: $h=35 \% ; c=5 ; p=$ $100 \% ; m=12 ; k=1.0,0.3,0.1,0.03$.

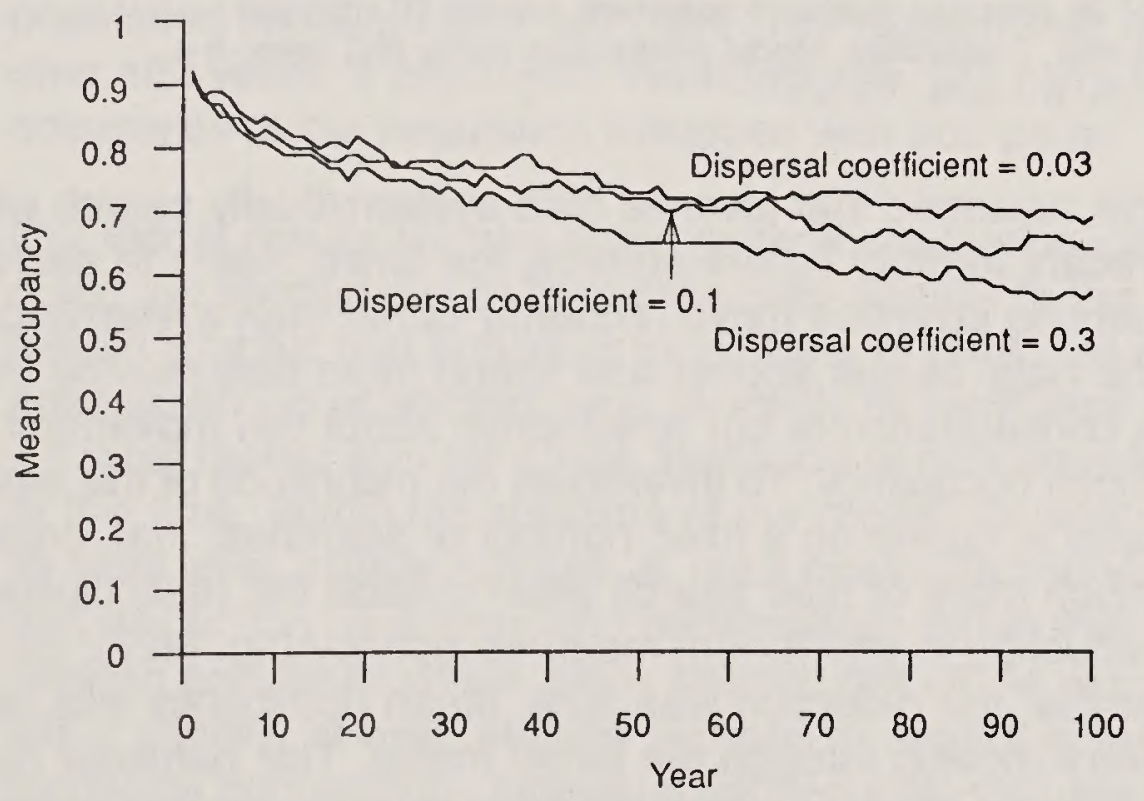

Figure M26-Mean cluster occupancy proportion against time for a 100-year simulation for three values of the dispersal coefficient. Cluster size was 20,10 of which were suitable. Model parameters (table M2) were: $h=35 \% ; c=20 ; p=$ $50 \% ; m=12 ; k=0.3,0.1,0.03$. 


\section{Appendix M: Population Models}

Allocating More SearchTime Outside the Natal Cluster

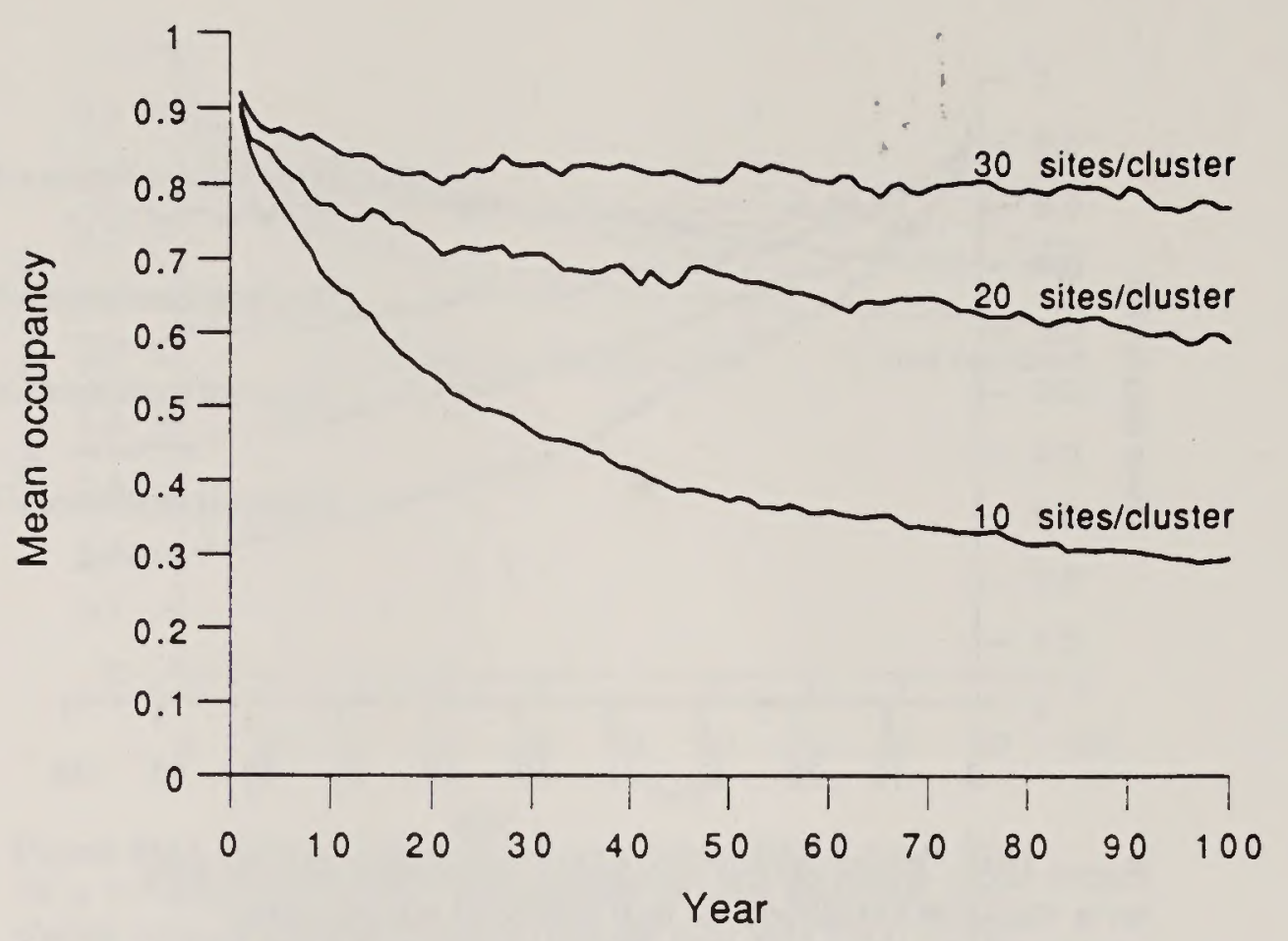

Figure M27-Mean cluster occupancy proportion against time for various numbers of sites per cluster The total number of possible searches was 30 . For 30 sites per cluster, 10 searches occurred within the natal cluster before emigration; for 20 sites per cluster, 6 searches; and for 10 sites per cluster, 3 searches. Model parameters (table M2) were: $h=$ $25 \% ; p=60 \% ; k=0.1$.

We assumed that juvenile owls systematically search within their natal cluster for a vacant territory before entering the forest matrix to search for another cluster. If dispersing juveniles move randomly rather than systematically, however, they will leave the natal cluster sooner and spend more time moving through the forest matrix. Thus, a consequence of our assumption about owl movement was an overestimation of mean occupancy. To investigate the magnitude of this effect, we performed several simulations, based on a fixed number of searches, that forced dispersing owls to expend much more of their search effort outside the natal cluster. The general result was a reduction in equilibrium mean occupancy (fig. M27); for clusters of size 20, for example, the reduction was $20 \%$. Mean occupancy was reduced because more owls were moving through the forest matrix. This behavior reduced both the likelihood of finding a vacancy within the natal clusters and the number of potential colonists arriving at a cluster. Collectively, these behaviors substantially reduced equilibrium mean occupancy.

The effects of total population size strongly depend on the spatial arrangement of that population number. For example, our models suggested that, for a given population size, if the population was arranged in clusters of five, it would slowly go to extinction (fig. M15). In contrast, if that same population number was arranged in clusters of 20, the population had a much higher likelihood of persisting beyond 100 years (fig. M15). An additional question was the effect on mean occupancy of initializing the simulation at different population sizes for a fixed cluster size. We explored this relation by assuming 20 sites per cluster, $75 \%$ of the sites suitable, and 12 searches per cluster (fig. M28). An initially low population (for example, 40 pairs) increased, but only very slowly. Even after 100 years, this population had achieved $<1 / 2$ the occupancy of the 


\section{Appendix M: Population Models}

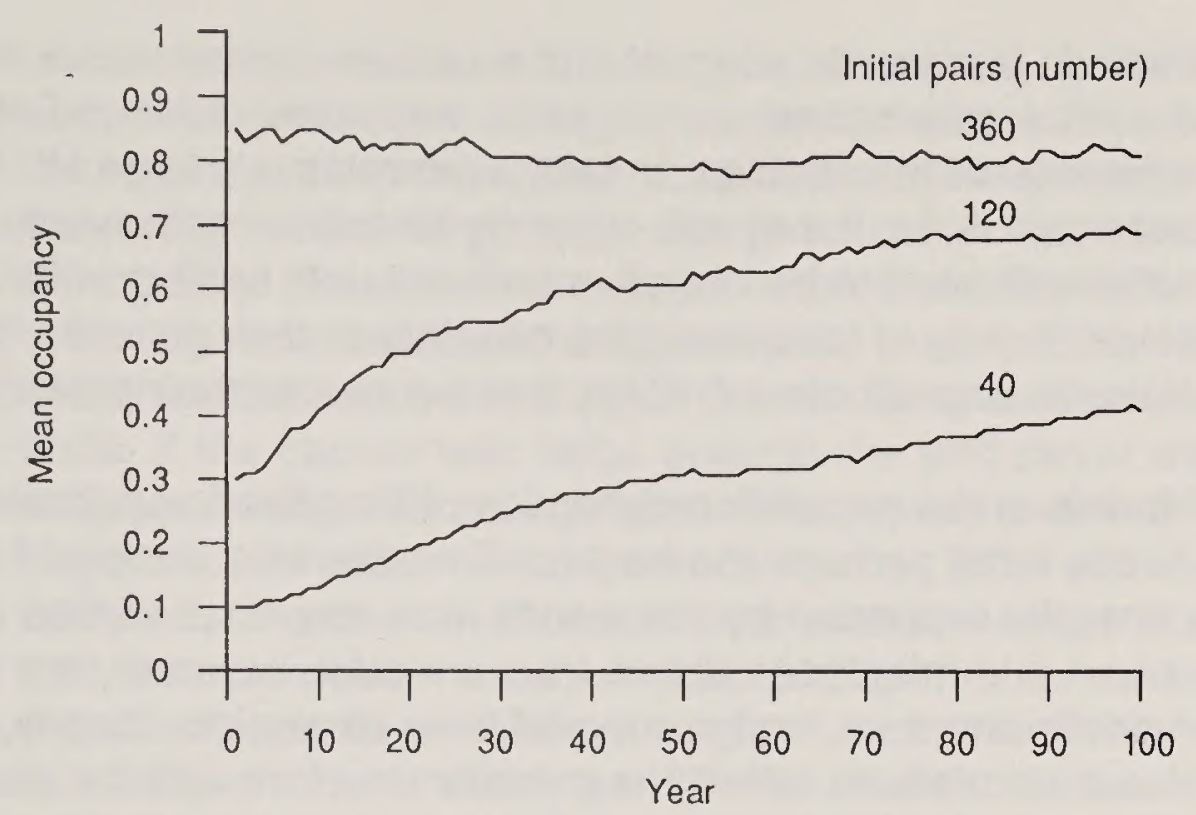

Figure M28-Mean cluster occupancy proportion against time for a 100-year simulation for three initial population values. Cluster size equaled $20,75 \%$ of which were suitable. Model parameters (table M2) were: $h=35 \% ; c=20 ; p=75 \% ; m=$ $12 ; k=0.1$.

DiscussionTerritory-Cluster Model population initialized with 360 pairs. The relation was nonlinear; however, because after 100 years, a population initialized with 120 pairs had attained about $80 \%$ of the occupancy of the population initialized with 360 pairs.

Our model results support some general conclusions that may prove useful in developing the spotted owl conservation plan. Similar to the findings of Doak (1989), our results suggest that providing for clusters of territories should increase the persistence likelihood of spotted owls, primarily by facilitating juvenile dispersal. Estimating a critical cluster size for a high likelihood of persistence is difficult, if not impossible, at this time. Within the structure of our model, clusters $\geq 15$ sites appeared stable; if all sites were initially suitable, at least moderate connectivity existed among clusters, and dispersing owls searched preferentially within their natal cluster. Under more realistic conditions where many spotted owl HCAs would not be continuous habitat, either initially, or ever, stability seemed to require at least 20-pair clusters and low to moderate connectivity. Individual spotted owls that are members of a large cluster population become less susceptible to the uncertainties of between-cluster dispersal and the character of the landscape matrix.

Cluster size, and the percentage of suitable sites, were highly interdependent. Suitable territories are less contiguous in HCAs that are below their potential carrying capacities. Successful within-HCA dispersal becomes more uncertain, rates of territorial replacement are lower when birds die, and more time is spent traveling through the surrounding forest matrix. Collectively, these factors all contribute to lower survival and fecundity rates and increase the risks to long-term viability. 


\section{Appendix M: Population Models}

Further, our results suggest that a conservation network that provides only for individdal pairs, or small clusters of pairs, has a low likelihood of providing for the continued existence of the species. In fact, even relatively large HCAs for spotted owls have uncertain fates, if they are currently far below their eventual carrying capacity. Such areas will need to be closely monitored until habitat within them has had time to recover. A way of increasing the certainty of their success is to initially position them close to large clusters (HCAs) that are nearer their potential carrying capacities.

Models of the population dynamics of long-lived vertebrates are difficult to validate. At this time, perhaps the best confirmation of our model inferences is that they are generally supported by the results from empirical studies (appendices $N, O, P$ ). The output and inferences drawn from a model, however, are always a reflection of the model's structure, and our model is no exception. Clearly, the patterns we observed in our simulations reflect the model's structure and the assumptions we made about spotted owl behavior. The usefulness of models can be defended to some extent if they accurately reflect key aspects of the species' ecology and behavior. We have attempted to structure our model in ways that reflect how we understand owls to behave. In some aspects of model structure, such as basic life-history patterns and the values of birth and death rates, we have more certainty than in others. For example, our model and its results are clearly the consequence of assumptions we have made about the dispersal behavior of juvenile owls within and between territory clusters.

Unfortunately, little is known of spotted owl dispersal behavior and owl movement patterns through heterogeneous landscapes.

One inference drawn from our results - the positive effect of increasing cluster sizehas much stronger support in both empirical and theoretical studies. Populations quickly escape from the dangers of demographic stochasticity with even slight increases in population size (Goodman 1987). Populations also gain security from environmental uncertainty with increasing numbers but at a much slower rate than from demographic effects (Shaffer 1987). Therefore, this model result was not surprising. Of interest, however, was the fact that marginal gains in mean occupancy were not constant with incremental increases in cluster size. Rather large gains resulted in moving from clusters of size 5 to clusters of size 10; much smaller gains were realized in moving from 10 to 20 territories per cluster.

In our individual-territory model, we assumed that all sites were equally likely to be searched until a suitable site was located or until the search capabilities were exceeded (that is, the owl died). The probabilities of finding a suitable site, or an individual of the opposite sex, became insurmountable when suitable habitat was less than about $20 \%$ of the landscape, or when the population was too low. The landscape was essentially infinite in scale but with distinct habitat boundaries (that is, we did not include edge effects). 


\section{Appendix M: Population Models}

In our second model, we invoked the concept of clusters, groups of two or more adjacent suitable sites. If a single, very large cluster is created with reflecting boundaries; however, it can begin to act just like our first model. If we begin to decrease the percentage of this large block that is suitable habitat and set limits to search, we can demonstate the same behavior as in the first model. Our cluster model did not have reflecting boundaries, but owls searched preferentially within their natal cluster before searching the matrix for another cluster. Because the total number of searches was finite, if the cluster was large enough the bird never searched outside the cluster. It simply exhausted its search capabilities before ever lea:'ing its natal cluster. For very large blocks then, the model can behave as if the boundaries are reflecting and virtually no movement occurs outside of clusters. Large clusters become very stable, and the model becomes insensitive to dispersal, and thus distance, between clusters. If spotted owls do not show strong preference for searching within clusters, then the suitability of the surrounding matrix becomes considerably more important. Assuming a fixed search effort, if less preference is shown for within-cluster search, then more effort must be spent searching among clusters. An important consequence of expending more search effort in the matrix is that the necessary cluster (HCA) size to achieve a given occupancy is increased.

If dispersing owls do preferentially search their natal cluster before entering the matrix, some long-term genetic consequences are possible. The general effect of subdividing the owl population into HCAs may be to slightly increase the total genetic variation in the metapopulation, but at the expense of decreasing genetic variation within HCAs (see Lande and Barrowclough 1987). Very large HCAs produce high demographic stability, but may lead to a decline in genetic variation from inbreeding. Smaller HCAS promote higher dispersal rates but may lead to demographic instability. Therefore, some optimal size for an HCA probably exists that achieves a balance between these two processes.

The extent to which our model results reflect the key consequences of movement in a spatially heterogeneous landscape is unknown. We assumed that risks to owl viability were more pronounced from demographic than genetic factors. This could be a significant omission if, for example, we have overestimated the vagility of dispersing owls in the forest matrix. If this is true, then there may be possible deleterious genetic effects from inbreeding within the large HCAs. We developed a model that we believe to be compatible with what is currently known about owl life-history structure, dispersal behavior, and population dynamics. To have a higher degree of confidence in the generality of our model results, however, will require a considerably deeper understanding of how spotted owls move through their environment and respond to habitat heterogeneity at a variety of spatial scales.

Allee, W. C. 1931. Animal aggregations. The University of Chicageo Press, Chicago, III.

Allee, W. C. 1938. The social life of animals. W.W. Norton and Company, New York.

Boyce, M. S. 1987 unpubl. A review of the U.S. Forest Service's viability analysis for the spotted owl. Final report to the National Council of the Paper Industry for Air and Stream Improvement. 50pp. 


\section{Appendix M: Population Models}

Dennis, B. 1989. Allee effects: Population growth, critical density, and the chance of extinction. Nat. Resour. Modeling 3:481-538.

Doak, D. 1989. Spotted owls and old growth logging in the Pacific Northwest. Conserv. Biol. 3:389-396.

Franklln, A. B., J. A. Blakesley, and R. J. Gutlérrez. 1990 unpubl. Population ecology of the northern spotted owl in northwestern California: Preliminary results, 1989. Final report submitted to the For. Serv. and the Calif. Dep. Fish and Game. $31 \mathrm{pp}$.

Goodman, D. 1987. The demography of chance extinction. Pp. 11-34 in M. E. Soulé, ed. Viable populations for conservation. Cambridge Univ. Press, Cambridge, U.K. 189pp.

Lamberson, R. H., R. McKelvey, B. R. Noon, and C. Voss. 1989 unpubl. The effects of varying dispersal capabilities on the population dynamics of the northern spotted owl: preliminary results.

Lande, R. Pers. comm. Univ. of Chicago, Dep. Ecol. and Evolu., Chicago, III.

Lande, R. 1987. Extinction thresholds in demographic models of territorial populations. Amer. Nat. 130:624-635.

Lande, R. 1988. Demographic models of the northern spotted owl (Strix occidentalis caurina). Oecologia 75:601-607.

Leslle, P. H. 1945. On the use of matrices in certain population mathematics. Biometrika 33:183-212.

Leslie, P. H. 1948. Some further notes on the use of matrices in population mathematics. Biometrika 35:213-245.

Lefkovltch, L. P. 1965. The study of population growth in organisms grouped by stages. Biometrics 21:1-18.

Marcot, B. G., and R. Holthausen. 1987. Analyzing population viability of the spotted owl in the Pacific Northwest. Trans. N. Amer. Wildl. Nat. Resources Conf. 52:333-347.

Noon, B. R., and C. M. Blles. 1990. The mathematical demography of the spotted owl in the Pacific northwest. J. Wildl. Manage. 54:18-27.

Shaffer, M. 1987. Minimum viable populations: coping with uncertainty. Pages 69-86 in Viable populations for conservation. M. E. Soulé, ed. Cambridge Univ. Press, Cambridge, U.K. 


\section{Appendix M: Population Models}

U.S. Department of Agriculture, Forest Service. 1988. Final supplement to the environmental impact statement for an admendment to the Pacific northwest regional guide. Two volumes. U.S. Department of Agriculture, Forest Service: Portland, Oreg. 



\section{Extinction of Species and Populations}

Causes of Extinction Our goal is to develop a plan that will ensure long-term survival of the northern spotted owl in well-distributed numbers throughout its range. In developing such a plan, reviewing factors known to cause species to disappear from all or portions of their native ranges is instructive.

As noted by Shaffer (1981), factors leading to population extinction fall into two broad categories: systematic pressures and stochastic perturbations. Systematic pressures are such factors as habitat loss, toxic substance accumulation in the environment, or unrelenting resource harvesting by humans. The ivory-billed woodpecker, for example, vanished from the southeastern United States when virgin bottomland forests in which it nested and foraged were cleared (Tanner 1942). The peregrine falcon, osprey, and bald eagle all experienced major population declines after World War II as a result of the widespread use of DDT and other persistent pesticides (Halliday 1978). And the passenger pigeon and Carolina parakeet were exterminated in large measure by hunting (Blockstein and Tordoff 1985).

Stochastic perturbations that affect population persistence fall into four categories: genetic deterioration, demographic stochasticity, environmental stochasticity, and metapopulation dynamics.

Genetic Stochasticity

Genetic stochasticity involves changes in gene frequencies from such factors as inbreeding and founder effects. Loss of genetic variability in populations can lead to reduced fertility, the establishment of deleterious traits within a population, or the inability to adapt to sudden environmental changes (Allendorf and Leary 1986, Ledig 1986, Ralls et al. 1986). Inbreeding and population bottlenecks, which can lead to a loss of genetic variability, are serious problems for small, isolated populations. Because interpatch dispersal is facilitated by management of the landscape matrix surrounding the HCAs that we propose (appendix P), deleterious genetic phenomena associated with small population size should not affect the persistence of the spotted owl under this conservation strategy.

Demographic Stochasticity

Demographic stochasticity is defined as chance events in the reproduction or survival of a finite number of individuals. For species that reproduce sexually, a healthy population must have not only enough individuals, but also the right mixture of sexes and the right age-structure. A highly skewed sex ratio, periods of poor reproduction, or excessive mortality of a particular age-class can threaten the long-term survival of some populations. To cite an extreme example, when the last six dusky seaside sparrows all turned out to be males, the recovery of this endangered bird became impossible. Some species may require a threshold number of individuals to avoid social dysfunction and to breed successfully. Below this threshold, individuals do not reproduce successfully at rates high enough to sustain the population. This problem 


\section{Appendix N: Extinction}

\section{Environmental \\ Stochasticity}

Metapopulation Effects might be expected to be most acute for species that breed in colonies. The HCAs, which are designed to support substantial numbers of owl pairs, should serve to lessen the negative consequences that small population sizes have on demographic factors that bear on spotted owl persistence (see appendix 0 ).

Environmental stochasticity refers to temporal variation in habitat attributes, as well as populations of competitors, predators, parasites, and diseases. Under most circumstances, environmental variation does not pose a serious threat to a large, welldistributed population. But when that population is much reduced in size or distribution, these temporal changes can push it towards extinction. Ehrlich et al. (1980), for example, document the extinction of several small butterfly populations during a 2-year drought in central California.

Natural catastrophes include the most extreme environmental events that affect population persistence. Fires, storms, and disease epidemics are rare events in the lifetime of the individual organism, but over long enough periods of time, such events inevitably occur, and they can eliminate both habitats and the populations they support. For example, an epidemic of canine distemper reduced the only sizable population of the endangered black-footed ferret from 128 individuals to about 18 in less than a year (May 1986). The Mount St. Helens eruption destroyed thousands of acres of habitat suitable for the spotted owl, as did fires in the Klamath National Forest in 1987.

Environmental stochasticity and catastrophes have been considered in this conservation strategy. The many large HCAs, distributed across a three-State region, should reduce to essentially zero the chance that environmental events, even of considerable magnitude, will threaten the spotted owl throughout its range (see appendix O).

Most species persist regionally as metapopulations, sets of populations that are linked by dispersing individuals, allowing for the recolonization of unoccupied habitat patches after local extinction events. Loss of suitable habitat patches, or disturbances in the surrounding landscape matrix, can disrupt metapopulation dynamics and this loss can contribute to the regional extinction of a species. Metapopulation dynamics have been documented for a wide variety of species from invertebrates (Bengtsson 1989), to cold-blooded vertebrates (Sjorgen 1988), to mammals (Smith 1980). All exhibit discrete local populations that are subject to extinction but regionally persist through recolonization from surviving neighboring populations. The spacing of HCAs and the character of habitats in the interconnecting landscape matrix specified for this conservation strategy (see appendices $P$ and $Q$ ) will facilitate the exchange of individual owls among available habitat patches. This design feature should preclude the isolation of habitat patches and of the demographic units that they support; hence, it should contribute to the persistence of interacting demographic units. 


\section{Appendix N: Extinction}

Effects of Stochastlc Perturbations
Stochastic perturbations have two important aspects. First, the smaller and more isolated a population is, the more vulnerable it is to genetic, demographic, and environmental perturbations, and to metapopulation disruption. Natural catastrophes, of course, can be destructive to both large and small populations. Second, stochastic perturbations differentially operate at different population sizes. A population large enough to avoid inbreeding may still be vulnerable to extinction from demographic fluctuations (such as the presently isolated population of spotted owls on the Olympic Peninsula). For wild populations in natural environments, therefore, demography is likely to be of more immediate importance than genetics in determining population viability (Lande 1988). Finally, stochastic perturbations normally act in concert and, in so doing, may accelerate the demise of a population. The best example of this acceleration is probably the heath hen (see Shaffer 1981, Dawson et al. 1986).

Originally abundant from New England to Virginia, the heath hen steadily declined as European settlement advanced. By 1876, heath hens survived only on Martha's Vineyard Island, Massachusetts. A refuge was established for the birds, and efforts were made to eliminate their predators. By 1915, heath hens could be found all over the island, and the population was estimated at 2000. In 1916, a fire destroyed most of the nests and habitat, and the following winter brought an invasion of predatory goshawks from the north. These two catastrophic events reduced the population to 100 to 150 individuals. The birds gradually increased, to about 200 in 1920 . That year, an epidemic disease reduced the population to less than 100 individuals. The remaining birds appeared to become increasingly sterile (perhaps because of genetic deterioration), and the population as a whole suffered from an excess of males (contributing to demographic imbalance). The last heath hen disappeared in 1932.

Important lessons can be learned from this example. A once widespread and abundant species was driven to extinction by habitat destruction and hunting pressure, which reduced its range to a small island and its numbers to a few hundred individuals. At that size, it was vulnerable to several stochastic perturbations. Had other populations been spared, heath hens might have survived the unfortunate but inevitable sequence of catastrophic events in their island refuge.

Similar phenomena currently place the spotted owl at risk. Systematic timber harvesting and, to a much lesser degree, stochastic natural environmental phenomena act in concert to destroy and fragment superior and suitable habitat for the owl.

We know that habitat loss, in particular, can facilitate extinction by turning large populations into smaller, more isolated ones. It does so through the process of habitat fragmentation, which occurs wherever a large, contiguous habitat is transformed into smaller patches that are isolated from each other by a landscape matrix unlike the original (Wilcove et al. 1986). This matrix can differ from the original habitat in either composition or structure; the crucial point is that it functions as either a partial or total barrier to dispersal for species associated with the original habitat. We must be careful to distinguish between fragmentation that isolates pairs and populations, and fragmentation within the home range of individual pairs. The former type of fragmentation is a clear threat to population viability. Owls on the Olympic Peninsula, for example, are demographically isolated as a result of habitat loss. The extent to which 


\section{Appendix N: Extinction}

\section{Other Factors}

\author{
Edge Effects
}

fragmentation within a home range is harmful is less well known. Individual owls tend to increase their home-range size in response to fragmentation (Carey et al. 1990, Forsman et al. 1984). The increase in home range may increase the risk of predation or place increased energetic demands on the birds as they forage. Data are insufficient to confirm or refute these hypotheses. Spotted owls can sustain some amount of fragmentation within their home ranges, however, as demonstrated by the presence of breeding owls in fragmented BLM lands in western Oregon.

The habitat conservation strategy proposed in this document describes specific habitat features for the landscape matrix surrounding HCAs. Those features (including retention of $50 \%$ of the forest in that landscape matrix in trees at least 11 inches in d.b.h., totaling at least $40 \%$ canopy cover-see appendices $P$ and Q) significantly reduce the contrast between HCAs and the surrounding landscape in which they are embedded. Combined with the large size of HCAs, the conservation strategy should adequately mitigate many of the negative consequences of habitat fragmentation as it affects populations.

In addition to these systematic and stochastic factors that cause extinctions, four mechanisms involving habitat fragmentation lead to extinction: edge effects and the influx of species from the outside matrix, secondary extinctions among coevolved species, loss of critical microhabitats, and loss of habitat refugia.

Discontinuities between ecological communities are among the most striking features of natural landscapes. Dramatic edges between habitat types not only contribute texture and physical diversity to ecosystems, they are primary determinants of regional species diversity. Wildlife biologists have long recognized that different habitat types support different sets of species and that the edges between habitats can be particularly rich in game species. Indeed edges between habitats often serve as distinct habitats themselves, supporting unique suites of edge-dependent species.

Those concerned with the conservation of certain forest-dwelling species, however, have noted that the increased ratios of forest edge to forest interior, which inevitably result from forest fragmentation, can have strong negative impacts on those species (Temple and Cary 1988, Whitaker 1980, Whitcomb et al. 1976, Wilcove 1985, Wilcove et al. 1986, Yahner 1988). Invasion by edge-dwelling species into interior environments can be a major threat to the survival of forest interior species (Ranney et al. 1981). For example, in the Eastern United States, edge-dwelling species include numerous predators and brood parasites of forest interior songbirds (Brittingham and Temple 1983, Whitcomb et al. 1981). As Harris (1988) points out, the magnitude of such "edge effects" tends to be inversely proportional to the quality of adjacent habitat patches; hence, the more extreme the structural difference across habitat edges, the more dramatic the effects on interior species.

Several scientists have hypothesized that predation on spotted owls by great horned owls, and competition from barred owls, may increase with increasing amounts of forest edge associated with the harvest of mature and old-growth timber. The abrupt edges created by clearcutting are also likely to increase the amount of blow-down in mature and old-growth timber, thereby reducing the amount of suitable spotted owl habitat. The extent to which this poses a serious problem in the conservation of the northern spotted owl is unknown (also see appendix O). 


\section{Appendix N: Extinction}

Secondary Effects and Extinctions
The scientific literature is replete with examples of interconnected life. Indeed the term "coevolution" was coined specifically to describe the evolution of mutualistic relationships or other interdependencies among species. Examples abound that document how the decline or loss of one species can produce a cascade of secondary effects that can range from the disruption of ecosystem functions, to an alteration of the population dynamics of surviving species, and even to additional extinctions (Gilbert 1980, Terborgh and Winter 1980, Wilcove et al. 1986).

For most ecosystems, the potential impact of a single species lost is impossible to determine a priori. For comparatively simple ecosystems with relatively low diversity, however, the role of a "keystone" species in ecosystem function may be relatively straightforward, and the effects of its removal may even be determined experimentally (Paine 1966). Large vertebrates certainly appear to play dominant roles in a wide variety of ecological communities, and their loss can have profound and immediately measurable effects.

A notable example can be drawn from studies on Barro Colorado Island, a former hilltop that became an island when the Chagres River was dammed during construction of the Panama Canal in 1914. Large predators such as jaguars, pumas, and harpy eagles quickly disappeared from the island. Perhaps because their main predators were gone, a variety of medium-sized mammals are now remarkably abundant. These include the collared peccary, agouti, coatimundi, and armadillos (Terborgh and Winter 1980). Many of these mammals are voracious consumers of bird eggs and young. Their abundance is thought to be one reason why 15 to 18 species of forest-dwelling birds have vanished from Barro Colorado Island (Willis 1974; but see Karr 1982 for evidence that the number may be considerably larger than that). Many of these birds share the trait of nesting on or near the ground.

Some of the best examples of how loss of a certain species can lead to secondary extinction are found in complex tropical ecosystems (for example, see Gilbert 1980, Terborgh 1974), although temperate-zone examples involving plants and invertebrates (Thomas 1976), small mammals and birds (Matthiae and Stearns 1981, Whitcomb et al. 1981), and dominant herbivores and predators (Wilcove et al. 1986) are common. Soulé et al. (1988) present evidence that the loss of coyotes from small, isolated patches ("islands") of chaparral habitat in California leads to secondary losses of native birds, in part attributable to increases in the numbers of small predators that were once kept in check by the coyotes.

The disruption of ecosystems, or the loss of additional species, is most likely to occur where a large, long-lived species that dominates a specific ecosystem function is at risk (Terborgh 1988). The role of the northern spotted owl as a predator of numerous small mammal species makes it an apt example of one such predatory species, the loss of which might well compromise ecosystem integrity and affect the population dynamics or persistence of co-occurring species. 


\section{Appendix N: Extinction}

Microhabitats

Habitat Refugia
Certain large-scale habitat landscape features are so clearly key to the survival of a species that loss of those features would assure the species' demise. The availability of prairie grassland for bison and shifting dune sand for fringe-toed lizards are obvious examples. Often, however, local species survival depends on the availability of specific microhabitats: small portions of a habitat providing resources or environmental conditions critical to some phase of the organism's life history. Conservation planning can be particularly challenging when microhabitats prove to be important to population persistence. Indeed, reserves based only on broad habitat requirements may very well fail if subtle or cryptic microhabitat requirements are overlooked.

The threatened bay checkerspot butterfly serves as a good illustration of how microhabitat suitability can vary across landscapes and through time (Murphy and Weiss 1988, Weiss et al. 1988). Although the host plants of the butterfly are distributed widely across its grassland habitats, the development and survival of its larvae vary greatly between slope exposures, and from one year to another. Populations in habitats without cool exposures are highly susceptible to local extinction from drought. Habitats without warm exposures may delay adult flight periods too late for reproduction to occur in some years. A full range of topographically defined microhabitats in a habitat patch helps to ensure that at least some individuals are in phase with host plant resources in all growing seasons. Furthermore, a proximate spatial arrangement of cool and warm microhabitats can facilitate dispersal between them, thus allowing larvae to respond to short-term variation in habitat quality.

Population dynamics of large, long-lived species may not respond as dramatically to fine-scale variation in habitat condition as do the butterflies. Spotted owls, however, do respond to the microclimates within their territories, choosing cooler or warmer spots in response to seasonal or even daily fluctuations. Thermoregulation has been cited as one reason why the owls are closely associated with structurally complex, mature and old-growth forests. Moreover, some of the small mammal prey species on which the spotted owl largely depends seem to depend on the availability of certain microhabitats: for example, those associated with microclimatic conditions (Belk et al. 1988, Getz 1965, Hoffman 1984) and specific resources (for example, fungi for flying squirrels, Maser et al. 1981) that may be narrowly distributed.

Both empirical evidence and common sense suggest that not all available habitat is equal, either in quality or importance to the persistence of populations. Certain portions of habitat may provide sparse resources, or resources may be available only during certain periods. Such habitat might be viewed as marginal in value to population persistence (appendix F). By contrast, other habitat many provide a full range of resources that are constantly available through time. Such habitat not only may be suitable, but it may also provide a refuge for individuals during environmental extremes that may render less-suitable habitat unavailable. Conservation planning that does not consider the differential ability of specific habitat areas to support target species at minimum population sizes through time may fail-even where extensive suitable habitat is protected, managed, or both. Habitat refugia are particularly important to the persistence of species in regions where environmental extremes are commonplace. 


\section{Appendix N: Extinction}

How habitat refugia can determine long-term persistence of animal populations is well illustrated by the Amargosa vole, a resident of a highly circumscribed marsh habitat in the Mojave Desert. Low-elevation habitat (that within the floodplain of the Amargosa River) constitutes nearly $90 \%$ of the area supporting resources for the vole. But that habitat is annually flooded and rendered uninhabitable. Habitat at moderate elevation floods less often (on the order of every 30 years or so) and is inhabitable between such events. At such times, the small percentage of habitat at the very highest elevations provides the only refuge for the species; hence, a small fraction of total habitat is absolutely essential to the persistence of the vole. Reserve design must include that habitat to achieve conservation of the species.

The recurrence of major natural catastrophes this century that have impacted significant portions of the distribution of the northern spotted owl (for example, the "blowdown" of 1921 on the Olympic Peninsula and the wildfires of 1987 in the Klamath Region), demonstrates that conservation planning for the owl must consider habitat refugia. Furthermore, during intensive harvest of private timberlands in the early 1900 s, the owl was sustained by habitat on FS lands that then provided refugia. The conservation strategy should assure habitat refugia, especially in larger HCAs, and many of these should be at lower elevations at inland locations.

\section{Additional Factors}

\section{Thresholds}

Three additional factors associated with habitat fragmentation must be considered in developing an effective conservation plan for the northern spotted owl: thresholds, packing phenomena, and the role of unoccupied habitat in the long-term survival of a population or species.

Threshold phenomena occur when relatively small changes in some component of an ecosystem induce dramatic, large-scale changes in some other component or components. For example, "Below a certain level of pollution, trees will survive in smog, but when a small increment in the local human population produces a small increment in smog, living trees become dead. Perhaps 500 people can live around a certain lake and dump their raw sewage into it, and its natural systems will be able to break down the sewage and keep the lake from undergoing rapid ecological change. But 505 people may overload the system and result in a polluted or eutrophic lake" (Ehrlich et al. 1970:727).

We need to be mindful of the possibility of threshold phenomena for spotted owls (see appendix M). One reasonable possibility, for example, is the fragmentation of suitable habitat. As total suitable habitat area declines and the mean distance between patches of suitable habitat increases, spotted owls may be able to survive and reproduce at apparently safe rates up to some threshold, either in total area of suitable habitat, mean distance between patches, or both. But a small, added increment of habitat loss might then put the birds on a steep and irretrievable trajectory to extinction.

We know that any number of factors associated with fragmentation can push a population towards extinction. But often we cannot assess the absolute importance of any single factor. Nonetheless, if they act in concert or if important thresholds exist, a relatively small increase in any one could be sufficient to tip the scales toward extinction. 


\section{Appendix N: Extinction}

\section{Packing Phenomena}

Unoccupled Habltat
Because birds and mammals are relatively long-lived and mobile, they can temporarily escape from a place where their habitat is being degraded or destroyed and move into nearby patches of undisturbed habitat. Thus, for short periods, densities of individuals within undisturbed patches may increase, a phenomenon known as packing.

Lovejoy et al. (1986), for example, netted and banded birds in an area of Brazil where the primary forests were being cleared for cattle pasture. They discovered that capture rates of various species in a particular forest plot increased dramatically as nearby areas were cleared. Densities remained high for several months, but eventually dropped. They concluded that the increase represented an influx of displaced birds from areas that had been recently cleared. Given the territorial nature of many bird species and the fact that only a finite amount of food or cover is available in a given area, that the displaced birds were unable to persist indefinitely in the forest plot is not surprising.

A consequence of packing, therefore, is an anomalous increase in density in remaining local patches of suitable habitat by a species whose population may be otherwise in decline as a result of habitat loss. Such local increases in density are not necessarily indicators of "healthy" population status or adequate reproductive output. As discussed in appendix L, packing appears to be occurring in several locations within the current range of the spotted owl (for example, on BLM lands in southern Oregon, and the Willow Creek study area and the Mad River redwood area, both in Humboldt County, California). The phenomenon of packing underscores the need to assess population trends on as large a geographic scale as possible.

The problem of identifying important habitat is magnified when that habitat is not permanently occupied by the species of concern. Migratory birds and salmon, for example, abandon some habitats for long periods; nonetheless, these areas are obviously essential to the survival of the species. More difficult to understand, however, is the role of unoccupied habitat for the many species that are neither migratory nor cyclical in their use of habitats. Is the unoccupied habitat of importance to their long-term conservation? The answer, in some cases, is yes. For these species, protecting unoccupied habitat can be as important to regional persistence as protecting of occupied habitat.

For species fitting this description, unoccupied habitat presents itself in two forms: as vacant habitat of marginal quality, contiguous with or adjacent to occupied habitat; and as distinct, separate, empty patches of high- or low-quality habitat. Unoccupied patches of either marginal or high-quality habitat can serve as occasional stepping stones for regional populations. These patches can facilitate gene flow between small populations and can provide routes for individuals to colonize surrounding habitats in which the species once occurred but is now gone. The loss of "stepping stone" habitat patches can even disrupt the dynamics of entire regional populations. For example, the once widespread and abundant Karner blue butterfly of the "pine bush" regions of New York and surrounding States disappeared from many regions as a result of the fragmentation and isolation of occupied and unoccupied habitat patches and the elimination of dispersal corridors. 


\section{Appendix N: Extinction}

Habitat of marginal quality, such as locations with few food sources or nest sites, may support a given species only under certain circumstances. For example, marginal habitats that are normally empty may serve as the only refugia for plants and animals during times of fire, drought, or other environmental extremes. Under favorable conditions, marginal habitat may also boost the carrying capacity of an area. The resulting population expansion can buffer the population against future periods of environmental stress. Populations of the bay checkerspot butterfly are a classic example (Murphy and Weiss 1988, Weiss et al. 1988). Checkerspot populations live mostly on mesic, north-facing, grassland slopes. Years of above-average rainfall, however, allow the butterfly to expand its range into more xeric, south-facing slopes. Although infrequent and short-term, such expansions can contribute to long-term population persistence, especially for species whose numbers are usually regulated by environmental factors rather than by competition with other members of the same species.

\section{Conclusions}

\section{References}

The Committee has concluded that persistence of the spotted owl is presently at risk in significant portions of its range as a result of continued destruction, and concomitant fragmentation, of its habitat. This loss has included much of the habitat that appears to be superior for the owl, especially that at lower elevations. The result of this process has been the fractioning of a formerly more continuous population of spotted owls into smaller, isolated demographic units, many of which are at risk of local extinction because of demographic factors and environmental phenomena.

Local habitat fragmentation presents additional specific risks, including the possible deleterious effects of increased habitat edges and the attendant increased risk of predation on adults and young, the loss of crucial microhabitats that serve to lessen the effects of weather and provide for prey species, and the potential loss of key habitat necessary to provide refugia during catastrophic environmental occurrences.

The effects of habitat fragmentation on the persistence of the northern spotted owl may be partially reduced by conservation planning. A habitat conservation strategy that attempts to provide the owl with habitat distributed across the landscape in a fashion most similar to its historical configuration should provide the best hedge against future extinction. Studies of other species suggest that a plan that incorporates three key considerations will have a substantial likelihood of success. These considerations include providing multiple, extensive, and continuous areas of superior and suitable habitat; distributing these areas across the landscape at distances that encourage demographic interaction among them; and providing adequate connectivity in the form of surrounding landscape features to facilitate that demographic interaction (see appendices $\mathrm{O}$ and $\mathrm{P}$ ).

Allendorf, F., and R. Leary. 1986. Heterozygosity and fitness in natural populations of animals. Pages 57-76 in M. Soule, ed. Conservation biology: The science of scarcity and diversity. Sinauer Associates, Sunderland, Mass.

Belk, M. C., H. D. Smlth, and J. Lawson. 1988. Use and partitioning of montane habitat by small mammals. J. Mammol. 69:688-696.

Bengtsson, J. 1989. Interspecific competition increases local extinction rate as determined by a stand transect technique. Ecol. Monogr. 38:269-308. 


\section{Appendix N: Extinction}

Blocksteln, D., and H. Tordoff. 1985. Gone forever-a contemporary look at the extinction of the passenger pigeon. Am. Birds 39:845-851.

Brlttingham, M. C., and S. A. Temple. 1983. Have cowbirds caused forest songbirds to decline? BioScience 33:31-35.

Carey, A. B., J. A. Reld, and S. P. Horton. 1990. Spotted owl home range and habitat use in southern Oregon Coast Ranges. J. Wildl. Manage. 54:11-17.

Dawson, W. R., J. L. LIgon, J. R. Murphy, J. P. Myers, D. SImberioff, and J. Verner. 1986. Report of the advisory panel on the spotted owl. Audubon Conserv. Rep. 7. 47pp.

Ehrilch, P. R., A. H. Ehrilch, and J. P. Holdren. 1970. Ecoscience: Population, resources, and environment. W. W. Freeman, San Francisco. 1052pp.

Ehrlich, P. R., D. D. Murphy, M. C. Singer, C. Sherwoud, R. R. White, and I. L. Brown. 1980. Extinction, reduction, stability, and increase: The responses of checkerspot butterfly populations to the California drought. Oecolgia 46:101-105.

Forsman, E. D., E. C. Meslow, and H. M. Wight. 1984. Distribution and biology of the spotted owl in Oregon. Wildl. Monogr. 87:1-64.

Getz, L. L. 1965. Humidities in vole runways. Ecology 46:548-550.

Gllbert, L. E. 1980. Food web organization and conservation of neotropical diversity. Pages 11-34 in M. Soulé and B. Wilcox, eds. Conservation biology: An evolutionary-ecological approach. Sinauer Associates, Sunderland, Mass.

Halllday, T. 1978. Vanishing birds: Their natural history and conservations. Holt, Reinhart, and Winston. New York. 296pp.

Harrls, L. D. 1988. Edge effects and conservation of biotic diversity. Conserv. Biol. 2:330-332.

Hoffman, R. S. 1984. Small mammals in winter: The effects of altitude, latitude, and geographic history. Pages $9-23$ in J. F. Merrit, ed. Winter ecology of small mammals. Spec. Publ. Carnegie Mus. Nat. Hist. 10.

Karr, J. R. 1982. Avian extinction on Barro Colorado Island, Panama: A reassessment. Am. Nat. 119:220-239.

Lande, R. 1988. Genetics and demography on biological conservation. Science $241: 1455-1460$.

Ledig F. 1986. Heterozygosity, heterosis, and fitness in outbreeding plants, Pages 77-104 in M. Soulé, ed. Conservation biology: The science of scarcity and diversity. Sinauer Associates, Sunderland, Mass. 


\section{Appendix N: Extinction}

Lovejoy, T. E., R. O. Blerregaard, Jr., A. B. Rylands, J. R. Malcolm, C. E. Qulntela, L. H. Harper, K. S. Brown, Jr., A. H. Powell, G. V. N. Powell, H. O. R. Schubart, and M. B. Hays. 1986. Edge and other effects of isolation on Amazon Forest fragments. Pages 257-285 in M. Soulé, ed. Conservation biology: The science of scarcity and diversity. Sinauer Associates, Sunderland, Mass.

Maser, C., B. R. Mate, J. F. Franklin, and C. T. Dyrness. 1981. Natural history of Oregon coast mammals. U.S. For. Serv., Gen. Tech. Rep. PNW-133. Portland, Oreg. 496pp.

Matthlae, P. E., and F. Stearns. 1981. Mammals in forest islands in southeastern Wisconsin. Pages 55-66 in R. L. Burgess and D. M. Sharpe, eds. Forest island dynamics in man-dominated landscape. Springer Verlag, New York.

May, R. 1986. The cautionary tale of the black-footed ferret. Nature 320:13-14.

Murphy, D. D., and S. B. Welss. 1988. Ecological studies and the conservation of the bay checkerspot butterfly, Euphydryas editha bayensis. Conserv. Biol. 46:183-200.

Palne, R. T. 1966. Food web complexity and species diversity. Am. Nat. 100:65-75.

Ralls, K., P. Harvey, and A. Lyles. 1986. Inbreeding in natural populations of birds and mammals. Pages 35-56 in M. Soulé, ed. Conservation biology: The science of scarcity and diversity. Sinauer Associates, Sunderland, Mass.

Ranney, J. W., M. C. Bruner, and J. B. Levenson. 1981. The importance of edge in the structure and dynamics of forest islands. Pages 67-95 in R. L. Burgess and D. M. Sharpe, eds. Forest island dynamics in man-dominated landscapes. Springer Verlag, New York.

Shaffer, M. L. 1981. Minimum population sizes for species conservation. BioScience 31:131-134.

Sjorgen, P. 1988. Metapopulation biology of Rana lessonae on the northern periphery of its range. Ph.D. Dissertation. Uppsala University, Sweden.

Smith, A. T. 1980. Temporal changes in insular populations of the pika (Ochotona princeps). Ecology $61: 8-13$.

Soulé, M. E., D. T. Bolger, A. C. Alberts, J. Wright, M. Sorlce, and S. HIII. 1988. Reconstructed dynamics of rapid extinctions of chaparral-requiring birds in urban habitat islands. Conserv. Biol. 2:75-92.

Tanner, J. T. 1942. The ivory-billed woodpecker. Natl. Audubon Soc. Res. Rep. 1. $111 \mathrm{pp}$.

Temple, S. A., and J. R. Cary. 1988. Modelling dynamics of habitat-interior bird populations in fragmented landscapes. Conserv. Biol. 2:340-347. 
Terborgh, J. 1974. Preservation of natural diversity: the problem of extinction prone species. BioScience 24:715-722.

Terborgh, J. 1988. The big things that run the world-a sequel to E. O. Wilson. Conserv. Biol. 2:402-403.

Terborgh, J., and B. Winter. 1980. Some causes of extinction. Pages 119-133 in M. Soulé and B. A. Wilcox, eds. Conservation biology: An ecological-evolutionary approach. Sinauer Associates, Sunderland, Mass.

Thomas, J. A. 1976. The ecology of the large blue butterfly, Annu. Rep., Inst. for Terrest. Ecol. 11:25-27.

Weiss, S. B., D. D. Murphy, and R. R. White. 1988. Sun, slope, and butterflies: topographic determinants of habitat quality for Euphydryas editha. Ecology 69:1486-1496.

Whitaker, J. O., Jr. 1980. The Audubon Society field guide to North American mammals. Chanticleer Press, New York.

Whitcomb, R. F., J. F. Lynch, P. A. Opler, and C. S. Robbins. 1976. Island biogeography and conservation: Strategies and limitations. Science 193: 1030-1032.

Whitcomb, R. F., C. S. Robbins, J. F. Lynch, B. L. Whitcomb, M. K. Klimklewicz and B. Bystrak. 1981. Effects of forest fragmentation on avifauna of the eastern deciduous forest. Pages 125-205 in R. L. Burgess and D. M. Sharpe, eds. Forest island dynamics in man-dominated landscapes. Springer Verlag, New York.

Wilcove, D. S. 1985. Nest predation in forest tracts and the decline of migratory songbirds. Ecology 66:1211-1214.

Wilcove, D. S., C. H. McLellan, and A. P. Dobson. 1986. Habitat fragmentation in the temperate zone. Pages 237-256 in M. Soulé, ed. Conservation biology: The science of scarcity and diversity. Sinauer Associates, Sunderland, Mass.

Wilils, E. D. 1974. Populations and local extinctions of birds on Barro Colorado Island, Panama. Ecol. Monogr. 44:153-169.

Yahner, R. H. 1988. Changes in wildlife communities near edges. Conserv. Biol. 2:333-339. 


\section{A Rationale for the Size and Spacing of Habitat Conservation Areas for Spotted Owls}

Introduction
The literature of conservation biology describes many examples where the fragmentation of formerly widespread, terrestrial habitats into remnants of various sizes and degrees of isolation has resulted in the extinction of bird species from blocks of remaining habitat. Examples include alpine habitats in the northern Andes (Vuilleumier 1970), Barro Colorado Island in the Panama Canal Zone (Karr 1982, Willis 1974), New Zealand forests (Diamond 1984a, Williams 1981), Brazilian forests (Lovejoy et al. 1984, Willis 1980), the eastern deciduous forests of the United States (Forman et al. 1976, Whitcomb et al. 1981), Java woodlands (Diamond et al. 1987), and chaparral habitats in San Diego County, California (Soulé et al. 1988). The last example is especially interesting because it involved urban spread throughout once extensive stands of native chaparral vegetation.

Residential and other urban landscaping would seem to provide convenient and reasonably safe avenues of dispersal for chaparral-dependent birds to move between remnant patches of chaparral. As the work by Soule and his colleagues shows, however, the distance between isolated patches of chaparral does not help to explain variation in the number of nonmigrant, chaparral-dependent species. Patch area (therefore, size of the original populations isolated) and the age since isolation explain most of the variation in numbers of chaparral-dependent species remaining in the patches. The vulnerability of a given species to local extinction was primarily explained by its original abundance in a patch and by its body size. Small populations disappeared at a high rate, and large-bodied birds were less extinction prone than small-bodied birds (as in the study by Pimm et al. 1988, described below). Soulé et al. conclude that virtually all chaparral-dependent species that exhibit little tendency to cross other habitat types are on an inevitable trajectory to extinction in the isolated patches of chaparral studied.

Recent focus on the role of habitat blocks in conservation biology has sparked much debate, discussion, and speculation. No specialist in the field, however, would dispute that habitat blocks should be a key component of a conservation strategy to assure the long-term persistence of a given species that is subject to widespread, systematic reduction in the amount of its suitable habitat. Much of the debate has focused on the "SLOSS" issue-whether a "single large or several small" blocks totaling the same area would be better for a reserve design (Diamond 1976, Simberloff and Abele 1976a, 1976b, 1982; Terborgh 1976, Whitcomb et al. 1976; see Shaffer and Samson 1985 for a recent summary). To the extent that the issue has focused on maintaining some amount of species richness in a region, we believe it has little relevance to the matter at hand. Our objective is to design a conservation strategy that assures 


\section{Appendix O: HCA Size and Spacing}

the persistence of a single species-the spotted owl. Although certain lessons can be learned from evidence marshalled for this debate, our challenge is not one of enhancing species richness in Pacific Northwest forests. Our challenge is to design an arrangement of habitat conservation areas (HCAs) specifically for spotted owls, accounting for their densities, reproductive biology, dispersal capabilities, and so on.

Those aspects of the SLOSS debate, and of island biogeographic theory in general, that bear on the spotted owl issue deal with the likelihood of local extinction in relation to the sizes of habitat islands (thus potential population sizes) and the distances separating islands. Diamond (1975) proposed several design criteria from island biogeographic theory that are relevant here. Although Diamond's concepts stemmed from an objective of maintaining or increasing species richness, the fundamental principles seek to minimize the risk of extinction for all sorts of species. Thus, the same general principles apply to all species but "different species require different minimum areas to have a reasonable chance of survival" (Diamond 1975:129). The fundamental difference between examples from true oceanic islands, and "islands" of different types of habitat in an extensive landscape, has to do with dispersal events. Transoceanic dispersal by land birds is more risky than dispersal across a landscape where opportunities exist to stop, rest, and forage (see Wiens 1989 for further discussion of this point).

Designing a

Conservation Strategy
The challenge for anyone designing a conservation strategy for a single species is to reconcile an ideal strategy with the real world. For spotted owls in the Western United States, habitat exists in a hodge-podge of gaps, troughs, and peaks in both distribution and abundance created by geographic, edaphic, topographic, climatic, and human-induced variety on the landscape. Once standards and guidelines have been devised for the ideal size and spatial arrangement of HCAs, we must then fit them as best we can to those real-world constraints.

The final size of a population provided by a conservation strategy is important, but it is not the only consideration. For example, most of Hawaii's endangered bird species now occupy less than $10 \%$ of their former range, even though a few have total populations estimated between 1000 and 10,000 . But most of the nonendangered forest birds in Hawaii occupy more than $10 \%$ of their former range, and some of those populations are estimated between 100 and 1000 birds (Scott et al. 1988). We believe that a population of 3000 spotted owl pairs with one type of habitat distribution and structure could easily be less viable than a population of 1500 pairs in a habitat with different distribution and structure. Studies of efforts to reintroduce species into native areas from which they have been extirpated indicate that several factors affect the likely persistence of release populations (Griffith et al. 1989). Among these factors, the number of animals released (population size), and habitat quality in the release site, are points to consider in developing a conservation strategy for spotted owls. 


\section{Appendix O: HCA Size and Spacing}

General Guidelines

Once the strategy provides habitat for some number of pairs with a reasonably high chance of long-term persistence, other elements of the strategy may become more important than increasing total population size. These elements include the extent of geographic distribution, the spacing of breeding units, and the provision of sufficient habitat (see appendix F) to assure successful breeding. A successful strategy also requires assuring that dispersing juveniles have a high probability of locating and filling vacancies created by deceased territory holders, assuring that local distributions foster successful population dynamics, and assuring that social interactions vital to a population's success can take place. The point is that, once these elements are assured, populations in a wide range of sizes can have an excellent chance of persisting well into the future.

Diamond offers some general guidelines for a conservation strategy. In general, we concur with them and believe they are consistent with recommendations by Harris (1984) and Noss and Harris (1986). We have outlined these guidelines below, with additional guidelines suggested from the work of den Boer (1981) and Wilcove et al. (1986). We believe the first five guidelines are equally and vitally important to a conservation strategy for spotted owls. But we have been mindful, as well, of the messages imparted by the remaining three.

- We begin by adding to Diamond's list den Boer's (1981) notion of spreading the risk. Ideally, blocks of habitat should be dispersed in a pattern corresponding to a species' full geographic distribution. This distribution is the key hedge against major catastrophes that could otherwise extinguish the sole remaining population of a once wide-spread species, as happened to the heath hen (see appendix $\mathrm{N})$. This provision is assured for the spotted owl because regulations pursuant to the National Forest Management Act require it. (It also presents a potential conflict with the guideline below to aggregate available areas into fewer large blocks, as opposed to many small ones.)

- Large blocks of habitat are better than small ones. We agree.

- Problems associated with fragmentation and edge effects (for example, Wilcove et al. 1986) indicate that blocks of contiguous habitat are better than loose aggregations of fragmented blocks. We agree.

- Blocks close together are better than blocks far apart. We agree. The distance between blocks must be well within the known dispersal capability of the species in question.

- Habitat between blocks should be suitable for movement and short stopovers by the species under consideration, to facilitate dispersal of juveniles (and adults) among blocks. We agree (see appendix P).

- The total area available for a reserve system should be divided into as few small blocks as possible (a corollary to "big blocks are better"). We generally agree, but fully implementing this guideline compromises the need to distribute blocks widely over a species' range. 


\section{Appendix O: HCA Size and Spacing}

\section{Population Size, Density, and Local Extinction}

- Separate habitat blocks should be grouped equidistant from each other, in contrast to a linear distribution. We agree, but the generally linear arrangement of the spotted owl's present geographic distribution imposes limits on our attaining this ideal.

- Habitat blocks should be as nearly circular as possible to minimize dispersal distances within them. This guideline may be true in an unrealistic world without topography and physiography. Realities of terrain and habitat, however, may also influence internal dispersal behavior. For instance, delineation of a single watershed, even if somewhat oblong, may be a superior strategy to a circle. And in a comprehensive set of reserves, occasional linear blocks, strategically situated, might increase the chance of "capturing" birds dispersing from other blocks. Whether this potential benefit would compensate for the lowered efficiency of within-block dispersal, in the long term, is unknown.

In sections that follow, we attempt to develop some of the specifics needed to apply these guidelines. And because the conservation strategy we propose departs so markedly from the one presently in place for spotted owls (the network of SOHAs), we also compare and contrast these alternatives.

Under present planning guidelines, single pairs of owls are provided for by SOHAs (appendix C). Without exception, empirical studies of the longevity of isolated populations show that those with fewer than two breeding pairs "wink out" (are subject to local extinction) at an unacceptably high rate (recent review in Diamond 1984b). Once stability is reached in the SOHA network (that is, most other available habitat has been made unsuitable for spotted owls, and the remaining population exists in units of one or two pairs), the rate of local extinction will inevitably be too high to assure long-term persistence.

Given that "bigger is better" in terms of habitat area and population size, what is big enough? Because their model did not factor in environmental stochasticity, we disagree with the conclusion by Richter-Dyn and Goel (1972) that, in a population with demographic attributes tending to favor population increase, once a critical population size of about 20 individuals (only 10 pairs) is attained, "extinction is very unlikely" and "expected persistence time immensely long." Empirical data and theoretical modeling indicate, however, that habitat blocks with as few as 15 to 20 pairs have a relatively low probability of winking out (see appendix M). We believe this low probability would hold for a system that includes many such habitat blocks separated by distances and connected by habitat features consistent with the known dispersal tendencies and capabilities of the target species (see appendix P). Indeed, we believe that such an arrangement of large habitat blocks probably functions more like a single, interacting population, than as isolated subpopulations. Haila and Hanski (1984) reached a similar conclusion, suggesting that the effective areas of habitat blocks are increased when birds can move between them with relative ease. Haila and Hanski contend that it may be more appropriate to regard the entire "archipelago" of patches as the habitat block.

Because the size of a population assured by an HCA is among the most important determinants of long-term population maintenance, we have summarized the key studies that examine persistence times in relation to population size. 


\section{Appendix O: HCA Size and Spacing}

Empirical Evidence
Southern (1970)_A study of tawny owls in Wytham Woods, near Oxford, England, began with a population of 17 pairs in 1947, after an unusually severe winter (Southern 1970). The population increased slowly during ensuing years, reaching 30 pairs in 1955 and 31 or 32 pairs in each year thereafter, until the study ended in 1959. Wytham Woods is part of an old estate about 4 miles northwest of Oxford, generally in an area of farmland. We have not been able to determine how far the area is from other subpopulations of tawny owls, however, or how large those subpopulations may be.

Jones et al. (1976)-Jones et al. (1976) reported on bird populations on the Channel Islands, off the coast of southern California, which range from 32 to 157 miles from the mainland. From figure 6 in Jones et al., we estimate that over a period of nearly 100 years of bird surveys there, extinction rates were about $10 \%$ for populations of 37 pairs, about $15 \%$ for populations of 20 pairs, and about $20 \%$ for populations of 12 pairs. These rates of extinction are slightly higher than indicated in the British islands reported in the next three studies below. This difference almost certainly reflects the smaller role of a "rescue effect" (immigrants entering a population at a rate high enough to slow or overcome extinction events-Brown and Kodric-Brown 1977) in the Channel Islands because they are much farther from the mainland than the British islands.

Diamond and May (1977) - A tabulation of bird censuses (Diamond and May 1977) on the Farne Islands (total area 79 acres, situated 3.1 miles from the mainland of Britain) reports on an uninternupted series of 29 years-1946 to 1974 (28 betweenyear intervals). Data are given for all species $(n=16)$ of land birds breeding on the islands. Considering the four large-bodied, nonmigrant species (see justification below, in summarization of Pimm et al. 1988), only the ringed plover persisted through the full period of the censuses. Its mean population size was 13 pairs. The moorhen was present as a single pair in 1947 and 1948. The stock dove occurred as a single pair in 1946 and 1972. A single pair of jackdaws was also present in 1949, and two pairs were present in 1964, 1965, and 1966. These findings indicate that a conservation strategy based on single-pair reserves should have limited success in assuring local persistence of a species.

Diamond (1984b)-Diamond (1984b) reported bird censuses over a period of 16 years (1954 to 1969-15 between-year intervals) on Bardsey Island, 445 acres and 3.1 miles from the coast of Britain. Again, looking only at the record for large-bodied, nonmigrant species (table O1), species with mean population sizes of $<2$ were present in only 3 of 16 years, but all others were present through all 16 years of the study, even those species that have population means of less than five pairs. Several of the species present in all years are capable of lengthy dispersal but are not necessarily inclined to cross a substantial water gap. Consequently, we cannot judge the extent to which persistence of these species resulted from population maintenance on the island, as opposed to rescue by immigrants from the mainland. 


\section{Appendix O: HCA Size and Spacing}

Tabie 01-Persistence of large-bodled, nonmigrant birds on Bardsey island from 1954 to 1969 (Diamond 1984b)

\begin{tabular}{llrrrr}
\hline & & \multicolumn{4}{c}{ Pairs present } \\
\cline { 3 - 6 } Species & Years present & Mean & SD & Min & Max \\
\hline Sparrowhawk & $1954,1955,1956$ & 1.0 & 0 & 1 & 1 \\
Moorhen & All & 3.5 & 2.3 & 1 & 8 \\
Ringed plover & 1968,1969 & 1.0 & 0 & 1 & 1 \\
Wood pigeon & $1966,1968,1969$ & 1.3 & 0.6 & 1 & 2 \\
Little owl & All & 4.8 & 1.3 & 3 & 7 \\
Raven & All & 2.3 & 1.5 & 1 & 3 \\
Carrion crow & All & 4.9 & 1.2 & 3 & 7 \\
Jackdaw & All & 30.1 & 15.9 & 20 & 50 \\
Chough & All & 2.7 & 1.0 & 1 & 4 \\
\hline
\end{tabular}

${ }^{a}$ Means are computed only for years when pairs were present on the island; that is, populations of zero were not considered.

Pimm et al. (1988)-Pimm et al. (1988) give empirical estimates of extinction rates of land birds, using data from consecutive annual censuses of bird populations on 16 islands off the coast of Britain (mean area $=0.96$ square mile, $S D=0.86$, range $=$ 0.03 to 3.0; mean distance from mainland $=4.4$ miles, $S D=6.9$, range $=0.6$ to 28 ). Data from Diamond and May (1977) and Diamond (1984b) were included to generate more robust estimates of times to extinction. Censuses covered many years, and on some islands many decades, to a maximum of 70 years (Pimm, pers. comm.). The shortest set of consecutive censuses covered 13 years and the longest 39 (Diamond and May 1977). Four conclusions apply to the development of a conservation strategy for spotted owls: The rate of extinction is largely explained by mean population size, declining sharply with larger populations; extinction rates are lower for resident birds than for migrants; extinction rates of small and large birds differ significantly; and rates of extinction increase with increasing annual variation in population size.

Because the spotted owl is nonmigratory over most of its range in Washington, Oregon, and northern California, and because it is a large-bodied species by the criteria of Pimm et al., we have used the appropriate subset of their data for our analyses.

Based on our own analyses of those data, a linear regression model best described the relation between population size and persistence in the British data (table $\mathrm{O} 2$ ). For a large-bodied, nonmigratory bird species, the model indicates an average persistence time of 2 years for populations with fewer than 2 pairs, about 25 years for a population of 10 pairs, and about 50 years for one of 20 pairs (table 03 ).

Another way to look at the data is through the frequency of recorded extinctions in relation to mean population size (table 04 ). Note that $76 \%$ of populations with fewer than 2 pairs became extinct in the study period; $40 \%$ of populations including 2 to 5 pairs did so; $21 \%$ of nine populations of 6 to 10 pairs became extinct; and none of the seven populations with 11 to 16 pairs did so. 


\section{Appendix O: HCA Size and Spacing}

Table 02-Three regresslon models describlng results in Pimm et al. (1988) from studles of extinctlon events on 16 islands around Britaln (pertalns only to large-bodied, nonmlgrant birds)

\begin{tabular}{llc}
\hline Model & Regression equation & Probability \\
\hline $\begin{array}{l}\text { Linear } \\
\begin{array}{l}\text { oog-transformation } \\
\text { of persistence time }\end{array}\end{array}$ & $T=-0.56+2.54 \mathrm{~N}$ & 0.008 \\
$\begin{array}{l}\text { Second-degree } \\
\text { polynomial }\end{array}$ & $\mathrm{T}=3.86 \mathrm{e}^{0.174 \mathrm{~N}}$ & 0.023 \\
\hline
\end{tabular}

Table 03-Projected extinction times (years) from models in the prevlous table, In relation to mean popuiation slze for large-bodled, nonmigrant birds

\begin{tabular}{lrrrrrrr}
\hline & \multicolumn{7}{c}{ Mean population size } \\
\cline { 2 - 8 } Model & 1 & 3 & 5 & 7 & 10 & 15 & 20 \\
\hline Linear & 2 & 7 & 12 & 17 & 25 & 38 & 50 \\
$\begin{array}{l}\text { Log-transformation } \\
\text { of persistence time }\end{array}$ & 5 & 7 & 9 & 13 & 22 & 52 & 125 \\
$\begin{array}{l}\text { Second-degree } \\
\text { polynomial }\end{array}$ & 3 & 6 & 10 & 14 & 23 & 41 & 66 \\
\hline
\end{tabular}

Table 04-Extinction rate as a function of mean population size In large-bodied, nonmigrant birds (based on data in Pimm et al. 1988)

\begin{tabular}{lccc}
\hline $\begin{array}{l}\text { Number } \\
\text { of pairs }\end{array}$ & $\begin{array}{c}\text { Number } \\
\text { of cases }\end{array}$ & $\begin{array}{c}\text { Number of } \\
\text { extinctions }\end{array}$ & Percent \\
\hline$<2$ & 42 & 32 & 76.2 \\
$2-5+$ & 37 & 15 & 40.5 \\
$6-10+$ & 9 & 2 & 22.2 \\
$11-15+$ & 5 & 0 & 0.0 \\
16 & 2 & 0 & 0.0 \\
\hline
\end{tabular}

These estimates came from true islands separated from the mainland by water, so dispersal of land birds from the mainland might occur at a lower frequency than dispersal between two mainland "islands" of habitat with patches and stringers of suitable movement cover between them (as would be true for a set of HCAs for spotted owls). On the other hand, the mean distance of the islands from the mainland in the study by Pimm et al. was only 4.2 miles, and six of the islands were within 1.2 miles of the mainland. These distances probably do not constitute a barrier for many species of land birds. The rescue effect probably plays a significant role in the dynamics of the British island situation. Whether these data overestimate or underestimate the true rate of extinction of large-bodied, nonmigrant birds from island habitats, they are among the best data available on this question. 


\section{Appendix O: HCA Size and Spacing}

Walter (unpubl. ms.)-On Socorro Island, about 285 miles SSE of the southern tip of Baja California, the Socorro Island red-tailed hawk population has numbered between 15 and 25 pairs per year for the past 20 to 25 years (Walter, unpubl. ms.; also see Jehl and Parkes 1982). Walter believes that the population is at or near carrying capacity, so its numbers have probably not been much greater at any time in recent history.

Significantly, the Socorro Island hawks are sufficiently distinct from mainland populations of red-tailed hawks to be described as an endemic subspecies (see Friedmann 1950). It is markedly melanistic, although not distinctly so from a mainland subspecies, but it has distinctly more robust legs and feet (Jehl and Parkes 1982). Although this differentiation may have resulted from the founder effect, it nonetheless suggests a long tenure of this population on Socorro Island. This example is not offered as evidence that such small populations can routinely be expected to persist for decades or centuries. We agree with Walter (unpubl. ms.) that this is not generally true. But this population has apparently survived a genetic bottleneck and persisted for a long time, with an average population size of about 20 pairs.

Dennls et al. (unpubl. ms.)- Other examples of small populations without access to rescue effects, but which have persisted for long periods of time, are reported by Dennis et al. (unpubl. ms.). For example, the whooping crane population in North America was estimated at 18 birds in 1938. The population fluctuated about that number for nearly 2 decades, when it slowly began to increase in the early 1960 s. This preceded serious conservation efforts to save whooping cranes. Puerto Rican parrots numbered in the low 20s in 1968, declined to fewer than 15 birds in the early 1970 s, and then slowly began to increase during the early 1980s, in response to heroic conservation efforts. (We have not yet learned of the full effect of a recent hurricane on Puerto Rican parrots, but the incident emphasizes our concern for spreading the risk by distributing a species widely throughout its range.) As with the Socorro Island red-tailed hawk, we consider these cases anomalous. Were either of these species' populations fortified by other subpopulations with which they could interact demographically, the outlook for both species would undoubtedly be brighter.

Ganey and Fletcher (pers. comm.)-Many populations of spotted owls in Arizona and New Mexico occur in relatively isolated mountain ranges, sometimes separated by wide expanses of Sonoran desert or other nonforested lands. Excerpts from a letter from Ganey (14 February 1990) follow: "The distributional pattern of spotted owls in southern Arizona remains incompletely known, the extent of suitable habitat per mountain island is unknown, and densities in different islands of habitat are unknown. What is clear about this region is that spotted owls are widely distributed throughout these mountain islands. Some...are large, appear to contain lots of suitable habitat, and probably support populations of greater than 30 pairs each. Others... are relatively small, and probably support only a few pairs. It is hard to envision stable, self-supporting populations in some of the smaller ranges. Therefore, I believe that dispersal must occur between these islands, although this has not been documented... Spotted owls may also find the lowlands between islands less hostile than I once thought. In recent years...[we have obtained] a number of verified occurrences of owls in these lowlands between November and April." 


\section{Appendix O: HCA Size and Spacing}

Modellng Results

We can draw only limited inferences from the spotted owl situation in the Southwest. First, we lack good data on population sizes and the distances between populations. Second, the spotted owl in Arizona and New Mexico is a different subspecies that has evolved in a different milieu from that in the conifer forests of the Pacific Northwest. The dispersal behavior of the northern spotted owl evolved over millenia in relatively continuous expanses of conifer forest. The Mexican spotted owl evolved in a landscape containing massive visual cues to the locations of suitable habitatmountain tops. But at least this case shows that one subspecies of spotted owls can maintain relatively small subpopulations in isolated mountain ranges, probably through rescue effects from larger populations many miles distant.

Shaffer and Samson (1985)-Setting an arbitrary criterion of $95 \%$ probability of persistence of the Yellowstone grizzly bear population for 100 years, Shaffer and Samson (1985) ran 50 simulations of population persistence for 100 years. They used "a discrete time, discrete number formulation employing the sex and age structure, mortality and reproductive rates, and density-dependent relationships" from an independent study by Craighead et al. (1974) with 12 years of data on grizzly bears in Yellowstone. Environmental and demographic stochasticity were introduced into the model.

Because the model assumed a homogeneous habitat - that is, no barriers to dispersal-and did not attempt to deal with catastrophes, it probably underestimates the probability of extinction. On the other hand, the model assumed a closed population, precluding a rescue effect. Populations benefiting from rescue effects would be expected to have lower extinction rates than those indicated by Shaffer and Samson's model. How these various factors would balance out is anyone's guess at this time. We present results of the grizzly bear models, however, as part of the information considered to arrive at a decision about the number of pairs needed in individual HCAs for spotted owls.

All 50 initial populations of 10 individual grizzly bears became extinct within 100 years, 32 populations of 20 individuals became extinct, 13 populations of 30,3 populations of 40 , and 1 population of 50 initial populations of 50 individuals became extinct. These results suggest that some number of grizzly bear pairs between 20 and 25 met the criterion of $95 \%$ confidence that a population would still be extant after 100 years.

Lamberson et al. (unpubl.) and additlonal modeling by our team-Details of simulations by Lamberson et al. (unpubl.) are given in appendix $M$ (especially see figs. M15, M16, and M17). Model parameters were based on estimated vital rates of the northern subspecies, integrated spatial distribution of blocks of habitat, dispersal parameters believed to be reasonable for spotted owls, and demographic and environmental stochasticity. Hundreds of simulation runs suggest that a system of HCAs containing somewhere between 15 and 20 pairs, with moderately effective betweenblock dispersal, shows marked persistence over a 100-year simulation period. 


\section{Appendix O: HCA Size and Spacing}

Dispersal

The study by Soule et al. (1988), briefly described above, emphasized the critical need for a conservation plan to assure that the species be able to move readily among blocks of suitable habitat. Without the availability of dispersal routes, populations supported by habitat blocks must be self-sustaining-an unlikely event in all but exceptionally large blocks that are capable of sustaining very large populations. The current management plan for spotted owls on Federal lands in Washington, Oregon, and California is based on a "network" of SOHAs, each intended to provide sufficient habitat for a single pair of owls to survive and reproduce (although some SOHAs may, in fact, provide for more than one pair-probably rarely more than two). SOHAs are dispersed across landscapes of National Forests and BLM Districts at distances typically ranging from 6 to 12 miles. This spacing assumes that dispersing juveniles (or displaced adults) will be able to locate suitable habitat for breeding in SOHAS vacated by death or emigration of former residents. The SOHA network has been widely criticized by conservation biologists as inadequate, but before suggesting an alternative approach we need to evaluate whether the network system is flawed in terms of dispersal. We believe it is, for at least two reasons.

First, as the SOHA system stabilizes (that is, as the surrounding landscape matrix is converted to younger-aged forests), spotted owls will be required to disperse across increasingly longer gaps of unsuitable or marginally suitable habitat. This decrease in the quality of this matrix makes it more and more imperative that dispersing owls quickly locate a SOHA. Second, we believe isolated SOHAs will markedly reduce the ability of dispersing individuals to locate suitable mates (the Allee effect). If the SOHA already has a breeding pair, a newcomer will not be able to establish a breeding territory there. If it has only one spotted owl in it when the newcomer arrives, that owl must be of the opposite sex for any chance of the newcomer's settling to breed. And if the SOHA is unoccupied when the newcomer arrives, it may be a long time before another newcomer of the opposite sex finds the same SOHA.

A system of HCAs has at least three dispersal advantages over SOHAs. First, it provides for turnover events based on internal recruitment and dispersal within each HCA (related to the point on floaters, below). We already know that this phenomenon occurs in relatively large, continuous populations of spotted owls (Franklin et al. 1989). Second, it enhances dispersal between HCAs because the very size of an HCA makes it more likely to be "hit" by a bird dispersing from another locality (see discussion of this point in Diamond 1984b). Furthermore, some purposeful arrangement of HCAs can be implemented to increase the likelihood of a dispersing bird encountering it, such as arranging oblong HCAs with their long dimension extending a substantial distance east-to-west or north-to-south. Third, if spotted owls tend to vocalize more frequently when in relatively dense populations than when isolated from other pairs, and if dispersing birds respond to calls of other owls to help guide them to suitable habitat, HCAs are more likely than isolated SOHAs to attract dispersers. 


\section{Appendix O: HCA Size and Spacing}

Pertinent vocalization phenomena have been shown in several bird species. Boag (1976) reported that "the establishment of ruffed grouse territories is not entirely in response to availability of potentially acceptable vegetation." His results suggested a "form of social interaction between established and establishing birds." With increased clumping of birds on perennial sites, yet more birds were attracted, leading to higher drumming rates, so that social interaction within the population increased with density. Similarly, Gochfeld (1978) found that the number of flight songs per male per minute was linearly related to group size in the pampas meadowlark. Kroodsma and Verner (1978) found that sedge wrens sang at a higher rate, and for a greater percentage of the time when a neighbor was singing, than when the neighbor was silent. Such behavior, called "countersinging," is widespread among birds. The result tends to be a self-accelerating generation of active vocalization by members of a population, as the songs and calls effectively enlarge the "detectable boundary" of a suitable habitat patch for birds seeking a potential territory. This added detectable boundary is equal to the audible range of the songs and calls produced. Such cues will be produced more continuously by a group than by a single bird or pair of birds, increasing the likelihood that a searching bird passing by will hear a cue. Although vocal cues of this sort do not assure that a searching bird will find an unoccupied territory, we believe they increase that chance.

The benefits of this auditory effect are minimal at best in a system of SOHAs capable of supporting single pairs. Only if an owl is established in a SOHA will calling have any chance of attracting another bird, because calls obviously will not emanate from vacant SOHAs capable of supporting only a single pair of birds. The irony is that an available but empty SOHA will lack any kind of vocal cue to its location.

Fragmentation and Edge Effects
Fragmentation and edge effects are a major concern for species threatened with the systematic removal of suitable habitat (see appendix N). Present evidence convinces us that fragmentation of homogeneous forest tracts tends to be accompanied by lowered spotted owl densities (see, for example, appendix $\mathrm{H}$ ). It also increases the vulnerability of remaining stands to windstorms. The relatively small size of SOHAs results in a high ratio of edge to habitat area, worsening problems of fragmentation and edge effects. But even more serious is the fact that SOHAs are themselves internally fragmented into smaller blocks of suitable habitat that further increase the ratio of edge to area. This condition would increase all detrimental effects of fragmentation, and might increase competition with barred owls and predation by great horned owls (see section on competition and predation, below; also appendix N).

On the other hand, HCAs, unfragmented by timber harvesting, would provide a significant hedge against fragmentation effects, at least at a scale of several square miles. Of course the full benefit will not be realized until already fragmented forests in proposed HCAs have regenerated. 


\section{Appendix O: HCA Size and Spacing}

\author{
Predation and \\ Interspecific \\ Competition
}

\section{Catastrophes}

The issues of predation on spotted owls, especially by great homed owls, and interspecific competition with barred owls, have surfaced repeatedly during the past decade or so (review in Hamer 1989). In each case, the expressed concern is that fragmentation, and the increasing extent of edges, favor the great horned and barred owls, and probably bring them into closer contact with spotted owls. Although these concerns have not been substantiated (see Hamer 1989), neither is easily researched. If either or both of them do have substance, however, the creation of large blocks of habitat as envisioned in the HCAs should lessen the effects of fragmentation and edges on spotted owls compared to SOHAs.

Catastrophes come in different sizes, as for example in the form of local to widespread droughts, small fires to major conflagrations, localized high winds to extensive and powerful storms, and so on. Habitat Conservation Areas offer some cushion against smaller, more localized catastrophes (see appendix N). Small fires, for example, could easily destroy entire SOHAs, or reduce the amount of suitable habitat in them to a point that they could no longer support a breeding pair of owls. Fires of the same size would have relatively little impact on an HCA of many square miles. We further believe that SOHAs, as presently configured with multiple patches of relatively small stands of forest, are particularly vulnerable to windstorms.

Careful planning and certain kinds of management within HCAs can lessen the negative consequences from events such as fire, insect infestations, and forest-tree diseases. We expect that certain types and intensities of prescribed fire fit that category. Elsewhere (appendix Q), we recommend the development of plans to reduce potential hazards from such events to HCAs. This recommendation is not a license to optimize planning for hazard reduction without regard for the needs of spotted owls within HCAs. But we do believe that opportunities exist to reduce such hazards without compromising the habitat value of HCAs for the owls.

Major catastrophes like the 1921 hurricane on the Olympic Peninsula, the extensive "Columbus Day storm" in Oregon in 1962, and the 1987 fires in California will affect extensive areas of the landscape regardless of HCA size. Local conservation planning cannot cope with the geographic scale of such catastrophes. Our hedge against such events causing regional extinction of the spotted owl is the widespread geographic distribution of HCAs recommended in this plan. Short of region-wide effects, such as a prolonged drought or global warming, major catastrophes tend to be on a scale that might destroy all or part of a single HCA or a number of SOHAs established in the same landscape. To that extent, the HCA system proposed here and the SOHA network system offer about the same amount of protection from major catastrophes. We can envision no system that is totally immune to major catastrophic events. We cannot control them, and we cannot guarantee security from them in any given conservation strategy that might be contrived for spotted owls. 


\section{Appendix O: HCA Size and Spacing}

\section{Providing for Floaters}

Number of Owls in Relation to the Amount of Suitable Habitat
Floaters are nonterritorial, nonbreeding birds generally considered surplus individuals or population reserves (Brown 1969). Their occurrence and dynamics are unquestionably among the most intractable aspects of avian ecology to study, because floaters in most species tend to remain silent and inconspicuous. Nonetheless, their existence among bird species is probably widespread in most or all populations at carrying capacity (for example, see Hensley and Cope 1951; Knapton and Krebs 1974; Krebs 1971; Rappole et al. 1977; Smith 1978, 1984; and Stewart and Aldrich 1951). Smith (pers. comm.) explains that floaters generally exhibit one of two divergent strategies. They form groups in suboptimal habitat (like the well-known case in red-winged blackbirds, Orians 1961) "...or they live singly and spend at least some time in areas defended as territories by owners. Owls would doubtless [sic] follow the latter strategy" (Smith, pers. comm.). Although no clear information is available on floaters in the northern spotted owl, studies of banded birds strongly suggest their presence (Forsman, pers. comm.; Franklin, pers. comm.)

The most intensive study of the general strategy, which Smith (pers. comm.) believes holds true for floaters in spotted owl populations, was undertaken in a population of rufous-collared sparrows in Costa Rica (Smith 1978). There, floaters "did not wander randomly; rather, they lived in well-defined, restricted home ranges within other birds' territories. Female home ranges were usually single territories; male ranges, usually three to four territories. Since range limits of both sexes coincide with territory boundaries, the net effect is two unique single-sex dominance hierarchies of floaters for each territory. When an owner dies, it is nearly always replaced very quickly by the dominant local [floater] bird of the appropriate sex." In a study of winter flocks of black-capped chickadees in Massachusetts, Smith (1984) reported similar dynamics among floaters. About $80 \%$ of the population remained in flocks with fixed home ranges, but $20 \%$ of the birds switched regularly among flocks. The surprising result was that when a high-ranking flock member disappeared during the winter, it was rapidly replaced by the dominant local floater of the appropriate sex-not by the next ranked regular flock member. Smith (1984) contends that 'the many similarities between chickadee flock switchers and [floaters among] rufous-collared sparrows suggest that complex organization among floaters may be widespread" among birds.

The HCAs proposed in this conservation strategy are more likely than SOHAs to include areas where floaters can persist, and these then serve as ready sources of replacements for birds that die or vacate their territories for other reasons (see comments on dispersal, above). We see little or no opportunity for such dynamics among floaters in single SOHAs. Indeed, we doubt that the SOHA system, when fully stabilized, would provide for floaters at all. In any event, if floaters are not integrated into populations of breeders, the rate at which deceased breeders are replaced by floaters would surely be significantly less than the rate in an HCA with many breeding pairs.

Single SOHAs need to provide sufficient suitable habitat for a single pair to breed successfully on a sustained basis. But isolated SOHAs cannot take advantage of the fact that neighboring owl pairs commonly share substantial portions of their home ranges. As a result, large HCAs should support more owl pairs in a given amount of suitable habitat than will numerous SOHAs that add up to the same amount. 


\section{Appendix O: HCA Size and Spacing}

\section{Social Facilitation}

\section{Monitoring}

\author{
Implementation
}

Social facilitation refers to the positive effects of interaction among animals in a population. Some studies (see Collias 1971) indicate that these effects markedly increase the likelihood, frequency, and success of pair bonding in birds. A manifestation of this effect, referred to in the above section on dispersal, is increased singing activity in a neighborhood of territorial male birds. If such a phenomenon plays a role in the breeding biology of spotted owls, it will be more effective in an HCA that includes many pairs than in an isolated SOHA with only one or two pairs.

We believe a strategy based on numerous, relatively large HCAs is amenable to a better and no more costly monitoring system than the one currently being used to monitor spotted owl occupancy in SOHAs (see appendix R). Start-up costs may be higher, however, to accomplish full inventories of spotted owls in the HCAs.

For several reasons, the arrangement of HCAs proposed in this plan would be markedly less complex to implement and manage than the current network of SOHAs. First, many fewer units are required and their large sizes allow better assessment of impacts and require less record-keeping to track them through time. Second, their boundaries can be more precisely delineated than those of SOHAs because they will not be subject to the timber-harvest activities that have created fragmented patches of suitable habitats in SOHAs. Third, standards and guides for HCAs will be simpler because future timber harvest will be excluded within their boundaries.

The distribution and arrangement of HCAs proposed in this plan will reduce one aspect of the well-distributed pattern of SOHAs in the current management scenario. On the one hand, at least in the short term, we expect the number of owl pairs now in the landscape matrix surrounding proposed HCAs to decline in abundance as the forest in that region is reduced. On the other hand, the total distribution of owls on a geographic scale should remain unchanged in the short term and should improve over the long term, as proposed HCAs (such as those in the Oregon Coast Range) develop forest conditions capable of supporting breeding owl populations. Furthermore, we believe that more owl pairs will be protected in proposed HCAs in the short term than the number now believed to be protected by SOHAs, and many more will be protected by HCAs in the long term (see appendix Q). On balance, the potential negative impacts of losing owls in areas between HCAs are most likely outweighed, by at least one order of magnitude, by the increased stability of populations within the HCAs.

We believe that most effects of increased owl density in the HCAs will have largely positive effects on population persistence, even though the potential rate of disease transmission is higher where more animals come into contact more frequently (Simberloff and Abele 1976a). We agree with Diamond (1976) that disease transmission is a trivial concern when weighed against the many advantages previously summarized. Predation might also increase in an area of higher density, but only if a given predator begins to specialize on spotted owls as a prey source. We consider this unlikely, given the fact that great horned owls and goshawks are probably the only species that occasionally prey on spotted owls. Goshawks tend to be prey generalists, taking a wide variety of birds; great horned owls prey more on mammals than on birds. In fact, we are more concerned about the likelihood that predation by great horned owls will increase in areas where the forest has been removed or thinned, because great horned owls are thought to be more abundant in less densely 


\section{Appendix O: HCA Size and Spacing}

forested habitats. As discussed previously, spotted owls are probably more secure from predation by great horned owls in undisturbed forests, especially those with multiple layers, where they have a better chance to outmaneuver an attacking great horned owl.

If a major catastrophic event should destroy an entire HCA, more pairs of owls would be lost than if the area had contained only widely dispersed SOHAs (see Simberloff and Abele 1976a). In either case, however, the event would create a worrisome increase in distance that owls would need to cross when dispersing through the area. We believe this disadvantage is more acute with SOHAs than with a system of larger HCAs. Again, the major advantage of having relatively stable breeding units in HCAs, in contrast to the highly extinction-prone SOHAs, far outweighs any potential advantage that SOHAs may offer in the event of a major catastrophe. Furthermore, as explained previously, SOHAs are much more vulnerable than large HCAs to complete destruction by smaller catastrophes at smaller geographic scales, which occur much more often than major ones.

Because proposed distances between HCAs are sometimes greater than distances between SOHAs, mammalian prey species of the spotted owl may not disperse as readily between them. First, we believe this would not happen, because the HCAs would be large enough that a dispersing small mammal would more likely encounter them than one of the few SOHAs scattered over the same area. Second, the proposed HCAs will be large enough to support viable populations of prey species. For example, studies indicate densities of flying squirrels of about one to two per acre (Carey, pers. comm.). Even a SOHA could be expected to have populations of a few thousand flying squirrels. Our proposed HCAs should have self-sustaining populations of all prey species taken frequently by spotted owls. We do not envision a crucial role for the rescue effect in maintaining these prey populations.

References

Boag, D. A. 1976. Influence of changing grouse density and forest attributes on the occupancy of a series of potential territories by male ruffed grouse. Can. J. Zool. 54:1727-1736.

Brown, J. H., and A. Kodric-Brown. 1977. Tumover rates in insular biogeography: Effect of immigration on extinction. Ecology 58:445-449.

Brown, J. L. 1969. Territorial behavior and population regulation in birds. Wilson Bull. 81:293-329.

Carey, A. B. 1989. Pers. comm. U.S. For. Serv., PNW, Olympia, Wash.

Coilias, N. E., J. K. Victoria, and R. J. Shallenberger. 1971. Social facilitation in weaverbirds: Importance of colony size. Ecology 52:823-828.

Craighead, J. J., J. R. Varner, and F. C. Cralghead, Jr. 1974. A population analysis of the Yellowstone grizzly bears. Bull. 40. Montana Forest Conserv. Exp. Stn., Univ. Montana, Missoula.

Den Boer, P. J. 1981. On the survival of populations in a heterogeneous and variable environment. Oecologia 50:39-53. 


\section{Appendix O: HCA Size and Spacing}

Dennis, B., P. L. Munholland, and J. M. Scott. Unpubl. ms. Estimation of growth and extinction parameters for endangered species. Univ. Idaho, Moscow, and Montana State Univ., Bozeman. Typescript.

Diamond, J. M. 1975. The island dilemma: Lessons of modern biogeographic studies for the design of natural reserves. Biol. Conserv. 7:129-146.

Dlamond, J. M. 1976. Island biogeography and conservation: Strategy and limitations. Science 193:1027-1029.

Dlamond, J. M. 1984a. Distributions of New Zealand birds on real and virtual islands. New Zealand J. Ecol. 7:37-55.

Dlamond, J. M. 1984b. "Normal" extinctions of isolated populations. Pages 191-246 in M. H. Nitecki, ed. Extinctions. Univ. Chicago Press, Chicago.

Dlamond, J. M., K. D. Bishop, and S. van Balen. 1987. Bird survival in an isolated Javan woodland: Island or mirror? Conserv. Biol. 1:132-142.

Dlamond, J. M., and R. M. May. 1977. Species turnover rates on islands: Dependence on census interval. Science 197:266-270.

Fletcher, K. W. Pers. comm. U.S. For. Serv., Albuquerque, N. Mex.

Forman, R. T. T., A. E. Galll, and C. F. Leck. 1976. Forest size and avian diversity in New Jersey woodlots with some land use implications. Oecologia 26:1-28.

Franklln, A. B., J. A. Blakesley, and R. J. Gutlérrez. 1989 unpubl. Population ecology of the northern spotted owl (Strix occidentalis caurina) in northwest California: Preliminary results, 1988. Report to the California Department of Fish and Game. Typescript.

Frledmann, H. 1950. The birds of North and Middle America. Vol. 11, Pt. II. U.S. Natl. Mus. Bull. 50. U.S. Gov. Print. Off., Washington, D.C. 793pp.

Ganey, J. L. Pers. comm. N. Ariz. Univ., Flagstaff.

Halla, Y., and I. K. Hanskl. 1984. Methodology for studying the effect of habitat fragmentation on land birds. Annales Zoologici Fennici 21:393-397.

Harrls, L. 1984. The fragmented forest. Univ. Chicago Press, Chicago. 211pp.

Hensley, M. M., and J. B. Cope. 1951. Further data on removal and repopulation of the breeding birds in a spruce-fir community. Auk 68:483-493.

Gochfeld, M. 1978. Social facilitation of singing, group size, and flight song rates in the pampas meadowlark Sturnella defilippii. Ibis 120:338-339.

Griffith, B., J. M. Scott, J. W. Carpenter, and C. Reed. 1989. Translocation as a species conservation tool: Status and strategy. Science 245:477-480. 


\section{Appendix O: HCA Size and Spacing}

Jehi, J. R., and K. C. Parkes. 1982. The status of the avifauna of the Revillagigedo Islands, Mexico. Wilson Bull. 94:1-19.

Jones, H. L., and J. M. Dlamond. 1976. Short-time-base studies of turnover in breeding bird populations on the California Channel Islands. Condor 78:526-549.

Karr, J. R. 1982. Avian extinction on Barro Colorado Island, Panama: A reassessment. Am. Nat. 119:220-239.

Knapton, R. W., and J. R. Krebs. 1974. Settlement patterns, territory size, and breeding density in the song sparrow (Melospiza melodia). Can. J. Zool. 52:1413-1420.

Krebs, J. R. 1971. Territory and breeding density in the great tit Parus major L. Ecology 52:2-22.

Kroodsma, D. E., and J. Verner. 1978. Complex singing behaviors among Cistothorus wrens. Auk 95:703-716.

Lamberson, R. H., R. McKelvey, B. R. Noon, and C. Voss. Unpubl. ms. The effects of varying dispersal capabilities on the population dynamics of the northern spotted owl-prelim. results.

Lovejoy, T. E., J. M. Rankin, R. O. Blerregaard, K. S. Brown, L. H. Emmons, and M. E. Van der Voort. 1984. Ecosystem decay of Amazon forest remnants. Pages 295-325 in M. H. Nitecki, ed. Extinctions. Univ. Chicago Press, Chicago.

Noss, R. F., and L. D. Harris. 1986. Nodes, networks, and MUMs: Preserving diversity at all scales. Environ. Manage. 10:299-309.

Orians, G. H. 1961. The ecology of blackbird (Agelaius) social systems. Ecol. Monogr. 31:285-312.

PImm, S. L., H. L. Jones, and J. Dlamond. 1988. On the risk of extinction. Am. Nat. 132:757-785.

PImm, S. L. Pers. comm. Univ. Tenn., Knoxville.

Rappole, J. H., D. W. Warner, and M. Ramos. 1977. Territoriality and population structure in a small passerine community. Am. Mid. Nat. 97:110-119.

Richter-Dyn, N., and N. S. Goel. 1972. On the extinction of a colonizing species. Theor. Popul. Biol. 3:406-433.

Scott, J. M., C. B. Kepler, C. van Riper III, and S. I. Fefer. 1988. Conservation of Hawaii's vanishing avifauna. BioScience 38:238-253.

Shaffer, M. L., and F. B. Samson. 1985. Population size and extinction: A note on determining critical population sizes. Am. Nat. 125:144-152. 


\section{Appendix O: HCA Size and Spacing}

SImberloff, D., and L. G. Abele. 1976a. Island biogeography theory and conservation practice. Science 191:285-287.

Simberioff, D., and L. G. Abele. 1976b. Island biogeography and conservation: Strategy and limitations. Science 193:1032.

Simberloff, D., and L. G. Abele. 1982. Refuge design and island biogeographic theory: Effects of fragmentation. Am. Nat. 120:41-50.

Smith, S. M. 1978. The "undenworld" in a territorial sparrow: Adaptive strategy for floaters. Am. Nat. 112:571-582.

Smith, S. M. 1984. Flock switching in chickadees: Why be a winter floater? Am. Nat. $12: 81-98$.

Smith, S. M. Pers. comm. Mount Holyoke Coll., South Hadley, Mass.

Soulé, M. E., D. T. Bolger, A. C. Alberts, J. Wright, M. Sorlce, and S. HIII. 1988. Reconstructed dynamics of rapid extinctions of chaparral-requiring birds in urban habitat islands. Conserv. Biol. 2:75-92.

Southern, H. N. 1970. The natural control of a population of tawny owls (Strix aluco). J. Zool. London 162:197-285.

Stewart, R. E., and J. W. Aldrich. 1951. Removal and repopulation of breeding birds in a spruce-fir community. Auk 68:471-482.

Terborgh, J. 1976. Island biogeography and conservation: Strategy and limitations. Science 193:1029-1030.

Vullleumler, F. 1970. Insular biogeography in continental regions. I. The northern Andes of South America. Am. Nat. 104:373-388.

Walter, H. L. Unpubl. ms. Small viable population: The red-tailed hawk of Socorro Island. Typescript.

Whitcomb, R. F., J. F. Lynch, P. A. Opler, and C. S. Robblns. 1976. Island biogeography and conservation: Strategy and limitations. Science 193:1030-1032.

Whitcomb, R. F., C. S. Robblns, J. F. Lynch, B. L. Whltcomb, M. K. Kllmklewicz, and D. Bystrak. 1981. Effects of forest fragmentation on avifauna of eastern deciduous forest. Pages 125-205 in R. L. Burgess and D. M. Sharpe, eds. Forest island dynamics in man-dominated landscapes. Springer Publishing Co., New York.

Wiens, J. A. 1989. The ecology of bird communities, Vol. 2: Processes and variations. Cambridge Univ. Press, Cambridge. 316pp. 


\section{Appendix O: HCA Size and Spacing}

Willcove, D. S., C. H. McLellan, and A. P. Dobson. 1986. Habitat fragmentation in the temperate zone. Pages 237-256 in M. Soulé and B. A. Wilcox, eds. Conservation biology: The science of scarcity and diversity. Sinauer Associates, Sunderland, Mass.

Williams, G. R. 1981. Aspects of avian island biogeography in New Zealand. J. Biogeogr. 8:439-456.

WIIIIS, E. O. 1974. Populations and local extinctions of birds on Barro Colorado Island, Panama. Ecol. Monogr. 44:153-169.

Wiliis, E. O. 1980. Species reduction in remanescent woodlots in southern Brazil. Pages 783-786 in R. Höhring, ed. Acta 19th Congressus Internationalis Ornithologici, Vol. 2. Deutsche Ornithologen-Gesellschaft, Berlin. 


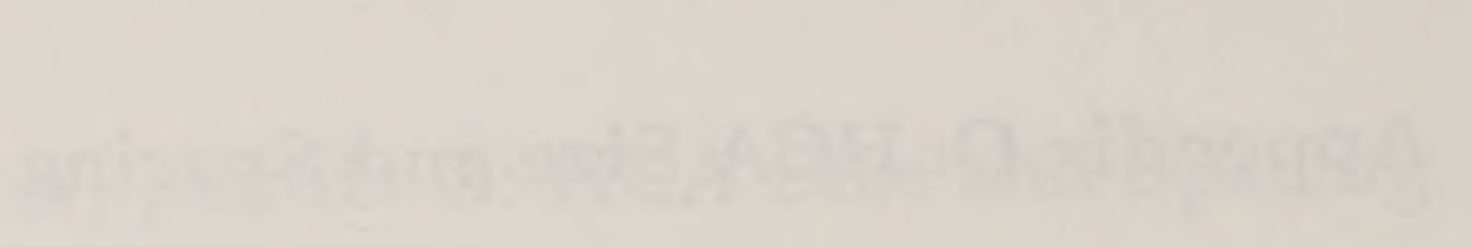




\section{Connectivity: Assuring Successful Dispersal}

Introduction

Dispersal
Elsewhere, we emphasized the vital need to assure that spotted owls can move with at least moderate success from one HCA to another (appendices $\mathrm{M}, \mathrm{N}, \mathrm{O}$, and P). Here, we develop more fully the concepts of dispersal and connectivity that are involved in this process, and apply the relevant information now available on spotted owls to assure this movement.

Dispersal in animals can be defined as the relatively permanent movement of individuals from one location to another. Usually dispersal is the movement of juveniles from their natal area to a site where they eventually settle to breed. Occasionally, adults disperse from one breeding site to another, typically in response to a disturbance in their former breeding area. The regular migratory movement of birds between breeding and nonbreeding areas is not dispersal. Although habitat destruction is probably the main reason for breeding adults to disperse in search of another breeding area, other factors may also induce adult dispersal. Successful dispersal is an essential feature of a conservation strategy: without it, deceased individuals in the breeding population will not be replaced by recruits among dispersing juveniles and displaced adults, and the population will decline to extinction.

Consensus exists among biologists that, all else being equal, continuous suitable habitat supports more individuals of a species targeted for conservation than does fragmented (discontinuous) habitat. Persistence times for populations that inhabit fragmented landscapes are thought to be greater where connectivity between habitats enhances the exchange of individuals. With that in mind, much recent literature in conservation biology supports the concept of providing "corridors" of suitable habitat between population centers (for example, Diamond 1975, Harris 1984, Noss and Harris 1986, Soulé et al. 1988, Terborgh 1975, Willis 1974, Wilson and Willis 1975). Evidence is scanty, however, on exactly what kind of corridors each particular species requires, and some authors suggest that attempts to provide corridors may sometimes turn out to be more detrimental than beneficial (see Noss 1987, Simberloff and Cox 1987, Soulé and Simberloff 1986). When large blocks of suitable habitat for a species exist, however, the rate of successful dispersal from one block to another clearly declines with increasing distance between them (see Diamond 1975, Gilpin and Diamond 1976, and appendix O). Our own modeling efforts indicate that long-term spotted owl persistence is unusually sensitive to the distance between blocks of suitable habitat in relation to the percentage of the landscape that a dispersing 


\section{Appendix P: Connectivity}

Observations on Dispersing Juveniles individual can search before perishing (appendix M). As Miller (1989:1-2) states, "The distance between adjacent pairs or groups of breeding owls should be such that dispersal of juveniles can replace losses (deaths or emigrations) among existing pairs and provide for the colonization of suitable, unoccupied habitats. An understanding of dispersal in juvenile spotted owls is thus basic to formulation of criteria for appropriate spacing of habitat to accommodate owl pairs."

The habitat conservation strategy proposed here does not depend on specific corridors for dispersal of the northern spotted owl. Instead, we provide recommendations for managing the landscape to facilitate movement of owls between HCAs. Here we address the essential elements of suitable spotted owl connectivity between HCAs. The following data on the dispersal capabilities of spotted owls, and the nature of connecting zones between HCAs, support plan guidelines.

Miller (1989) carried out the most extensive study to date, monitoring dispersing juveniles over a 4-year period. He reported that 32 of 48 juveniles in western Oregon, fitted with radio transmitters shortly after leaving their nest, survived to disperse from the natal areas (an average of 104 days after fledging). Twenty-seven (84\%) initiated dispersal between mid-September and mid-October. Their initial movement was usually rapid, and "...most juveniles settled into well-defined areas for their first winter after the initial dispersal movements. Those...surviving their first winter often began moving again in late winter or early spring." Males dispersed an average of 16.2 miles $(S D=14.6 ; n=7)$ and females an average of $20.4(S D=6.6 ; n=6$, not significantly different), from a subset of birds positively identified to sex. Directions taken by dispersing juveniles did not differ from a random distribution, although six of nine juveniles in 1983 dispersed down the McKenzie River drainage from the H.J. Andrews Experimental Forest. Miller found no significant relation between forest fragmentation and either the final distance moved or the number of days survived by birds in his study. Dispersing juveniles used a wide variety of habitats, but 12 of 18 birds exhibited significant selection for old-growth and mature forests.

In a study of 23 dispersing juveniles in northwestern California (11 in 1983 and 12 in 1984), Gutiérrez et al. (1985) reported departure dates from natal areas from 22 September to 5 October. These dates were within the range of those reported by Miller (1989) for western Oregon. In 1983, dispersing juveniles moved an average of 5 miles per day (range 1 to 11), compared to just 1.3 miles per day in 1984 (range 0.8 to 6.4). The difference was statistically significant. Directions taken by dispersing birds varied. Gutierrez et al. found no relation between "...dispersal direction and the geographic orientation of drainages or ridges." During the first 80 days of dispersal, individual juveniles in this study dispersed total distances from 15.3 to 92.9 miles $(n=11)$ in 1983, and from 0.7 to 62.8 miles $(n=7)$ in 1984. Total distance is the sum of all segments between successive locations as birds were followed during dispersal. Total distance is greater than the straight-line distance between beginning and ending points. 


\section{Appendix P: Connectivity}

Estimating Dispersal Distances
In addition to these more extensive radio-transmitter studies of dispersing juveniles, we have compiled results from all sources into a data base used to estimate dispersal distances of juvenile spotted owls after they leave their natal areas (table P1). We have also compiled a smaller data set from known dispersal distances of colorbanded juveniles (table P2). Both data sets have limitations. Radio-transmitter studies usually allowed observers to relocate birds at regular intervals until the transmitters failed or the birds disappeared or died. Consequently, the results were not constrained by any boundaries within which searching occurred. Only one bird from the collected surveys was later found to be paired with a mate on a territory, although it apparently never nested (Gutiérrez, pers. comm.). All other birds $(n=55)$ either died $(68 \%)$, their transmitters failed $(27 \%)$, or they disappeared $(5 \%)$. Although juvenile birds of all species tend to have high mortality rates, results from the radio-marked birds may be biased by the possible effects of radio-transmitters.

Table P1-Number of radlo-marked juvenlles that dispersed different distances (Intervals grouped by mlles) (from Forsman 1980, Gutlérrez et al. 1985, Laymon 1988, Meslow and Miller 1986, and Miller 1989)

\begin{tabular}{lccc}
\hline $\begin{array}{l}\text { Distance } \\
\text { intervals } \\
\text { (miles) }\end{array}$ & $\begin{array}{c}\text { Maximum } \\
\text { dispersal } \\
\text { distance }\end{array}$ & $\begin{array}{c}\text { Final }^{b} \\
\text { dispersal } \\
\text { distance }\end{array}$ & $\begin{array}{c}\text { Total }^{c} \\
\text { dispersal } \\
\text { distance }\end{array}$ \\
\hline $0-4.9$ & 6 & 8 & 3 \\
$5-9.9$ & 8 & 6 & 2 \\
$10-14.9$ & 6 & 9 & 1 \\
$15-19.9$ & 12 & 8 & 2 \\
$20-24.9$ & 6 & 6 & 2 \\
$25-29.9$ & 7 & 5 & 5 \\
$30-34.9$ & 3 & 2 & 0 \\
$35-39.9$ & 3 & 2 & 2 \\
$40-44.9$ & 0 & 1 & 3 \\
$45-49.9$ & 3 & 1 & 5 \\
$50+$ & 2 & & \\
Sample size & 56 & 50 & 26 \\
Mean & 20.1 & 18.0 & 34.1 \\
SD & 14.0 & 13.3 & 26.3 \\
CV & $69.9 \%$ & $74.0 \%$ & $77.3 \%$ \\
Median & 17.5 & 16.4 & 27.0 \\
Percent $>7$ miles & & & 76.9 \\
Percent $>12$ miles & 80.4 & 76.0 & 73.1 \\
Percent $>17$ miles & 67.9 & 64.0 & 69.2 \\
\hline
\end{tabular}

\footnotetext{
Maximum distance is the greatest linear distance the juvenile traveled from the natal area.

${ }^{b}$ Final distance is the linear distance from the natal area to the last point of detection.

c Total distance is defined as the sum of all segments between successive location established as the bird dispersed from its natal area.
} 


\section{Appendix P: Connectivity}

Table P2-Dispersal distances of color-banded, juvenlle spotted owls that survived at least 1 year

\begin{tabular}{|c|c|c|c|c|}
\hline Source of data ${ }^{a}$ & Sex & $\begin{array}{c}\text { Year } \\
\text { banded }\end{array}$ & $\begin{array}{c}\text { Year } \\
\text { resighted }\end{array}$ & $\begin{array}{l}\text { Distance } \\
\text { (miles) }\end{array}$ \\
\hline Eugene District, BLM & $\mathrm{F}$ & 1986 & 1987 & 7.5 \\
\hline Eugene District, BLM & M & 1987 & 1988 & 16.0 \\
\hline Roseburg District, BLM & $\mathrm{F}$ & 1986 & 1987 & 5.5 \\
\hline Roseburg District, BLM & U & 1986 & 1987 & 18.0 \\
\hline Roseburg District, BLM & $\mathrm{F}$ & 1986 & 1988 & 9.0 \\
\hline Roseburg District, BLM & $M$ & 1986 & 1988 & 7.8 \\
\hline Roseburg District, BLM & $M$ & 1986 & 1989 & 7.0 \\
\hline Roseburg District, BLM & $M$ & 1986 & 1989 & 5.0 \\
\hline Roseburg District, BLM & U & 1986 & 1989 & 38.0 \\
\hline Roseburg District, BLM & M & 1987 & 1988 & 4.3 \\
\hline Roseburg District, BLM & M & 1987 & 1988 & 2.5 \\
\hline Roseburg District, BLM & $M$ & 1987 & 1989 & 7.5 \\
\hline Roseburg District, BLM & $\mathrm{F}$ & 1988 & 1989 & 10.0 \\
\hline Medford District, BLM & $M$ & 1986 & 1987 & 6.0 \\
\hline Medford District, BLM & $\mathrm{F}$ & 1988 & 1989 & 41.0 \\
\hline Salem District, BLM & M & 1986 & 1988 & 1.7 \\
\hline Miller (pers. comm.) & $\mathrm{F}$ & 1987 & 1989 & 9.7 \\
\hline Miller (pers. comm.) & M & 1987 & 1989 & 5.0 \\
\hline Miller (pers. comm.) & M & 1988 & 1989 & 9.2 \\
\hline Miller (pers. comm.) & $\mathrm{F}$ & 1988 & 1989 & 19.0 \\
\hline & & & \multicolumn{2}{|c|}{$\begin{aligned} n & =20 \\
\text { mean } & =12.0 \\
S D & =10.7 \\
\text { median } & =8.4\end{aligned}$} \\
\hline
\end{tabular}

a BLM data from files in District offices.

If juveniles carrying radio transmitters tend to die sooner than normal, we might expect our results to underestimate dispersal distance. Using the full data base, we found no significant difference in mean dispersal distances or number of days survived between the subset of birds $(n=25)$ that ceased dispersing at least 45 days before they died or their transmitters failed, and the subset $(n=30)$ for which information was lacking about when they ceased dispersing in relation to death or transmitter failure. To further test the hypothesis that transmitters had no effect on maximum dispersal distance, we computed a simple correlation. No relation between maximum dispersal distance and the period that birds wore transmitters $(r=-0.04)$ was evident. We next subdivided the transmitter data into three groups (birds that carried radios from 1 to 150 days, 151 to 300 days, and $>300$ days), then computed means of the maximum linear distances these birds were recorded from their natal areas. Group means were 18.3 miles ( $S D=13.0, n=29$ ), 23.7 miles ( $S D=16.1$, $n=20$ ), and 20.9 miles ( $S D=11.7 ; n=5$ ), respectively. No pair of means differed significantly (ANOVA $-\mathrm{F}$-value $=0.846 ; P>0.43$; chi-square approximation by Kruskal-Wallis test- $X^{2}=1.52 ; P>0.47$ ), again indicating that transmitters did not affect our estimates of dispersal distances. We have therefore used the full data set when estimating dispersal distances of radio-marked, juvenile spotted owls. 


\section{Appendix P: Connectivity}

\section{Appropriate Distances Between HCAs}

Data from color-banded birds used to compile table P2 present a different problem. Because the area searched was constrained by field operation boundaries of the BLM in parts of Oregon where the birds were banded, no opportunity existed to relocate birds that may have dispersed beyond those boundaries. We believe the estimate of mean dispersal distance from the banding data, therefore, underestimates the true mean by an unknown and potentially significant amount. The fact that the mean dispersal distance estimated from banded birds is lower than each of three estimates from radio-marked birds (table $\mathrm{P} 1$ ) is not surprising.

Success of the spotted owl conservation strategy proposed here depends on frequent dispersal between HCAs, which means that HCAs must be separated by distances well within the known dispersal ranges of juveniles. We based our determination of appropriate distances between HCAs primarily on results from radio-marked birds (table P1), because we believe distances based on banded birds (table P2) underestimated true dispersal distances of juvenile spotted owls. We have not been able to determine a fully objective method to set a "safe" distance between HCAs, based on owl dispersal distances. That the distance need not include dispersal distances of $100 \%$ of the juveniles listed in table P1, however, seemed obvious. (One of those owls settled in its parents' home range, giving it a final disperal distance of 0 miles.) On the other hand, we believe the distances between HCAs should be well within the known dispersal distances of at least $50 \%$ of all juveniles. After lengthy discussions of this matter among all members of the Committee and advisors, and consultation with other authorities not closely affiliated with our efforts, we believe the distances between HCAs should be within the known dispersal distances of at least two-thirds $(67 \%)$ of all juveniles. By setting the maximum allowable distance between the nearest points of contact of neighboring HCAs at 12 miles, we satisfy the $67 \%$ criterion for all three measures of dispersal distance in table P1. Visual comparison of the dispersal distances of radio-marked birds and distances between nearest neighbor HCAs (fig. P1) clearly shows that most HCAs are separated by distances well within the dispersal distances of juvenile spotted owls.

Birds that tended to disperse less than 12 miles would still have opportunities to join the floater population (see discussion in appendix O) in their natal HCA and eventually find vacancies in the breeding population there. Indeed, we contend that replacement of adults lost from the breeding population by recruits from within their natal HCA is the primary reason why larger blocks of habitat (hence more pairs of birds) tend to persist longer than smaller blocks with fewer pairs (appendices $M$ and 0 ). This opportunity would seldom be available in a fully developed network of SOHAs, however, because a bird that dispersed a relatively short distance would usually find itself in unsuitable habitat for breeding, and its natal area (the SOHA) would usually still be occupied by its parents. Birds dispersing from SOHAs would need to locate another SOHA to find suitable breeding habitat, and its availability would depend on whether the appropriate sex was missing from the pair in that SOHA. 


\section{Appendix P: Connectivity}
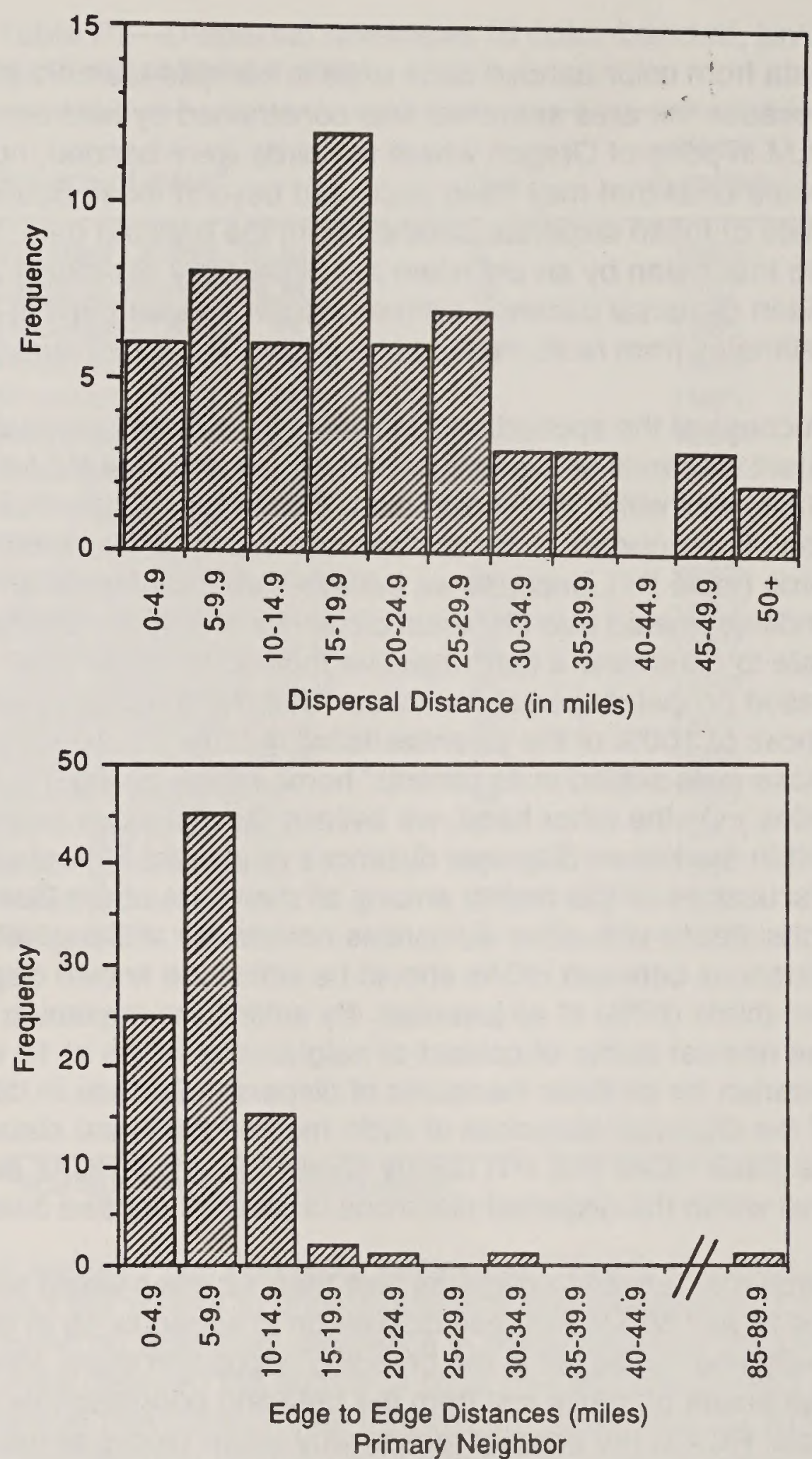

Figure P1-Comparison of maximum dispersal distances of radio-marked juveniles (upper histogram) and nearest distances between edges of neighboring HCAs (lower histogram).

Existing conditions in some locations precluded designation of HCAs with habitat adequate to support at least 20 pairs, either now or in the future. Some HCAs provide for even fewer than 10 pairs (see appendix Q). All else being equal, populations in these areas are likely to be more prone to local extinction than populations supported by larger areas. To provide an additional measure of security for small HCAs, we opted to increase the likelihood of successful dispersal from one to another by setting shorter distances between them (see appendix $Q$ for specific guidelines). The distance selected, 7 miles, is less than the median distance estimated from banded birds (table $\mathrm{P} 2$ ) and is within the dispersal range of more than $75 \%$ of all radiomarked juveniles (table P1). 


\section{Appendix P: Connectivity}

\section{Connectivity}

\author{
Guidelines for Habitat \\ Conditions in \\ Connecting Zones \\ Between HCAs
}

We use "connectivity" to mean the kinds and amounts of habitat occurring in the zones between HCAs. Conditions there must be compatible with the movement of spotted owls, such that they are both capable of moving through these habitats and inclined to do so. Although connecting zones need not assure habitat capable of supporting a pair of breeding owls, they do need to provide stopover places where owls can find suitable cover and, especially, foraging opportunities. To that extent, then, we believe that the connecting zones between HCAs must include some forested landscapes.

We prefer to call areas of the forest matrix between HCAs the "connecting zones," because we do not envision them as discrete corridors as implied in much recent literature (review in Wiens 1989). Available data do not allow formulation of specific corridor attributes for spotted owls, such as habitat features or configuration. Wiens (1989:217) cogently argues that "A focus exclusively on fragmentation of habitats misses the point that it is often the structure of an entire landscape mosaic rather than the size or shape of individual patches that is important to birds. The likelihood that dispersal can occur between fragments and forestall the extinction of sensitive species on a regional scale is influenced by the configuration of the fragments and the landscape mosaic in which they are embedded." Elsewhere, Wiens (1989:227) again emphasizes the importance of the landscape context of habitat patches, pointing out that "To establish reserves according to ecological insights requires both a consideration of broad-scale landscape configurations and knowledge of the ecological requirements of the species that are important in particular situations." This is the context within which we have formulated our recommendations on connectivity to assure the dispersal of owls between HCAs.

Studies indicate that juvenile spotted owls move freely through the landscape surrounding suitable habitat; hence, we believe they would generally ignore corridors designed especially to facilitate their dispersal between HCAs. Finally, we are concerned by speculation that relatively wide, linear strips of habitat suitable for spotted owls are likely to become havens for predatory species like great horned owls. Therefore, we have not planned for discrete corridors, but instead have developed management standards for the intervening matrix in the connecting zones between HCAs.

We prefer an option in which a major portion of the landscape in the connecting zones is potential dispersal habitat for owls, because we believe that a well-managed landscape matrix surrounding HCAs would facilitate dispersal among them while reducing the potential disadvantages of true corridors. These zones are not designated for preservation. Many existing management practices, including those associated with certain timber harvest methods, provide habitat attributes conducive to spotted owl dispersal. Examples include visual corridors, riparian corridors, and streamsidemanagement zones, which contain possible stopover spots. These habitat areas tend to be linear in configuration. Additional forested patches that can serve for dispersal remain unharvested for other reasons. Forests on lands incapable of commercial timber production, on soils prone to slumping, and in special management areas for pileated woodpeckers and pine martens are examples of potentially suitable dispersal habitat for spotted owls. Furthermore, $50 \%$ of the landbase in a regulated forest would be older than 40 years, even with a rotation schedule of only 80 years. We expect much of that managed landbase to be suitable for passage by dispersing spotted owls (appendix $\mathrm{R}$ recommends studies to evaluate this expectation). 


\section{Appendix P: Connectivity}

Standards and guidelines in this conservation strategy also specify that at least $50 \%$ of the forest matrix outside HCAs be maintained in stands of timber with a mean d.b.h. of 11 inches or greater, with at least $40 \%$ canopy closure. They also specify the retention of at least 80 acres of suitable owl habitat within a 1/4-mile of the nest tree or center of the presumed nest stand of all known pairs, up to seven per township, that are not included in other HCAs (see appendix Q). Although we believe these patches occasionally will be used by dispersing spotted owls, their primary value should be as nuclei of older forest, surviving from the current stand, that will become core areas for breeding pairs of spotted owls in the future, as the surrounding forest matrix grows up around them. We have seen numerous examples of this phenomenon throughout the range of the northern spotted owl. Old-growth patches in younger stands result from fires that left unburned segments of forest scattered here and there. Severe windstorms, and even inefficient logging practices in past years, have produced similar patchiness.

To explore the effectiveness of these guidelines for connectivity, we have mapped in detail the connecting zones between HCAs to show the distribution of stream corridors, forest stands by rotation age, forest patches reserved for a variety of other reasons, and the patches of forest that will be retained as HCA's around known pairs' activity centers (see figures P2, P3). We carefully chose connecting zones that represent the range of conditions on Federal land today. One zone is from the Mount Hood National Forest in Oregon (fig. P2), and the other is from the GiffordPinchot National Forest in Washington (fig. P3). Maps of these zones are included as a part of the documentation of this conservation strategy.

We believe standards developed here will provide for juvenile dispersal at rates sufficiently high to assure effective demographic interaction among HCAs. We also recognize that many dispersing juveniles will perish because they disperse in the wrong direction, starve to death for lack of experience in capturing prey, or fall to predators. But high mortality rates are the rule among juvenile birds, for these and other reasons. It is normal and should be expected. 


\section{Appendix P: Connectivity}

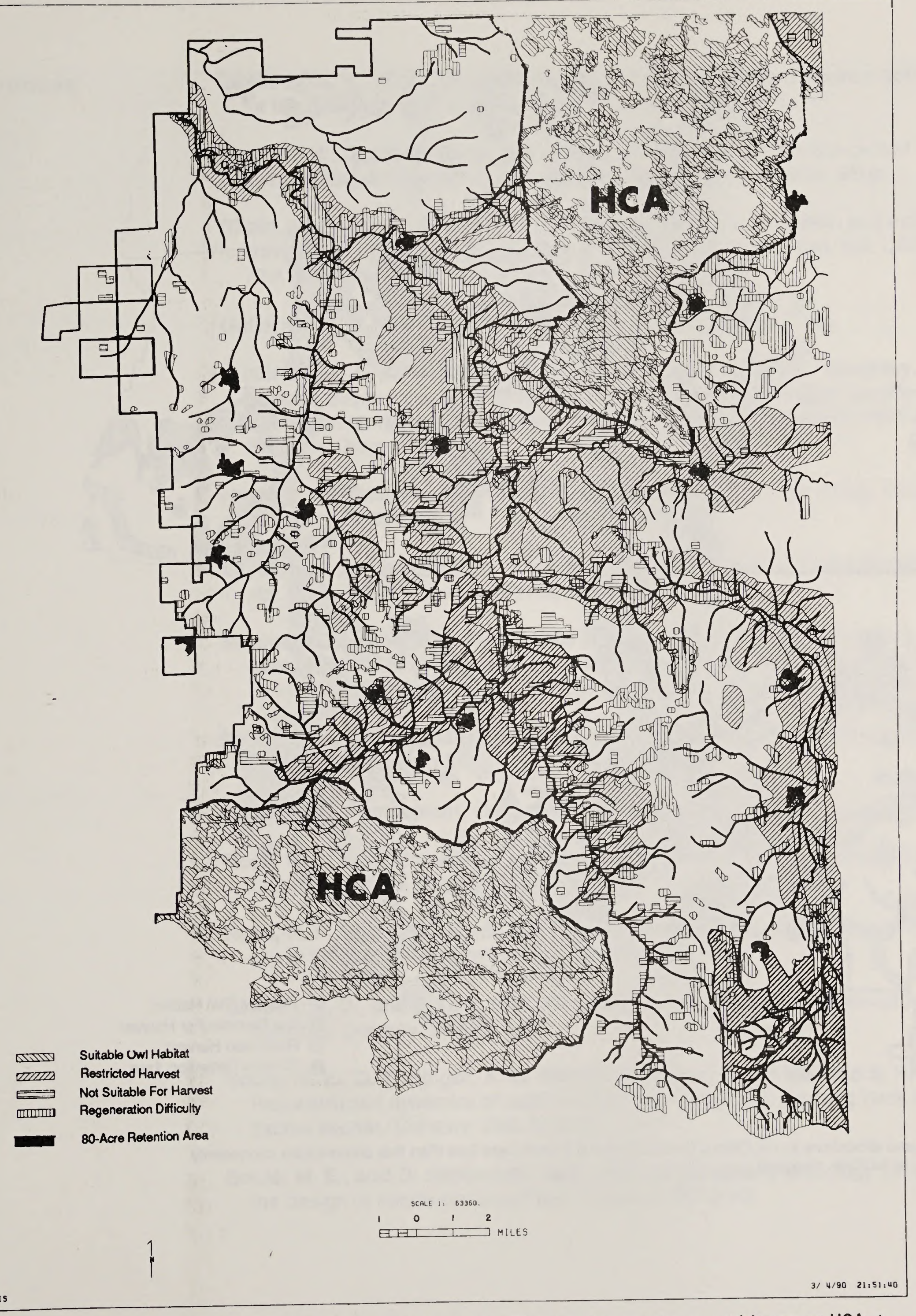

Figure P2-Land allocations in the Mount Hood National Forest Land-Use Plan that der,ionstrate connectivity among HCAs to facilitate dispersal. 


\section{Appendix P: Connectivity}

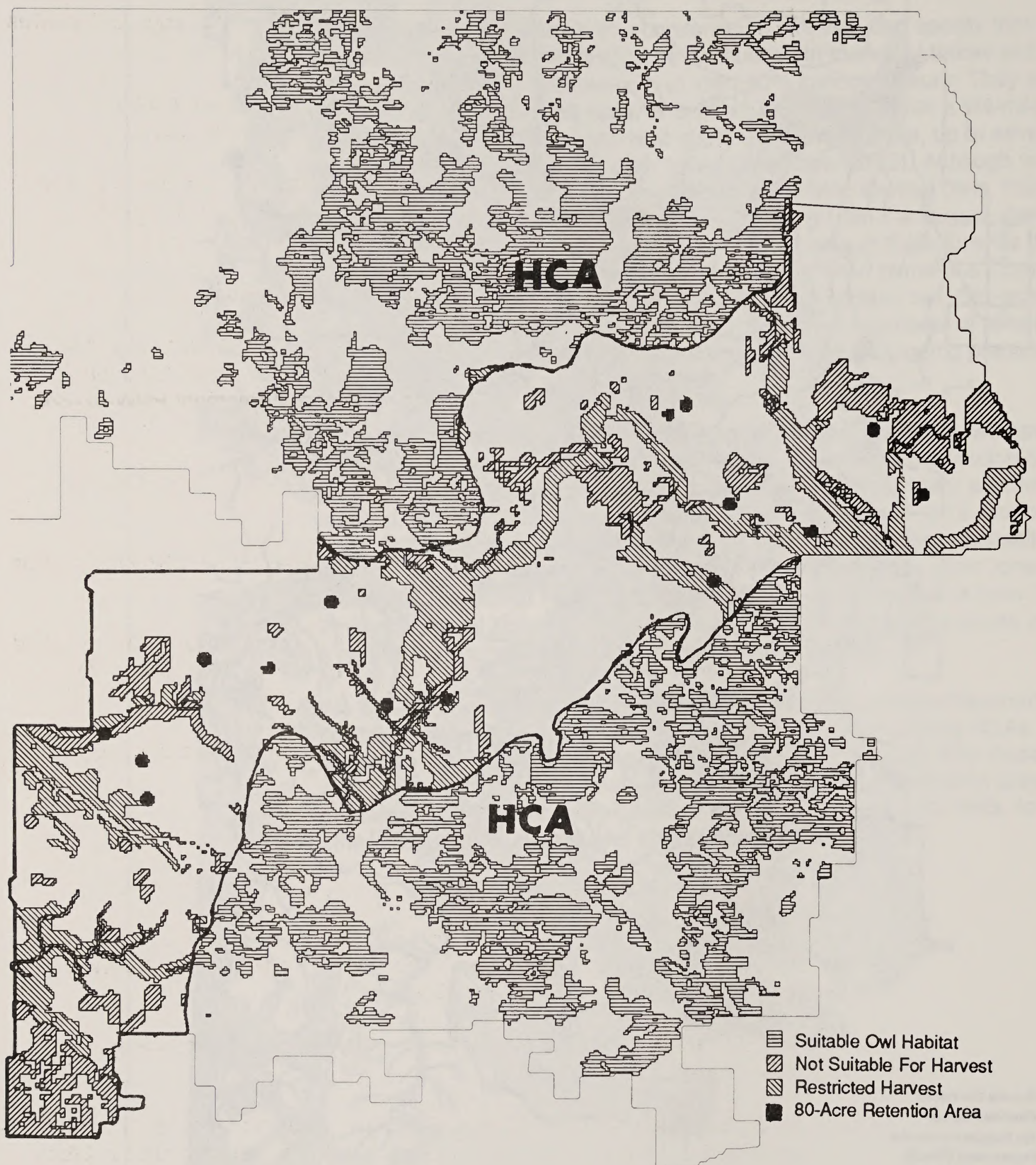

Figure P3 - Land allocations in the Gifford Pinchot National Forest Land-Use Plan that demonstrate connectivity among HCAs to facilitate dispersal. 


\section{Appendix P: Connectivity}

References

Dlamond, J. M. 1975. The island dilemma: Lessons of modern biogeographic studies for the design of natural reserves. Biol. Conserv. 7:129-146.

Forsman, E. D. 1980. Habitat utilization by spotted owls in the west-central Cascades of Oregon. Ph.D. Thesis, Oreg. State Univ., Corvallis. 95pp.

GilpIn, M. E., and J. M. Dlamond. 1976. Calculation of immigration and extinction curves from the species-area-distance relation. Proc. Natl. Acad. Sci. USA 73:4130-4134.

Gutlérrez, R. J. Pers. comm. Humboldt State Univ., Arcata, Calif.

Gutlérrez, R. J., J. P. Ward, A. B. Franklln, W. LaHaye, and V. Meretsky. 1985 unpubl. Dispersal ecology of juvenile northern spotted owls (Strix occidentalis caurina) in northwestern California. Final rep. on Coop. Agreement PNW-82-226, Portland, Oreg. 48pp.

Harris, L. D. 1984. The fragmented forest. University of Chicago Press, Chicago. $211 \mathrm{pp}$.

Laymon, S. A. 1988. Ecology of the spotted owl in the central Sierra Nevada, California. Ph.D. Thesis. Univ. California, Berkeley. 257pp.

Meslow, E. C., and G. S. Miller. 1986 unpubl. Dispersal of juvenile northern spotted owls in the Pacific Northwest Douglas-fir region. Progr. rep. Oreg. Coop. Wildl. Res. Unit, Dep. Fisheries and Wildlife, Oreg. State Univ., Corvallis.

Miller, G. S. 1989. Dispersal of juvenile northern spotted owls in western Oregon. M.S. Thesis. Oregon State Univ., Corvallis. 139pp.

Miller, G. S. Pers. comm. Oreg. State Univ., Corvallis.

Noss, R. F. 1987. Corridors in real landscapes: A reply to Simberloff and Cox. Conserv. Biol. 1:159-164.

Noss, R. F., and L. D. Harrls. 1986. Nodes, networks, and MUMs: Preserving diversity at all scales. Environ. Manage. 10:299-309.

Simberloff, D., and J. Cox. 1987. Consequences and costs of conservation corridors. Conserv. Biol. 1:63-71.

Soulé, M. E., D. T. Bolger, A. C. Alberts, J. Wright, M. Sorice, and S. HIII. 1988. Reconstructed dynamics of rapid extinctions of chaparral-requiring birds in urban habitat islands. Conserv. Biol. 2:76-92.

Soulé, M. E., and D. SImberloff. 1986. What do genetics and ecology tell us about the design of nature reserves? Biol. Conserv. 35:19-40. 


\section{Appendix P: Connectivity}

Terborgh, J. 1975. Faunal equilibria and the design of wildife preserves. Pages 369-380 in Tropical ecological systems: Trends in terrestrial and aquatic research (F. Golley and E. Medina, eds.). Springer-Verlag, New York.

Wiens, J. A. 1989. The ecology of bird communities. Vol. 2: Processes and variations. Cambridge Univ. Press, New York.

Willis, E. O. 1974. Populations and local extinctions of birds on Barro Colorado Island, Panama. Ecol. Monogr. 44:153-169.

Wilson, E. O., and E. O. Wilils. 1975. Applied biogeography. Pages 522-534 in Ecology and evolution of communities (M. L. Cody and J. M. Diamond, eds.). Belknap Press of Harvard Univ. Cambridge, Mass. 


\section{Standards and Guidelines}

Goals

\section{Objectives}

\section{Description of the Conservation Strategy}

Habitat Conservation Area (HCA)
The Committee used the following standards and guidelines to achieve the goals and objectives of the conservation strategy and to delineate HCAs on individual State maps.

- Maintain, over the forest landscape, a population of northern spotted owls that has a high probability of continued existence throughout its range.

- Identify and protect, in the short term, key habitat areas and pairs of owls.

The following objectives are to be met within the proposed planning period of 50 to 100 years.

- Manage for continued distribution of breeding pairs throughout the owl's current range.

- Manage for restoration of breeding pairs in key areas of the owl's historic range.

- Manage habitat and owl distribution so that pairs and subpopulations of owls interact genetically and demographically, to minimize risks to long-term viability.

- Monitor and conduct research to evaluate whether the goals and objectives are being met and to facilitate adaptive management.

The following provides a description and outline of the conservation strategy.

\section{Definition:}

- A contiguous block of habitat to be managed and conserved for breeding pairs, connectivity, and distribution of owls. Application may vary throughout the range according to local conditions. A schematic diagram of the strategy is provided in figure Q1.

\section{Categories of HCAs (tabie Q1):}

- Category 1-blocks of habitat to support at least 20 pairs.

- Category 2-blocks of habitat to support 2 to 19 pairs.

- Category 3-blocks of habitat to support individual pairs.

- Category 4-blocks of habitat that may be smaller than the median annual home-range size but provide connectivity or potential habitat for future nest sites. 


\section{Appendix Q: Standards and Guidelines}
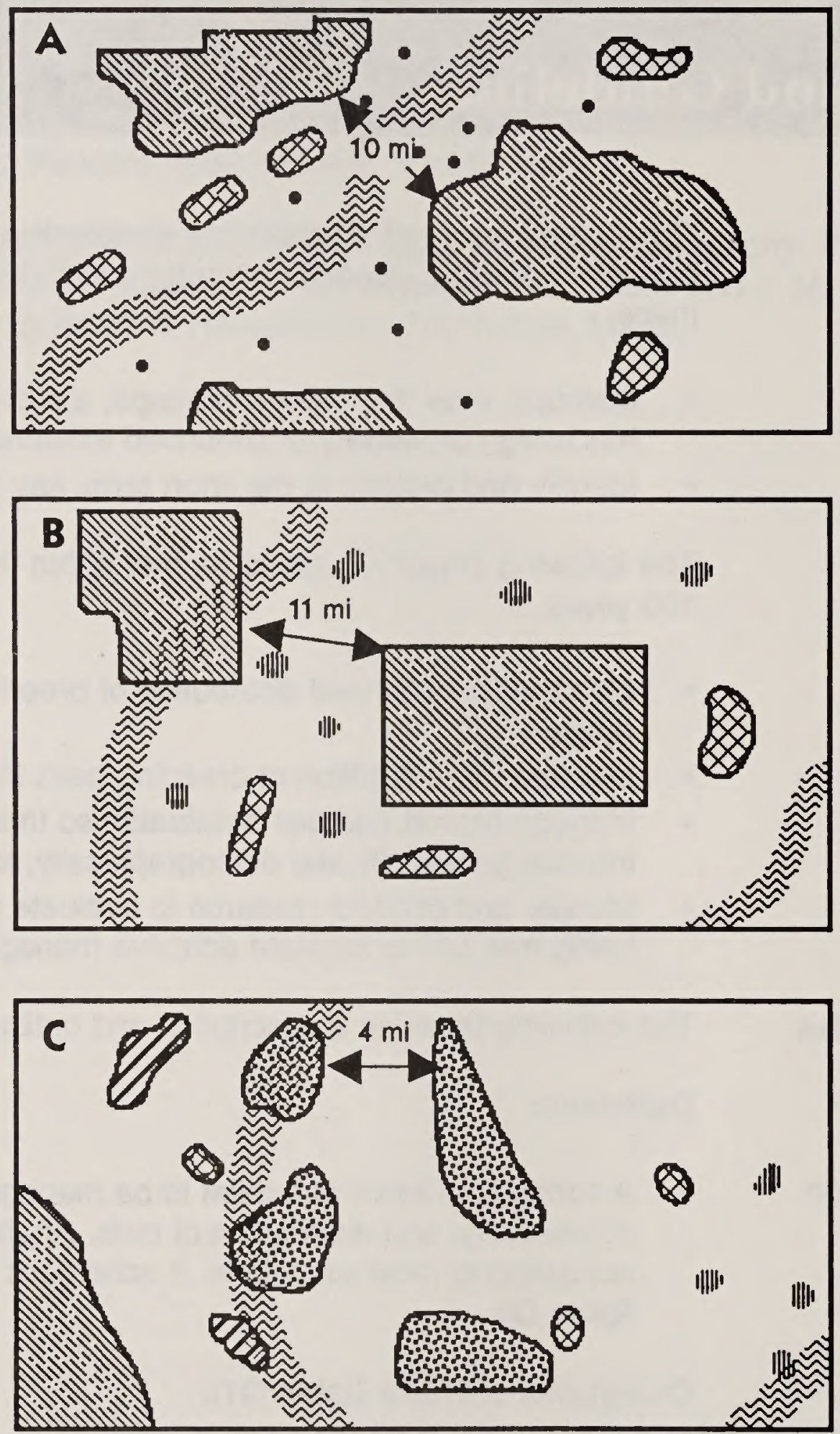

$\begin{array}{lll}\text { HCA with } 20 \text { pairs of owls } & \begin{array}{l}\text { Forested withdrawn area } \\ \text { (for example, soil instability) }\end{array} \\ \text { HCA with } 10 \text { pairs of owls } & \begin{array}{l}\text { Retention areas for owl centers } \\ \text { of activity (about } 80 \text { acres each) }\end{array} \\ \text { HCA with } 5 \text { pairs of owls } & \text { HCA with individuai pair of owls }\end{array}$

Figure Q1-Schematic drawings of the elements of the conservation strategy as it might apply to three different landscapes: scenarios for $A$, Category $1, \geq 20$ pairs of owls currently; B, Category $1, \geq 20$ pairs not currently present; and C, Categories 2 (2 to 19 pairs) and 3 (blocks to support individual pairs). 


\section{Appendix Q: Standards and Guidelines}

Table Q1-Description of categories

\begin{tabular}{|c|c|}
\hline Strategy & Types \\
\hline \multicolumn{2}{|l|}{ Habitat Conservation Area } \\
\hline $\begin{array}{l}\text { Categories }{ }^{a} \text { : } \\
\text { 1. Blocks of habitat to support } \geq 20 \text { pairs } \\
\text { 2. Blocks of habitat to support }<20 \text { pairs } \\
\text { 3. Blocks of habitat to support individual pairs } \\
\text { 4. Blocks of habitat that may be smaller } \\
\text { than median annual home-range size }\end{array}$ & $\begin{array}{l}\text { (see figure Q1 and State maps) } \\
\text { (see figure Q1 and State maps) } \\
\text { a. Small blocks (delineated on State maps) } \\
\text { b. Radius-based circle (not delineated on } \\
\text { State maps) } \\
\text { a. Small blocks (delineated) } \\
\text { b. } 80 \text {-acre retention areas (not delineated) }\end{array}$ \\
\hline \multicolumn{2}{|l|}{ Forest Matrix } \\
\hline $\begin{array}{l}\text { Categories }^{a} \text { : } \\
\text { 1. Lands suited for timber production: } \\
\text { - Long rotations } \\
\text { - Intensively managed lands }\end{array}$ & $\begin{array}{l}\text { Visual corridors, deer winter range, } \\
\text { old-growth retention areas } \\
\text { Timber production lands }\end{array}$ \\
\hline $\begin{array}{l}\text { 2. Lands unsuited }{ }^{b} \text { for timber production: } \\
\text { - Allocation } \\
\text { - Technical }\end{array}$ & $\begin{array}{l}\text { Stream corridors } \\
\text { Soil, regeneration problems }\end{array}$ \\
\hline 3. Reserved lands ${ }^{b}$ outside HCAs: & Parks, Wilderness Area \\
\hline
\end{tabular}

a Categories are listed in order of importance to owls and availability of current or potential habitat. ${ }^{b}$ Although most unsuited and reserved lands are too small or of insufficient quality to be considered part of individual HCAs, some low-elevation areas provide significant amounts of suitable habitat.

intent:

- To assure population viability by providing for long-term occupancy and by reducing risks of local isolation and extinction.

- To support a minimum of 20 pairs wherever possible.

- To provide for owl distribution throughout the range.

- To enhance habitat continuity and quality (that is, maintain the integrity of the interior forest environment).

- To mitigate or reverse local or regional adverse habitat or population trends.

- To hedge against catastrophic loss and adverse effects of timber management (for example, reduce edge effects, mitigate the likelihood of fire or wind effects).

\section{Definition:}

- All forest lands outside of designated HCAs.

\section{Categories of Forest Matrix (table Q1):}

- Lands suited for timber production

- Lands unsuited for timber production

- Reserved lands 


\section{Appendix Q: Standards and Guidelines}

Guidelines Used in Delineating HCAs

Location of Individual HCAs

Size of Individual HCAs
Intent:

- To provide connectivity for dispersal and interaction of owls among HCAs. See appendix $\mathrm{P}$ (figs. P2 and P3) for maps of portions of two National Forests that demonstrate connectivity between HCAs provided by the forest matrix.

- To maintain options for returning owls to the forest matrix by retaining older forest structures in the managed landscape.

- To develop and apply experimental silvicultural treatments that may support a viable owl population in the forest matrix.

- To contribute toward a short-term viable population (less than 50 years).

The following guidelines were used to establish the location, size, spacing, shape, and quality of individual HCAs on the enclosed State maps.

Location of individual HCAs was based on the following considerations:

- Land ownership (primarily on public lands).

Note: Some HCAs are recommended for State, tribal, and private lands (dashed lines on State maps). See Description of State Strategy later in this appendix.

- Current and future population distribution to assure viability.

- Occurrence of known pairs and availability of suitable habitat.

- Availability of, or potential for, sufficient pairs to support target densities.

- Ability of reserve lands to support owls.

- Inclusion of the full range of elevational gradients to maintain a diversity of habitats.

- Proximity to other HCAs (see spacing below).

HCA size was based on the following considerations (see table Q2 for application):

- The ability of an area to support a minimum of 20 currently known ${ }^{1}$ pairs, estimated, or expected based on the presence of pairs, single owls, or the amount of suitable habitat (Category 1).

The size of the HCA was established by delineating an area to support the target number of pairs using median annual home-range and density information as a guide (see appendix I).

- The inability to support at least 20 pairs because of natural landscape limitations, limited availability of public lands, or local human-induced extirpation.

The size of Category 2 HCAs ( 2 to 19 pairs) was established by delineating an area to accommodate as many known, estimated, or potential pairs as possible, using median annual home-range size (see appendix I).

\footnotetext{
${ }^{1}$ Currently known pair is defined as the presence of any pair observed during the past 5 years within the designated area.
} 


\section{Appendix Q: Standards and Guidelines}

Table Q2-Application of management strategles

\begin{tabular}{llc} 
Area & HCA \\
\hline
\end{tabular}

WASHINGTON

Cascade Province (east and west):

South Cascades

North Cascades

North Cascades/east

Columbia River Gorge

Olympic Peninsula

Southwest Washington

\section{OREGON}

Cascade Province (east and west):

Cascade/west

Columbia River Gorge

Cascades/east

Coast Range Province ${ }^{a}$

Klamath Province

\section{CALIFORNIA}

Klamath Province:

North Klamath Mountains

South Mendocino NF

Cascade/Modoc Province:

Shasta/McCloud Region

North Coast Range Province
South of Mount Rainier

North of Mount Rainier

Wenatchee (Entiat and Chelan Ranger

Districts) and Okanogan National Fore sts

South of Gifford-Pinchot National

Forest to river

Olympic Peninsula

South of Olympic Peninsula and west of Gifford Pinchot National Forest

California border to Mount Hood

North of Mount Hood to river

Deschutes National Forest (north of Bend)

Deschutes National Forest (south of Bend)

West of 1.5 and north of Highway 38

Roseburg south into California

Yolla Bolly Wilderness north into Orego:?

South of Yolla Bolly Wilderness

East and north of Clair Engle Reservoir

West and south of National Forest
1,4 (retention areas)

2,4 (retention areas)

3 (radius-based)

1

1,3 (radius-based)

1

$1,2,4$ (retention areas)

1

2,4 (retention areas)

3 (radius-based)

1,2,3 (radius-based)

1,4 (retention areas)

$1,2,4$ (retention areas)

1,2,3 (mapped)

4 (retention areas)

2,3 (mapped and radiusbased)

4 (mapped)

1,2,3,4 (mapped)

${ }^{a}$ For this table, part of the southern Coast Range between Highways 38 and 42 are included in the Klamath Province.

The size of Category 3 HCAs (single-pair HCAs) was determined either by (a) using the median annual home-range size (for HCAs delineated on the maps) or (b) using a radius to encompass the estimated home-range size for each State (for those HCAs not delineated on the maps-see Guidelines for Delineating Nonmapped HCAs later in this appendix).

The size of Category 4 HCAs (connector and retention areas) was determined either from (a) the availability of existing blocks under public ownership (for HCAs delineated on the maps) or (b) retention of at least 80 acres of suitable habitat around a known pair's center of activity (for those areas not delineated on the maps-see Guidelines for Delineating Nonmapped HCAs later in this appendix). 


\section{Appendix Q: Standards and Guidelines}

Shape and Quallty
of HCAs

Spacing between HCAs

Testing Application of the Guidelines

Test 1
The shape and quality of individual HCAs were based on the following considerations:

- Local topography and distribution of public lands.

- Provision of suitable habitat, or future capability to provide suitable habitat, with the structure and composition necessary to support the target number of pairs.

- Provision of contiguous suitable habitat within individual HCAs, given landscape constraints.

Spacing between individual HCAs was based on the following considerations:

- A maximum of 12 miles between Category 1 HCAs measured edge to edge (see appendix P).

- A maximum of 7 miles between Category 2 HCAs measured edge to edge (see appendix P).

- Spacing may be closer or farther for all categories of HCAs because of other circumstances or constraints (such as land ownership and landscape potential).

The following algorithm was used to test the application of the guidelines on the size of each HCA delineated on the State maps. This test was particularly useful in helping to establish HCA size in areas where 20 pairs may not currently exist.

\section{Steps:}

- We compiled the available home-range and density information by physiographic province; density information was restricted to density studies-that is, censuses of known areas, not surveys (see appendix l).

- We calculated the median annual home-range size of pairs by using the $100 \%$ minimum convex polygon method with an average overlap among adjacent pairs of $25 \%$, which gave an overlap correction factor of $(1-0.25)=0.75$ (see appendix I).

- We proposed an initial target population size (in number of pair sites) for a specific HCA and calculated the size of the HCA as follows:

(target number of pairs) $X$ (median annual home-range size) $\times(0.75)=$ estimated HCA size.

For example: (20 pairs) $\times(4000$ acres/pair)

$$
X(0.75)=60,000 \text { acres. }
$$

- Data used in the test were as geographically specific as possible because attributes such as density and home-range size vary geographically. If necessary, the HCA size was corrected for any included areas of permanently unsuitable habitat such as lakes, towns, and agricultural lands.

- We then determined if the HCA size was within $\pm 10 \%$ of the size projected from home-range or density information. If not, HCA size or the projected number of pair sites was re-evaluated or readjusted, as appropriate. 


\section{Appendix Q: Standards and Guidelines}

Adjusting Pair Projections From Test 1:

Direct application of the home-range or density algorithms used in Test 1 overestimate the expected number of pairs, because pair occupancy, at any given point, would be influenced by the dynamic and uncertain nature of past birth and death rates. For the spotted owl, these rates are strongly affected by processes arising from the patchy and irregular distribution of suitable habitat.

Factors that affect dispersal and mating success are functions of HCA size, the amount of suitable habitat within an HCA (percentage of the HCA that is, or will be, suitable habitat), and the spacing among HCAs. In general, smaller HCAs, or those with less suitable habitat, will have lower expected pair occupancy. The goal of the following adjustment is to correct expected pair-occupancy numbers to reflect demographic and mild environmental uncertainty.

\section{Steps:}

- The total number of pair sites in an HCA is estimated by both the application of the home-range and density algorithms. These two projections are averaged.

- The number of projected suitable pair sites at 100 years is taken from the results of Test 1 , above. The ratio of suitable to total pair sites is an estimate of the percentage of the HCA that is suitable.

- We computed model-based correction factors for average pair occupancy for HCAs ranging from 5 to 30 pair sites. We assumed a constant pair occupancy, and that $35 \%$ of the forested landscape was contained within the HCAs.

According to our estimates of forest land within HCAs and recent FS and BLM statistics, the current estimated percentage of suitable habitat in HCAs in the Pacific Northwest Region is about $38 \%$ and about $21 \%$ for the Pacific Southwest Region.

- We adjusted previous estimates of future expected pairs (Test 1) to account for HCA size, spacing, future percentage of suitable pair sites, and demographic and environmental uncertainty. Adjustment factors (table Q3) were based on the dynamic, metapopulation model described in appendix $M$.

Example: Assume an HCA with a projected number of future suitable pair sites equal to 10 , and an estimated total number of pair sites equal to 20 . The estimated percentage of sites suitable within the HCA is $50 \%(=10 / 20)$. In this example, the tabulated entry (table Q3) we use is for an HCA size of 20 sites and a percentage of suitable sites of $50 \%$. We enter table Q2 at row " 20 " and column "50." The correction factor is equal to 0.78 . The adjusted, future pairs is then equal to $0.78 \times 10$ pairs $=8$ pairs. (If the total number of sites is not tabulated, we round both to the closest tabulated value.)

Test 2

On completion of the above steps, a draft map for each State was available for testing the logical coherence of one or more map properties, such as HCA size, shape, and connectivity. 


\section{Appendix Q: Standards and Guidelines}

Table Q3 - Correction for projections of future expected pairs ${ }^{a}$

\begin{tabular}{lllllllll}
\hline $\begin{array}{l}\text { Total number } \\
\text { of pair sites } \\
\text { in the HCA }\end{array}$ & \multicolumn{7}{c}{ Percentage of HCA pair sites that are suitable } \\
\cline { 2 - 9 } & 30 & 40 & 50 & 60 & 70 & 80 & 90 & 100 \\
\hline 5 & 26 & 32 & 44 & 45 & 62 & 62 & 68 & 71 \\
7 & 29 & 39 & 52 & 54 & 63 & 72 & 74 & 75 \\
10 & 32 & 49 & 60 & 68 & 73 & 83 & 85 & 88 \\
12 & 43 & 57 & 65 & 70 & 78 & 82 & 88 & 88 \\
15 & 46 & 55 & 73 & 77 & 81 & 85 & 87 & 88 \\
17 & 47 & 63 & 76 & 79 & 84 & 89 & 90 & 90 \\
20 & 54 & 75 & 78 & 85 & 87 & 89 & 92 & 93 \\
25 & 65 & 76 & 82 & 88 & 92 & 92 & 93 & 94 \\
30 & 65 & 76 & 82 & 88 & 92 & 92 & 93 & 94 \\
\hline
\end{tabular}

a Tabled entries are the expected percentage, mean pair occupancies at 100 years. Computations were based on the assumption that $35 \%$ of the forested landscape was within the HCAs. See text for explanation.

\section{Steps:}

- We estimated several regression models to test the null hypothesis of no relation between the expected future number of pairs (dependent variable) and HCA size and perimeter (independent variables). The null hypothesis was rejected if one or more of the estimated regression coefficients were significantly different from zero.

- The best-fit regression model ${ }^{2}$ for all three States was:

$$
\begin{aligned}
\ln (\text { expected prs })= & b_{0}+b_{1} \ln (\text { HCA size }) \\
& +b_{2} \ln (\text { HCA perimeter) } .
\end{aligned}
$$

- We found, from all three States, a significant regression of expected number of pairs on HCA size and perimeter. Therefore, the hypothesis of logical consistency in this property (HCA expected pairs, size, and shape) of the map was supported.

- We used this regression model to further refine the map and improve its internal consistency. This refinement was done by using regression diagnostics to: determine observations with undue influence on the estimation of the regression model, identify observations with large standardized residuals, or identify HCAs with a large difference between the observed and predicted number of pairs.

- This process was continued iteratively until a satisfactory fit was found between the map and all the information that could be brought to bear to test the properties of the map.

Guidelines to Use in Delineating Nonmapped HCAs

Management of Habitat for Individual Pairs (Category 3)
Guidelines for agencies to use in delineating nonmapped HCAs (Category 3 radiusbased HCAs and Category 4 retention areas) should consider the criteria stated earlier for mapped HCAs for shape and quality. Guidelines for location and size are explained below; spacing did not apply.

Maintaining and recruiting suitable habitat around individual pairs is necessary in portions of the owl's range and is a further requirement of this strategy. These areas are to be retained regardless of changes in occupancy. For some Forests and BLM Districts, this requirement is in addition to other strategies (see table Q2 and description of State strategy).

\footnotetext{
${ }^{2}$ In = log normal; b = regression factor.
} 


\section{Appendix Q: Standards and Guidelines}

The following areas should establish Category 3 HCAs.

Washington:

Okanogan National Forest

Wenatchee National Forest (Entiat and Chelan Ranger Districts)

Olympic National Forest

Oregon:

Deschutes National Forest south of Bend

Siuslaw National Forest

BLM Districts north of Highway 38, west of $1-5$

California:

Shasta and Klamath National Forests north and east of Clair Engle reservoir and north and east of mapped HCAs

\section{Location}

- Availability of existing suitable habitat.

- Occurrence of a known pair or both known and future pairs (for further discussion, see Description of State Strategy later in this appendix).

- For those areas where protection outside of mapped HCAs is an additional requirement, the following applies:

Olympic Peninsula-protect all currently known pairs.

Oregon Coast Range (north of Highway 38)-protect all known and future pairs within a 12-mile-wide band around each HCA (measured from the edge) or half the distance to the next HCA if the distance is less than 12 miles.

Shasta/McCloud Area of Special Concern (north and east of Clair Engle Reservoir within the area of delineated HCAs) - protect all known and future pairs within a 12-mile-wide band around each Category 1 and 2 HCA (measured from the edge) or half the distance to the next Category 1 or 2 HCA if the distance is less than 12 miles; protect all known and future pairs in other areas until the possibility of improving the Category 3 situation in these areas can be assessed by the oversight committee established under this strategy.

Pairs outside of Category 1 and 2 HCAs should be protected until the number of pair areas outside the HCA, plus the number of known pairs within that HCA (as verified from 3 consecutive years of surveys), match the projected target for that HCA. The number of pair areas can be reduced proportionally as the number of pairs within the HCA approaches the target for that HCA according to the following formula:

(target number of pairs) - (known number of pairs inside $\mathrm{HCA})=$ number of pairs to be protected outside HCA.

Example: If the target number of pairs for an HCA is 20 and only 7 pairs are currently known within the HCA, then at least 13 pairs or the number of known 


\section{Appendix Q: Standards and Guidelines}

pairs (up to 13 after completion of surveys) outside of the HCA must be protected. If three additional pairs are located within the HCA (verified from 3 consecutive years of surveys using standard protocols), the number of pairs (or pair areas) protected outside of the HCA can be reduced by three.

- Surveys are sometimes incomplete and present data insufficient to establish the presence of pairs of spotted owls.

In the Shasta/McCloud Area of Special Concern (north and east of mapped HCAs), surveys to verify the presence of pairs of owls must be conducted for 3 consecutive years. Category 3 HCAs should be established for all verified pairs and for the repeated presence (within one location) of single owls during this period until the surveys are completed and the status of the owl population in this area can be determined by the committee established under this strategy.

\section{Size}

Retention Areas (Category 4)
- Delineate an area of suitable habitat using a circle with a 2.1-mile radius in Washington, a 1.5-mile radius in Oregon, and a 1.2-mile radius California. Adjust the circle to include the pair's center of activity (nest site or primary roost area) and the best arrangement of suitable habitat; the center of activity should be at least $1 / 4$ mile from the edge of the HCA, except where precluded by ownership boundaries or past logging.

Adjust boundaries, if necessary, to follow landscape configurations such as roads, streams, ridge tops, or previous sale boundaries, so long as suitable habitat encompassed by the original circle has not been reduced.

Centers of activity for currently known pairs of owls will be retained in addition to the HCAs that have been delineated on the maps. These areas will provide potential nesting habitat during subsequent rotations and offer the opportunity to return owls to the forest matrix in the future.

\section{Location}

- Occurence of known pairs throughout the owl's range, except in those areas where the only strategy is protection of all known pairs.

- $\quad$ Not to exceed 7 pairs (areas) per township.

\section{Size}

- Delineate the stand of trees containing the center of activity (nest site, principal roosting area, or both) and additional suitable habitat in the vicinity until at least 80 acres are designated or a distance of $1 / 4$ mile from the center of activity is reached, whichever occurs first.

- The center of activity need not be located in the geometric center of the designated acres, given topographic features and availability of suitable habitat; the 80 acres should be as contiguous as possible. 


\section{Appendix Q: Standards and Guidelines}

Management Prescriptions

Management Activities Within the HCA
The Committee believes the following management activities apply and need to be included in the conservation strategy. These management prescriptions apply to federally managed lands and are recommended for other land ownerships.

The HCA is the cornerstone of the conservation strategy. The success of the strategy depends on the habitat conditions in the HCAs. The following elements are important to ensure both short- and long-term viability of the northern spotted owl. To be consistent with the intent of this document, site-specific management plans must be developed for each Category 1, 2, or 3 HCA, explaining allowable, desired, and planned management activities in each area.

\section{Inventory and Monitoring}

- Within 3 years, determine owl densities within each HCA.

- Conduct (or have conducted within the past 2 years) at least six owl survey visits with a minimum of three visits in any one year before harvest of all sales under contract and any sales placed under contract in FY90. If pair occupancy is confirmed, refer to Timber Management section that follows.

- Monitor demographic and habitat trends in replicated samples of HCAs in each physiographic province, including banding all owls in selected areas.

\section{Timber Management}

- Prohibit timber harvest of any age-class of forest, except:

Sale units presently under contract that are more than $1 / 2$ mile from the center of activity of a known pair. Modify sales or sale units that are within 1/2 mile of pairs;

Substitute sales outside the HCA for any currently planned but unsold timber sales for FY90. If substitution is not an option, follow the stipulations described above; and

Review proposals case by case to remove individual or small groups of trees for administrative needs (for example, hazard trees or rock pit expansion) or for other resource management programs (for example, campground developments).

- Allow silvicultural treatments that have been tested or demonstrated through experimentation to facilitate the development of suitable habitat, such as planting trees (see appendix S).

- Prohibit firewood cutting, except for removal of logging slash from previously awarded units that exceed the dead-and-downed component.

- Prohibit salvage of any downed or standing trees. For special situations where salvage of extensive areas may be proposed, salvage activities must be approved by the interagency body organized to review implementation of the conservation strategy. 


\title{
Appendix Q: Standards and Guidelines
}

\author{
Fire Management
}

- Prepare a fire-management plan for each HCA.

\section{Road Construction}

- Road construction diminishes the quality and amount of owl habitat. Roads should be located in HCAs only when no feasible alternative is possible. When roads are constructed, they should be located and engineered to minimize the loss and alteration of habitat and should be situated at least $1 / 4$ mile from the activity center of any known pair.

\section{Land Exchanges}

- Prohibit exchange of forested lands from Federal ownership without approval of the interagency body organized to review implementation of the conservation strategy.

- Consider land exchanges to improve existing HCAs, especially in lands where public and private lands are intermingled (for example, BLM areas).

\section{Mining Operations}

Management Activities Within the Forest Matrix Outside of HCAs
- To determine effects on known pairs and suitable habitat, mining activities should be reviewed case by case for approval by the interagency body organized to review implementation of this conservation strategy.

Connectivity and retention of habitat characteristics for future breeding sites are important aspects of the conservation strategy in the long- and short-terms. To assure that adequate dispersal habitat and options to apply adaptive management are available in the forest matrix, the following prescriptions are required within the owl's range.

\section{Reserved Lands}

- No decrease will be made in the present direction of management for all forested lands in this category.

\section{Lands Unsulted for Timber Production}

- No decrease will be made in the present direction of management for all forested lands in this category.

\section{Lands Sulted for Timber Production}

- Retain existing considerations for other resource values such as wildlife trees and downed-wood retention.

- Establish 80-acre retention areas (Category 4 HCAs) around known pairs as previously discussed (see Guidelines to Use in Delineating Nonmapped HCAs), where all known pairs are not otherwise delineated. 


\section{Appendix Q: Standards and Guidelines}

- For every quarter township, timber harvest shall be permitted only when $50 \%$ of the forest landscape consists of forest stands with a mean d.b.h. of 11 inches and a canopy closure of $40 \%$ (50-11-40 rule). All land-use allocations on forest lands (except Category 1, 2, or 3 HCAs) and all ownerships within the quarter township contribute to meeting this rule.

\section{Steps:}

The percentage of the forest landscape (minus acreage in any Category 1,2 , or $3 \mathrm{HCA}$ ) is computed to meet the 50-11-40 rule for the quarter township where the proposed action is located.

Where the quarter township contains multiple ownerships, the percentage is computed separately for each owner, based on the amount of ownership.

Example: If owner $\mathrm{A}$ has 2880 acres in the quarter township, it would have a 1440-acre quota under the 50-11-40 rule before harvest would be permitted. If owners B and C each had 1440 acres, their quota under the rule would be 720 acres of forest stands, each with a mean d.b.h. of 11 inches and a $40 \%$ canopy closure.

Prorated quotas will be required for 3 years after the implementation of the conservation strategy. At the end of the 3-year period, the interagency body appointed to oversee the plan's implementation will re-evaluate the 50-11-40 rule as it applies in multiple-ownership areas.

- We recommend experimentation and testing of silvicultural treatments that improve, maintain, or develop suitable habitat over time (see appendix S). A long-term goal is to provide an opportunity for owls to occur in the managed forest matrix at populations sufficient to warrant review of the need to continue HCAs.

Description of the State Strategies

California
The following provides a brief description of the application of the guidelines used to delineate HCAs that were drawn by the Committee on the enclosed maps for each State (see appendix C and figure C3 for description of Areas of Special Concern).

In California, $99 \mathrm{HCAs}$ were established within the three physiographic provinces (table Q4). 


\section{Appendix Q: Standards and Guidelines}

Table Q4-Analysis of Habltat Conservation Areas in Callfornla (comments on Individual HCAs are IIsted at the end of table)

\begin{tabular}{|c|c|c|c|c|c|}
\hline $\begin{array}{l}\text { Habitat } \\
\text { Conservation } \\
\text { Area }\end{array}$ & $\begin{array}{c}\text { Gross }^{a} \\
\text { area } \\
\text { (acres) }\end{array}$ & $\begin{array}{c}\text { Known } \\
\text { pairs }\end{array}$ & $\begin{array}{c}\text { Total }^{c} \\
\text { estimated } \\
\text { pairs }\end{array}$ & $\begin{array}{l}\text { Future }^{d} \\
\text { expected } \\
\text { pairs }\end{array}$ & $\begin{array}{l}\text { Adjusted }^{\ominus} \\
\text { future } \\
\text { expected } \\
\text { pairs }\end{array}$ \\
\hline \multicolumn{6}{|c|}{ Forest Service Lands } \\
\hline C-1 & 113,000 & 14 & 18 & 26 & 25 \\
\hline$C-2$ & 55,000 & 8 & 17 & 20 & 18 \\
\hline$C-3$ & 40,000 & 23 & 25 & 24 & 22 \\
\hline C-4 & 57,000 & 19 & 20 & 25 & 23 \\
\hline$C-5$ & 83,000 & 10 & 16 & 22 & 19 \\
\hline C-6 & 48,000 & 11 & 16 & 20 & 19 \\
\hline C-7 & 11,000 & 7 & 7 & 5 & 3 \\
\hline C-8 & 145,000 & 19 & 30 & 40 & 37 \\
\hline C-9 & 7,000 & 3 & 3 & 3 & 2 \\
\hline$C-10$ & 52,000 & 14 & 18 & 22 & 20 \\
\hline C-11 & 183,000 & 20 & 28 & 40 & 36 \\
\hline C-12 & 58,000 & 16 & 18 & 24 & 22 \\
\hline$C-13$ & 44,000 & 15 & 18 & 22 & 20 \\
\hline C-14 & 45,000 & 8 & 8 & 10 & 7 \\
\hline C-15 & 87,000 & 11 & 20 & 21 & 18 \\
\hline C-16 & 71,000 & 7 & 11 & 20 & 18 \\
\hline$C-17$ & 46,000 & 3 & 5 & 14 & 12 \\
\hline C-18 & 43,000 & 2 & 4 & 12 & 10 \\
\hline C-19 & 29,000 & 4 & 4 & 7 & 2 \\
\hline C-20 & 5,600 & 4 & 4 & 3 & 2 \\
\hline C-21 & 16,000 & 1 & 3 & 5 & 3 \\
\hline$C-22$ & 4,000 & 1 & 1 & 1 & 0 \\
\hline C-23 & 4,800 & 1 & 1 & 1 & 0 \\
\hline$C-24$ & 2,900 & 1 & 1 & 1 & 0 \\
\hline C-25 & 400 & 1 & 1 & 1 & 0 \\
\hline$C-26$ & 1,500 & 1 & 1 & 1 & 0 \\
\hline$C-27$ & 2,300 & 1 & 1 & 1 & 0 \\
\hline C-28 & 43,000 & 6 & 6 & 6 & 4 \\
\hline C-29 & 30,000 & 2 & 3 & 5 & 2 \\
\hline C-30 & 14,000 & 1 & 2 & 3 & 1 \\
\hline$C-31$ & 50,000 & 4 & 5 & 7 & 3 \\
\hline C-32 & 4,400 & 2 & 2 & 2 & 1 \\
\hline C-33 & 3,800 & 1 & 1 & 1 & 0 \\
\hline$C-34$ & 3,000 & 1 & 1 & 1 & 1 \\
\hline C-35 & 5,700 & 1 & 1 & 2 & 1 \\
\hline$C-36$ & 2,300 & 1 & 1 & 1 & 0 \\
\hline C-37 & 5,500 & 2 & 2 & 2 & 1 \\
\hline C-38 & 4,300 & 0 & 0 & 2 & 1 \\
\hline C-39 & 3,900 & 0 & 0 & 1 & 0 \\
\hline$C-40$ & 2,400 & 0 & 1 & 1 & 0 \\
\hline$C-41$ & 2,600 & 0 & 0 & 1 & 0 \\
\hline C-42 & 64,000 & 7 & 10 & 15 & 12 \\
\hline See footnote on to & wing page. & & & & \\
\hline
\end{tabular}




\section{Appendix Q: Standards and Guidelines}

Table Q4-continued

\begin{tabular}{|c|c|c|c|c|c|}
\hline $\begin{array}{l}\text { Habitat } \\
\text { Conservation } \\
\text { Area }\end{array}$ & $\begin{array}{c}\text { Gross }^{a} \\
\text { area } \\
\text { (acres) }\end{array}$ & $\begin{array}{c}\text { Known } \\
\text { pairs }\end{array}$ & $\begin{array}{c}\text { Total }^{c} \\
\text { estimated } \\
\text { pairs }\end{array}$ & $\begin{array}{l}\text { Future }^{d} \\
\text { expected } \\
\text { pairs }\end{array}$ & $\begin{array}{l}\text { Adjusted }^{e} \\
\text { future } \\
\text { expected } \\
\text { pairs }\end{array}$ \\
\hline C-43 & 14,000 & 2 & 3 & 4 & 3 \\
\hline C-44 & 11,000 & 2 & 2 & 3 & 2 \\
\hline C-45 & 37,000 & 1 & 2 & 4 & 2 \\
\hline Subtotal & & 258 & 341 & 452 & 372 \\
\hline \multicolumn{6}{|c|}{ Other Federal, State, and Private Lands $f$} \\
\hline C-46 & $N A^{f}$ & $N A^{f}$ & 15 & 25 & 23 \\
\hline C-47 & 26,000 & 0 & 3 & 4 & 1 \\
\hline C-48 & 77,000 & 0 & 15 & 30 & 28 \\
\hline C-49 & 51,000 & 2 & 5 & 10 & 6 \\
\hline C-50 & 67,000 & 5 & 8 & 12 & 8 \\
\hline$C-51$ & 50,000 & 3 & 6 & 10 & 6 \\
\hline C-52 & 27,000 & 3 & 25 & 25 & 23 \\
\hline$C-53$ & 4,500 & 1 & 2 & 2 & 1 \\
\hline C-54 & 1,000 & 1 & 1 & 1 & 0 \\
\hline C-55 & 300 & 0 & 0 & 1 & 0 \\
\hline$C-56$ & 2,500 & 4 & 4 & 2 & 1 \\
\hline$C-57$ & 2,600 & 0 & 1 & 1 & 0 \\
\hline C-58 & 1,200 & 0 & $?^{g}$ & $?^{g}$ & $?^{g}$ \\
\hline C-59 & 2,900 & 0 & $?$ & $?$ & $?$ \\
\hline C- 60 & 1,800 & 0 & ? & $?$ & $?$ \\
\hline C-61 & 3,000 & 2 & 2 & 1 & 0 \\
\hline C-62 & 1,400 & 0 & $?$ & $?$ & $?$ \\
\hline C- 63 & 3,000 & 1 & 2 & 1 & 0 \\
\hline C-64 & 9,000 & 0 & 2 & 2 & 1 \\
\hline C- 65 & 7,300 & 1 & 1 & 2 & 1 \\
\hline C-66 & 11,800 & 0 & $?$ & 3 & 1 \\
\hline C- 67 & 6,900 & 1 & 1 & 2 & 1 \\
\hline$C-68$ & 1,500 & 0 & $?$ & $?$ & $?$ \\
\hline C- 69 & 1,400 & 0 & $?$ & $?$ & ? \\
\hline C-70 & 1,800 & 0 & $?$ & ? & ? \\
\hline C-71 & 800 & 0 & ? & ? & ? \\
\hline C-72 & 11,100 & 0 & 2 & 5 & 3 \\
\hline C-73 & 19,600 & 0 & 4 & 8 & 6 \\
\hline C-74 & 7,000 & 0 & $?$ & 1 & 0 \\
\hline C-75 & 4,700 & 0 & ? & $?$ & $?$ \\
\hline C-76 & 900 & 0 & $?$ & $?$ & $?$ \\
\hline C-77 & 1,700 & 0 & $?$ & $?$ & $?$ \\
\hline C-78 & 900 & 0 & 0 & 1 & 0 \\
\hline C-79 & 2,700 & 0 & $?$ & $?$ & $?$ \\
\hline$C-80$ & 4,800 & 0 & $?$ & $?$ & $?$ \\
\hline$C-81$ & 1,400 & 0 & $?$ & $?$ & ? \\
\hline
\end{tabular}




\begin{tabular}{|c|c|c|c|c|c|}
\hline $\begin{array}{l}\text { Habitat } \\
\text { Conservation } \\
\text { Area }\end{array}$ & $\begin{array}{c}\text { Gross }^{a} \\
\text { area } \\
\text { (acres) }\end{array}$ & $\begin{array}{c}\text { Known } \\
\text { pairs }\end{array}$ & $\begin{array}{c}\text { Total }^{c} \\
\text { estimated } \\
\text { pairs }\end{array}$ & $\begin{array}{l}\text { Future }^{d} \\
\text { expected } \\
\text { pairs }\end{array}$ & $\begin{array}{l}\text { Adjusted }^{\epsilon} \\
\text { future } \\
\text { expectec } \\
\text { pairs }\end{array}$ \\
\hline C-82 & 400 & 1 & 1 & 1 & 0 \\
\hline C-83 & 600 & 0 & 0 & 1 & 0 \\
\hline C- 84 & 1,400 & 0 & 1 & 1 & 0 \\
\hline C-85 & 1,700 & 0 & 1 & 1 & 0 \\
\hline C-86 & 50 & 1 & 1 & 0 & ? \\
\hline C-87 & 700 & 0 & 1 & 1 & 0 \\
\hline C-88 & 500 & 0 & 1 & 1 & 0 \\
\hline C-89 & 2,200 & 0 & 1 & 1 & 0 \\
\hline C-90 & 1,300 & 0 & 1 & 1 & 0 \\
\hline C-91 & 700 & 6 & 6 & 1 & 0 \\
\hline C-92 & 800 & 0 & 0 & 1 & 0 \\
\hline C-93 & 200 & 0 & 1 & 0 & 0 \\
\hline C-94 & 4,700 & 0 & 0 & 2 & 1 \\
\hline C-95 & 5,000 & 1 & 1 & 1 & 0 \\
\hline C-96 & 3,700 & 0 & $?$ & $?$ & $?$ \\
\hline C-97 & 1,900 & 1 & 1 & 1 & 0 \\
\hline C-98 & 4,900 & 1 & 1 & 2 & 0 \\
\hline C-99 & $N A^{f}$ & $N A^{f}$ & 195 & 205 & 185 \\
\hline Subtotal & & 35 & 312 & 370 & 296 \\
\hline Total & & 293 & 653 & 822 & 668 \\
\hline
\end{tabular}

a Gross acres include all land ownerships within the HCAs, and rivers, lakes, nonforested land, and other areas that will never provide spotted owl habitat. Private lands that may never provide suitable spotted owl habitat are also included.

${ }^{b}$ Number of known spotted owl pairs found in proposed HCAs during 1985-89. Forest Service records were used for National Forests; BLM, National Park, and California Department of Fish and Game records were used for all other lands.

${ }^{c}$ Total numbers of pairs estimated to occur in the HCA. Based on an assessment of several factors that include known locations, home-ranges of owls representative of the area, amounts of suitable habitat, elevation, and intensity of survey effort in the area.

Estimates of the number of pairs that could be expected when habitat fully recovers are based on the factors in footnote 3 above, plus an assessment of the proportion of the HCA that would become suitable. This assumes all pair areas within HCAs are 100\% occupied.

- Estimates of the number of pairs that could be expected when habitat fully recovers (as above in 4) but adjusted for demographic and environmental uncertainty.

' $N A$ = data not available; acreage totals and present number of pairs for BLM, State, and private lands are estimated, habitat capability unknown, or not available; private totals not included until the State-initiated habitat conservation plan is implemented.

$g$ Presence of pairs (estimated or future) is dependent upon availability of suitable habitat sufficient to support 1 or more pairs. 


\section{Appendix Q: Standards and Guidelines}

Table Q4-continued

Habitat

Conservation

Area

Comments

$\mathrm{C}-1$ and $\mathrm{C}-2$,

C-5 and C-6, C-10, $\mathrm{C}-12$ and $\mathrm{C}-13$ and $\mathrm{C}-16$

C-7 and C-9

C-14

C-17 through $\mathrm{C}-21$

C-22

C-23 through C-27, C-32 through $\mathrm{C}-41$

C-28 through C-31, C-42 through $\mathrm{C}-45$

C-46

C-47 through C-52
These HCAs contain 10 or more estimated pairs; all are expected to support 20 or more pairs in the future. Delineating habitat to support 20 current pairs would have included considerably larger amounts of unsuitable habitat and would have reduced interaction between pairs because of lack of continuity.

These HCAs do not support 20 pairs. Their function is to provide connectivity around a high-elevation Wilderness Area and to HCAs farther east.

Drier conditions have created a naturally fragmented landscape that may only support an estimated 10 pairs.

This drier and naturally fragmented habitat will not support more than 10 to 15 pairs in the future.

No other pair opportunity exists, and demographic support for a larger HCA (C-21) is needed at this edge of the subspecies' range.

Because of the naturally fragmented landscape, larger multipair HCAs are not possible. These HCAs provide connectivity to HCAs to the west and provide the link between the range of the northern spotted owl and the California spotted owl in the Sierra Nevada.

No opportunities exist to support Category 1 HCAs. HCAs are delineated where owls are currently known, future habitat opportunities sccur, and where the only demographic support for this local population is possible. Suitable habitat is not uniformly distributed over this region because of moisture and soil conditions.

Drier conditions have created a naturally fragmented landscape. Owl habitat on private lands is important for connectivity between HCAs and to provide additional support to the local population; this need currently being addressed in the State-initiated conservation plan.

Limited Federal land ownership does not provide opportunities to delineate Category 1 HCAs. These areas are critical for demographic support of the owl population in the northern California Coast Range. HCAs also provide for connectivity with HCAs on FS lands. 


\section{Appendix Q: Standards and Guidelines}

Table Q4-continued

Habitat

Conservation

Area

Comments

C-53 through C-81

All BLM parcels in the Northern California Coast Range Area of Special Concern are delineated as HCAs. Their size and distribution limits the ability of each parcel to support 20 pairs. Two areas may have the potential to support more than two pairs. Many of these small HCAs may not be able to support even a single pair of owls without additional suitable habitat on surrounding State or private lands. The value of these areas is to connect suitable habitats throughout the north coast area and to provide short-term demographic support and future nesting areas in conjunction with suitable habitat on private lands.

C-82 through C-98

These HCAs are small State parks that are managed for their natural forest values. Size and distribution limit their ability to support more than one or two pairs. They are included in this plan, but their role depends on the development of a State-sponsored habitat conservation plan. The value of these areas is the same as that explained above for the BLM parcels.

C-99

This HCA includes all private lands in the North Coastal Area of Special Concern being addressed in the Stateinitiated conservation plan. This plan will provide the long-term demographic base for the owl population in this area and connectivity between public lands.

\section{Category 1:}

The HCAs were designated, where possible, on the Six Rivers, Klamath, Trinity, and Mendocino National Forests in the Klamath physiographic province in California. National Forest lands in these areas presently contain some large blocks of contiguous suitable habitat and lands capable of becoming suitable habitat. Limited options exist to delineate Category $1 \mathrm{HCAs}$ because of topographic and landscape conditions; however, 13 Category 1 HCAs were delineated in these areas. Two Category 1 HCAs were delineated in the Coast Range (see below).

\section{Categories 2 and 3:}

In addition, 84 smaller HCAs were delineated on Forest Service land and other ownerships to meet the goals and objectives of this strategy, because of such problems as availability of public lands, land ownership, and natural landscape limitations. On the Shasta/McCloud Area of Special Concern, all known and future owls found in areas north and east of the delineated HCAs are designated as Category 3 HCAs. Category 3 designation applies until the species' status is determined for extreme 


\section{Appendix Q: Standards and Guidelines}

eastern Siskiyou County and Modoc County and better HCAs can be delineated (see previous Guidelines to Use in Delineating Nonmapped HCAs). Otherwise, all known and future pairs of owls located in the area north and east of Clair Engle Reservoir will be maintained as Category 3 HCAs until target densities are reached within this Area of Concern.

\section{Category 4:}

Category 4 ( 80 -acre retention areas) will be designated to retain habitat around the centers of activity or known pairs of owls to provide connectivity and opportunities for future nest sites.

\section{State, Tribal, and Private Lands:}

Private lands in northern California currently support a significant portion of the spotted owl population in northern California. Inadequate Federal land exists in these areas to fully apply the standards and guidelines to sustain owl viability. Maintaining a viable owl population on these lands is critical. Unless these populations are maintained, a dramatic reduction in the owl population will occur in the coastal area from Marin County north to Humboldt County, and in the area east of Clair Engle Reservoir. Tribal lands in these areas are also important, particularly those of the Hoopa Indian Nation.

We designated the existing large parcels of State and Federal lands as HCAs to maintain multiple pairs. Only two of these HCAs (C-48, C-52) are capable of supporting 20 or more pairs. In addition, we designated all of the small scattered BLM and appropriate State Park parcels as Category $4 \mathrm{HCAs}$ to provide connectivity, and as habitat to support owls in conjunction with private lands. In the short term, these public lands contribute toward population distribution.

The system of HCAs on Federal lands may result in an average density of about 1.7 pairs per township. Given the owl populations now on private lands in the Shastal McCloud and northern California Coast range, a similar density on the higher site quality, lower elevation lands in private ownership would be possible. We recommend that a State-initiated habitat conservation plan be written to provide a system to augment owls on Federal lands. Designated HCAs on private lands in the Shasta/ $\mathrm{McCloud}$ area should provide an area-wide density similar to that on Forest Service lands ( 1.7 pairs per township). In the northern California Coast Range, tribal and private lands should provide additional suitable habitat so that owl populations achieve an area-wide density similar to that on Forest Service lands (1.7 pairs per township) including all land ownerships. Pairs should be interactive but also maintain wide-spread distribution.

The Committee recommends that surveys should be conducted on tribal lands in consultation with agency biologists, and that HCAs be delineated to complement or support HCAs on Federal lands. 


\section{Appendix Q: Standards and Guidelines}

Oregon

The State of California has expertise in wildlife biology and forestry, a long record of cooperative ventures with private landowners and Federal land management agencies, and legal mandates to regulate forestry practices and manage wildlife on State and private lands. Some private landholders have recently begun to inventory and study the owl. The Committee recognizes that management on private and State lands represents a considerably different scenario than does management on Federal lands. Therefore, we believe that management of suitable habitat on private and State lands should be carried out under the leadership of the State with cooperation of private landowners. The State, with its cooperators, should prepare a habitat conservation plan within 1 year that specifies how the owl population is to be maintained, and how the necessary monitoring and research to guide adaptive management will be carried out.

In Oregon, $50 \mathrm{HCAs}$ were established within the four identified physiographic provinces (table Q5).

\section{Category 1:}

In the Cascades (west side), Klamath, and southern portion of the Coast Range provinces, 39 Category 1 HCAs were delineated, accounting for nearly $78 \%$ of the HCA locations in the State. The other $22 \%$ of the HCAs were treated case by case, depending on local habitat conditions. Explanations of these HCAs are contained in table Q5.

\section{Categories 2 and 3:}

In addition, 10 Category $2 \mathrm{HCAs}$ were delineated, 5 in the northern portion of the Deschutes National Forest, 3 in the Coast Range Area of Special Concern, 1 as a connector between the Cascades and Coast Ranges, and 1 as a connector to the Goosenest Ranger District in California. For the southern portion of the Deschutes National Forest, Category 3 HCAs will be designated for all known pairs of owls. In the Coast Range Area of Special Concern, Category 3 HCAs will be designated for all additional known and future pairs (see previous Guidelines to Use in Delineating Nonmapped HCAs). Protection of these pairs is necessary until target densities are reached for HCAs within this area of concern. One HCA (0-1) is significantly larger than the others because it occurs in proximity to the Columbia River and constitutes a critical connection between Oregon and Washington. For further details, see Table Q5.

\section{Category 4:}

Category 4 (80-acre retention areas) will be designated to retain habitat around the centers of activity or known pairs of owls to provide connectivity and opportunities for future nest sites. 


\section{Appendix Q: Standards and Guidelines}

Table Q5-Anaiysis of Habitat Conservation Areas in Oregon (comments on individual HCAs listed at end of tabie)

\begin{tabular}{|c|c|c|c|c|c|}
\hline $\begin{array}{l}\text { Habitat } \\
\text { Conservation } \\
\text { Area }\end{array}$ & $\begin{array}{c}\text { Gross }^{a} \\
\text { area } \\
\text { (acres) }\end{array}$ & $\begin{array}{c}\text { Known } \\
\text { pairs }\end{array}$ & $\begin{array}{c}\text { Total }^{c} \\
\text { estimated } \\
\text { pairs }\end{array}$ & $\begin{array}{l}\text { Future }^{d} \\
\text { expected } \\
\text { pairs }\end{array}$ & $\begin{array}{l}\text { Adjusted }^{\theta} \\
\text { future } \\
\text { expected } \\
\text { pairs }\end{array}$ \\
\hline \multicolumn{6}{|c|}{ Forest Service and Bureau of Land Management Lands } \\
\hline $0-1$ & 136,000 & 8 & 35 & 40 & 37 \\
\hline $0-2$ & 67,000 & 6 & 20 & 23 & 21 \\
\hline $0-3$ & 81,000 & 6 & 20 & 25 & 23 \\
\hline $0-4$ & 80,000 & 8 & 20 & 27 & 25 \\
\hline $0-5$ & 75,000 & 13 & 20 & 25 & 23 \\
\hline $0-6$ & 78,000 & 18 & 25 & 25 & 23 \\
\hline $0-7$ & 69,000 & 19 & 21 & 27 & 25 \\
\hline $0-8$ & 93,000 & 12 & 24 & 25 & 22 \\
\hline $0-9$ & 82,000 & 11 & 21 & 26 & 24 \\
\hline $0-10$ & 65,000 & 9 & 20 & 23 & 21 \\
\hline $0-11$ & 77,000 & 18 & 22 & 24 & 22 \\
\hline $0-12$ & 86,000 & 30 & 30 & 26 & 24 \\
\hline $0-13$ & 84,000 & 10 & 25 & 26 & 24 \\
\hline $0-14$ & 80,000 & 13 & 24 & 27 & 25 \\
\hline $0-15$ & 89,000 & 8 & 20 & 23 & 20 \\
\hline $0-16$ & 84,000 & 19 & 21 & 24 & 22 \\
\hline $0-17$ & 55,000 & 24 & 25 & 27 & 25 \\
\hline $0-18$ & 66,000 & 13 & 20 & 22 & 20 \\
\hline $0-19$ & 93,000 & 14 & 23 & 32 & 29 \\
\hline O-20 & 67,000 & 14 & 20 & 20 & 17 \\
\hline $0-21$ & 77,000 & 8 & 20 & 24 & 22 \\
\hline $0-22$ & 64,000 & 13 & 20 & 21 & 20 \\
\hline $0-23$ & 115,000 & 2 & 20 & 25 & 21 \\
\hline $0-24$ & 75,000 & 6 & 20 & 22 & 20 \\
\hline $0-25$ & 78,000 & 9 & 20 & 26 & 24 \\
\hline $0-26$ & 86,000 & 18 & 21 & 25 & 23 \\
\hline $0-27$ & 76,000 & 14 & 20 & 30 & 28 \\
\hline $0-28$ & 78,000 & 21 & 23 & 26 & 24 \\
\hline $0-29$ & 60,000 & 6 & 15 & 21 & 20 \\
\hline $0-30$ & 76,000 & 10 & 12 & 27 & 25 \\
\hline $0-31$ & 68,000 & 10 & 15 & 25 & 23 \\
\hline $0-32$ & 68,000 & 5 & 11 & 23 & 21 \\
\hline $0-33$ & 55,000 & 4 & 9 & 22 & 20 \\
\hline $0-34$ & 59,000 & 5 & 10 & 23 & 21 \\
\hline $0-35$ & 53,000 & 2 & 5 & 21 & 20 \\
\hline $0-36$ & 74,000 & 1 & 3 & 28 & 26 \\
\hline $0-37$ & 47,000 & 3 & 3 & 18 & 17 \\
\hline $0-38$ & 18,000 & 2 & 3 & 7 & 5 \\
\hline $0-39$ & 23,000 & 2 & 2 & 5 & 2 \\
\hline $0-40$ & 42,000 & 6 & 11 & 16 & 14 \\
\hline $0-41$ & 8,000 & 1 & 1 & 2 & 1 \\
\hline $0-42$ & 20,000 & 4 & 4 & 4 & 2 \\
\hline
\end{tabular}




\section{Appendix Q: Standards and Guidelines}

Table Q5-continued

\begin{tabular}{|c|c|c|c|c|c|}
\hline $\begin{array}{l}\text { Habitat } \\
\text { Conservation } \\
\text { Area }\end{array}$ & $\begin{array}{c}\text { Gross }^{a} \\
\text { area } \\
\text { (acres) }\end{array}$ & $\begin{array}{c}\text { Known } \\
\text { pairs }\end{array}$ & $\begin{array}{c}\text { Total }^{c} \\
\text { estimated } \\
\text { pairs }\end{array}$ & $\begin{array}{l}\text { Futured } \\
\text { expected } \\
\text { pairs }\end{array}$ & $\begin{array}{c}\text { Adjusted }^{\epsilon} \\
\text { future } \\
\text { expected } \\
\text { pairs }\end{array}$ \\
\hline 0.43 & 12,000 & 2 & 3 & 3 & 1 \\
\hline $0-44$ & 11,000 & 2 & 2 & 3 & 1 \\
\hline $0-45$ & 15,000 & 1 & 3 & 3 & 1 \\
\hline Subtotal & & 430 & 732 & 967 & 874 \\
\hline \multicolumn{6}{|l|}{ State Lands } \\
\hline 0.46 & 65,000 & 0 & 0 & 25 & 23 \\
\hline $0-47$ & 58,000 & 0 & 0 & 23 & 22 \\
\hline $0-48$ & 65,000 & 0 & 2 & 26 & 24 \\
\hline $0-49$ & 21,000 & 0 & 1 & 4 & 2 \\
\hline $0-50$ & 8,000 & 0 & 1 & 2 & 1 \\
\hline Subtotal & & 0 & 4 & 80 & 72 \\
\hline Total & & 430 & 736 & 1047 & 946 \\
\hline
\end{tabular}

a Gross acres include all land ownerships within the HCAs, and rivers, lakes, nonforested areas, and other areas that will never provide spotted owl habitat. Private lands that may never provide suitable spotted owl habitat area are also included.

${ }^{b}$ Number of known spotted owl pairs found in proposed HCAs during 1985-89. Forest Service records were used for National Forests; BLM records for all Bureau lands, National Park Service records were used for National Parks, and Oregon Department of Fish and Wildlife records were used for State and Private lands.

c Total numbers of pairs estimated to occur in the HCA. Based on an assessment of several factors that include known locations, home ranges of owls representative of the area, amounts of suitable habitat, elevation, and intensity of survey effort in the area.

${ }^{d}$ Estimates of the number of pairs that could be expected when habitat fully recovers are based on the factors in footnote 3 above, plus an assessment of the proportion of the HCA that would become suitable. This assumes all pair areas within HCAs are $100 \%$ occupied.

Estimates of the number of pairs that could be expected when habitat fully recovers (as above in 4) but adjusted for demographic and environmental uncertainty. 


\section{Appendix Q: Standards and Guidelines}

Table Q5-continued

Habitat

Conservation

Area

Comments

$0-29$ through $0-36$

Low densities of owls prevented delineating HCAs supporting 20 interacting pairs. HCAs were established which, on habitat recovery, will support 20 interacting pairs.

$0-37$ through $0-39$

Low densities of owls prevented delineating HCAs supporting 20 interacting pairs. In addition, Federal land is insufficient to create an area capable of supporting 20 pairs even in the future. These HCAs are important for connectivity and as multipair areas.

$0-40$

$0-41$ through $0-45$

$0-46$ through $0-49$

$0-50$
This HCA was delineated to provide connectivity to HCA C-28 in California.

The scattered distribution of owls and habitat arrangement on the northern Deschutes National Forest prevented delineating a large HCA capable of supporting 20 pairs of owls either now or in the future.

These HCA's are on lands administered by the Oregon Department of Forestry and fall within the Oregon Coast Range Area of Special Concern. As a result of wildfires, forests are generally 40 to 90 years old. Currently, owl densities are extremely low, but with recovery of suitable habitat, each of these areas could support 20 pairs. These HCAs will provide connectivity from northwestern Oregon to southwestern Washington and the Olympic Peninsula.

This small HCA is administered by Oregon Department of Forestry. It currently includes some older stands and may support a pair of spotted owls. This HCA also contributes to supporting owl pairs on adjacent BLM lands (HCA $0-4$ ).

State, Tribal, and Private Lands:

The HCAs in Oregon are comprised primarily of lands administered by the Forest Service, BLM, and the State of Oregon. In some instances, particularly in the Klamath and Coast Range provinces, the BLM lands are intermingled with private timber company lands. Although management of intermingled lands may not produce superior habitat for owls, we propose that private landowners manage their lands to provide foraging habitat to support owls that are nesting on adjacent BLM lands. The HCAs on lands administered by the Oregon Department of Forestry in northwest Oregon are the sole opportunity for re-establishing the owl in a key portion of its historic range; thus, they are important to the success of this strategy. 


\section{Appendix Q: Standards and Guidelines}

Washington
The Committee recognizes that management on private and State lands differs considerably from management on Federal lands. Therefore, we believe that management of suitable habitat on private and State lands should be carried out under the leadership of the State with the cooperation of private land owners. The State, with its cooperators, should prepare a habitat conservation plan, as is the State of California, that specifies how an owl population is to be managed, and how the necessary monitoring and research to guide adaptive management will be carried out.

The Committee recommends that surveys should be conducted on tribal lands in consultation with agency biologists, and that HCAs be delineated to complement or support HCAs on Federal lands.

In Washington, 44 HCAs were established (table Q6).

\section{Category 1:}

HCAs were delineated, where possible, on all of the Gifford Pinchot National Forest south of Mount Rainier, including potentially suitable habitat in Mount Rainier National Park and the Goat Rocks Wilderness. One HCA (W-1) was significantly larger than the other two in this area because of its proximity to the Columbia Gorge and concerns for demographic and genetic interaction between owls in Oregon and Washington. See table Q6 for further details.

Geographic areas capable of supporting potential 20-pair areas include the broad band of intermingled ownership lands known as the "I-90 corridor," the Swauk Pass and Lake Wenatchee regions of the Wenatchee National Forest, and portions of the Darrington and Mount Baker Ranger Districts on the Mount Baker-Snoqualmie National Forest. Six Category 1 HCAs were established in these areas. They are currently estimated to average 10 pairs of spotted owls each.

\section{Categorles 2 and 3:}

Because of low densities of spotted owls north and east of Mount Rainier National Park, delineating HCAs that could currently contain 20 pairs would require the inclusion of broad geographic areas that would probably not function to provide suitable habitat for an interactive subpopulation. This area includes all of the Mount Baker-Snoqualmie, Wenatchee, and Okanogan National Forests and the North Cascades National Park. Much of the moderate elevational forest land that exists in this region has been heavily logged and supports reduced populations of owls. Therefore, 24 Category 2 HCAs were delineated in these areas.

Because of the low number and patchy distribution of suitable owl habitat in the northeast Cascades, all known pairs on the Okanogan National Forest and Entiat and Chelan Ranger Districts of the Wenatchee National Forest are designated as Category 3 HCA's (see previous Guidelines to Use in Delineating Nonmapped HCAs). 


\section{Appendix Q: Standards and Guidelines}

Table Q6-Analysis of Habltat Conservation Areas in Washington (comments on indiviuai HCAs iisted at end of tabie)

\begin{tabular}{|c|c|c|c|c|c|}
\hline $\begin{array}{l}\text { Habitat } \\
\text { Conservation } \\
\text { Area }\end{array}$ & $\begin{array}{c}\text { Gross }^{a} \\
\text { area } \\
\text { (acres) }\end{array}$ & $\begin{array}{c}\text { Known } \\
\text { pairs }\end{array}$ & $\begin{array}{l}\text { Total }^{c} \\
\text { estimated } \\
\text { pairs }\end{array}$ & $\begin{array}{l}\text { Future }^{d} \\
\text { expected } \\
\text { pairs }\end{array}$ & $\begin{array}{l}\text { Adjusted }^{\theta} \\
\text { future } \\
\text { expected } \\
\text { pairs }\end{array}$ \\
\hline \multicolumn{6}{|c|}{ Forest Service and National Park Lands } \\
\hline W-1 & 176,000 & 20 & 23 & 35 & 33 \\
\hline W-2 & 146,000 & 22 & 24 & 28 & 26 \\
\hline W-3 & 132,000 & 17 & 21 & 25 & 23 \\
\hline$W-4$ & 140,000 & 12 & 12 & 30 & 28 \\
\hline W-5 & 126,000 & 7 & 9 & 25 & 23 \\
\hline W-6 & 119,000 & 11 & 15 & 25 & 23 \\
\hline$W-7$ & 112,000 & 6 & 10 & 22 & 21 \\
\hline$W-8$ & 111,000 & 4 & 5 & 23 & 22 \\
\hline W-9 & 106,000 & 11 & 11 & 20 & 19 \\
\hline$W-10$ & 49,000 & 3 & 3 & 10 & 9 \\
\hline W-11 & 16,000 & 2 & 2 & 3 & 2 \\
\hline W-12 & 26,000 & 2 & 3 & 4 & 2 \\
\hline$W-13$ & 13,000 & 2 & 2 & 2 & 1 \\
\hline$W-14$ & 10,000 & 2 & 2 & 2 & 1 \\
\hline$W-15$ & 35,000 & 1 & 3 & 6 & 4 \\
\hline$W-16$ & 59,000 & 8 & 9 & 12 & 11 \\
\hline$W-17$ & 28,000 & 1 & 1 & 5 & 3 \\
\hline$W-18$ & 29,000 & 2 & 2 & 4 & 3 \\
\hline$W-19$ & 67,000 & 2 & 4 & 10 & 8 \\
\hline$W-20$ & 23,000 & 3 & 3 & 4 & 2 \\
\hline$W-21$ & 11,000 & 2 & 2 & 2 & 1 \\
\hline$W-22$ & 8,000 & 1 & 2 & 2 & 1 \\
\hline$W-23$ & 13,000 & 1 & 2 & 2 & 1 \\
\hline$W-24$ & 39,000 & 6 & 7 & 7 & 5 \\
\hline W-25 & 25,000 & 2 & 2 & 4 & 2 \\
\hline W-26 & 27,000 & 4 & 5 & 5 & 3 \\
\hline$W-27$ & 15,000 & 2 & 3 & 3 & 2 \\
\hline W-28 & 73,000 & 5 & 8 & 12 & 10 \\
\hline W-29 & 27,000 & 0 & 2 & 5 & 3 \\
\hline$W-30$ & 16,000 & 1 & 2 & 3 & 2 \\
\hline$W-31$ & 23,000 & 1 & 2 & 4 & 3 \\
\hline W-32 & 41,000 & 3 & 4 & 7 & 5 \\
\hline W-33 & 39,000 & 0 & 2 & 5 & 3 \\
\hline W-34 & 101,000 & 0 & 5 & 14 & 11 \\
\hline$W-35$ & 16,000 & 0 & 1 & 2 & 1 \\
\hline$W-36$ & 676,000 & 54 & 131 & 146 & 137 \\
\hline Subtotal & & 220 & 344 & 518 & 454 \\
\hline \multicolumn{6}{|c|}{ State and Other Federal Lands } \\
\hline W-37 & 12,000 & 1 & 1 & 1 & 0 \\
\hline W-38 & 64,000 & 4 & 5 & 8 & 6 \\
\hline
\end{tabular}




\section{Appendix Q: Standards and Guidelines}

Table Q6-contInued

\begin{tabular}{lccccc}
\hline $\begin{array}{l}\text { Habitat } \\
\text { Conservation } \\
\text { Area }\end{array}$ & $\begin{array}{c}\text { Gross }^{a} \\
\text { area } \\
\text { (acres) }\end{array}$ & $\begin{array}{c}\text { Known }^{b} \\
\text { pairs }\end{array}$ & $\begin{array}{c}\text { Total }^{c} \\
\text { estimated } \\
\text { pairs }\end{array}$ & $\begin{array}{c}\text { Future }^{d} \\
\text { expected } \\
\text { pairs }\end{array}$ & $\begin{array}{c}\text { Adjusted }^{e} \\
\text { future }^{\text {expected }} \\
\text { pairs }\end{array}$ \\
\hline W-39 & 82,000 & 0 & 0 & 17 & 15 \\
W-40 & 129,000 & 0 & 0 & 27 & 25 \\
W-41 & 104,000 & 0 & 0 & 22 & 20 \\
W-42 & 94,000 & 1 & 4 & 20 & 19 \\
W-43 & 68,000 & 0 & 0 & 14 & 12 \\
W-44 & 33,000 & 0 & 0 & 6 & 4 \\
\cline { 3 - 6 } Subtotal & & 6 & 10 & 115 & 101 \\
\cline { 3 - 6 } Total & & 226 & 354 & 633 & 555 \\
\hline
\end{tabular}

a Gross acres include all land ownerships within the HCAs, and rivers, lakes, nonforested areas, and other areas that will never provide spotted owl habitat. Private lands that may never provide suitable or superior spotted owl habitat are included.

${ }^{b}$ Known locations of spotted owl pairs found in proposed HCAs during 1985-89. Forest Service records were used for National Forests, Washington Department of Wildlife and National Park Service records were used for National Parks, and Washington Department of Wildlife records were used for State and private lands.

${ }^{c}$ Total numbers of pairs estimated to occur in the HCA. Based on an assessment of several factors that include known locations, home ranges of owls representative of the area, amounts of suitable habitat, elevation, and intensity of survey effort in the area.

Estimates of the number of pairs that could be expected when habitat fully recovers are based on the factors in footnote 3 above, plus an assessment of the proportion of the HCA that would become suitable. This assumes all pair areas within HCAs are $100 \%$ occupied.

- Estimates of the number of pairs could be expected when habitat fully recovers (as above in 4) but adjusted for demographic and environmental uncertainty.

HCA number

Comments

W-4 through W-9

These HCAs are currently estimated to contain fewer than 20 pairs of owls, each with potential to increase to 20 pairs. Smaller, multipair areas were delineated in this area to address local demographic, distribution, and linkage concerns.

W-10

This HCA is surrounded by intensively managed private timber lands and is separated from the Gifford Pinchot National Forest by about 12 miles. It is important for genetic connectivity between the Cascade Range and the Olympic Peninsula.

W-11 through W-35

Because of natural habitat limitations and low population densities, HCA's were delineated for potentially 2 to 14 pairs of owls. 


\section{Appendix Q: Standards and Guidelines}

Table Q6-continued

HCA number

Comments

W-36

An HCA was established around the Olympic National

Park to increase habitat connectivity between major drainages, to include habitat at a variety of elevations, and to support a potentially isolated population.

W-37, W-38

These HCA's are adjacent to the Olympic National Park on State lands administered by the Washington Department of Natural Resources. These HCAs are necessary to demographically support the local owl population.

W-39 through W-41

These HCA's are located on lands administered by the Washington Department of Natural Resources. Forests are generally less than 70 years old as a result of windstorms and logging. Although no owls are presently known to occur here, these HCAs are necessary to improve connectivity between the Olympic Peninsula, the Oregon Coast Range, and the Washington Cascades.

W-42

This HCA is important to maintain demographic connectivity between the Oregon and Washington populations of owls.

W-43

This HCA is located entirely on the Fort Lewis Military Reservation. Forests are generally less than 70 years old. We recommend that lands be managed to improve connectivity with the Washington Cascades and the Olympic Peninsula population.

W-44

This forest land is administered by Washington Department of Wildlife. Stands are generally less than 30 years old but are expected to provide future owl habitat. When combined with HCA W-16, they form a contiguous block capable of supporting about 20 pairs of owls.

\section{Category 4:}

Category 4 ( 80 -acre retention areas) will be designated to retain habitat around the centers of activity or known pairs of owls to provide connectivity and opportunities for future nest sites. 


\section{Appendix Q: Standards and Guidelines}

\section{Olympic Peninsula:}

On the Olympic Peninsula, one large HCA (W-36) was delineated to encompass a contiguous band of habitat surrounding the perimeter of Olympic National Park. Potential owl habitat essentially takes the shape of a large doughnut, with the center being an impassable mountain barrier. This band of habitat will provide for a welldistributed population at a range of elevations on the Olympic National Forest, and will increase connectivity between large tracts of habitat in major drainages of the Peninsula. In addition, all currently known pairs in the Olympic Peninsula Area of Special Concern are designated as Category 3 HCAs. Protection of these pairs is necessary until the target density is reached for the HCA established in this area.

Two smaller HCAs (W-37, W-38) were delineated on State lands adjacent to Federal lands on the Peninsula. Both HCAs will be contiguous with W-36, and add to the number and distribution of spotted owls on the Peninsula. The Committee strongly recommends to the State of Washington that these HCAs be established.

\section{Other State, Trlbal, and Private Lands:}

Four HCAs (W-39 to W-42) were delineated on State lands in southwest Washington and the Columbia Gorge. These HCAs are located in Areas of Special Concern, and we strongly recommend to the State of Washington that they be established. An HCA (W-17) was delineated in the Cedar River Watershed near North Bend. Lands within W-17 are comprised of alternating sections of City of Seattle and Forest Service ownership. The Committee strongly recommends to the City of Seattle that they manage their lands within this area as an HCA.

The Committee recognizes that management on private and State lands differs considerably from management on Federal lands. Therefore, we believe that management of suitable habitat on private and State lands should be carried out under the leadership of the State with the cooperation of private land owners. The State, with its cooperators, should prepare a habitat conservation plan, as is the State of California, that specifies how an owl population can be managed, and how the necessary monitoring and research to guide adaptive management will be carried out.

Spotted owls are known to occur on lands of the Yakima and Quinault Indian Nations. No HCAs were delineated on these or other tribal lands because maps and habitat information are lacking. The Committee recommends that Indian Nations, in consultation with State and Federal biologists, establish HCAs on their lands to maintain connectivity between HCAs on Forest Service lands.

Summary of Acreage Totals in HCAs for All Lands
Table Q7 contains an estimate of the gross acreage totals by land ownership for those lands included in the HCAs delineated on the State maps. Acreage for nonmapped HCAs are not included.

- Gross areas include all lands within the designated borders of each HCA regardless of their potential for owl habitat (for example, roads, lakes, meadows); actual amount of currently suitable habitat within HCAs was not calculated. 


\section{Appendix Q: Standards and Guidelines}

- Acres of habitat within Wilderness Areas are totaled separately. Acres for other reserved or withdrawn areas have not been calculated; they are included in the totals for all lands (other than Wilderness Areas).

- Acreage estimates for lands suited for timber production are included in the total column with other reserved and withdrawn lands; they are not identified separately.

Table Q7-Estimated acreage by State and agency In mapped HCAs ${ }^{a}$

\begin{tabular}{|c|c|c|c|}
\hline $\begin{array}{l}\text { State } \\
\text { Agency }\end{array}$ & $\begin{array}{c}\text { Wilderness Areas } \\
\text { or Parks }\end{array}$ & $\begin{array}{l}\text { Outside Wilderness } \\
\text { Areas or Parks }\end{array}$ & Total \\
\hline \multicolumn{4}{|l|}{ California } \\
\hline Forest Service & 365,000 & $1,199,000^{b}$ & $1,564,000$ \\
\hline Bureau of Land Management & 5,000 & $175,000^{b}$ & 180,000 \\
\hline National Park Service & 86,000 & - & 86,000 \\
\hline State ${ }^{c}$ & 129,000 & 50,000 & 179,000 \\
\hline Private $^{d}$ & - & N/A & N/A \\
\hline Subtotal: & 585,000 & $1,424,000^{b}$ & $2,009,000$ \\
\hline \multicolumn{4}{|l|}{ Oregon } \\
\hline Forest Service & 447,000 & $1,381,000^{b}$ & $1,828,000$ \\
\hline Bureau of Land Management & 15,000 & $749,000^{b}$ & 764,000 \\
\hline National Park Service & - & - & - \\
\hline State ${ }^{c}$ & - & 204,000 & 204,000 \\
\hline Private $^{d}$ & - & N/A & N/A \\
\hline Subtotal: & 462,000 & $2,334,000^{b}$ & $2,796,000$ \\
\hline \multicolumn{4}{|l|}{ Washington } \\
\hline Forest Service & 313,000 & $1,627,000^{b}$ & $1,940,000$ \\
\hline Bureau of Land Management & - & - & - \\
\hline National Park Service & 537,000 & - & 537,000 \\
\hline Other Federal (Fort Lewis) & - & 67,000 & 67,000 \\
\hline State $^{c}$ & - & 375,000 & 375,000 \\
\hline Private $^{d}$ & - & N/A & N/A \\
\hline Subtotal: & 850,000 & $2,069,000^{b}$ & $2,919,000$ \\
\hline \multicolumn{4}{|c|}{ Summary - California, Oregon, and Washington } \\
\hline Forest Service & $1,125,000$ & $4,207,000^{b}$ & $5,332,000$ \\
\hline Bureau of Land Management & 20,000 & $924,000^{6}$ & 944,000 \\
\hline National Park Service & 623,000 & - & 623,000 \\
\hline Other Federal (Fort Lewis) & - & 67,000 & 67,000 \\
\hline State ${ }^{c}$ & 129,000 & 629,000 & 758,000 \\
\hline Private $^{d}$ & - & N/A & N/A \\
\hline Total: & $1,897,000$ & $5,827,000^{b}$ & $7,724,000$ \\
\hline
\end{tabular}

a These are gross acreage figures (rounded to the nearest 1000) that include all land types within HCAs, including lakes, streams, roads, meadows, and other land forms that may never be owl habitat; acreage figures for nonmapped HCAs have not been calculated.

$b$ Includes 20 to $30 \%$ (actual estimates not calculated) lands allocated to uses other than timber production such as roadless recreation areas, riparian corridors, and wild and senic rivers, or lands unsuitable for timber production because of unstable soils or tree regeneration problems; the balance may be currently suited for timber production.

Acreage of State lands recommended to be included in the HCAs.

d Private land acreages in HCAs are not applicable (N/A) and were not included in table; the Committee recommends that private land owners modify forest practices through innovative silviculture so that lands both inside and outside HCAs can support spotted owls. 



\section{Adaptive Management}

\section{Introduction}

Adaptlve Management Concepts
Although significant information attests to the effects of widespread clearcutting in sites occupied by spotted owls, we do not know how to schedule timber harvests safely in and around habitats occupied by spotted owls. Thus, we recommend an initially conservative strategy that protects spotted owls in HCAs. Here, we propose a responsive process that combines monitoring and research into a dynamic program that can evaluate and incrementally improve the conservation strategy, and also deliberately probe for new information that may increase compatibility between forestry and spotted owls.

The program explicitly promises, as rapidly as can be developed, an objective examination of the possible management-option combinations that may result in minimizing opportunity costs to wood production while maintaining a well-distributed and persistent population of spotted owls. Modifications to the conservation strategy that result from the monitoring and research program may range from increasing protection to allowing timber harvests inside HCAs, where and when either is deemed consistent with objectives for spotted owls. Any such scenarios for spotted owl management must be based on new information and experience expressly sought by implementing and testing the conservation strategy as a management hypothesis that may be modified or rejected in favor of an alternative.

Questions about the long-term effects of the conservation strategy on the persistence of spotted owls cannot be answered with a high degree of precision or certainty, and they require unacceptable amounts of time. Instead, we suggest answering the alternative question, "What are the avallable and potential landscape configurations and forest stand treatments that might improve habitat and distribution of spotted owis, and how can such strategles be implemented most effectively?" Management experiments can answer the latter question fairly quickly by simultaneously testing hypotheses associated with the conservation strategy and specific alternative options.

Adaptive management is a process that can improve management practices incrementally by implementing plans in ways that maximize opportunities to learn from experience. Adaptive management (Eberhardt 1988; Holling 1978; MacNab 1983, 1985; Romesburg 1981; Walters 1986) can provide a reliable means for assessing the conservation strategy, producing better ecological knowledge, and developing appropriate modifications to improve forest management. The primary challenge for using an adaptive management approach is to demonstrate simply and clearly why a change in management would be worthwhile. 


\section{Appendix R: Adaptive Management}

Concept of Management Experimentation
Two types of adaptive management activities are possible: passive and active (Walters 1986, Walters and Hilborn 1978). Passive adaptive management implements the best consensus plan as if it were correct. Subsequent monitoring gives better estimates (for example, for home-range size), and mistakes point the way to improve management. When resources are renewable only over long periods, however, such as the structural components commonly associated with old-growth forests, passive adaptive management could lead to resource depletion in the short run (Walters 1986). Moreover, by itself, passive adaptive management cannot provide answers to ecological questions on underlying biological processes. Most importantly, passive adaptive management cannot reveal additional options for consideration by managers.

On the other hand, active adaptive management implements policy decisions in the form of rigorously designed management experiments, which force a blending of monitoring and research. Active adaptive management can evaluate the conservation strategy and seek to answer ecological questions that bear on that strategy. Moreover, active adaptive management can lead to broader options that may alter the course of management. Therefore, we recommend a carefully orchestrated, active adaptive management program.

The active adaptive management program described herein should be predicated on the broad question, "What landscape- and stand-scale management experiments can lead to a greater understanding of the key ecological processes that most influence population viability of spotted owls?" Active adaptive management should provide the fastest and most efficient means for the agencies to determine if the simultaneous goals of maintaining population viability for northern spotted owls and sustaining forestry to produce wood products can be attained. If so, the program should also discover the means by which the goals may be achieved. Note that active adaptive management can be applied to other resource topics associated with integrated forest management.

The challenge to testing hypotheses in the conservation strategy is to verify that spotted owl populations will persist through natural disturbance events, alternative harvest schedules, and modified forestry practices within and between HCAs. Management experiments involving spotted owls in the managed forest matrix provide the basis for ultimately using silvicultural treatments in the HCAs, if such management produces habitat for spotted owls that successfully reproduce over time and over sufficient areas.

Simultaneous evaluation of the conservation strategy and the various options that may be applied is the major strength of the adaptive management program. We have identified several strategies for landscape mosaics (appendix $Q$ ) and stand management treatments (appendix S) that may be applied in different areas and under different conditions. Some alternative landscape and stand strategies already have been implemented in some areas in the course of pursuing other management objectives. Research and monitoring of owl responses to the prescribed strategy and to alternative landscape mosaics and various stand treatments will provide essential information for suggesting potential changes to the course of management. 


\section{Appendix R: Adaptive Management}

Suggested Research and Monitoring Program
We believe the spotted owl population response to implementing the conservation strategy will be manifest only over broad scales of space and time, because of relatively sparse population densities and expected delayed responses to habitat changes associated with the owl's long life span and fidelity to nesting sites (Noon and Biles 1990). Also, the basic biological processes involved (for example, juvenile dispersal, habitat selection, and population regulation) require detailed research investment. Therefore, we must achieve an understanding of spotted owl responses to the landscape pattern, as well as to the dynamics of forest stands, because these are manageable components that link spotted owls to their environments.

In active adaptive management, research blends with monitoring. While monitoring tests hypotheses specific to the conservation strategy, research will compare predictions and assumptions of hypotheses stemming from the conservation strategy and alternative landscape options and stand treatments. Thus, we recommend giving high priority to research projects that are designed to make use of data collected in monitoring.

Recent field evidence suggests that some suitable habitat for northern spotted owls has resulted from previous forestry practices, as indicated by owls in relatively high owl densities and evidence of breeding. This phenomenon has been observed in some northern California forests, in a few western Oregon areas, and in some selectively harvested forests east of the Washington Cascades (Irwin 1989, Irwin et al. 1989a, b). If such forestry practices fortuitously produced suitable habitats where owls can breed successfully, suitable habitat probably could be produced by silvicultural design in the same forests and possibly in other forests. Such options, discussed in appendix $S$, provide opportunities for management experiments to enlarge the zone of compatibility between spotted owls and forestry practices.

The following sections for research and monitoring align with an emerging interest within agencies and the scientific community to increase the retention of large trees, snags, dead-and-downed woody debris; to minimize the effects of fragmentation; and to extend harvest rotations in some areas. For example, these interests have resulted in a new FS research and development program on "New Perspectives in Forestry" that aims to balance biological diversity with management practices that produce a sustained supply of goods and services.

We propose a series of management experiments from which research and monitoring can evaluate hypotheses about relationships between spotted owls and their environments, and can determine how those relationships may be affected by implementing the conservation strategy and various options. Alternative management strategies listed in appendix $Q$ and specific testable hypotheses identified by the Committee are listed in table R1. Locations where the specific hypotheses could be tested most effectively and efficiently should be identified (perhaps by geographic information system (GIS), as described below), because they provide opportunities to evaluate predictions inherent in the conservation strategy. Also, as timber harvest proceeds in the forest matrix, some landscapes will "pass through" various options that could be associated with the selected landscape strategy, as the HCAs become more distinct from the surrounding managed-forest mosaic. 


\section{Appendix R: Adaptive Management}

Table R1-Matrlx of testable null hypotheses assoclated with the conservation strategy and assoclated options

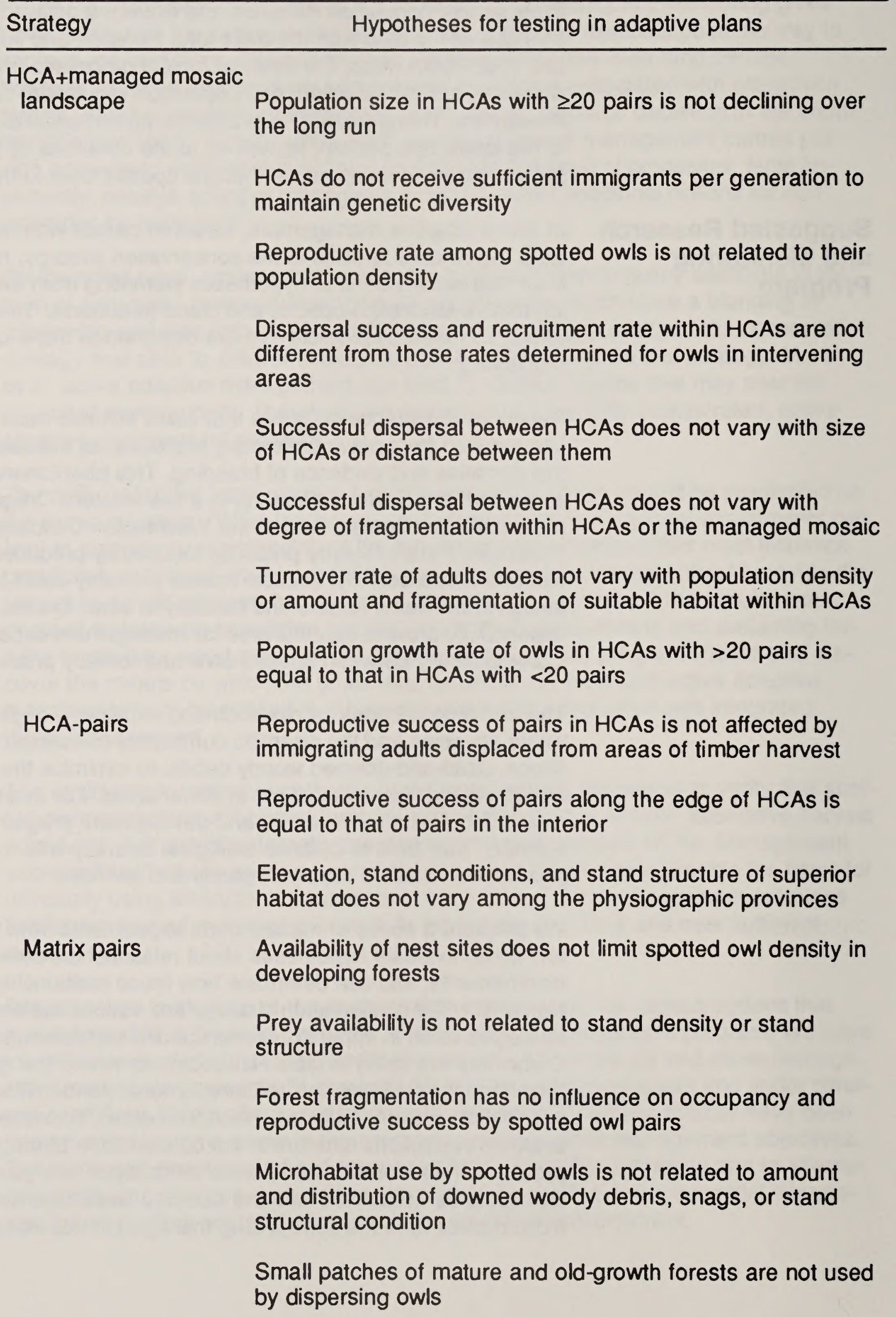




\section{Appendix R: Adaptive Management}

Table R1-continued

\begin{tabular}{ll}
\hline Strategy & \multicolumn{1}{c}{ Hypotheses for testing in adaptive plans } \\
\hline $\begin{array}{l}\text { Spotted owls occurring in small patches of forest suitable for } \\
\text { nesting surrounded by forests suitable for foraging reproduce } \\
\text { as often as those with large amounts of superior and suitable } \\
\text { habitat }\end{array}$ \\
$\begin{array}{l}\text { Modified silvicultural techniques provide for occupancy and } \\
\text { reproduction of spotted owls that are equal to those in } \\
\text { unharvested sites }\end{array}$ \\
$\begin{array}{l}\text { HCA+single-pair HCA } \\
\text { landscape }\end{array}$ \\
$\begin{array}{l}\text { Populations of owls in HCAs with intervening single-pair } \\
\text { HCAs are not less stable than those in HCAs plus additional } \\
\text { owls in the intervening matrix }\end{array}$ \\
$\begin{array}{l}\text { Reproductive success is not related to fragmentation within } \\
\text { and among HCAs with small numbers of pairs }\end{array}$ \\
$\begin{array}{l}\text { Occupancy and reproductive success in single-pair HCAs } \\
\text { is equal to that of pairs in HCAs with 20 pairs }\end{array}$ \\
$\begin{array}{l}\text { Successful dispersal is not related to distance between } \\
\text { single-pair HCAs }\end{array}$ \\
landscape
\end{tabular}

The set of clearly defined, measurable objectives described in appendix $Q$, in association with testable hypotheses listed in table R1, provides a quantified basis for monitoring to evaluate and improve the conservation strategy. We propose to test those hypotheses by monitoring spotted owls and habitats in sampling units that include two HCAs and the intervening forest mosaic (fig. R1). The number of units to be monitored in each physiographic province would be set, after consultation with statisticians, relative to specific hypotheses to be tested. Owls in each unit would be sampled as in current demographic studies. All adults would be individually marked by colored leg-bands. Intensive searches would be conducted annually to locate all birds (in both the HCAs and the intervening matrix). All newcomers and young would be banded. 


\section{Appendix R: Adaptive Management}

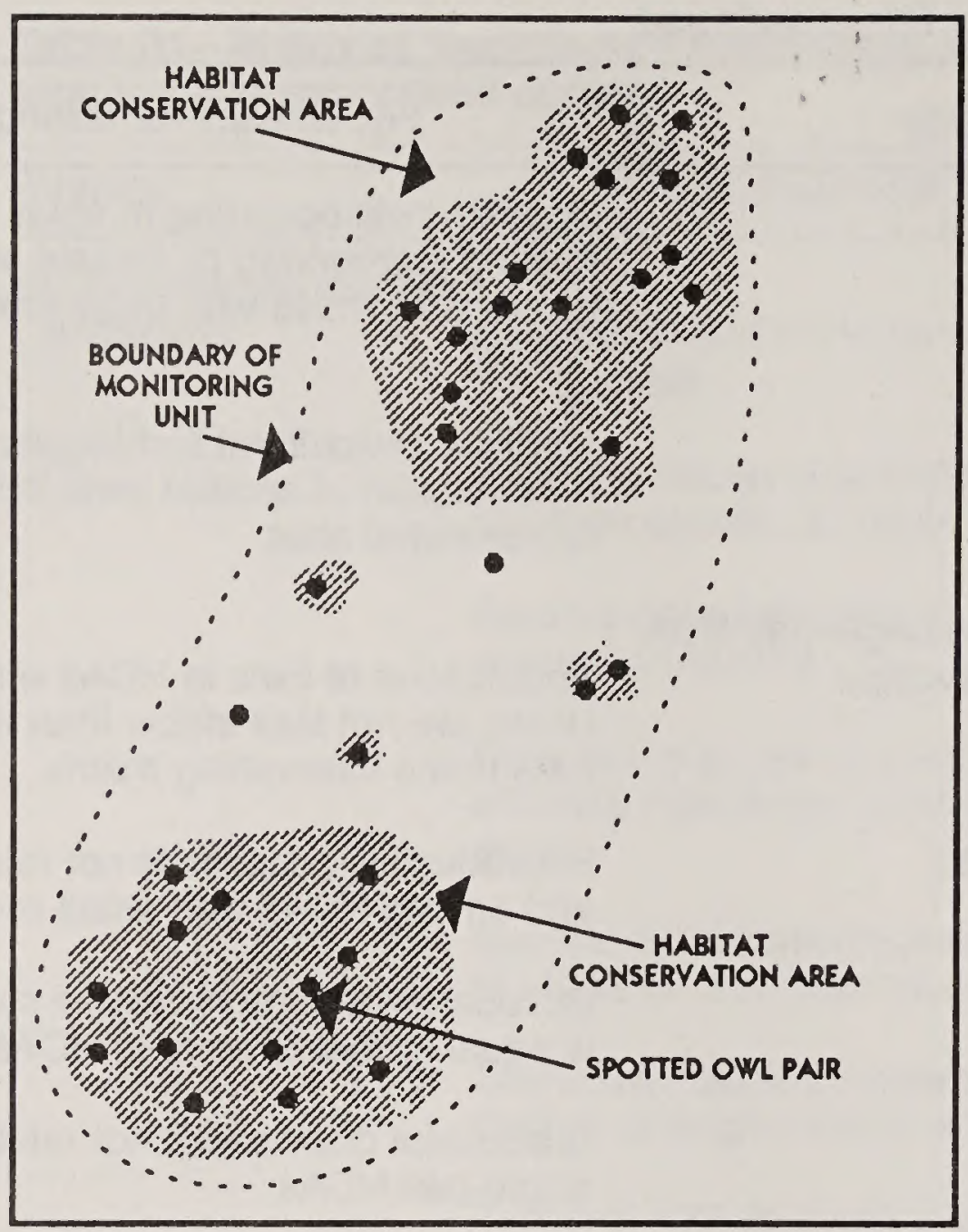

Figure R1-Suggested sampling unit for monitoring spotted owl responses to the conservation strategy.

Important measurements include juvenile survival and dispersal success relative to the size of the HCAs, the amount and arrangement of habitat within the HCAs, and to other factors, such as the distance between HCAs and the composition and configuration of the intervening matrix, or mosaic of managed forest patches. Included, for example, would be measures of habitat fragmentation and distances between nodes of suitable habitat. Sex ratio, reproductive rates, indices to social patterns (for example, mate fidelity), and turnover among known adults also are important parameters. Over time, age-specific reproductive rates could be determined to aid informative demographic projections or population viability analyses.

Monitoring habitats in HCAs would include measures of the proportion of suitable habitat, the area of each suitable stand, indices showing forest fragmentation (Forman and Godron 1986, O'Neill et al. 1988, Turner 1989), and distances to the nearest adjacent HCA and patch ( $>25$ acres) of suitable habitat (that is, a node or area occupied by one or more pairs). For nodes and pair-areas in the matrix, habitat measures might include indices to fragmentation and amounts of suitable habitat. 


\section{Appendix R: Adaptive Management}

The Committee recognized the inherent fallacy in a monitoring plan that only serves to point out problems or mistakes (for example, increasing mortality rates or habitat loss). Monitoring also should be capable of pointing out positive influences on owl welfare. For example, management treatments, such as fertilization or modified silvicultural practices (see appendix S), might improve numbers and availability of prey, which may result in improved reproduction and survival among spotted owls. Or developing methods for determining the rate of owl colonization in managed forests might be useful. Random sampling for owls in 1000-acre sites in the forest matrix and in pristine, reserved areas may be a way to determine the rate of colonization, with sites picked by using stratified random sampling procedures and GIS (described below).

Additional work is required to establish the sampling design for the revamped monitoring program, which should be tied to the objectives for evaluating each parameter of interest. The sampling design would include sample sizes and acceptable precision and accuracy for estimating parameter values, according to the degree of reliability desired for detecting differences (changes). Sample sizes required to detect certain amounts of change (for example, in reproductive rate) that may trigger changes in statistical management also may involve power analysis (Zar 1984). Power analysis provides a way to reduce Type 2 statistical errors-concluding no difference existed in parameters measured when, in fact, differences did exist. The consequence of Type 2 errors (failing to reject a false null hypothesis) might include the failure to modify management appropriately and at the right time.

\section{Additional Inventory Suggested}

Although owl surveys have been extensive in some areas, not all forests that may support owls have been surveyed adequately, and some extensive areas of forest remain unsurveyed. Surveys are needed in the backcountry of all of the large Parks, most Wilderness Areas, and private and State lands in all three States, particularly along the Pacific Coast. Uncertainty also exists about the range of forest types used by the owl in many areas. Moreover, intensive, field-based inventory efforts are needed for most lands to determine the distribution and amount of suitable habitat. Some specific areas needing owl surveys that were brought to our attention include the following list.

Washington-Olympic National Park, North Cascades National Park, Fort Lewis Military Reservation, tribal and State lands on the Olympic Peninsula and the east side of the Cascades, and lands within the Columbia Gorge.

Oregon-Clatsop, Elliott, Santiam, Sun Pass, and Tillamook State Forests; State Parks; Grand Ronde, Warm Springs, Siletz Indian Reservations; and Crater Lake National Park.

Cailfornia-Point Reyes National Seashore, Whiskeytown National Recreation Area, Redwood National Park, State Parks on the north coast, the Hoopa and Round Valley Indian Reservations, and the foothill oak woodlands of the Sacramento Valley. 


\section{Appendix R: Adaptive Management}

\author{
Research Program
}

We emphasize strong attempts to gather research information from owl pairs that will be influenced by timber harvesting in the forest matrix between HCAs. We further suggest that some research should be undertaken in full cooperation among concerned groups, who can help by implementing specified silvicultural treatments as part of management experiments.

In addition to testing the hypotheses listed in table R2, the most important research questions that bear on adaptive management can be answered through experimental designs that account for variation in habitat conditions in managed stands and landscapes. For example, by expressly examining spotted owl responses to structural variation in stand conditions or successional stages, management experiments may be useful in developing new silvicultural options.

Simultaneous hypothesis-testing associated with the conservation strategy and alternative options for managing landscapes and stands requires a clear appreciation for functional relationships operating at each ecological scale. Important landscape-scale interactions include responses of dispersing juveniles and nonterritorial adults (floaters) to the several landscape mosaics. Understanding functional relations at the stand scale requires detailed knowledge of basic structural determinants of habitat selection, or of the habitat niche. Understanding the habitat niche provides a basis for maintaining or creating owl habitat by using silvicultural treatments. The envisioned research program, therefore, seeks reliable information on juvenile dispersal, basic determinants of habitat selection, and factors that regulate spotted owl populations at landscape scales.

Forsman et al. (1984) pointed out that young Douglas-fir forests in western Oregon provide at least marginal foraging habitat after 25 to 35 years of development. Silvicultural treatments may be able to accelerate the development of marginally suitable habitat (as defined in appendix F) from unsuitable habitat via precommercial and commercial thinnings. If sites within the forest matrix between HCAs occur in forests younger than about 60 years, then habitat-selection studies could examine owl response to thinnings or other silvicultural treatments, such as under-planting for a second tree layer.

Spotted owls occurring in the forest matrix between HCAs could provide opportunities for understanding potential threshold responses by pairs and individuals to fragmentation. Specific locations where such research could be undertaken were discussed in appendix $C$. Other sites include sections (square miles) of State "school" lands that may represent small amounts of suitable habitat embedded within a matrix of advanced successional stages.

Additional understanding could be developed by tracking owl responses to increasing fragmentation in habitats surrounding core-area patches that are recommended for retention (that is, 80 acres within $1 / 4$ mile of nest sites or core areas). For example, an ongoing study is examining several measures of forest fragmentation at 100 of over 450 known owl sites on BLM lands in western Oregon (Meyer et al. 1990). Preliminary data suggest that site selection may be affected by the amount and standsize of superior habitat up to 8800 acres around owl sites, but site selection is influenced most strongly within an inner core of 500 acres. A core area of 500 acres fits theoretical predictions based on body size (Inwin 1986). 


\section{Appendix R: Adaptive Management}

Table R2 - List of additlonal research questlons assoclated with the conservation strategy according to toplc and scale of appllcation

Stand- or drainage-scale or individual-pair considerations

Habitat studies

What range of forest conditions is occupied by the owl in each province?

What age and condition in forests support successful reproduction?

What components should be used in developing a reliable habitat capability model?

Prey studies

What is the relation between prey size and owl abundance and reproductive success?

What is the relation between dwarfmistletoe and populations of owl prey?

How can silvicultural practices be used to produce a more diverse and accessible prey base?

How does forest fertilization influence populations of prey for spotted owls?

Studies of movements, physiology, and behavior

What happens to adult owls displaced from areas that are intensively harvested?

What is the effect of transmitters on movements, home range, and habitat use?

How does social facilitation play a role in reproductive behavior?

What are the energetic costs and benefits of capturing prey in different habitats?

What specific stand structural features influence habitat use by spotted owls in each physiographic province?

Do artificial nest structures induce owls to use intermediate-aged forests without nesting opportunities?

How do owls respond to small clearcuts ( $<100$ feet in diameter) with larger intervening leave patches?

What limits the elevational and latitudinal distribution of northern spotted owls in each province?

Can young spotted owls be imprinted on relatively young forests so they return as adults to breed there? 


\section{Appendix R: Adaptive Management}

Table R2-continued

Landscape-scale or population considerations

Demographic studies

What rate and amount of timber harvesting can occur without impacting owl reproduction or survival?

What factors influence owl recolonization of forests that have been harvested and regenerated?

How does marginal habitat influence juvenile dispersal, provide habitat for floaters, or both?

How do population dynamics of owls in highly fragmented areas, such as on BLM ownership, compare to those for owls in less-fragmented forests?

Habitat

How can forest harvests be scheduled over time and space to maintain spotted owl habitat in sufficient amount and distribution so as to perpetuate a breeding population?

What are the fire- and timber-management histories of sites in managed forests that have breeding owls?

How much marginal, suitable, and superior habitat exists in each physiographic province?

Community studies

What is the influence of fragmentation on the relation between spotted owls and great horned owls?

To what extent does competition with barred owls influence populations of spotted owls?

Modeling studies

What is the most reliable structure for a spatially explicit model that predicts population persistence of owls in relation to the landscape mosaic?

Also, mature and old-growth forest stands in the forest matrix provide opportunities to examine owl responses to a variety of current and innovative silvicultural treatments. Monitoring owls in these sites within the matrix may aid in understanding landscapescale questions that relate to connectivity to larger patches by having corridors or "stepping stone" patches of foraging habitat.

Additional important research includes the need to develop a reliable model that integrates the dynamics of pairs and habitats over time and space to predict the probability of long-term persistence in association with the conservation strategy. Also, forest-growth models that contain critical features of spotted owl habitat must be developed. Finally, other tools are needed, such as a spatially explicit model of landscape relationships linked to a habitat-relationships model that predicts stand conditions. Together, these models could enhance the ability to predict the consequences of management decisions over space and time. 


\section{Appendix R: Adaptive Management}

GIS: Suggested Technology to Ald Research and Monitoring
We developed an additional list of questions for research (table R2) through our discussions and from topics raised in the appendices. Some questions address assumptions and predictions of theories that relate to interactions of population and habitat.

We recommend that the monitoring and research programs develop and use GIS These systems can be defined as automated, internally referenced, spatial information systems designed for data management, mapping, and analysis (Berry 1987a). A GIS can be linked to computer models for spatial-pattern analyses, forest growth and yield projections, and habitat capability indices, expanding the ability to integrate space and time into monitoring and planning management experiments. For example, a GIS could store locational data on forest inventory by categories (for example, ageand structure-class), and be able to simulate future landscapes, including the probability of fire, windstorms, and other catastrophes. The GIS eventually selected should be standardized across the range of northern spotted owls.

The GIS also could generate a list of candidate stands that may be selected for silvicultural treatment or evaluated in management experiments. For example, a spectral "signature" can be generated via GIS analysis of known owl nesting sites that are mapped on Landsat or other satellite imagery. Then the GIS might be used to locate new, unsurveyed sites that have the same spectral signature, which would be predicted to contain nesting pairs. "Ground-truthing" by checking those sites for owls might lead to a reliable and relatively inexpensive mode for an indirect owl "census" in such habitats. The GIS also could help in testing and refining the habitat capability model described in the FS's Final Supplemental Environmental Impact Statement (USDA 1988, Vol. 2: B21-22).

Berry (1987b) discussed a fundamental mathematical approach to GIS analyses that treats entire maps (landscapes) as variables. The set of analytical procedures for processing mapped data, or spatial statistics, forms a mathematical structure analogous to traditional statistics and algebra. Spatial statistics characterize the geographic pattern or distribution of mapped data by describing spatial variation, instead of distilling data by using central-tendency statistics. Information from traditional and spatial statistics can be combined for interpretations of information from GISs.

Computerized GIS analyses force users to consider carefully the scale at which the data being processed apply, and to examine carefully the structure of models, such as spotted owl habitat capability models or viability models. These processes enable administrators to understand more fully the analytical process, make comments to analysts on model weightings (such as juvenile dispersal distance or habitat capability ratings), or identify erroneous assumptions in models being applied. 


\section{Appendix R: Adaptive Management}

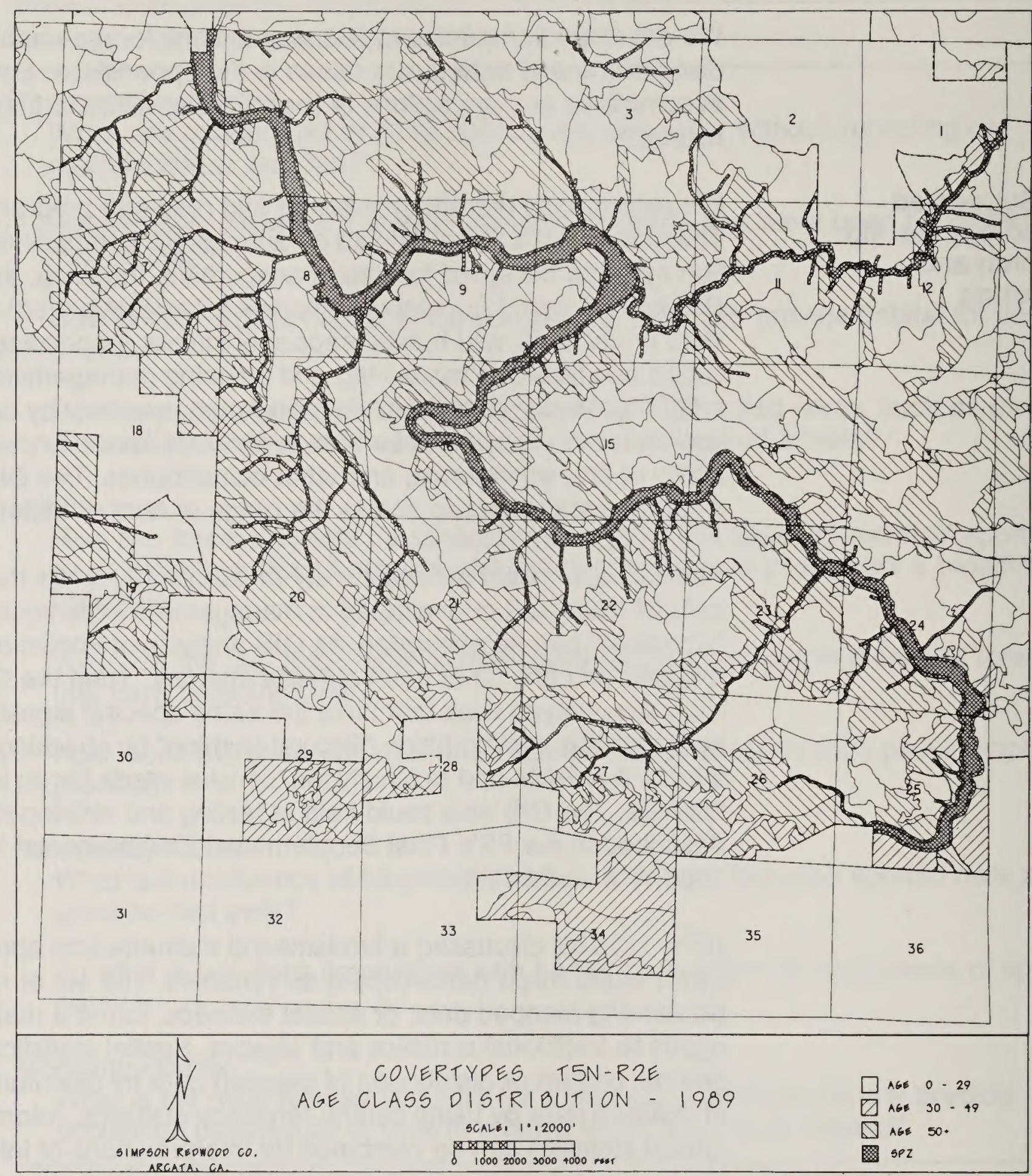

Figure R2-Forest stands by age-class, redwood forest type in northern California, 1989. Courtesy of Simpson Redwood Co., Arcata.

Geographic information system technology may provide a tool for scheduling silvicultural treatments in areas that are currently occupied by northern spotted owls or may be occupied in the future. To illustrate the possibility for a GIS to aid in developing a schedule of timber harvests that results in suitable habitat over time, we show a GIS-generated cover-type map for three age-classes of coastal redwood forest in northern California (fig. R2). This particular tract of land, including about 16,400 acres that were logged completely and burned after the turn of the 20th century, was known to contain more than 25 spotted owls in 1989, including several pairs observed with fledglings (Diller 1989). 


\section{Appendix R: Adaptive Management}

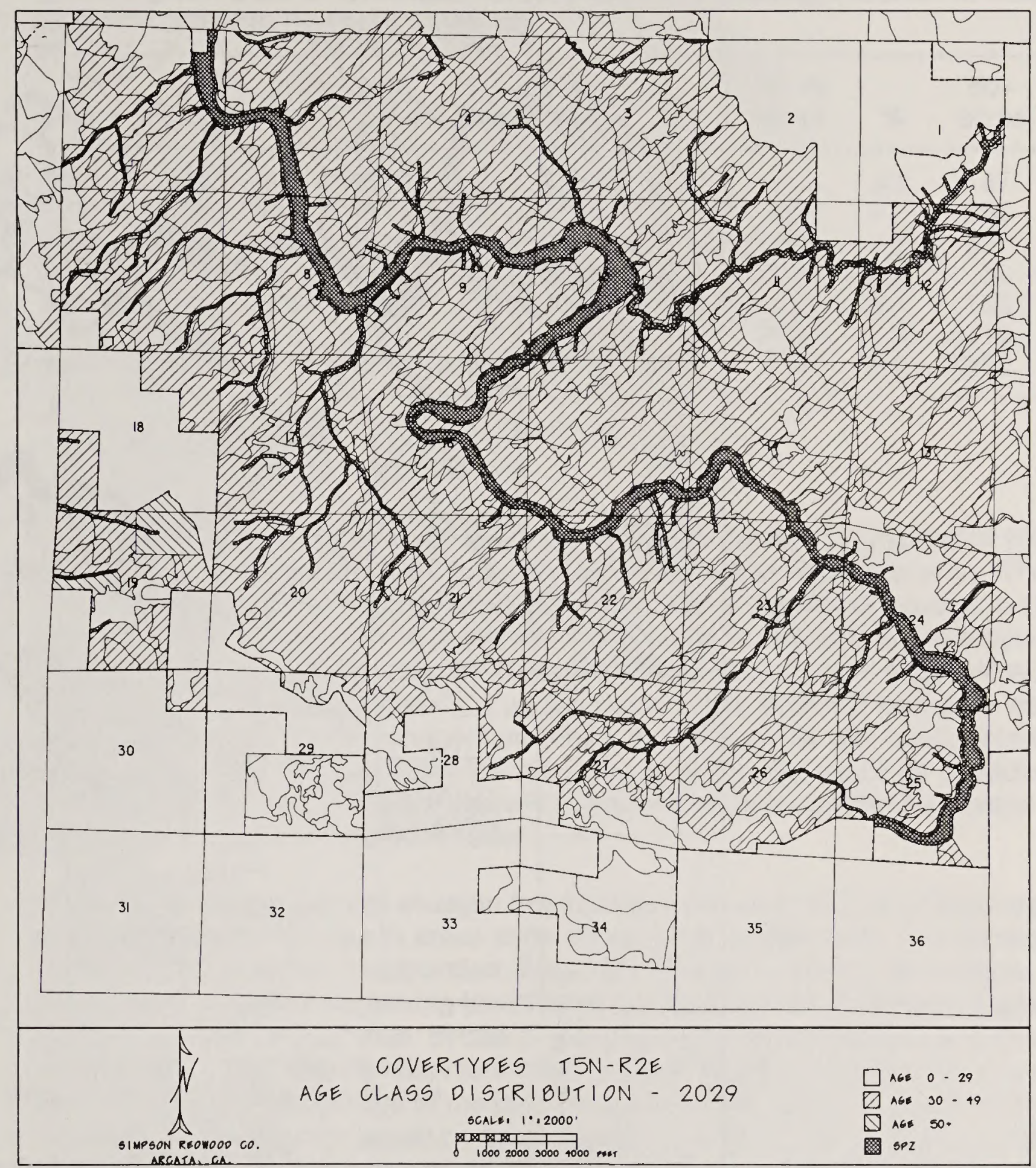

Figure R3-GIS-simulated forest stands in fig. R2 by age-class in the year 2029, redwood forest type in northern California. Courtesy of Simpson Redwood Co., Arcata.

Given a set of simplified assumptions, the GIS-simulated forest conditions for the same landscape in 2029 (fig. R3) and 2049 (fig. R4). For illustration only, the assumptions that were used to determine a particular stand's age-class included:

- Stands 59 years old in 1989 are harvested in 1990. Such stands will be 19 years old in 2009 and 39 years old in 2029.

- Stands are harvested at age 60 and regeneration occurs without delay. Thus, if a stand is harvested in 2000, the subsequent stand is 1 year old in 2001.

- If an area is classified as nonforest in 1989, it is expected to be nonforest in 2029 and 2049. 


\section{Appendix R: Adaptive Management}

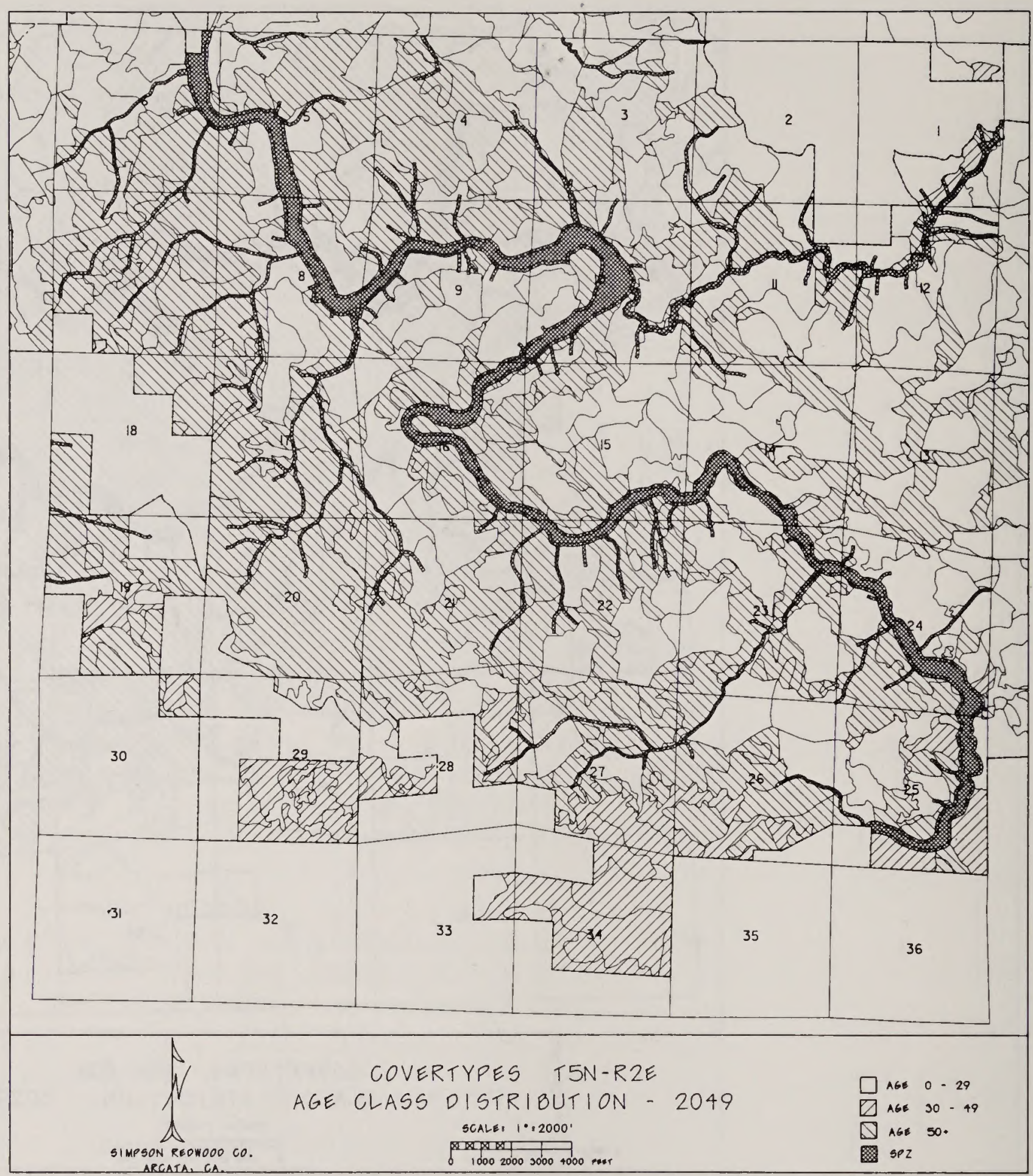

Figure R4-GIS-simulated forest stands in fig. R2 by age-class in the year 2049, redwood forest type in northern California. Courtesy of Simpson Redwood Co., Arcata.

Note that the assumptions described above are highly simplified and do not represent any real or planned future situation because the simulation was not constrained by management or other considerations. These scenarios would never occur exactly as depicted, and they represent minimal estimates of forest. They simply illustrate the capability of GISs for simulating future landscapes, and possibly spotted owl habitat, on the basis of a hypothesized set of management plans. 


\section{Appendix R: Adaptive Management}

Table R3-Example of GIS-sImulations for acreage of forest by age-class (years), given a set of assumptlons on harvesting and regeneration In coastal redwood forest in northern Callfornla

\begin{tabular}{rrrrrrrrrrr}
\hline Year & $\begin{array}{l}\mathrm{SPZ}^{a} \\
\text { acres }\end{array}$ & $\%$ & \multicolumn{1}{c}{$\begin{array}{c}\text { Non }^{b} \\
\text { acres }\end{array}$} & $\%$ & $\begin{array}{r}0-29 \\
\text { acres }\end{array}$ & $\%$ & $\begin{array}{r}30-49 \\
\text { acres }\end{array}$ & $\begin{array}{r}\text { \% } \\
\text { acres }\end{array}$ & $\%$ \\
\hline 1989 & 1343 & 8.2 & 1515 & 9.2 & 5387 & 32.8 & 995 & 6.1 & 7167 & 43.7 \\
1999 & 1343 & 8.2 & 1515 & 9.2 & 12502 & 76.2 & 679 & 4.1 & 368 & 2.2 \\
2009 & 1343 & 8.2 & 1515 & 9.2 & 12733 & 77.7 & 188 & 1.1 & 627 & 3.8 \\
2019 & 1343 & 8.2 & 1515 & 9.2 & 8251 & 50.3 & 5246 & 32.0 & 52 & 0.3 \\
2029 & 1343 & 8.2 & 1515 & 9.2 & 1047 & 6.4 & 12366 & 75.4 & 136 & 0.8 \\
2039 & 1343 & 8.2 & 1515 & 9.2 & 815 & 5.0 & 7623 & 46.5 & 5110 & 31.1 \\
2049 & 1343 & 8.2 & 1515 & 9.2 & 5298 & 32.3 & 995 & 6.1 & 7256 & 44.2 \\
\hline
\end{tabular}

Streamside protection zone.

${ }^{b}$ Nonforested acres.

Because the simulation assumed all stands $>59$ years old were harvested in 1990 , spotted owls would be predicted to be absent for more than a decade or so. The simulated landscape for the year 2029 (fig. R3) contains significant acreage $(>12,000$ acres) in the 30- to 49-year-old class, which should be useful as foraging habitat for spotted owls in redwood forests. By 2029 , the simulated landscape might already have some owls that recolonized the area, assuming that potential nest sites would be retained in streamside-management zones and other areas with constraints on timber harvest. By the year 2049, the simulated area (fig. R4) would be predicted to have over 7000 acres of habitat (table R3) that ostensibly is suitable for several pairs of owls, based on real data from 1989.

If a landscape management situation like this one were actually part of a strategy for scheduling timber harvests in areas to be occupied by spotted owls, several other topics would have to be incorporated. They include the requirement of a refuge, such as an HCA, to provide dispersing juveniles for recolonizing the area when it again contains suitable habitat. Also, details of stand conditions would be needed, perhaps obtained by using stand-development models coupled with ground-truthed information. Furthermore, knowledge of the proportion of suitable habitat required within a specified landscape area would be needed (Mickey, pers. comm.). And information is needed on spotted owl responses to rapidly changing landscapes. Ultimately, the value to long-term population persistence of landscapes that alternatively are suitable, marginally suitable, or unsuitable would have to be determined, in association with nearby refugia.

Thus, GIS technology provides a tool that may result in more ecologically based policy decisions because of better linkages between researchers and managers. Working GISs are, or soon will be, available at most National Forests, BLM Districts, and State wildlife and land management agencies. Numerous private industrial organizations already have operational GISs. In fact, spotted owl habitat has been analyzed using Landsat imagery in numerous areas. 


\section{Appendix R: Adaptive Management}

\section{Conceptual Basis for Reviewing the Conservation Plan}

We believe that GISs provide the best available technology for integrating monitoring and research, and for increasing communication among managers, researchers, and biologists. Moreover, GISs appear capable of aiding interpretations that can lead to needed or justifiable adjustments in the conservation strategy. The coordination of the database for spotted owls, including GIS capabilities, requires active participation by public and private organizations.

An objective basis must be developed to evaluate the results of management experiments and monitoring so as to signify when a review of the conservation strategy is warranted and to modify it appropriately when necessary or desirable. Feedback from monitoring and research to management policy requires articulation of expected responses to our initially prescribed landscape scenario and alternative management hypotheses that can be tested. Risk analysis procedures may be integrated with the adaptive management approach for assessing the efficacy of the conservation strategy, and determining the potential for change (Marcot 1986).

The basis for review and modification could include a series of "if-then" statements associated with predictions from each management strategy that is tested (fig. R5). A rule set should be identified that describes how to interpret the results of field comparisons of alternative hypotheses at each scale. Establishing such a rule set requires evaluation criteria for important biological parameters, and for the amount of change that will modify management at each scale.

Specifically, the rule set might include: determine how observed trends compare to expected trends in important life-history parameters; state inappropriate and appropriate statistical comparisons, interpretations, assumptions, and inferences; decide at what point, and how, observed trends trigger review of the conservation strategy, study designs, specific management direction, or the objectives and intent of the management direction. This process may entail identifying thresholds or ranges of values of parameters and their trends.

The adaptive management program should develop explicit criteria for measuring vital life-history parameters that would result in changes of management practices to ameliorate undesired amounts, rates, or trends, or conversely, that would allow relaxation of constraints. What those levels should be is not immediately clear. Research appears necessary to develop the early warning signals that could indicate that changes are needed-say increased protection (for example, unusual adult turnover rate, or unusually low mate fidelity). The potential for using the results of monitoring and research to determine that alternative management is indicated should identify the scale at which such changes may take place. 


\section{Appendix R: Adaptive Management}

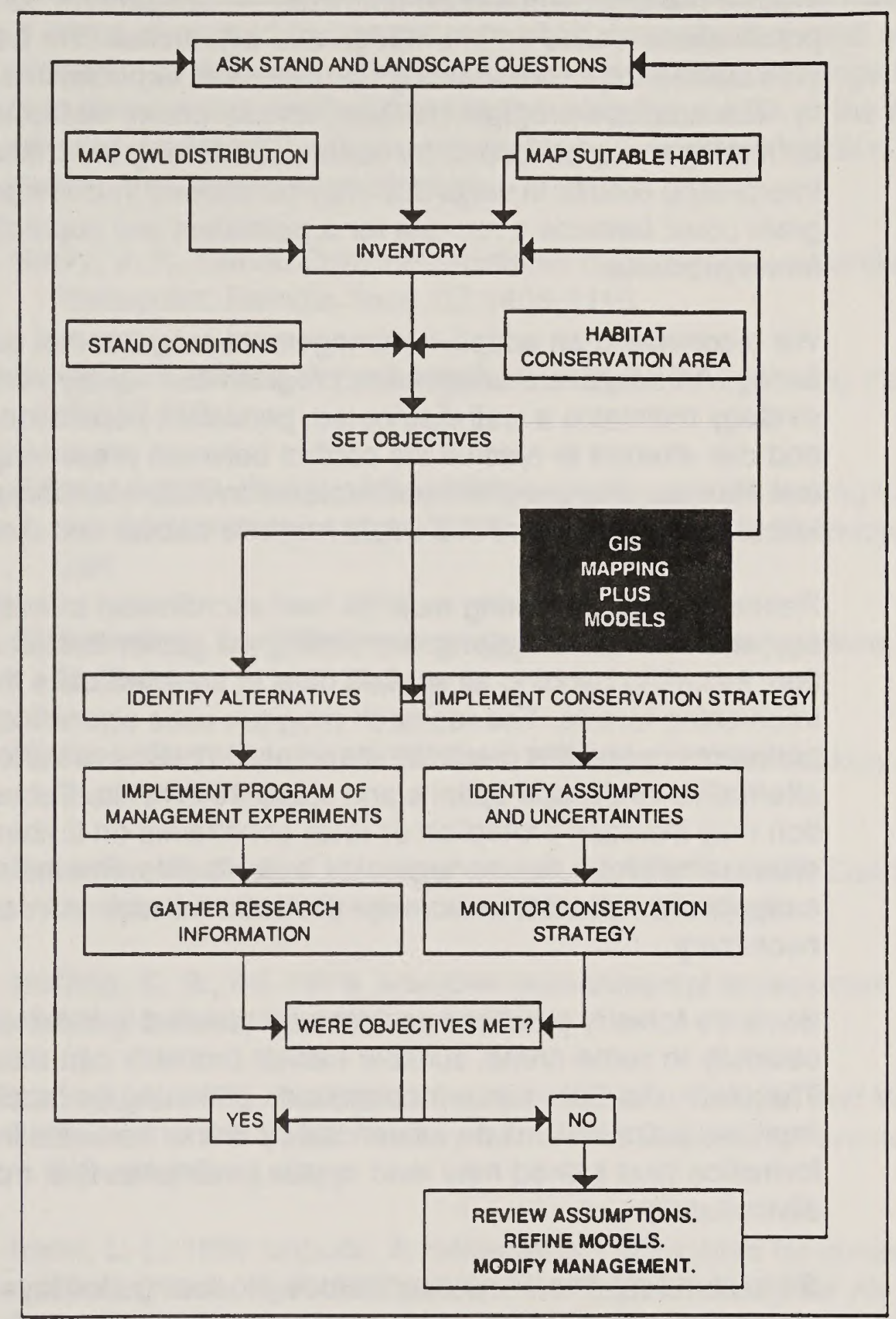

Figure R5--Conceptual basis for adaptive management to modify the conservation strategy through management experiments and monitoring.

Finally, we recommend that agencies responsible for managing northern spotted owls develop an interagency technical committee that would develop protocols for monitoring, and set priorities for research, as set forth herein and in accordance with the conservation strategy. This group would manage the database for spotted owls, including coordinating GIS-based information. Finally, this committee would be responsible for ensuring the recommended strategy is implemented fully, and would make recommendations on appropriate modifications to the conservation strategy. The interagency committee should be supervised by a program leader employed by one of the Federal agencies. We suggest that personnel serving on the technical committee should be selected from the respective State and Federal agencies, interest groups, and from the forest products industry. 


\section{Appendix R: Adaptive Management}

\author{
Summary
}

Wildlife management has no final truth - management consists of successive approximations based on knowledge and experience. We believe we have identified a safe course to pursue, holding no unrealistic expectations that the truth will come easily. The adaptive program that we propose allows interested groups to work together in framing the questions to be asked, conducting the management experiments, and interpreting results in ways that may be applied in management. We believe the program could become a formula for a persistent owl population and a sustained yield of forest products.

We recommend an adaptive management program that combines research and monitoring. An adaptive management program can rapidly verify that the conservation strategy maintains a well-distributed, persistent population of northern spotted owls, and can attempt to resolve the conflict between preserving and managing spotted owl habitats. The program can evaluate available landscape strategies and potential forest stand treatments that might improve habitat and distribution of spotted owls.

Research and monitoring must be well coordinated to evaluate the conservation strategy and alternative options. Monitoring will gather habitat and demographic information, including banding all spotted owls in selected units that include two HCAs and intervening forests. The research program uses scientifically driven management experiments to test the predictions and assumptions of the conservation strategy and alternative landscape options and stand treatments. Subsequent management direction may increase protection or relax constraints on timber harvest, based on experience gained from the management experiments. For the next several years, significant options will exist to increase protection if such increases are determined to be necessary.

Because forestry practices accidentally resulted in habitats in which owls breed successfully in some areas, suitable habitat probably can result from silvicultural design. Therefore, the Committee recommends gathering as much information as possible from owl pairs that will be influenced by timber harvests in sites between HCAs. Information thus gained may lead to new treatments that maintain or create owl habitat silviculturally.

Silvicultural modifications may include producing multilayered stands and leaving structures such as large trees, snags, and downed woody debris. Over time, timber harvests may be scheduled in HCAs. Allowing significant timber harvesting in HCAs logically would follow from data that conclusively showed the owl population was stable or increasing, and after verifying a positive owl response to stands that have been treated silviculturally.

The Committee recommends the development and use of a GIS that is linked with computer programs for predicting forest growth and yield and also for predicting the forest's capacity to support pairs of owls. A GIS can simulate and analyze changes in forest stands and landscapes in terms of owl habitat, expanding the ability to plan management experiments or schedule stand treatments with owls in mind. The GIS would enable decision makers to understand and comment on the analytical process, resulting in an ecologically based policy because of better linkages between researchers and managers. 


\section{Appendix R: Adaptive Management}

Altogether, the adaptive management program must determine the aggregate value, in terms of spotted owl persistence of HCAs, individual- and multiple-pair areas, and managed forests with suitable habitat. The primary challenge for the immediate future is to develop a quantified process for using the results of the adaptive management program to determine the necessity for or provide justification to review, and perhaps modify, the conservation strategy.

Berry, J. K. 1987a. Computer-assisted map analysis: potential and pitfalls. Am. Soc. Photogram. Remote Sens. 53:1405-1410.

Berry, J. K. 1987b. A mathematical structure for analyzing maps. Environ. Manage. $11: 317-325$

Diller, L. 1989. Status of the northern spotted owl in managed forests on Simpson redwood lands in northern California. Prelim. rep., Simpson Timber Co., Arcata, Calif.

Eberhardt, L. L. 1988. Testing hypotheses about populations. J. Wildl. Manage. 52:50-56.

Forman, R. T. T., and M. Godron. 1986. Landscape ecology. John Wiley \& Sons, New York. 619pp.

Forsman, E. D., E. C. Meslow, and H. M. Wight. 1984. Distribution and biology of the spotted owl in Oregon. Wildl. Monogr. 87. 64pp.

Holling, C. S., ed. 1978. Adaptive environmental assessment and management. John Wiley \& Sons, New York.

IrwIn, L. L. 1986. Ecology of the spotted owl in Oregon and Washington. National Council of the Paper Industry for Air and Stream improvement. Tech. Bull. 509. Corvallis, Oreg. 58pp.

IrwIn, L. L. 1989 unpubl. A management alternative for conservation of northern spotted owls. National Council of the Paper Industry for Air and Stream Improvement, Corvallis, Oreg. 33pp.

IrwIn, L. L., J. B. Buchanan, T. L. FlemIng, and S. M. Spelch. 1989a. Wildlife use of managed forests in Washington: a review. Washington Dep. Nat. Resour. Publ. TFW-89-04. 176pp.

IrwIn, L. L., S. Self, and L. Smith. 1989b. Status of northern spotted owls on managed forestlands in northern California. Timber Assoc. Calif., Sacramento.

MacNab, J. 1983. Wildlife management as scientific experimentation. Wildl. Soc. Bull. 11:397-401.

MacNab, J. 1985. Carrying capacity and related slippery shibboleths. Wildl. Soc. Bull. 13:403-410. 


\section{Appendix R: Adaptive Management}

Marcot, B. B. 1986. Concepts of risk analysis as applied to viable population assessment and planning. In B. A. Wilcox, P. F. Brussard, and B. G. Marcot, eds. The management of viable populations: theory, applications and case studies. Center for Conserv. Biol., Dep. Biol. Sci., Stanford Univ., Palo Alto, Calif.

Meyer, J. S., L. L. Irwin, and M. S. Boyce. 1990 unpubl. Influence of habitat fragmentation on spotted own site selection, site occupancy, and reproductive status in western Oregon. Progr. rep. 46pp.

Mickey, R. Pers. comm. Actively managing for suitable spotted owl habitat. 13 Feb. 1990. Northwest Timber Association, Eugene, Oreg.

Noon, B. R., and C. M. Blles. 1990. Mathematical demography of spotted owls in the Pacific Northwest. J. Wildl. Manage. 54:18-27.

O'NellI, R. V., J. R. Krummel, R. H. Gardner, G. Suglhara, B. Jackson, D. L. DeAngells, B. T. MIIne, M. G. Turner, B. Zygmunt, S. W. Chrlstensen, V. H. Dale, and R. L. Graham. 1988. Indices of landscape pattern. Landscape Ecol. 1:153-162.

Romesburg, H. C. 1981. Wildlife science: gaining reliable knowledge. J. Wildl. Manage. 45:293-313.

Turner, M. G. 1989. Landscape ecology: the effect of pattern on process. Annu. Rev. Ecol. Syst. 20:171-197.

U.S. Department of Agriculture. 1988. Final supplement to the environmental impact statement for an amendment to the regional guide. Vol. 2, appendices. Spotted owl guidelines. U.S. For. Serv., Pac. Northwest Reg. Off., Portland, Oreg.

Walters, C. J. 1986. Adaptive management of renewable resources. MacMillan Publ. Co., New York. 374pp.

Walters, C. J., and R. HIlborn. 1978. Ecological optimization and adaptive management. Annu. Rev. Ecol. Syst. 9:157-188.

Zar, J.J. 1984. Biostatistical analysis. Prentice-Hall, Englewood Cliffs, N.J. 718pp. 


\section{Silvicultural Experiments for Habitat Management}

Introduction
Silviculturists, foresters, and wildlife biologists must begin to experiment with new approaches to forest management to determine if suitable habitat for spotted owls can be created over time or retained at the same time that commodity values are extracted from stands in managed forests. We believe the desired stand condition to be produced by silvicultural design includes multilayered and relatively closed canopies, mixed species composition dominated by large trees, numerous large snags, and considerable amounts of large logs and other woody debris on the ground (Forsman et al. 1984, Gutiérrez et al. 1984, Irwin et al. 1989, LaHaye 1988). Large trees with broken tops, secondary crowns, large limbs, hollow boles, and clusters of limbs infected by dwarfmistletoe should be created or maintained, either in clumps or as scattered individuals within the stand.

We do not yet know if creating these structural conditions in stands will retain spotted owls and allow them to breed successfully. Some evidence suggests, however, that historical methods of logging, which left numerous remnant trees or patches of trees and large amounts of woody debris, could produce suitable habitat in a much shorter period than can the contemporary emphasis on clearcutting and burning (Inwin 1989 unpubl.). We are aware of only limited evidence that indicates clearcutting and burning methods may create suitable owl habitat in less than 100 years-the highly productive coastal redwood zone of northern California (Diller 1989, Pious 1989, Inwin et al. 1989 unpubl., see also appendix G).

Here, we present a first approximation of the silvicultural systems and treatments that might be used to produce the appropriate stand conditions in which spotted owls can breed successfully. We hypothesize that spotted owl habitat can be developed through silvicultural systems and treatments. The need is urgent to develop operational experiments specific to each physiographic province to test this hypothesis, as described in appendix R. For example, experiments designed to show how prey species respond to forest understory manipulation will likely target woodrats in California and southern Oregon, and flying squirrels in Washington and northwestern Oregon.

We focused on the forest stand because it is the unit for which silvicultural prescriptions are developed and to which treatments are applied. Although silvicultural prescriptions are developed stand by stand, spotted owl habitat is composed of an aggregation of many stands that comprise a landscape. Given the variation of site conditions and stand structure across a landscape, no single silvicultural system will suffice. Therefore, silvicultural prescriptions need to be developed after careful thought to site-specific conditions, stand structure, and the appropriate arrangement of stands across a landscape as large as the home range for a pair of owls. Such prescriptions for landscapes require knowledge of how spotted owls respond to the mosaic of stands with varying conditions over space and time. 


\section{Appendix S: Silviculture}

Importance and Role of Silviculture
Silvicultural

Treatments and Stand Development Patterns
Spotted owls occur in a variety of forest types. Each type has a somewhat particular species composition of trees, shrubs, and forbs, and other environmental variables such as windthrow, root disease, fire history, and microclimates that affect the practice of silviculture, the rate of stand development, and the spotted owl response. The rate of development of structures suitable for owl habitat will depend on both the current stand structure and the site quality or rates of growth. We do not attempt, therefore, to offer specific prescriptions for each forest type. Instead, we provide some general approaches that would be applicable to most forest types.

Forest stands are dynamic, changing with time as individual trees and other plants are established, grow, and die. Such changes, and opportunities to influence them, must be considered in long-term plans to provide spotted owl habitat. The rate and significance of changes vary with stand age and condition. Young stands become more dense as trees grow larger in diameter and height (McArdle et al. 1961). Very old stands may make no net growth, but species differences in mortality rates and regeneration are substantial (DeBell and Franklin 1987). Thus, with time, some suitable habitat will deteriorate and other stands may develop into suitable habitat. Such natural patterns of development vary with forest type. Silvicultural knowledge can help predict the rate and direction of stand changes. The need and opportunity for habitat manipulation vary with forest type, stand age, and condition.

Current silvicultural manipulations that might be used in experimental designs are:

- Enhanclng sultable or marginaily suitabie habitat-For example, understory thickets can be thinned to test if such activities will increase prey numbers and owl use in those areas. Downed trees and snags can be created to see if prey density can be increased.

- Maintalning suitable habltat within a managed, multlple-use forest-Harvest systems that provide for continuous production of spotted owl habitat and wood products at the same time and place can be tested.

- Accelerating the development or creatlon of habitat in stands now unsultable for spotted owis-Sometimes, natural trends toward developing suitable habitat can be accelerated silviculturally. In other instances, habitat is unlikely to develop naturally under current management, unless silvicultural activities are designed to create it.

We describe two basic stand structures, define major silvicultural treatments, and show likely development patterns for these structures (see figure S1). The major options are cross-referenced to stand diagrams, using a number-letter convention. These diagrams represent a range of stand conditions or structures that could be developed from single-layered or multilayered stands. The purpose of these diagrams is to show patterns of stand structural development that are likely to apply in most forest types.

Single-canopy structure-Single-canopy structure generally occurs in even-aged, single-species stands or stands of two or more species with similar growth patterns. A common example can be found in single-species stands of Douglas-fir or western hemlock. 


\section{Appendix S: Silviculture}

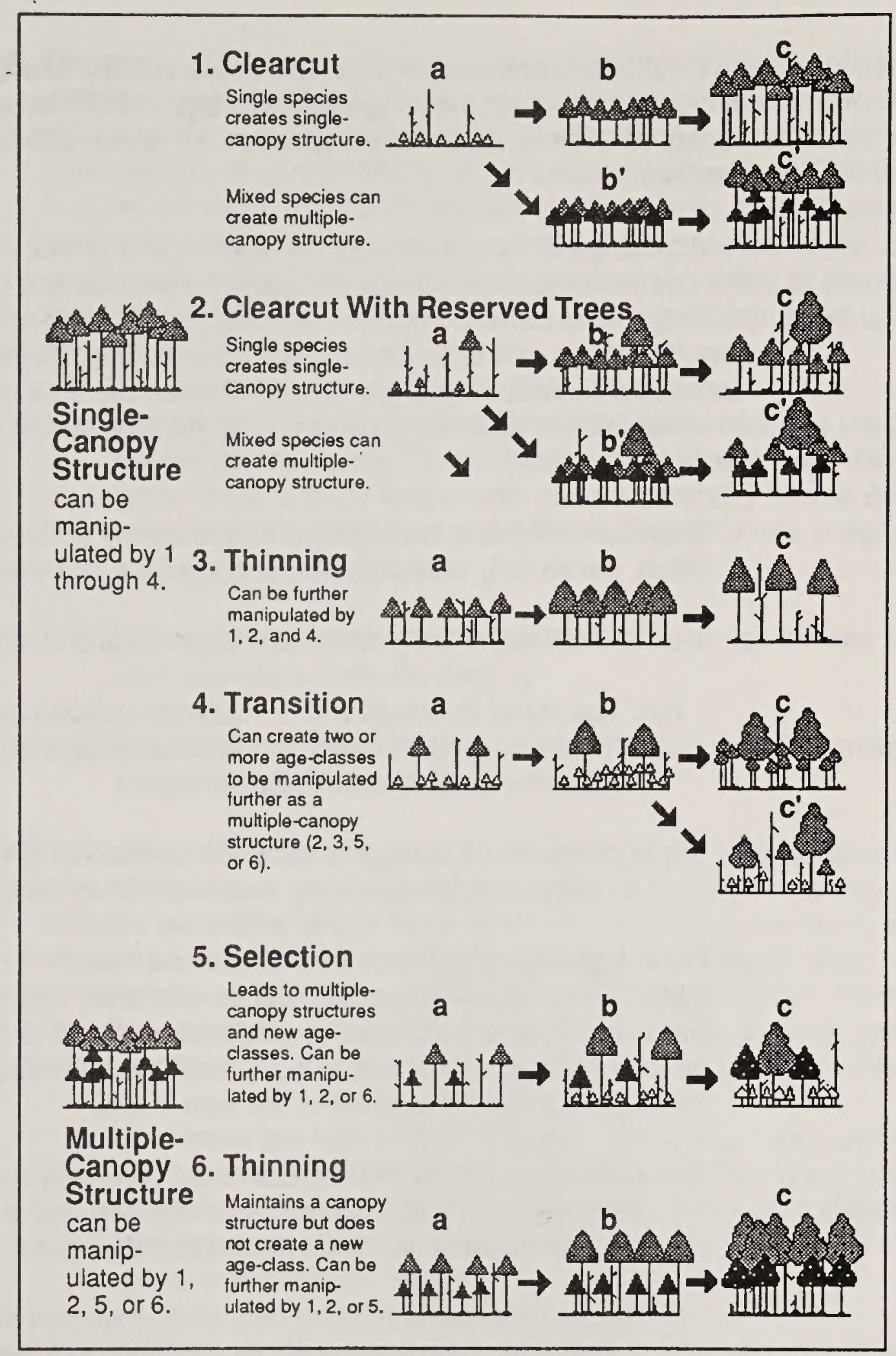

Figure S1-Generalized silvicultural approaches for manipulating forest structure.

Such stands, with crowns of all trees in the same general stratum, can occur at all ages. Although stands of this type are characteristically uniform, trees can differ widely in vigor and susceptibility to insects and diseases.

Multiple-canopy structure-Multiple-canopy structure can occur in both even-aged and uneven-aged stands. It is commonly found in even-aged stands where one species overtops the others and forms two or more canopy layers. Stands that are truly uneven-aged look superficially similar but have differing histories. 


\section{Appendix S: Silviculture}

\section{Single-Canopy Structure}

Silvicultural treatments-Both the single-canopy and the multiple-canopy structures can occur within a wide range of stand ages. Each structure can be manipulated in a variety of ways to determine if spotted owl habitat can be provided during portions of a rotation.

A wide range of treatments can be applied to a stand, depending on its condition and the desired objectives. Common examples include site preparation, natural or artificial regeneration, weed control, thinning, fertilization, pruning, genetic improvement, creating snags and logs, and regeneration cutting. Some of these operations can accelerate individual tree growth and shorten the time required to reach a desired structure. Other treatments can prolong the time during which a stand produces desirable habitat.

1. Clearcut-All trees are felled, and a relatively uniform, even-aged stand develops. Often, particularly on public lands, snags are retained or created from living trees.

a. The old stand is removed and a new stand is initiated.

b,c. The stand develops with a relatively uniform canopy and contains species with similar growth patterns. Such conditions do not appear to be favorable habitat for northern spotted owls.

$b^{\prime}, c^{\prime}$. If the stand is regenerated with species of differing growth patterns, it may develop a multiple-canopy structure (Oliver 1980).

2. Even-Aged Management With Reserved Trees-Trees left after clearcutting (reserved trees) are physically stable, windfirm, vigorous enough to survive release, not in overly exposed areas, and expected to live for a substantial period. We need to test the effects of both "healthy" and "decadent" trees on spotted owl habitat and the development of the new stand.

a. Most trees are harvested, but some dominant and codominant trees, as well as snags and logs, are retained. The practice of leaving reserved trees in clumps or well distributed throughout the stand should be tested.

b. The juvenile stand may be thinned to maintain tree vigor and allow trees to grow faster. The hypothesis that thinning will increase spotted owl use should be tested. The young age-class can develop a single-canopy structure; but if more than one species regenerates, the stand may develop a multiple-canopy structure (panels $2 b^{\prime}, c^{\prime}$ ).

c. As the stand matures, snags can be created and the stand thinned to obtain revenue. We would expect this treatment to increase growth and maintain stability and vigor. Some reserved trees may be intentionally killed to create large snags and prevent suppression of the lower stratum. 


\section{Appendix S: Silviculture}

3. Thinning-Thinning is suitable where dominant trees are physically stable and windfirm, and the stand is not in an area exposed to extreme winds. Thinning needs to be tested to determine what role, if any, it may have where stands are managed on long rotations to attain spotted owl habitat. Thinning has been shown to maintain stand vigor and stability, produce large trees, increase timber values, and initiate the development of understory trees; however, its application to spotted owl management must be evaluated. A variety of stand densities should be evaluated. Stands with this structure can be manipulated by another system at any time (panels 1,2 , or 4 ).

a. Intermediate and suppressed trees are either killed to create snags or harvested commercially. Dominant and codominant trees are spaced widely to allow them to grow longer and maintain stability. Some dominant and codominant trees may be killed and left standing to create snags, or felled to provide large woody debris.

b. The remaining trees grow larger, and their dense crowns tend to prevent a new age-class from developing.

c. The stand may be thinned again to maintain stability, growth, and vigor. Larger snags and logs can be created.

4. Transition-Transition is a special technique that is applicable where the objective is to move from a single-canopy structure to a multiple-canopy structure. It is a suitable technique where trees to be left behind are physically stable, windfirm, vigorous enough to survive release, and not in exposed areas. In addition, the overstory trees should be evaluated both in terms of their effect on the understory and their suitability for habitat. Decadent trees may provide desirable habitat; however, they could sometimes adversely affect understory development.

a. Most trees are harvested. Snags are created or retained from the previous stand, along with some large logs. Scattered dominant and codominant trees are left, and a new stand grows beneath them after planting or natural regeneration. This young stand may be overly dense, and thinning may be needed to maintain vigor.

b. As the new age-class develops, managed density may become increasingly important. If trees are crowded within the same age-class or crown layer, thinning may be needed to maintain growth and vigor. Also, if the residual overstory excessively shades the younger age-class, some older trees may be harvested or killed to create snags.

c. The stand can be maintained as two age-classes by thinning the overstory and understory lightly. Further manipulation would follow the processes shown in panels $2,3,5$, or 6 .

c'. More age-classes can be created by thinning the overstory and understory heavily. Further manipulation would follow panels $2,3,5$, or 6 . 


\section{Appendix S: Silviculture}

\section{Multiple-Canopy Structure}

Stands with multiple canopies can develop from several conditions:

Logging or natural disturbances that remove the least vigorous trees but leave more vigorous and healthy trees. Under these conditions, a vigorous new canopy can develop below the residual stand where densities have been reduced adequately.

"High-grading" or selective logging. Past logging in some areas has degraded residual stands by leaving diseased or weakened trees with little growth potential. This approach has created stands that are now providing spotted owl habitat in portions of the range. Many of these stands have poor long-range stability and growth potential. Where these stands have not been excessively degraded, opportunities exist for retaining healthy dominant and codominant trees of suitable species.

Mixed species, even-aged stands that develop after major (stand-replacing) disturbances can form multiple-canopy strata if the different species grow at different rates.

1. Selection-Selection follows the same general sequences described in the transition method.

2. Thinning - Thinning is suitable where trees to be left are physically stable, windfirm, vigorous enough to survive release, and not in exposed areas. Trees badly infected with dwarfmistletoe may not be suitable because they can be weakened, break or die, or infect much of the younger age-classes.

a. Intermediate and suppressed trees of each canopy layer are killed or removed, and dominants and codominants are spaced to allow them to grow larger and maintain stability. Some trees can be used to produce snags or downed woody debris.

b. Remaining trees grow larger, and increasing density tends to exclude the development of a new age-class.

c. The stand may be thinned again and larger snags created and large logs left, allowing the stand to maintain stability and grow more vigorously. The stand could be further manipulated by clearcutting, even-aged management with reserved trees, or selection systems (panels 1,2 , or 5 ).

\section{Implementation}

Implementing silvicultural systems to provide spotted owl habitat will require considerable thought and skill. Stands with multiple layers will need careful diagnosis and prescription to determine treatment response. Growth models for mixed species and multilayered stands are not generally available to help with this assessment. Harvest methods will be of particular concern, especially on steep slopes. Creating openings and releasing trees from above in multilayered stands has been done successfully on small, well-administered operations, but extending these methods on a large scale must be carefully considered. Safety, increased cost, and the need for close supervision are major concerns. Experienced silviculturists, wildlife biologists, and other 


\section{Appendix S: Silviculture}

specialists must provide time and resources for careful analysis, implementing prescriptions, and monitoring treatments. Managing for these complex structures cannot be by such methods as "loggers choice" nor can implementing the techniques be left to inexperienced, unskilled personnel.

From the perspective of silvicultural knowledge, most of the techniques we described could be used now, but to make the step from hypothesis to action, we believe several steps are needed:

Spotted owl habitat descriptions need to be more precise. Habitats could be unique to certain plant communities, physiographic regions, or major forest types. The silviculturist and wildlife ecologist need to jointly develop quantitative and qualitative descriptions of desired forest conditions for spotted owl habitat.

Silvicultural methods and systems need to be refined. We see much of this activity as an extension of the thoughts presented in this paper, an extension of our suggested methodologies and applications.

Silviculturists need specific training to recognize spotted owl habitat attributes and methods for developing them.

Technology for linking stand-scale and landscape-scale analysis and treatment must be refined.

We need to look closely at the quality of habitat we are attempting to create with new silvicultural systems. A long-term view cannot be focused on providing minimum requirements for spotted owls while maximizing revenue. We need to focus on creating superior habitat in HCAs and less than optimum, yet biologically functional habitat in the forest matrix. Currently, we believe the best way to create superior habitat for spotted owls is to develop stand characteristics that mimic as closely as possible current old-growth conditions. Our long-term goal is to return spotted owls to the general forest matrix and no longer require HCAs with defined boundaries. We will only be able to attain this goal when silvicultural systems are applied in a way that tests the quality and quantity of owl habitat that can be produced.

\section{References}

DeBell, D. S., and J. F. Franklln. 1987. Old-growth Douglas-fir and western hemlock: a 36-year record of growth and mortality. West. J. Appl. For. 2(4):111-114.

DIller, L. 1989 unpubl. Status of the northern spotted owl in managed forests on Simpson redwood lands in northern California. Interim rep. submitted to Simpson Redwood Co., Arcata, Calif., 20 Oct. 1989

Forsman, E. D., E. C. Meslow, and H.M. WIght. 1984. Distribution and biology of the spotted owl in Oregon. Wildl. Monogr. 87.

Gutlérrez, R. J., D. M. Solls, and C. Clsco. 1984. Habitat ecology of the spotted owl in northwestern California: Implications for management. Pages 368-373 in New forests for a changing world, Proc. of 1983 Convention, Portland, Oreg., Soc. Am. For. 


\section{Appendix S: Silviculture}

IrwIn, L. L. 1986. Ecology of the spotted owl' in Oregon and Washington. Tech. Bull. 509. National Council of the Paper Industry for Air and Stream Improvement (NCASI). 58pp.

IrwIn, L. L. 1989 unpubl. A management alternative for conservation of the northern spotted owl. Rep. for NCASI. Corvallis, Oreg.

IrwIn, L. L., J. Buchanan, E. McCutcheon, and C. Phillips. 1989 unpubl. Characteristics of spotted owl nest sites in the Wenatchee National Forest. Rep. for NCASI. Corvallis, Oreg.

LaHaye, W. 1988. Nest site selection and nesting habitat of the northern spotted owl in northwestern California. M.S. Thesis, Humboldt State University, Arcata, Calif. $111 \mathrm{pp}$.

McArdle, R. E., W. H. Meyer, and D. Bruce. 1961. The yield of Douglas-fir in the Pacific Northwest. USDA Tech. Bull. 201 (rev.), 74pp.

Ollver, C. D. 1980. Even-aged development of mixed species stands. J. For. 78:201-203.

Plous, M. 1989 unpubl. The northern spotted owl in managed, second-growth coastal redwood forests. Mendocino County, California: Preliminary results. LousianaPacific Corp., Calpella, Calif. 105pp.

Smlth, D. M. 1962. The practice of silviculture. 7th ed. John Wiley and Sons, New York. 578pp.

Troup, R. S. 1952. Silvicultural systems, 2nd ed. E. W. Jones, ed. Oxford Univ. Press, London. 


\section{Viability Risk Assessment}

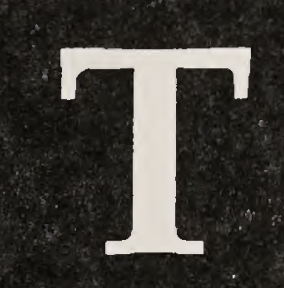

\author{
Maintaining \\ Population Viability
}

The chance or likelihood that a wildlife population will continue to exist in an area is known as its viability (Samson et al. 1985, Schonewald-Cox et al. 1983, Shaffer 1983). A population with high viability has a high likelihood of persistence. Maintaining the viability of spotted owl populations entails ensuring adequate amounts and distributions of habitat for all life needs. Populations should be able to interact and should be of sufficient size that risks of declines are very low over a period of at least a century or longer (Conner 1988, Shaffer 1981).

The ultimate goal of maintaining population viability is to provide for long-term genetic evolution, on the order of thousands or tens of thousands of generations (Barrowclough 1980, Emigh and Pollak 1979). At this extreme time scale, we are scarcely able to conceive the many factors that influence evolution, and are unable to predict long-term and large-scale changes effected by such influences as climate (Graham 1988), vegetation and habitats (Quinn 1989), and species interactions. Our focus under this strategy, therefore, is on the order of 6 to 12 generations (50 to 100 years) for a long-lived species such as the spotted owl.

In general, smaller and more isolated populations are much more susceptible to higher viability risks than are larger, interacting populations (Iwasa and Mochizuki 1988). Thus, viability is better ensured when populations-and habitats for breeding, feeding, dispersal, and other life needs-occur in widely distributed, contiguous patterns (Shaffer and Samson 1985; also, for example, see the island archipelago model of Harris 1983).

Viable spotted owl populations should be able to persist despite threats to their continued existence. Specific objectives for maintaining population viability include providing habitats that are

- Of high quality and of sufficient size and proximity to ensure high rates of reproductive pair occupancy;

- Spaced closely enough and of sufficient size to ensure high probabilities of being locally recolonized (Brown and Kodric-Brown 1977); and

- Distributed so as to ensure that individuals interact among geographic locations, providing for populations that do not become demographically isolated (Hastings and Wolin 1989).

Most of these factors are addressed in appendices $\mathrm{M}, \mathrm{N}, \mathrm{O}$, and $\mathrm{P}$. These appendices should be consulted for explanations of how guidelines for HCAs deal with some of these viability objectives. 


\section{Appendix T: Risk Assessment}

The conservation strategy provides for the following viability objectives. First, large blocks (HCAs) of high-quality habitat sufficient for holding at least 20 reproductive spotted owl pairs meet the first two viability objectives, ensuring occupancy and local recolonization. Such blocks need to be large enough to ensure very high occupancy rates by reproductive pairs over time. Block occupancy is expected to remain high when blocks are large and of high habitat quality, or when recolonization rates are high, or both. Local pair densities or comparison with the size of the annual home ranges of spotted owl pairs can help verify the size of blocks needed (appendix I). Large blocks, as suggested by this conservation strategy, would be large enough to provide locally high densities and would provide for at least median home-range sizes. Contiguous habitat within such blocks would help avoid adverse results from habitat fragmentation (Wilcove 1987) and edge effects (Harris 1988). It would also provide forest interior conditions, and increase the likelihood of successful dispersal (appendices $\mathrm{M}$ and $\mathrm{P}$ ).

Large blocks of habitats (HCAs), distributed at generally regular intervals across geographic and elevational gradients and throughout the range of the subspecies, meet the third objective. The conservation strategy calls for spacing HCAs at distances well within the dispersal capacities of most juvenile spotted owls. This spacing helps ensure that a habitat block would be recolonized if its population of owls disappears, and also helps ensure broad distribution across a full range of habitat qualities.

Empirical studies of juvenile spotted owls occurred in landscapes offering at least some degree of suitable roosting and travel conditions. Use of observed dispersal distances to plan spacing among HCAs is most appropriate when the landscape between HCAs matches that in the studies (that is, when the intervening landscape offers some degree of suitable roosting and travel conditions). The conservation strategy calls for such habitat to be provided between the HCAs in forested habitat reserved for allocations other than for spotted owls, including streamside and visual corridors, older forest management areas for other wildlife species such as pine marten and pileated woodpeckers, retention of older forest patches centered on known owl nest sites, and some lands unsuited for timber production (appendices $P$ and $Q$ ). In addition, the 50-11-40 rule (appendix Q) stipulates that nonreserved lands between HCAs be managed to maintain forest conditions that are useful to dispersing owls.

Viability Effects

Many factors can affect population viability (Soulé 1986, Soulé and Wilcox 1980 , Wilcox 1986). Many of these factors are common or normal for most wildlife populations. Some, taken alone, may have a positive impact, such as local increases in prey densities. Of concern to us are factors that can operate individually or together to cause local or widespread decline, especially in areas where low densities or fragmented populations occur. Such declines may ultimately result in the local elimination of the owl, or lead to extinction. 


\section{Appendix T: Risk Assessment}

The following conditions of environments, habitats, or populations interact to affect viability:

Environmental conditions

- Environmental variation-which results in low survival and reproductive ratessuch as fluctuations in prey densities or periods of harsh weather.

- Environmental catastrophes - which result in direct habitat loss, population reduction, or isolation-such as wildfire, windstorms, and volcanoes.

- Local increases in other species, especially predators, competitors, parasites, and disease.

Habitat conditions

- Systematic habitat loss - such as the widespread and rapid conversion of old forests to young forests-by natural occurrences and human activities.

- Forest stand fragmentation-of owl habitat at both local or regional scales-such as from logging activities (principally clearcutting forest stands).

- Connectivity loss-resulting in uneven distribution of spotted owl habitat across physiographic provinces-such as from different patterns of land ownership.

Population conditions

- Random variation in survival and fecundity among individuals within small, isolated populations.

- Loss of genetic variation or length of time in a genetic bottleneck, resulting in reduced fecundity and adaptability, and increased mortality rates, especially in small, isolated populations.

Elements of population viability are displayed in table T1. Specifically listed are the principal factors potentially affecting spotted owl populations, how those factors put spotted owl populations at risk of decline or local extinction, references to conservation strategy guidelines designed to reduce risks, and proposed monitoring and research activities that would reduce scientific uncertainty and aid in higher likelihoods of population viability.

Designing a Conservation Plan for Population Viability
Although risk factors in Table T1 are listed as independent elements, they often compound and interact to create greater degrees of risk than when taken separately. Habitat fragmentation in a watershed, for example, could cause local reproductive success to decline. This decline would reduce the numbers of dispersing juveniles across a landscape, which in turn might cause demographic isolation of owls in parts of its range. Such isolation could increase the likelihood that local populations would decline or become extinct, as a result of environmental variation. Thus, in this example, one factor-habitat fragmentation-could cause greater risk to viability from another factor-environmental variation. 


\section{Appendix T: Risk Assessment}

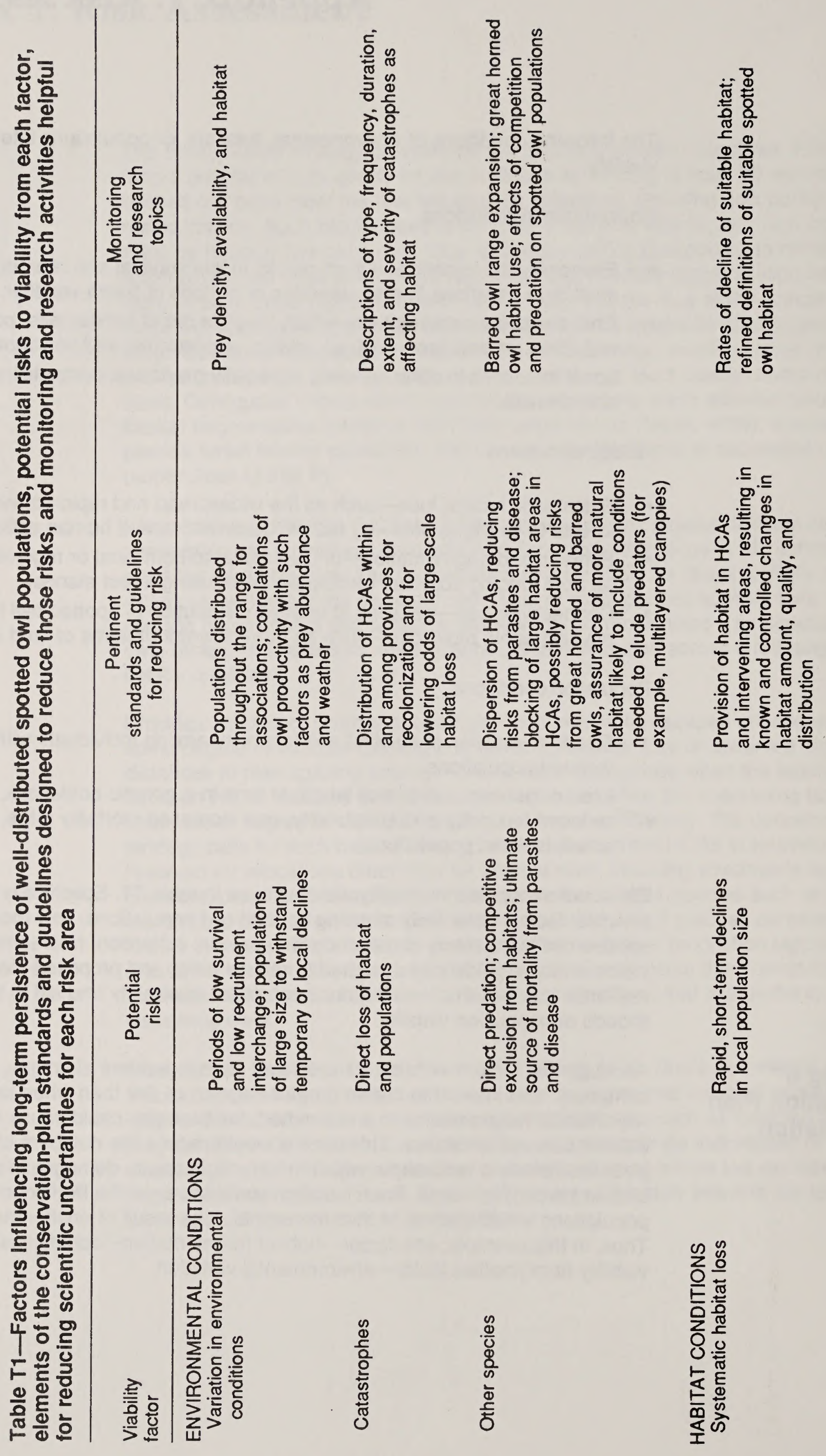




\section{Appendix T: Risk Assessment}

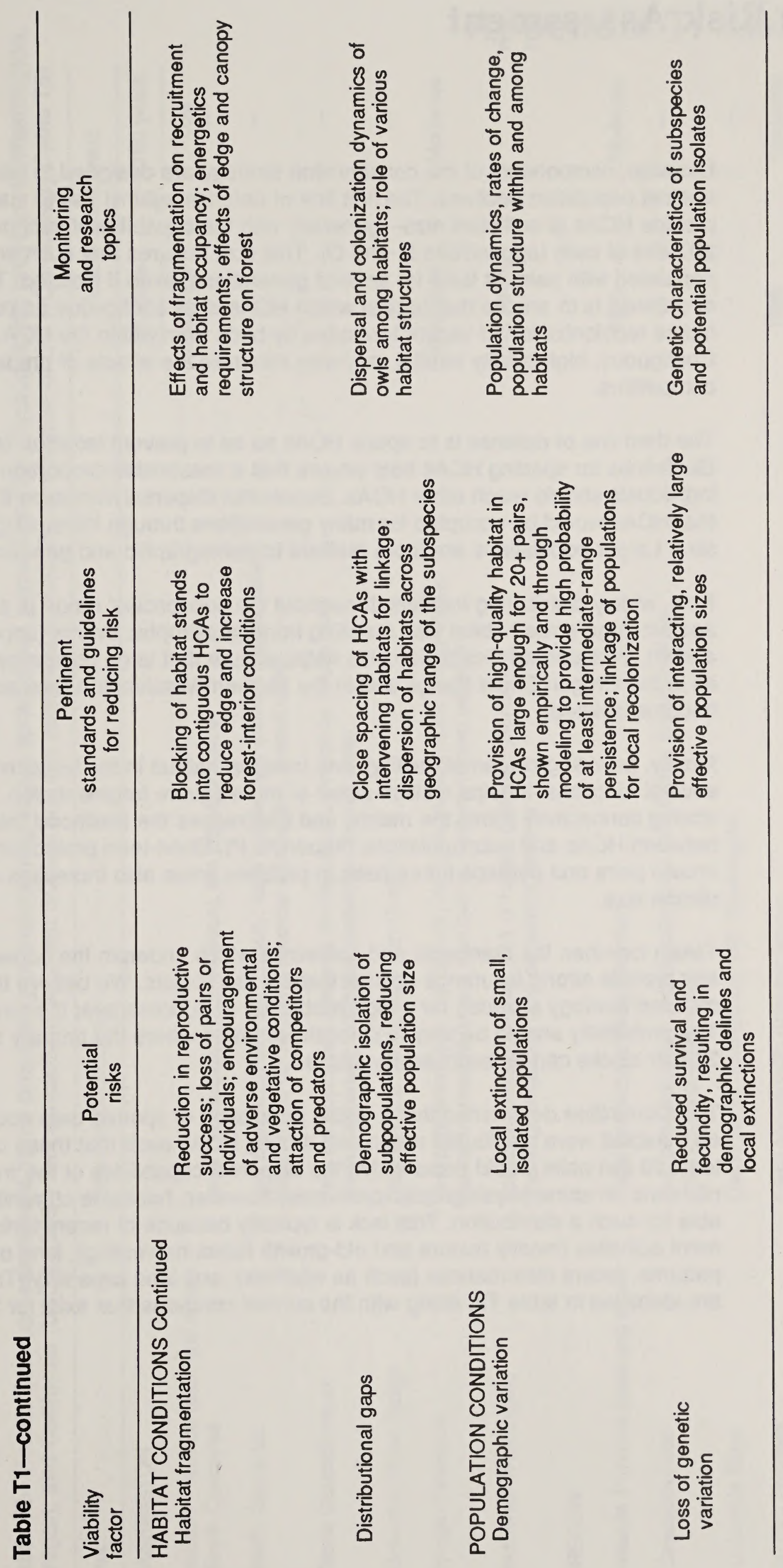




\section{Appendix T: Risk Assessment}

Likewise, components of the conservation strategy are designed to interact as hedges against population declines. The first line of defense against risk to viability is to provide HCAs of sufficient size - generally with the capability of supporting at least 20 pairs of owls (appendices $M$ and 0 ). This size ensures that such areas remain populated with pairs at least for several generations, even if isolated. The second line of defense is to ensure that habitat within HCAs is as contiguous as possible to enhance recolonization of vacant territories by birds from within the HCA (appendix $M$ ). Contiguous, high-quality habitat may also minimize the effects of predators and competitors.

The third line of defense is to space HCAs so as to prevent isolation (appendix P). Guidelines for spacing HCAs help ensure that a reasonable proportion of dispersing individuals should reach other HCAs. Successful dispersal increases the likelihood that HCAs would be occupied for many generations through increasing population size. Larger populations are more resilient to demographic and genetic risk factors.

Next, widely distributing habitats throughout the subspecies' range is a defense against large-scale habitat loss resulting from catastrophic events (appendices $\mathrm{N}$ and $\mathrm{O}$ ). Widespread distribution also helps ensure that large population areas, such as in the Oregon Coast Range and in the northern Washington Cascades, do not become isolated.

Finally, providing dispersal, resting, and foraging habitat in the forest matrix serves several functions: it helps reclaim areas of more severe fragmentation, thereby restoring connectivity within the matrix; and it increases the likelihood that owls interact between HCAs and subpopulations (appendix P). Short-term protection of additional known pairs and perhaps future pairs in problem areas also increases effective population size.

Taken together, the standards and guidelines which underpin the conservation strategy provide strong insurance against viability risk factors. We believe that the recommended strategy provides for a high probability of success over the next 100 years. The probability should be very high for those areas where the primary strategy of 20-pair blocks can be successfully applied.

Areas With Problems of Habitat Distribution
The Committee determined that a viable population of spotted owls could be supported if habitat were distributed within and among HCAs such that those containing at least 20 owl pairs would occur within the dispersal capabilities of the majority of juvenile owls. In some physiographic provinces, however, habitat is currently not available for such a distribution. This lack is typically because of recent timber management activities (mostly mature and old-growth forest harvesting), land ownership patterns, recent disturbances (such as wildfires), and land capability. These areas are identified in table T2, along with the current concerns that exist for these areas. 


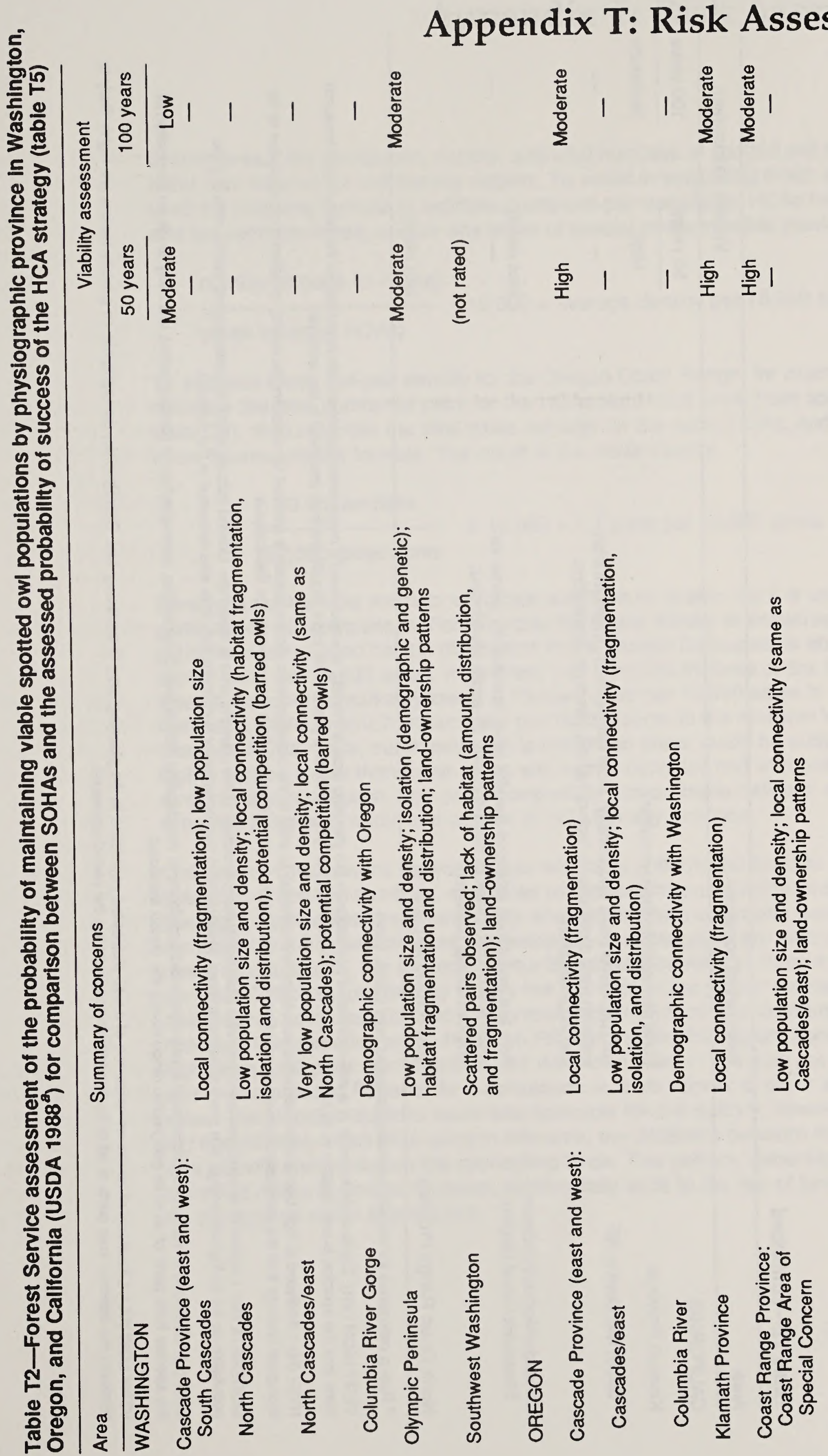

Appendix T: Risk Assessment

点| | 喜喜| 
Appendix T: Risk Assessment

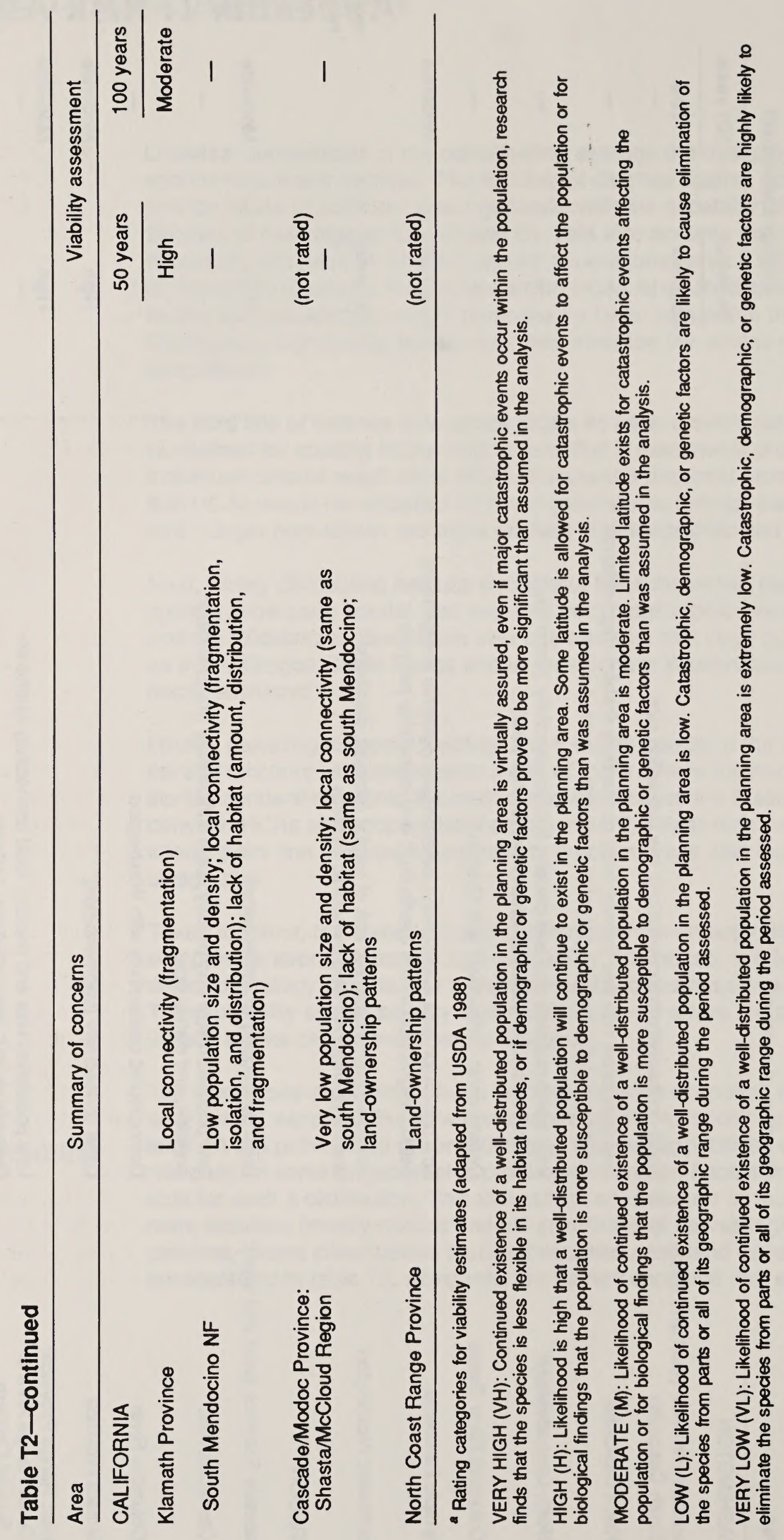




\section{Appendix T: Risk Assessment}

In such areas, the distribution, density, and total numbers of spotted owl pairs is lower than desired for maintaining viability. To assist in evaluating these areas, we used the following formula to estimate crude owl-pair density for HCAs located within and between provinces, and for any areas of special concern within provinces:

number of pairs (in HCAs)

gross acres (in HCAs) $\times 10,000=$ average density per 10,000 acres.

To estimate crude owl-pair density for the Oregon Coast Range, for example, first calculate the total number of pairs for the HCAs within that area (from appendix Q, table Q5), then calculate the total gross acreage for the same HCAs, and insert those figures into the formula. The result is the crude density.

83 known pairs

732,000 gross acres

$X 10,000=1.1$ pairs per 10,000 acres.

Density is not the best indicator of habitat condition or quality, but it is useful for the purposes of this comparison. For example, the crude density of known spotted owl pairs, in areas of good habitat distribution in the Oregon Cascades, is about 1.5 known pairs per 10,000 acres. In contrast, pair densities in some of the Areas of Special Concern is markedly lower: 0.7 known pairs per 10,000 acres in the Olympic Peninsula HCAs, and 0.7 known pairs per 10,000 acres in the northern Washington Cascade HCAs. Thus, our expectation is that these areas would be subject to a higher degree of risk than those areas with higher densities and with better habitat amounts and distribution. The same comparison can be made between estimated or expected pairs both within and outside of HCAs in any province.

Owl density comparisons between areas with fairly uniform distributions of both suitable habitat and owl numbers, and areas with discontinuous distributions, are misleading. Discrepancies most commonly arise when areas under one ownership are compared to areas with multiple ownership, or when densities are estimated at different spatial scales. For example, in the Shasta/Modoc Area of Special Concern in northern California, owl density is very low because of the patchy distribution of suitable habitat, which results from checkerboard land ownership and different land-use histories. Owl densities within HCAs on FS lands within this region, however, are high (about 1.8 pairs per 10,000 acres). All known pairs in this area are within HCAs and are confined to FS land. As a consequence, owls appear to occur at high densities. The situation appears much less favorable for owl viability, however, considering the relatively small HCA sizes in this area, the distances between them, and the lack of owls and habitat on the intervening lands. This pattern, generally true for all identified Areas of Special Concern, substantially adds to the risk of long-term viability for the spotted owl in these areas. 


\section{Appendix T: Risk Assessment}

Relative Security From Factors that Could Threaten Population Viability
For similar reasons, the checkerboard land ownership pattern of BLM lands within the range of the owl increases the risk for long-term owl viability in these areas. BLM lands are, nevertheless, extremely important for connectivity between populations of owls in the Cascade, Klamath, and Coast Range provinces in Oregon, and between HCAs in the Coast Range and Klamath provinces in California, for maintaining viable populations in these areas, and for restoring populations in the Oregon Coast Range.

Existing situations also vary within as well as among provinces because of differences in the amount and distribution of available habitat, and in land ownership. For example, significantly fewer owls and patches of suitable habitat occur in the identified Area of Special Concern in the northern part than in the remainder of the Oregon Coast Range. Owl densities in the Area of Special Concern are 0.8 known pairs per 10,000 acres versus 2.3 pairs per 10,000 acres in the southern part of the Coast Range. Compare these estimates to the 1.1 pairs per 10,000 acres in calculated above for the whole Coast Range. Similar situations exist in the North Cascades Area of Special Concern in Washington (density of 0.7 pairs per 10,000 acres), the Mendocino Area of Special Concern in California (density of 1.0 pairs per 10,000 acres), and others (see appendices $C$ and $Q$ ).

Problem areas-those HCAs with low densities of owls-encounter additional viability threats. Suitable territories in these HCAs are less contiguous. The result is that successful dispersal within HCAs becomes more uncertain, rates of territorial replacement when birds die are lower, and owls spend more time traveling through the surrounding forest matrix (see appendices $M$ and $P$ ). These factors collectively contribute to low survival and fecundity rates and to increased viability risks in those areas.

The combination of low pair densities, low total number of pairs, low numbers of recruits and dispersing owls, and the resulting low dispersal success, results in a substantially higher risk that the HCAs in these areas will not be occupied by reproductive pairs over the long term. We believe that individual, isolated pairs or small numbers of pairs (for example, less than 10 , see appendices $M, N$, and $O$ ) in such problem areas have, at best, a low to moderate likelihood of continued existence beyond four or five generations. Occupied sites in many such areas, if not supplied with additional new habitat and with new immigrants, would likely begin to wink out beyond that time.

The methods we used to assess viability risks were independent of those used by the FS in their 1988 Supplemental EIS (USDA 1988). In general, we explored the dynamics of a population experiencing habitat loss and decreases in population number in the context of a spatial simulation model (appendix M). Our analyses allowed us to explore the effect which varying spatial arrangements and suitable habitat amounts would have on owl population dynamics, and its likelihood of persistence. Despite the differences between our analyses, we found some similarities. Both analyses, for example, 'recognized' the impossibility, given our current understanding, of assigning quantitative values to risk factors. We adopted a qualitative index for assigning risks to categories, similar to what was used by the FS (USDA 1988; table T2). 


\section{Appendix T: Risk Assessment}

Previous FS analyses of viability risks assessed a system of individual pair SOHAs, or two- to three-pair clusters of SOHAs (USDA 1988). The informal risk analysis of our conservation strategy assessed, for the most part, the efficacy of at least 20-pair HCAs compared to HCAs providing for many fewer pair territories (appendix M). Because we proposed a strategy that differs significantly from the current SOHA network, we compared the projected number of pairs sustained in both the short and long terms between the SOHA system and this strategy (tables T3 and T4). Little difference appeared in numbers projected over the short term. In the long term, however, the HCA system provides for significantly greater pair numbers. Perhaps of greater importance than increased pair numbers in the HCA system is the greatly increased likelihood of persistence that results from arranging suitable owl territories in contiguous clusters of 20 or more territories (see appendices $\mathrm{M}, \mathrm{N}$, and O). In fact, the difference between the strategy we proposed and the probabilities associated with the SOHA system may be greater than we have predicted because we believe that the FS's estimate of the success of the SOHA system was too high.

Table T3-Comparisons of estimated number of pairs to be protected by the SOHA and HCA strategies

\begin{tabular}{|c|c|c|c|}
\hline \multirow[b]{2}{*}{ Management strategy } & \multirow[b]{2}{*}{ Number of sites } & \multicolumn{2}{|c|}{ Estimated number of pairs } \\
\hline & & Short term & Long term \\
\hline $\begin{array}{l}\text { SOHA Strategy } \\
\text { Forest Service } \\
\text { SOHAs } \\
\text { Wilderness }\end{array}$ & 654 & $\begin{array}{l}506 \\
180^{a}\end{array}$ & $\begin{array}{l}365 \\
180\end{array}$ \\
\hline $\begin{array}{l}\text { Bureau of Land Management } \\
\text { SOHAs } \\
\text { Wilderness }\end{array}$ & 109 & $\begin{array}{l}97 \\
15\end{array}$ & $\begin{array}{l}65 \\
15\end{array}$ \\
\hline National Park Service & & 75 & 75 \\
\hline SOHA Totals & 763 & 876 & 739 \\
\hline $\begin{array}{l}\text { HCA Strategy } \\
\text { HCAs (FS, BLM, NPS lands) } \\
\text { Areas reserved from timber } \\
\text { harvest outside of HCAs }\end{array}$ & 157 & $\begin{array}{r}1465 \\
71^{a} \\
\end{array}$ & $\begin{array}{r}1759 \\
71 \\
\end{array}$ \\
\hline HCA Totals & 157 & 1536 & 1820 \\
\hline
\end{tabular}

Assumes pairs in wilderness outside of protection areas (SOHAs or HCAs) will persist, which may be optimistic.

${ }^{b}$ Additional pairs in HCAs on other ownerships, if established, will provide even greater security, especially in Areas of Special Concern. 


\section{Appendix T: Risk Assessment}

\begin{tabular}{lc} 
Table T4_Known pairs outside HCAs but located in \\
Wilderness Areas, National Parks, or otherwise protected \\
areas $^{2}$ & Number of known pairs \\
\hline Ownership & 1 \\
\hline Washington & 26 \\
Fish and Wildlife Service & 5 \\
Forest Service & \\
Tribal & 15 \\
Oregon & 5 \\
Forest Service & 9 \\
National Park Service & 1 \\
Bureau of Land Management & \\
State Parks & 10 \\
California & 72 \\
Forest Service & \\
Total pairs & \\
\hline
\end{tabular}

a Pairs documented in the last 5 years. Data from National Forests, BLM Districts, and other agencies.

We have concluded that the risk to the owl population is significant under a management scenario based on single or one- to three-pair SOHAs (for further discussion on the risk associated with the SOHA system see appendix O). For some areas within the range of the owl, however, we have no choice but to designate HCAs that may support only a few pairs. We recognize the problems inherent in this approach, and have concluded that the long-term risk to such areas is greater than to areas with a preponderance of larger HCAs. The risk in areas augmented by smaller HCAs is less than it would be if only SOHA management were done. The spacing between these areas, the expected quality and contiguity of the included habitat, and the proximity to larger HCAs results in enhanced opportunities for owl recolonization or for sustained owl occupancy in the small HCAs, thus reducing risk to long-term persistence.

Owl population viability on the Olympic Peninsula was assessed separately from the remainder of the population because of the lack of connectivity between the Peninsula and the Washington Cascades and the Oregon Coast Range. The long-term risks to population viability on the Peninsula would be greatly reduced if HCAs were established on intervening lands, or if those lands were managed to provide for successful dispersal. The Committee believes that the probability of long-term success would be high if the strategy is fully implemented on all lands.

The potential for success of the conservation strategy varies between and within provinces because of the differences in owl numbers, suitable habitat amounts, distances between HCAs, relative isolation, and other factors discussed in this and other appendices. In the Areas of Special Concern, the probability of long-term success may be substantially lower because of their higher risks. Nevertheless, with full implementation of the conservation strategy (table T5), we believe that a high to very high probability of long-term success exists for maintaining population viability for the northern spotted owl through the next 100 years over its current range. 


\section{Appendix T: Risk Assessment}

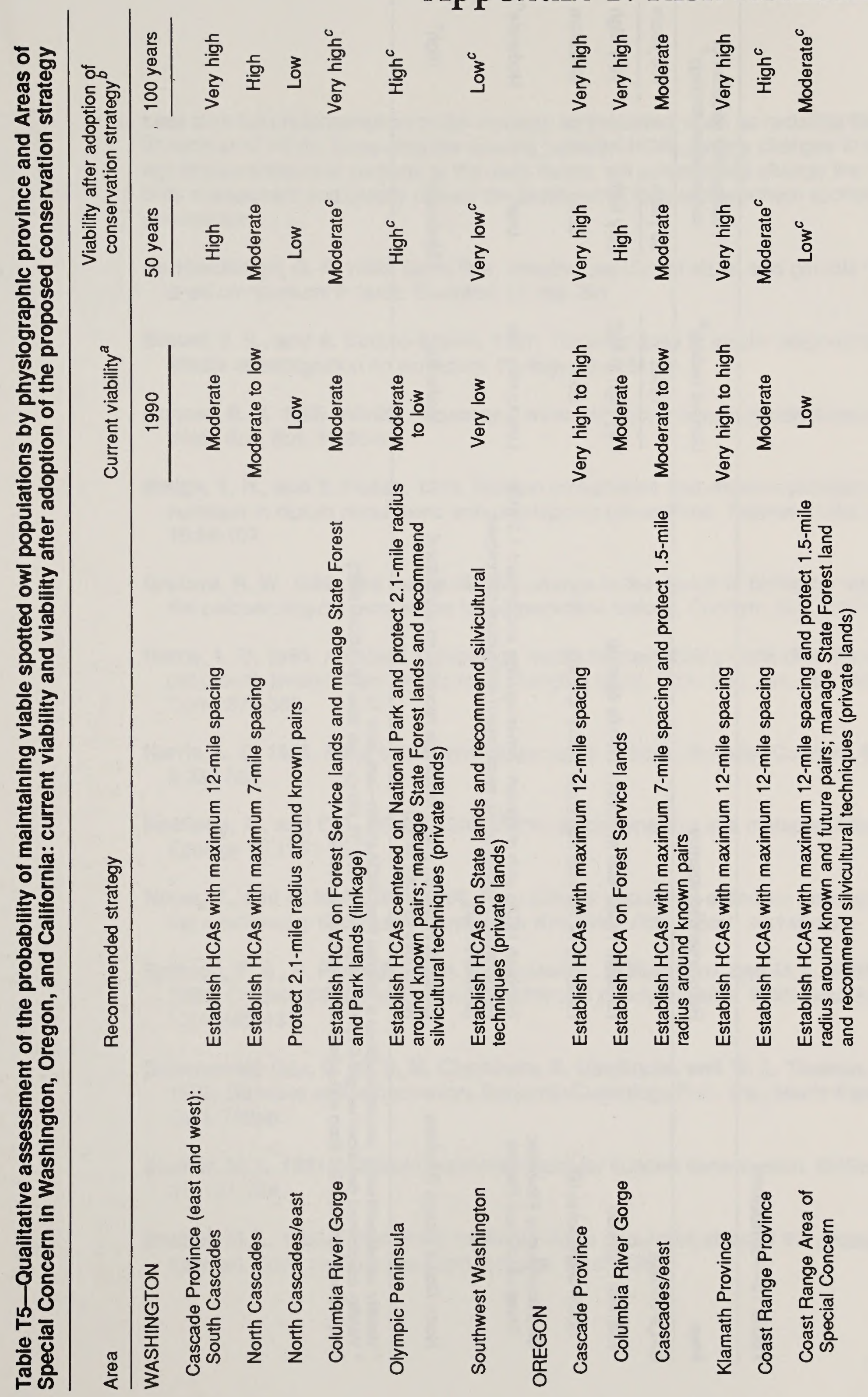




\section{Appendix T: Risk Assessment}

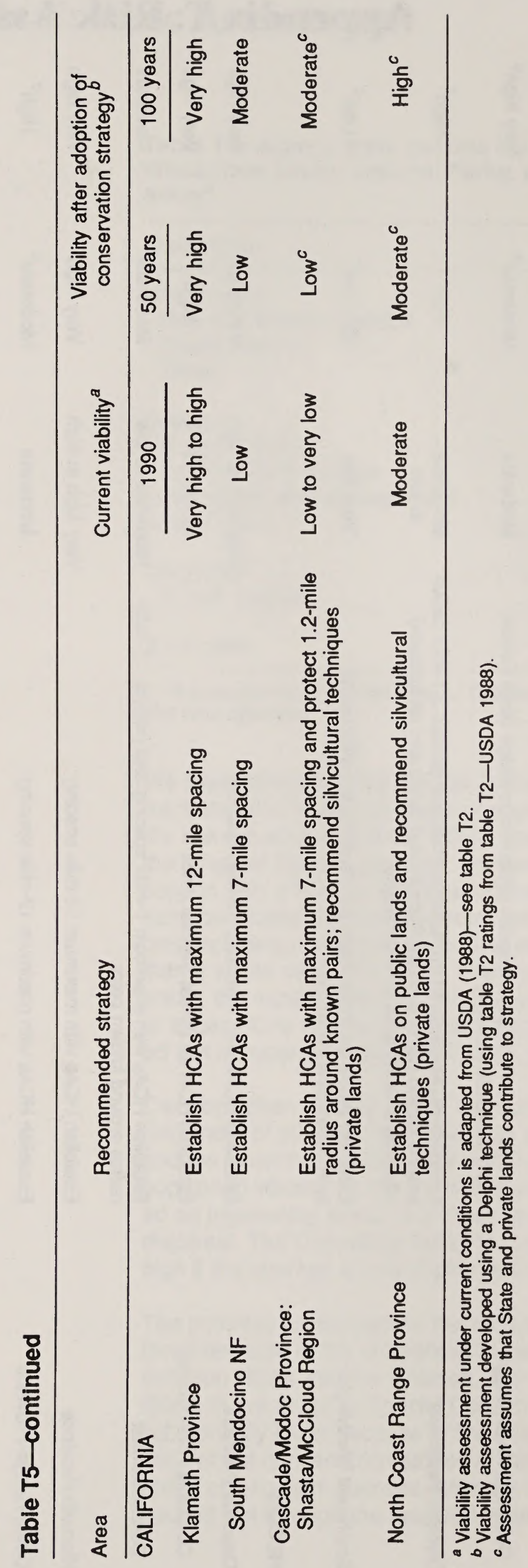




\section{Appendix T: Risk Assessment}

References

Less than full implementation of the strategy, as proposed, such as reducing the size or number of HCAs, increasing the spacing between HCAs, or any changes in strategy implementation in portions of the owl's range, will substantially change the viability assessment and greatly reduce the likelihood of long-term northern spotted owl persistence.

Barrowclough, G. F. 1980. Gene flow, effective population sizes, and genetic variance components in birds. Evolution 34:789-798.

Brown, J. H., and A. Kodrlc-Brown. 1977. Tumover rates in insular biogeography: effects of immigration on extinction. Ecology 58:445-449.

Conner, R. N. 1988. Wildlife populations: minimally viable or ecologically functional? Wildl. Soc. Bull. 16:80-84.

Emlgh, T. H., and E. Pollak. 1979. Fixation probabilities and effective population numbers in diploid populations with overlapping generations. Theoret. Popul. Biol. 15:86-107.

Graham, R. W. 1988. The role of climatic change in the design of biological reserves: the paleoecological perspective for conservation biology. Conserv. Biol. 2:391-394.

Harrls, L. D. 1983. An island archipelago model for maintaining biotic diversity in old-growth forests. New forests for a changing world, Proc. Soc. Am. For. Natl. Conv.:378-382.

Harrls, L. D. 1988. Edge effects and conservation of biotic diversity. Conserv. Biol. 2:330-332.

Hastlings, A., and C. L. Wolln. 1989. Within-patch dynamics in a metapopulation. Ecology 70:1261-1266.

Iwasa, Y., and H. Mochlzukl. 1988. Probability of population extinction accompanying a temporary decrease of population size. Res. Popul. Ecol. 30:145-164.

Samson, F. B., F. Perez-Trejo, H. Salwasser, L. F. Rugglero, and M. L. Shaffer. 1985. On determining and managing minimum population size. Wildl. Soc. Bull. 13(4):425-433.

Schonewald-Cox, C. M., S. M. Chambers, B. MacBryde, and W. L. Thomas. 1983. Genetics and conservation. Benjamin/Cummings Publ. Co., Menlo Park, Calif. 722pp.

Shaffer, M. L. 1981. Minimum population sizes for species conservation. BioScience 31: 131-134.

Shaffer, M. L. 1983. Determining minimum viable population sizes of the grizzly bear. Internatl. Conf. on Bear Res. and Manage. 5:133-139. 


\section{Appendix T: Risk Assessment}

Shaffer, M. L., and F. B. Samson. 1985. Population size and extinction: a note on determining critical population sizes. Am. Nat. 125:144-152.

Soulé, M. E., ed. 1986. Conservation biology: The science of scarcity and diversity. Sinauer Assoc., Sunderland, Mass. 584pp.

Soulé, M. E., and B. A. Wilcox, eds. 1980. Conservation biology: An evolutionaryecological perspective. Sinauer Assoc., Sunderland, Mass.

U.S. Department of Agriculture, Forest Service. 1988. Final supplement to the Environmental Impact Statement for an amendment to the Pacific Northwest regional guide. USDA For. Serv., Pacific NW Region. Portland, Oreg.

Wilcox, B. A. 1986. Extinction models and conservation. Tree 1:46-48.

Wilcove, D. S. 1987. From fragmentation to extinction. Nat. Areas J. 7:23-29. 


\section{The Committee}

Operations of the Committee

Qualifications of the Committee Members
The six-member Committee was expected to sign and stand fully responsible for the report. On the rare occasions when all members of the team did not agree on some point, the Committee made the decision. On some other rare occasions, some members of the Committee were not present when decisions were made. Agreement or disagreement of the observer-advisor-staff group with all aspects of the report is thus not implied.

All team members participated fully in all aspects of the effort, and all were accorded the opportunity to assume the same roles in analyzing, interpreting, and formulating the plan. A key objective of the process was to move toward a final decision through achieving consensus at each intermediate step. The filing of a minority report was initially considered possible if substantial disagreement developed among the Committee, but no minority report was needed.

All team members available at particular times participated fully in all activities. Data analysis, synthesis, administrative chores, mapping, writing, technical review, and so on were assigned to the best qualified persons, regardless of their "category" on the team. All team members had equal opportunity to participate.

The entire process was open: anyone who wished to observe Committee activities was welcome, and anyone who wished to present information germane to the mission of the Committee was invited to do so. This open process was followed from the beginning of our activities until March 1, 1990, when activities were confined to the Committee and invited technical assistants, to allow preparation of the final report. At that point, all deliberations were complete except for some fine tuning and adjustments resulting from peer review.

All members of the team were qualified and experienced biologists. Twelve of the 17 team members (and 5 of 6 Committee members) were experienced in dealing with the biology of the northern spotted owl. The curricula vitae of each of team member are detailed below. 


\section{Appendix U: The Committee}

\section{MARY ANNE BISHOP}

Academic Training

Work Experience

Present Position

Publications

Professional Socleties

Special Assignments

Awards

1982-83 Rob and Bessie Welder Wildlife Foundation Fellow

1985 Economics

Ph.D. University of Florida; 1988 Wildlife Ecology Garden and Aquarium, San Antonio, Texas Society Research Department, Rockport, Texas of Florida, Gainesville, Florida Gainesville, Florida behavior, and endangered species management.

American Ornithologist's Union

Wilson Ornithological Society

Society for Conservation Biology

North American Crane Working Group Sinica, Xining, People's Republic of China of Bhutan People's Republic of China
B.B.A. University of Wisconsin-Madison; 1974 Real Estate and Urban Land

M.S. $\quad$ Texas A\&M University; 1984 Wildlife and Fisheries Sciences

1979 Avicultural intern, International Crane Foundation, Baraboo, Wisconsin

1977-80 Zoo keeper, Bird and Large Mammal Departments, San Antonio Zoological

1980-82 Biological consultant to Whooping Crane Project, National Audubon

1983-88 Project biologist, Department of Wildlife and Range Sciences, University

1988-89 Technician, Malacology Lab, Florida Museum of Natural History,

1989-90 Wildlife biologist, Forestry and Range Sciences Laboratory, USDA Forest Service, Pacific Northwest Experiment Station, La Grande, Oregon

More than 10 scientific publications primarily dealing with crane ecology and

1987 Visiting researcher, Northwest Plateau Institute of Biology, Academia

1989 Visiting researcher, Royal Society for the Protection of Nature, Kingdom

1989 Consultant, Bombay Natural History Society, Bombay, India, for the U.S. Fish and Wildlife Service, Office of International Affairs

1990 Visiting researcher, Tibet Plateau Institute of Biology, Lhasa, Tibet,

Research grant, National Audubon Society Science and Sanctuaries Division

1985-86 Research grants, Florida Chapter Sierra Club 


\section{Appendix U: The Committee}

\section{CHARLES R. BRUCE}

Academic Training

Work Experience

Present Position

Awards

Professionai Socleties

Experience With Spotted Owi Biology and

Management
B.S. Lewis and Clark College 1969; Biology

B.S. Oregon State University 1971; Wildlife Science

1971-90 Nongame wildlife biologist, Oregon Department of Fish and Wildlife at Portland and Corvallis, Oregon

Regional nongame biologist, Northwest Region, Oregon Department of Fish and Wildlife, Convallis, Oregon

1989 Pride award, Oregon Deptartment of Fish and Wildlife

The Wildlife Society

1988-89 President, Oregon Chapter

Interagency management experience for 17 years, including population surveys and development of 1977 and 1981 Oregon spotted owl management plans; chaired Interagency Spotted Owl Subcommittee, which drafted management guidelines for the owl throughout its range (1988) 


\section{Appendix U: The Committee}

\section{ERIC FORSMAN}

Academic Training

Work Experlence

Present Position

Publications

Awards

Experience With Spotted Owls
B.S. Oregon State University; 1972 Wildlife Management

M.S. Oregon State University; 1976 Wildlife Management

Ph.D. Oregon State University; 1980 Wildlife Management

1980-87 Independent wildlife consultant

1987-89 Research wildlife biologist, USDA Forest Service

Team leader for Spotted Owl Research, USDA Forest Service, Pacific Northwest Experiment Station, Olympia, Washington

Approximately 20 , mostly dealing with the biology and management of the spotted owl and other owl species

1984 Publication award for monographs, The Wildlife Society

1972-75 Together with Howard Wight at Oregon State University, investigated the distribution and biology of the spotted owl in Oregon; in addition to surveys to determine the distribution and abundance of the owl, collected information on nest site characteristics, diet, behavior, molt patterns, and roost site selection

1975-80 Conducted a Ph.D study using radio-telemetry to examine habitat use by spotted owls on the west slope of the Cascades in Oregon

1976 Conducted a survey comparing the relative abundance of spotted owls in young forests and old-growth forests in northwestern Oregon

1977 While taking a graduate course at Northern Arizona University, collected information on the distribution and diet of the spotted owl in the Chiricahua Mountains in southeastern Arizona

1980 Designed and conducted a radio-telemetry study of spotted owls on the Eugene District of the Bureau of Land Management

1982 Designed and carried out a study in which we measured and compared structural characteristics of old-growth, mature, and young forests of Douglas-fir and western hemlock in northwestern Oregon

1983-84 Developed and implemented a computerized data base for storing information on the distribution and habitat of spotted owls in Oregon

1984 Proposed, designed, and carried out a study of the distribution, abundance, and habitat of the great gray owl in south-central Oregon

1985 Designed and carried out the first extensive survey of spotted owls in British Columbia 


\section{Appendix U: The Committee}

\section{ERIC FORSMAN-continued}

1985 Bureau of Land Management, Roseburg, Oregon. Assisted with the initiation of a banding study of spotted owls on the Roseburg District

1986 Designed and conducted a survey of spotted owls within the Skagit River drainage in British Columbia

1986 Assisted in an inventory of spotted owls on the Siuslaw National Forest

1986 Conducted a survey to determine the relative abundance of spotted owls in young forests in the northern Coast Ranges of Oregon (a follow-up to the study conducted in 1976)

1973-90 Participated in most of the deliberations of the various committees assembled to address the spotted owl issue in Oregon. These included the Oregon Endangered Species Task Force, the Oregon-Washington Interagency Wildlife Committee, and the Oregon-Washington Interagency Spotted Owl Subcommittee

1987- As research Wildlife Biologist for the U.S. Forest Service, PNW Research present Laboratory in Olympia, Washington, directed several demographic and habitat-use studies on the northern spotted owl in Oregon and Washington 


\section{Appendix U: The Committee}

GORDON I. GOULD, Jr.

Academic Tralning

Work Experlence

Present Position

Publlcatlons and Papers
A.B. University of California, Berkeley; 1966 Zoology

M.S. Humboldt State University; 1973 Wildlife Management

1973-74 Contract wildlife biologist, California Department of Fish and Game, U.S. Forest Service, and National Park Service, Sacramento and San Francisco, California

1974-77 Unit wildlife biologist, California Department of Fish and Game, Blythe, California

1977-79 Nongame/furbearer biologist, California Department of Fish and Game, Sacramento, California

Nongame bird and mammal and furbearer subproject leader, Wildlife Management Division, California Department of Fish and Game, Sacramento, California

Gould, G. I. 1974. The status of the spotted owl in California. California Department of Fish and Game, Wildlife Management Branch. Administrative Report 74-6. 35pp.

Gould, G. I. 1975. Habitat requirements of the spotted owl in California. Cal-Neva Wildl. Trans.:102-117.

Gould, G. I. 1977. Distribution of the spotted owl in California. Western Birds 8:131-146.

Gould, G. I. 1979. Status and management of elf and spotted owls in California. Pages 86-97 in P. P. Schaeffer and S. M. Ehlers, eds. Symposium on owls of the West, their ecology and conservation. National Audubon Society, Tiburon, CA.

Gould, G. I. 1985. Management of spotted owls by the California Department of Fish and Game. Pages 21-26 in R. J. Gutiérrez and A. B. Carey, eds. Ecology and management of the spotted owl in the Pacific Northwest. USDA Forest Service Gen. Tech. Rep. PNW-185., Portland, OR.

Gould, G. I. 1985. Current and future distribution and abundance of spotted owls in California. Paper presentation and abstract. Symposium on the biology, status, and management of owls, Nov. 9-10, 1985. Raptor Research Found., Sacramento, CA.

Gould, G. 1987. Geography and population trends of spotted owls in California. Presented at Biology and Management of the Spotted Owl-A Briefing for the Chief and Staff, Affected Forest Service Resource Staffs, and Associated Federal and State Agencies, July 27, 1987. USDA Forest Service. Rosslyn, VA.

Gould, G. 1987. Suitable habitat areas for occupancy, reproduction, and dispersal. Presented at Biology and Management of the Spotted Owl-A Briefing for the Chief and Staff, Affected Forest Service Resource Staffs, and Associated Federal and State Agencies, July 27, 1987. USDA Forest Service. Rosslyn, VA. 


\section{Appendix U: The Committee}

GORDON I. GOULD, Jr.-continued

Additional publications include about 15 more titles on spotted owls, 20 on bobcats, and 25 on other nongame bird, mammal, and furbearer topics

Professionai Societies

Special Conservation

Bloiogy Assignments

Experience With

Spotted Owi Biology

or Management
The Wildlife Society

Western Field Ornithologists

U.S. Fish and Wildlife Service, Endangered Species Scientific Authority, Committee of Bobcat Biologists-Federal Court Case Defense Team

Directed and performed the first two major surveys for spotted owls in California

Directed four other major surveys in Califomia

Maintain the spotted owl sighting and location information data base for California

Planned and was the contract administrator for 15 years of research in five major demographic studies

Contract administrator for three habitat studies

Helped write the standards and guidelines to establish the current U.S. Forest Service spotted owl management system

Performed oversight function on the implementation of the U.S. Forest Service's current spotted owl management system

Helped develop the current monitoring system for the U.S. Forest Service's spotted owl management system

Has personal knowledge of northern spotted owls, habitat conditions, or both at more than 200 sites in last 17 years 


\section{Appendix U: The Committee}

\section{A. GRANT GUNDERSON}

Academic Training

Work Experience

Present Position
Awards
Professional Societies
Experience With
Spotted Owi Biology
or Management

B.S. California State University, San Jose 1972; Conservation/Wildlife Management

1973-74 Wildlife biologist, USDI Bureau of Land Management, San Luis Resource Area, Alamosa, Colorado

1974-76 Field biologist, USDI Fish and Wildlife Service, Division of Ecological Services, Lafayette, Louisiana

1976-79 Area wildlife biologist, USDI Bureau of Land Management, Northeast Resource Area, Wheatridge, Colorado

1980-86 District wildlife biologist, USDA Forest Service, Snow Mountain Ranger District, Ochoco National Forest, Hines, Oregon

1986 Wildlife biologist, USDA Forest Service, Mount Hood National Forest Supervisor's Office, Gresham, Oregon

1986-88 Wildlife biologist, USDA Forest Service, Pacific Northwest Regional Office, Portland, Oregon

Wildlife biologist, Regional Spotted Owl Coordinator, USDA Forest Service, Pacific Northwest Regional Office, Portland, Oregon

1970, 1977-Outstanding performance awards, USDI Bureau of Land Management $1985,1988,1989,1990$ - Certificates of merit, USDA Forest Service

The Wildife Society

Prepared environmental analysis of the effects of timber sales on spotted owls and other wildlife species in the Mount Hood National Forest

Served as a member of the Forest Service interdisciplinary team that prepared the Supplemental Environmental Impact Statement for spotted owl guidelines in the Pacific Northwest Region; provided guidance to National Forests in Oregon and Washington during the implementation phase after the Chief's Record of Decision, which adopted a management strategy for the spotted owl; reviewed Forest's spotted owl networks. Coordinated the spotted owl Section 7 conferences between National Forests and the U.S. Fish and Wildife Service Field Offices 


\title{
Appendix U: The Committee
}

\author{
DAVID W. HAYS
}

Academic Training

Work Experience

Present Position

Professional Societles

Experience With Spotted Owl Blology and Management
B.S. Washington State University; Wildlife Biology

1981-82 Wildlife biologist, Okanogan National Forest

1983 Wildlife biologist, Washington Department of Wildlife

1983-84 Wildlife biologist, Biosystems Analysis, Inc.

1985 Wildlife biologist, Washington Department of Wildlife

1986-88 Wildlife biologist, Beak Consultants, Inc.

Wildlife biologist, Nongame Program, Washington Department of Wildlife, Olympia, Washington

The Wildlife Society

1982 Surveyed and assessed timber-sale impacts to spotted owls

1983-85 Radio-telemetry research and habitat evaluation in the Cascade Range of Washington

1987-88 Surveyed and assessed impacts of a proposed ski development to spotted owls in the southern Cascades of Oregon

1988- Currently addresses spotted owl management issues in Washington for Washington Department of Wildlife 


\section{Appendix U: The Committee}

DOUGLAS B. HOUSTON

Academic Training

Work Experience

Present Position

Publications

Academic Appointments

Awards

Professionai Societies

Special Conservation Assignments
B.S. Humboldt State University; 1962 Wildlife Management

M.A. University of Wyoming; 1963 Zoology

Ph.D. University of Wyoming; 1967 Zoology

1967-70 Research biologist, National Park Service; Grand Teton National Park 1970-80 Research biologist, National Park Service; Yellowstone National Park

Research biologist, National Park Service, Northwest Parks Research Group, Olympic National Park

About 55 publications, primarily on the ecology of moose, elk, and mountain goats, and on the management of National Park ecosystems; includes book: The northern Yellowstone elk: Ecology and management, which received the Wildife Society Publication Award for 1984

1979-81 Adjunct assistant professor, Oregon State University

1984-90 Adjunct assistant professor, University of Idaho

1979 and 1983 - Superior performance award, National Park Service 1984-Wildlife Society publication award

Ecological Society of America

British Ecological Society

Natural Areas Association

Northwest Scientific Association

Northwest Vertebrate Biology Society

1973 Determine status of the gray wolf in the greater Yellowstone ecosystem 1988 Poland; review management of National Parks

1989 Alaska; document effects of oil spill on National Parks 


\section{Appendix U: The Committee}

Academic Training

Theses

Professional Interests

Professlonal Experlence

Publications

Academlc Appolntments

Present Position

Research In Progress
B.S. University of Montana; 1970 Wildlife Biology

M.S. University of Idaho, 1974 Wildlife Management

Ph.D. University of Idaho, 1978 Wildlife Science

Relationships between deer and moose on a burn in northeastern Minnesota. M.S. Thesis. 53 pp.

Relationships between intensive timber culture, big game habitats, and elk habitat selection in northern Idaho. Ph.D. Dissertation. 282 pp.

Relationships between wildlife populations and their habitats; habitat evaluation for wildlife; habitat management for large mammals; plant succession/wildfire/wildlife management

1970-72 Biology and general science teacher, Darby, Montana

1972-74 Graduate research assistant, University of Minnesota and University of Idaho

1974-78 Research associate and research instructor, University of Idaho

1978-86 Assistant and associate professor (tenured), University of Wyoming

1986-

present Wildlife program leader, NCASI, Corvallis, Oregon

1975-85 More than 30 scientific publications, primarily dealing with large mammals and habitat relationships, including forest understory succession

1986-90 Ten publications and reports on northern spotted owls, indicator species, and biodiversity in managed forests; 8 publications on large mammals

1976-78 Research Instructor, University of Idaho

1978-86 Assistant and Associate Professor, University of Wyoming

Adjunct Associate Professor, Oregon State University

Habitat ecology of Rocky Mountain bighorn sheep, a 6-year program including four coordinated studies on winter range

Relationships among deer and elk in managed forests of Washington and Oregon; an experiment with trained elk for gathering data on physiological responses to forests

Habitat ecology of northern spotted owls in managed forests in Washington, Oregon, and northern California

Demography of northern spotted owls in managed and unmanaged forests, central Washington 


\section{Appendix U: The Committee}

\section{LARRY L. IRWIN-contInued}

Habitat use and home range of northern spotted owls in managed forests, western Oregon

Biology and forestry implications of marbled murrelets in the Pacific Northwest; survey, capture, and telemetry techniques

Awards

Professional Socletles

\section{Experience With} Spotted Owl Blology or Management
1974 First Pope and Young Club conservation award

1986 Charles A. Lindbergh grant award for research on balance between man and environment

1989 Wildlife scientist of the year award, Foundation for North American Wild Sheep

The Wildlife Society

Society for Range Management

Interagency Spotted Owl Subcommittee, ad hoc committee on spotted owl guidelines Spotted Owl Recovery Plan Committee for State of Washington

Supervise several research projects (see Research in Progress, above) 


\section{Appendix U: The Committee}

Academic Training

Work Experience

Present Position

Awards

Professional Societies

Experience With Spotted OwI Blology or Management
JOSEPH B. LINT

B.S. West Virginia University; 1970 Forest Management

M.S. Virginia Tech; 1975 Wildlife Management

1974-78 Resource Area and District wildlife biologist, Bureau of Land Management at Coeur d'Alene, Idaho

District wildlife biologist, Roseburg District, Bureau of Land Management, Roseburg, Oregon since 1978

1983, 1987-Sustained superior performance awards-quality step increase, Bureau of Land Management

1988-Oregon Society of American Foresters appreciation award

The Wildlife Society

1973 President, Virginia Tech Student Chapter

1982-86 Secretary Treasurer, President-elect, President and Past-President, Oregon Chapter

1980 Certified Wildlife Biologist

1978-90 Participant in continuing development and implementation of strategies for maintaining spotted owl habitat on BLM lands in western Oregon

1983-90 Field experience in spotted owl surveys for gathering data on spotted owl occupancy and reproduction

1986-90 Liaison role in cooperative radio-telemetry study in Roseburg area between BLM and USFS Pacific NW Research Station

1987-90 Cooperator in demographic study of spotted owls in Roseburg area in conjunction with USFS Pacific NW Research Station 


\section{Appendix U: The Committee}

\section{BRUCE MARCOT}

Academic Training

Work Experience

Present Position

Publications/Reports

Awards
B.S. Humboldt State University; 1977 Natural Resources Planning and Interpretation

M.S. Humboldt State University; 1978 Natural Resources Science, Wildlife Emphasis

Ph.D. Oregon State University; 1984 Wildlife Science

1977-78 Contract ecologist, Six Rivers National Forest, Eureka, California

1978-79 Biological technician, Six Rivers National Forest, Eureka, California

1980-81 Instructor, Wildlife Department, College of Natural Resources, Humboldt State University, Arcata, California

1981-83 Graduate research assistant, Cooperative Wildlife Research Unit, Oregon State University, Corvallis

1983-84 Contract ecologist, Fish and Wildlife Service, Corvallis, Oregon

1985 Research associate, Cooperative Wildlife Research Unit, Oregon State University, Corvallis

1985-88 Regional wildlife ecologist, Pacific Northwest Region, Portland, Oregon

Area wildlife ecologist, Mount Hood and Gifford Pinchot National Forests, USDA Forest Service, Gresham, Oregon

Forty-eight publications primarily in ecology and wildlife management, expert systems, and artificial intelligence programming.

1971 Larry Headlee Scholastic achievement award, Saddleback Valley Young Republicans, California; scholarship award and special recognition

1976 Academic achievement award, Xi Sigma Pi, Humboldt State University, Arcata, California; scholarship award and special recognition

1976-77 Academic honors, Master's Program, Humboldt State University, Arcata, California

1977 Certificate of appreciation, The Wildlife Society, Humboldt chapter, for outstanding service as Chair of Conservation Committee

1977 Joseph S. Woolford, M.D., Rotary Club of Eureka student grant award; scholarship award and special recognition 


\section{Appendix U: The Committee}

\section{BRUCE MARCOT-contInued}

1979 Performance award, USDA Forest Service, 1979. For work, attitude, and contributions at Forest and Regional levels on the Wildlife Habitat Relationships Program, Pacific Southwest Region

1985-86 Listed in Who's Who in Frontiers of Science and Technology

1986 Performance award, USDA Forest Service, for work on analyzing spotted owl population viability, draft spotted owl Supplemental EIS, USDA Forest Service, Pacific Northwest Region, Oregon

1987 Performance award, USDA Forest Service, for teaching ecology and planning of viable populations at Wildlife Habitat Shortcourses

1989 Performance award, USDA Forest Service, special recognition for teaching Forest Service Habitat Shortcourses

1990 Performance award, USDA Forest Service, special recognition for work on Spotted Owl Environmental Impact Statement

The Wildlife Society

Computer Applications Committee, 1985-present

Chairman, Conservation Committee, Humboldt Chapter 1977-78

Cooper Ornithological Society

Ecological Society of America

Society for Conservation Biology

Northwest Scientific Association

The Nature Conservancy

American Association for Artificial Intelligence

Computer Society for Social Responsibility

Honor Societies in Natural Resources and Forestry:

Sigma Xi, Xi Sigma Pi, Phi Kappa Phi, Gamma Sigma Delta 


\section{Appendix U: The Committee}

\section{E. CHARLES MESLOW}

Academic Training

Work Experience

Present Position

Publications

\section{Awards}

Professional Societles

Special Conservation Biology Assignments
B.S. University of Minnesota; 1959 Fish and Wildlife Management

M.S. University of Minnesota; 1966 Wildlife Management

Ph.D. University of Wisconsin; 1970 Wildlife Ecology/Zoology

1959-62 U.S. Navy

1968-71 Assistant professor, Zoology/Neterinary Science, North Dakota State University, Fargo

1971-75 Assistant leader, Oregon Cooperative Wildlife Research Unit, U.S. Fish and Wildlife Service, and Assistant Professor Wildlife Ecology, Oregon State University, Corvallis

Leader, Oregon Cooperative Wildlife Research Unit, U.S. Fish and Wildlife Service, and Professor Wildlife Ecology, Oregon State University

Publications deal largely with forest wildlife and habitat relationships: spotted owls, pileated woodpeckers, snags, forest bird communities, old-growth forest wildlife relationships, black bear ecology, snowshoe hares, great horned owls, Columbian white-tailed deer, and accipiter hawks

1984 Publication award, The Wildlife Society

The Wildlife Society 1975

President, Oregon Chapter 1977-80

NW Regional Representative 1981-82

Vice President 1983-86

President-Elect, President, Past-President

Society of American Foresters

American Society of Mammalogists

American Ornithologists' Union

Cooper Ornithological Society

Wilson Ornithological Society

Ecological Society of America

Society for Conservation Biology

Northwest Scientific Association

International Bear Biology and Management Association

Pacific Northwest Bird and Mammal Society

1976-present-Columbian White-tailed Deer Recovery Team

1978-present-IUCN Survival Services Commission, Deer Advisory Group

1983-present-Mount St. Helens Scientific Advisory Board 


\section{Appendix U: The Committee}

Experience With Spotted Owl Blology or Management

\section{E. CHARLES MESLOW-continued}

Principal investigator since 1975 on a succession of northern spotted owl research contracts to Oregon Cooperative Wildlife Research Unit through Oregon State University; contracting agencies include: U.S. Forest Service, Bureau of Land Management, U.S. Fish and Wildlife Service, and Oregon Department of Fish and Wildlife; research topics include: spotted owl distribution, life history, home-range and habitat use, juvenile dispersal, habitat characteristics, great horned owl-spotted owl relation to forest fragmentation, demographic studies, prey ecology, and population studies.

Major professor for E. D. Forsman, G.S. Miller, and three current graduate degree candidates with thesis topics on spotted owls

Since mid-1970's, member of Interagency Spotted OwI Management Committees. Member U.S. Fish and Wildlife Service 1989 Northern Spotted Owl Supplementary Status Review Team 


\title{
Appendix U: The Committee
}

\section{DENNIS DANIEL MURPHY}

\author{
Academic Training \\ B.S. University of California, Berkeley; 1974 \\ Ph.D. Stanford University, Palo Alto; 1981 \\ Professional Positions \\ 1982-83 Postdoctoral Fellow, Stanford University \\ 1983-87 Research Associate, Stanford University \\ Present Position \\ Senior research associate and Director of the Center for Conservation Biology, \\ Stanford University
}

Publlcations

About 100 publications including original research, reviews, and discussion papers on the taxonomy, ecology, genetics, and conservation of butterflies; pertinent to this project and publications on habitat fragmentation and extinction, reserve design and management, population viability analysis, hypothesis testing in conservation biology, and endangered species monitoring; work has appeared in Ecology, American Naturalist, Oecologia, Systematic Zoology, Natural History, Oikos, Conservation Biology, Biological Conservation, Endangered Species Update, Canadian Journal of Zoology, and others, as well as a dozen book chapters

Pertinent Activities

Consultant to U.S. Fish and Wildlife Service on endangered species actions; member, science policy council for Glacier National Park; member, Oregon Silverspot Butterfly Recovery Team; member, California Nature Conservancy research committee; designer, Kirby Canyon Conservation Agreement (section 7 consultation); consultant, San Bruno Mountain Habitat Conservation Plan amendment process; consultant to the Pine Barrens Habitat Restoration and Management Plan (Albany, NY); recipient of 1988 Chevron Conservation Award 


\section{Appendix U: The Committee}

\section{BARRY STUART MULDER}

Academic Training

Work Experience

Present Position

Publications/Reports

Academic Experience
B.S. University of Michigan; 1973 Biology

M.S. University of Michigan; 1975 Ecology and Animal Behavior

1978 Wildlife biologist, Bureau of Land Management, Riverside, California

1979-84 Wildlife biologist, Division of Endangered Species, U.S. Fish and Wildlife Service, Washington, D.C.

1984-88 Supervisory fish and wildlife biologist, Division of Endangered Species, U.S. Fish and Wildlife Service, Denver, Colorado; Chairman, Upper Colorado River Endangered Fishes Coordinating Committee

Coordinator, Spotted OwI Program, U.S. Fish and Wildlife Service, Portland, Oregon

USDi. 1987. Upper Colorado River Endangered Fishes Conservation Plan. Interagency Report. U.S. Fish and Wildlife Service. Denver, Colorado

USDI. 1987. The Northern Spotted OwI Status Review. Final Report. U.S. Fish and Wildlife Service. Portland, Oregon

USDI. 1989. The Northern Spotted OwI Status Review Supplement. Final Report.

U.S. Fish and Wildlife Service. Portland, Oregon

1975-78 Teaching assistant, Biology Department, University of Michigan 


\section{Appendix U: The Committee}

\section{BARRY RICHARD NOON}

Academic Training

Postdoctorai

Experiences

Work Experience

Present Position

Publications

Awards
B.A. Princeton University; 1971 Biology University of Vermont; $1972-73$ Biology

Ph.D. State University of New York; 1977 Biology

1977-78 Research scientist (statistical analysis and computer programming), New York State Department of Health, Department of Epidemiology and Human Ecology, Albany, New York

1978-79 Instructor of field ornithology, College of Environmental Science and Forestry, State University of New York, Syracuse, New York

1978-79 Assistant professor, Department of Biology, Siena College, Loudonville, New York

1979-81 Wildlife biologist, Patuxent Wildlife Research Center, U.S. Fish and Wildlife Service, Laurel, Maryland

1980-85 Senior adjunct research associate, Adirondack Ecological Center, Department of Environmental and Forest Biology, State University of New York, Syracuse

1986-87 Director of graduate studies, College of Natural Resources, Humboldt State University, Arcata, California

1980-87 Associate professor, Department of Wildlife, College of Natural Resources, Humboldt State University, Arcata, California

Project leader, USDA Forest Service, Redwood Sciences Laboratory, Arcata, California

Forty publications, primarily in avian ecology, population and community ecology, and biometrics.

1975 Sigma Xi Award

1976 American Ornithologist's Union Student Membership Award

1977 Wilson Ornithological Society Student Membership Award

1977 Marcia Brady Tucker Award; awarded by the American Ornithologist's Union to enable presentation of a graduate student paper at the AOU's annual meeting

1979 Paul C. Lemon Award; awarded by the State University of New York at Albany for the outstanding doctoral thesis in environmental biology/ecology for the years 1977-78 


\section{Appendix U: The Committee}

\section{BARRY RICHARD NOON-continued}

1980-85 Senior adjunct research associate, State University of New York at Syracuse; title granted for continuing research and involvement with graduate students at the Adirondack Ecological Center, Newcomb, New York

1986 Honorary position of Elective Fellow of the American Ornithologist's Union for significant contributions to the field of ornithology

1986 Certificate of appreciation from the U.S. Forest Service for significant contributions to the Old-Growth Wildlife-Habitat Research Program

1987 Meritorious performance award from the College of Natural Resources, Humboldt State University, for excellence in teaching and service

Memberships in Professional Societies

\section{Experience With} Spotted Owis
The American Ornithologists' Union

The American Society of Naturalists

The Cooper Ornithological Society

The Ecological Society of America

The Wildife Society

Wilson Ornithological Society

Leader of large wildlife research unit which, as part of its mission, has been conducting research on the spotted owl, and its primary prey, for $31 / 2$ years; for the last 2 years, along with several colleagues, have been studying the mathematical demography and population ecology of spotted owls 


\section{Appendix U: The Committee}

\section{JACK WARD THOMAS}
Academic Training B.S. Texas A\&M University; 1957 Wildlife Management
M.S. West Virginia University; 1969 Wildlife Ecology
Ph.D. University of Massachusetts; 1972 Forestry (Natural Resources Planning Option)

Work Experience

1957-66 Wildlife biologist and project leader, Texas Parks and Wildlife Department at Sonora and Llano, Texas

1966-70 Research wildlife biologist, USDA Forest Service, Morgantown, West Virginia

1970-74 Research wildlife biologist and project leader for Urban Forestry Research, USDA Forest Service, Amherst, Massachusetts

Present Position

Project leader and chief research wildlife biologist, Range and Wildlife Habitat Research, USDA Forest Service, Pacific Northwest Research Station, La Grande, Oregon

Publications

About 250; primarily in elk, deer, and turkey biology; wildlife disease; wildlife habitat; songbird ecology, and land-use planning; publications both in technical formats and popularized form includes several award-winning books-The Elk of North America-Ecology and Management, Wildlife Habitats in Managed Forests-The Blue Mountains of Oregon and Washington, and Wildlife Habitats in Managed Rangelands-The Great Basin of Southeastern Oregon

Academic Appointments

Awards Include
1966-70

1970-73

1973-present

1974-present

1975-present

1976-present

1976 and 1983

1979

1981

1967, 1969, 1972,

$1976,1979,1980$, 1982, 1984, 1987, and 1989 (2)

1983

1983

1984

1985

1985

1986
Adjunct professor, West Virginia University

Adjunct faculty, University of Massachusetts

Adjunct professor, Eastern Oregon State College

Adjunct professor, Oregon State University

Adjunct professor, Washington State University

Adjunct professor, University of Idaho

Publication awards, The Wildlife Society

Oregon Wildlife Society award

Einarsen award, NW Section, The Wildlife Society

Certificates of merit with cash awards, USDA Forest Service Gulf Oil conservation award

Special recognition award; service award, The Wildlife Society Natural Resource employee of the year for Oregon, National Wildlife Federation

Distinguished service award (the highest award that can be made to a USDA employee), U.S. Department of Agriculture Earle A. Childs Award, High Desert Museum, Bend, OR Distinguished citizen of the year award, Eastern Oregon State College 


\section{Appendix U: The Committee}

\section{Professional Societles}

Special Assignments
Society of American Foresters

1981-84 Editorial Board, Journal of Forestry

1985-90 Editorial Board, Western Journal of Applied Forestry

1982 Publicity chairman, Oregon Society of American Foresters, Annual Meeting

1983-84 SAF Task Force on Harvest Scheduling of Old-Growth Forests 1986 Elected Fellow

1988-90 Committee to Select Recipient of Research Achievement Award, Oregon SAF

The Wildife Society

1966-67 President, Texas Chapter

1966-67 Various committee assignments including: Nominations Committee (Chairman); Ad Hoc Committee to Prepare Position Statement of Old-Growth Forests (Chairman); Leopold Medal Committee (Chairman); Leopold Medal Committee (member)

1971-72 NE Regional Representative

1976-78 President-Elect, President, and Past-President

The Society for Range Management

The Wilson Ornithological Society

American Society of Mammalogists

American Ornithologists' Union

Society for Conservation Biology

1980 Pakistan, PL-480 assignment to set up big-game surveys

1980-81 National Academy of Sciences (National Research Council) Committee to Evaluate the Status of Management of the Public Rangelands

1982 India, PL-480 assignment to train wildlife/forestry professional

1987 U.S. representative, Workshop on Wildlife Utilization, Assissi, Italy

1989 Ecological Review Team, Yellowstone National Park

1989-90 National Academy of Sciences (National Research Council) Committee to Evaluate the National Status of Rangeland Inventories

1989-91 U.S. Teaching Team (USDA Forest Service) for Graduate Training, Wildlife Institute of India 


\section{Appendix U: The Committee}

\section{JARED VERNER}

Academlc Tralning

Work Experlence

Present Position

Publications
B.S. Washington State University; 1957 Wildlife Management
M.S. Louisiana State University; 1959 Zoology
Ph.D. University of Washington; 1963 Zoology

\section{3-65 Postdoctoral research fellow, University of California, Berkeley}

1965-73 Assistant professor, Associate professor, and professor of biology, Central Washington University, Ellensburg

1973-76 Professor of ecology, Illinois State University, Normal; Section Head, Environmental and Systematic Biology, 1974-76

1976-86 Principal research wildlife biologist and project leader, Wildlife and Range Research, USDA Forest Service, Fresno, California

Project leader and chief research wildlife biologist; Wildlife, Range, and Monitoring Research, USDA Forest Service, Pacific Southwest Forest and Range Station, Fresno, California

Ninety publications, more than half in refereed outlets. Most have treated aspects of the ecology, behavior, evolution, management, and monitoring of birds; includes lead editorship of two award-winning books: California Wildlife and Their Habitats: Western Sierra Nevada, and Wildlife 2000: Modeling Habitat Relationships of Terrestrial Vertebrates.

1983, 1984, Lions' Club scholarship Phi Sigma (scholastic honorary society) Phi Beta Kappa and Phi Kappa Phi (scholastic honoraries) Sigma Xi Tucker Award, American Ornithologists' Union 1960,1961 , and 1962 1963-65 1966,1968 1971 1977 1980 1980

Predoctoral fellowships, National Science Foundation Postdoctoral fellowship, National Science Foundation Research grants, National Science Foundation Elected voting member of the American Ornithologists' Union Elected Fellow of the American Ornithologists' Union Quality step increase Publication award, National Association of Government Communicators, Washington, D.C.

1982 and Special commendations from review boards for Combined 1987 Program reviews, citing individual research accomplishments and leadership for productivity of the research work unit in Fresno 


\section{Appendix U: The Committee}

\section{JARED VERNER—continued}

1987

Distinguished Scientist, with Cash Award, USDA Forest Service, Pacific Southwest Forest and Range Experiment Station

Professional Societies

Special Assignments
American Ornithologists' Union

1975-76 Brewster and Coues Awards Committee

1975-79 Committee on Public Concerns

1984-87 Nominations Committee for Elective Members and Fellows; Chairman, 1985-86

Cooper Ornithological Society

1977 and Conservation and Resolutions Committee;

1983-85 Chairman

1984-87 Board of Directors

1985 Chairman, Nomination Committee for Board of Directors

1985-86 Chairman, By-Laws Committee

1987-89 President Elect

1989-91 President

Wilson Ornithological Society

1975-77 Fuertes/Nice Awards Committee

1976-77 Chairman

International Commission on Bird Preservation

1982-85 Habitat Committee, World Working Group on Birds of Prey

Ecological Society of American

The Wildlife Society

Society for Conservation Biology

Association of Field Ornithologists

Western Field Ornithologists

North American Bird Banding Association

1982

Technical advisory group to develop guidelines for the USDA Research and Development Program on Old-Growth Forest in the Pacific Northwest, USDA Forest Service

1977-present California Condor Recovery Team

1981-present Pacific Southwest Forest and Range Experiment Station's representative on the national steering committee for developing the Wildlife-Habitat Relationships Program

1985-1986

Member, National Audubon Society's "Blue Ribbon Panel" to evaluate the management program for the northern spotted owl

1989-1990
Member, Planning Team for National Workshop on Monitoring of Biological Resources, USDA Forest Service, Washington, D.C. 


\section{Appendix U: The Committee}

\section{DAVID SAMUEL WILCOVE}

Academic Tralning

Work Experience

Present Position

Publications

Professional Appointments
B.S. Yale University; 1980 Biology

M.A. Princeton University; 1982 Biology

Ph.D. Princeton University; 1985 Biology

1980-84 Teaching assistant, Princeton University

1985-86 Research scientist in zoology, The Nature Conservancy

Senior ecologist, The Wilderness Society, Washington, DC

Over 30 publications, including original research, reviews, and popular articles on conservation biology and ornithology; work has appeared in Ecology, Wilson Bulletin, Nature, Conservation Biology, Natural History, Audubon, and as chapters in several books.

1989- Board of Editors, Conservation Biology

present

1989- Board of Directors, International Council for Bird Preservation, U.S. and

present Pan American Sections

1989- Chairman, Committee on Public Responsibilities, American Ornithologists'

present Union

1987-90 Board of Directors, Natural Areas Association 


\section{Glossary}

ACEC-area of critical environmental concern; used specifically on lands administered by the BLM

adaptlve management-process of implementing policy decisions as scientifically driven management experiments that test predictions and assumptions in management plans

agreement areas-also BLM-ODFW agreement areas; spotted owl habitat areas protected by the BLM under a cooperative agreement with the ODFW

algorlthm -mathematical rule for solving a problem

Allee effect-a depression in the encounter rate between males and females resulting from low population densities; the probability of finding a mate drops below that required to maintain the reproductive rates necessary to support the population

anImal damage - damage caused to trees by animals, often by rodents or large mammals

awarded sales-Federal timber sales that have been let to the successful bidder through a formal contract

basal area-the area of the cross-section of a tree stem near its base, generally at breast height and inclusive of bark

blological diversity - the variety of life's forms - that is plants, birds, insects, and so on

blomass-the total quantity (at any given time) of living organisms of one or more species per unit of space, or of all the species in a biotic community

birth-pulse population-a population assumed to produce all of its offspring at an identical, and instantaneous, point during the annual cycle

blowdown-trees felled by high winds

bottleneck-see "population bottleneck" 


\section{Appendix V: Glossary and Scientific Names}

broom trees-trees in which tops have broken off and secondary limbs have grown up to overtop the stump, forming a group of tops that are often broom-shaped

California Habitat Conservation Plan-a conservation plan for the northern spotted owl currently being developed by the California Resources Agency

canopy ciosure - the degree to which the crowns of trees are nearing general contact with one another

carrying capacity - the maximum number of animals that can be sustained over the long-term on a specified land area

center of activity-owl's nest site or primary roost area

checkerboard ownership - a land ownership pattern in which every other section (square mile) is in Federal ownership as a result of Federal land grants to early western railroad companies

closed population-an isolated population of individuals that receives no immigrants from other populations

coevolution-sharing a common, and interdependent, evolutionary history

cohort-individuals all resulting from the same birth-pulse, and thus all of the same age

colonization-the act or process of establishing a new colony or population

commercial forest land-forest land tentatively suitable for the production of crops of timber and that has not been withdrawn for other reasons

connectivity-a measure of the extent to which intervening habitat truly connects HCAs for juvenile spotted owls dispersing between them

core area-a defined area that includes the center of activity of a pair including the nest site if known

corridor-a defined tract of land, usually linear, through which a species must travel to reach habitat suitable for reproduction and other life-sustaining needs

dedicated iand-lands that are withdrawn from production of commodity resources

Delphi technique - the process of combining expert opinions into a consensus; a method of making predictions

demographic stochasticity-random fluctuations in birth and death rates

density-dependent-a process, such as fecundity, whose value depends on the number of animals in the population per unit area 


\section{Appendix V: Glossary and Scientific Names}

depensatory fecundity-the maximum value for fecundity occurs at some optimal density, with fecundity decreasing at either higher or lower densities

dispersal -the movement, usually one way, and on any time scale, of plants or animals from their point of origin to another location where they subsequently produce offspring

dispersal corrldor-a corridor through which young disperse from their area of birth

dispersal capabllity-ability of members of a species to move from their area of birth to another suitable location and subsequently breed

dlspersal distance - a straight-line distance that an individual travels from its birth place until it stops dispersing (assumed to be a breeding site) or dies

ecological dependency-an absolute reliance on one or more environmental factors for viability; removal of the factor(s) will lead to the species' extinction

ecologlcal Integrity-the condition in which all key components of an ecological system are intact and functioning normally

ecosystem texture-see "texture of an ecosystem"

edge-dependent species-species that require the interface between two adjacent plant communities or successional stages to meet habitat requirements

edge effects-differences in microclimate, flora, fauna, stand structure, habitat values, stand integrity (including resistance to being blown down by high winds) that occurs in or as a result of a transition zone where two plant communities or successional stages are joined

emigration-permanent movement of individuals of a species from a population

environmental stochasticlty-random variation in environmental attributes such as temperature, precipitation, and fire frequency

eutrophlc - condition of a body of water in which the increase of mineral and organic nutrients has reduced the dissolved oxygen, producing an environment that favors plants over animal life

even-aged forest - a forest stand composed of trees with less than a 20-year difference in age

extinction rate-the number of elements (individuals, populations, species) lost per unit of time

extInction time-predicted period of time for a population to become extinct 


\section{Appendix V: Glossary and Scientific Names}

feathered-condition of a stand in which the basal area per unit area is gradually reduced, through selective harvest, from a natural or fully stocked stand outward toward a clearcut

fecundity - number of female young produced per adult female

fioaters - nonbreeding adults and subadults that move and live within a breeding population, often replacing breeding adults that die; nonterritorial individuals

forest landscape-land presently forested or formerly forested and not currently developed for nonforest use

founder effects-decrease in genetic variability from establishment of a new population by few individuals

fragmentation-process of reducing size and connectivity of stands that comprise a forest

fuel loading - the amount of combustible material present per unit of area, usually expressed in tons per acre

gene flow-rate of movement of genetic material between populations

gene frequency - how often a particular gene is encountered among a random sample of individuals

genetic deterioration-loss of genetic variability that results from population isolation or decline

genetic stochasticity-random changes in gene frequencies from such factors as inbreeding

genetic variabiiity - the number of different genes possessed by an individual or population

habitat capability - capacity of a habitat to support an estimated number of pairs of a species

Habitat Conservation Area-a contiguous block of habitat to be managed and conserved for breeding pairs, connectivity, and distribution of owls; application may vary throughout the range according to local conditions

habitat fragmentation-see "fragmentation"

habitat mosaic - the mix of habitat conditions across the landscape

habitat-niche-the specific arrangement of food, cover, and water that meets the annual requirements of a particular species

Hatfield-Adams amendment-Section 318 of Public Law 101-121, October 1989 


\section{Appendix V: Glossary and Scientific Names}

home range - the area to which the activities of an animal are confined during a defined period of time

home-range of a pair-the sum of the home ranges of each member of a pair minus the area of home-range overlap

home-range overlap_-percentage of the home ranges of two adjacent individuals that they share

interbIrth Interval-the interval between birth pulses

internal recruitment-maturing of new breeding individuals in a local population that were born within that same population

keystone species-an individual species that dominates structure and function in an ecosystem, and on which the viabilities of one or more additional species may depend

lambda - the finite rate of population change (population size in year 2 divided by the population size in year 1)

lands not suited for timber production-lands incapable of producing 20 cubic feet per acre per year or lands withdrawn from commercial forest harvest for other reasons (see reserved lands)

lands sulted for timber production-commercial forest land identified as appropriate for timber production

large sawtimber-forest stands that are characterized by trees that are $\geq 21$ inches in d.b.h.

leave strips-generally narrow bands of forest trees that are left along streams and rivers to buffer aquatic habitats from upslope forest management activities

legacy-remnant trees of original forest stands, both alive and dead, that are left on harvest units to assist in meeting habitat requirements of various species in the next forest rotation, as well as to provide genetic continuity

Lesile matrix - a two-dimensional array (rows and columns) whose elements represent the birth and death rates of a population

life table-mathematical table illustrating the age-specific birth and death rates of a population

linear model-a combination of random variables none of which have exponents that differ from 1.0

IInear regression model-an equation that explains some amount of the variation in a dependent variable with a linear combination of one or more independent variables

long term-here, 50 to 100 years and sometimes beyond 


\section{Appendix V: Glossary and Scientific Names}

managed forest-forest land that is harvested on a scheduled basis and contributes to an allowable sale quantity

metapopulation-a population comprised of a set of populations that are linked by migrants, allowing for recolonization of unoccupied habitat patches after local extinction events

microenvironment-the sum total of all the external conditions that may influence organisms and that come to bear in a small or restricted area

microhabitats-a restricted set of distinctive environmental conditions that constitute a small habitat, such as the area under a log

minimum convex polygon technique-a method of estimating home-range size, in which the smallest possible convex polygon is drawn around the outermost locations where an animal was observed; the area within the polygon is then calculated

mixed-conifer forest-a forest community that is dominated by two or more coniferous species

mixed-evergreen forest-a forest community that is dominated by two or more species of broad-leaved hardwoods whose foliage persists for several years; important western species include madrone, tanoak, chinkapin, canyon live oak, and California-laurel

model-an idealized representation of reality developed to describe, analyze, or understand the behavior of some aspect of it; a mathematical representation of the relationships under study

monitoring - a process of collecting information to evaluate whether or not objectives of a management plan are being realized

monitoring program—see "monitoring"; the program used to monitor a population and its habitat

mutualism-a positive association between two organisms; a symbiotic relation

natal cluster-a group of adjacent animal territories, in one of which an individual was born

niche—see "habitat niche"

null hypothesis-no difference is anticipated in test comparisons

old growth-a forest stand with moderate to high canopy closure; a multilayered, multispecies canopy dominated by large overstory trees; a high incidence of large trees with large, broken tops, and other indications of decadence; numerous large snags; and heavy accumulations of logs and other woody debris on the ground 


\section{Appendix V: Glossary and Scientific Names}

pair site -an amount of habitat that is considered capable of supporting one pair of spotted owls

physlographlc province-a geographic region in which climate and geology have given rise to a distinct array of land forms and habitats

population-a collection of individuals that share a common gene pool

populatlon bottleneck - the phenomenon experienced by a small population that is susceptible to the deleterious effects of demographic and genetic stochasticity; also a zone of constriction in the distribution of a population

population density-number of individuals of a species per unit area

population persistence - general term for the capacity of a population to maintain sufficient numbers and distribution over time

population vlabllity - probability that a population will persist for a specified period of time across its range despite normal fluctuations in population and environmental conditions

power analysis - a statistical method for controlling for the probability of making a type 2 error, or attempting to place limits on the probability of failing to reject a null hypothesis that is false

refugla-havens of safety where populations have high probability of surviving periods of adversity

regulated forest-theoretical managed forest from which the same acreage of stands can be harvested annually in perpetuity

rescue effect-periodic immigration of new individuals sufficient to maintain a population that might otherwise decline toward extinction

reserved land-Federal lands, often in preserved or protected status, that have been removed from the acreage base used to calculate timber yields: for example, Wilderness Areas or Parks

reserves - tract of forest temporarily or permanently set aside from timber harvesting restrlcted harvest-land either withdrawn from timber harvest or where timber production is limited to less than clearcutting

rotation-the planned number of years between the regeneration of an even-aged stand and its final cutting at a specified stage

sale under contract-Federal timber sales that have been let to the successful bidder through a formal contract 


\section{Appendix V: Glossary and Scientific Names}

search capablilty - the ability of a dispersing juvenile or adult owl to locate suitable habitat

search efficiency-proportion of dispersing juveniles or adults that locate minimally suitable habitat before they die

search time-number of days required for an average dispersing individual to locate suitable or better habitat

secondary crown-live limbs that grow upward to form a new crown in a tree after the original top breaks off

secondary population-population occupying suboptimal habitat

sensitivity coefficlent-term that measures relative degree of change in outcome of a mathematical expression or equation after a specified change in an individual component

short term-here, 1 to 50 years

sink-population whose average reproductive rate is less than its average rate of mortality; area that attracts immigrants not expected to contribute significantly to future populations (see "source")

SLOSS debate-disagreement among scientists as to the relative value to the conservation of biological diversity provided by a "single large or several small" reserves totaling the same area

snag-standing dead tree

social facilltation-process of aiding a biological function or activity through behavioral interaction

soclai stimulation-biological process that increases in intensity or effect through group behavior of a species

source-an actively breeding population that has an average birth rate that exceeds its average death rate; produces an excess number of juveniles that may disperse to other areas

spectral signature - specific combination of wavelengths of light energy reflected or radiated from a land surface, or, in forestry, a wavelength combination that more or less characterizes a specific forest condition or successional stage

standards and guidelines-directions generated and followed by the Committee in developing the HCAs and their location in the landscape: the standards and guidelines also provide instructions to managers for use in carrying out the management strategy 


\section{Appendix V: Glossary and Scientific Names}

stepping stones-relatively small, isolated patches of habitat that provide sufficient resources to support individuals as they disperse from one location to another

stochastic-random, uncertain; involving a random variable

stochastic fecundity-random fluctuation in a population's rate of producing female offspring

subpopulation-a well-defined set of interacting individuals that comprise a proportion of a larger, interbreeding population

sultable habltat-here, an area of forest vegetation with the age-class, species of trees, structure, sufficient area, and adequate food source to meet some or all of the life needs of the northern spotted owl

superior habitat-here, habitat selected in excess of availability by the majority of individual northern spotted owls

sustained yieid or production-the amount of timber that a forest can produce continuously from a given intensity of management; implies continuous production; a primary goal is to achieve a balance between incremental growth and cutting

territory - the area that an animal defends, usually during breeding season, against intruders of its own species

texture of an ecosystem-relative surface smoothness of an ecosystem as determined by remote sensing technology, or the distinctiveness of the transition between two distinct ecosystems

threshold phenomenon-pattern or trend in population growth rate that exhibits relatively long periods of slow change followed by precipitous increase or decrease in response to an environmental gradient

turnover-a term in population analysis that indicates the rate or number of identifiable adults that die during a specified period

type 2 error-statistical term for the error that is made when a null hypothesis that is false is not rejected; that is, concluding that no difference exists in a comparison between two populations when a difference does exist

vagillity-capacity of any organism to become widely dispersed

variance-a statistical term that indicates a measure of variability within a finite population of a sample; the total of the squared deviations of each observation from the arithmetical mean divided by one less than the total number of observations

vlability-ability of a population to maintain sufficient size so that it persists over time in spite of normal fluctuations in numbers; usually expressed as a probability of maintaining a specific population for a specified period 


\section{Appendix V: Glossary and Scientific Names}

vital rate - collective term for the age-specific birth and death rates of a population wIndthrow-a tree or group of trees uprooted by the wind wink out-local extinction of subpopulations of a larger population 


\section{Appendix V: Glossary and Scientific Names}

Tabie V1-Scientific names of piants and animais mentioned in this report

\begin{tabular}{|c|c|}
\hline Common name & Scientific name \\
\hline \multicolumn{2}{|l|}{ Birds } \\
\hline blackbird, red-winged & Agelaius phoeniceus \\
\hline chickadee, black-capped & Parus atricapillus \\
\hline chough & Pyrrhocorax pyrrhocorax \\
\hline crane, whooping & Grus americana \\
\hline crow, carrion & Corvus corone \\
\hline dove, stock & Columba livia \\
\hline bald & Haliaeetus leucocephalus \\
\hline harpy & Harpia harpyja \\
\hline falcon, peregrine & Falco peregrinus \\
\hline goshawk, northern & Accipiter gentilis \\
\hline hawk & Bonasa umbellus \\
\hline Cooper's & Accipiter cooperii \\
\hline Socorro Island red-tailed & Buteo jamaicensis socorroensis \\
\hline hen, heath & Tympanuchus cupido cupido \\
\hline jackdaw & Convus modelula \\
\hline meadowlark, pampas & Sturnella defilippii \\
\hline moorhen & Gallinula chloropus \\
\hline osprey & Pandion haliaetus \\
\hline \multicolumn{2}{|l|}{ owl } \\
\hline barred & Strix varia \\
\hline California spotted & Strix occidentalis occidentalis \\
\hline great horned & Bubo virginianus \\
\hline little & Athene noctua \\
\hline Mexican spotted & Strix occidentalis lucida \\
\hline northern spotted & Strix occidentalis caurina \\
\hline tawny & Strix aluco \\
\hline parakeet, Carolina & Conuropsis carolinensis \\
\hline parrot, Puerto Rican & Amazona vittata \\
\hline \multicolumn{2}{|l|}{ pigeon } \\
\hline passenger & Ectopistes migratorius \\
\hline wood & Columba palumbas \\
\hline plover, ringed & Charadrius hiaticula \\
\hline raven & Corvus corax \\
\hline \multicolumn{2}{|l|}{ sparrow } \\
\hline $\begin{array}{l}\text { dusky seaside } \\
\text { rufous-collared }\end{array}$ & $\begin{array}{l}\text { Ammodramus maritimus nigrescens } \\
\text { Zonotrichia capensis }\end{array}$ \\
\hline sparrowhawk & Accipiter nisus \\
\hline \multicolumn{2}{|l|}{ woodpecker } \\
\hline ivory-billed & Campephilus principalis \\
\hline pileated & Dryocopus pileatus \\
\hline wren, sedge & Cistothorus platensis \\
\hline \multicolumn{2}{|l|}{ Fish } \\
\hline salmon & Oncorhynchus spp. \\
\hline
\end{tabular}




\section{Appendix V: Glossary and Scientific Names}

Table V1-continued

\begin{tabular}{|c|c|}
\hline Common name & Scientific name \\
\hline $\begin{array}{l}\text { Insects } \\
\text { butterfly } \\
\text { bay checkerspot } \\
\text { Karner blue } \\
\text { large blue }\end{array}$ & $\begin{array}{l}\text { Euphydryas editha bayensis } \\
\text { Lycaeides melissa samuelis } \\
\text { Maculinea arion }\end{array}$ \\
\hline $\begin{array}{l}\text { Mammals } \\
\text { agouti } \\
\text { armadillo } \\
\text { bear, grizzly } \\
\text { bison } \\
\text { coatimundi } \\
\text { ferret, black-footed } \\
\text { gopher, pocket } \\
\text { hare, snowshoe } \\
\text { jaguar } \\
\text { marten, pine } \\
\text { mouse } \\
\text { deer } \\
\text { forest deer } \\
\text { peccary, collared } \\
\text { pika } \\
\text { puma } \\
\text { rabbit, brush } \\
\text { squirrel, northern flying } \\
\text { woodrat } \\
\text { bushy-tailed } \\
\text { dusky-footed } \\
\text { vole } \\
\text { Amargosa meadow } \\
\text { redtree } \\
\text { southern red-backed } \\
\text { western red-backed }\end{array}$ & $\begin{array}{l}\text { Dasyprocta spp. } \\
\text { Dasypus novemcinctus } \\
\text { Ursus arctos horribilis } \\
\text { Bison bison } \\
\text { Nasua narica } \\
\text { Mustela nigripes } \\
\text { Thomomys spp. } \\
\text { Lepus americanus } \\
\text { Panthera onca } \\
\text { Martes americana } \\
\text { Peromyscus spp. } \\
\text { Peromyscus oreas } \\
\text { Tayasso tajacu } \\
\text { Ochotona princeps } \\
\text { Felis concolor } \\
\text { Sylvilagus bachmani } \\
\text { Glaucomys sabrinus } \\
\text { Neotoma cinerea } \\
\text { Neotoma fuscipes } \\
\text { Microtus californicus scirpensis } \\
\text { Arborimus longicaudus } \\
\text { Clethrionomys occidentalis } \\
\text { Clethrionomys gapperi }\end{array}$ \\
\hline $\begin{array}{l}\text { Reptiles } \\
\text { lizard, fringe-toed }\end{array}$ & Uma notata \\
\hline $\begin{array}{l}\text { Trees } \\
\text { alder, red } \\
\text { buckeye, California } \\
\text { California-laurel } \\
\text { chinkapin, giant } \\
\text { Douglas-fir } \\
\text { fir } \\
\text { grand } \\
\text { Pacific silver } \\
\text { white } \\
\text { hemlock, western } \\
\text { incense-cedar } \\
\text { madrone, Pacific }\end{array}$ & $\begin{array}{l}\text { Alnus rubra } \\
\text { Aesculus californica } \\
\text { Umbellularia californica } \\
\text { Castanopsis chrysophylla } \\
\text { Pseudotsuga menziesii } \\
\text { Abies grandis } \\
\text { Abies amabilis } \\
\text { Abies concolor } \\
\text { Tsuga heterophylla } \\
\text { Libocedrus decurrens } \\
\text { Arbutus menziesii }\end{array}$ \\
\hline
\end{tabular}




\section{Appendix V: Glossary and Scientific Names}

\begin{tabular}{ll} 
Table V1-contlnued & \\
\hline Common name & \multicolumn{1}{c}{ Scientific name } \\
\hline oak & \\
blue & Quercus douglasii \\
California black & Quercus kellogii \\
canyon live & Quercus chrsolepis \\
interior live & Quercus wislizèni \\
Oregon white & Quercus garryana \\
pine & Pinus ponderosa \\
ponderosa & Pinus lambertiana \\
sugar & Chamaecyparis lawsoniana \\
Port-Orford-cedar & Thuja plicata \\
redcedar, western & Sequoia sempervirens \\
redwood & Picea sitchensis \\
spruce, sitka & Platanus racemosa \\
sycamore, California & Lithocarpus densiflorus \\
tanoak & \\
Diseases & \\
dwarfmistletoe & Arceuthobium spp. \\
\hline
\end{tabular}




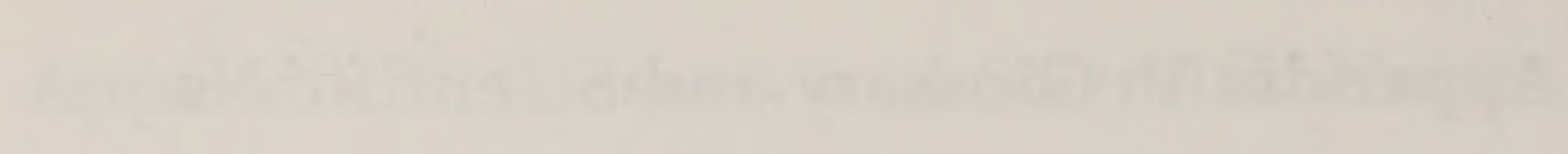






\section{NORTHERN}

\section{SPOTTED OWL}

\section{CONSERVATION PLAN}

State of Washington 


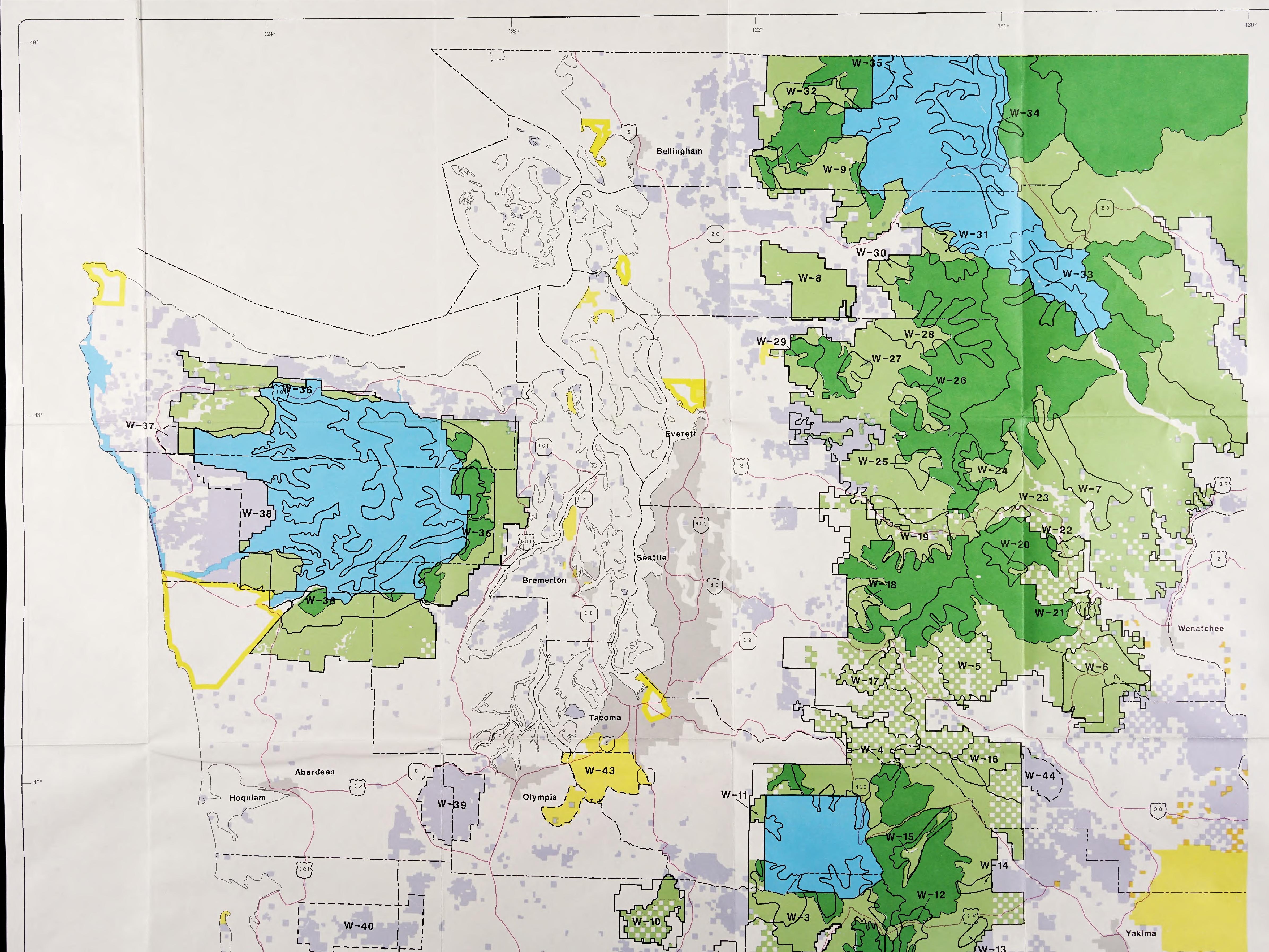




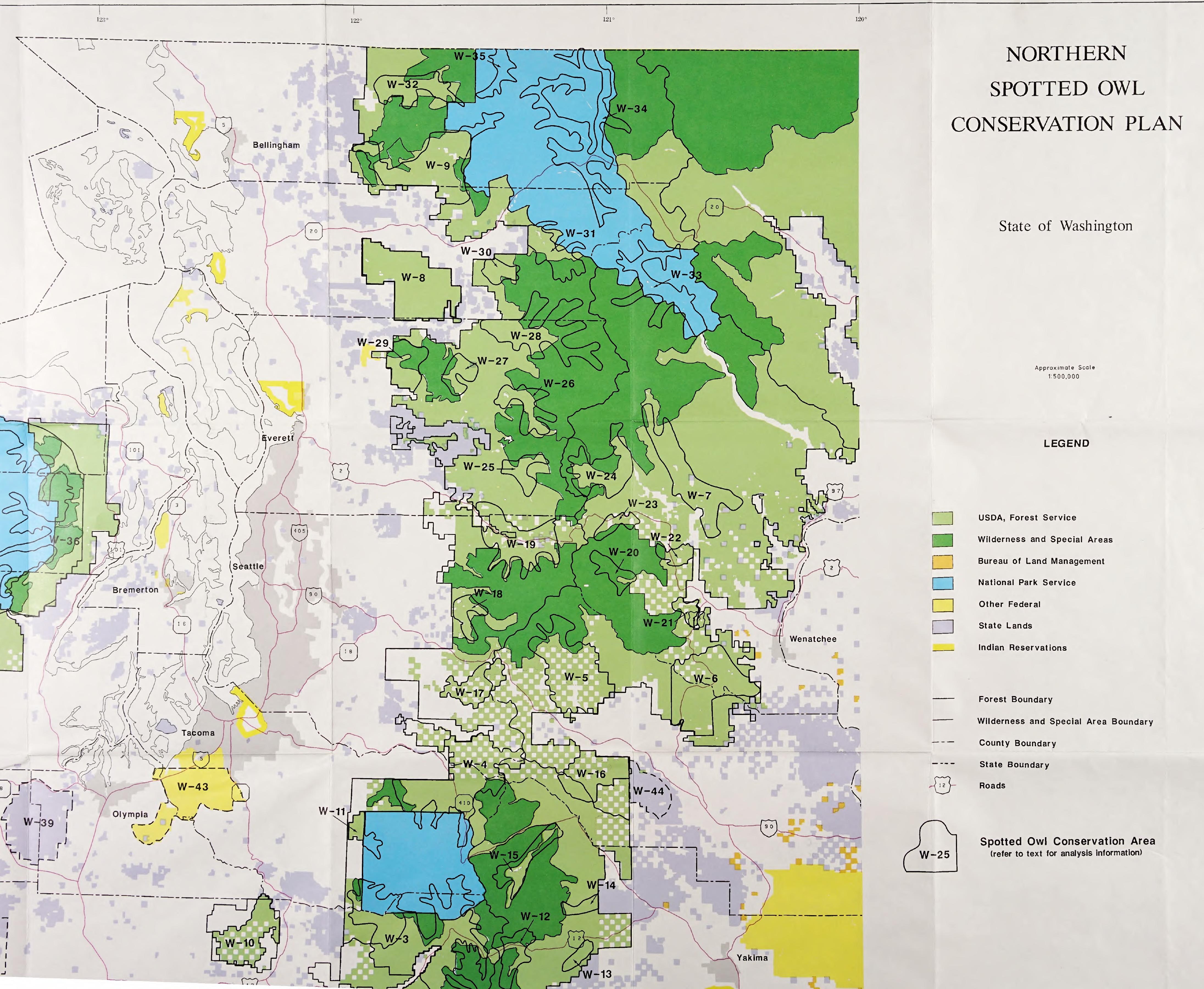




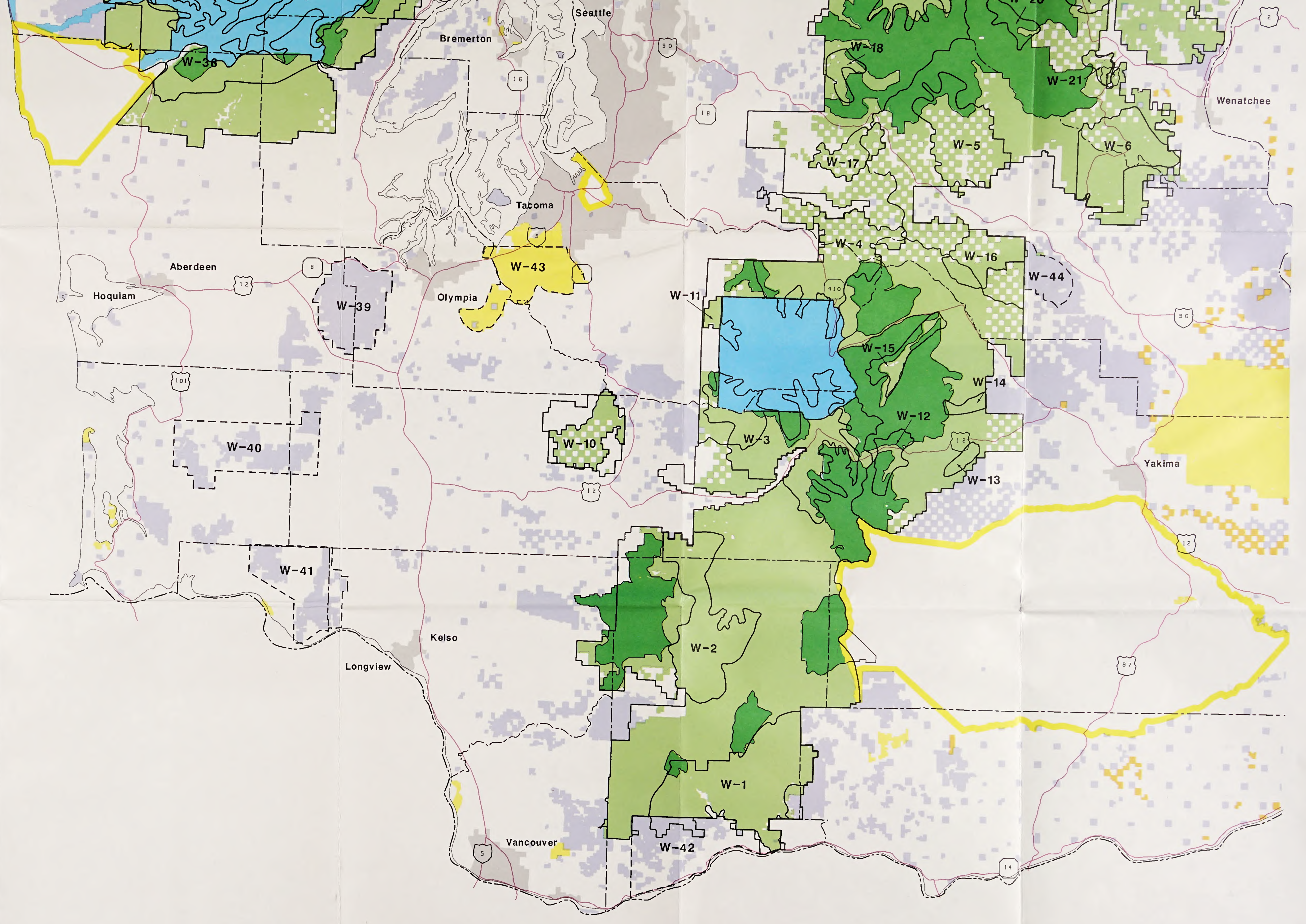




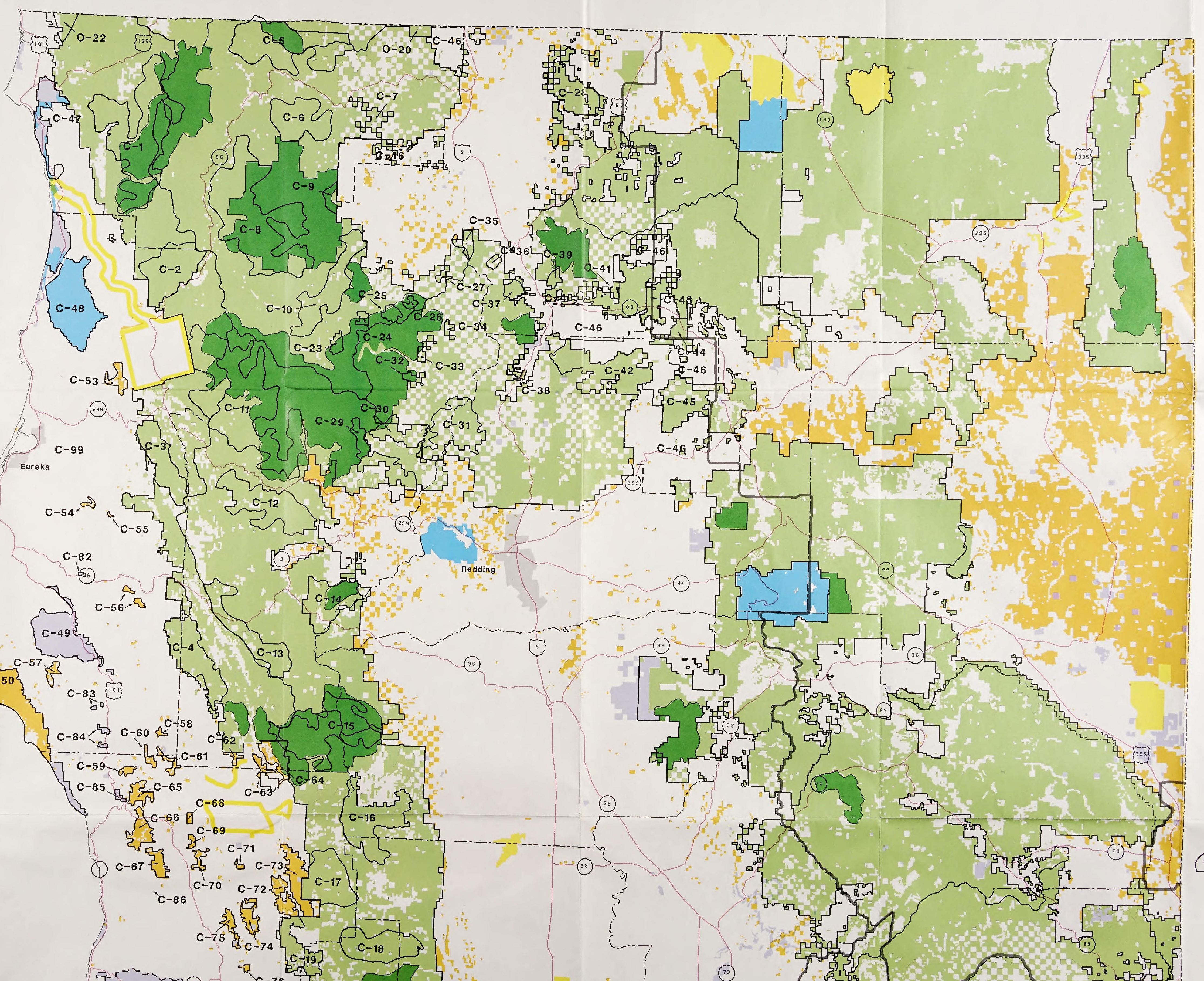




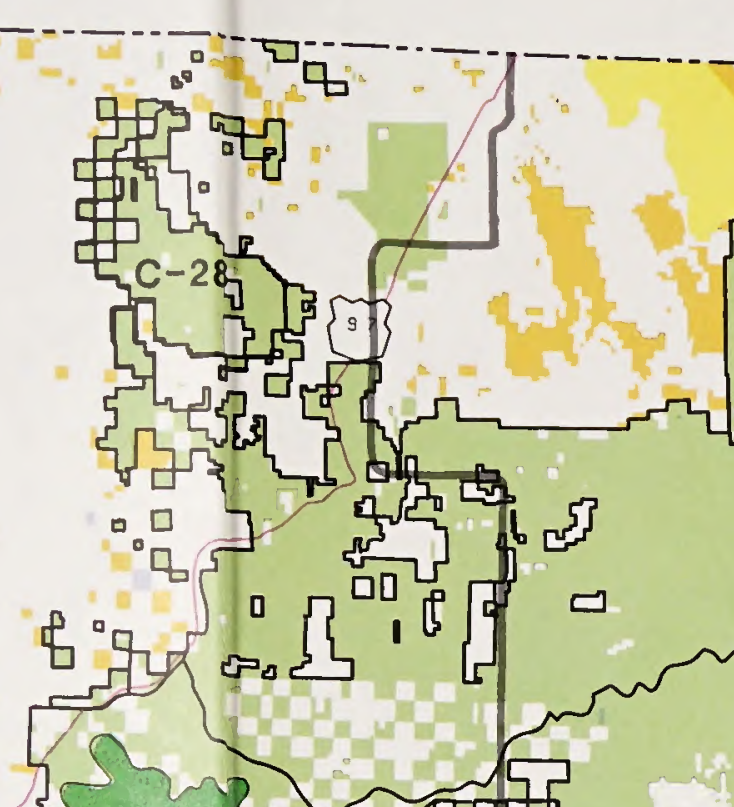

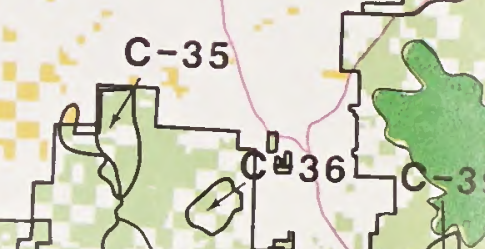

2025

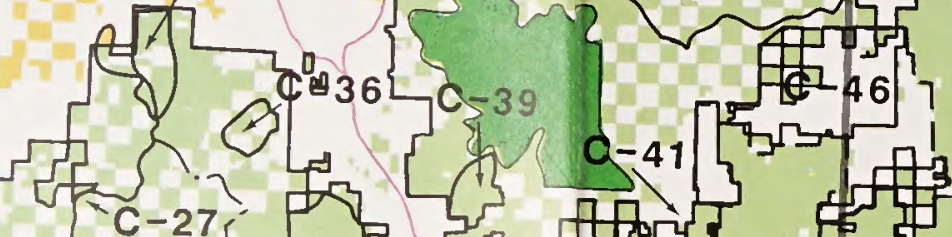

C-10 F $3-25$ (5)

(1)
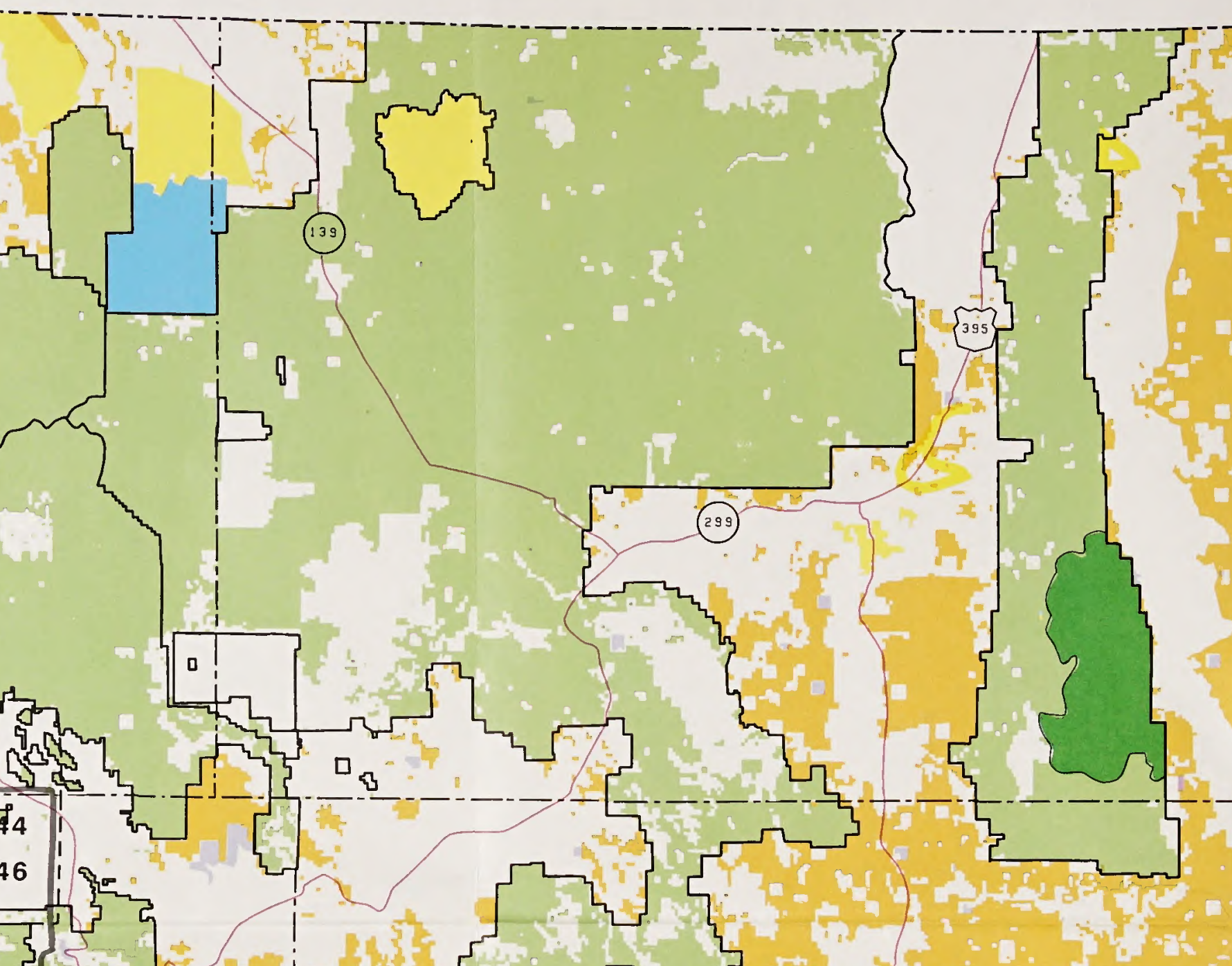

(c)

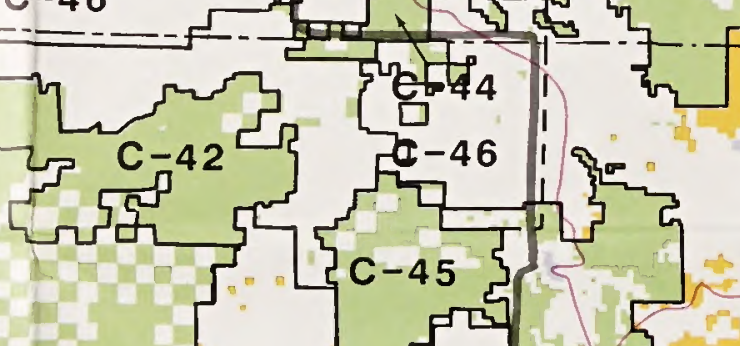

c-48

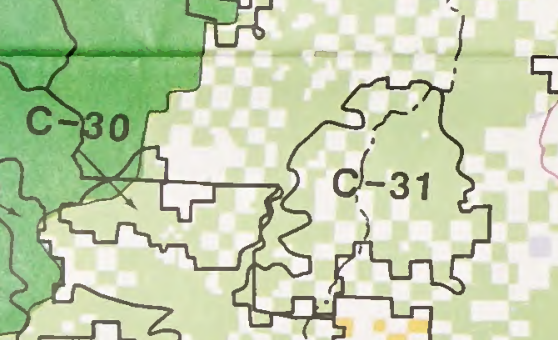

$\Omega_{c-12}^{2}$

$2 c^{-12}$

$55^{2}$

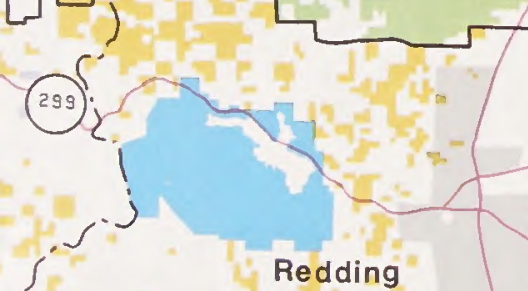

-68

$\int_{c-13}$

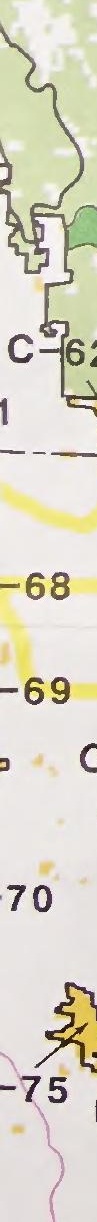

(3)

象

3 द 250

c-63 $c-64$

出 $c-73$ है

c-72 ${ }^{2}$ C

हैद

$b_{C-74}{ }_{C-19} C_{C-18}$

$\Leftrightarrow$

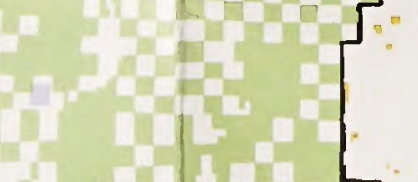

5.

质

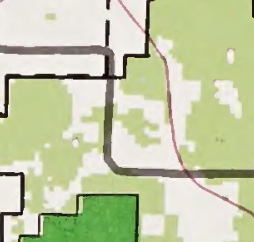

(1)
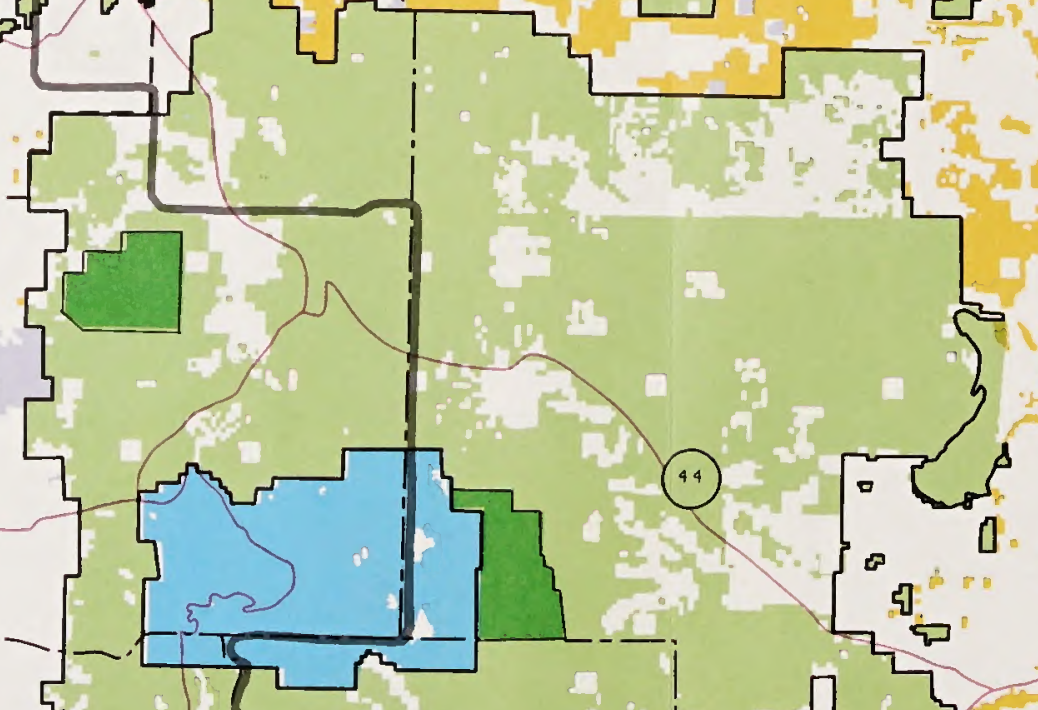

?

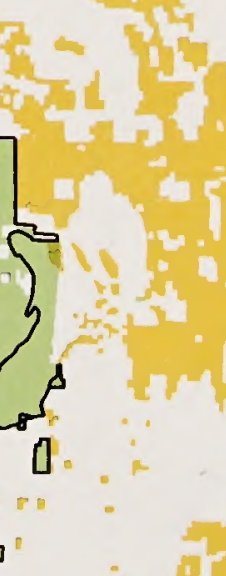




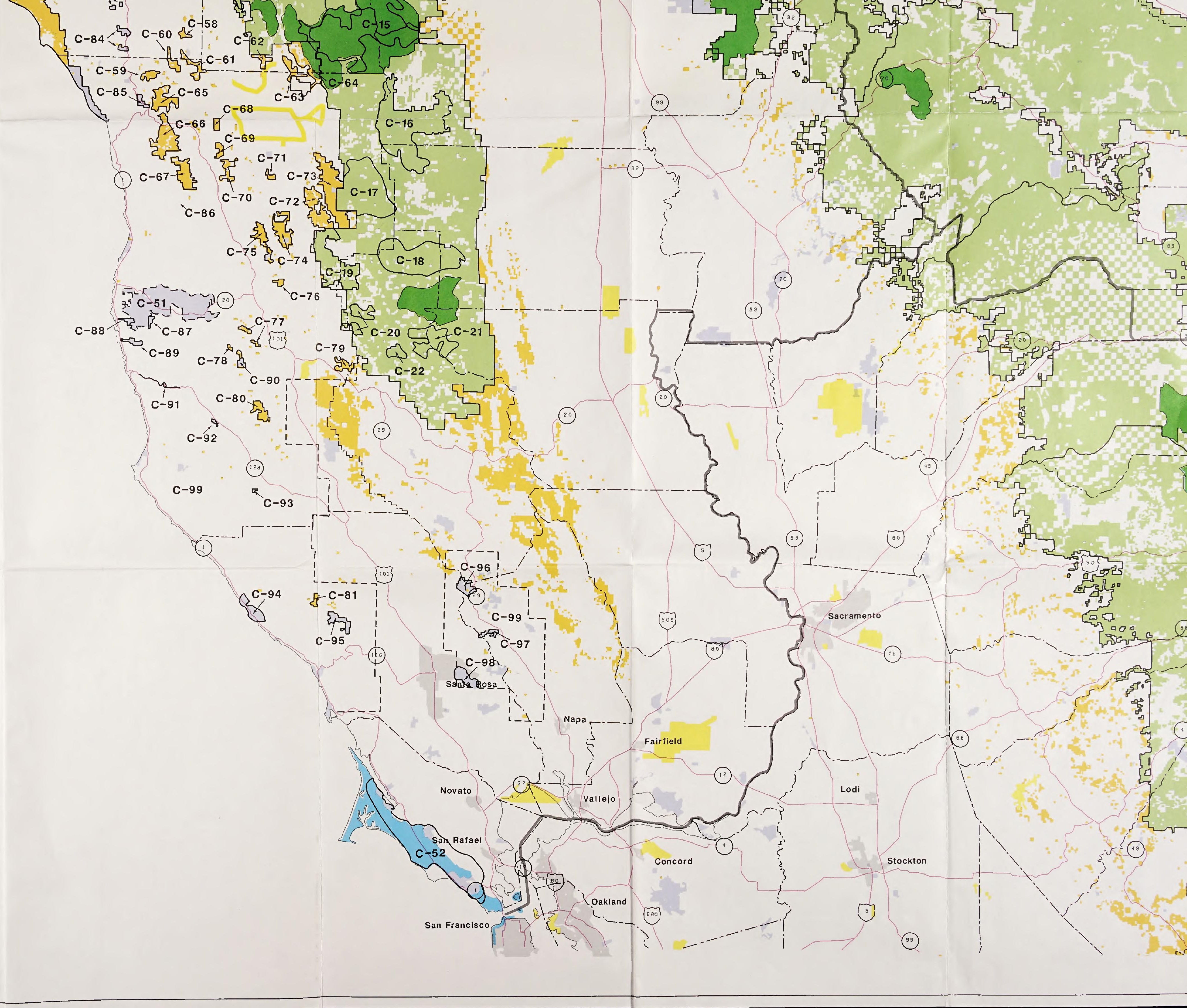




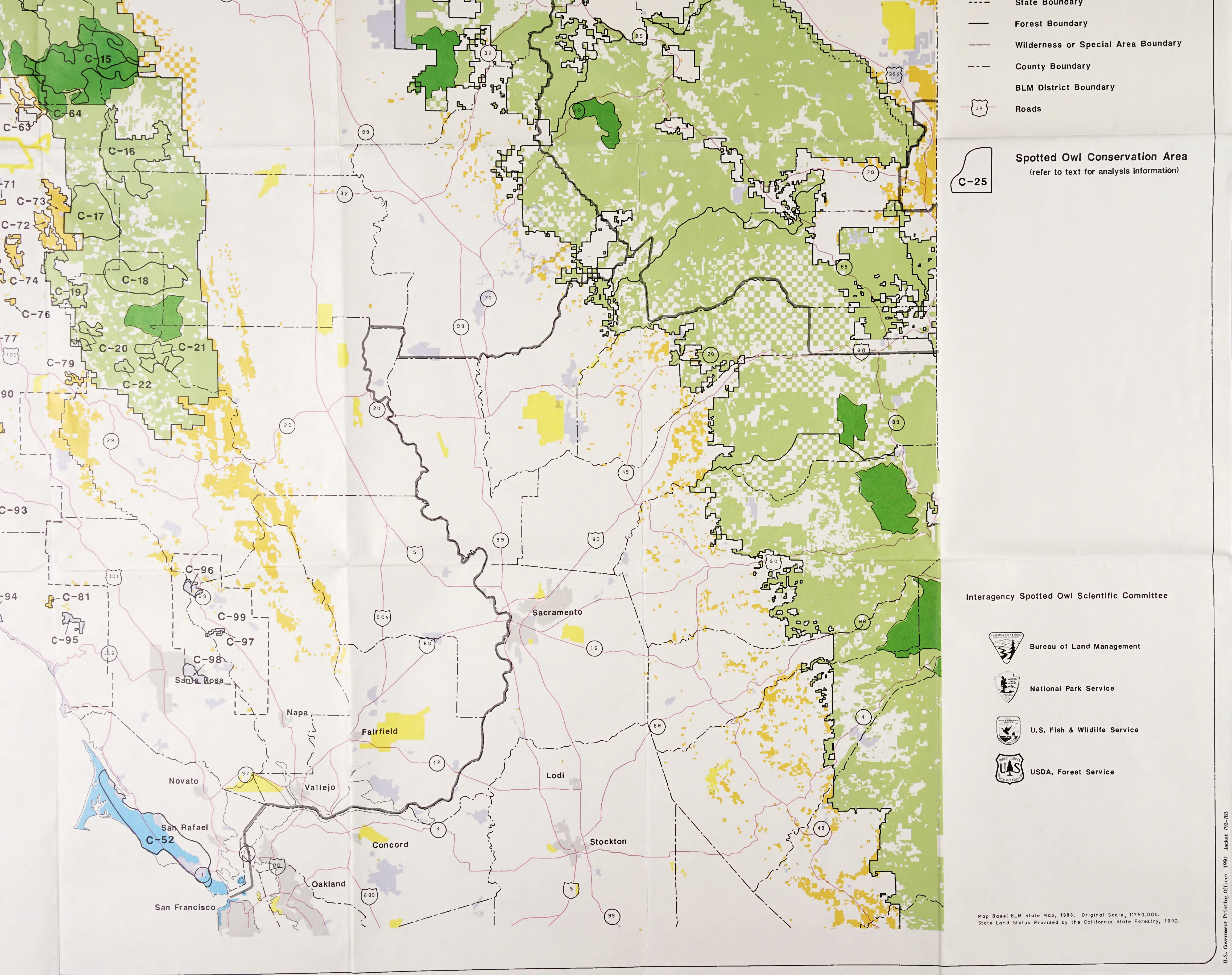




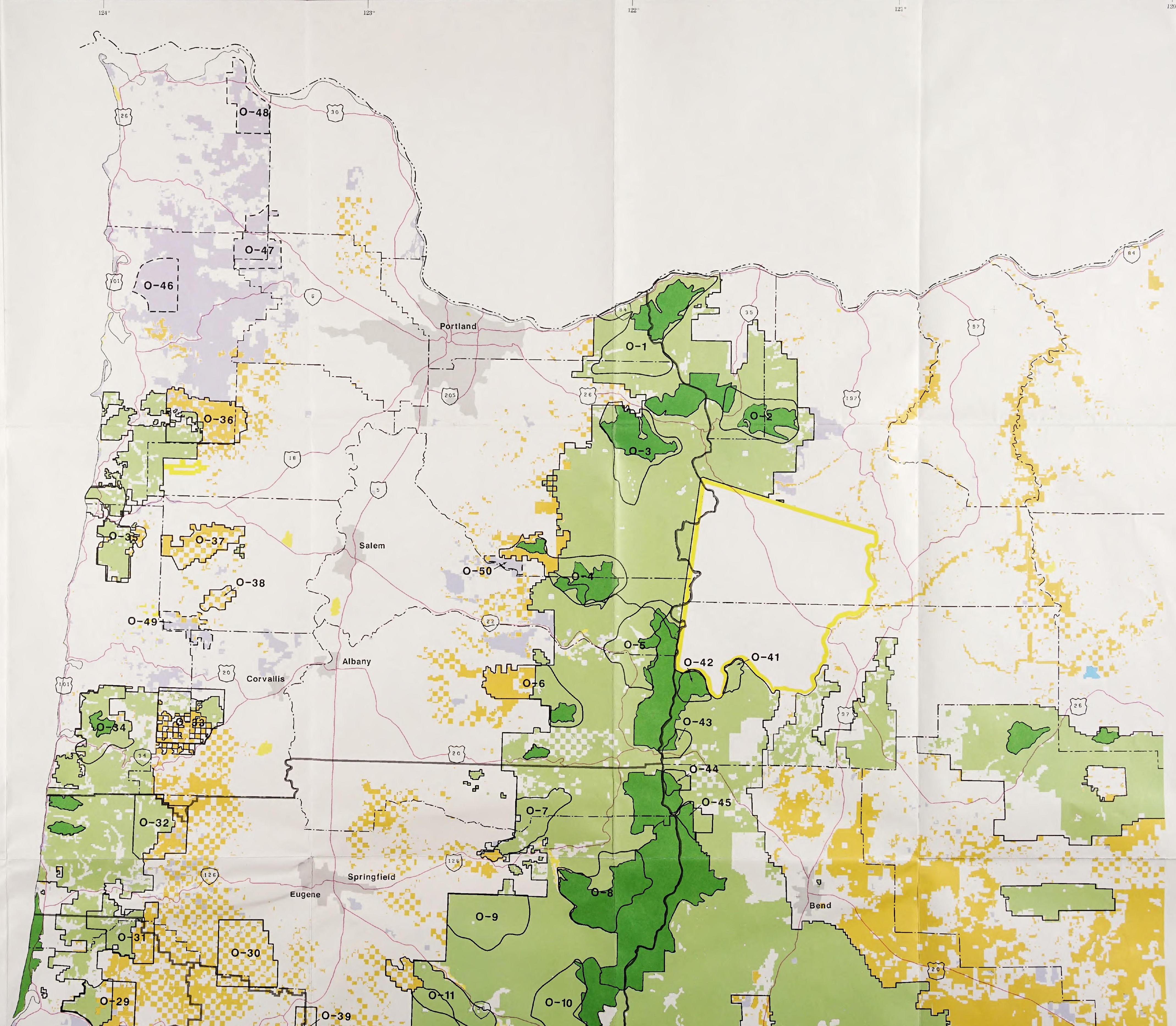




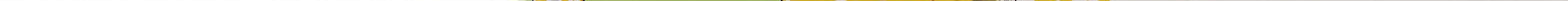




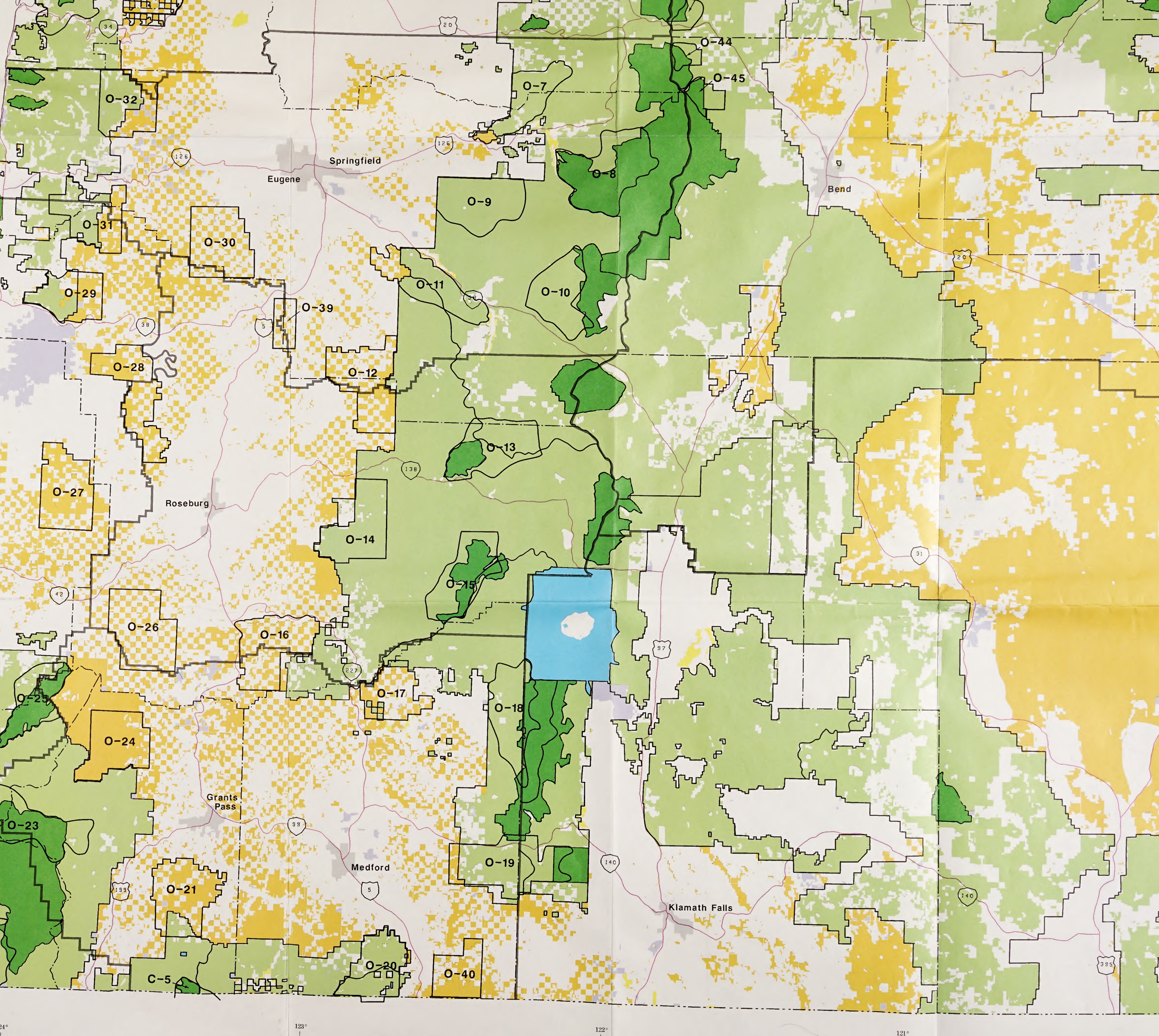




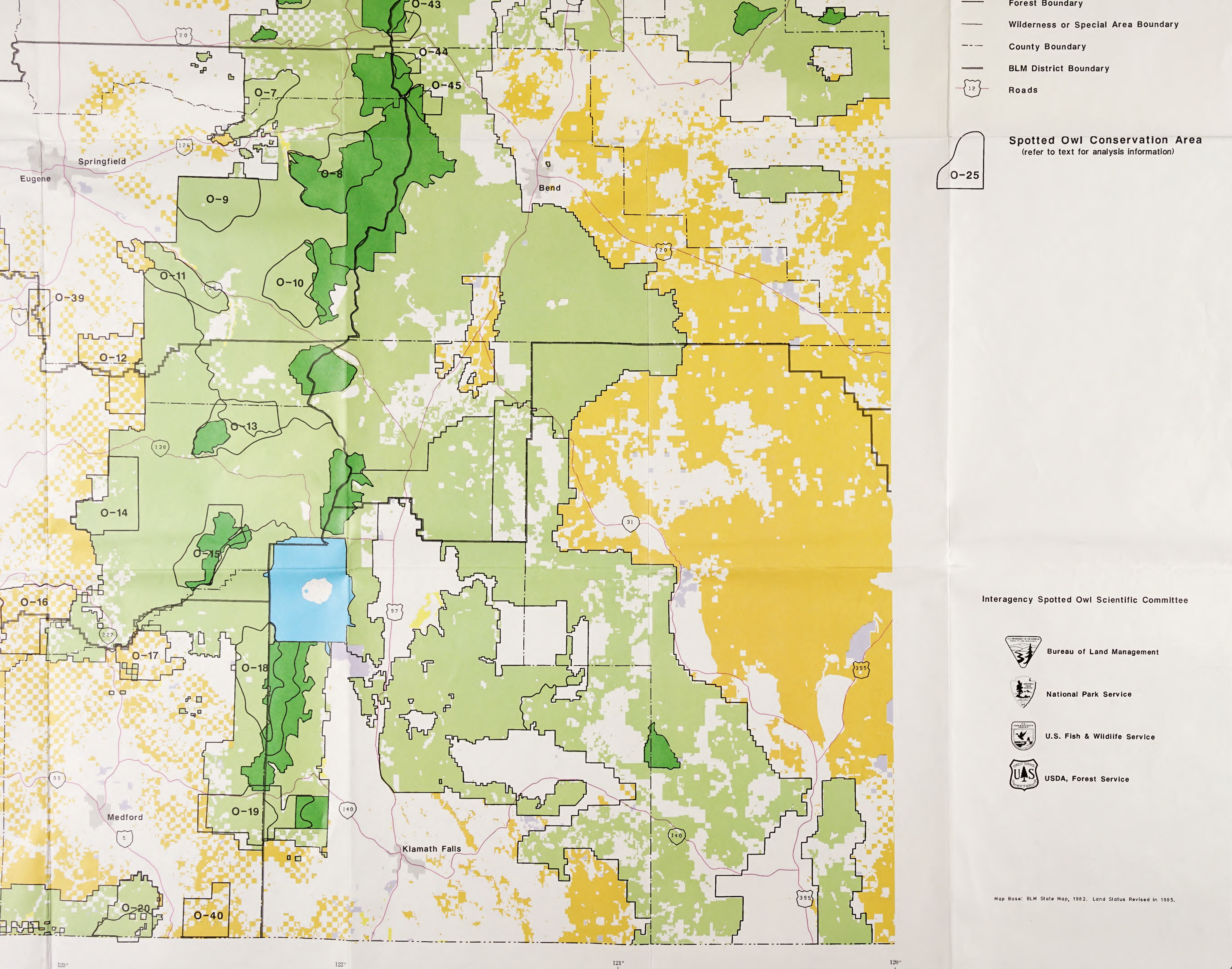




\section{speoy

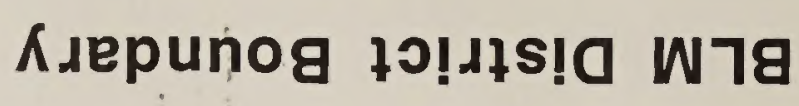 \\ Ksepunog Kłunoo}

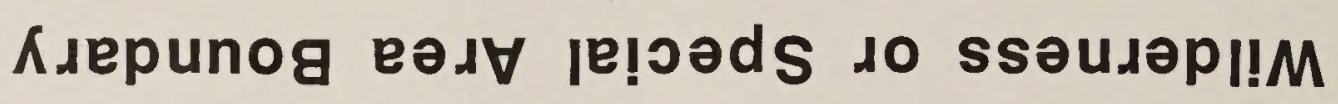

Ksepunog tsadog

Ksepunog әғенS

suo!fe^dəsəy ue!pul

spue 7 әңенs

ןеләрәу ләчнО

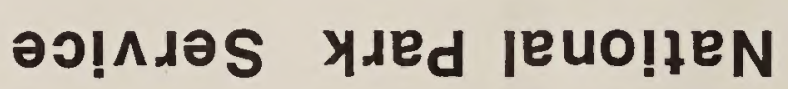

quәшәбеuеw pue 7 to neəang

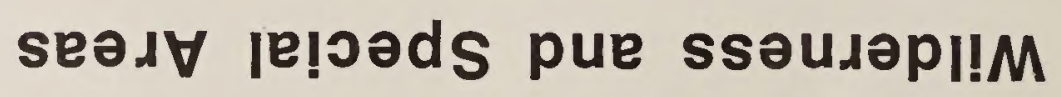

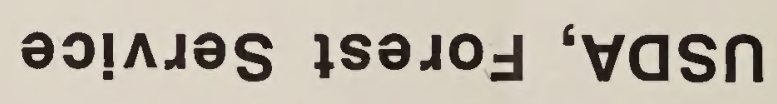




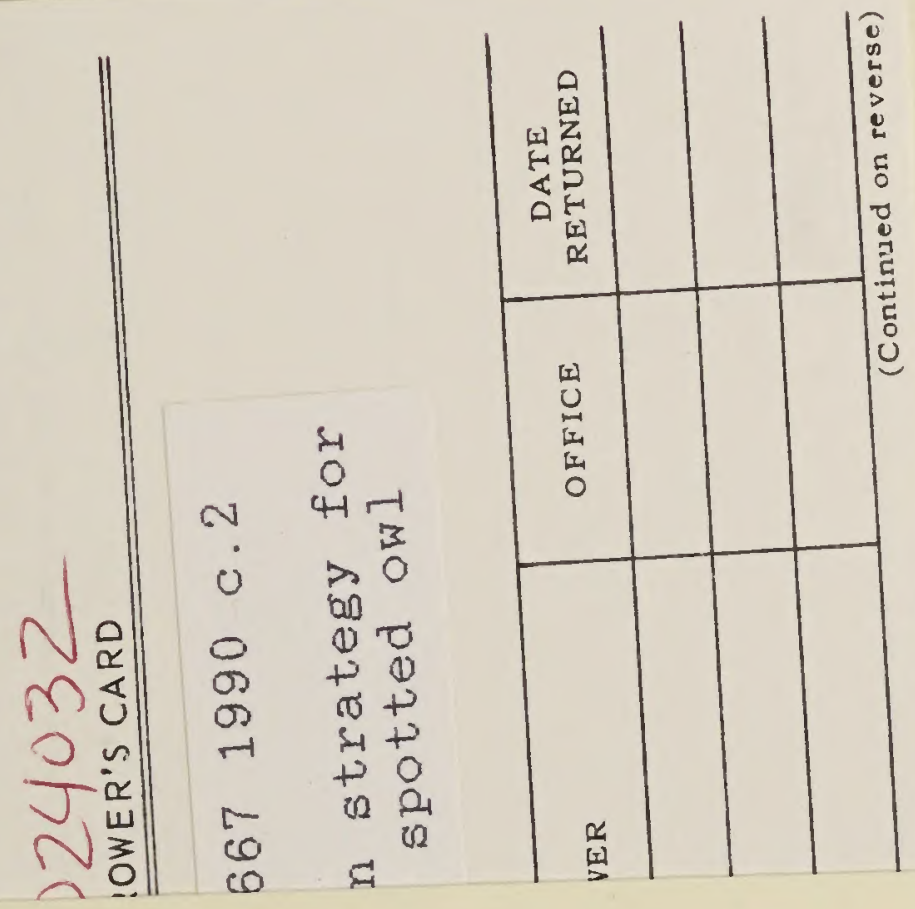

BLMLIBRARY

SC. 653 , BLDG. 50 ENVER FEDERAL CENTER P. O. BOX 25047 DENVER, CO 80225 
